

\section{HARVARD UNIVERSITY}

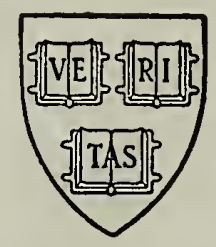

\section{LIBRARY}

OF THE

Museum of Comparative Zoölogy 





\title{
Das Tierreich.
}

Eine Zusammenstellung und Kennzeichnung der rezenten Tierformen.

- Begründet von der Deutschen Zoologischen Gesellschaft.

Im Auftrage der

Königl. Preuß. Akademie der Wissenschaften zu Berlin heransgegeben von

Franz Eilhard Schulze.

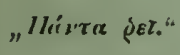
"Sine systemate chaos."

22. Lieferung.

Lepidoptera.

Redakteur: A. Seit\%.

\section{Heliconiidae}

hearbeitet von

\begin{abstract}
H. Stichel und H. Riffarth
\end{abstract}
in $\mathrm{Hagen}$ i. Westr. in Berlin.

Mit 50 Abbildungen.

\section{$\checkmark$ Berlin.}

Vorlag von R. Friedländer und Sohn.

A usgegeben im Oktober 1905. 


\title{
R. Friedländer \& Sohn, Berlin NW. 6, Karlstr. 11.
}

\section{Das Tierreich.}

\section{Eine Zusammenstellung und Kennzeichnung der rezenten Tierformen.}

Begründet von der Deutschen Zoologischen Gesellschaft.

\author{
Im Auftrage der
}

\section{Königl. Preuß. Akademie der Wissenschaften zu Berlin}

herausgegeben von

Franz Eilhard Schulze.

839083

Seit Linnés Systema naturae ist die Zahl der bekannten Tierformen so angewachsen, daß eine neue, umfassende Übersicht des Systems, die als Abschluß der bisherigen und als Grundlage künftiger systematischer Forschung dienen kann, ein dringendes Bedürfnis geworden ist. Um diese Aufgabe zu erfüllen, hat die Deutsche Zoologische Gesellschaft das vorliegende Werk begründet und dessen wissenschaftliche Leitung Herrn Geh. Reg.-Rat Prof. F. E. Schulze in Berlin anvertraut, dem eine Auzahl Beiräte zur Seite stehen. Das gewaltige Unternehmen fand die Unterstützung der Königlich PreuBischen Akademie der Wissenschaften, die in Würdigung der Bedeutung des Werkes im Jahre 1902 die Herausgahe ïbernommen hat.

Die einheitliche Durchführung des Werkes ist durch eine Reihe wohldurchdachter Bestimmungen gesichert. Für die Beneunung der Tierformen und ihrer systematischen Kategorien gelten die ron dem 5. internationalen Zoologen-Kongreß zu Berlin (1901) angenommenen Regeln.

Die Herausgabe findet in Lieferungen statt, die je eine oder mehrere nahestehende Gruppen behandeln, jedoch mnabhängig von einer systematischen Folge erscheinen. Nach Abschluß einer jeden in mehreren Lieferungen behandelten Hauptabteilung erscheint ein Gesamtregister.

Jede Lieferung ist einzeln käuflich. Dem Umfang entsprechend jst der Preis der Lieferungen verschieden; jedoch wird für die Subskribenten, die sich auf 5 Jahre hinaus für die Abnahme aller in diesem Zeitraum erscheinenden Lieferungen verpflichten, der Berechnung der durchschnittliche. Preis von Mark 0,70 für den Druckbogen zu grunde gelegt. Der EinzelLadenpreis für jede vollständige Lieferung erhöht sich gegen den Snlskriptionspreis um ein Drittel. 
Y

\section{,}




\title{
Das Tierreich.
}

Eine Zusammenstellung und Kennzeichnung der rezenten Tierformen.

Begründet von der Deutschen Zoologischen Gesellschaft.

Im Auftrage der

Königl. Preuß. Akademie der Wissenschaften zu Berlin herausgegeben von

Franz Eilhard Schulze.

"Hlivica pez."

„Sine systemate chaos."

22. Lieferung.

Lepidoptera.

Redakteur: A. Seitz.

\section{Heliconiidae}

bearbeitet ron

\begin{abstract}
H. Stichel und H. Riffarth in Hageni. Westf. in Berlin.
\end{abstract}

Mit 50 Abbildungen.

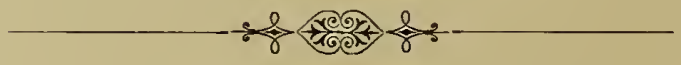

Berlin.

Verlag von R. Friedländer und Sobn. Ausgegeben im Oktober 1905. 



\section{Inhalt.}

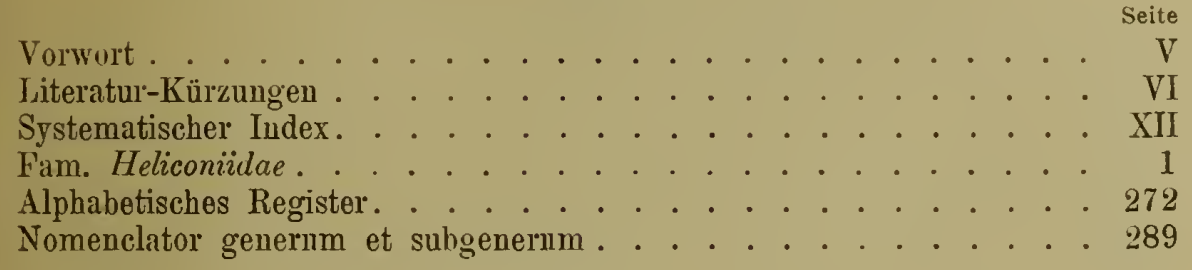

\section{Vorwort.}

An der Bearbeitung der Gattung Heliconius sind beide Verfasser gemeinschaftlich beteiligt, die Gattung Eueides wurde von H. Stichol allein bearbeitet. Der Abschluß der Arbeit erfolgte im Juli 1903, jedoch konnte während des Druckes die Literatur bis zum .Juli 1905 herücksichtigt werden. 


\section{Literatur-Kürzungen.}

Abh. Senckenb. Ges. - Abhandlungen herausgegeben ron der Senckenbergischen naturforschenden Gesellschaft. Frankfurt a. M. 4.

Acta Soc. Sci. Fenn. - Acta Societatis Scientiarum Fennicae. Helsingfors. 4.

Ann. nat. Hist. - The Annals and Magazine of natural History, including Zoology, Botany, and Geology. London. 8.

Anı. Soc. ent. Belgique - Anuales de la Socićté entomologique de Belgique. Bruxelles. 8. Am. Soc. ent. France - Annales de la Société entomologique de France. Paris. 8. Bates, Natu f. Amazonenstr. - Der Naturforscher am Amazonenstrom. Leben der Thiere, Sitten und Gebräuche der Berrohner, Schilderung der Natur unter dem Aequator und Abenteuer während eines elfjährigen Aufenthalts von Henry Walter Bates. Aus dem Englischen. Leipzig. 1866. 8.

Berlin. ent. Z. - Berliner entomologische Zeitschrift. Berlin. 8.

Billberg, Enum. Ins. - Enumeratio Insectorum in MIuseo Gust. Joh. Billberg. [Holmiae.] 1820. 4.

Biol. Centr.-Amer. - Biologia Centrali-Americana; or, Contributions to the Knowledge of the Fauna and Flora of Mexico and Central America. Edited by F. Ducane Godin an land Osbert Salvin|. - Zoology. Insceta. Lepidoptera-Rhopalocera. By Frederick Ducane Godman and Osbert Salvin. [Vol. 2:] With a Note on the Group Eumaeidi, by Samuel Hubbard Scudder.| Vol. 1. 2; Plates (Vol. 3). London. 1879-1901 (1879-86, 1901), 87-1901. 4.

Boislural, Consid. Lép. Guatemala - Considérations sur des Lépidoptères envoyés du Guatemala à M. de l'Orza par [Jean A.] Boisduval. Parìs. 1870. 8.

Boischuval \& Leconte, Lép. Amér. sept. - Histoire générale et Iconographie des Lépidoptères et des Chenilles de l'A mérique septentrionale, par [Jean A.]B oisdura et Joln [Eatton] Leconte. Tom. I. Paris. 1833 (1829-42). 8.

Boiscluval. Spec. gén. Lép. - Histoire naturelle des Iusectes. Species général des Lépidoptères, par [J.A.] Boisduval. Tom. 1; Planches. Puris. 1836. 8.

Buchecker, Syst. Ent. - Henrici Bu checker Systema Entomologiae sistens Insectorum Classes, Genera, Species. - Lepidoptcra. [München.] [1880?] 8.

Bull. Buffalo Soc. - Bulletin of the Buffalo Society of natural Sciences. Buffalo. 8.

Bull.U.S. Mus. - Bulletin of the United States national Museum. Washington. 8.

Butler, Cat. Jiurn. Lep. Fabr. - Catalogue of diurnal Lepidoptera described by Fabricius in the Collection of the British IInseum. By Arthur Gardiner Butlel: London. 1869. 8.

Canad. Ent. -- The Canadian Entomologist. Toronto, London. 8.

$C B$. Ver. Regensburg - Correspondenz-Blatt des zoologisch-mineralogischen Vereines in Regensburg. Regeusburg. 8.

Chenı, Enc. Hist. nat. - Encyclopédie d'Histoire naturelle ou 'Traité conılet de cette Science d'après les Travaux des Naturalistes les plus éminents de tous les Pays et de toutes les Époques.... Par [Jean Charles] Chenu. - Papillons [diurues]. Arec la Collaboration de H. Lucas. Paris. [1851.] 4.

Chenu \& Lucas, Enc. Hist.nat., Pap. diurn. - Tide: Chenu, Enc. Hist. nat.

Cistula ent. - Cistula entomologica. London. 8.

Clerck, Icon. Ins. - Caroli Clerck Icones Insectorum rariorum cum Nomiuibus eorum trivialibus, Locisqre e C. Lin na ei Syst. Nat. allegatis. Sectio 1. 2. Holmiae. $1759,[1764]$. 4 . 
Cramer, Pap. exot. - De uitlaudsche Kapellen voorkonende in de drie WaereldDeelen Asia, Africa en Ameriea, by een rerzameld en besehrecren door Pieter Cramer. Papillons exotiques des trois Parties du Monde l'Asie, l'Afrique et l'Amerique. Rassemblés et déerits par Pierre Cramer. Deel ('́ome) 1-4. Ansteldam. Utrecht. $1779(1775,76), 79$ (1777), 82 (1779, 80), $82(1780,81,82) * 4$.

Cuvier, Règne an. - Le Rìgne animal distribué d'après son Organisation, pour serví de Base ì l'Histoire naturelle des Animaux et d'Introduction ì l'Anatomie

- eomparie. Par [Georges] Cuvier. Tom. 1-4. Paris. 1817. 8.

D. ent. Z. Lep. - Deutsehe entomologisehe Zeitschrift, herausgegeben ron der Gesellschaft Iris zu Dresden in Verbindung mit der Deutschen entomologischen Gesellscbaft zu Berlin. Lepidopterologische Hefte. Dresden. 8.

Lurbleday, List Lep. Brit. Arus. - List of the Speeimens of Lepidopterous Inseets in the Colleetion of the British Museum. [By Edward Doubleday.] Part 1, 2; Appendix. Linndou. 1844,$47 ; 48.12$.

INoublerlay \& Westwood, Gen. diurn. Lep. - The Genera of diurnal Lepidoptera: eomprising their generic Characters, a Notice of their Habits and 'Transformations, and a Catalogue of the Species of each Genus. By Edward Doubled ay and John O. Westwood. Illustrated with 86 Plates, by Willian C. Hewitson. Vol. 1, 2. London. 1816-50,50-52. 2.

Drury, Ill. nat. Hist. - Illustrations of natural History. Wherein are exhibited upwards of .... Figures of exotic Insects, aecording to their differeut Genera; . . With a particular Description of each Inseet: interspersed with Remarks and Reflectious ou the Nature and Properties of many of them. By D. Drury. Vol. 1-3. London. 1770, 73, 82. 4.

Dunceu, Foreign Butt. - The Naturalist's Library. Conducted by William Jardine. Entomology. Vol. 5. Foreign Butterflies. By James Dunean. Edinburgh. 1837. 8.

Eduarls, Butt. N.-Amer. - The Butterflies of North America. By William H.Edwards. Vol. (Series) 1-3. New York (Boston) (Boston and New York). 1868-72, $84(1874-84), 97$ (1887-97). 4.

Enc. méth. - Encyclopédie méthodique, ou par Ordre de Matières; par une Société de Gens de Lettres, de Savans et d'Artistes. - Histoire nat urelle. Tom. 4-10: Insectes (Ent omologie). Paris. Liège (Paris). 1789, 90, 91, 92. 1811 [\& 1812vir], $19[\& 1824 \mathrm{yII}], 25[\& 1828] . * *) 4$.

Ent. monthly Mag. - The Entomologist's monthly Magazine. London. 8.

Ent. Nachr. - Entomologisehe Nachrichten. Quedlinburg (Putbus) (Berlin). 8.

Ent. Teres Philad. - Entomological News and Proeeedings of the entomologieal Section of the Academy of natural Sciences of Philadelphia'. Philadelphia. 8.

Entomologist - The Entomologist. An illustrated Journal of general Entomology. London. 8.

Ent. Rec. - The Entonologist's Kecord and Journal of Variation. London. 8.

Ent. Zeit. Stettin - Entomologische Zeitung. Heransgegeben von dem entomologischen Vereine zu Stettin. Stettin. 8.

Ent. Z. Guben - Entomologische Zeitschrift. Central-Organ des internationalen entomologischen Vereins. Guben. 4.

Fubricius, Ent. syst. - Joh. Christ. Fabrieii Entomologia systematica emendata et aueta. Secundum Classes, Ordines, Genera, Species adjectis Synonimis, Locis, Obserrationibus, Descriptionibus. Tom. 1-4. [Cum Ind.:] Index alphabeticus in J. C. Fabriei Entomologiam systematicam, emendatam et auctam, Ordines, Genera et Species continens. [Cum Suppl.:] Joh. Christ. Fabricii Supplementum Entomologiae systematicae. [Cum Ind. Suppl.:] Index alphabeticus in J. C. Fabricii Supplementum Entomologiae systematicae, Ordines, Genera et Species continens. Hafniae. $1792,93,93 / 94,94 ; 96 ; 98 ; 99.8$.

*) Cfr.: Carolus Davies Sherborn in: Index An., v. 1 (1902) p. XX.

**) Cfr.: C. Daries Sherborn \& H. H. Woodwald in: P. zool. Soc. London, 1893 p. 583 \& 1899 p. 595. 
Fabricius, Gen. Ins. - Ioh. Christ. Fabricii Genera Insectorum eorumque Characteres naturales secundum Numerum, Figuram, Situm et Proportionem omnium Partium Oris adiecta Mantissa Specierum uuper detectarum. Chilonii. [1777.] 8.

Eabricius, Mant. Ins. - Ioh. Christ. Fabricii Mantissa Insectorum sistens eorum Species nuper detectas adiectis Characteribus genericis, Differentiis specificis, Emendationibus, Observationibus. Tom. 1, 2. Hafniae. 1787. 8.

Fabricius, Spec. Ins. - Ioh. Christ. Fabricii Species Insectorum exbibentes eorum Differentias specificas, Synonyma Auctorum, Loca natalia, Metamorphosin adiectis Observationibus, Descriptionibus. Tom. 1, 2. Hamburgi et Kilonii. 1781. 8.

Fabricius, Syst. Ent. - Io. Christ. Fabricii Systema Entomologiae, sistens Insectorum Classes, Ordines, Genera, Species, adiectis Synonymis, Locis, Descriptionibus. Observationibus. Flensburgi et Lipsiae. 1775. 8.

Feuille Natural. - Feuille des jeunes Naturalistes. Paris. 8.

Geyer, Exot. Schmett. - Vide: Hübner (Geyer), Exot. Schmett.

Geyer, Zutr. cxot. Schmett. -- Vide: Hübner (Geyer), Zutr. exot. Schmett.

Gmelin, Syst. Nat. - Caroli a Lin né Systema Naturae per Regna tria Naturae, secundum Classes, Ordines, Genera, Species, cum Characteribus, Differentiis, Synonymis, Locis. Editio XIII, aucta, reformata. Cura Jo. Frid. Gmelin. - Tomus I. Pars 1-7. Lipsiae. 1788 [Pars 6 \& 7: 1791]. 8.

Goeze, Ent. Beytr. - Entomologische Beyträge zu des Ritter Linné zwölften Ausgabe des Natursystems von Joh. Aug. Ephraim Goeze. Theil 1, 2, 3I-IV. Leipzig. 1777, $78,79,80,81,83.8$.

Griffith. An. Kingdom - The Animal Kingdom arranged in Conformity with its Organization, bysthe Baron [Georges] Cuvier, with additional Descriptions of all the Species bitherto named, and of many not before noticed (with supplementary Additions to each Order), by Edward Griffith aud other's. Vol. 1-15, Index. London. 1824-35. 8.

Grose-Smith, Rhop. exot. - Vide: Smith \& Kirby (Grose-Smith), Rhop. cxot.

Guérin-Méneville, Iconogr. Règne an. - Iconographie du Règne animal de G. Curier. ou Représentation d'après Nature de l'une des Espèces les plus remarquables et souvent non encore figurées, de chaque Genre d'Animaux. Avec un Texte descriptif mis au Courant de la Science. Par F. E. Guérin-MLéueville. Tom. 1-3. Paris, Londres. 1829-44. 4 (\& 8).

Gundlach, Contr. Ent. Cubana - Contribucion á la Entomologia Cubana, por Juan Gundlach. Parte 1. Lepidópteros. Habana. 1881. 8.

Herbst, Naturs. Ins. Schmett. - Vide: Jablonsky (Herbst), Naturs. Ins. Schmett.

Hewitson, Equat. Lep. - Equatorial Lepidoptera collected by Buckley, described by W. C. Hewitson. Irondon. 1869, 70, 77. 8.

Hewitson, Exot. Butt. - Illustrations of new Species of exotic Butterflies, selected chiefly from the Collections of W. Wilson Saunders and William C. Hewitsou (selected chiefly from his own Collection). By William C. Hewitson. Vol. $1-5$. Londou. $(185 l-56), 57-61,62-66,67-71$, 72-76. 4 .

Hist. An. artic. - Histoire naturelle des Animaux articulés, Annelides, Crustacés, Arachnides, Myriapodes et Insectes. — Histoire naturelle des Insectes Orthoptères, Névroptères, Hémiptères, Hyménoptères, Lepidoptères et Diptères, par Émile Blanchard. T'om. 3. Paris. 1840. 8.

Hübner (Geyer), Exot. Schmctt. - Sammlung exotischer Schmetterlinge, errichtet von Jacob Hübner ([Band 3:] von Carl Geyer). Band 1-3. Augsburg. 1806 $\left.[1806-19], 06[1820-26],[1826-41]^{*}\right) .4$.

Hïbner (Geyer), Zutr. exot. Schmett. - Zuträge zur Sammlung exotischer Schmettlinge (Schmetterlinge), bestehend in Bekundigung einzelner Fliegmuster (Bekanntmachung einzelner Geschlechter) ..., von Jacob (Jakob) Hü bn e r ( [4. \& 5 . Hundert:] von Carl Geyer). 1.-5. Hundert. Augsburg. 1818, 23, 25, 32, 37. 4.

*) Cfr.: Samuel H. Scuddcr in: P. Amer. Ac.: v. 10 (1875) p. 96. 
Hübner, Verz. Sehmett. - Verzeichniß bekannter Schmettlinge verfaßt ron Jacob Hübner. Augsburg. 1816. 8.

Humbolat \& Bonpland, Voy. Amér. - Al. de Humboldt et A. Bonpland, Voyage daus l'Intérieur de l'Amérique dans les Années 1799-1804. — Recueil d'Observations de Zoologie et d'Anatomie comparée, faitcs dans l'Océan atlantique, dans l'Intérieur du nouveau Continent et dans la Mer du Sud pendant les Années 1799-1803; par Al. de Humboldt et A. Bonpland. Vol. 1, 2. Paris. $1811(1805-12), 33(1813-32) *)$. 4.

Ins.-Börse - Insekten-Börse. Internationales Wochenblatt der Entomologie. Leipzig. 4.

Jablonsky (Herbst), Naturs. Ins. Schmett. - Natursystem aller bekannten in- und ausländischen Insekten. Nach dem System des Ritters Carl von Linn é bearbeitet (Als eine Fortsetzung der von Büffouschen Naturgeschichte). Ton Carl Gustav Jablonsky ([Theil 3-11:] Von Johann Friedrich Wilhelm Herbst). Schmetterlinge. 'Theil 1-11. Berlin. 1783, 84, 88, 90, 92, 93, 94, 96, 98, $1800,04.8$.

J. Ent. - The Journal of Entomology. Descriptive and geographical. Jondon. 8.

Kirby, Cat. diurn. Lep. - A synonymic Catalogue of diurnal Lepidoptera, by W. F. Kirby. Cum Suppl. London \& Berlin (London). 1871, 77. 8.

Kirby, Exot. Schmett. Hïbner - J. Hï bner exotische Schmctterlinge, nebst Zuträge von C. Geyer. Lepidoptères exotiques. Exotic Butterflies. Nouvelle Édition revue, corrigée et augmentée, publiée sous la Direction du W. F. Kirby, P. Wytsman. Livr. 1-51. Bruxelles. 1891-1903. 4.

Latreille, Gen. Crust. Ins. - P. A. Latreille Genera Crustaceorum et Insectorum secundum Ordinem naturalem in Familias disposita, Iconitus Exemplisque plurimis explicata. Tom. 1-4. Parisiis et Argentorati. 1806, 07, 07, 09. 8.

Latreille, Hist. Crust. Ins. - Histoire naturelle, générale et particulière, des Crustacés et des Insectes. Ourrage faisant Suite anx Oeuvres de Leclerc de Buffon, et Partie de Cours complet d'Histoire naturelle rédigé par C. S. Sonnini. Par P. A. Latreille. Tom. 1-14. Paris. X-XIII [1802-1805]. 8.

Linné, Mant. Plant. II. -- Car. a Li nuć MIantissa Plantarum altera Generum Editionis VI. et Specierum Editionis II. Holmiae. 1771. 8.

Linné, Mus. Ludov. Ulr. - MIuseun S. R. M. Ludoricae Ulricae Reginae Srecorum, . . . . in quo Animalia rariora, exotica, imprimis Insecta et Conchilia describuntur et determinantur Prodromi instar editum. A Carolo v. Linné. Holmiae. 1761. 8.

Linné, Syst. Nat., ed. 10 - Caroli Linnaci Systema Naturae per Regna tria Naturae, secundum Classes, Ordines, Genera, Species, cum Characteribus, Differentiis, Synonymis, Locis. Editio X, reformata. -- 'Tomus I. Holmiae. 1758. 8.

Linne, Syst. Nat., ed. 12 - C'aroli a Linné Systema Naturae per Regna tria Naturae, secundum Classes, Ordines, Genera, Species, cum Characteribus, Differentiis, Synonymis, Locis. Editio XII, reformata. - Tomus I. Pars 1, 2. Holniae. 1766, 67. 8.

Lucas, Hist. Lép. exot. - Histoire naturelle des Lépidoptìres exotiques, par H. Lucas. Paris. 1835. 8.

Mag. Insektenk. - Magazin für Insektenkunde. herausgegeben von Karl Illiger. Braunschweig. 8.

Ménétriés, Lép. Ac. St.-Pétersb. -- Enumeratio Corporum Animaliun Musei Imperialis Academiae Scientiarum Petropolitanae. Classis InsectorumOrdo Lcpidopterorum. Catalogue de la Collection entomologique de l'Académie Inúriale des Sciences de St.-l'étersbourg. Lépidoptères. (Descriptions des nouvelles Espèces de Lépidoptères de la Collection de l'Académie Impériale des Sciences.) Par E. Ménétriés. Pars (Partie) 1-3. Petropoli. 1855, 57,63. 8.

*) Cfr.: C. Davies Sherborn in: Ann. nat. Hist., ser. 7 v.3 (1899) p. 428. 
Merian, Ins. Surin. - Metamorphosis Insectorum Surinamensium. In qua Erucae ac Vermes Surinamenses, cum omnibus suis Transformationibus, ad vivum deliueantur et describuntur, singulis eorum in Plantas, Flores et Fructus collocatis, in quibus reperta sunt; tunc etiam Generatio Ranarum, Bufonum rariorum, Lacertarum, Serpentum, Araneorum, et Formicarum exhibetur; omnia in America ad virum naturali Magnitudine picta atque descripta per Mariam Sibyllam Merian. Amstelodami. 1705. 2.

Wt. Mïnch.ent.Ver. - Nittheilungen des Münchener entonılogischen Vereins. Mlünchen. 8. Vüller, Naturs. Linné - Des Ritters Carl von Linné vollständiges Natursystem nach der zwölften lateinischen Ausgabe und nach Anleitung des Holländischen Honttuynischen Werks| mit einer ausführlichen Erklärung ausgefertigt ron Philipp Ludwig Statius II üller. Theil 1-4, 5 I \& II, 6 I \& II; Supplementund Register-Band. Nürnberg. 1773, 73, 74, 74, 74, 75, 75, 75; 89 (76). 8 .

Yov. zool. - Novitates zoologicae. A Journal of Zoology in Connection with the Tring Huseum. Tring. 8.

Wherthür, Étud. Ent. - Études d'Entomologie. Faunes entomologiques. Descriptions d'Insectes noureaux ou peu connus. Par Charles Oberthïr. Lirraison 1-21. Renues. 1876-1902. 8(4).

When, Lehrb. Naturg. - - [Lorenz von] Okens Lehrbuch der Naturgeschichte. - 3. Theil. Zoologie. Abtheilung 1,2. Mlit 1 Atlas. Leipzig und Jena (Leipzig). $1815,16.8 \& 4$.

P. Ac. Plitad. - Proceedings of the Academy of natural Sciences of Philadelphia. Philadelphia. 8.

P. Amer. Ac. - Proceediugs of the American Academy of Arts and Sciences. Boston and Cambridge. 8.

Papilio - Papilio: The Organ of the New York entomological Club. Devoted exclusively to Lepidoptera. New York (Philadelphia). 8.

P. ent. Soc. Washington - Proceedings of the entomological Society of Washington. Washington. 8.

Petiver, Gazophyl. - Gazophylacii Naturae et Artis Decas I.(-X.) In qua Animalia,... Descriptionibus brevibus et Iconibus illustrant ur. Patronis suis et Moecenatibus D. D. D. Jacobus Petiver. Londini. 1702-11. 8(2).

Phil. Mag. - The philosophical llagazine. London. 8.

P. N. Engl. zool. Club - Proceedings of the New England zoological Club. Boston, Mass. 8.

P. zool. Soc. London -- Proceedings of the zoological Society of London. London. 8.

Reise Novara - Reise der Österreichischen Fregatte "Norara" um die Erde in den Jahren 1857, 1858, 1859 unter den Befehlen des Commodore B. ronW üll er st or fUrbair. Wissenschaftlicher Theil. - Zoologischer Theil. 2. Band. II. Abtheilung. Lepidoptera ron Cajetan und Rndolf Felder und Alois F. Rogenhofer. Wien. 1861-75. 4.

Rösel, Insecten-Belustig. - Der monathlich=herausgegebeuen Insecten=Belustigung ... Theil, ... von August Johann Rösel von Rosenlıof. Theil 1-4. Nürnberg $[1746,49], 55,61.4$.

Schomburgk, Guiana - Reisen in Britisch-Guiana in den Jahren 1840-44. Im Auftrage Sr. Majestät des Königs von Prenssen ausgeführt von Richard Schomburgk. - 3. Theil. Versuch einer Fauna und Flora von BritischGuiana. Nach Vorlagen ron Johannes Hüller, Ehrenberg, Erichson, Klotzseh, Troschel, Cabanis und andern. Systematisch bearbeitet rou Richard Schomburglk. Leipzig. 1848. 4.

Scopoli, Annus I.(-V.) hist.-nat. - Ioannis Antonii Scopoli Annus I.(-V.) listorico-naturalis. Lipsiae. $1769,69,69,70,72.8$.

Seba, Thesaurus - Locupletissimi Rerum naturalium Thesauri accurata Descriptio, et Iconibus artificiosissimis Expressio, per universam Physices Historiam. Opus, cui in hoc Rerum Genere, nullum par exstitit. Ex toto Terrarum Orbe collegit, digessit. descripsit, et depingendum curavit Albertus Seba. Tom. 1-4. Amstelaedami. 1734. 35, 61, 65. 2. 
Sepp, Surin. Ilinders - [Johann Sepp] Surinaamsche Vlinders. Naar let Lueven geteckend. Papillons de Surinam. Dessinés d'après Nature. Deel 1-3. Austerdam, J. C. Scpp en Zoon. [1828-48, 48-.., . -52.] 4 .

Shaw, Gen. Zool. - General Zoology, or systematic natural History by George Shaw ([Vol. 9-14:] commenced by the late George Shaw. By James Francis Stepheis). Vol. 1I \& II-14I \& I. London. 1800-26. 8.

Smith \& Kirby (Grosc-Smith), Rhop. exot. - Rhopalocera exotica, being Illustrations of new, rare, or (and) unfigured Species of Butterflies. By H. Grose Smith and W. F. Kirby ([V'ol. 3:] By Henley Grose Grose-Sinith). Vol.1-3. London. 1887-92, 92-97, 97-1902. 4.

Staudinger \& Schatz, Exot. Schmett. - Exotische Schmetterlinge von O. Staudinger. und E.Schatz. 1. Theil: Exotische Tagfalter in systematischer Reihenfolge mit Berücksichtigung neuer Arten von $O$. Staudinger unter teehnischer Jitwirkung von H. Langhans. 2. Theil: Die Fanilien und Gattungen der Tagfalter systematisch und analytisch bearbeitet von E. Schatz, nach deul Tode des Verfassers fortgesetzt von J. Röber. Fürth. 1888 (1884vi一1888xI). 92 (1885xil-92п1). 4.

Stoll, Suppl. Pap. exot. -- Aanhangsel rau het Werk, De uitlundscle Kapellen, roorkomende in de drie Waereld-Deelen Asia, Africa en America, door Pieter Cramer, ...'By een rerzameld en beschreeven door Caspar Stoll. Supplément à l'Ourrage, intitulé les Papillons exotiques, des trois Parties du Honde l'Asic, l'Afrique et l'Amerique; par Pierre Cramer,... Rassemblées et décrits par C. Stoll. Amsteldam. $\left.1791(1787,90)^{*}\right) .4$.

Svenska Ak. Handl. - Kongligu Srenska Vetenskaps-Akademiens Handlingar. Stockholm. $8(4)$.

Thunberg: Mus. Ac. Cpsal. - D. D. MIuseum Naturalium Acadeniae Upsaliensis. Cujus Partem 1. (2., . . 33., - - -) (Append. 1. (2., . . 26.)) Consensu (Venia) Exp. Fac. Jed. Upsal. Praeside Carol. Pet. Thunberg publico Examini proponit (resp.) Fridericus Wilhelm. Radloff (Laur. Magı. Holmer,...). Upsaliae. $1787-1821,27,27 ; 1791-1819.8$.

Tijdschr. Ent. - Tijdschrift roor Entomologie. Uitgegeren door de Nederlandsche entomulogische Vereeniging. Leiden,.... 8 .

Tr. Amer. cnt. Sor. - Transactions of the American entomological Society. I'hiladel phia. 8 Tr. ent. Soc, London - The Transactions of the entomological Socicty of London. London. 8.

Tr. Limn. Soc. London -.- The Transactions of the Jinnean Society of London. [Ser. 2:] Zoology: London. 4.

Terh. Ges. Wien - Verhandlungen der kaiserlich-königlichen zoologisch-botanischen (resellschaft in Wien. Wien. 8.

Terh. Ter. Hamburg - Verhandlungen des Vereins für natmwissenschaftliche Unterhaltung zu Hamburg. Hamburg. 8.

Weymer d Maassen, Lep. Reise Stïbel - W. Reiss und A. Stiibel, Reisen in SïdAmerika. Lepidopteren gesammelt auf einer Reise durch Colombia, Ecuador. Perú, Brasilien, Argentinien und Bolivien in den Jahren 1868-77 von Alphons Stiibel. Bearbeitet ron Gustav Weymer und Peter Maassen. Berlin, 1890. 4.

Wien. ent. Monschr. - Wiener entomologische Monatschrift. Wien. $\star$.

Zool. Jahrb. - Zoologische Jahrbücher. Zeitschrift fïr Systematik. Geographie und Biologie der Thiere. Jena. 8.

*) Cfr.: Carolus Davies Sherborn in: Index An.. r. 1 (1902) p. XX 


\section{Systematischer Index.}

Fam. Heliconiidae . . . . . 1

1. Gen. Heliconius L. . . . . 2

I. Sect. Opisogymni . . . . 38

a. Coh. Silvaniformes. . . . 38

-1. H. narcaea (Godart) . . . 39

- 1a." " narcaea (Godart) 40

-1b.," " polychrous C.\& R.

Felder. . . . . 41

2. " ismenius Latr. . . . . 41

- 2a." " ismenius Latr. . 12

2b." " fasciatus Salv. \&

Godm. . . . . 42

2c." " faunus Staud.. . 13

2d." " hermanni Riff. . 43

-2e." " $"$ telchinia (Doubl.) 43

-2f." " clarescens Butl. . 14

3. ", hippola (Hew.) . . . . 44

3а.," " hippola (Hew.) . 45

3b.," " lyreaeus Weym. . 45

4. "numatus (Cramı.). . . . 45

-4a." " numatus (Cram.). 46

4b." " isabellinus Bates 48

4c." " mavors Werm. . 18

$4 d . " \quad$ " superioris Butl. . 49

-4e.;, " gordius Weym. . 19

4f." " nubifer Butl. . . 50

5. "silvana (Cram.) . . . 50

- 5а.," $"$ silvana (Cram.). 51

5 b." " $\quad$ robigus Weym. . 52

5c. " " metaphorus Weym. 53

- 5d." " ethra (Hb.). . . 54

6. " ethilla (Godart). . . 54

-6a.," " ethilla (Godart). 55

-6b." " eucomus (Hb.) . 56

6c." " tyndarus Weym. . 57

6d.," ., numismaticus

Weym. . . . 58

$-6 \mathrm{e} ., "$ metalilis Butl. . 58

<6f." " mentor Weym. . 58

$-6 \mathrm{~g} . ., \quad . . \quad$ semiflavidus Weym. 59
-6h.H. ethilla claudia Gorm. \& Salr. . . . . 59

6i. " " juntanus Riff.. . 59

6j. " " cephallenia C. \& R.

Felder. . . . . 60

- 6k. " " aërotome C. \& R.

Felder. . . . 60

7. " gradatus Werm. . . . 61

7a. " " gradatus Weym. . 62

7b. " . thielei Riff. . . 62

- 8. " sulphureus Weym. . . . 62

9. " paraensis Riff. . . . . 63

9a." " paraensis Riff. . $6 \pm$

9b. ." " latus Riff. . . . $6 t$

10. ", aulicus Weyn. . . . 65

- 11. "schulzi Riff. . . . . 65

12. "vetustus Butl. . . . . 66

12a. " " vetustus Butl. . 67

12b. " " metellus Werm. . 68

13. "novatus Bates . . . 68

14. "hecale (F.) . . . . . 70

15. " aristiona (Hew.) . . . 71

15a." " aristiona (Hew.). 73

15l." " timaeus Weym. . 73

-15c." " bicoloratus Butl. $7 t$

15d." " phalaris Weym. . it

-15e. " " messene C. \& R.

Felder. . . . 75

-15f. " " euphrasius Werm. 75

15g." " euphone C. \& R.

Felder . . . . $7 \overline{6}$

- 15h., ". tarapotensis Riff. 76

15i. ", lenaeus Weym. .

-15j. " $"$ idalion Weym. . 77

-15k... .. aurora Bates . . 78

-15l. " " arcuella Druce . 99

$15 \mathrm{~m} . ", \quad$ staudingeri Werm. 80

16. "ithaka C. \& R. Felder . 80

16a. ". ithaka C. \& R.

Felder. . . . . 81 
Seite

-16b.H. ithaka vittatus Butl. . 82

-16c." " marius Weym. . 82 17. . pardalinus Bates. . . 82

17a. , .. pardalinus Bates 84 17b. " " lucescens Weym. 84 17c. .. .. radiosus Butl. . 85 17 d. . " maeon Weym. . 85 17e. " " tithoreides Staud. 86 18. "fortunatus Weym. . . 86 18a. " " fortunatus Weym. 87 18b. .. .. spurius Weym. . 87 19. "sergestus Werm. . . 88 20. " ennius Weym. . . . . 89 21. , quitalenus (Hew.) . . 90 21a. . .. quitalenus (Hew.) 91 -21b." .. felix Weym. . . 92 2lc. ". .. versicolor Weym. 93 21d." " sisyphus Salv. . 93 22. ", anderida (Hew.) . . . 94

-22a. " " anderida (Hew.) 95

226. .. " melicerta Bates 95 22 c.,,$\quad$ semiphorus Staud. 97 22d. .. " annetta Riff.. . 97 -22e.." " albucilla Bates . 98 -22f. . " " zuleika (Hew.) . 98 -22g. : : formarina (Hew.) 100 - " arcuatus E. Kirby . . 101 f.u. th " euclea (Godart) . . . 101

b. Coh. Cydnoformes . . . . 101 23. H. cydno (Doubl.) . . . 102 23a. .. " cydno (Doubl.) . 102 23b. " " cydnides Staud. 103 23c. ." " alithea (Hew.) . 104 23d." " hahneli Staud. . 105 23e. ." " temerinda (Hew.) 105 23f. .. ". hermogenes(Hew.) 105 23g. ." " chioneus Bates . 106 23h. " " galantbus Bates 106 23i. " " zelinde Butl.. . 107 24. " weymeri Staud. . . . 107 25. "pachinus Salr.. . . 108 c. Coh. Melpomeneformes . . 109 26. H. rubellius Grose Sm. \& F. Kirby . . . . . . 110 27. "heurippa (Hew.) . . . 110 28. " melpomene (L.) • . . 110 28a. " " melpomene (L.) 111 28b.,$"$ aphrodyte Staud. 114 28c. " " funebris Möschl. 114 28d." " tyche Bates . . 116 28e. " " thelxiope (Hb.). 117 28f. H. melpomeno thelxiopeia

\begin{tabular}{|c|c|c|c|}
\hline $28 \mathrm{~g} . "$ & " & bari (C. Oberth.) & 120 \\
\hline [28h.", & $i$ & elevatus Nöldner & $120 \Delta \%$. \\
\hline 28i. ", & .. & $\begin{array}{l}\text { aglaope C. \& R. } \\
\text { Felder . . . . }\end{array}$ & 121 \\
\hline $28 \mathrm{j} . "$ & .. & vicinus (Ménétr.) & 122 \\
\hline 28k. , & $\because$ & eulalia Riff.. . & 123 \\
\hline 281. & " & penelope Staud. & 124 \\
\hline $28 \mathrm{~m} .$, & $"$ & timareta (Hew.) & 125 \\
\hline 28n. , & " & erebius Riff. . . & 127 \\
\hline & 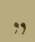 & amandus Grose Sm. &.$\&$ \\
\hline & & F. Kirby . . . & 127 \\
\hline
\end{tabular}

29. " amaryllis C. \& R. Felder 128

29a. " " amatyllis C. \& R.

Felder . . . 129

29b. " " euryades Riff. . 129

29c. " " rosina (Boisd.) . 130

30. " vulcanus (Butl.) . . . 131

-30a." " vulcanus (Butl.) 131

-30b. " " cythera (Hew.) . 132

31. " batesi Riff. . . . . 133

32. "namma Stich. . . . . 134

-33. " besckei (Ménétr.) . . . 135

d. Coh. Atthidiformes . . . 135

34. H. atthis (Doubl.) . . . 136

II. Sect. Opisorhypari . . 137

a. Coh. Hecalesiformes . . . 137

35. H. crispus Staud. . . . 138

36. "hecuba (Hew.) . . . 138

37. " choarinus (Hew.) . . . 139

38. " cassandra C. \& R. Felder 140

-39. " hecalesia (Hew.) . . . 140

39a. " " hecalesia (Hew.) 141

39b. " " formosus Bates. 142

39c. " " gynaesius (Hew.) 142

-40. "octavia Bates . . . . 143

41. " longarenus (Hew.) . . 143

b. Coh. Aoediformes. . . . 144

-42. H. godmani Staud. . . 145

-43. "metharme (Er.) . . . 145

-44. " aoede (Hb.) . . . . . 146

44a. " " aoede (Hb.) . . 147

44b. " " astydamia (Er.) 148

44c. " " lucretius Weym. 148

44d." " bartletti Druce . 149

c. Cob. Xantbocledoformes . . 149

45. H. xanthocles Bates . . . 150

45a. " " xanthocles Bates 151

45b." " vala Staud. . . 151

45c. " " paraplesius Bates 152 
Seite

45d.H. xanthocles melete C. \& $\mathbf{R}$.

Felder . . . . . . 152

45 e., " melior Staud. . 153

45 f. " " melittus Staud. 153

d. Coh. Egeriformes. . . . 154

-46. H. egeria (Cram.) . . . . 154

46a.," " egeria (Cram.) - 155

46b." " egerides Staud. 155

46c." " hyas Weym. . . 156

46d." " astraea Staud. . 156

-47. ", burneyi (Hb.) . . . . 157

47a." " burneyi (Hb.) . 158

$47 \mathrm{~b} ., \quad " \quad$ huebneri Staud. 159

47 c.,$\quad " \quad$ catharinae Staud. 159

47 d., $" \quad$ lindigii C. \& R.

Felder . . . 160

e. Coh. Doridiformes . . . 160

-48. H. doris (L.) . . . . . . 161

48a." " doris (L.) . . . 162

48b.," " transiens Staud. 165

$48 \mathrm{c} . ", \quad$ viridis Staud. . 165

48d." " $"$ aristomache Riff. 166

<49. "hierax (Hew.) . . . . 167

" cinereofuscus F. Kirby . 168

f. Coh. Wallaceiformes . . . 168

-50. H. wallacei Reak. . . . . 169

50a.,$\quad$ wallacei Reak. . 169

50b." " mimulinus Butl. 170

50c." " colon Weym. • 170

g. Coh. Sapphoformes . . . 172

-51. H. sapho (Drury) . . . . 172

51a.," " sapho (Drury) . 173

5lb." " leuce (Doubl.) . 174

51c." " eleusinus Staud. 175

51d." " primularis Butl. 175

51e.," $"$ eleuchia (Hew.) 176

52. " hewitsoni Staud. . . . 176

<53. " congener Weym. . . . 177

h. Coh. Antiochiformes . . . 178

54. H. antiochus (L.) . . . . 178

54a." " antiochus (L.) . 179

-54b." " zobeide Butl. . 180

-54c.," " aranea (F.) . . 180

$54 \mathrm{~d} ., " \quad "$ ocannensis Stich. 181

-54e." " salvinii Dewitz . 181

- 55. " leucadia Bates. . . 181

55a." " leucadia Bates . 182

55b." " pseudorhea Staud. 182

$1 / 2$ 2 56. " sara (F.). . . . 182

56a." " $" \quad \operatorname{sara}(\mathrm{F}.) . \quad . \quad 183$

$56 \mathrm{~b} . " \quad " \quad$ apseudes $(\mathrm{Hb}$.) 184 56c. H. sara brevimaculatus

$\begin{array}{cccc} & & \text { Staud. . . . } 185 \\ 256 \mathrm{~d} . " & \text { sprucei Bates } & 185 \\ 56 \mathrm{e} . " & \text { thamal (Hb.) } & 185 \\ 56 \mathrm{f} . " & . & \text { veraepacis Bates } 186 \\ 56 \mathrm{~g} \cdot " & \text { theudela (Hew.) } & 186\end{array}$

i. Coh. Eratoformes . . . 187

257. H. himera (Hew.) . . . 187

58. ., xenoclea (Hew.) . . . 188

58a." " xenoclea (Hew.) 188

58b.., " notabilis Salv. \&

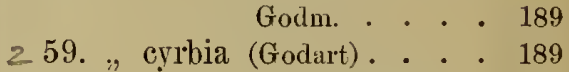

59a." " cyrbia (Godart). 190

5yb." " venus Staud.. . 191

59c., " juno Riff. . . 191

60. " favorinus Hopff. . . . 191

561. " petiveranus (Doubl.). . 192

61a." " petiveranus

(Doubl.) . . . 193

61b., " demophoon

(Ménétr.) . . . 193

62. " hydarus (Hew.). . . . 194

62a." " hydarus (Hew.). 194

62b." " guarica Reak. . 195

62c.," " moliua Grose Sm. 195

62d." " colombinus Stand. 195

62e., . antigona Riff. . 196

z 62f." " chestertonii (Hew.) 196

3.63. " elato (L.) . . . . . 197

63a." " erato (L.). . . 198

3 63b." " amazona Staud. 201

263 c." " cybelinus Staud. 201

63d." " $"$ callycopis (Cram.) 202

४ 63e.," " magnificus Riff. 204

-63f." " estrella Bates . 205

$63 \mathrm{~g} ., \%$ demeter Staud. . 206

$63 \mathrm{~h} ., "$ bouqueti Nöldner 207

63i. " " lativitta Butl. . 207

63j., " " anactorie (Doubl.) 207

3463k., " phyllis (F.) . 208

631. . " anacreon Grose Sm.\&

F. Kirby . . 210

64. , amphitrite Riff. . . 211

2 65. "hermathena (Hew.) . . 212

" carolina (Herbst) . . . 213

j. Coh. Charithoniformes . . 213

66. H. charithonia (L.) . . . 213

66a." " charithonia (L.) 214

66b., " peruvianns (C. \& R.

Felder) . . . 216 
67. H. nattereri C. \& R. Felder 217 68. "fruhstorferi Riff. . . . 218 k. Coh. Clysonymoformes . . 218 1069. H. clysonymus Latr. . . 219 69a." " clysonymusIsatr. 219 69b." " montauus Salv. 220 1069c." " hygiana (Hew.). 221 \70. " hortense (Guér.) . . . 221 271. "telesiphe (Doubl.) . . . 222 7 1a." " telesiphe (Doubl.) 223 7 lb." " sotericus Salr. . 224

2. Gen. Eueides Hb. . . . . 224

I. Sect. Macroscenae . . . 231

i. Coh. Dianassiformes . . . 231

1. A. dianassa Hb. . . . . 232 2. " isabella (Cram.) •. 234 2a." " isabella (Cram.) 235 2b." " hippolinus Butl. 236 2c. " $" \quad$ seitzi Stich. . . 237 2d." " dissolutus Stich. 237 2e." " " pellucidus Sruka 238 2f. " " huibneri Ménétr. 239 $2 \mathrm{~g} . ", \quad " \quad$ arquatus Stich. . 240 3. "cleobaea Geyer. . . 240 3a." " cleobaea Geyer. 242 3b., " zorcaon Reak. . 242

b. Coh. Riciniformes . . . 243 4. E. ricini (L.) . . . . . . 243

II. Sect. Brachyscenae . . . 244

a. Coh. Lampetoformes . . . 244 5. E. lampeto Bates . . . . 245 5a., " lampeto Bates . 246 5b." " fuliginosus Stich. 246 5c. $"$ " acacates Hew. . 247 b. Coh. Vibiliiformes . . . 248 6. E. edias Hew. . . . . . 218 6a." " edias Hew. . . 249 6b." " " luminosus Stich. 250 fic. H. edias vulgiformis Butl. \&

Druce . . . 251

6d., " ellysaces Hew. 251

7. ., procilla Doubl. . . . . 252

8. " vibilia (Godart) . . . . 253

8a." " vibilia (Godart). 254

8 b., " vicinalis Stich. . 256

8c., . vialis Stich. . . 256

8d., " unifasciatus Butl. 256

9. " pavana Mćnétr. . . . 257

10. " lineatus Salv. \& Godm. . 258

10a." " lineatus Salv. \&

Godm. . . . . 259

10b." " libitina Stand. . 260

c. Coh. Lubiilformes . . . . 260

11. E. aliphera (Godart) . . . 260

11a., " aliphera (Godart) 261

11b." " gracilis Stich. . 262

12. "lybia (F.) . . . . . 262

12a." " lybia (F.) . . . 262

12b." " lybioides Staud. 263

13. "olympia (F.) . . . . 263

d. Coh. Thaletoformes . . . 264

14. E. tales (Cram.). . . . . 264

14a." " tales (Cram.). . 265

14b., " pythagoras F.

Kirby • • • 266

14c.. $" \quad$ surdus Stich. . 267

15. "heliconioides C. \& R.

Felder . . . 267

15a." " heliconioides C. \&

R. Felder . . . 268

15b., " xenophanes C. \& R. Felder . . 268

16. "eanes Hew. . . . . . 268

16a." " eanes Hew. . . 269

16b., " eanides Stich. . 270

16c." " felderi Stich. . 271

$16 \mathrm{~d} ., \quad " \quad$ riflarthi Stich. . 271 



\section{Fam. Heliconiidae}

1827 Heliconidae, W. Swainson in: Phil. Mag., n. ser. v.1 p. $187 \mid 1833$ „Hcliconides“, Boisduval \& Leconte, Lép. Amér. sept., v. 1 p. $138 \mid 1836$ „Heliconides“, Boisduval, Spéc. gén. Lćp., v. 1 p. 165 | 1840 "Heliconites" (part.), E. Blanchard in: Hist. An. artic., v. 3 p. 436 | 1844 Heliconidae (part.), E. Doubleday, List. Lep. Brit. N us., v. 1 p. 52 | 1847 H., E. Doubleday (\& Westwood), Gen. diurn. Lep., v. 1 p.96| 1851 T'rib. H. (part.) + Divis. Argynitae (part.), Chenu \& H. Lucas, Line. Hist. nat., Yap. diurn. p. 66, $80 \mid 1853$ $H$. (part.), A. R. Wallace in: Tr. ent. Soc. London, n. ser. v. 2 p. $258 \mid 1862$ AcraeoidHeliconidae, Subfum. Heliconinae, H.W. Bates in: Tr. Linn. Soc. London, v. 23 p. 496; 515,553 | 1862 Heliconiidae, C. \& R. Felder in: Wien. ent. Mlonschr., v. 6 p. 79 | 1864 Heliconina (part.). Herrich-Schäffer in: CB. Ver. Regensburg, v. 18 p. 96, $175 \mid 1864$ Subfam. Heliconinae, H. W. Bates in: J. Ent., v. 2 p. $176 \mid 1869$ Subfam. H. (part.), A. G. Butler, Cat. diurn. Lep. Fabr., p. $119 \mid 1870$ "Heliconides" (part.) + "Acréides" (part.), Boisduval, Consid. Lép. Guatemala, p. 28. 35|1871 Subfam. Heliconinae, W. F. Kirby, Cat. diurn. Lep., p. 138 | 1874 Trib. "Helironides" (part.). Capronnier in: Ann. Soc. ent. Belgique, v. 17 p. $23 \mid 1874$ Subfam. Heliconinae, A. (1. Butler \& Herb. Druce in: P. zool. Soc. London, p. $350 \mid 1875$ Heliconidae (part.), S. H. Scudder in: Bull. Buffalo Soc., v. 2 p. $245 \mid 1877$ H. (part.), Fritz Müller in: Ent. Zeit. Stettin, v. 38 p. $492 \mid 1877$ Subfam. Heliconinae, A. G. Butler in: Ann. nat. Hist., ser. 4 v. 20 p. $119 \mid 1877$ H., A. G. Butler in: 'Tr. ent. Soc. London, p. 123 | 1878 Trib. "Héliconidcs", Bar in: Ann. Soc. ent. France, ser. 5 v. 8 p. 23 ! 1881 Subfam. Heliconinae, F. D. Godman \& O. Salvin in: Biol. Centr.-Amer., Lep.-Rhop. v. 1 p. $143 \mid 1886$ H., G. W. Müller in: Zool. Jahrb., v. 1 p. 428 | 1887 Heliconina (part.), P. Snellen in: Tijdschr. Ent., v. 30 p. $13 \mid 1887$ "Heliconiden", (O. Staudinger \&) Schatz, Exot. Schmett., v. 2 p. $104 \mid 1891$ Subfam. Heliconinae, E. Haase in: D. ent. Z. Lep., v. 4 p. 32 | 1893 "Heliconiden", Weymer in: D. ent. Z. Lep., v. 6 p. 281 | 1895 Heliconidi, T. A. Chapman in: Ent. Rec., v. 6 p. 152 | 1896 "Heliconiden", Subfan. Heliconiinae (part.), E. Reuter in: Acta Soc. Sei. Fenn., v. 22 p. 48; 554 | 1898 Subfam. Heliconiinae, E. Reuter in: Ent. Rec., v. 10 p. $96 \mid 1898$ Subfam. H., K. Jordan in: Nov, zool., v.5 p.387/ 1900 Subfam. H., W. F. Kirby, Exot. Sehmett. Hübner, p. $10 \mid 1902$ Heliconidae, Dyar in: Bull. U. S. Mus., v. 52 p. 32.

Körper sehlank. Kopf breit. mit großen, elliptischen, gewölbten Augen. Antennen verschieden gebildet. Palpen aufrecht, deutlich dreiteilig, wenig über den Kopf hervorragend, mit einem dorsal sitzenden Haarschopf am distalen Teil des Mittelgliedes, ihr Querschnitt eirund. Vorderbeine bei beiden Geschlechtern verkümmert.

Vorderflügel länglich mit abgerundetem Apex (Torderwinkel, Flügelspitze), zuweilen stumpf dreieckig; Distalrand (AuBemrand) hinter dem Apex seltener geeckt und ausgeschnitten. Subcostalis fünf-ästig; Zelle lang, geschlossen; Submediana an der Wurzel nicht gegabelt, Mediana proximal mit kurzem, nach hinten gerichtetem Dorn (Mediansporn). - Hinterflügel fast eirund oder stumpf dreieckig, mit wenig hervortretendem Apex und abgerundetem Hinterwinkel. Zelle kurz und schmal, geschlossen: Costalis in den Apex mündend, Praecostalis gegen die Flügelwurzel gericlıtet;

Das Tierreich. 22. Lief.: H. Stichel \& H. Riffarth, Heliconiidae. 
Hinterrand ohne eine den Leib umschließende Falte, Distalrand eben oder schwach gewellt.

Raupen walzenförmig, mit verzweigten Dornen besetzt. Puppe hängend, dor'nig, stachelig oder warzig.

Bau des Falters, Form der Raupe, aufgehängte Puppe sprechen für nahe Verwandtschaft mit den Nymphalidae, zu denen die Gattungen Colaenis, Dione und Cethosia wegen gleicher Lebensgewohnheiten und Nahrungspflanzen (Passifloren) der gleichen Dornenraupen einen unverkennbaren natürlichen Übergang bilden. Morphologisch getrennt von diesen sind die Heliconiidae durch die vollkommen röhrig entwickelte hintere Discocellularis des Hinterflügels. Von den Neotropidae, denen viele Heliconiidae in Zeichnung und Gestalt täuschend ähneln, sind diese unterschieden durch die Gestaltung der Submediana des Vorderflügels, die bei ihnen ungegabelt, dagegen bei den Neotropidae ebenso wie bei den Danaidae an der Wurzel gegabelt ist. Von den Acraeidae sind die Heliconiidae unterschieden durch die Palpen, meist entgegengesetzte Richtung der Praecostalis und den MLediansporn. Den Heliconiidae ähnliche Formen gibt es auch unter den Pieridae (Dismorphia) und den echten Nymphalidae (Eresia), die indes unschwer an den besonderen Familienmerkmalen zu erkennen sind.

Süd- und Mittel-Amerika, Antillen, südliches Nord-Amerika.

2 Gattungen, 87 sichere Arten, von denen 49 in 214 Unterarten zerfallen, und 4 unsichere Arten.

Übersicht der Gattungen:

Antennen dünn, über halber Länge des Vorderrandes, distal schwach keulenförmig verdickt, dorsal nur in der proximalen Hälfte dicht beschuppt . . . . .

Antennen unter halber Länge des Vorderrandes, distal mit dentlich abgesetztem Kolben, dorsal bis auf das letzte Glied dicht beschuppt. . . . . . . . 2. Gen. Eueides . . p. 224

\section{Gen. Heliconius L.}

1758 Papilio, [Subgen.] Heliconius (part.), Linné, Syst. Nat., ed. 10 p.458, 465 | 1805 $H$., Latreille, Hist. Crust. Ins., v. 14 p. $108 \mid 1809 H$. (part.), Latreille, Gen. Crust. Ins., v. 4 p. $200 \mid 1815 H$. (part.), Oken, Lehrb. Naturg., v. 1 p. $725 \mid 1817$ H. (part.), Latreille n: G. Cuvier, Règne an., v. 3 p. $519 \mid 1819$ H. (part.), Latreille (\& J. B. Godart) in: Enc. méth., v. 9 p. $10 \mid 1832$ H., G. R. Gray in: E. Griffith, An. Kingdom, v. 15 p. $586 \mid$ $1862 H$., H. W. Bates in: Tr. Linn. Soc. London, v. 23 p. $553 \mid 1862$ H., C. \& R. Felder in: Wien. ent. Monschr., v. 6 p.79 | 1875 H., S. H. Scudder in: P. Amer. Ac., v.10 p.185 | $1875 H$., S. H. Scudder in: Bull. Buffalo Soc., v. 2 p. $235 \mid 1877 H$., Fritz Müller in: Ent. Zeit. Stettin, v. 38 p.492 | 1881 H., F. D. Godman \& O. Salvin in: Biol. Centr.-Amer., Lep.-Rhop. v. 1 p. $143 \mid 1887$ H., (O. Staudinger \&) Schatz, Exot. Schmett., v. 2 p. 105 \} 1893 H., Weymer in: D. ent. Z. Lep., v. 6 p. 281 । 1900 H., W. F. Kirby, Exot. Schmett. Hübner, p. $10 \mid 1900$ \& 01 H., Riffarth in: Berlin. ent. Z., v. 45 p. $183 ; v .46$ p. $25 \mid 1807$ Mechanitis (part.), (J. C. Fabricius in:) Illiger in: Mag. Insektenk, v. 6 p. 284 | 1822-26 M., Mechanites, Jac. Hübner, Exot. Schmett., v. 2 | 1816 Eueides (part.) + Melinaea (part.) + Migonitis (non Rafinesque 1815, Mollusea!) (part.) + Sunias + Apostraphia (part.) + Sycionia, Sicyonia + Ajantis, Jac. Hübner, Verz. Schmett., p. 11-13 | 1819 Heliconic (part.), (Latreille \&) J. B. Godart in: Enc. méth., v. 9 p. 203 | 1833 H. (part.), Boisduval \& J. E. Leconte, Lép. Amér. sept., v. 1 p. $138 \mid 1837$ H. (part.), Jam. Duncan, Foreign Butt., p. 133 | 1844 H. (part.). E. Doubleday, List Lep. Brit. ILus., v. 1 p. 53 | $1847 H$. (part.), E. Doubleday (\& Westwood), Gen. diurn. Lep., v. 1 p. $101 \mid 1851$ H. (part.), Chenu \& H. Lucas, Enc. Hist. nat., Pap. diurn. p. $67 \mid 1862$ \& 64 H., HerrichSchäffer in: CB. Ver. Regensburg, v. 16 p. 28, 146; v. 18 p. $97,179 \mid 1870$ H., Boisduval, Consid. Lép. Guatemala, p. 28 | 1820 Laparus, Billberg, Enum. Ins., p. $77 \mid 1822-26$ Phlogris (Sp. un.: P. melpomene), Jac. Hübner, Exot. Schmett., v. 2 t. (5) | 1880 ? Blanchardia (Sp. un.: B. dismorphia), Buchecker, Syst. Ent., Lep. t. $51 \mid 1896$ Heliconias, Bönninghausen in: Verh. Ver. Hamburg, v. 9 p. 32. 
Körper schlank, kurz und dicht behaart und beschuppt. Abdomen schlank, meist über den Hinterflügel hinausragend, selten kïrzer, beim o zuweilen am Hinterende keulenförmig verdickt. Kopf breit, Angen elliptiscll, gewölbt, nackt. Antennen gerade, dünn, wenig kürzer oder etwas länger als die \%elle des Vorderflügels, ohne deutlich abgesetzten Kolben, distal allmählich verdickt, an der Spitze wiederum verjüngt, ventral nackt, dorsal in der proximalen Hälfte dicht mit schmalen Schuppen besetzt, in der distalen Hälfte spärlich oder gar nicht beschuppt. Palpen nur wenig über den Kopf hinausiagend, diesem eng anliegend, ihr Querschnitt eirund; Wurzelglied kurz, aufwärts gekrümmt, Mittelglied fast gleich stark, etwas mehr als doppelt so lang wie ersteres, schwach S-förmig aufwärts gebogen; Endglied kurz, spitz, etwas

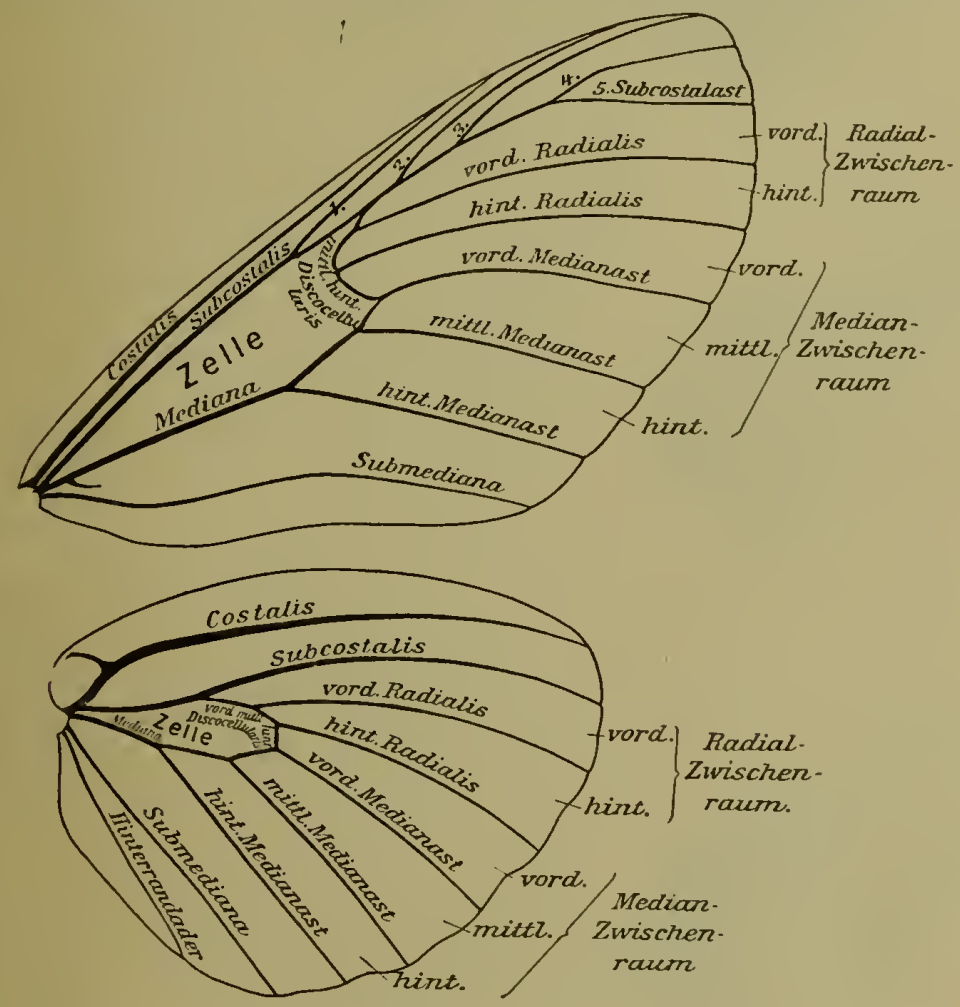

Fig. 1. H. antiochus, $\sigma^{\pi}(\% / 1)$. Flügelgeäder.

nach vorn gerichtet. Alle Glieder der Palpen dicht beschuppt und spärlicher behaart; die dorsal stehenden Haare am distalen Teil des mittleren Gliedes dicht gedrängt, aufwärts gebogen und einen der Stirn anliegenden, schopfartigen Büschel bildend. Vorderbein des Ơ glatt und dicht beschuppt, spärlicher behaart, mit einem länglichen, ungegliederten, an der Spitze verjüngten Tarsus, der ungefähr halb so lang wie die Tibia ist; letztere etwa so lang wie das Femur. Vorderbein des o mit fünfgliedrigem Tarsus; jedes Glied des Tarsus distal mit einem Paar kurzer Dor'ıen, das letzte mit einem kurzen spitzen klauenartigen Fortsatz, versehen, erstes Glied länger als die vier anderen zusammen; Femur etwas länger als die Tibia, diese doppelt so lang wie der Tarsus; alle Teile dicht beschuppt, spärlich behaart, Haare besonder's an der Seite von Femur und Tibia in beiden Geschlechtern leicht gescheitelt. 
Tordertlügel (Fig. 1) länglich, gestreckt, seltener stumpf dreieckig. Vorderrind schwach gekrimmt, Apex abgerundet, selten spitzer. Distalrand schwach kouvex, selten konkav hinter einer vorspringenden Ecke. Hinterwinkel stumpf, mehr oder weniger abgerundet, Hinterrand sanft geschweift, bedeutend kürzer als der Vorderrand. Costalis und Subcostalis getrennt. Erstere bis ïber die Mitte des Vorderrandes reichend. Subcostalis in den Vorder- und Distalrand müıdend, fünf-ästig. Der erste Ast entspringt proximal von der vorderen Ecke des Zellendes, der zweite Ast meist in mäßigem Abstande distal von derselben. oder aber dicht an der Zellecke, beide in den Vorderrand laufend. Die Iage des \%weiten Subcostalastes ist unbeständig und selbst bei ein und derselben Art Schwankungen unterworfen. Der dritte Ast liegt etwa auf der Hälfte zwischen dem zweiten und vierten, und endet am Apex; vierter und fünfter Ast eine mäßig lange Gabel bildend, ersterer kurz, letzterer etwas weiter hinter dem Apex in den Distalrand nündend. Vordere Discocellularis sehr kurz, mitunter ganz verkiimmert, mittlere und hintere etwa gleich lang, winklig in die Zelle eingeschoben oder einen kurzen Konkarbogen bildend, zuweilen mit 1 oder 2 kleinen, proximal gerichteten Aderansätzen. Mediana dicht an der Wurzel hinten mit einem distalwärts gekrümmten Sporı, in dessen Verlängerung sich eine leicht gebogene, schwache Faltenader bis zum Distalrande verfolgen läßt. - Hinterflügel (Fig. 1) elliptisch, am Vorderrande abgeflacht, oder abgestumpft dreieckig mit konvex gekrïmmten Seiten. Vorderrand beim $\sigma^{*}$ stärker gekrïmmt als beim $q$. Costalis ron der Subcostalis weit getrennt. Erstere verlänft beim $\sigma^{\sigma}$ in weit flacherem Bogen als der Vorderrand, beim $q$ in etwa gleich gekrümmtem Bogen wie dieser in den Apex. Praecostalis schief nach der Wurzel gekrümmt. Distalrand eben oder schwach gewellt. Kelle schmal und kurz. Discocellulares deutlich röhrig; vordere und mittlere schräg distalwärts gerichtet, hintere weniger schräg oder quer in den vorderen Medianast einlaufend; alle drei fast gleich lang, oder die mittlere verkürzt und die vordere wesentlich verlängert. nahe der Flügelwurzel aus der Subcostalis entspringend. Hinterrandader zart, geschweift und im distalen Drittel des Hinterrandes endigend. Länge des Vorderflïgels etwa $30-50 \mathrm{~mm}$. Flingel meist lebhaft und bunt gefärbt, mit schwarzen Zeichnungen auf hellem, oder farbigen Zeichnungen auf schwarzem oder dunklem Grunde.

Raupe an Passifloren (gesellig?), walzenförmig, unansehnlich gefürbt, mit verzweigten Dornen und zwei mäBig divergierenden Hörnerı am Kopf. — Puppe schlank. hängend, Flügelscheide ventral vorgezogen, Körper dorsal dementsprechend eingedrïckt, dornig und höckerig oder warzig, mit zwei Fortsätzen am Kopf ind drei seitlich bewegbaren Gelenkrerbindungen.

Die Angehörigen der Gattung sind sowohl in Zeichnung als in Färbung der Flügel vielfach außerordentlich rariabel und unbeständig, so daß Kennzeichen zur Trennung der Arten und Unterarten schwierig festzulegen sind. Die Grundfarbe der Flügeloberseite kann durch die anders gefärbte Zeichnung mehr oder weniger eingeschränkt. unter Umständen auf dem Vorder- oder Hinterflügel auch ganz verdrängt werden. Dies betrifft namentlich die Vertreter der Silvaniformes. Diese und zwei einer anderen Gruppe angehörigen Formen (H. hecalesia hecalesia und H.h.formosus) sind dadurch gekennzeichnet, daB die Grundfarbe des Vorder-oder Hinterflüg els oder beider braun oder gelb ist (vgl. die folgende Übersicht), und sie lassen sich sämtlich auf die in Fig. 2 dargestellte Form zurückführen. Die Grundfarbe der Flügel ist hell- bis mahagonibraun. Der Yorderflügel besitzt eine schräge hellere (gelbe oder weiße) Querbinde. A pex schwarz, ebenso ein sich längs der Submediana hinziehender, bald schmalerer, bald breiterer Streif (Submedianstreif). Fleckenzeichnungen ebenfalls schwarz, und zwar: ein Fleck in der Mitte der Zelle, der in 
proximaler Richtung, unmittelbar oder schmal getrennt, inehr ader woniger wisch-oder keilartig verlïngert sein kann (Keilfleck); ein Fleck im distalen l'eil cler Zelle, meist mit dem scliwarzen Vorderrande verflossen (Endzellfleck); zwei Flecke hintereinander im proximalen Teil des hinteren und inittleren Medianzwischenraumes, dicht an Zellende (vorderer und hinterer Medianfleck); cin dreieckiger, streifen- oder hakenförmiger Fleck im distalen Teil des linteren Medianzwischenraumes (R andfleck). Endzellfleck, Medianflecke und Randfleck können unter sich und auclı mit dem verbreiterten schwarzen Apicalteil zusammenfließen, so daß die helle Querbinde ron der (Yrundfarbe nbgeschnitten und durchbrochen wird und sich in melır oder weniger zusammenhängende oder ganz getrennte Flecke verwandelt (Fig. 3). In weiteren können sich Submedianstreif und Keilfleck verbreitern, zusammenfließen und mit der bereits scluwarz gelärbten distalen Hälfte vereinigen, so daß von der Grundfarbe nur eine braune Wurzelbestäubung zurückbleibt (Fig. 4) oder selbst diese verschwindet. in welchem Falle jedoch stets der Hinterflïgel vorherrschend braun bleibt. Der Hinterflügel ist entweder ganz braun, ohne wesentliche Zcichnung. oder hat (wie in Fig. 2) eine schwarze Saumbinde und eine gleiche Mittelbinde, die auch verkürzt, versclımälert oder in Flecke aufgelöst sein köunen. Öfter's hängen aber auch Yittel- und Saumbinde mehr oder weniger zusnmmen; zuweilen eutsteht dann ein eirunder schwarzer Fleck, der so groß werden kann, daß er den gauzen Flügel bis auf den Apex einnimmt. In diesem Falle ist aber die braune Grundfarbe auf dem Vorderflügel in ihrer ursprünglichen Ausdehnung verblieben ( $H$. aristiona). - Auf der Unterseite ist für of ein schwärzlicher, den Vorderrand selbst schmal freilassender Streif vor der Costalis (Costalstreif) und ein solcher zwischen Costalis und Subcostalis (Subcostalstreif) bezeichnend. Diese Streife fehlen selten oder sind rückgebildet, dagegen ist der Subcostalstreif nahe der Mitte oft braun oder gelb unterbrochen. Beim $q$ ist in der Regel nur der Subcostalstreif, und zwar nicht nur unterseits, sondern auch oberseits vorhanden. - In demselben IIaße, wenngleich in ganz anderer Weise rariiert die Zeichnung bei den Gruppen der Melpomeneformes und Eratoformes, die dadurch gekennzeiclinet sind, daß die Grundfarbe schwarz. sehwarzbrau oder blau ist (rgl. die folgende Übersicht). Hier besitzt der Vorderflügel einen in der Mlitte gelegenen, bindenartigen, farbigen Fleck. der durch den Einfluß der

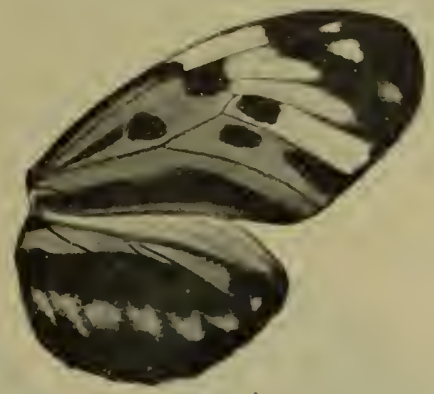

Fig. 2.

H. numatus superioris, forma principalis.

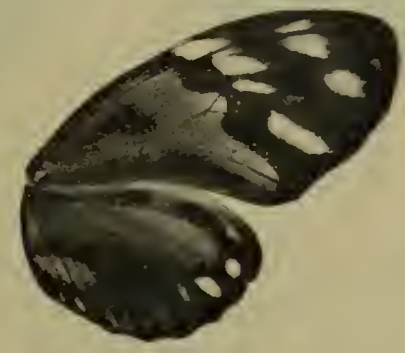

Fig. 3.

H. numatus superioris, forma geminata.

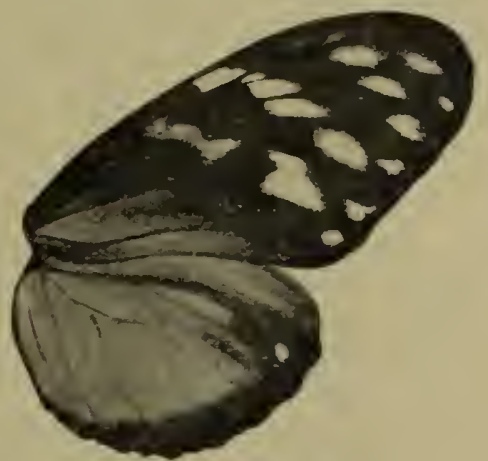

Fig. 4 .

H. anderida zuleika, forma principalis.

Grundfarbe in rerschiedenartige Zeichnungen zerlegt wird. Als einfachste dieser Formen ist die in Fig. 5 dargestellte anzusehen: Vorderflügel mit geschlossener breiter Schrägbinde. In diese dringt ron hinten und aus der Jitte die dunkle Grundfarbe ein und durchsetzt dieselbe derart, daß eine unregelmäßige, nicht genau zu bestimmende Zeichnung entsteht (Fig. 6). Schreitet die Zersetzung noch weiter fort, so bleibt am distalen Zellende eine Gruppe getrennter Flecke oder ein einzelner Flleck übrig und in einiger Entfernung distal ron demselben eine Fleckengruppe oder Binde (Fıg. 7). 
In allen drei Fällen tritt außerdem oft rote Bestäubung von der Wurzel aus auf, die mit der Zeichnung der Flügelmitte zusammenfließen kann und, wenn diese der in Fig. 5 dargestellteu Form entspricht, die Grundfarbe wesentlich einschränkt. Rote und gelbe Färbung ist unbeständig, tritt je für sich oder nebeneinander, und zwar entweder getrennt oder auch in ein und derselben Zeichnungsanlage auf. Hinterflügel im einfachsten Falle einfarbig oder aber mit Strahlen- oder Binden-Zeichnung oder mit beiden, meist in einer, seltener in beideu Farben (gelb und rot), zuweilen einen größeren Teil des Flïgels einnehmend, jedoch nie so, daß die schwarze Grundfarbe zu verkennen ist. Die Zeichnungen der Vertreter aller anderen Gruppen sind, wenn teilweise zwar auch

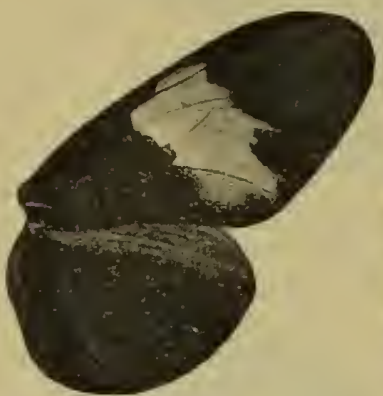

Fig. 5.

H. erato callycopis, forma viculata.

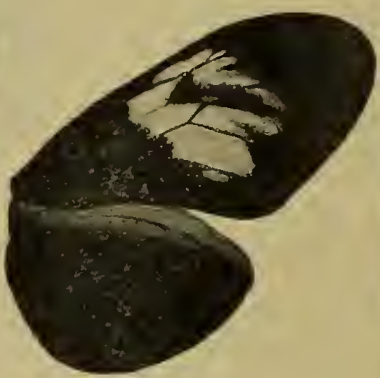

Fig. 6.

H. erato callycopis forma principalis.

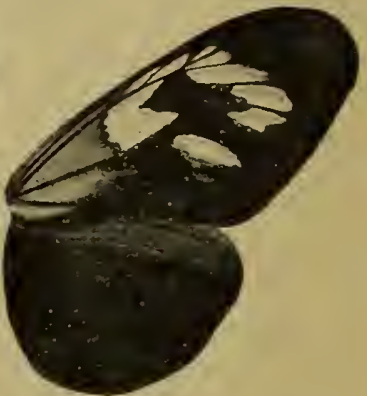

Fig. 7.

H. erato cybelinus, forma amalfreda.

variabel, so doch in solchem $\mathrm{Haße}$ begrenzt, daß sie aus den Kennzeichnungen in der Übersicht ohne weiteres erkannt werden können.

Fast über das ganze tropische und subtropische Süd-Amerika verbreitet, namentlich Bewohner des äquatorialen Gürtels, südlich etwa bis zum 32. Breitengrad, nördlich durch Mittel-Amerika bis Mexiko, eine Art. (H. charithonia) bis in die gemäßigte Zone Nord-Amerikas (Florida und Texas) und aut den Antillen. - Die Tiere lieben sonnige Stellen des Waldes und Waldränder, auch feuchte Niederungen; sie steigen im Grebirge in Höhen bis $2000 \mathrm{~m}$ und darüber. Ihr Flug ist langsam und segelnd, sie ruheu mit aufgerichtcten Flügeln auf Blättern und Blüten.

71 sichere Arten, von denen 38 in 179 Unterarten zerfallen, und 4 unsichere Arten.

Übersicht der sicheren Arten und der Unterarten:

$\left\{\begin{array}{l}\text { Grundfarbe*) des Vorder- oder Hinter- } \\ \text { flügels oder beider braun oder } \\ \text { gelb }-2 \text {. }\end{array}\right.$

Grundfarbe beider Flïgel schwarz, schwarzbraun oder blau - 103.

Vorderflügeloberseite vorherrschend schwarz bis auf bräunliche Wurzel-

2 ) bestäubung - 3 .

Vorderflügeloberseite nicht vorherrschend schwarz -6 .

Vorderflügeloberseite mit vier Reihen

$3\{$ weißer Flecke - 4.

Vorderflügeloberseite mit vier Reihen gelber Flecke - 5 .

*) Vgl. die Kennzeichnung der Gattung (S. 4-6). 
4

(

$\left\{\begin{array}{c}\text { Vorderflügel proximal reichlich braun } \\ \text { bestäubt } \ldots \\ \begin{array}{c}\text { Vorderflügel proximal wenig braun } \\ \text { bestäubt oder ganz schwarz }\end{array}\end{array}\right.$

Vorderflügel obne Querbinde, die heller

Vorderflügel mit gelber oder gelblicher, schrägliegender Querbinde - 31 .

Vorderflügel vorherrschend schwefel-

7 gelb, auch proximal......

Vorderflügel hell- bis dunkelbraun - 8.

$8\left\{\begin{array}{l}\text { Apex des Vorderflügels schmal schwarz } \\ \text { oder breiter schwarz schattiert }-8 .\end{array}\right.$

I A pex des Vorderflïgels breit schwarz - 15 .

( Vorderflügel ohne gelbe Flecke im

$9\{$ Apex - 10.

Vorderflügel mit gelben Flecken im Apex - 11.

Hinterfliigel bis auf einen distalen Teil

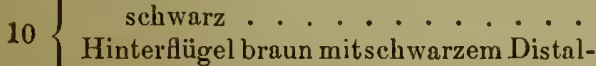
saum und ebensolcher Mittelbinde

15d. H. aristiona phalaris . . . p. 74

151. H. aristiona arcuella . . p. 79
$22 \mathrm{f}$. H. anderida zuleika, forma jucunda. . . . . p. 100

22 f. H. anderida zuleika, forma albipunctata .... p. 99

xanthica ..... p. 100

$22 \mathrm{f}$. H. anderida zuleika, forma principalis . . . . p. 98
$22 \mathrm{f} . \mathrm{H}$. anderida zuleika, forma

8. H. sulphureus . . . . p. 62

Schwarze Saumbinde des Hinterflügels

11 in Gestalt spitzer Dreiecke - 12.

Schwarze Saumbinde des Hinterflügels voll, geschlossen - 13 .

Saumdreiecke des Hinterflügels zusammenhängend . . . . .

Saumdreiecke des Hinterflügels getrennt oder verloschen .....

17c. H. pardalinus radiosus, forma principalis ... p. 85

17e. H. pardalinus radiosus, forma dilata .... p. 85

Die Saumbinde des Hinterflügels reicht bis zum Vorderrande und ist von der Mlittelbinde stets getrennt ....

Die Saumbinde des Hinterflügels erreicht den Apex nicht und fließt zuweilen mit der Mittelbinde zusammen - 14 .

(Apex des Vorderflügels vorherrschend braun mit großen gelben Flecken

14 Apex des Vorderflügels schwärzlich schattiert mit kleinen gelblichen oder braunen Flecken. . . . 15k. H. aristiona aurora, forma florida....... p. 79 
Die distale schwarze Färbung des Vorderflïgels reicht bis in die Zelle - 16.

Die distale schwarze Färbung des Vorderflügels erreicht die Zelle nicht - 18.

Vorderflügel mit einer Reihe weißer Flecke im Apex ....... Vorderflügel mit zwei Reihen weißer Flecke im Apex - 17.

Hinterflügel mit durchgehender 17 schwarzer Mittelbinde..... Hinterflügel mit Ansatz einer schwarzen Mittelbinde, ausgehend rom Apex

Im Apicalteil des Vorderflügels gelbe Flecke - 19. $18\left\{\begin{array}{l}\text { Ohne Flecke im Apicalteil dés Vorder- } \\ \text { flügels - 25. }\end{array}\right.$

Die gelben Flecke des Vorderflügels 19

Die gelben Flecke des Vorderflügels deutlich getrennt - 20 .

Saumbinde des Hinterflïgels aus spitzen keilförmigen Flecken bestehend - 21 .

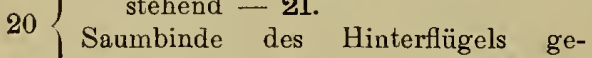
schlossen, zuweilen mit der Mittelbinde zusammengeflossen - 22 .

$21\left\{\begin{array}{c}\text { Mittelbinde des Hinterflügels in Flecke } \\ \text { aufgelöst . . . . . . . . . . . . . . . . . } \\ \text { Mittelbinde des Hinterflügels zusammen- } \\ \text { hängend . . . }\end{array}\right.$

Keilfleck in der Zelle des Vorderflügels $22\{$ fast kreisiund -23.

Keilfleck in der Zelle des Vorderflügels langgestreckt -24 .

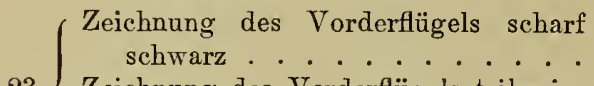

Zeichnung des Vorderflügels teilweise verloschen oder durch dunkelbraune Schattierung ersetzt.....

(Schwarze Zeichnung im mittleren Teil des Vorderflügels teilweise zusammengeflossen ......

Schwarze Zeichnung im mittleren Teil des Vorderflügels aus getrennten Flecken bestehend ......

\footnotetext{
25 $\begin{gathered}\text { Hinterflügel einfarbig braun oder nur } \\ \text { mit Ansatz einer Mittelbinde }\end{gathered}$

Hinterflügel mit weiteren Zeichnungen -26 .
}

2d. H. ismenius hermanni . . p. 43

2b. H. ismenius fasciatus . . p. 42

2a. H. ismenius ismenius . . p. 42

15k. H. aristiona aurora,

forma principalis . , . p. 78

17d. H. pardalinus maeon . . p. 85

17e. H. pardalinus tithoreides, forma secunda . . . p. 86

4b. H. numatus isabellinus . p. 48

4c. H. numatus mavors . . . p. 48

21b. H. quitalenus felix, forma concors ...... p. 93

21d. H. quitalenus sisyphus, forma jonas ..... p. 94

3b. H. hippola lyreaeus . . p 45 
$26\{$ Hinterflügcl mit deutlicher Mittel- und

Hinterflügel vorherrschend schwarz -30 .

Die Saumbinde des Hinterflügels er-

27 reicht den Apex nicht - 28.

Die Saumbinde des Hinterflügels erreicht den Apex - 29.

(Schwarze Zeichnung im mittleren Teil des Vorderflügels schräg bindenartig zusammengeflossen . . . 15k. H. aristiona aurora, forma seraphion ..... p. 79

Schwarze Zeichnung im mittleren Teil des Vorderflügels aus getrennteu gleichmäßigen Flecken bestehend.

15b. H. aristiona timaeus . . p. 73

Saumbinde des Hinterflügcls in Apex mit der Mittelbinde vereinigt . .

Saumbinde des Hinterflügels im Apex

29 von der Mittelbinde getreunt oder nur durch einen Bogenstrich verbunden

3a. H. hippola hippola . . . p. 45

21d. H. quitalenus sisyphus, forma principalis . . . p. 93

Proximales Feld des Vorderflïgels schwarz . . . . . . . .

Proximales Feld des Vorderfügels malıagonibraun ....... .

Proximales Feld des Vorderflügels vorherrschend in der Grundfarbe

15c. H. aristiona bicoloratus - p. 74

15a. H. aristiona aristiona, forma splendida . . p. 73

15a. H. aristiona aristiona, forma principalis ... p. 73

31 Apex des Vorderflügels schmal schwarz oder schwärzlich schattiert $-\mathbf{3 2}$.

A pex des Vorderflïgels breit schwarz - 36 .

Submedianstreif des Vorderflügels distal breit dreieckig, lanzenförmig auslaufend .........

Submedianstreif distal gleichmäßig zugespitzt -- 33.

6k. H. ethilla aërotome, forma prima ...... p. 60

Hinterer Mediantleck des Vorderflügels fehlt .........

Hinterer Medianfleck vorhanden - 34 .

Die Saumbinde des Hinterflügels erreicht den Apex . . . . ... .

Die Saumbinde des Hinterflügels erreicht den Apex nicht - 35.

21c. H. quitalenus versicolor - p. 93

4e. H. numatus gordius . . . p. 49

Apex des Vorderflügels rotbraun, im 'Ton der Grundfarbe mit kleinen gelben Flecken....... .

$15 \mathrm{~m} . \mathrm{H}$. aristiona staudingeri,

Apex des Vorderflügels schwärzlich schattiert, mit großeu gelben Flecken forma principalis . . . p. 80

$15 \mathrm{~m} . \mathrm{H}$. alistiona staudingeri, forma pretiosa.... p. 80

$36\{$ Vorderflügel olne Flecke im Apex - 37. I A pex des Vorderflïgels gefleckt - 51 .

$37\left\{\begin{array}{l}\text { Vorderflügélzelle ohne Keilfleck } . . \\ \text { Vorderflïgelzelle mit Keilfleck }-38 .\end{array}\right.$

68. H. fruhstorferi . . . . p. 218 
$38\left\{\begin{array}{r}\text { Hintertlügel bis auf den Saum ein- } \\ \text { farbig braun oder nur mit Spuren } \\ \text { einer JIittelbinde. . . . . . }\end{array}\right.$ Hinterflügel nicht ein farbig braun -39 .

$\left\{\begin{array}{c}\text { Hinterflügel ohne deutlich getrennte } \\ \text { Nittelbinde }-40 .\end{array}\right.$

39 Hinterflügel mit deutlich getrennter Mittelbinde - 43.

$40\left\{\begin{array}{c}\text { Hinterflügel ganz schwarz oder nur } \\ \text { proximal braun bestäubt - 41. } \\ \text { Hinterflügel im Hinterwinkelteil bis } \\ \text { nabe zur Mitte schwarz, am Vorder- } \\ \text { und Distalrande braun - } 42 .\end{array}\right.$

( Vorderflügel mit rundlichem Keilfleck in der Zelle, der nicht mit dem Vorderrande zusammenhängt und keinen Ausläufer nach der Wurzel

41 besitzt..........

Vorderflügel mit breitem Keilfleck in der Zelle, der voru mit dem schwarzen Vorderrande zusammenbängt und bis zur Flügelwurzel verlängert ist

Vorderflügel proximal reichlich schwarz, Keilfleck in der Zelle nach hinten nur durch die braune Mediana vom

42 Submedianstreif getrennt .... Keilfleck in der Vorderflügelzelle durch die Grundfarbe breit vom Submedianstreif getrennt .....

Mittelbinde des Hinterflügels unvoll$43\left\{\begin{array}{l}\text { Mittelbinde des Hinterfugels unvoll- } \\ \text { ständig, distal den Apex oder Distal- } \\ \text { rand nicht erreichend -- } 44 .\end{array}\right.$

Saum- und Mittelbinde vollständig $\mathbf{- 4 6}$.

4 Saumbinde des Hinterflügels schmal,

$44\left\{\begin{array}{c}\text { aber vollständig bis zum Apex. } \\ \text { Saumbinde verkürzt oder verloschen - } 45 .\end{array}\right.$

(Mittelbinde des Hinterflügels strahlenartig, vorn zusammenhängend oder nur durch die Adern getrennt .. Mittelbinde in eckige Flecke aufgelöst
Endzellfleck und Medianflecke des Endzellfleck und Medianflecke deutlich und scharf begrenzt - 47 .

Mittelbinde des Hinterflügels in keil-

47 förmige Fleckchen aufgelöst . . . Mittelbinde des Hinterflügels zusammenhängend -48 .

Saumbinde des Hinterflügels aus spitzen

Saumbinde des Hinterflügels geschlossen - 49.
(Der Submedianstreif des Vorderflügels $49\left\{\begin{array}{l}\text { endet stumpf distal von der Mitte } \\ \text { der Submediana . . . }\end{array}\right.$ Der Submedianstreif reicht bis zum Hinterwinkel -50 .

15i. H. aristiona lenaeus . . . p. 77

12b. H. vetustus metellus . . p. 68

16a. H. ithaka ithaka . . . p. 81

15e. H. aristiona messene . . p. 75

15f. H. aristiona euphrasius . p. 75

19. H. sergestus . . . . p. 88

15g. H. aristiona euphon $\Theta$. . p. 76

15h. H. aristiona tarapotensis. p. 76

7a. H. gradatus gradatus . . p. 62

16c. H. ithaka marius . . . p. 82

18a. H. fortunatus fortunatus . p. 87

16b. H. ithaka vittatus . . . p. 82 

$50\left\{\begin{array}{l}\text { Mittelbinde des Hinterflïgels hinten } \\ \text { strahleniörmig } . . .\end{array}\right.$ Mittelbinde des Hinterflügels hinten fast glattrandig. . . . . .
Ein Fleck oder Doppelfleck im Apex $51\left\{\begin{array}{l}\text { Ein Fleck oder Doppelfleck im Apex } \\ \text { des Vorderflügels - 52. } \\ \text { Zwei oder mehr getrennte Flecke } \\ \text { daselbst }-55 .\end{array}\right.$

Gelbe Schrägbinde des Vorderflügels proximal über das Zellende ver$52\{$ breitert, zum 'Teil durch die schwarze

Zeichnung der Mitte längs geteilt

Die gelbe Schrägbinde liegt distal vom Zellende - $5 \mathbf{5 3}$

$53\left\{\begin{array}{l}\text { Fleck im Apex des Vorderflügels gelb } \\ \text { Fleck im Apex des Vorderflügels weiß }-54\end{array}\right.$

Hinterflügel vor der Mittelbinde gelb

54

Hinterflügel vor der Mittelbinde braun

(Die helle Schrägbindé des Vorderflügels liegt ganz oder teilweise proximal rom Zellende oder ist proximal und hinten in das Zellende und den hinteren Medianzwischenraum ausgeflossen und stellenweise von der schwarzen Zeichnung der Mitte durchbrochen (in zweifelhaften Fällen ist die Unterseite maBgebend) - 56 .

Die helle Schrägbinde des Vorderflügels liegt distal vom Zellende - 77 .

Schrägbinde des Vorderflügels weiß bis grau, namentlich proximal . . .

Sclirägbinde des Vorderflügels gelb - 57.

Schrägbinde des Vorderflügels voll und geschlossen, proximal von dem Keilfleck begrenzt, unterseits deut-

57 licher sichtbar -58.

Schrägbinde des Vorderflügels mehr oder weniger von den schwarzen Zeichnungen der Mitte durchsetzt - 62 .

Hinterflügel vorherrschend braun mit $58\{$ Ansatz zur Mittelbinde rom Apex Hinterflügel mit Mittelbinde - $5 \dot{0}$.

Mittelbinde des Hinterflügels mit der Saumbinde fleckartig verflossen .

Mittelbinde des Hinterflügels in ganzer Ausdehnung von der Saumbinde getrennt - 60 .

Mittelbinde des Hinterflügels schwach S-förmig gebogen.......

60

Mittelbinde des Hinterflügels gleichmäßig flach kreisbogenförmig, manchmal in Flecke aufgelöst - 61 . 1a. H. narcaea narcaea, forma flavomaculata.... p. 40

10. H. aulicus . . . . p. 65

6i. H. ethilla juntanus. . . . p. 59

1b. H. narcaea polychrous . . p. 41

1a. H. narcaea narcaea, $=44$. p. 40
forma principalis

1a. H. narcaea narcaea, forma satis ........ p. 40

22e. H. anderida albucilla . p. 98

5c. H. silvana metaphorus . . p. 53

5a. H. silvana silvana, forma principalis .... p. 51

5a. H. silvana silvana, forma diffusa....... p. 52 
61 Hinterflügel vor der Mittelbinde gelb Hinterflügel vor der Mittelbinde braun

Saumbinde des Hinterflügels aus spitzen 62

Saumbinde des Hinterflügels geschlossen -64 .

$63\left\{\begin{array}{l}\text { Grundfarbe hellbraun ...... } \\ \text { Grundfarbe tief rotbraun ..... }\end{array}\right.$

$\left\{\begin{array}{c}\text { Ohne abgesetzte Mittelbinde des Hinter- } \\ \text { flügels }-65 .\end{array}\right.$

64 Mit Mittelbinde des Hinterflügels oder Ansatz zu solcher - 68 .

$65\left\{\begin{array}{l}\text { Distalsaum des Hinterflügels schmal } \\ \text { schwarz, im Apex etwas verbreitert-66. } \\ \text { Distalsaum des Hinterflügels breit } \\ \text { schwarz }-67 .\end{array}\right.$

Hinterflügel hinter der Subcostalis mit einem gelben Wisch. Der Keilfleck des Vorderflïgels füllt die Zelle fast ganz aus........ .

Hinterflügel ohne gelben Wisch . . .

$67\left\{\begin{array}{c}\text { Die Apicalflecke des Vorderflügels } \\ \text { setzen sich am Distalrande in den } \\ \text { Medianzwischenräumen bogenför- } \\ \text { mig bis zum Hinterwinkel fort.. } \\ \text { Vorderflügel ohne Saumflecke in den } \\ \text { Iedianzwischenräumen. Hinter- } \\ \text { flügel bis nahe zur Mitte schwarz }\end{array}\right.$

Mittelbinde des Hinterflügels unvollständig - 69 .

Mittelbinde des Hinterflügels vollständig -71 .

Keilfleck in der Zelle des Vorderflügels $\left\{\begin{array}{l}\text { fast kreisrund; im Hinterwinkel } \\ \text { deutliche Saumfleckchen.... }\end{array}\right.$

Keilfleck in der Zelle des Vorderflügels länglich - 70 .

Stellung des Keilfleckes wagerecht und frei in der Grundfarbe; Hinterwinkel des Vorderflügels oberseits ohne Saumflecke . . . . . .

Keilfleck schräg über die ganze Breite der Zelle gelagert, hinter der Subcostalis nach der Flügelwurzel zu ausgeflossen ....

Mittelbinde des Hinterflügels mehr oder weniger in Flecke aufgelöst - $\mathbf{7 2}$.

Mittelbinde des Hinterflügels geschlossen, ihre hintere Begrenzung zuweilen gezackt - 73 . 5d. H. silvana ethra . . . p. 54

5 b. H. silvana robigus . . . p. 52

17e. H. pardalinus tithoreides, forma prima . . . p. 86

17b. H. pardalinus lucescens · p. 84

22f. H. anderida zuleika, forma

chrysantis . . . . p. 99

22f. H. anderida zuleika, forma

discomaculata . . . p. 99

22b. H. anderida melicerta . . p. 95

6h. H. ethilla claudia . . . . p. 59

22 c. H. anderida semiphorus, forma principalis . . . p. 97

2c. H. ismenius faunus . . p. 43

22d. H. anderida annetta . . p. 97 
$72\left\{\begin{array}{c}\text { Schwarze Zeichnung in der Mitte des } \\ \text { Vorderflügels teilweise zusammen- } \\ \text { geflossell . . . . . . . . . . } \\ \text { Schwarze Zeichnung in der Mitte des } \\ \text { Vorderflügels aus getrennten, regel- } \\ \text { mäßigen Flecken bestehend . . }\end{array}\right.$

$73\left\{\begin{array}{r}\text { Vorderflügel ohne Submedianstreif, nur } \\ \text { die Ader fein schwarz . . . . }\end{array}\right.$ Vorderflügel mit starkem Submedianstreif $-\mathbf{7 4}$.

Gelbe Schrägbinde des Vorderflügels durch die ausgeflossene schwurze Zeichnung der Mitte nahezu verdrängt. . . . . . . . .

Gelbe Schrägbinde des Vorderflïgels größtenteils frei $-\mathbf{7 5}$.

Der freie T'eil der Schrägbinde des Vorderfliigels liegt proximal vom Zellende.........

Der freie Teil der Schrägbinde des Vorderflügels liegt vorwiegend distal vom Zellende - 76.

Hinterflügel zwischen den schwarzen Binden braun ........

Hinterflügel $z$ wischen den schwarzen Binden gelb........

Binde des Vorderflügels subapical, in schräg gestellte Flecke aufgelöst, die vorderen zuweilen zusammenhängend - 78 .

Binde des Vorderflügels mehr oder weniger geschlossen - $\mathbf{8 2}$.

$78\left\{\begin{array}{l}\text { Apicalflecke des Vorderflügels in deut- } \\ \text { licher Saumfleckenreihe bis zum } \\ \text { Hinterwinkel fortgesetzt. . . . } \\ \text { Vorderflügel ohne Saumflecke }-79 .\end{array}\right.$

$79\left\{\begin{array}{l}\text { Hinterflïgel ohne Mittelbinde } . \\ \text { Hinterflügel mit Mittelbinde }-\mathbf{8 0} .\end{array}\right.$

Mittelbinde des Hinterflügels mit Saumbinde teilweise zusammengeflossen oder hierzu neigend. . . . . .

Mittelbinde und Saumbinde des Hinterflügels durch die Grundfarbe breit getrennt $-\mathbf{8 1}$.

Mittelbinde des Hinterflïgels hinten gezähnt, bis in den Apex reicliend

Mittelbinde des Hinterfliigels glattrandig, distal in kurzen Bogen nach vorn in den Vorderrand verlaufend .........
13. H. novatus, forma mira . p. 70

13. H. novatus, forma principalis p. 69

22a. H. anderida anderida . . p. 95

21a. H. quitalenus quitalenus . p. 91

22 c. H. anderida semiphorus, forma holcophora. . . p. 97

6g. H. ethilla semiflavidus . . p. 59

6a. H. ethilla ethilla. . . . p. 55

40. H. octavia . . . . . p. 143

2f. H. ismenius clarescens. . p. 44

4d. H. numatus superioris, forma geminata . . . p. 49

6f. H. ethilla mentor . . p. 58

2e. H. ismenius telchinia. . . p. 43 
Gelbe Schrägbinde des Vorderflügels durch proximal verbreiterten schwarzen Apex und durch stärkere Zeichnung der Flügelmitte eingeschränkt - 83.

Gelbe Schrägbinde des Vorderflügels fieiliegend, höchstens die getrennten Medianflecke einschließend - 86.

(Binde des Vorderflügels leicht bräunlich bestäubt... . . . . . Binde des Vordertlügels rein gelb $\mathbf{- 8 4}$. Mittelbinde des Hinterfiugels in Drei-

$84\left\{\begin{array}{r}\text { ecke aufgelöst . . . . } 21 \mathrm{~b} . \\ \text { Mittelbinde des Hinter } 4 \text { ügels geschlossen }-85\end{array}\right.$

6e. H. ethilla metalilis . . . p. 58

21b. H. quitalenus felix, forma principalis . . . . . p. 92 85.

Endzell- und vorderer Medianfleck des Vorderflügels breit zusammen-

Endzell- und vorderer Medianfleck getrennt . . . . . . . .

86

Hinterflügel vorwiegend schwarz - 87.

Hinterflügel vorwiegend braun - 89 .

Hinterflügel mit undeutlicher Mittelbinde, die distal breit mit der Saumbinde verflossen ist, proximal spitz ausläuft . . . . . . . . .

Hinterflügel ohne erkennbare Mittelbinde - 88 .

Submedianstreif des Vorderflügels im Hinterwinkel breit in die nach hinten verlängerte schwarze $\mathrm{Be}$ stäubung des Apex übergehend; Keilfleck in der Zelle sehr klein.

Submedianstreif des Vorderflügels schmal und ziemlich gleichmäßig, am hinteren Medianast durch die Grundfarbe von der schwarzen Bestäubung des Apex getrennt . . . . .

Submedianstreif ebenfalls frei endigend, aber breiter, distal verjüngt und in einer herz- oder keilförmigen Spitze endigend. Nächst dem Distalsaum des Hinterflügels parweise gelbe Strichfleckchen . . . . . . .

6j. H. ethilla cephallenia . . p. 60

20. H. ennius, forma nigrofasciata p. 90

6d. H. ethilla numismaticus . p. 58

4a. H. numatus numatus, forma guiensis . . . . . p. 47

4a. H. numatus numatus, forma melanops...... p. 48

Grundfarbe beider Flügel dunkelbraun - 90.

12a. H. vetustus vetustus . . p. 67

( Mittelbinde des Hinterflügels zu-

$90\{$ sammenhängend - 91.

Mittelbinde des Hinterflügels in Flecke aufgelöst - 92.

$91 \int$ Medianflecke des Vorderflügels getrennt Medianflecke des $V$ orderflügels zu einem Quadrat verflossen ......

17a. H. pardalinus pardalinus. p. 84 4f. H. numatus nubifer . . . p. 

Keilfleck in der Zelle des Vorder- Hügels länglich, proximal mit Aus- läufer zur Flügelwurzel; Hinter- winkel gelb gefleckt .....
Keilfleck fast kreisrund, Ausläufer zur Fliigelwurzel schwach oder ver- loschen; Hinterwinkel ungefleckt.
Saumbinde des Hinterflügels unvoll- ständig, den A pex nicht erreichend;
$93\left\{\begin{array}{l}\text { die Mittelbinde besteht aus langen } \\ \text { strahlenförmigen Flecken . . . }\end{array}\right.$ Saumbinde des Hinterflügels voll- ständig -94 .
Mittelbinde des Hinterflügels mit der
$94\left\{\begin{array}{l}\text { Saumbinde teilweise verflossen - }-95 \text {. } \\ \text { Mittelbinde von der Saumbinde deut- }\end{array}\right.$ lich getrennt -96.

\begin{abstract}
( Mit großen herzförmigen hellen Flecken im schwarzen Hinterwinkel des Vorderflügels . . . . . . .

95 Ohne Flecke in. Hinterwinkel des Vorderflügels; die braune Grundfarbe reicht distal bis zum schmal schwarzen Saum ......
\end{abstract}
Medianflecke des Vorderflügels fast ganz verloschen -97 .
$96\left\{\begin{array}{c}\text { ganz ver } \\ \text { Medianflecke des Vorderflügels scharf }\end{array}\right.$ und deutlich - 98.

$97\left\{\begin{array}{c}\text { Submedianstreif desVorderflügels distal } \\ \text { mit dem schwarzen Distalrande im } \\ \text { Hinterwinkel zusammenhängend . } \\ \text { Der Submedianstreif erreicht den } \\ \text { Hinterwinkel nicht . . . . . . }\end{array}\right.$
$98\left\{\begin{array}{l}\text { Jinterflügel vor der Mittelbinde gelb } \\ \text {. }\end{array}\right.$
Hinterflïgel vor ‘der Mittelbinde braun - 99.

$99\left\{\begin{array}{c}\text { Keilfleck in der Zielle des Vorderflügels } \\ \text { breit, distal abgerundet - 100. } \\ \text { Keilfleck selimal länglich oder eirund-101. }\end{array}\right.$

6c. H. etbilla tyndarus. . . . p. 57

13. H. novatus, forma leopardus p. 70

15j. H. aristiona idalion . . p. 77

11. H. schulzi . . . . p. 65

ta. H. numatus numatus, forma principalis . . . p. 47

20. H. ennius, forma principalis p. 89 .

7b. H. gradatus thielei . . . p. 62

6b. H. ethilla eucomus, forma

flavofasciata ..... p. 57
100

Die schwarze Bestäubung im Apex des Vorderflügels reicht am Distalrande hinten nur bis zur gelben Schrägbinde .......

Die schwarze Bestäubung des Apex setzt sich am Distalrande nach hinten ziemlich breit bis zum Hinterwinkel fort. . . . . . .

Mittelbinde des Hinterflügels breit,

101 vorn bis in die Zelle reichend . . hinter der Zelle liegend oder diese kaum berührend - 102. 
Der Submedianstreif des Vorderflügels läuft distal spitz oder verloschen 102

Der Submedianstreif läuft gleichmäßig breit in den schwarzen Hinterwinkel aus .........

$103\left\{\begin{array}{c}\text { Vorderflügel einfarbig, glänzend blau- } \\ \text { schwarz - 104. }\end{array}\right.$

Vorderflügel mitfarbigen Zeichnungen - 105 .

Hinterflügel mit breiter gelber Querbinde ......... .

104 Hinterflügel mit verloschenem Ansatz einer gelben Querbinde am Hinterrande .........

Zeichnungen desVorderflügels in e in e r Farbe (Gelb und WeiB, in einem Zeichnungsteil rereinigt und ineinander übergehend, ist nur als

105 eine Farbe anzusehen und zwar als die, welche überwiegt) - 106.

Zeichnungen in zwei oder mehr Farben (der Wurzelstrahl längs der Mediana gilt als Zeichnung) - 225 .

$106\{$ Zeichnungen rot -107.

Zeichuungen gelb oder weiß - 147.

Vorderflügel mit zwei deutlich voneinander getrennten schrägen Binden oder bindenartigen Flecken, darou eine discal, die andere apical oder subapical - 108.

Vorderflügel nur mit einer zuweilen dureh die Grundfarbe zerrissenen, oder gar keiner Schrägbinde; im letzteren Falle reichliche rote proximale Bestäubung vorhanden - 111.

108 Hinterflügel einfarbig schwarz -109.

Hinterflïgel mit Querbinde - 110 .

Discalbinde des Vorderflügels in der Zelle beiderseits eingeschnürt. Vorderrandfeld des Hinterflügels beim $\sigma$ glänzend hellgrau. . . . . .

Discalbinde des Vorderflügels annähernd gleichmäßig breit. Vorderrandfeld des Hinterflügels beim ơ mattgrau

$110\{$ Querbinde des Hinterflïgels weiß . . Querbinde des Hinterflügels gelb. .

Hinterflügel oben einfarbig schwarz

$111\{$ oder nur mit verloschenen Spuren einer Saumbinde - 112.

Hinterflügel gezeichnet - 131 .

$112\left\{\begin{array}{l}\text { Vorderflügel proximal mehr oder weniger } \\ \text { rot - 113. } \\ \text { Vorderflügel proximal schwarz - } 115 .\end{array}\right.$ 6b. H. ethilla eucomus, forma principalis ..... p. 56

9a. H. paraensis paraensis . . p. 64 forma principalis . . . p. 196

62f. H. hydarus chestertonii, forma nocturna . . . p. 196

31. H. batesi . . . . . p. 133

58a. H. xenoclea xenoclea . p. 188

71a. H. telesiphe telesiphe . . p. 223

71b. H. telesiphe sotericus . . p. 224 
113

Schrägbinde des Vorderflügels geschlossen.........

Schrägbinde des Vorderflügels in unregelmäßige Fleçke aufgelöst - 114 .

Distale Begrenzung der Vorderflügelbinde zerklïftet ......

114 Distale Begrenzung der Vorderflügelbinde glattrandig; letztere selbst mit schwarzem Mittelfleck . . . . 63d. H. erato callycopis, forma dryope. . . . . . p. 204 63d. H. erato callycopis, forma coralii . . . . . p. 203 63d. H. erato callycopis, forma elimaea . . . . p. 203

$115\left\{\begin{array}{l}\text { Vorderflügel oben mit blauem Schiller - 116. } \\ \text { Vorderflügel oben ohne blauen Schiller - 121. }\end{array}\right.$

$116\{$ Hinterflügel urten mit gelber Binde -117 .

Hinterflügel unten ohnegelbe Binde - 119.

Querbinde auf der Unterseite des Hinterflügels distal bei der Sub-

117 costalis nach rorn gebogen . . 59b. H. cyrbia venus . . . p. 191 Querbinde auf der Unterseite des Hinterflügels distal hinter der Subcostalis endend - 118.

Schrägbinde des Vorderflügels schmal, proximal nur die ron den Discocellulares gebildeten spitzen Winkel der Zelle ausfüllend. . . . . .

Schrägbinde des Vorderflügels breit,

den distalen Zellteil ausfüllend . . 30a. H. vulcanus vulcanus . . p.131

(Seitliche Begrenzung der Vorderfügelbinde ungewiß zerstäubt. Yorderrandfeld des Hinterflügels beim $\delta$ hellgrau glänzend.......

Seitliche Begrenzung der VorderAlügelbinde bestimmiter. Vorderrandfeld des Hinterflügels beim $\delta$ dunkelgrau - 120.

( Kleinere Falter, Vorderfflügellänge bis $39 \mathrm{~mm}$. Binde des Torderflügels gestreckt, $6-8 \mathrm{~mm}$ breit . . . . Größe wie vorher, aber Binde des Vorderflügels wesentlich schmaler, beide Flügel lebhaft stahlblau glänzend. . . . . . . .

Größere Falter, Vorderfliigellänge über $40 \mathrm{~mm}$. Binde des Vorderflügels breit, gedrungen ......

30b. H. vulcanus cythera, forma modesta . . . . . p. 133

29c. H. amaryllis rosina, forma euryas . . . . . . p. 131 62b. H. hydarus guariea . . p. 195

62c. H. hydarus molina . . . p. 195

63e. H. erato magnificus . . p. 204

\footnotetext{
$121\left\{\begin{array}{l}\text { Schrägbinde des Vorderflügels durch } \\ \text { die Grundfarbe zerklïftet und ein- } \\ \text { geschränkt -- } 122 .\end{array}\right.$

Schrägbinde des Vorderflügels geschlossen - 124
} 
Distale Begrenzung der Binde des Vorderflügels unbestimmt und zerstäubt. Vorderrandfeld des Hinterflügels beim $\widehat{o}$ hellgrau glänzend .

Distale Begrenzung der Binde des Vorderflügels bestimmter; Gegend um das Zellende inmitten der Binde meist reichlich schwarz. Vorderrandfeld des Hinterflügels beim $ठ 7$ dunkelgrau - 123.

Binde des Yorderflügels distal zerklüftet . . . . . . . . .

Binde des Vorderflügels distal glattrandig, mit breitern schwarzem Mittelfleck . . . . . . . .

\section{3d. H. erato callycopis, forma} principalis . . . . p. 202

63d. H. erato callycopis, forma callista. . . . . p. 203

28a. H. melpomene melpomene, forma melpomenides . . p. 113

Schrägbinde des Vordertlügels sehr 124
Schrägbinde des Vordertlügels breiter, mehr fleckartig - 125.

Hinterfiügel unten an der Wurzel vor der Mediana mit einem gelblichen Fleckchen - 126.

Hinterflügel unten an der Wurzel hinter der Mediana mit einem gelblichen Fleckchen oder ohne solches - 130.

Die Schrägbinde des Vorderflügels wird rom hinteren Medianast begrenzt - 127.

126

Die Schrägbinde des Vorderflügels reicht bis hinter den hinteren Medianast - 128.

Grundfarbe der Flügel blauschwarz. Größere Falter, Vorderflügellänge wenigstens $37 \mathrm{~mm}$. . . . . .

Grundfarbe b̀raunschwarz. Kleinere Falter, Vorderflügellänge bis $37 \mathrm{~mm}$

59c. H. cyrbia juno. . . . p. 191

61b. H. petiveranus demophoon, forma tristis . . . . p. 194

Schrägbinde des Vorderflïgels zieg elrot mit scharfem schwarzem Fleckehen

128 an der hinteren Radialis. . . . Schrägbinde des Vorderflügels hochrot -129.

Begrenzung der Binde des Vorderflügels stark zerklüftet, namentlich distal zackig . . . . . . .

Binde des Vorderflügels vorwiegend glattrandig . . . . . . . . .
64. H. amphitrite . . . . p. 211

63d. H. erato callycopis, forma viculata . . . . . p. 204

62a. H. hydarus hydarus . . p. 194 
Binde des Vorderflügels distal und hinten gegen den Hinterwinkel

130 schmal ausgezogen ......

Binde des Vorderflügels in ganzer Länge annähernd gleich breit, fast so breit wie lang. . . . . .

28a. H. melpomene melpomene,

forma principalis . . . p. 112

29b. H. amaryllis euryades . . p. 129

Hinterflügel mit weißer, an den Adern unterbrochener Binde am Distalrande - 132.

131

Hinterflïgel ohne Binde am Distalrande -133.

Vorderflügelbinde sehr schmal, etwa $4 \mathrm{~mm}$ breit, nach hinten meist spitz auslaufend ........

132

Vorderflügelbinde breiter, über $6 \mathrm{~mm}$, in ganzer Breite dem hinteren Jedianast aufsitzend .....

(1)

Hinterflügel mit gelber Querbinde - 134

Hinterflïgel mit roten Zeichnungen rerschiedener Art - 141.

$134\left\{\begin{array}{c}\text { Hinterflügel unten an der Wurzel mit } \\ \text { einem gelblichen Fleckehen vor der } \\ \text { MIediana - 135. } \\ \text { Hinterflügel obne ein solches Fleckchen }\end{array}\right.$

$-140$.

Die Binde des Vorderflügels endet breit und bestimmt im hinteren Medianzwischenraum - 136.

Die Binde des Vorderflügels reicht nur bis zum hinteren MIedianast, selten in Spuren darüber hinaus - 137.

Grundfarbe beider Flügel matt schwarz-

$136\left\{\begin{array}{c}\text { braun } \\ \text { Grundfarbe beider Flügel tief blau- }\end{array}\right.$ glänzend . . . . . . .

62d. H. hydarus colombinus. . p. 195

62e. H. hydarus antigona . . p. 196

$63 \mathrm{k} . \mathrm{H}$. erato phyllis, forma

amata ...... p. 210

Hinterflügelbinde geschlossen - 138 .

Hinterflügel unten ohne rote Wurzelpunkte..........

Hinterflügel unten mit roten Wurzelpunkten - 139.

Hinterflügelbinde oben schmal, annähernd gleichmäßig in ganzer Ausdehnung . . . . . . .

139 Hinterflügelbinde breiter, spindelförmig, das spitzere Ende nach dem Apex gerichtet. . . . . . . . 59a. H. cyrbia cyrbia, forma principalis ......p. 190

99. H. cyrbia cyrbia, forma

diformata ..... p. 190 
$140\left\{\begin{array}{l}\text { Vorderflügelbinde breit, fleckartig . . } \\ \text { Vorderflügelbinde scbmaler, bandartig }\end{array}\right.$

29a. H. amaryllis amaryllis . . p. 129

29c. H. amaryllis rosina, forma

principalis ..... p. 130

$141\left\{\begin{array}{c}\text { An der.Wurzel des Hinterflügels ein roter } \\ \text { Wurzelstreif quer über die Zelle - } 142 . \\ \text { An der.Wurzel des Hinterflügels ein roter } \\ \text { Wurzelstreif längs in der Zelle }-144 .\end{array}\right.$

Hinter dem roten Wurzelstreif des

$142\left\{\begin{array}{r}\text { Hinterflügels lange rote Strahlen } \\ \text { Wurzelstreif des Hinterflügels keil- }\end{array}\right.$

28d. H. melpomene tyche, forma principalis ... p. 116

förmig, keine Strahlenbildung hinter demselben - 143.

Vorderflügel ohne discale Querbinde, proximal rot bestäubt.....

Vorderflïgel mit roter discaler Querbinde, proximal ebenfalls rot...

28c. H. melpomene funebris, forma principalis . . p. 115

28c. H. melpomene funebris, forma diana. . . . . p. 115

Vorderflügelbiude geschlossen - 145 .

$144\{$ Vorderfliigelbinde von der Grundfarbe zerrissen, zum Teil in Flecke aufgelöst -- 146.

Die Binde des Vorderflügels ist gestreckt, reicht bis über den hinteren Medianast und nahe bis zum Hinterwinkel . . . . . . . .

63a. H. erato erato, forma erythrea . . . . p. 200

Die Binde des Vorderflügels ist unregelmäßig, fleckartig, reicht nur bis zum hinteren Medianast, bleibt vom Hinterwinkel weit entfernt und ist zuweilen mit dem roten Wurzelfelde verflossen. . . . . . .

6.3j. H. erato anactorie, forma sanguinea . . . . p. 208

Distale Begrenzung der Vorderflügelbinde unregelmäßig zackig. . . .

63a. H. erato erato, forma udalrica ..... p. 200

Distale Begrenzung der Vorderflügelbinde glattrandig, letztere in der Mitte. der Länge nach, von der Grundfarbe durchsetzt. . . . ..

\section{3a. H. erato erato, forma} andremona. . . . p. 200

Hinterflïgel mit deutlichen Rand- und $/$ a $^{\prime \prime} ;$ Mittelzeichnungen, nicht nur mit Saum- und Apicalpunkten - 148 .

Hinterflügel einfarbig schwarz oder schwarzblau oder mit Spuren einer Randzeichnung oder mit kleinen isolierten Saum- und A picalpunkten - 191.

Hinterflügel mit isolierter. nächst der IVurzel am Hinterrande begionender, gestreckter Querbinde - 149. mit einer anders verlaufenden Querbinde - 162. 
$149\left\{\begin{array}{l}\text { Binde des Hinterflügels rot oder rot- } \\ \text { braun }-150 . \\ \text { Bindc des Hinterflügels gelb }-156 .\end{array}\right.$

$150\left\{\begin{array}{c}\text { Hinter der Binde des Hinterflügels } \\ \text { eine geschwungene Reihe großer } \\ \text { gelber, fast randständiger Flecke-151. } \\ \text { Hinterflïgel ohne Fleckenreihe nahe } \\ \text { dem Distalrande hinter der Binde - } 152 .\end{array}\right.$

$151\left\{\begin{array}{c}\text { Hinterrand des Vorderflügels distal } \\ \text { mit einem gelben Streif . . . . . . . . . . }\end{array}\right.$

42. H. godmani . . . . p. 145

$152\left\{\begin{array}{l}\text { Vorderflügel mit Apicalfleckchen - . 69c. H. clysonymus hygiana p. } 221 \\ \text { Vorderflïgel ohne Apicalfleckchen - 153. }\end{array}\right.$

39c. H. hecalesia gynaesius . p. 142 $153\left\{\begin{array}{c}\text { Distalrand des Vorderflügels hinter dem } \\ \text { Apex an der hinteren Radialis vor- } \\ \text { springend, dann stark konkav, bei } \\ \text { beiden Flügeln gewellt . . . . } \\ \text { Apex des Vorderflügels abgerundet, } \\ \text { Distalrand nicht konkav -. 154. }\end{array}\right.$

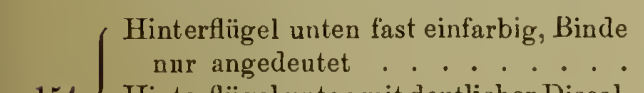

154 Hinterflügel unten mit deutlicher Discalbinde und langen, zwischen den Adern liegenden, dunklen Strahlen - 155. $155\left\{\begin{array}{c}\text { Binde des Hinterflügels schmaler als } \\ \text { das schwarze Feld hinter ihr } \\ \text { Binde des Hinterflügels breiter als das } \\ \text { schwarze Feld hinter ihr . . . }\end{array}\right.$

Hinterflügel nahe dem Distalrande ohne Zeichnung -157.

Hinterflïgel nahe dem Distalrande mit Zeichnungen - 159.

Zelle des Vorderflügels hinten mit breitem gelbem Streif, der sich gegen den Distalrand ror dem hinteren Medianast fortsetzt . . . . .

Zelle proximal in hinteren Teil einfarbig oder nur mit schmalem gelbem Strich vor der Mediana - 158.

(Vorderflügel blauschwarz mit einzelnen verwischten weißlichen Flecken. .

Vorderflügel mit schmuler Apical- und Discalbinde. Hinterflïgel unten proximal mit roten Flecken und rotem Streif .........

Vorderflügel mit einer Fleckenreihe nahe dem Apex und einer in der Mitte unterbrochenen Discalbinde. Hinterflügel proximal ohne Rot.
70. H. hortense . . . . p. 221

57. H. himera . . . . p. 187 69a. H. clysonymus clysonymus p. 219

69b. H. clysonymus montanus p. 220

67. H. nattereri . . . . p. 217

24. H. weymeri, forma gustavi p. 108

54e. H. antiochus salvinii . p. 181

24. H. weymeri, forma principalis p. 108 
$159\left\{\begin{array}{c}\text { Hinterflügel unten mit braunen Zeich- } \\ \text { nungen hinter einer geschwungenen, } \\ \text { fastrandständigen Fleckenreihe - } 160 . \\ \text { Hinterflügel unten ohne braune Zeich- } \\ \text { nung - 161. }\end{array}\right.$

Kleinere Falter, Vorderflügellänge bis $39 \mathrm{~mm}$. Das Abdomen ragt bei wagerecht gespannten Tieren beträchtlich über den Hinterflügel hinaus. Vorderrandfeld des Hinterflügels beim ot hellgrau . . . . .

Größere, kräftige Falter. Das Abdomen ragt nicht über den Hinterflügel hinaus. Vorderrandfeld des Hinterflügels beim ơ matt dunkelgrau .

Zelle des Vorderflügels hinten mit gelbem Streif. der an der Wurzel beginnt, sich distal verbreitert und bis zum Distalrande fortsetzt . .

Zelle des Vorderflügels mit ebensolchem Streif, der sich distal aber wenig fortsetzt und etwa in der Mitte des Flïgels endet. . . . . .

66b. H. charithonia peruvianus p. 216

34. H. atthis . . . . . p. 136

35. H. crispus . . . . . p. 138

66a. H. charithonia charithonia p. 214
Hinterflügel mit Strahlenzeichnung in der Mitte - 163.

Hinterflügel ohne Strahlenzeichnung in der Mitte - 169.

Vorderflügel bis auf etliche Apicalfleckchen schwarz. Strahlen des Hinterflügels rot, blau oder grün

Vorderflügel mit Apical- und Discalflecken oder nur mit letzteren -- 164.

48c. H. doris viridis, forma obscura . . . . p. 166

48c. H. doris viridis, forma principalis . . . . p. 165

Die einzelnen Strahlen des Hinterflügels entspringen frei aus der Grundfarbe hinter der Zelle, vorn breit zusammenhängend . . . . .

Die einzelnen Strahlen entspringen 28m. H. melpomene timareta, forma contigua . . . p. 126 ebenso, sind aber sehr schmal, nagelförmig, untereinander fast röllig getrennt, nur vorn lose zusammenhängend . . . . . .

$28 \mathrm{~m}$. H. melpomene timareta,

forma virgata . . p. 126 
Die Strahlen fließen vorn zu einem breiten roteu Proximalfelde zusammen und werden nur von den fein schwarz angelegten Adern geschnitten . . . . . . . .

167

Hinterflügel olıne solche Streife, höchstens am Hinterrande Spuren derselben vorhanden - 168.

Strahlenzeiclınung des Hinterfiügels oben ultramarinblau. . . . .

Hinterflügel unten mit deutlichen roten Streifen zwischen den Adern hinter der Zelle

48a. H. doris doris, forma principalis ..... p. 163

48d. H. doris aristomache. . p. 166

48c. H. doris viridis, forma

luminosa . . . . p. 166

48b. H. doris transiens . . . p. 165

$169\left\{\begin{array}{r}\text { Hinterflügel am Hinterrande oder } \\ \text { proximal mehr oder weniger rot- } \\ \text { brang }\end{array}\right.$

Hinterflügel ohne rotbraune Färbung - 171 .

(Hinterflügel mit einer vollständigen Reihe großer gelber herzförmiger

170 Flecke nahe dem Iistalrande.. Hinterflügel uur mit kleinen Flecken

nahe dem Distalrande. . . . 39b. H. hecalesia formosus . . p.142

(Hinterflügel am Distallande mit weißlichen Längsstreifen oder paarweise stehenden Flecken, im übrigen einfarbig - 172.

171

Hinterflügel mit Bindenzeichnung, die nicht in unmittelbarer Nähe der Wurzel am Hinterrande beginnt (vgl. Nr. 148) - 174.

Vorderflïgel mit je einer discalen und apicalen Schrägbinde ..... .

Vorderflügel mit einem discalen Fleck 56g. H. sara theudela . . . . p. 186 oder Doppelfleck, der nicht über den hinteren Medianast reicht, und mit apicalen Fleckchen _. 173.

39a. H. hecalesia hecalesia . . p. 141




Vorderflïgel mit zwei getrennten, manchmal durchbrochenen Quer-

175 binden, die discal und subapical schräg verlaufen - 176.

Vorderflügel mit einer schrägen discalen Querbinde - 178.

Saumbinde des Hinterflügels breit, bis reichlich zur Mitte ausgedehnt,

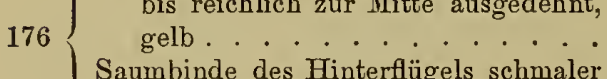

Saumbinde des Hinterflügels schmaler
als die halbe Flügelbreite, wei $B-177$.

51d. H. sapho primularis . . p. 175

(Hinterflügel unten proximal mit reichlichen und scharf abgegrenzten roten Flecken ......... .

Hinterflügel unten proximal ohne rote

51e. H. sapho eleuchia . . . p. 176

177 Flecke, dagegen mit zwei rotbraunen, vom Hinterrande ausgehenden, etwas verwaschenen, gekrümmten Binden...... .

23b. H. cydno cydnides, forma epicydnides . . . . . p. 104

Hinterflügel unten proximal mit reichlichen und scharf abgegrenzten roten Flecken ..........

178 Hinterflügel unten proximal nicht rot 51a. H. sapho sapho . . . p. 173 gefleckt, dagegen mit ein oder zwei rotbraunen, manchmal verwaschenen, vom Hinterrande ausgehenden Binden - 179.

$179\left\{\begin{array}{l}\text { Zeichnungen beider Flügel oben gelb } \\ \text { Zeichnungen beider Flügel oben weiß }\end{array}\right.$

23c. H. cydno alithea, forma

principalis . . . . p. 104

23c. H. cydno alithea, forma haenschi ...... p. 105

$180\left\{\begin{array}{c}\text { Vorderflügel mit Apicalflecken, die sich } \\ \text { meist am Distalrande bis zum Hinter- } \\ \text { winkel fortsetzen - 181. } \\ \text { Vorderflügel ohne A pical- und Distal- } \\ \text { randflecke - 186. }\end{array}\right.$

Hinterflügelbinde gestreckt, unmittelbar hinter dem Zellende gelegen.

181 Distalrand des Flügels mit kleinen

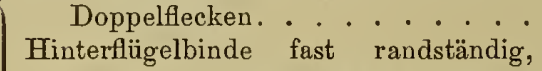
36. H. hecuba . . . . p. 138 parallel zum Distalrande - 182.

$182\left\{\begin{array}{c}\text { Zelle des Vorderflügels im distalen } \\ \text { Teil mit ein oder zwei Flecken }-183 . \\ \text { ZelledesVorderflügels ungefleckt-185. }\end{array}\right.$

Die distal von der Zelle liegende

$183\left\{\begin{array}{l}\text { Binde des Vorderflügels in Flecke } \\ \text { anfgelöst. . . . . . }\end{array}\right.$ Diese Binde geschlossen - 184.

23f. H. cydno hermogenes . . p. 105

$184\{$ Hinterflügelbinde weiß . . . . 23d. H. cydno hahneli . . . p. 105

$184\{$ Hinterflügelbinde gelb . . . . . 23e. H. cydno temerinda . . p. 105 

$185\left\{\begin{array}{l}\text { Hinterflügel unten mit einer rost- } \\ \text { braunen Discalbinde. . . . } \\ \text { Hinterflügel unten mit zwei rostbraunen } \\ \text { Binden, eine am Vorderrande, die } \\ \text { andere in der Mitte ..... }\end{array}\right.$

38. H. cassandra . . . . p. 140

37. H. choarinus. . . . p. 139

$186\left\{\begin{array}{l}\text { Vorderflügel mit einer schrägen Quer- } \\ \text { binde - 187. } \\ \text { Vorderflügel mit zwei deutlich und } \\ \text { vollkommen getrennten Quer- } \\ \text { binden - 188. }\end{array}\right.$

$187\{$ Binde des Vorderflügels weiß . . . 23g. H. cydno chioneus . . . . p. 106

\{ Binde des Vorderflügels gelb . . . 23a. H. cydno cydno . . . . . p. 102

Hinterflügel unten proximal mit scharfer roter Zeichnung - 189.

188 Hinterflügel unten proximal ohne rote Zeichnung, dagegen mit zwei l'ostbraunen, rom Hinterrande ausgehenden, verwaschenen Binden -190 .

Die Querbinde des Vorderflügels liegt

$189\left\{\begin{array}{l}\text { im distalen Teil der Zelle... . } \\ \text { Die Querbinde liegt distal vou der }\end{array}\right.$

52. H. hewitsoni . . . . p. 176 Zelle in deren unmittelbarer Nälı

25. H. pachinus . . . . p. 108

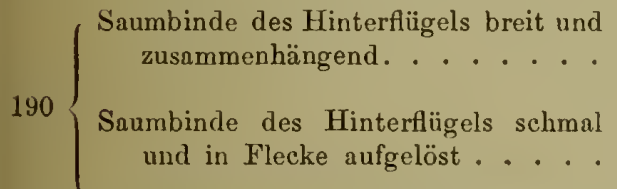

23b. H. cydno cydnides, forma principalis . . . . p. 103

23b. H. cydno cydnides, forma subcydnides . . . . p. 104

$191\left\{\begin{array}{l}\text { Vorderflügel ohne Zeichnung im Apex - } 192 . \\ \text { Vorderflügel mit Flecken oder einer }\end{array}\right.$

orderflügel mit Flecken oder einer
Schrägbinde im Apex - 198.

Grundfarbe beider Flügel mattschwarz - 193. $192\left\{\begin{array}{c}\text { Grundfarbe beider Flugel mattschwarz } \\ \text { schwarz - } 195 .\end{array}\right.$

Vorderflïgel mit zerstreuten gelben Flecken (zerrissener Discalbinde), deren einer abgetrennt im distalen Teil der Zelle liegt. . . . . .

Vorderflïgel mit deutlich zusammen-

28f. H. melpomene thelxiopeia, forma melanippe... p. 120 hängender discaler Schrägbinde -194.

$194\left\{\begin{array}{c}\text { Die Schrägbinde des Vorderflügels } \\ \text { berührt die Zelle nicht ... } \\ \text { Die Schrägbinde des Vorderflügels } \\ \text { durchquert den distalen Teil der } \\ \text { Zelle . . . . . . . . }\end{array}\right.$

Hinterflügel unten proximal mit scharf gezeichneten roten Flecken - 196.

Hinterflügel unten ohne solche Flecke,

195 dagegen mit ein oder zwei rotbraunen, zuweilen rerwaschenen, rom Hinterrande ausgehenden Binden - 197. 28i. H. melpomene aglaope, forma mirabilis . . . . p. 122

$28 \mathrm{~m}$. H. melpomene timareta, forma principalis . . . p. 125 
Vorderflügel mit sehr breiter, distal bis nahe zum Apex ausgedehnter Querbinde mit zahnartigem Vorsprunge gegen den Distalrand . .

Vorderflügel mit ähnlicher Binde, die aber durch die Grundfarbe längs des vorderen MIedianastes bis auf einen etwa $2 \mathrm{~mm}$ breiten vorderen Steg durchbrochen ist. . . . .

Vorderflügel ohne weiße Flecke am Distalrande. Hinterflügel unten mit braunem Costalstreif . . . . .

Vorderflügel mit deutlichen weißen Fleckchen am Distalrande. Vorderrand des Hinterflügels unten gelb und braun ........

Hinterflügel unten ohne rote Wurzel-

Hinterflügel unten mit roten Wurzelflecken - 202

Grundfarbe beider Flügel glänzend blauschwarz - 200.

Grundfarbe beider Flïgel mattsehwarz - 201.

Vorderflügel mit breiter Querbinde, die bis zum hinteren Medianast reicht, uud mit einer Reihe Apicalfleckchen

Vorderflügel mit Querbinde, die bis zum Hinterrande reicht, und mit zwei Reihen Distalrandfleckchen.

Vorderflügel mit gelber, durchbrochener Querbinde und zwei Reihen Apicalfleckchen . . . . . . . .

Vorderflügel mit weißer, durchbrochener Querbinde und einer Reihe Apicalfleckchen. . . . . . . .

Fransen des Hinterflügels weiß und schwarz gescheckt, d. h. an den Aderausläufen und in der Mitte zwischen diesen schwarz, sonst weiß. Grundfarbenton des Hinterflügels unten gegen den Distalrand aufgehellt, meist mit weißlichen Längsstreifen - 203.

Fransen des Hinterflügels durchgehends weiß oder nur an den Adern fein schwarz unterbrochen. Grundfarbenton des Hinterflügels unten gleichmäßig auf der ganzen Fläche - 210 .

Grundfarbe beider Flügel oben ohne blauen Glanz. Hinterflügel mit weißen Saumfleckchen......

Grundfarbe beider Flügel tief blau-

48a. H. doris doris, forma

metharmina . . . . p. 165 51b. H. sapho leuce. . . . p.174

51c. H. sapho eleusinus . . p. 175

23h. H. cydno galanthus, forma

23h. H. cydno galanthus, forma diotrephes . . . . . p. 107

23i. H. cydno zelinde . . . . p. 107

23h. H. cydno galanthus, forma stübeli. . . . . . p. 107

22g. H. anderida fornarina . . p. 100

14. H. hecale . . . . . p. 70 principalis . . . . . p. 106 glänzend -204. 
$204\left\{\begin{array}{c}\text { Zeichnung in der Mitte des Vorder- } \\ \text { flügels bindenartig }-205 . \\ \text { Zeichnung in der Mitte des Vorder- } \\ \text { flügels fleckartig }-207 .\end{array}\right.$ 205

Vorderflügelbinde gelb - 206.

Zwischen Wurzel und Binde des Vorderflügels an der Costalis, Subcostalis und Mediana gelbe Bestäubung .

Zwischen Wurzel und Binde des Vorderflügels reine Grundfarbe, nur an der Subcostalis ein gelber Wisch...

Fleckzeichnung des Torderflügels weiß -208.

Fleckzeichnung des Vorderflügels gelb - 209.

(Vorderflügel mit nur einem großen Discalfleck . . . . . . .

$208\left\{\begin{array}{l}\text { Vorderflügel mit zwei kleinen Discal- } \\ \text { flecken, daron einer in der Zelle, }\end{array}\right.$ der andere im hinteren Medianzwischenraum. . . . . . .

Vorderflïgel mit einem großen zusammenhängenden Discalfleck . .

Vorderfügel mit zwei oder drei getrennten Discalflecken.

Zeichnung in der Mitte des Vorderflügels fleckartig - 211 .

Zeichnung in der Mitte des Vorderflügels bindenartig - 214 .

Zwei bis vier einzelne Flecke in der $211\left\{\begin{array}{l}\text { Mitte des Vorderflügels } \\ \text { Ein zusammenhängender Fleck } \cdot \dot{\text { da- }}\end{array}\right.$ selbst - 212.

Der Discalfleck des Vorderflügels reicht nur bis zum hinteren Medianast.

212 Der. Discalfleck des Vorderflügels reicht bis über den hintereu Jedianast hinaus - 213.

$213\left\{\begin{array}{l}\text { Discalfleck des Vorderflügels gelb . } \\ \text { Discalfleck des Vorderflügels weiß . }\end{array}\right.$

Die Binde in Apex des Vorderfügels liegt genau in der Mitte zwischen der Discalbinde und dem Rande des Apex .........

Die Binde im Apex des Vorderflügels liegt näher dem Rande des Apex als der Discalbinde - 215. 50c. H. wallacei colon, forma clytia . . . . . p. 171

50a. H. wallacei wallacei,

forma elsa..... p. 170

๖0b. H. wallacei mimulinus. . p. 170

50a. H. wallacei wallacei, forma principalis . . . . p. 170

50c. H. wallacei colon, forma principalis . . . . p. 171

50c. H. wallacei colon, forma flavescens . . . . p. 172

50c. H. wallacei colon, forma parvinaculata. . . p. 172

56c.-H. sara brevimaculatus - p. 185

55b. H. leucadia pseudorhea . p. 182

56e. H. sara thamar, forma principalis . . . . . p. 186

56e. H. sara thamar, forma albinea . . . . p. 186

53. H. congener . . . . p. 177 
$215\left\{\begin{array}{l}\text { Hinterflügel unten mit scharfem rotem } \\ \text { WVurzelstrahl längs und hinter dem } \\ \text { Vorderrande - 216. } \\ \text { Hinterflügel unten mit roten rund- } \\ \text { lichen Wurzelflecken, ohne Wurzel- } \\ \text { strahl - 220. }\end{array}\right.$

$216\{$ Discalbinde desVorderflügels gelb - 217 .

\{ Discalbinde desVorderflügels weiß - 218.

$217\left\{\begin{array}{c}\text { Vorderflügel mit gelbem Streif in der } \\ \text { Zelle vor der Mediana . . . . } \\ \text { Vorderflugel ohne-gelben Streif in der } \\ \text { Zelle; Discalbinde geteilt . . . . }\end{array}\right.$

54c. H. antiochus aranea . . p. 180

54d. H. antiochus ocánnensis - p. 181

$218\left\{\begin{array}{l}\text { Discalbinde des Vorderflügels geteilt . } \\ \text { Discalbinde des Vorderflügels ge- } \\ \text { schlossen - } 219 .\end{array}\right.$

$219\left\{\begin{array}{c}\text { Zelle des Vorderflügels mit gelbem } \\ \text { Streif vor der Mlediana .... } \\ \text { Zelle des Vorderflügels ohne Streif . }\end{array}\right.$

54b. H. antiochus zobeide. . p. 180

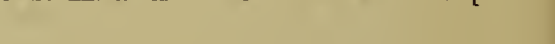

54a. H. antiochus antiochus, forma principalis . . p. 179

54a. H. antiochus antiochus, forma alba ...... p. 180

$220\left\{\begin{array}{l}\text { Zeichnung der Mitte des Vorderflügels } \\ \text { weiß - 221. } \\ \text { Zeichnung der Mitte des Vorderffügels } \\ \text { gelb - 222. }\end{array}\right.$

Discalbinde des Vorderflügels breit, etwa 5-6 $\mathrm{mm}$, füllt proximal den Winkel am Ursprunge des hinteren Medianastes aus und ist etwas rötlich überstäubt . . . . . . .

Discalbinde des Vorderflügels schmaler, unter $5 \mathrm{~mm}$, läßt proximal den genannten Winkel frei . . . .

56b. H. sara apseudes, forma albula . . . . . p. 184

56a. H. sara sara, forma albimaculata..... p. 184

Die Discalbinde des Vorderflügels reicht distal in den mittleren Medianzwischenraum . . . . . . .

Die Discalbinde des Vorderflügels reicht 56f. H. sara veraepacis . . . p. 186 distal nicht in den mittleren Medianzwischenraum - 223.

$223\left\{\begin{array}{c}\text { Fransen des Hinterflügels geschlossen } \\ \text { breit weiß, Distalrand wellig . . } \\ \text { Fransen des Hinterflügels an den Adern } \\ \text { schwarz unterbrochen - 224. }\end{array}\right.$

56d. H. sara sprucei . . . p. 185

Hinterflügel unten mit roten Wurzelpunkten und einer gebogenen Reihe roter Flecke, die von der Mitte des Hinterrandes ausgeht . . . 56b. H. sara apseudes, forma

Hinterflügel un ten nur mit roten Wurzelpunkten, ohne Fleckenreihe oder nur mit Ansatz einer solchen . 56a. H. sara sara, forma principalis p. 183 
Hinterflïgcl einfarbig oder nur mit roten Wurzelpunkten oder proximal mit ganz kleinen, fast unkenntlichen, roten Wischen - 226.

Hinterflügel mit deutlich hervortretenden Zeichnungen - 238.

$226\left\{\begin{array}{l}\text { Vorderflügel im proximalen Teil rot }-227 . \\ \text { Vorderflüggel }\end{array}\right.$
Vorderflïgel mit Apicalflecken und 227 gelber, zum Teil zerrissener Discal- binde . . . . . . 45a. H. xanthocles xanthocles. p. 151
Vorderflügel olne A picalflecke - 228.

\begin{abstract}
(Abdomen lateral mit deutlich getrennten runden gelben Flecken. Vordcrer Wurzelpuukt auf der Unterseite des Hinterfliigels wischartig ausgezogen 228 Abdomen lateral olne ruude Flecke, aber mit sclimalen unterbrochenen gelben Linien. Rote Wurzelpunkte des Hinterflügels unten alle rundlich -229.
\end{abstract}

$229\left\{\begin{array}{l}\text { Vorderflügel mit einer zersprengten } \\ \text { gelben Discalbinde im distalen Teil } \\ \text { der Zelle } \\ \text { Zelle des Vorderflügels ohne Fleck }\end{array}\right.$ 63c. H. erato cybelinus, forma
amalfreda - * - . . p. 202
63c. H. erato cybelinus, forma 44b. H. aoede astydamia . . p. 148

Vorderflïgel mit zwei, rot und weiß in rerschiedeucr Zusammensetzung gefärbten F'lecken, discal und subapical gelegen ....... 58b. H. xenoclea notabilis . . p. 189

Vorderflügelzeichnungen rot und gelb -231 . $231\left\{\begin{array}{l}\text { Vorderflügelzeichnung fleckartig - } 232 . \\ \text { Vordcrflïgelzeichnung in der Haupt- } \\ \text { sache bindenartig - 233. }\end{array}\right.$

Mit einem großen, rot und gelb gefärbten Vorderrandfleck im distalen Teil des V'orderflügels. . . . . .

Mit ähnlichem; aber weniger lebhaftem und nur gelbem Vorderrandfleck und mit roter Überstäubung hinter demselben . . . . . . .

Im distalen Teil der Vorderflügelzelle ein deutlich abgesonderter, zuweilen fast unkenntlicher, gelber Fleck; distal ron der Zelle eiue rote, proximal läufig gelb gerandete Fleckenbiude

Vorderflügel ohne abgesonderten Fleck in der Zelle - 234. 28i. H. melpomene aglaope, forma unimaculata . . p. 122

28a. H. melpomene melpomene, forma karschi .... p. 114

28a. H. melpomene melpomene, forma lucia..... p. 113 

(Vorderflügel mit geschlossener, vorn nicht gegabelter, discaler Schräg- binde - 235.
Vorderflügel mit einer vorn gegabelten oder am Zelleude unterbrochenen, discalen Schrägbinde - 236.

Binde des Vorderflügels im distalen Teil der Zelle gelb, sonst rot, distal stark und unregelmäßig gezackt, gegen den Hinterwinkel verschmälert . . . . . . . .

Binde des Vorderflügels in ganzer Länge fast gleich breit, distal gewölbt, rot, proximal stark gelb angeflogen ..........

Die gelbe Discalbinde des Vorderflügels reicht bis nahe zur Submediana; distal anschließend breit rote Färbung. . . . . . . .

Die gelbe Discalbinde des Vorderflügels reicht nur bis zum hinteren Medianast - 237.

(Discalbinde des Vorderflügels distal mit roter Berandung, die sich hinten bis nahe zum Hinterwinkel

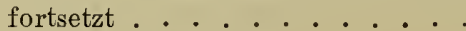

Discalbinde des Vorderflügels ohne rote Berandung, aber distal von derselben ein getrennter roter unregelmäßiger Streif . . . . . .

Hinterflügel mit Saumbinde, randständiger oder fast randständiger Fleckenbinde - 239.

Hinterflügel ohne solche Binden, mit anderen Zeichnungen verschiedener Art - 242.

Hinterflügel im übrigen ohne weitere Zeichnung - $\mathbf{2 4 0}$.

Hinterflügel im übrigen mit farbiger Querbinde - 241.

Vorderflügel mit breiter, proximal gelber, distal roter, discaler Schrägbinde . . . . . . . . .

Vorderflügel mit schmaler, vorwiegend roter, proximal weiß bestäubter, discaler Schrägbinde; Grundfarbe tief blauglänzeud . . . . . . .

Hinterflügel mit roter Querbinde und einer Reihe fast randständiger länglicher Flecke... . . . . .

Hinterflügel mit gelber Querbinde, einer Reihe randständiger Punkte und einer Reihe Fleckchen nahe dem Rande .......... 28b. H. melpomene aphrodyte. p. 114

28a. H. melpomene melpomene, forma lucinda . . . p. 113

27. H. heurippa . . . . . p. 110

28j. H. melpomene vicinus, forma amor . . . . . p. 123

28n. H. melpomene erebius . . p. 127

26. H. rubellius . . . . . p. 110

30b. H. vulcanus cythera, forma principalis . . . p. 132

41. H. longarenus . . . . p. 143

65. . hermathena..... p. 212 
$2+2\left\{\begin{array}{r}\text { Hinterfligel nit ciner in unmittelbarer } \\ \text { Näle der Wuzel vom Hinterande } \\ \text { ausgelrenden, gelben. zuweilen leicht } \\ \text { rot überstäubten Querbinde }-243 .\end{array}\right.$

Hinterflïgel olne solche Querbinde - 253.
Hinterflïgel mit roter Strahlenbildung in und hinter del Binde - 244.
Hinterflïgel ohne rote Strahlenbildung hinter der Binde - 247.

Gelbe Querbinde des Hinterflügels unten schmal, bis nahe an den Rand des Apex reichend; oben mindestens ein roter, in proximalen Teil der

$2 \pm 4$ Zelle liegender Streif ror und in der Binde - 245.

Gelbe Querbinde oben und unten distal nur bis etwa zum letzteu Drittel der Flügellänge reichend - 246.

Discale Querbinde des Vorderflügels 1*ot Discale Querbinde des T orderflügels gelb

$2 \pm 6$

Discale Querbinde cles Vrorderflügels rot Discale Querbinde des Vorderflïgels gelb

Vorderfligel in der Mitte mit großem gelbem biudenartigen Fleck; hinter demselben im Hinterwinkel ein kleiner roter Fleck . . . . . .

Vorderflügel mit discaler roter Querbinde -248 . $248\left\{\begin{array}{c}\text { Hinterflügel unten mit roter Saumlinie } \\ \text { Hinterflügel unten ohne rote Saum- } \\ \text { linie }-249 .\end{array}\right.$

( Hinterflügel unten stets ohne gelbe Apicalfleckchen. Distale Begrenzung der roten Vorderflügelbinde der Oberseite zerstäubt — $\mathbf{2 5 0}$.

249 Hinterflïgel unten mit gelben Apicalfleckchen, die selten fehlen. Distale Begrenzung der roten Vorderflügelbinde der Oberseite bestimmt und scharf -251.

Rote Discalbinde des Trorderflügels distal mit zwei oder drei nahe zum Distalrande rorspringenden Zälınen am hinteren und mittleren Medianast, proximal nur die distalen Winkel
631. H. erato anacreon, forma principalis . . . . p. 210

631. H. erato anacreon, forma ottonis . . . . . p. 211

281. H. melpomene penelope, forma penelamanda . . p. 125

281. H. melpomene penelope, forma margarita . . . p. 124

281. H. melpomene penelope, forma pluto . . . . p. 125

33. H. besckei . . . . . . p. 135 
Vorderflügelbinde distal nur mit einem stumpfen Zahn am hinteren Medianast, proximal weit in die Zelle hineinreichend . . . . . .

28o. H. melpomene amandus · p. 127

Querbinde des Hinterflügels schwärzlich überstäubt, besonders an den Adern

63k. H. erato phyllis, forma

Querbinde des Hinterflügels reingelb - 252. phyllidis . . . . . p. 210

Hinter der Hinterflügelbinde keine, oder höchstens ein oder zwei rote Flecke

63k. H. erato phyllis, forma

252 Hinter der Hinterfiügelbinde eine Reihe von drei oder mehr roten Flecken

63k. H. exato phyllis, forma principalis - $\cdot 52222 \times 7-$ p. 209 artifex... 220 p. 210

Hinterflügel ohne eigentliche Strahlenzeichnung, zuweilen aber proximal

253 mit strahlenartigen Wischen - 254.

Hinterflügel mit Strahlenzeichnung hinter der Zelle - 261.

$254\left\{\begin{array}{l}\text { Vorderflügel mit A picalfleckchen - } 255 . \\ \text { Vorderflügel ohne A picalfleckchen - 257. }\end{array}\right.$

Hinterflügel mit breitem schwarzem Randfelde und schwarzem Vorderrande, sonst rot. . . . . . .

Hinterflügel fast ganz schwarz, nur

49. H. hierax . . . . . p. 167 mit einigen kleinen roten Wischen an der Wurzel - 256.

Vorderflügel in der Mitte mit drei getrennten Flecken, deren einer in der Zelle, zwei distal von dieser liegen ......... Vorderflügel in der Mitte mit einem geschlossenen, nur an den Adern durchschnittenen Fleck . . . .

47c. H. burneyi catharinae . . p. 159

47d. H. burneyi lindigii . . . p. p. 160

Fransen des Hinterflügels schwarz und weiß gescheckt. Vorderflügel proximal rot, in der Mitte mit sechs

257 gelben Flecken, von denen einer in der Zelle liegt. . . . . . . . Fransen des Hinterflügels wie die Grundfarbe - 258.

Zelle des Vorderflügels ohne gelben Fleck, distal von der Zelle eine rot und gelbe Fleckenbinde .. .

Zelle des Vorderflügels distal mit gelbem

28c. H. melpomene funebris, forma deinia . . . . p. 115 Fleck -- 259.
$\left\{\begin{array}{c}\text { Distal von der 'Zelle des Vorderflügels } \\ \text { eine gelb und rote Fleckenbinde . }\end{array}\right.$
Distal von der Zelle eine rein gelbe Fleckenbinde oder Gruppe von Flecken - 260.

46b. H. egeria egerides . . . . p. 155

28c. H. melpomene funebris, forma faustina .... p. 116 


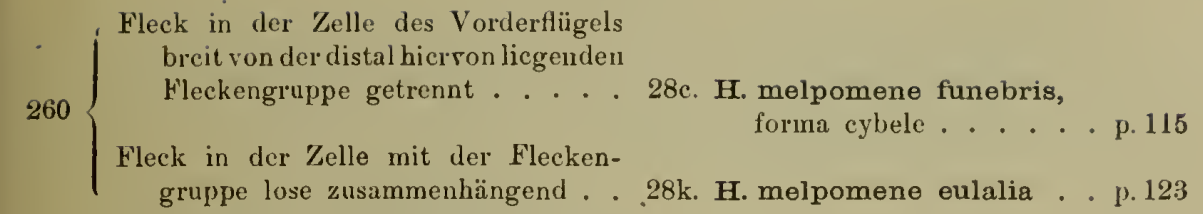

$261\left\{\begin{array}{l}\text { Vorderflügel mit A picalfleckchen - 262. } \\ \text { Vorderflügel ohne A picalfleckchen - 269. }\end{array}\right.$

\section{Strahlenzeichnung des Hinterflügels rot mit vollkonmener blauer Um- randung ......... \\ Strahlenzeichnung des Hinterfligcls nur rot, zuweilen schwach grün oder - blau gesäumt -263 .
Fransen des Hinterflügels schwarz und weiB gescheckt -264 .
Fransen des Hinterflügels wie die Grund- farbe -265 .

Vorderflügel in der Mitte mit drei oder vier lose zusammenhängenden oder ganz getrenuten Flecken, deren größter in der Zelle, die andern distal von derselben stehen und länglich gestaltet sind.....

Vorderflïgel in der Mitte mit ähnlicher Zeichnung, aber die Fleckengruppe nahe zusammengerückt, die distal stehenden Flecke rundlich oder dreieckig. . . . . . . . .

47a. H. burneyi burneyi . . p. 158

48a. H. doris doris, forma amathusia . . . . p. 163

47b. H. burneyi huebneri . . p. 159

Vorderflïgel in der Mitte mit einer ron der Grundfarbe in einzelne Flecke zersprengten Querbindc. die 265 in den Jedianzwischenräumen distal weit vorspringt -266.

Vorderfliigel mit einer ganz oder wenigstens lose zusaumenhängenden Fleckengruppe - 268.

Hinterflügel mit sechs vollkommenen,

$266\left\{\begin{array}{c}\text { Her schmalen rotgelben Strahleu }-2 \\ \text { Hinterfügel mit sieben oder acht breiten } \\ \text { roten Strahlen . . . . . . }\end{array}\right.$ 267.

Hinterwinkel des Vorderflügels cin gelber Fleck, vor den roten Strahlen des Hinterflügels ein gretrennt liegender, die Zelle durchquerender, roter Streif .........

45c. H. xanthocles paraplesius p. 152

Im Hinterwinkel des Vorderflügels

28g. H. melpomene bari . . p. 120 kein gelber Fleck, vor den Strahlen des Hinterflügels ein abgetrennter, in der Zelle längs licgender, roter Streif . . . . . . 45b. H. xanthocles vala. . . p. 151

Das Tierreich. 22. Lief.: H. Stichel \& H. Riffarth, Heliconiidae. 
Hinterflïgel unten ebenfalls mit langen roten Strablen, die oben hinter der Zelle getrennt sind . . . .

Hinterflügel nur oben mit roten Strahlen, die auch noch hinter der Zelle zusammenhängen . . . . . .

Die Strahlen des Hinterflügels entspringen frei in der schwarzen Grundfarbe hinter der Zelle. Vorderflügel im Hinterwinkel mit roten Wischflecken .........

Strahlen des Hinterflügels vorn in gerader Linie abgeschnitten und von einer vor denselben liegenden schmalen roten Binde deutlich getrennt - 270.

Strahlen des Hinterflügels nicht gerade abgeschnitten, sondern mehr oder weniger rund um die Zelle gruppiert, vorn öfters ganz zusammenhängend - 281 .

Yorderflügel mit einer durch die Grundfarbe in Flecke zersprengten Querbinde; im distalen Teil der Zelle meist ein isolier ter Fleck-271.

Vorderflügel mit einer zusamamenhängenden Fleckengruppe in der Mitte oder mit einer distal von der Zelle liegenden schrägen Querbinde -275 .

Distal der Zelle liegende Fleckengruppe des Yorderflügels rot und gelb - 272.

Distal der Zelle liegende Fleckengruppe des V orderflügels nurgelb-273.

Fleck im distalen Teil der Zelle des Vorderflügels rein gelb . . . .

Fleck im distalen Teil der Zelle des Vorderflügels trüb gelb .....

Fleckengruppe des Vorderflügels ver273

Fleckengruppe des Vorderflïgels rein gelb - 274.

Querbinde des Hinterflügels vor den Strahlen in der Zelle endigend. .

Querbinde des Hinterflügels länger als die Zelle........

Fleckengruppe oder Binde des Vorder275 flügels gelb und rot - 276.

Fleckengruppe oder Binde des Vorderflügels rein gelb - 277 . 48a. H. doris doris, forma delila p. 164

48c. H. doris viridis, forma eratonia . . . . p. 166

$28 \mathrm{~m}$. H. melpomene timareta, forma contigua secunda - p. 126

28f. H. melpomene thelxiopeia, forma augusta . . . p. 119

28d. H. melpomene tyche, forma hippolyte. . . . . p. 117

28f. H. melpomene thelxiopeia, forma aglaopeia. . . p. 120

28f. H. melpomene thelxiopeia, forma principalis . . . p. 119

28e. H. melpomene thelxiope . p. 117 
Fleckengruppe des Vorderflügels distal rot gerandet . . . . . . .

Fleckengruppe des Vorderflügels distal reichlich rot überstäubt . . . .

Strahlen des Hinterflügels hinter der abgetrennten Querbinde im vorderen Teil breit zusammengeflossen. . .

Strahlen des Hinterflügels von vorn an deutlich voneinandergetrennt-278.

Ein großer Fleck der Gruppe in der Mitte des Vorderflügels liegt im distalen Teil der Zelle - 279.

Zelle des Vorderflügels ohne Fleck oder nur mit Andeutung eines solchen -280 .

Proximales Feld des Vorderflügels und Strahlen des Hinterfliggels rotgelb; der hinterste, distal ron der Zelle des Vorderflügels liegende Fleck diese nicht berührend . . . . .

Die vorher genannten Teile dunkelrot; die distal von der Zelle liegende Binde berührt jene in ilhrem hintersten 'Teil . . . . .

Ohne gelbe Fleckchen im Hinterwinkel 280

Mit gelbeu Fleckchen daselbst ... 28j. H. melpomene vicinus, forma rufolimbata. . . p. 123

281. H. melpomene penelope, forma penelopeia . . p. 125

$28 \mathrm{~m}$. H. melpomene timareta, forma richardi . . . p. 127

28j. H. melpomene vicinus, forma principalis ... . p. 123

281. H. melpomene penelope, forma principalis . . . p. 124

28i. H. melpomene aglaope, forma principalis . . p. 122

28h. H.(melpomeng elevatus · p. 120 $\mathrm{PP}$.

Abdomen lateral mit deutlichen runden gelben Fleckchen oderPunkten - 282.

Abdomen lateral ohne runde Fleckchen, sondern mit stellenweise unterbrochenen gelben Längslinien - 285 .

Segmenteinschnitte des A bdomen dorsal deutlich gelb -283.

Segmenteinschnitte des Abdumen dorsal von der Grundfarbe nicht verschieden -284 .

Bindenzeichnung der Mitte des Vorderflügels den distalen Teil der Zelle ausfüllend .........

45d-H. xanthocles melete. . p. 152

Bindenzeichnung der Mitte des Vorderflügels im distaleu Teil der Zelle bis auf ein am hinteren Winkel liegendes gelbes Dreieck reduziert

45f. H. xanthocles melittus . - p. 153

Bindenzeichnung der Jitte des Vorderflügels die Zelle gänzlich frei lassend ......... 
Vorderflügel mit gelbem Fleck im distalen Teil der Zelle und abgesonderter, distal von dieser liegender Fleckenbinde (zersprengter Querbinde).........

Vorderflügel im dístalen Teil der Zelle gelb, mit einer das Zellende umschließenden, zusammenhängenden Fleckengruppe . . . . . .

Vorderflügel ohne Fleck in der Zelle, distal von dieser eine gelbe Fleckenbinde .........

Hinterflügel unten an der Wurzel, vor der Mediana, ohne gelbliches Fleckchen - 286.

Hinterflïgel unten an der Wurzel, vor der Mlediana. mit einem gelblichen Fleckchen - 288.

Strahlen des Hinterflügels kurz und wischartig, vorn und proximal bis über die Flügelmitte breit rot zusammengeflossen . . . . .

Strahlen des Hinterflïgels lang und streifenförmig - 287.

Der hintere Fleck der distal von der Zelle liegenden Fleckenbinde des Vorderflügels füllt den hinteren Medianzwischenraum in seiner ganzen Breite aus und stößt proximal an die Zelle . . . . . . .

Die distal von der Zelle liegende gelbe Fleckenbinde des Vorderflïgels reicht nur bis zum mittleren Mledianast oder höchstens in Spuren darüber hinaus . . . . . . . . Teil, namentliclı proximal, breit zusammenhängend - 289.

288 Stralılen des Hinterflügels in ganzer Länge voneinander getrennt und von einem in der Zelle liegrnden roten Streif durch die Grundfarbe geschieden - 290.

Zelle des Vorderflügels distal mit gelbem Fleck, distal von ersterer eine abgesondert liegende gelbe Fleckenbinde..........

Zelle des Vorderfügels ohne gelben Fleck, distal von ersterer eine teilweise etwas trübe Fleckenbinde.

44a. H. aoede aoede . . . p. 147

44c. H. aoede lucretius . . . p. 148

44d. H. aoede bartletti . . . p. 149

46a. H. egeria egeria . . . p. 155

46e. H. egeria hyas . . . . p. 156

46d. H. egeria astraea . . p. 156

63h. H. erato bouqueti . . . p. 207

63g. H. erato demeter . . . p. 206 
Fleckengruppe des Vorderflügels bindenartig zusaminenhängend: vorherrschend rot, proximal gelb ... . .

Fleckengruppe des Vorderflügels zerrissen, rot, am Vorderrande proximal gelblich .........

Zelle des Vorderflügels distal ohne 292 Gelb oder nur mit spuren gelblicher Zelle des Vorderflügels distal ganz oder fast ganz gelb ausgefüllt - 294 .

Vorderflügel miteinem unregelmäßigen, etwa cirunden, von den schwarzen Adern durehsclinittenen, subapicalen Fleck nächst dem Vorderrande

Vorderflügel nuit einer distal ron der Zelle liegenden, sclimalen und kurzen Fleckenbinde . . . . . . . . .

Vorderffügel mit einer distal ron der. Zelle liegenden und sie beriihrenden, breiten, gelben Binde . . . . .

Vorderflügel in der Mitte mit einer die Zelle mindestens vorn berührenden Fleckengruppe oder Binde - 295. Vorderflügel ohne solchermaßen angeordnete Fleckengruppe oder Binde - 298.

Zeichnung der Vorderflügelmitte in Gestalt einer Fleckengruppe; der hintere Fleck berührt die Zelle nicht, an der Abzweigung der hinteren Radialis ein schwarzer Fleck . . . . . . . . .

Zeichnung der Vorderflïgelmitte kurz bindenartig, nur von den fein schwarzen Adern durchschnitten; der im mittleren Medianzwischenraun gelegene Teil berührt die Zelle; proxinale rote Bestäabung an den Adern breit schwarz unterbrochen

Zeichnung der Vorderflügelmitte ebenfalls bindenartig, aber länger, distal bis kurz an den Distalrand reichend; rote Bestäubung des proximalen Feldes nur von den fein schwarzen Adern durchschnitten . . . . . Distal von der Zelle des Vorderfliigels keine gelben Flecke...... Distal von der Zelle des Vorderflïgels ein oderzwei, manchinal undeutliche, gelbe Flecke in den Jledianzwischenräumen . . . . . . .

Distal von der Zelle des Vorderflügels eine gebogene gelbe Fleckenbinde, der hinterste Fleck abgesondert - 297.
$63 \mathrm{j} . \mathrm{H}$. erato anactorie, forma principalis . . p. 208

63a. H. erato erato, forma udalrica . . . . . p. 200

63f. H. erato estrella, forma etylus p. 206

63f. H. erato estrella, forma emma p. 206

63f. H. erato estrella, forma principalis ...... p. 205

63i. H. erato lativitta . . . p. 207

63 j. H. erato anactorie, forma venusta . . . . p. 208

63a. H. erato erato, forma tellus p. 201

63a. H. erato erato, forma oberthüri p. 200

63a. H. erato erato, forma leda. p. 199 
Bestäubung des Wurzelfeldes des Vorderflügels und Strahlen des Hinterflügels lebhaft rot, selten gelbrot; Strahlen schmal und spitz, im Radialzwischenraum verkürzt .

63a. H. erato erato, forma

principalis . . . . . p. 198

Bestäubung des Wurzelfeldes des Vorderflügels und Strahlen des Hinterflïgels orangerot; Strahlen breit und stumpf, im Radialzwischenraum deutlich und kräftig

63b. H. erato amazona . . . p. 201

\section{Sect. Opis ogymni}

Unterseite des Vorderflügels beim $0^{7}$ hinter der Zelle, abweichend von der Grundfarbe, heller oder dunkler grau ohne eigentliche farbige Zeichnung, aber seidenglänzend bis unmittelbar zur Mediana. Vorderer Teil des Hinterflügels beim $O^{\top}$ bis zur Subcostalis meist hellgrau, stark glänzend, zuweilen etwas dunkler umrandet, der Vorderrand selbst dann aber schmal hellgrau, ausgenommen ein kleinerer Teil der Silvaniformes mit etwas trüberer grauer Bestäubung des Vorderrandfeldes.

\section{a. Coh. Silvaniformes}

Kopf schwarz, vorn mit vier, vor und hinter den Antennen par'weise nebeneinander stehenden weißen oder gelblichen Fleckchen oder Punkten zwischen den Augen, von denen die unteren länglich, streifenartig und von den Palpen teilweise verdeckt sind. Augen schwarzbraun, hinten gelb, gelblich oder weiß gesäumt, oben häufig noch mit je einem kleinen hellen Punkt. Antennen wenig länger als die Zelle des Vorderflügels; Antennenwurzel ventral gelblich oder weiß; übrige Färbung verschieden, beim $0^{\pi}$ meist schwarzbraun mit gelblicher Keulenspitze, beim $q$ entweder die distalen zwei Drittel oder die Keule allein ockergelb. Palpen gelb oder gelblich, Spitze oder distales Glied schwarz. Thorax und Abdomen schwarz bis schwarzbraun. Halskragen oben mit 2 und vorderer Teil des Thorax mit 4 nebeneinander von eimer zur anderen Flügelwurzel angeordneten, gelben, gelblichen oder weißen Punkten. Thorax dorsal mit einem breiten, in der Mitte schmal unterbrochenen Querbande von gleicher Farbe wie die Halspunkte, hinten gelblich behaart. Thorax lateral zwischen und hinter den Coxae gelb. Abdomen weit über den Hinterflügel hinausragend, ventral gelb, vorn, namentlich lateral, ebenfalls gelb behaart, mit je drei, bei getrockneten Tieren teilweise undeutlich wahrnehmbaren und unterbrochenen Längsstreifen an der Seite, von denen die beiden unteren dicht nebeneinander laufen, der obere etwas abgerückt ist; einer von letzteren ist häufig ganz in einer Längsfalte des eingeschrumpften Leibes verborgen. Tibia der Vorderbeine an der nach außen gekehrten Seite weißlich oder gelb; die übrigen Beine schwarz, Tibia und Femur meist weißlich bestäubt. Alle gelbe oder gelbliche Zeichnung und Behaarung des Körpers kann verdunkelt und abgeschwächt auftreten oder bei Formen mit Flügeln ohne gelbe oder weiße Zeichnung fehlen und in Braun oder Rotbraun übergehen. - Vorderflügel gestreckt, Apex abgerundet, Hinterrand viel kürzer als der Vorderrand, Hinterflügel fast eirund. Flügel meist braun oder gelbbraun, Vorderflügel mit schwarzer Fleckenzeichnung im proximalen und mittleren Teil, häufig mit gelber oder weißer Schräghinde und gelben oder weißen Flecken im distalen Teil, seltener dunkelbraun oder schwarz mit heller Discalbinde oder mehreren Fleckenreihen; Hinterflügel mit schwarzer Saum- und Mittelbinde, 
seltener olne Zeichnung braun oder auch vorwiegend oder ganz schwarz. In Betreff del Zeichnung, vgl. S. 4. - 0 mit heller oder dunkler grauein, bis unmittelbar zur Mediana reichendem Hinterrandteil auf der Unterseite des Vorderflïgels und grauglänzendem Vorderrandfelde des Hinterflïgels. o mit stumpfem, meist wie die Grundfarbe gefürbtem Hinterrandteil auf der Cnterseite des Vordertlïgels und mattem, bräunlichem oder schwärzlichem Vorderrandfelde des Hinterflïgels.

22 sichere Arten, ron denen 15 in 71 Unterarten zerfallen, und 2 unsichere Arten.

1. H. narcaea (Godart)

${ }^{7}$. Stirnpunkte weiß, Punktierung des Hinterkopfes, Halskragens und Thorax gelb. Antennen schwarz, Keule unterseits gelb. Vorderbeine weißlich. Grundfarbe beider Flïgel oben hellbraun. - Vorderflïgel schlank, mit flach gebogenem Vorderrande. rundlichem Apex. stumpfem Hinterwinkel und schwach geschweiftem Hinterrande. Torderrand und Fleckenzeichunng schwar?, nnd zwar: Keilfleck in der Zelle länglich eirund, gegen die Flügelwurzel spitz auslaufend; Endzellfleck in der Regel deutlich: meist zwei Medianflecke, ron denen der hintere rudinentär auftreten oder ganz fehlen killn; Randfleck am Distalrande stets mit dem breit schwarzen Apex verflossen. Distal vou der Zelle eine schwefelgelbe schrägliegende Querbinde. In der Zelle zwischen Keilfleck und Endzellfleck häufig gelbliche Bestäubung. In schwarzen Apex ein großer weißer oder gelblicher Fleck oder Doppelfleck. Distalland, soweit nicht der schwarze Apicalteil reiclit, schmal schwarz, Fransen schwarz. Hinterrand im Ton der Grundfarbe, Submedianstreif schmal, zuweilen etwas breiter, den Hinterwinkel meist erreichend. Unterseite matter, die dunklen Zeichnungen schwarzbraun, im Apex meist 3 oder 4 weiße Fleckchen dicht am Saum. Hinterflïgel fast eirund, mit bräunlichgrauem, seidenglänzendem, etwas dunkler umraudetem Vorderrandfelde und schwarzer Mittelbinde. Letztere vorn glatt begrenzt, die Zelle nicht berührend, binten an den Adern gekerbt, in den schwarzen Apex mündend. In diesem zurveilen 1 oder 2 weißliche oder gelbe Fleckchen. Vor der Binde meist breit gelb bestäubt, hierauf ein schmaler schwarzer Streif längs der Subcostalis, der sich nahe dem Apex mit der Mittelbinde rereinigt. Distalsaum schwarz, proximale Begrenzung dieser Umrandung scharf, an den Adern schwach gezähnt. Unterseite matter, Vorderrandfeld bräunlich, dicht vor der Costalis und der Subcostalis je ein schwarzer bis zum Apex reichender Streif. Mittelhinde stärker gekerbt, fast in eirunde Flecke aufgelöst. In schwarzen Distalsaum in den Aderzwischenräumen weißliche Strichflecke. 1 oder 2 weiße Apicalflecke deutlich. Bei frischen Stücken alle schwarzen Zeichnungen eigentümlich violettgläuzend. - $-q$. Im allgemeinen wie das $\delta^{\circ}$. An den schwarzen Antenuen die ganze Keule rötlichgelb. Endrell-, Median- und Randfleck des Vorderflïgels fist immer mehr oder weniger unter sich und mit dem scliwarzen Torderrande zusammengeflossen, so daß sie eine unregelmäßig begrenzte. schwar\%e Binde bilden, welche die schwefelgelbe Querbinde ron der lebhaft gelbbraunen Gruudfarbe trennt. Fransen des Distalrandes stellenweise weiß. Torderrandfeld des Hinterflügels kaum merklich lıeller als die Grundfarbe, Distalrand auch oben meist mit weißen Saumfleckchell. Läng's der Subcostalis des Hinterflügels und ror derselben ein breiterer schwarzer Streif, der sich nahe dem Apex mit der rundlich nach vorn gebogenen Mittelbinde vereinigt und durch die gelbbraune Grundfarbe deutlich ron dem schwirzen Distalrande abgesetzt ist. Auf der Unterseite fehlt der schwarze Streif ror der Costalis.

Siidliches Brasilien.

Diese Art zerfällt in 2 Unterarten: 
1 a. H. narcaea narcaea (Godart) 1819 Heliconia n., (Latreille \&) J. B. Godart in: Enc. méth., v. 9 p. 217 | 1900 Heliconius n., W. F. Kirby, Exot. Schmett. Hübner, p. $11 \mid 1835$ Heliconia narcea, H. Lucas, Hist. Lép. exot., p. 96 t. 50 f. 3 | 1851 H. n., Chenu \& H. Lucas, Enc. Hist. nat., Pap. diurn. p. 68 f. 158 | 1822-26 Mechanites eucrate, Mechanitis e., Jac. Hübner, Exot. Schmett., v.2 t. [1] | 1847 Heliconia e., E. Doubleday (\& Westwood), Gen. diurn. Lep., v.1 p. $104 \mid 1871$ Heliconius e., W. F. Kirby, Cat. diurn. Lep., p. 139 | 1880 ? H. e., Buchecker. Syst. Ent., Lep. t. 54 f. 8. 9 | 1883 H. e., Mleldola in: Tr. ent. Soc. London, p.XXIII | 1885 H. e., O. Staudinger (\& Schatz), Exot. Schmett., v. 1 p. 74 t. $31 \mid 1886$ H. e., G.W. Mlüller in: Zool. Jahrb., v. 1 p. 428 (Biol.) $\mid 1890$ H. e., Scitz in: Ent. Zeit. Stettin, v.51 p. $92 \mid 1865$ Heliconia eucrato, Prittwitz in: Ent. Zeit. Stettin, v. 26 p. 136 | 1875 Hcliconius satis, (Plötz iu MS.) Weymer in: Ent. Zeit. Stettin, $v .36$ p. 380 t. 1 f. 6 (forma s.)| 1877 H. s., W. F. Kirby, Cat. diurn. Lep., Suppl. p.722 (forma s.) ( 1885 H. encrate var. infuscata, O. Staudinger (\& Schatz), Exot. Schmett., $v .1$ p. 75 (forma satis) | 1893 H. narcaea + H. n. var. flavomaculatus + H. n. var. satis, Weymer in: D. ent.Z. Lep., v. 6 p. 340 ; p. 341 (forma flaromaculata); p. 341 (forma s.) $1896 \mathrm{Heli}$ conias eucrate + H.s., Bönninghausen in:

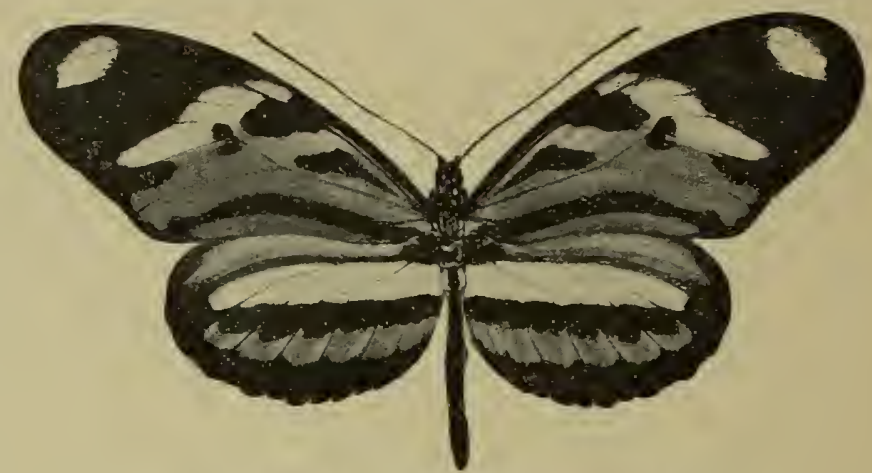

Fig. 8. H. narcaea narcaea, forma principalis, $\delta(1 / 1)$.

Verh. Ver. Hamburg, v. 9 p. 32 ; p. 32 (forma s.)। 1901 Heliconius naveaea $+H . n$. flavomaculatus + H.n.s., Riffarth in: Berlin. ent. Z., v. 46 p. 28 ; p. 28 (forma flavornaculata); p. 28 (forma s.).

Forma principalis. Fleck im Apex des Vorderflïgels (Fig. 1) weiß, scharf begrenzt und ziemlich groß. Die schwefelgelbe Querbinde schmal, meist nur $4-5 \mathrm{~mm}$ breit, auf den Aderu braun bestäubt. Hinterflügel vor der: Mittelbinde sehr lebhaft und breit schwefelgelb, so daß diese Bestäubung: vorherrscht. Vorderflügellänge $40-44 \mathrm{~mm}$.

Ei gelb, einzeln an der Spitze von jungen Ranken der Passiflora alata Ait., seltener Passiflora edulis Sims. -- Raupe in der .Jugend gelb, borstig, mit Andeutung schwarzer Zeichnungen; Kopf mit zwei langen, mäßig dirergicrenden, schlanken, nach hinten gebogenen, schwarzen Hörncrn; Körper später weiß, mit wohl entwickelten schwarzen Dornen, auf jedem Segment mit drei Querreihen von schwarzen Punkten. Puppe licht braungelb. schwarzbraun gemischt, mit undeutlichen Längsstreifen. Flügelscheiden weit vorgezogen, Rücken sattelartig eingedrïckt, stark höckcrig, mit schwarzen Dornen; drei seitlich bewegbare Segmentverbindungen, lateral mit silberglänzeuden Flecken. Kopf mit zwei Hörnern.

Bahia, Espirito Santo, Rio de Janeiro, Santa Catharina (Blumenau).

Forma flavomaculata. Zeichnung wie bei der Hauptform. Fleck im Apex des Vorderflügels schwefel- oder bräunlichgelb anstatt weiß. Hinterflügel oben auch beim $\sigma^{\pi}$ zuweilen mit weißen Saumfleckchen.

Bahia, Pernambuco, Rio de Janeiro. Neben der Hauptform.

Forma satis. Zeichnung wie bei der Hauptform, aber der weiße, sehr selten gelbe Fleck in Apex des Vorderflügels kleiner und schwärzlich überstäubt. Die schwefelgelbe Querbinde meist fast doppelt so breit wie bei 
der Hauptform. Hinterflügel vor der Mittelbinde nicht gelb, sondern gelbbraun wie die Grundfarbe.

São Paulo, Espirito Santo, Minas Geræes. Neben der Hauptform.

1 b. H. narcaea polychrous C. \& R. Felder 1865 H. p., C. \& R. Felder in: Reise Novara, $v .211$ l. 375 t. 47 f. 7 | 1871 H. p., W. F. Kirby, Cat. diurn. Lep., p.139| 1893 H. narcaea var. p., Weymer in: D. ent. Z. Lep., v.6 p.311| 1901 II.n.p., Riffarth. in: Berlin. ent. Z., v. 46 p. 29.

Durelischnittlich etwas kleiner als die vorhergehenden Formen. Zeichnung im allgemeinen wie bei der Hauptform der typischen Unterart, aber die gelbe Bestäubung der Querbinde des Vorderflügels fließt gegen die Wurzel über die ganze Zelle, den mittleren und manchnal auch über einen Teil des hinteren Medianzwischeuraunes aus. Submedianstreif sehr breit, vorn zuweilen ungewiß begrenzt und zerstiubt. Keilfleck in der Zelle manchmal mit dem schwarzen Vorderrande rerflossen. Fleck in Apex weib, sehr grob. Hinterflügel vor der Mittelbinde rein schwefelgelb, breiter als bei den inderen Formen der Art, nur am Vorderrande ein schmaler braungelber Streif. Vorderflïgellänge bis $44 \mathrm{~mm}$.

São Paulo, Rio Grande do Sul.

2. H. ismenius Latr.

ठ․ Stirnpunkte weiß, Punktierung des Halskragens und des Thorax, sowie die übrige von der dunklen Grundfarbe des Körpers abweichende Beharung oder Zeichnung gelb. Antennen dicht an der Wurzel weiß, sodann auf etwal ein Viertel bis ein Drittel der Länge schwarzbaun, im übrigen ockergelb. Grundfarbe der Flügel gelbbraun. - Vorderflügel gestreckt, mit. schwach gebogenem $V^{r}$ orderrande. rundlichem Apex, stumpfem Hinterwinkel und gegen die Wurzel sanft geschweiftem Hinterrande. Vorder'rand scliwarz, Keilfleck meist groß, läıglich oder eckig, zuweilen nach der Flügelwurzel zu spitz auslaufend. Endzellfleck mit dem schwarzen Vorderrande eimerseits und mit den Medianflecken und dem Randfleck andererseits zu einer breiten schwarzen Masse zusammengeflossen, die in weiterer Verschmelzung mit dem schwarzen Apex fast die ganze distale Flügelhälfte einnimmt und sich hinter der Zelle im mittleren Mledianzwischenraum, diesen zum Teil oder ganz ausfüllend, wurzelwärts bis zur Mediana ausdehnt. In der schwarzen Fläche zwei schräggestellte Reihen weißer oder gelber Flecke, und zwar subapical 4 meist. lumdliche, von denen je 2 am Vorderrande und am Distalraude paarweise aneinander liegen und in der Mitte von einem weiteren Zwischemraun getrennt sind, ferner nahe der Zelle eine lose zusammenhängende Fleckenbinde oder eine Reihe vou 4 oder 5 länglichen, einzeln stehenden Flecken, den Resten der der Gruppe eigentümlichen Querbinde. Hinter dieser Fleckenbinde, im mittleren Medianzwischenlaum, in gewissen Fällen noch ein gesonderter länglicher Wischfleck oder etwas gelbe Bestäubung, im Apex endlich eine Reihe mebr oder miuder deutlicher Saumflecke, die jedoch auch fehlen können. und im distalen Ende der Zelle hinten an der Mediana manchmal ein leichter, weißlicher oder gelblicher Anflug. Distalrand, soweit der schwarze Apicalteil nicht reicht, schmal schwarz gesäumt, oder der Hinterwinkel schwärzlich auscrefüllt. Fransen schwarz und schmal weiB gescheckt. Suburedianstreif mäßig breit vder ganz feblend, Hinterrand ganz schınal schwar\% gesäunt. An der Wurzel nächst deni Körper Spuren gelblicher Bestäubung. Unterseite matter gefärbt. Der zwischen dem Keilfleck und dem schwarzen Zellende liegende Teil manchmal weißliclı überstäubt. Saumflecke am Apex und Distalrande deutlicher. - Hinterflïgel mit oder obne Mittelbinde oder 
Teilen einer solchen. Die Mittelbinde, wenı vollständig vorhanden, selten die Zelle berührend, nach hinten schwach gebogen und gekerbt, im vorderen Radialzwischenraum nächst dem Apex nach vorn gekrümmt und in das grau glänzende, dunkler gesäumte Vorderrandfeld auslaufend. Wenn nur der distale Teil der Mittelbinde vorhanden, so ist dieser nach hinten stark gezähnt oder besteht aus lose zusammenhüngenden länglichen Flecken. Am Distalrande eine schwarze, etwa $3-5 \mathrm{~mm}$ breite, ziemlich gleichmäßige und volle Saumbinde. In derselben zuweilen kleine weiße Saumflecke in Fortsetzung der weißgescheckten, an den Aderenden schwarzen Fransen. Im Apex zuweilen 1 oder 2 weißliche Flecke. Sämtliche Adern ganz oder größtenteils schwarz bestäubt. Unterseite zwischen Costalis und Subcostalis gänzlich, vor ersterer teilweise, namentlich im distalen Teil schwarz, die weißen Apicalflecke deutlicher und größer, im schwarzen Saum stets deutliche weiße Strichflecke, deren je zwei in jedem Aderzwischenraum stehen. Schwarze Zeichnung in gewissen Fällen eigentümlich metallisch blauglänzend. - - o. Zeichnung und Färbung im allgemeinen wie die des $0^{*}$. Vorderrandfeld des Hinterffügels nur wenig von der Grundfarbe abweichend, teilweise leicht schwärzlich bestäubt, und diese Bestäubung bogenförmig nächst dem Apex mit der Mittelbinde vereinigt. Adern des Hinterfliigels wenig oder gar nicht schwarz bestäubt.

Colombia, Hittel-Amerika.

Diese Art zertällt in 6 Unterarten:

2a. H. ismenius ismenius Latr. 1817 H. i., Latreille in: Humboldt \& Bonpland, Voy. Amér., v. 2 p. 125 t. 41 f. 5, 6 | 1871 H. i., W. F. Kirby, Cat. diurn. Lep., p. $144 \mid$ 1879 H. i., Hopffer in: Ent. Zeit. Stettin, v. 40 p. $434 \mid 1884$ H. i., Weymer in: Ent. Zeit. Stettin, v.45 p. $27 \mid 1885$ H. i., O. Staudinger (\& Schatz), Exot. Schmett.. v. 1 p. $75 \mid 1890$ H. i., Weymer (\& Mlaassen), Lep. Reise Stübel, p. $9 \mid 1893$ H. i., Weymer in: D. ent. Z. Lep., v. 6 p. $342 \mid 1901$ H. $i$. (H. distincta Plötz in IIS.), Riffarth in: Berlin. ent. Z., v. 46 p. $31 \mid 1819$ Heliconia ismenia. (Latreille \&) J. B. Godart in: Enc. méth., v.9 p.223 | 1872 Heliconius fritschei, Möschler in: Ent. Zeit. Stettin, v.33 p.336 | 1877 H. f., W. F. Kirby, Cat. diurn. Lep., Suppl. p. 722.

Sämtliche Flecke im schwarzen Flügelteil rein weiß. Schwarzer Keilfleck in der Zelle rhombisch oder länglich rund, groß, meist an die Mediana angelehnt, selten mit kurzem, gegen die Flügelwurzel gerichtetem Fortsatz, die Umgebung leicht schwärzlich bestäubt. Die Flecke außerhalb der Zelle weiß oder gelb, nur von geringer Größe, manchmal bis auf die vorderen fehlend, der distal gelegene, wenn vorhanden. abgesondert, lang und schmal, die übrigen näher aneinander, rundlicher. Saumflecke im Apex oben und unten deutlich. Hinterwinkel meist schwarz bestäubt, 1 oder 2 kleine Flecke der Grundfarbe einschließend. In der Mitte des hinteren Medianzwischenraumes kurz vor dem hinteren Medianast ein länglicher weißer Fleck, die schwarze Bestäubung unterbrechend. Submedianstreif sehr schmal oder auf schwarze Bestäubung der Submediana beschränkt. - Hinterflügel nur miit unvollkommener Mittelbinde im distalen Teil. In der schwarzen Besäumung oben zuweilen, unten stets, weiße, paarweis gestellte, strichähnliche Saumflecke. - Vorderflügellänge $45-50 \mathrm{~mm}$.

Es finden sich Übergänge zu den nächstfolgenden Unterarten.

Colombia.

2b. H. ismenius fasciatus Salv. \& Godm. 1877 H.f., O. Salvin \& F. D. Godman in: P. zool. Soc. London, p. $62 \mid 1881$ H. f., F. D. Godman \& O. Salvin in: Biol. Centr.Amer., Lep.-Rhop. $v .1$ p.150 t. 17 f. 3, 4 | 1893 H. f., Weymer in: D. ent. Z. Lep., v. 6 p. 2951901 H. ismenius f., Riffarth in: Berlin. ent. Z., v. 46 p. 31. 
Wie die typische Unterart, nur Hinterflügel mit vollständig ausgebildeter Mittelbinde vom Hinterrande bis kurz vor den Apex.

Panama (Veragua, Lion-Hill-Station).

2 c. H. ismenius faunus Staud. 1885 H. f., O. Staudinger (\& Schatz), Exot. Sehmett., v. 1 p. 74 t. $31 \mid 1893$ H. metaphorus var. f., Weymer in: D. ent. Z. Lep., v. 6 p. $295 \mid 1901 H$. ismenius $f$., Riffarth in: Berlin. ent. Z., v. 46 p. 31.

Hauptmerkmale wie bei der typischen Unterart. In der Zelle des Vorderflüg'els tritt aber die schwarze Bestäubung bis in den äuBersten distalen Teil zurück, der ganze vordere Teil der \%elle bis in die vordere bcke und nach hinten bis zum Keilfleck schwefelgelb. Auf der Oberseite sämtliche Flecke schwefelgelb statt weiß. Dieselbe Farbe im hinteren Medianzwischenraum vorherrschend. Die außerhalh der Zelle gelegene Querbinde sehr undeutlich, nur voru nächst dem Vorderrande in 2 oder 3 gelben Fleckchen zu erkeunen, die hinteren durch Schwarz verdrängt. Subapical 3 oder 4 sehr deutliche Flecke. Hinterfïgel mit unvollkommener Mittelbinde im distalen Flügelteil, die in seltenen Fällen etwas vollstïndiger, daun aber nach hinten tief gekerbt und im proximalen Teil verloschen ist.

Colombia (Tal des Rio San Juán).

2 d. H. ismenius hermanni Riff. 1899 H. i. var.h., Riffarth in: Berlin. ent. Z, ข. 43 p. 407 ! 1901 H. i.h., Riffarth in: Berlin, ent. Z., v. 46 p. 32.

Von der typischen Unterart dadnrch unterschieden, daß die außerhalb der Zelle gelegene weiße Fleckenbinde des Vorderflïgels vollstündig fehlt und durch Schwarz verdrängt ist. In der Mitte des mittleren Medianzwischenraumes nächst dem binteren Medianast und der hinteren Ecke der Mittelzelle schwach weiße Fleckbestäubung. Submedianstreif etwa $2 \mathrm{~mm}$ breit, vollständig, distal verbreitert und mit dem Schwarz des mittleren Medianzwischenranmes zusammenfließend. Keilfleck grol, mit Spitzenansatz, der das proximale Ende der Zelle nicht erreicht. Unten zwischen Keilfleck und Endzellfleck weiße Bestäubung. - Hinterflügel mit sehr breiter Mittelbinde, die vorn undeutlich zerstäubt, linten lang gezähnt ist und sich gegen den Hinterrand in der Grundfarbe verliert. Distalrand schwarz gesäumt wie bei H. i. telchinia.

\section{Südliches Colombia?}

2e. H. ismenius telchinia (Doubl.) 1847 Heliconia t., E. Doubleday (\& Westwood), Gen. diurn. Lep., v. 1 p. $10+$ t. 14 f. 4 | 1871. Heliconius t., W. F. Kirby, Cat. diurn. Lep., p. $139 \mid 1874 H . t$., A. G. Butler \& Herb. Druce in: P. zool. Soc. London. p. $351 \mid 1880$ ? H. t., Buchecker, Syst. Ent., Lep. t. 53 f. 6 , 1881 H. t., F. D. Godman \& O. Salvin in: Biol. Centr.-Amer., Lep.-Rhop. v. 1 p. 149 | 1893 H.t., Weymer in: D. ent. Z. Lep., v. 6 p. $3421901 H$. ismenius $t$., Riffarth in: Berlin. ent. Z., v. 46 p. $30 \mid 1901$ H.t., F. D. Godman \& O. Salvin in: Biol. Centr.-Amer., Lep.-Rhop. v. 2 p. 667.

Keilfleck länglich, schräg in der Mitte der Zelle, am vorderen Fnde nächst der Subcostalis nach der Flügelwnrzel spitz auslaufend. \%elle ohne gelbe Bestäubung, ihr distaler Teil schwarz. Die distal von der Zelle gelegene Fleckenbinde meist aus lose zusammenhängenden, schwefelgelhell, manchinal rotbraun gesäumten, länglichen Flecken gebildet, deren distaler manchmal, namentlich beim 0 , sehr schınal ist und isoliert in mittleren Medianzwischenraum liegt. Im Apex 4 schwefelgelbe Flecke in schräger Reihe, und zwar zwei kleinere nächst dem Vorder- und Distulrande und zwei gröBere. mittlere Flecke, die weiter von einander stehen als von den Endflecken, denen sie 
dicht anliegen. Der schwarze Apical- und Discalteil des Vorderflügels bildet hinter der 'Mediana einen derselben dicht anliegenden, wurzelwärts gerichteten scharfen Zahu und füllt den binteren Medianzwischenraum etwa zur Hälfte aus. Distalrand hinter der schwarzen Fläche schmal schwarz, Fransen schmal schwarz und weiß gescheckt, was namentlich gegen den Hinterwinkel und am Apex deutlicher zu bemerken ist. Submedianstreif kräftig schwarz, mäßig. etwa $2-3 \mathrm{~mm}$, breit, beim $\delta^{\pi}$ breiter und voller als beim $q .-$ Hinterflügel beim $\sigma^{\top}$ mit grauglänzendem Vorderrandfelde und vollkommener Mittelbinde, die sich nächst dem Apex in kurzem Bogen nach rorn lichtet und in die Vorderrandbestäubung einläuft. Saum schwar'z mit kleinen, von den weißscheckigen Stellen der Fransen fortgesetzten Randflecken, namentlich beim o. - Unterseite mit der Zeichnung der oberen Seite. Vorderflügel mit einer Reibe von 4 oder 5 weißen Apicalflecken und zuweilen mit einigen sehr kleinen Distalrandflecken nächst dem Hinterwinkel. Vorderrand des Hinterflügels schmal gelbbraun, dahinter ein breites schwarzes Feld bis zur Mediana. das distal nächst dem Apex mit der Mittelbinde bogenförmig verbunden ist; ein weißer Subapicalfleck. Randflecke gröBer und deutlicher als oben; alle schwarzen Zeichnungen des Hinterfägels metallisch schwarzblau schillernd. - Vorderflügellänge $40-50 \mathrm{~mm}$.

Guatemala, Honduras, nördliches Colombia.

2 f. H. ismenius clarescens Butl. 1875 H. c., A. G. Butler in: Ann. nat. Hist., ser.4 v.15 p. 223 | 1877 H. c., W. F. Kirby, Cat. diurn. Lep., Suppl. p. 722 | 1881 H.c., F. D. Godman \& O. Salvin in: Biol. Centr.-Amer., Lep.-Rhop. v. 1 p. 150 t. 17 f. $5,6 \mid$ 1885 H.c., O. Staudinger (\& Schatz), Exot. Schmett., v. 1 p. $75 \mid 1893$ H.c.. Weymer in: D. ent. Z. Lep., v. 6 p. $342 \mid 1901$ H. ismenius c., Riffarth in: Berlin. ent. Z., $v .46$ p. 30.

Zeichnung und Färbung im ganzen wie bei $H$. i. telchinia, aber Keilfleck schmal und länglich, ohne oder mit unvollkommenem, gegen die Flügelwurzel gerichtetem, spitzem Ausläufer. Ausdehnung und Zeichung: des schwarzen Apical- und Discalteiles des Vorderflügels wie bei $H$. i. telchinia, aber im hinteren Medianzwischenraum manchmal etwas gelbe Bestäubung. Der Submedianstreif fehlt und ist nur durch schwarze Bestäubung auf der Submediana angedeutet. - Hinterflügel gänzlich ohne Mittelbinde oder nur mit einem kleinen Ansatz einer solchen nächst dem Apex. Saum schmal schwarz, zuweilen mit kleinen weißen Randfleckchen. Vorderrandfeld der Unterseite höchstens in der distalen Hälfte bis zur Subcostalis geschwärzt, zuweilen ganz frei von schwarzer Bestäubung. - Größe wie bei H. i. telchinia.

Es finden sich Übergänge zu H. i. telchinia.

Panama (Chiriqui. Veragua). In Höhen ron $600-900 \mathrm{~m}$.

3. H. hippola (Hew.)

Punktierung auf Kopf, Halskragen und Thorax weißlich- oder rötlichbraun. Antennen proximal auf etwa ein Drittel bis ein Halb der Länge schwarz, sodann ockergelb. Flügel oben rötlichbraun mit schwarzen Zeichnungen. - Vorderflügel gestreckt, Torderrand schwach gekrümmt, Apex abgerundet, Distalrand konvex, Hinterwinkel stumpf, abgerundet, Hinterrand leicht geschweift. Vorderrand schwarz. Keilfleck in der Zelle rundlich mit spitzem, fast bis zur Flügelwurzel reichendem Ausläufer. Fndzellfleck groß, fast rechtéckig; Medianflecke getrennt, der hintere meist kleiner als der vordere. Eine von der Grundfarbe abweichende Querbinde fehlt. Ihre Lage wird durch die discalen Flecke einerseits und den schwarzen Apex andererseits angedeutet. Apex breit schwarz ohne Flecke, proximal in den Aderzwischenräumen tief 
gekerbt, hinten mit dem Randfleck rerfossen. Distalrand hiuter letzterem schmal schwarz. Submedianstreif mäßig breit. Unterseite wie Oberseite, Medianflecke cinerseits, sowie Keilfleck und Endzellfleck andererseits zuweilen zusammengeflossen. -- Hinterflügel fast eirund, mit mehr oder minder breitem, schwarzem Distalriude und zusimmeuhängender Mittelbinde, die indes auch verküınmert sein oder ganz fehlen kann. Apical- und Saumflecke fehlen. Untere Seite der oberen entsprechend, Mittelhinde rollkommen oder rerkümmert, in letaterem Falle ihre Lage durch einen subapicalen Fleck angedeutet, der mit einem mehr oder weniger durchbrochenen schwärzichen Subcostalstreif verflossen ist.

Süd-Amerika.

Diese Art zerfällt in 2 Unterarten:

33. H. hippola hippola (Hew.) 1867 Heliconia h., Hewitson, Exot. Butt., v. 4 Heliconia t. 5 f. $13 \mid 1871$ Heliconius h., W. F. Kirby, Cat. diurn. Lep., 1) 139 | 1893 $H . h .$, Weymer in: D. ent. Z. Lep., $v .6$ p. 33321901 H.h., Riffarth in: Berlin. ent. Z., v. 46 p. 32.

Punktierung des Kopfes und Rücliens weißlich. - Sclıwarze Flecke des Vorderfliigels alle deutlich getrennt auBer dem Randfleck. der rorn mit dem schwarzen Apicalfeld zusammengetlossen ist. Submedianstreif gleichmäBig etwa $1.5 \mathrm{~mm}$ breit. den Hinterwinkel nicht erreichend, sondern nur in ungewisser Schattierung an diesem endigend. - Hinterflügel mit $2-2.5 \mathrm{~mm}$ breitem, schwarzem Distalsaum. dieser rorn leicht gekerbt. im Apex breiter. Mittelbinde linter der Zelle voll, mäBig breit. ziemlich gleichmäßig aber nicht scharf begrent. im Apex mit der Sammbinde zusammengeflossen. - Vorderflïgellänge etwa $38-40 \mathrm{~mm}$.

Süd-Amerika (nähere Fundortangabe fehlt).

3 b. H. hippola lyrcaeus Weym. 1890 H. l., Weymer in: Lint. Zeit. Stettin, v. 51 p. $286 \mid 1893$ H. l., Weymer in: D. ent. Z. Lep., v. $6^{\circ}$ p.332| 1901 H. hippola l., Riffarth in: Berlin. ent. Z., $v .46$ f. 33.

Punkticrung auf Kopf und Rücken, sowie Binde quer über den Thorax gelbbraun wic die Grundfarbe der Flügel. - Vorderflïgel im allgemeinen wie bei der typischen Euterart, die schwarzen Flecke aher durehschnittlich größer als bei dieser. I lie im Grundfurbenton gehaltene. distal von der Zelle gelegene Binde an der distalen Beraudung stark gez,ihnt, Begrenzung beiderseits scharf abgesetzt. Submedianstreif in der Mitte rerbreitert, gegen deu schmal schwarz gesäumten Hinterwinkel spitz. anslaufend. - Hinterflügel fast ohne Zeichuung. Distalrand schmal (kamm $1 \mathrm{~mm}$ ) schwarz, an den Adern etwas gewellt. Im Apex ein 2-3 $\mathrm{mm}$ großer eirunder schwarzer Wisch oder Fleck, der Rest der bei der typischen Unterart vorhandeneu Mittelbiude. Unterseite des Hinterflügels mit einem unterbrochenen schwarzen Streif an der Subcostalis, der mit dem erwähnten Apicalfleck zusammenfließt. - Vorderflügcllänge bis $\$ 4 \mathrm{~mm}$.

Peru?

\section{H. numatus (Cram.)}

§. Stirupunkte des Kopfes weiß; Punkticrung auf dem Hinterkopfe, Halskragen und Thorax, sowie sonstige Zeichnung oder von der Grundfurbe abweichende Färbung des Leibes gelb. Antennen auf etwa ein Viertel bis ein Drittel der Länge von der Wurzel aus schwarz oder schwarzbraun, sonst 
ockergelb. Vorderflügel ziemlich schlank, Vorderrand leicht gekrümmt, Apex abgerundet, Hinterwinkel zurücktretend, stumpf, Hinterrand an der Flügelwurzel flach geschweift. Hinterflügel fast eirund. Adern beider Flügel scharf schwar\% bestäubt. - Vorderrand des Vorderflügels schmal schwarz, zuweilen kaum $1 \mathrm{~mm}$ breit. Grundfarbe gelb- bis rotbraun, im distalen Teil der Zelle zuweilen gelbliche Bestäubung. Keilfleck in der Regel rundlich, mit oder ohne Spitzenausläufer gegen die Flügelwurzel; wenn solcher vorhanden, so ist er unmittelbar mit dem Keilfleck verbunden oder schmal getrennt. Endzellfleck meist deutlich und isoliert. ebenso die Medianflecke und der Randfleck. Distal von der Zelle eine meist schwefelgelbe, von den schwarzen Adern durchzogene, schrägliegende Querbinde, die bei einzelnen Formen den Ton der Grundfarbe annimmt und dann als solche nur mit Hilfe der die Proximalgrenze bildenden schwarzen Endzell-, Median- und Randflecke zu erkennen ist. Apex breit schwarz mit drei schräg gestellten, gelben oder bräunlichen Flecken nahe dem Rande und zuweilen mit einer zweiten Reihe von Saumflecken derselben Farbe. Distalrand, soweit sich der schwarze Apicalteil an demselben nicht ausdehnt, schmal schwarz gesäumt, Hinterwinkel manchmal schwärzlich bestäubt. Submedianstreif meist breit und kräftig, Hinterrand schmal schwarz gesäumt. - Hinterflügel am Vorderrande silbergrau glänzend, Mittelbinde stets vorhanden. Dieselbe verbreitert sich zuweilen nach vorn derart, daß ein Teil der Zelle eingenommen wird, und nach hinten so weit, daß sie mit der schwarzen Saumbinde namentlich im mittleren Teil zusammenfliebt. Im Apex zuweilen ein oder seltener mehrere gelbe Flecke. Sammbinde in der Regel rein schwarz, nur selten mit strichförmigen, gelben oder weißlichen Randflecken. - Untere Seite der oberen im allgemeinen entsprechend, im Apex des Vorderflügels deutlichere weiße Fleckchen, Mittelbinde des Hinterflïgels an der hiuteren Begrenzung stark gekerbt oder aus lose zusammenhängenden, zuweilen auch ganz voneinander getrennten, in den Aderzwischenräumen liegenden, länglichen Flecken zusammengefügt. Wurzel des Hinterflügels gelb gefleckt. Vor der Costalis und Subcostalis je ein schwarzer Streif, ersterer im Apex mit dem schwarzen Saum verschmolzen, letzterer in der Mitte unterbrochen, und diese Unterbrechung meist gelb bestäubt. Weiße Apical- und Saumflecke deutlicher und größer. - ○. Wie das $0^{\top}$, aber ohne schwarze Adern. Endzellfleck, Medianflecke und Randfleck zuweilen zu einem unregelmäßigen schwarzen Bande zusammengeflossen. Vorderrandfeld des Hinterflügels matt, in der Grundfarbe, auch oben mit einem schwarzen Streif vor der Subcostalis, der sich nächst dem Apex mit der Mittelbinde oder dem schwarzen Apicalteil vereinigt. Dieser Streif ist oben und auch unten manchmal in der Mitte unterbrochen.

Nördliches Süd-Amerika.

Diese Art zerfällt in 6 Unterarten:

4a. H. numatus numatus (Cram.) $1780 \& 82$, Numata“, Papilio numata, P. Cramer, Pap. exot., v. 4 p. 17 t. 297 f. c, D ; p.251 | 1790 P.n., J. F. W. Herbst, Naturs. Ins. Schmett. v.4 p. 121 t. 70 f. 5, 6 | 1819 Heliconia n., (Latreille \&) J. B. Godart in: Enc. méth., v. 9 p. $217 \mid$ 1847 H. n., E. Doubleday (\& Westwood), Gen. diurn. Lep., v. 1 p. $104 \mid 1862$ Heliconius n., H. W. Bates in: Tr. Linn. Soc. London, v. 23 p. 553 | 1871 H. n., W. F. Kirby, Cat. diurn. Lep., p. 138 | 1880? H. n., Buchecker, Syst. Ent., Lep. t. 52 f. $4 \mid 1885$ H. n., O. Staudinger (\& Schatz), Exot. Schmett., v.1 p. $74 \mid 1816$ Eueides pione, Jac. Hübner, Verz. Schmett., p. $11 \mid 1893$ Heliconius numata $+H$. $n$. var. melanops, Weymer in: D. ent. Z. Lep., v. 6 p. 304; p. 304 (forma m.) | 1900 H. n. guiensis, Riffarth in: Berlin. ent. Z., v. 45 p. 198 (forma g.) | 1901 H. n. + H. n. melanops $+H . n . g$. , Riffarth in: Berlin. ent. Z., v. 46 p. 33; p. 35 (forma m.); p. 35 (forma g.). 
Forma principalis. Grundfarbe der Flügel meist gelblichbraun, nur selten etwas dunkler. - Vorderrand des Vorderflïgels schwarz, beim o sehr schnal. Geäder des ơ schwarz. Keilfleck rundliclı bis cirund, in der Größe unbestäudig, mit einem zuweilen durch die Gruudfarbe algetremiten, spitzen Ausläufer gegen die Flïgelwurzel. Endzellfleck grob, fist quadratisch, mit dem schwarzen Vorderrande zusimmenhängend. Zwei meist deutlich getrennte Medianflecke, deren vorderer in der Regel etwas größer als der hintere ist; letzterer manchmal unbestimmt und nicht selır kräftig aufgetragen. Die außerhalb der Zelle gelegene Querbinde ist nneist gegen den Vorderrand etwas verschmälert, in der distalen Begrenzung an den Adern gekerbt und von diesen schmal schwarz durchschnitten. In dem mittleren Medianzwischenraum springt dieselbe etwas eckig vor und endet kurz vor dem Distalrande. Im hinteren Medianzwischenranm und in der Zelle zwischen Keil- und Fndzellffeck tritt selten gelbe Bestäubung auf. Apex breit schwarz, nahe dem Rande mit 3 oder 4 gelben oder weißlichgelben Flecken, die in der Größe variicren. Die auf der Unterseite stets vorhandenen Saumfleckchen sind beim o oben zuweilen gelb angedeutet. Der hinter der gelben Querbinde im hinteren Medianzwischenraum, dicht an der hinteren Mediana liegende Randfleck dreieckig oder streifenförmig, etwa von halber Breite und Länge des Zwischenraumes. Distalrand hinter demselben schmal schwarz, oben und unten gänzlich ungefleckt. Hinterrand schınal, beim $q$ etwas breiter schwarz gesäumt, schwarzer Submedianstreif meist breit und glatt in den Hinterwinkel einlaufend, in der proximalen Hälfte manchmal etwas zerstäubt und verloschen. Unterseite matter in der Farbe, namentlich das Apicalfeld nur schwarzbraun; Keilfleck in der Zelle gänzlich isoliert, Randfleck meist etwas rom Distalrande abgerückt. - Hinterflügel des ơ mit stark grauglänzendem Vorderrandfelde ohne scliwarze Umrandung, beim $o$ ohne wesentliche Abtönung der Farbe, aber mit schwarzem Streif vor der Subcostalis. Mittelbiude voll schwarz, vorn ganzrandig. meist durch die hintere Ecke der Zelle gehend, hinten an den Adern mehr oder weniger ansgeflossen und mit dem breit schwarzen Distalrande zusammenhängend. Die zwischen diesen Ausläufern verbleibenden, länglichen oder quadratischen Flecke der Grundfarbe manchmal schwar' bestäubt und in der Längsrichtung der Medianäste in der Vitte häufig durch stärkere Schwärzung gespalten. Im Apex vereinigt sich beim o die Binde bogenförmig mit dem Subcostalstreif. Apicalfeld schwarz, zuweilen mit einem gelblichen Fleckchen. Distalsaum in der Regel ungefleckt, zuweilen scheinen jedoch die Saumflecke der Unterseite schwach durch. Auf der Unterseite ist die Nittelbinde hinten an den Adern tief gekerbt, zuweilen nahezu oder ginzlich in längliche Flecke zerteilt, entweder vou dem zwischen den Adern nach vorn ausgebuchteten, schwarzen Distalrande getrennt oder mit diesem in der Mitte oder im distalen Teil zusammengeflossen. Vorderrand der Unterseite schmal gelbhraun, vor der Subcostalis und Costalis je ein schwarzer Streif bis zum A pex. Letzterer in der Mitte gelb unterbrochen. Dicht an der Flügelwurzel ein gelber Fleck. Die Saumflecke berühren den Distalrand nicht. - Vorderflïgellänge $37-43 \mathrm{~mm}$.

Häufig mit H. ethilla eucomus (S. 56) verwechselt, von diesem sicher durch das hellglänzende Vorderrandfeld des Hinterflügels und die schwarzen Adern des o zu. unterscheiden.

Niederländisch- und Britisch-Guayana.

F orma guiensis. Q. Mittelbinde des Hinterflügels nicht gleichmäßig breit, sondern keulenförmig, vom Hinterrande schmal ausgehend, gegen den Apex stark verbreitert und abgerundet. Farbe der Binde 
tief schwarz, dunkler als der Distalrand. Apex des Hinterflügels mit zwei gelben Flecken. Im übrigen wie die Hauptform.

Weibliche Aberration.

Britisch-Guayana.

Forma melanops. Mittelbinde des Hinterflügels mit dem schwarzen Distalrande in ganzer Ausdehnung zusammengeflossen, so daß der Hinterflügel bis auf den Wurzelteil einfarbig schwarz ist. Im übrigen wie die Hauptform.

Französisch-, Niederländisch- und Britisch-Gruayana.

4b. H. numatus isabellinus Bates 1862 H. numata vur. i., H. W. Bates in: Tr. Linn. Soc. London, $v .23$ p. 554 187I H. n. var. i., W. F. Kirby, Cat. diurn. Lep., p. $138 \mid 1885 H$. aurora var. $i$., O. Staudinger (\& Schatz). Exot. Schmett., $v .1$ p. 75 | 1893 H. numata var. i., Weymer in: D. ent. Z. Lep., v. 6 p. $304 \mid 1901$ H. n. i., Riffarth in: Berlin. ent. Z., v. 46 p. 36.

Färbung und Zeichnung (F'ig. 9) im ganzen wie bei der trpischen Unterart, nur mit dem Unterschiede, daß die außerhalb der Zelle geelegene Querbinde nicht schwefelgelb von der Grundfarbe abgesetzt. sondern dieser Flügelteil ebenso wie die Grundfarbe gelbbraun ist. Keilfleck in der Zelle kreis- oder eirund, mit mehr oder minder kräftig" angelegtem Ausläufer nach der Wurzel. Randfleck, MedianHecke und Endzellfleck deut-

lich gesondert, Flecke im schwarzen Apex gelb, teil-

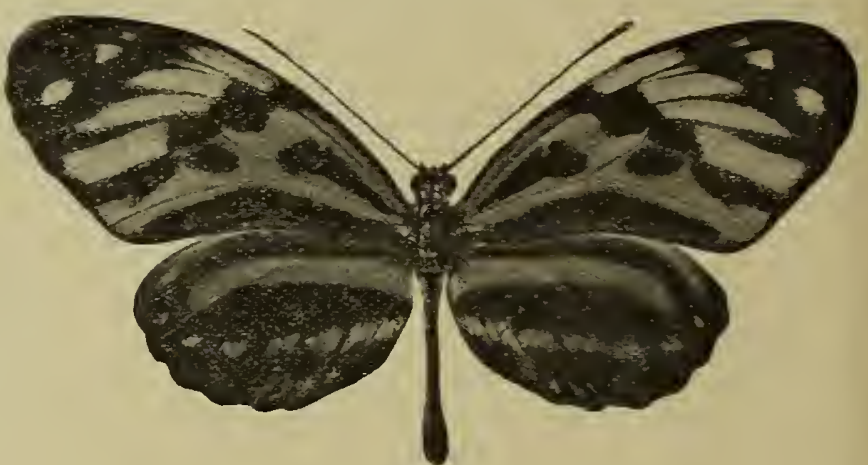

Fig. 9. H. numatus isabellinus, 우 $(1 / 1)$.

weise rötlichbraun überstäubt. Hinterflügel mit breiter Mittel- und Saumbinde. Die Adern beider Flügel schwarz. Auf der Cnterseite des Torderflügels ist die Querbinde als solche deutlicher ausgeprägt, gelblich überstäubt und gegen den schwarzbraunen Apex ungewiß begrenzt. Hinterflügel in der Regel nur mit verloschenen Saumflecken. Nur geringe Größe, Vorderflügellänge $37-39 \mathrm{~mm}$.

Forma tempestatis?

Nördliches Brasilien (Obidos, Amazonas). Peru (Iquitos, Iurimaguas).

4c. H. numatus mavors Weym. 1893 H. superioris var. m., Wesmer in: D. ent. Z. Lep., v. 6 p. 305 | 1901 H. numata $m$., Riffarth in: Berlin. ent. Z., v.46 p.36.

Im allgemeinen wie H. n. isabellinus, aber dunkler braun, auch die Querbinde und die Flecke im Apex des Torderflügels. Submedianstreif bis auf eine schwarze Bestäubung in der Nähe des Hinter'winkels reduziert. Keilfleck mit schwach angedeutetem Ausläufer nach der Wurzel. Saumflecke des Hinterflügels auf der Unterseite grau statt weiß. Zuweilen sind die fehlenden Teile der schwarzen Zeichnungen durch dunklere rotbraune Farbe ersetzt.

Nördliches Brasilien (Obidos), Niederläudisch-Guayana. 
1(. H. numatus superioris Butl. 1475 H.s., A. (i. Butler in: Anu. nat. Hisl..

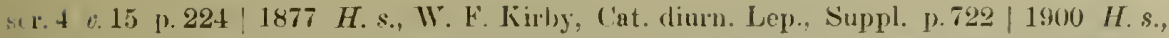
Fiftarth in: Berlin. ent. \%.. v.45 p.214 (forma gominata) 1893 H.geminatus + H.mumatu vor. macceras + H. s., Weyner in: L). ent. \%. Lsel., e.6 p.299 t. 4 f.3 (forma geminata);

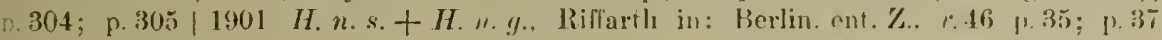
(forแa greminata).

L'orna principalis. Forderflïgel in allgemeineu wie bei der typischen Tuterart oder H. n. isabellinus, aber die Querhinde schwefelgell, meist schmaler und durcli verstärkte schwarze Bestäubung an den Adem inanchmal in Flecke aufgelöst. zuweilen jedoch auch breiter. in der distalen Begrenzung verwaschen und mit Spuren rotbrauncr Scluppen überstäubt, eine lirscheinung, die namentlich auf der Enterseite in ausgiebigem Nabe bemerkbar ist. Medianflecke und Randfleck beim o meist deutlich getrenut (mecenus Weymer), beim häufiger zusanmengeflossen (sin)erioris typ.). - Hinterflügel mit deutlich inn der scliwarzen Sammbinde getreinter Mittelbinde. Der zwischen beideu liegende Streif der Grundfarbe vou den mehr oder weniger schwarz bestäubten Adern durchschnitten, so daß eine Reihe länglich und unregelmäßig vier(ckiger oder fast halbmondförmiger rotbrauner Flecke entsteht. In der Saumbinde zuweilen. namentlich beim $\circ$, eine Reihe länglicher, dem Saum nicht aufsitzender, gelber oder weißlicher Wischflecke und $1-3$ gelbe Apicalflecke, die sich in seltenen Fällen zwischen den schwarzen Binden in den rotbraunen Iderzwischenrïumen fortsetzen, beim $ᄋ$ fast bis zum Hinterrande, heim $\sigma^{x}$ nur bis etwa zum mittleren Medianzwischenraum.

Nördliches-Brasilien (Villa Bella. Teffi, Santarem. Itaituba, Obidos, Parai).

Forma geminata. Querbinde des Vorderfliigels schwefelgelb, zusammenlängend oder (beim o) durch schwarze Bestäubung im hinteren 'l'eil derart zerrissen. dis im inittleren Medianzwischenraum ein isolierter, länglicher, gelber Fleck steht. Sämtliche schwarze Zeichmngen roller als hei H. n. isaliellinus, die ganze Anlage näler der tỵpischen Cnterart, aber wegen des Fluggrebietes nicht mit dieser zu rereinigen. Keilfleck der VorderHügelzelle rundlich oder cckig. mit unmittelbar anschließendem oder abgetrenutem Spitzenansläufer : Endzellfleck, Medianflecke und Randfleck entweder getrennt orler (beim o) zil einer schwarzen unvegelmäBigen Binde zilsammengeflossen. Submedianstreif deutlich. $2-4$ gelbe Apicalfleckchen ummittelbar am Flïgelsaum. Hinterflügel mit dem für die Art charakteristischen. unten in der Mitte gelb unterbrochenen Subcostalstreif. Mittelhinde vorhanden. entweder in Flecke aufgrelöst, dam in dem mittleren Teil rerbreitert und dem Distalrande nahe gerïekt, oder zusammeuhängent und in mittleren 'T'eil mit den Distalrande zusammengeflossen. Die Type in erstgedachter Art gezeichnet, jedoch röllig in letztgedachte Form ïbergehend. ㄴ nder 3 riemlich große gelbe Flecke im Apex und kleine, meist undeutliche, gelbliche Strichflecke am Distalıande. - Eine sehı unbeständige Form, die dardurch am hesten gekenmzeichnet erscheint, dab die Mittelbinde des Hinterflügels nit der Saumbinde im mittleren Teil \%usammenlı̈̈ngt oder doch entschiedene Neigung hierzu verät, und dab im Apes des Hintertlïgels mindestens 2 auffillige gelbe Flerke stehen.

Nördliches Brasilien (Pará, 'T'effé. Obidos).

4e. H. numatus gordius Weym. 1893 H. g., Weymer in: I). ent. Z. Lep., $\imath .6$ p. 312 t. 4 t. 9 | 1901 H. mumata g., Riffarth in: Berl. ent. Z., v. 46 p. 35.

Querbinde des Torderfliigels schmefelgell, durch rotlichl)raune Überstäubung mit den 4 seht großen Flecken im Apex schwach verbunden.

Das Tierreich. 22. Lief.: H. Stichel \& H. Riffarth, Heliconidae. 
Keiltleck lünglich, unit anschlieBendem Ausläufer nach der Wurzel. Vorderer Medianfleck mit dem Randfleck verflossel, hinterer Medianfleck fehlend. Submedianstreif voll nnd breit, spitz in den Hinterwinkel anslanfend. HinterHïgel mit dentlicher, nach vorn konrexer, nach hinten gekerbter Mittelbinde und breitem, durch einen nur vou den schwarzen Adern durchzogenen Stre if der gelbbramen Grundfarbe von ersterer getrennten schwarzem Samm.

Westliches Amazonas (Saõ Paulo de Olivenca).

4f. H. numatus nubifer Butl. $1875 \mathrm{H}$. nubifer, A. G. Butler in: Ana, wat. Hist., ser. 4 v. 15 p. 224 | 1877 H. n.. W. F. Kirby, Cat. diurn. Lep.. Suppl. 11. 722 | 18!:? $H . n$., Weymer in: D. ent. Z. Lep., $x .6$ p. 314|1901 H. mumate mulifor, hilfarth in: Berlin. ent. Z.. $x .46$ p. 36.

Grundfarbe mahagonibram. Medianflecke miteinander zu einem sroben quadratischen Fleck unter sich und mit dem Randfleck hiudenartig verflossen. Binden des Hinterflügels hreit. Im übrigen wie H. n. smperioris (S. 49). nur anf der Unterseite des Hinterflügels ohue gelben Apicaltleck. In der Halıptsache: durch die dinklere Grundfarbe von den vorhero*ehenden Unterarten unterschieden, da die dem Typus eigenen Zeichnungsmerkmale anch hei der typischen Unterart und bei H. n. superioris rorkommen.

Westliche's Amazonas (Fonteboa).

5. H. silvana (Cram.)

o. Stirnpunkte weiß, Punkte auf Hinterkopt. Halskragen und Thorax, sowie die ïbrige Zeichnung und von der Grundfarbe abweichende Behaarung des Körpers gelb. Antennen gewöhnlich bis auf die Keule dınkelbraum. diese ockergelb. Ausdehnung des Dunkelbraun indes nmbeständig; diese Färbung kann sich nur auf die dorsale Seite des Stieles heschränken, so daß der größere Teil desselben ockergelb verbleibt. Grundfarbe der Flügel gelbbraun. - Vorderflügel gestreckt, Vorderrand schwach gekrümmt, Apex abgerundet. Hinterwinkel stumpf, Hinterrand fast gerade, nur gegen die Wurzel sanft geschweift. Vorderrand des Torderflügels sehr schmal schwar\%. Keilfleck klein und rundlich, meist ohne. seltener mit spitzem Ausläufer nach der Flügelwurzel. Endzellfleck. vorderer Medianfleck ınd Randfleck unter sich und mit dem schwarzen Apicalfelde zn einer großen. schwarzen. fast die ganze distale Hälfte des Flügels einnehmenden Fläclıe verflossen. Proximal von dieser, die Zelle halb ausfiillend und schräg his nahe zum Hinterwinkel reichend, eine schwefelgelbe Querbinde, die in einzelnen Fällen, namentlich im vorderen Teil, weniger dentlich ist und in dic braune Grundfarbe übergeht. Der hintere Medianfleck fehlt meistens. Im schwarzen Apex 3 oder 4 in den Aderzwischenräumen liegende. gelbe vder gelblichweiße. meist große Flecke, die beiden vorderen oft rnsammenhängend, der vierte, hintere, wenn vorhanden, klein und mehr oder weniger schwar\% bestänbt. Zwischen diesen und dem Zellende zumeilen eine Schrägreihe voli mehr oder minder deutlichen. gelben Flecken oder Wischen. deren hinterer, nächst dem Distalrande liegender isoliert und reiner gelb ist. Uumittelbar am Saum im Apex können manclimal außerdem 2 oder 3 weiße Fleckchen auftretell. Distalrand hinter der schwarzen Bestäubung des Apex schmal schwarz, Hinterwinkel meist schwärzlich überstäubt. Hinterrand sehr schmal schwarz gesäumt, Submediaustreif meist schmal nnd nur anf die schwarze Färbung der Ader beschränkt, oder in seltneren Fällen breiter und deutlich in den schwarzen Hinterwinkel einlaufend. Adern teilweise oder sämtlich schwarz, soweit sie durch die helleren Fïgelteile laufen. 


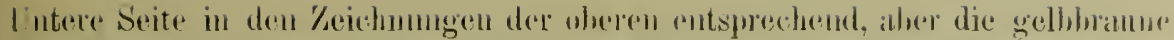
(irumdfabe auf die proximale Hälffe der \%elle und einen neln oder weniga ansgedehnten Fleck im Hinterwinkel beschränkt. Selıwaryo Färbung weniger tiof. die zwischen dem \%ellende und den $\Lambda$ picalflecken gelegene Fleckemeihe, wenu rorhanden, mit der durch die \%olle gehenden gaclben Schrïghinde teilweise rerHossen, so dab EndzellHeck. rorderer Medianfleck und Randfleck gesondert in dor celben Bestäubung liegen und deutlich in ihrer charakteristischen Gestalt unrl Lage zu erkennen sind. 3 oder + deutliche Simmfleckchen im Apex. - HinterHiigel fast eirund, in Apex etwas spitzer. aber nicht eckig. Vorderrandfeld grancläm\%end, ohne dunkle Besïunung. Mittelhinde vorhanden, isoliert oder mit der Saumbinde in mittleren und distalen 'Teil verflossen oder auch un alrudimentiirer Ansatz im Apex vorlanden. Vor der isolierten Mittelhindo in gewissen Fällen schwefelgelbe liestäubung. Im schwarzen Apes 1-3. den Distalrande folgende, gellse Plecke, an letrteren, namentlich in de. Nälo des Hinterwinkels, gelle oder gelbliche, deu Raude nicht anfsitzend". lïngliche Saumflecko paarweise in den Aderzwischenrämnen. Untere Snitu in den \%eichnugen der oberen annïhernd entsprechend. Mittelbinde. wenn vorhanden, in einzelne. mohr oder weniger lose zusammenhängende Flechr infgelöst: ro Costitlis und Subcostalis meist je ein in den schwarzen Ipex anslaufender schwarzer Streif. dor indes aluch mur schattenliaft auftreten uder fohlen kann. Subcostalstreif. wenn vorhanden, in dor Mitte meist gell, unterbrohen. Apiealflecke weil., solten golblich, deutlicher und grölsor. Sammflecke obenfills größer, rein weik. jaartweise in vollständiger Reilı" nom Apex bis zum Hinterwinkel, manchmal dem Rande anfsitzend. - - 5 . lu allgemeinen wie das $C^{\circ}$. Antemen stets $n^{\circ}$ im Wurzelteil, anf etwa ${ }^{1}{ }_{3}$ łer Läuge dunkelhram, im ührigen ackergell). Vorderrandfeld des HinterHügels nut wenig hellel als die Grundfarbe. rom Apex aus his etwa \%ur Witte leicht schwäl\%lich üborstä̈ut.

förlliches und mittlems siid-smerika.

Jiese Art \%erfillt in I I'nternten:

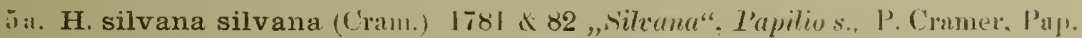
(xol., r.4 j. 143 t. $36+$ f. (c, w); p. 252 । 1790 P. s., .l. F. W. Herbst, Naturs. Ins. Schmett., r. I 1. 123 t. 71 f. 1. $2 / 1816$ Melinaea clare (elr., non Papilio c. J. (\%. Fabricius 1793!). Jac. Hübner, Verz. Schmett., p. 11/1819 Heliconia sylvana, (Latreille \&) J. B. (Hodart in: Hne. méth., เ. 9 p.215 | 1837 H. s., Jam. Duncan, Foreign Butt.. p. 138 | 1847 H. s., E. Doubleday (\& Irestwood), Fen. dinru. Lep., v. 1 p. 104| 1862 Heliconius s.,

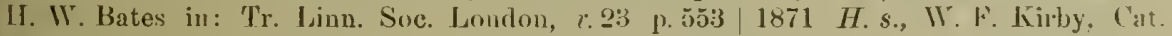
‘ium. Lep., p. 138 1880? H. s., Buchecker, Syst. Fint.. Lep. t. 52 โ. 3 | 1885 H. s.. 1. Staudinger (\& Schatz), Wxot. Schmett., 1. 1 p. $74 \mid 1873$ H. cliffusus, A. 1. Butler in: (Yistula ent., $v .1$ l. 168 (forna diffusa) 1877 H. d., W. F. Kirby, ('at. diurn. I,ep..

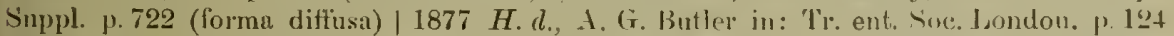
llorma diffusa) | $1893 \quad H$. sileana $+H$. d. Weymer in: D. ent. \%. Lep., v. 6 p. 296 ;

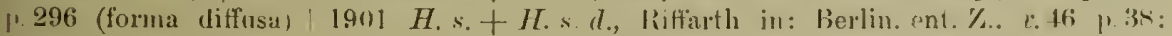
1. 39 (forma diffusa).

Forma principalis. Dio im proximalen T'eil des Vorderflügels crhaltene Gruudfarbe lebhaft gelbbraun. leicht rötlich. Vorderrand schmal schwar\%. schwarzer Keilfleck in der Mitte der \%elle auf der Greu\%e \%wischen Grundfarbe und schwefelgelber Querbinde eirund, nur wenig groß, meist obme Ausläufer lach der Flügelwurzel, manchmal rudimentäı. Hinterer MedianHeck fehlt. Eudzellfleck, vorderer Medianfleck nud Randfleck nur zuweilen. namentlich bein $O^{2}$. auf der Tuterseite 7.11 erkemen. oben stets mutereinander 
und mit dem schwarzen Apicalteil verflossen. S'Shwefelgelbe, durch die distale Hälfte der \%elle schräg bis nahe zum Hinterwinkel verlaufende Querbinde in der proximalen Begrenzung allmählich in die Grundfarbe übergehend. distal scharf ron dem schwarzen Flügelteil begrenzt. Distal von der Zelle rine Reihe gelher, teilweise ungewiB schwärzlich überstänbter, schräg stehender Flecke, deren hinterer länglich, etwas abgesondert und greller gefärbt ist: sodamn 3 oder 4 ziemlich große, gelbe oder (beim of) gelblichweiße Subapiealflecke und in seltenen Fällen 2 oder 3 Apicalfteckehen, die unten stets

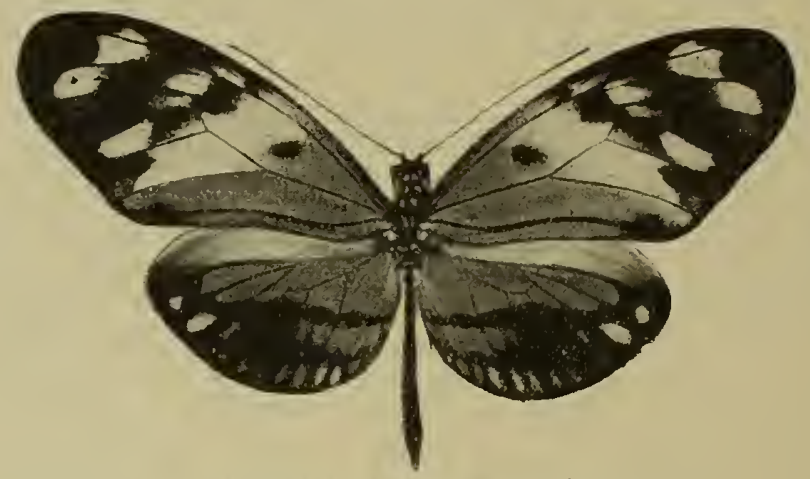

Fig. 10. H. silvana silvana, forma principalis, $\delta(1 / 1 \%$

deutlich wahrzunebmen sind. - Hinterflügel mit schwarzer Mittelbinde. die gegen deu Hinterrand verschmälert oder sogar in Flecke aufgelöst ist. in der Mitte und im distalen Teil dagegen mit dem verbreiterten schwarzen saum zusammenfließt. Auf der Unterseite ist die Mittelbinde in einzelne. in den Aderzwischemräumen stehende, runde oder längliche Flecke aufgelöst, deren mittlere und distale mehr oder weniger unter sich, mehr aber mit der verbreiterten Saumbinde verflossen sind. Dicht vor dem Distalrande mehr oder weniger ansgeprägte, paarweise in den Aderzwischemräumen stehende, gelblichweiße Saumfleckchen, die oben manchmal ganz fehlen oder auf den dem Hinterrande zunächstliegenden Teil beschränkt, unten aber stets deutlich vorbanden sind. Im Apex 2 oder 3 größere gelbe Flecke. - Vorderflügellänge $34-42 \mathrm{~mm}$.

Nördliches Brasilien (Yará, Obidos. Santarem, Massauary, Manicoré), Peru (Pehas. Tyuitos, Yurimaguas). Guayana. Veneznela.

Forma diffusa. Tordertlügel wie bei der Hauptform. Keilfleck bei dem Typus rudimentär. Mittelbinde des Hinterflügels vollständig, nur an der hintereu Berandung etwas gekerbt, in ganzer Ausdehnung von dem schwarzen Distalsaum getrennt und nicht mit demselben zusammengeflossen. Apical- und Saumfleckchen des Hinterflïgels oben wie auch unten kleiner als hei der Hauptform.

Pará. Noben der Hauptform.

ऽb. H. silvana robigus Weym. 1875 H. $\%$ Weymer in: Ent. Zeit. Stettin, n. 36 p. 382 t. 2 f. $5 \mid 1877$ H. r., W. F. Kirby. Cat. diurn. Lep., Suppl. p. 722 | 1893 H. r., Weymer in: D. ent. Z. Luep., $t .6$ p. 296 | $1901 H$. silvana $r$, Riffarth in: Berlin. ent. Z., v. 46 p. 39 | 1896 Heliconias $\%$, Bïnninghausen in: Verh. Ver. Hamburg, n. 9 p. 32. 
Keilfleck des Vorderflïgels mäbig crob. airuml, meist mit mdimmtimm

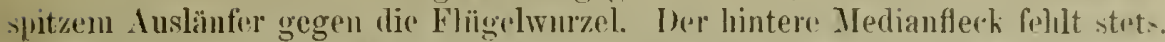

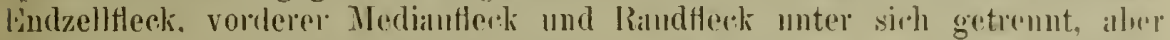

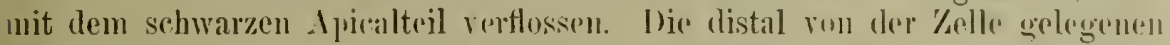

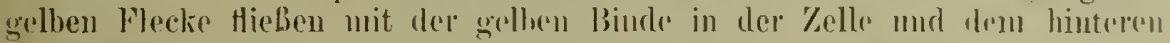

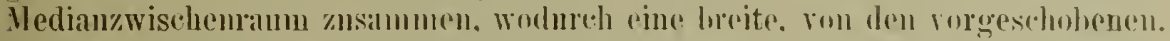

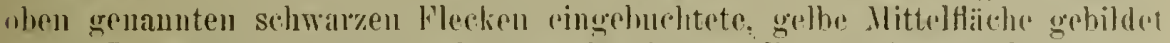

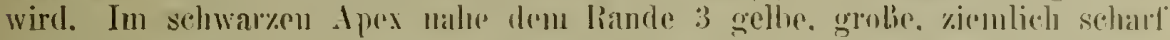

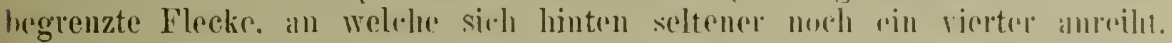

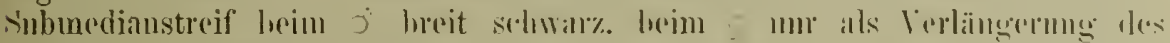

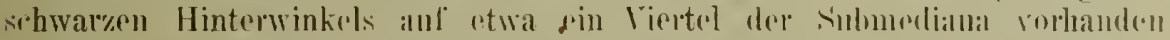

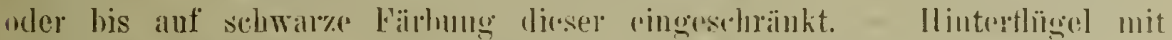

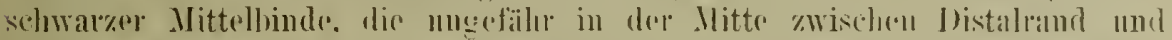

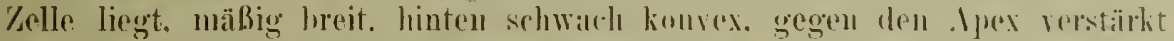

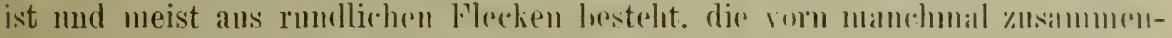

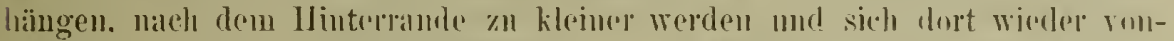

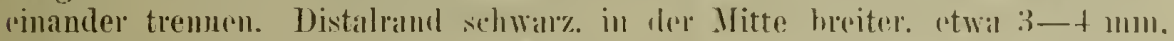
rorn manchmal Hach gekerbt. Oben mejst mur rin golhes, mutroll \%uri weibe Ipicalfleckehen und schr dentliche. rom Rande getrenute. wrilir.

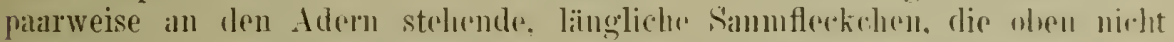

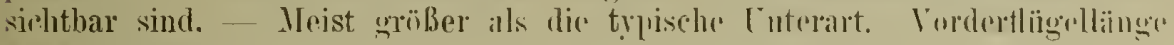
rtwal $42 \mathrm{~mm}$.

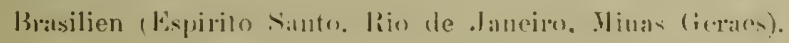

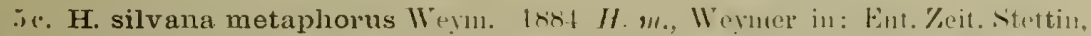

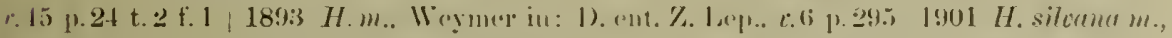

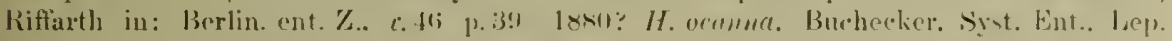

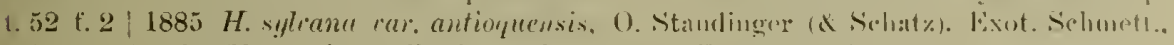

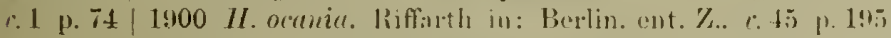

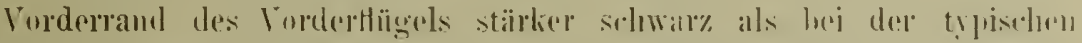

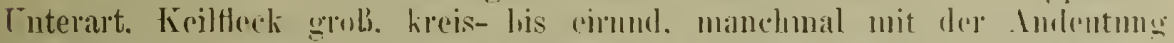

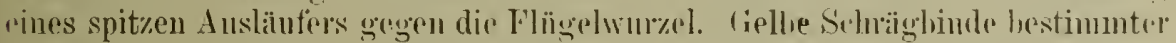

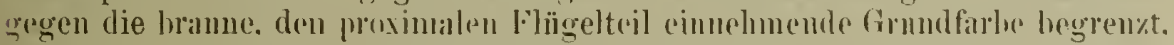

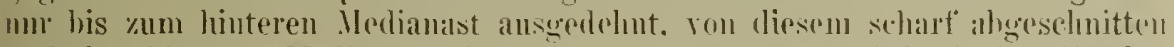

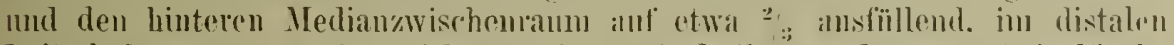

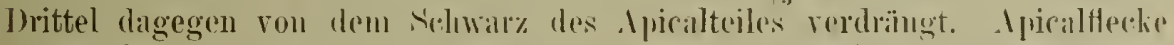

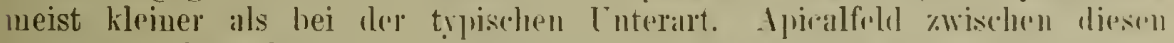

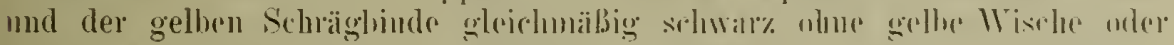

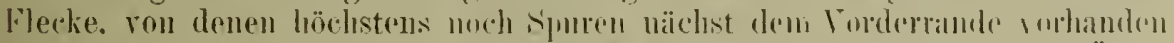

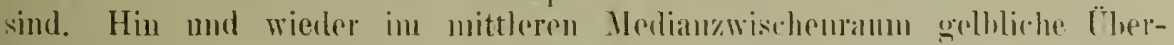

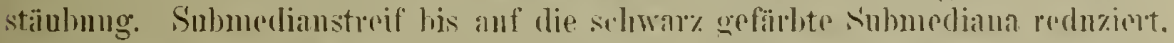

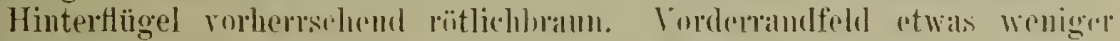

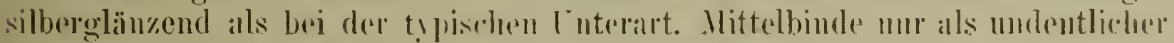

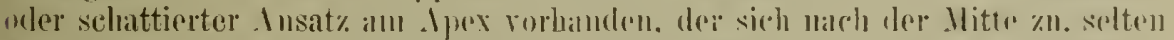
(erst an Hinterrande. in veroschene Elocke anflist. Distalsaum loreit schwar\%,

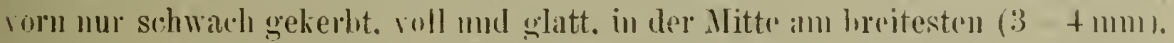

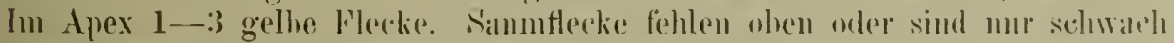
angedeutet, unten dentlich, dem liande sufsit\%end. - Tnterseite im ïlorigen ulum

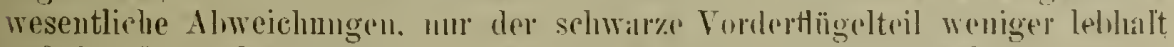

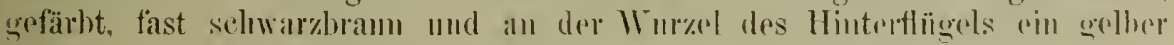
lileck. - Vorderflügelläıge fll mm.

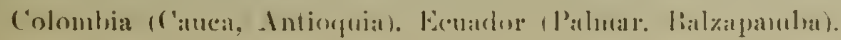




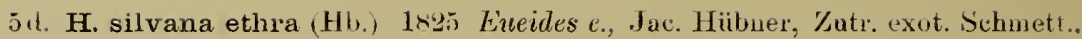
c. 3 p. 35 t. f. 553, 554 1847 Heliconia e., E. Doubleday (\& Westwood). Gen. diurn. Lep., c. 1 p. $104 \mid 1901$ Heliconius silvana e., Riffarth in: Berlin. ent. Z., e. 46 p. $40 \mid 1869$ $H$. dryalus, Hopffer in: Ent. Zeit. Stettin. c.30 p. 452 | $1871 H . d$. , W. F. Kirby. Cat.

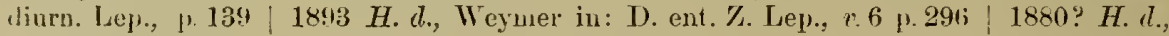
Buchecker, Syst. Ent.. Lep. t. 53 f. [7]; t. 54 t. 10.11.

Meist kleiner als die vorige Unterart, sonst dieser ähnlich. - Keiltleck (les Vorderflügels stets nit einem kräftigen Spitzenansatz wurzelwärts, der aber die Flügelwurzel nicht ganz erreicht. Gelbe Schrägbinde weniger leuchtend sehvefelfarben, leicht bräunlich getönt, namentlich an dem Vorderrande und ler proximalen Grenze. Submedianstreif breit. -- Hinterflügel mit geschlossener. durchgehender. an den Adern hinten schwach gekerbter, schwarzer Mittelhinde dicht hinter der Zelle. Das Feld ror derselben bis zum Vorderrande vanz odel zum größten 'Teil schwefelgelb. Distalraud schmal schwarz, durch einen in der Mitte etwa 3-4 mm breiten Streif der reinen gelbhraumen Grundfarbe, der sich am Hinterrande mo Apex allmählich zuspitzt, von der Mittellinde getremnt. Adern seluwarz. - Vorderflïgellänge 38 mm.

Brasilien (Bahia).

6. H. ethilla (Godart)

Stirmpunkte weils oder gell,. Punkte auf Hinterkopf. Halskiagen und 'Ihorax, sowie sonstige Zeichnung und die von der Grundfärbmmg ahweichende Behaarung des ïbrigen Körper's gell. Antennen schwarz, Keule unterseits, znweilen auch das distale Ende des Stieles ockergelb. Grundfarbe der Flügel gelbbraun bis dunkelbraun. - Vorderflügel stumpfwinklig dreieckig, Vorderrand schwach gekrümmt, Apex stark abgerundet, Hinterrand etwa ron 2) der lä̈nge des Torderrandes, gegen die Wurzel sanft geschweift. Torderrand zienlich breit schwarz, froximaler Flïgelteil bis zum Zellende in der Grundfarbe. schwar\%er Keilfleck länglich eirund. mit langer Spitze zur Fiügelwurzel, diese meisteus berülırend. Endzellfleck deutlich, mit dem schwarzen Vordenande zusammenhängend. Medianflecke und Raudfleck häntig isoliert nnd dentlich, in selteneren Fällen unter sich teilweise oder alle zusammengeflossen, anch manchmal längs dor Ider'u mit dem schwarzen Apicalfelde verhunden. Distal von der \%elle eine meist geschlossene oder nur von den dunkler hestäubten Adern durchbrochene. schräg liegende, sclıvefelgelbe Binde von gröBerer oder geringerer Breite, die hinten in der Regel im mittleren Medianzwischemram kur\% vor dem Distalraude endet. Apex bis zu dieser Binde meist schwarz, ımr selten rotbram über'stüuht, nahe dem Rande in den Aderzwischenräumen 1nit :3 oder 4 schräg gestellten. mehr oder weniger großen, zuweilen zusammengeflosseneu, gelben Flecken, die aber auch ausnahmsweise fehlen könne», nud zuweilen mit einigen undentlichen Saumfleckcheı. Distalrand hinter den sehwarzen Apicalteil schmal schwarz. Hinterwinkel mehr oder weniger schwarz üherstäubt. Hinterrand ohne schwarzen Saum, höchstens vom Hinterwinkel ans etwas gesehwärt, Submedianstreif ron der Wuryel an meist kräftig angelegt, gegen den Hinterwinkel meistens rerjüngt. aber auch in ganzer lä̈nge breit und kräftig schattiert. Unterseite matter, schwarze. Färbung weniger leblaft, Sammflecke in Apex deutlicher, rein weiß oder gelb. oder auch, wie oben, fehlend. - Hinterflïgel nahezu eirumd. gegen die Wurzel etras ansgezogen. Torder'andfeld bräunlichgrau. mehlig, teilmeise mit dunklerer Unmandung, matter als hei der vorigen Art. Meist mit schwarzer. duchgehender Mittelhinde, die in der Regel mit dem selıwarzen Distalrande in Apex zusammenhängt, vor'u glatt begrenzt. linten mehr oder 


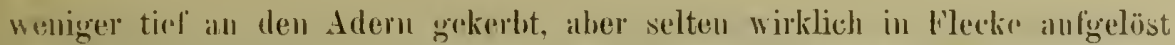
ist. Apex moist mit 1 oder 2 gelben Flecken. Schwar\% Bincle am Distalrandr durehsichnittlich von der Breite rler Nittelbincle, ihre vordere Begrenzung manchulal an den Adern gekerht. meist mit gehben oder weiBhichen, paarweisu in den Ader\%wischemämmen stehenten lïnglichen Sanumflecken. I"uterseito mit relben Fleck an der Wumel, je einem schwal\%en Struf vor der Costalis und Sulnostilis: prsterer fehlt zuweilen. letsterer in der Mitte meist unterirnchen. heirle aber anch sehr kräftig auftretend, verflossen und das gan\%e Vorderraudfeld his zur Zolle verdunkelnd. Mittelbinde linten meist stäkn' ringekerht. hogenförmig mit den Costalstroif rerbunden; Wlecke iu Ipex

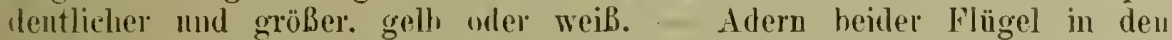
hraumen unl gethen Fläthen uic sehwar\%, sonderı höchstens ctwas rötlichhraun ihgesetzt. - - . . lı Keichnungs- und Färbungsmerkmalen wio das $0^{\circ}$. Intennen vur aut etwa ein Drittel vom der Wurzel ilus schwar\%, sonst whorgolls. Endzellfleck. Medianflocke und liandfleck des Vorderflügels ïfters \%ı rincr die Grundfarbe von der gelben Schräghinde scheidenden. schwirzcu, umegelnäBigen Binde verflossen. Vorderandfeld des Hinterflügels wroig hellel als die Grundfarbe, vor der Subcostalis rin schwarzer. iın Apex hogenförmign mit der Mittelhinde verbunlener Streif. Mittelbinde ii) der Regrel breiter als heiur ô.

Nïrdliches und mittleres siid-Amerika, 'Jrinidal.

1)irse Art \%erfält in 11 linterinen:

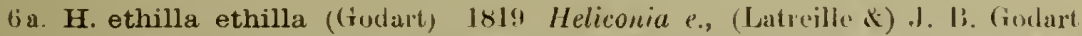
in: linc. méth., e.9 p. $219 \mid 1871$ Heliconius e., IV. F. Kirlyy; Cat. diurn. Lep., 1. 144

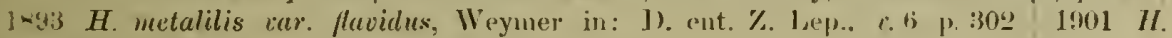
funme $f$. . Rifinth in: Rerlin. (snt. \%., $\ell .46$ 1. 4.5.

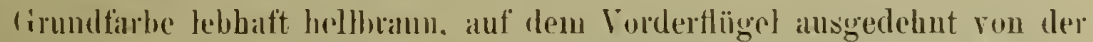
Wurzel und dem Hinterrande his zun Endzellteck, dem nittleren Median\%wischenrum und dem schmal schwarzen Distalrande hinter dem Raudfleck.

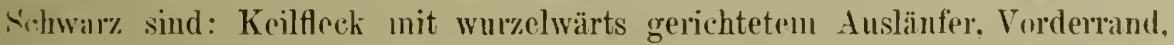
der daunit verflossenr Butzollffeck. die Medianflecke. Apex mul Submedianstreif. Keilfleck schüig. cirund oder fast rechteckig, stets mit stakem. spitzrm Insläufer nach der Wurzel. der mit ihm umnittelbar zusanmenhängt. Endzallfleck nuregehmäßiy, fast rechteckig. Vorderer Mediantleck distal längs des inittleren mul rorderen Medianastes bis in den schwarzen Apicalteil mo an Arn Randfleck ausgeflusisen, wolurch der hintere 'Tril der roingelhen Schüï口hindי als linglicher l'leck in mittlereu Medianzwischenram abgetrennt wirl. Hintrere Medianfleck eirund, vout rorderen mu sehunal getreunt. Dire zwischen tlem Zollende und dem schwarzen Apicalteil liegende schwefelgelbo Binde im vorleren Terlauf roll, mur durch die schmal schwar\%e Subestalis Eeschnittrol. Hintero Radialis fein bram angelegt. Das Goll, dieser Bincle froximal etwas ansgeflossen, so dab der clistale T'eil ter \%elle und ter hrauno 'Teil des hinteren Mediunzwischemrames gelblich ïberstäubt ist. Litwas velbe Firbung anch selbst in hinteren Medianzwischenram. Submedianstreif rienulich stark, in letzten Drittel etwas verjüngt, meist voll. Wenu anch schunlev bis zum Hinterwinkel laufend und tort wieder fleckartig verdickt.

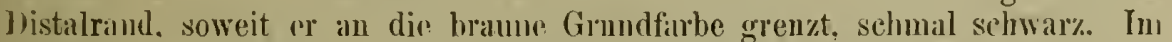
schwarzen Ipicalfelde nahe den Rande 3 sehräg gestelle gelbe Flecke, von dencon dir heiden vorderen mur schnal dureh die Subcostalis getrennt sind.

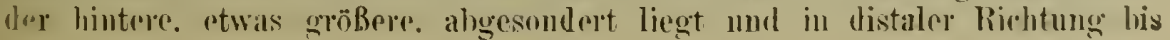


mahe zum 1)istalrande vorgeschoben ist. Unterseite matter; die lieflere hrinte Grundfarbe nur in schmalen Umrissen nächst den seliwarzen Zeichumugen erbalten. in Apex eine Reilse kleiner weißer Randflecke. - Hinterflügel init schwarzer Mittel- und Randbind'. Iet\%tero in der Mitte an hreitesten, etwa 4 mm, im Hinterwinkel und gegen den Apox verschnälert. vorn schwach gezähnt. Mittelbinde mäßig hreit, vorn ziemlich glatt abgeschnitten dicht hinter dem Zei ende verlaufeud, binten schwach konvex, melu oder weniger gekerht, beim in den schwar\%en Apex oder in die dort endigende Randbinde einlanfend. beirs o einerseits mit dem schwarzen Apicalfelie verflossen, andererseits in knrzem Bogen nach vorn mit dem sehwarzen Sulcostalstreif verbunden. Forderrandfeid beim $\sigma^{2}$ breit hräunliclgran gliunzend, heim o bräunlich. Der 'Teil zwischen ihru und der Mittelbinde rein schwefelgelh, derjenige hinter letzterer rötlichhrsuri. ınehr oder weniger gelb bestänht. In schwarzen Apex ein gellos Florkehsu oder Doppelfleckchen, am Distalrande eine Reihe parweise in don Ade:\%wischenrüumen stehender. kurz strichförmiger. goller Saumfleckehen. Inte:seite matter. ot mit deutlichem schwarmbraunem c'ostal- nul Subcostalstre:t. letaterer etwa hinter der Mitte lurehbrochen. die Lürkr gelb ansgefïllt:

nur mit letzterem. Nächst den Vorderrande ein goelber Wurelstreif, der Vorderrand selbst auBer an der Wurzel sehmal hrann. Mittelhinde hinten stärker gekerbt. die Apical- md Sammflecke gröber, weib. -- Tordertlïgellïngr etwa $39 \mathrm{~mm}$.

\section{Trinidad, Venernela.}

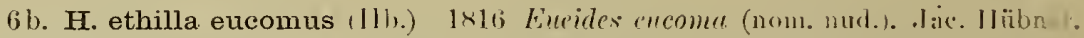
Ver\%. Selmett., p. 11 | 1825 E. c., Jac. Hülmer. Kutr. exnt. Schmett. i, 3 p. 3n t.

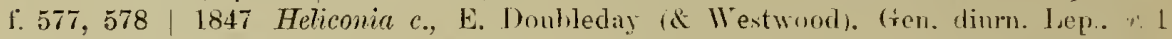
p. $104 \mid 1862$ Hcliconius e., Bates in: Tr. Linu. Soc. Lontom, r: 23 p. $554 \mid 1871$ H. . W. F. Kirby. Cat. diurn. Lep.. 1. 138 1883 H.e., In̈schler in: Verh. Ges. Wien, r. 32 Abh. p. 3151893 H. e. + H. e. car). Aacofasciatus. Weyner in: W. ent. \%. Lep.. " 6 p. 302 ; p. 303 (Forma Havofasciata) 1901 H.e. +H.e.t., Riffirth in: Berlin. ent Z.. r. 46 P. $41 ;$ 1. 42 (forma Harofasciata).

Forma principalis. (immdfarbe (Fig. 11) leblat gelblichliraun. auf dem Vorderflügel ausgedehnt ron der Wurzel und dem Hinterrande his zum kindzellfleck, mittleren Medimzwischenraum und zum schmal schwarzen Istalrande hinter dem Randtleck. Schwar\% sind: Keiltleck mit wurelwärs

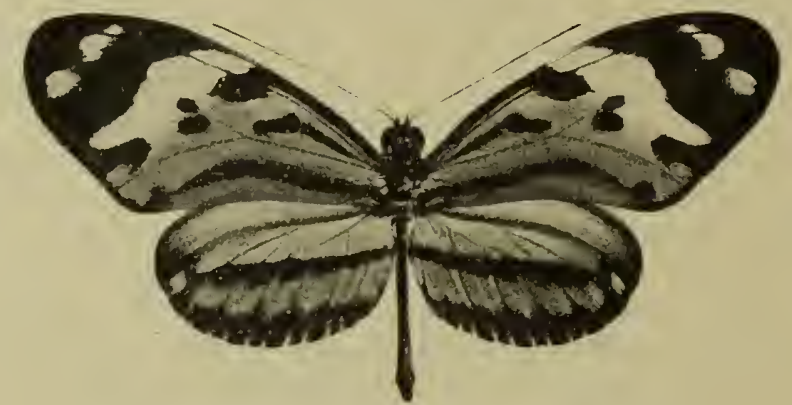

Fig. 11. H. ethilla elicomus, forma principalis, $\delta(11)$.

gerichtetem Ausläufer: Vorderand. der dimit rettossene butzelltheck. Medianflecke. Apex und Submedianstreif. Keiltheck schräg. eirund oder fast rectutackig: stets mit spitzem Ausläufer nach der Wurzel. der mit ihm ummittelhar

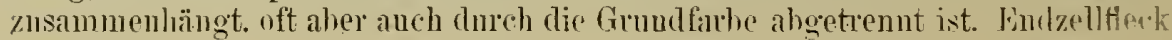


muregelmäßig, vorderer Mediantteck meist rekig, der Mediana anliogent. hinterer Medianfleck rundlich, einzeln stehend, dicht hinter denn mittleren Medianast. Raudfleck im mittle»en Medianzwischemaun nuregelmäbig länglich. uach hinten selıwach hakenförmig. unnittelhar den Rande anfsit\%end und vol"u mit dem schwarzen Apex am distalen bude rertlossen. Submedianstreif ziemlich hreit, nahe an Hinterwinkel endigend, ror demselben wesentlich verschunilert mod spit\% in einen schwär\%lichen Fleck eimmündend. Zrischen Zellende und

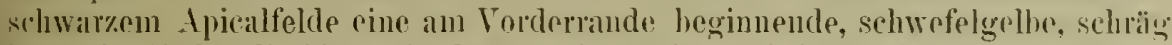
liegende Binde, die hinten in der Regel ron dem mittleren Medianast hegrenzt wird. unanchmal aber in selwäleherer Bestäubung auch noch in dem hinteren Iledianzwischemramm wahrzunchmeri ist mud dort dann allmählich in die brame

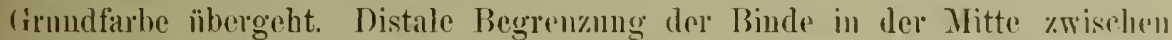
Zellende und Flïgelspitze, meist ziemlich glitt. zuweilen an den Idern etwiss

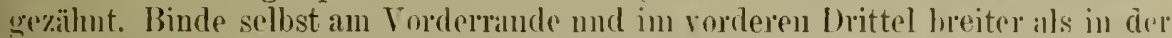

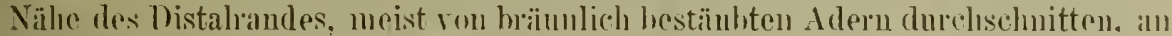
die sich sehr selten Spuren schmälrlirher Bestäubung seitlich anlagerm. Die

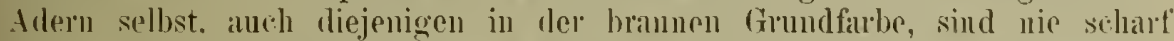
selwar\%, wie dies hei H. mumatus (s. +5). welehe Art mit des vorliegenden

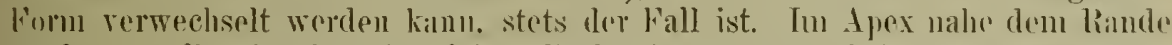
2 odre 3 gelle, häufig sehr kleine Plecke, im mannen Teil des Hinterwinkols melı oder minder dentliche Spuren graber Eleckehen. Höchst selten in der Zolle in rorderen Teil zwischen Kreilfleck mod Endzellfleck Spuren gelhlicher

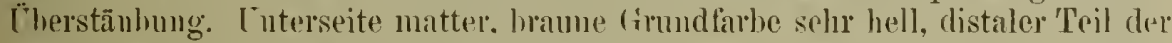
\%elle znweilen gollolich wie die Qnerhinde. Apex in weniger tiefen showar, zwischen der Querbinde mol den Apicalflecken manchmal brame Bostänlunger. nälist dem Rande im spex ringe weibe orler gelbe samutleckehen. Hinterfligel gelhlichbraum bis auf den Teil ror dor Suheostalis, der heim o lö̈unlichgran. heim schwïl"hlich ist. mit einer schwar"zen Mittel- und ebcolsolehen Sammbinde. Letatere wir hei der typischen Vuterart. Mittolhinde rersehieden breit, rom zicmlich glatt aligeschnitteu, dic hintere \%ellecke

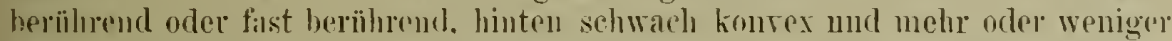
urekerht. sonst wir bei der typischen Cnterart. In Apex 1 oder 2 gollw Flecke, dem Distalrande sitzen moist lïugliche gelhe uler lorïnuliclue samm-

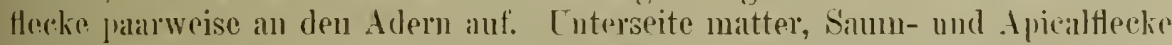
dontlicher. meistens gelh, seltou weib. mit schwarzeu streif ron Costalis

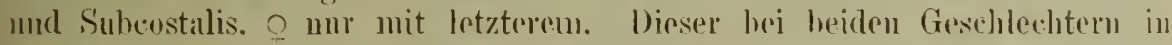
der Mitte meist gelh unterhorelen. Mittolbiude stälker gekerht. last in Flecke

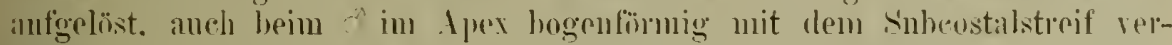

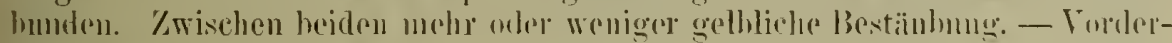
Hiiggellïnge rotwal :3!) mm.

Brasilion (l'arál. Itaiłuba).

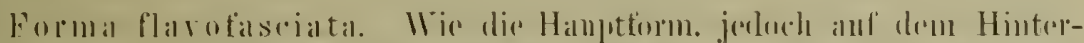

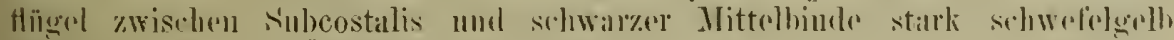
lestänlit. les gilot C̈bergänge zul Hanptform.

l'ará. Neben der Hauptfirm.

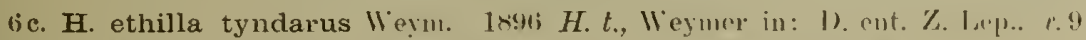

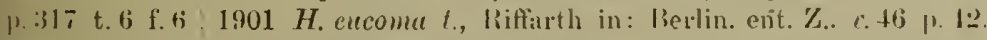

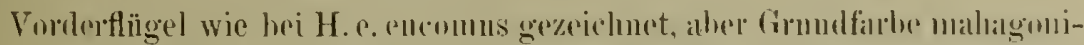

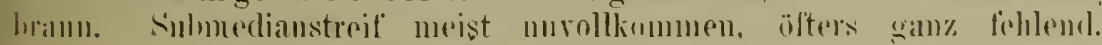


Hinterflügel mit schwarzer Mittelbinde, die iudes nur im distalen Drittel zusammenhängt, sich nach dem Hinterraude hin in einzelne Flecke auflöst. diesen gewöhnlich nicht erreichend, manchmal schon in der Mitte des Flügels ('ndigend. Im Apex zuweileu ein schwefelgelber Fleck. - Unterseite mit weißen, parrweise an den Adern stehenden, den Distalrand nicht ganz berührenden Saumfleckchen. Grundfarbe violett schillerud. - Größe und sonstige Zeichnung wie hei H. e. encomus.

Bolivia (Coroico).

6i. H. ethilla numismaticus Weym. $1893 \mathrm{H}$. eucoma var. u., (Standinger in IIS.) Weymer in: D. ent. Z. Lep., v. 6 1. 303 t. + f. + (q) 1901 H. e. u., Riffarth in: Berlin. ent. Z., $x .46$ 1. $4 \%$.

Grundfarbe wie bei H. e. encomus (S. 56). das Gelb der Binde proximal nicht ausgeflossen wie bei der typischen Unterart, aber die sonstige Zeichnung des Vorderflügels wie bei dieser, also der vordere Medianfleck vorn und hinteu in distalel Richtung ausgeflossen und mit dem Schwal'z des Apicalfeldes zusammenhäugend, wodurch der hintere Teil der gelben Querbinde abgetrennt wird und als besonderer Fleck im mittleren Medianzwischentaum liegt. Der 'Tyjus der Cnterart zeigt im Hinterwinkel des Vorderflügels + schwefelgelbe, paarweise im hinteren Median- und Submediauzwischemraum gelegene Fleckchen und in der schwarzen Saumbinde des Hinterflügels sehr dentliche, dem Raude aufsitzende, paarweise an den Rippen angeordnete, längliche Fleckchen. Das Auftreten dieser Fleckchen ist Abänderungen unterworfen. Es kommen C̈hergänge zur uächstfolgenden Unterart vor. Vorderflügellänge bis $42 \mathrm{~mm}$.

Brasilien (Santarem, Itaituba).

fje. H. ethilla metalilis Butl, 1873 H. m., A. G. Butler in: C'istula ent.. $r .1$ p. $167 \mid 1880$ H. m., F. D. Godman \& O. Salvia in: Tr, ent. Soc. London, 1. 12: | 188. H. m., (). Staudinger (\& Schatz), Fxot. Schmett., \&.1 p. $75 \mid 1893$ H. m., Weymer in: D. ent. Z. Lep., t. 6 p. $301 / 1901$ H. cucoma m., Riffarth in: Berlin. ent. Z.. v. 46 p. 43 1895 Heliconia m., P'. Snellen in: Tijdschr. Ent., 0. 38 p. $12 \mid 1877$ Heliconius metabilis, W. F. Kirby, Cat. diurn. Lep.. S'uppl. p. 722 | 1887 Heliconia m., P. Snellen in: Tijdschr. Eint., t: 30 p. 15 t. 1 f. 2.

Grundfarhe gelblichbraun. meist 4 Flecke im schwarzen Apicalfelde. von denen die drei vorderen distal rundlich. scharf begrenzt, proximal verwaschen und ungerviß begrenzt sind, der vierte, hintere uur undeutlich auftritt. Nächst dem Rande im Apex einige, von unten durchgeschlagene, trïb weißliche Saumfleckchen. Vorderer Medianfleck vergrößert, an dem mittleren nnd hinteren Medianast ausgeflossen und mit den schwarzen Apicalteil einerseits und dem Randfleck andererseits vereinigt. Der hintere Teil der Binde lierdurch als länglicher, allseitig schwarz eingefaßter Fleck im hinteven Medianzwischenranm abgesondert. Medianflecke untereinander meist zusammengeflossen. Tiandfleck nitunter hinten durch die Grundfarbe vom schwarzen Distalrande gretrennt. Endzellfleck vergrößert, die gelbe Binde im rorderen 'Teil lierdurch ringeschnïrt. Die Binde fermer. mamentlich im mittleren Teil, an Rande und in dem hinteren, abgesonderten Fleck bräumlich überstäuht. Sonst wie H. e. (ncermus (S. 56). Vorderflügellïuge $40-44 \mathrm{~mm}$.

Venezuela (Puerto Cabello, Mérida), Curacao, Colombia.

il. H. ethilla mentor Weym. 188t $H$. m., Weymer in: Ent. Zeit. Stettin, 0.45 p. 22 t. 1 f. 3 | 1893 H. m., Weymer in: D. ent. Z. Lep., $c .6$ 1. 302 1901 H. euroma m., Riffarth in: Berlin. ent. Z., v. 46 p. 43. 
In allgeneruen wir H. ' metalilis, Flügelschnitt "twas wenigar schlank, rohräghinde des Vordertlïgols nicht bräunlich bestänbt, sondern rein schwefol(s)lh, durch die verhroiterten schwar\%('n \%eichnungen eingeschräukt und schnaler. subipiealflecke kleimer. In der Mitte der \%elle und im hinteren Medianzischen-

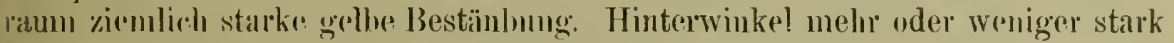
whwar\% hestänlt. Submedianstereif seluvach, in der distal('u Hälfte manchmal fohlend. Hinterfliiga! mit Mittolhinde. die zuweilen in Flecke anfgelöst "und segen den Hinterand wesentlich verschnillert und zugespitzt ist; Fleckehen in der Distalramdbindr schwach, gelllichweiß. Hintertlügel auf der Tnterseite: zovischen Suberstalis mol Mittelhinde ganz oder zam gröbten Teil sehwefel-

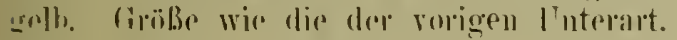

('olombia (cauca-'Til).

lig. H. ethilla semiflavidus $W$ rym. $1893 \mathrm{H}$. medulilis eto.s., Weymer in: D. ent.

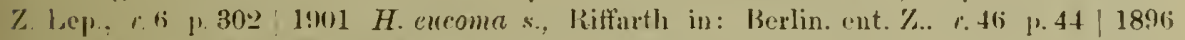

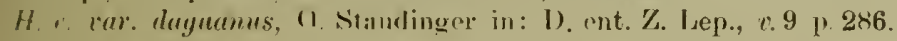

Wir H. r. mrtalilis, alore die Shehräghinde lebhaft schwefelgoll, das (relh

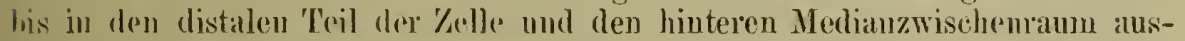
geclelnt und letrter'en fast gan\% ansfiillend. Trenuung durch deu ausgeflossenen vorcleren Mediantlock fist stets vorhanden, nur in seltenen Fällen Medianflecke hleinro und firei stehend. sn dab die Biude in ihrer ganzen Ausdehunng

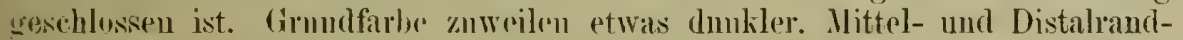

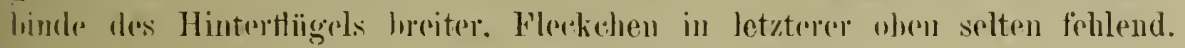

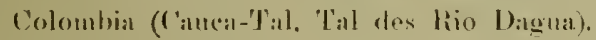

(ih. H. ethilla claudia (iodm. \& Salv. 1881 H. c., F. J). Godman \& O. Salvin in: Bw. Centr.-Amer., Lep.-Rlop. $r: 1$ p. 145| 1885 H. r., O. Staudinger (\& Sehatz). Exol.

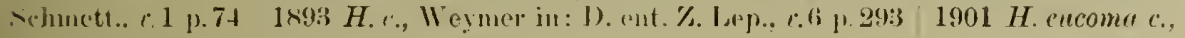
Riffirtlı in: Berlin. (11t. \%.. r. 16 p. 14.

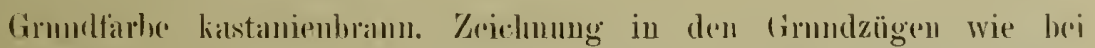
H. ^. metalilis, mit folgzenden Kinzelheiten: Keilteck des Vurderflügels eirund. velıräg gestellt. mit langem Ausläufer nach der Flïgelwurzel: Fudzellfleck lneit in den schmal seliwatron Vorderand ausfliebend; Medianfleche nittel-

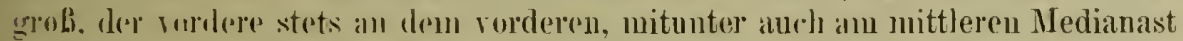

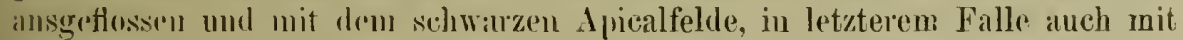
drm Randfleck \%usinmmpnhängend. in linteren T'eil der Querbiude einen länglichen Irleck ahtremond. Binde sellsst bis in den hinteren Medianzwisehemraum insggedohnt. an hinteren Mrolianast endigend und den distalen Teil der Zello his zum Keilfleck ansfïllend. Apex breit und rein schwar\% olno Flecke. Submedianstreif hreit, meist aloer nur in der distalen Hälfte der Suhmediana rorliandeı. Hinterflïg(el nit zusimmengeflossener Rand- und Mittelhinde. 1. h. der distale nud lintere 'l'eil des Fligels breit schwar\% his an die hintere

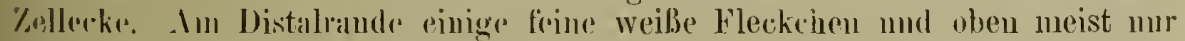

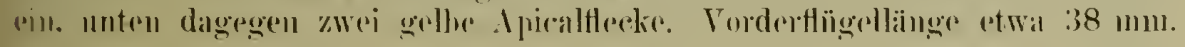

Panamal (Calohres.

(ii. H. ethilla juntanus lifir. 1900 H. encoma juntune, (Standinger in MS.)

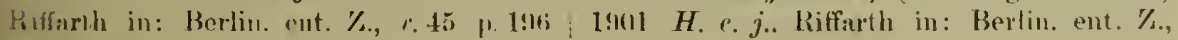
r. 46 1. 44 .

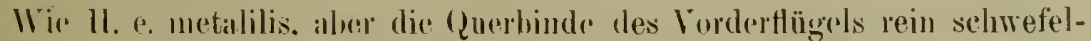

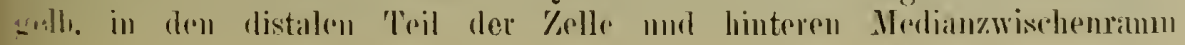


ansgedehnt wie bei H. e. semiflavidus (S. 59). Ipicalteil des Vordertlügels furt ganz schwarz, ohne oder nur mit geringen Spmen von Flecken. Fordu:Hlïgellänge his t4 mm.

Bolivia ('Tal des Rio funtas).

(ij. H. ethilla cephallenia C. \& R. Felder 1865 H. c., ( $\&$ \& R. Felder in: Reis Novara, $x .2$ II $1.273 \mid 1893$ H.c., Wevmer in: D. ent.Z. Le 1., $x .6$ 1. 293 , 1901 H. cucomme. Riffartl in: Berlin. ent. \%.. r. 46 p. 45.

Vorderthügelzeichmmug im Grunctzug wie bei H.e.encomus (S. sti). KeilHeck, Submedianstreif und Randfleck wie bei dieser Cuterart. Randfleck mit schwefelgelbem Kern, dahinter, im Submedianzwischemram, ein weiterer gelber Wleck. Hndzellfleck rhombisch, kam mit dem sehr schmal schwarz gesïumtu Torderande znsammenhängend. Vorderer. von der hell gelhbraumen (irnnifarbe muschlossener Medianfleck klein, fast rerloschen. der hintere fehlt ganz. S'chwefelgelbe Qnerbinde schmaler als bei der typischen Unterart. gleicnmäBiger, die dieselbe dmchquerenden Adern braun bestänbt. Drei grobe schwefelgelbe Flecke im scliwarzen Apicalfelde. die heiden rorder'n dicht. hei einander stehend, der hintere etwas abgerückt. Cinterseits 4 weiße doppelte. Saumfleckchen. - Hinterflügel mit völlig zusanmengeflossener Mittel- unu Randbinde. also vorherrschend schwarzbraun bis anf einen schmalen, $2-3 \mathrm{~mm}$ breiten, gelbbraunen Streif hinter dem hellgranen Vorderrandfelde des c. welchrs von dem schwarzbraunen Distalteil in gerader. seharfer; durch dic hintere Heke der Zelle gehender linie alygeschniten wird. Am Distahrande. ron Apex ausgehend, schwefelgelbe, parweise an den Adern angeordnete. wisctartige Sammfleckchen, die gegen den Hinterwinkel allmählich verschwinden. Zwischen dem gelbbrannen Snbcostalstreif und dem Distalrande ein einzelues: gelhes subapicales Fleckchen. Cnterseits dagegen zwei weilhe Apicalthrekchen und eine Reihe dem Distahande anfsitzender meiber Samntleckchen: im Hinterwinkel, die 'l'ennungsstelle der Mittel- nud Randbinde andentend, spme'n der brannen Grundfarbe. - Vorderthïgellï̈nge $39 \mathrm{~mm}$.

Niederländisch-(iuayana.

6k. H. ethilla aërotome O. \& R. Felder 1862 II. a, ( \&. R. Felder in: Wi.

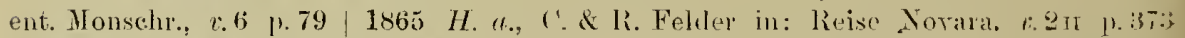

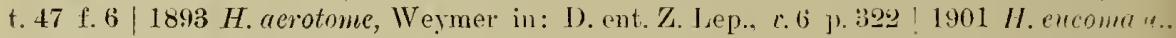
Riffarth in: Berliu. ent. $\%$.. v. 46 b. 46.

In der Zeichnung sich an H.e.netalilis (S. 5̌ ) anschließend, in einzelnu durch folgende Merkmale gekennzeichnet: Gelbbraune. etwas roriusterto Grundfarbe ansgedelunter, anch im Apex vorlerrschend: die schwar\%e Pitstänbmng tritt dort in der Regel nur in der Rundung der Flïg(clspitze am Riund». an den Adem und der distalen Grenze der hellen Qnerbinde melr ader weniger anf, ganz ist das Bram im Apicalteil nie rerdrängt. Keilfleck grob. eirund oder rhombisch, mit ansitzendem, heitem. spitz auslaufenden Wurzelstrahl, häutig die Breite der Zelle bis auf einen schmalen Streif beiderseits ausfüllend. Endzellfleck groh, rhombisch. mit dem sehwarzen Torderrande mnd anch mit den ebenfalls unter sich nud mit dem liandfleck rerflosseners Medianflecken zusammenhängend. Es entsteht hierdurch eine mreggelmäBige. schwar"ze, anBerhalb der \%elle gelegene. schräg liegende Querbinde. in welcher der hintere Medianfleck einen gegen den Distalrand vorgeschobenen Ziahn hinter der Mediana bildet. Die dieser Binde folgende hellore Schräghindr. entweder scliwefelgelh (forma prima). oder hrämulich hestäul und rom 


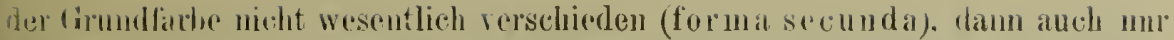
schmal. durch den distal vorgeschohenen vorderen Medianfleck eingeschnürt. yul ilı hinterer 'Teil vor dem mittleren Mediunast als einzeluer länglicher Heck abgetrenut. Bisweilen ist diese Schrägbinde auch ganz durch schwarzo iestänbmug an den Adern in 4 oder 5 Flecke aufgelöst. Im Apex 3 großr, - hwefelgelbe. schwal\% eingefaßte Flecke und munittelbar an Ramde einige undentliche helle Sammfleckehen. Distalrand schwar, vor der mittleren Mediana erbreitert, Randfleck oft vom Samm abgerïckt und dureh die Grundfarbe cetrenut. Hinterwinkel braun, schmal sehwar\% gesäumt wie auch der Hinterand. Submedianstreif glcichmäBig, etwa $3 \mathrm{~mm}$ breit, distal nächst dem Hinterwinkel in eine dreicekige oder lanzenförmige \%eichnung auslaufend. Hinter dem zusammengeflossenen linteren Medianfleck und Randfleck im mittleren Mcdianzwischenraum und im distalen Teil der Yelle zwischen Keiland Enclzelltheck bei forma prima zuweilen noch gelbhiche Bestäubung, die suf der Unterscite ganz reingelh auftritt und sich in der Zelle hinter dem Wurzelstrahl bis zur Flügelwurzel ausdehnt. — Hinterflügel mit breiter, ziemlich greader. rorn durch die hintere /ellecke gehender Nittelbinde, dic nach hinten an den Adern stark gekerbt, in der Mitte am breitesten $(5-6 \mathrm{~mm})$ ist, ich sowohl gegen den Hinterrand als anch gegen den Apex rerschmälert. n letzterem gegen den Vorderrand gohogen ist und lort in einem schmalen chwarzen Strahl hinter der Subcostalis ausläuft. Distalrand nit riemlich gleichmäßiger. schmal schwarzer Sạmbinde, die unweit des Hinterwinkols upitz ausläuft. 1 oder 2 schwefelgelbe Flecke im Apex, in der Sanmbinde oft kleine, dem Rande aufsitzende Fleckchen, die auf der Unterseite größer ind reinweils sind. Unten zwischen Subcostalis und Mittelbinde ein gelber treif. der in der /olle teilweise schwarbrann unterbrochen ist. Binde hinten +iefer gelierlot als auf' der Oberseite. - Vorderflïgellänge $32-40 \mathrm{~mm}$.

Brasilien (Oberlaut des Rio Negro). Pern (Taraproto).

7. H. gradatus Weym.

Kopf schwar\% mit weiben Punkten, Intennen an der Wrurzel his anf 'in Viertel der Länge schwarz. im übrigen schwefelgelb. Ahdomen ventral zelb. lateral mit undeutlichen gelben Linien. - o . Frundfarbe rötlich gellbrann. Torderflïgel länglich. stumpfwinklig dreieckig. Vorderrand schwach gebogen, Apex ahgerundet. Hinterrand sanft geschweift. Schwarzer Zellfleck fundlich mit anhängendem spitzem Ansläufer bis zur Flügelwurzel. Endsellfleck. Medianflecke und Randfleck felılend oder nur angedeutet. Distal von der Zelle eine lreite, gegen den Apex gleichmïBig Hach abgermudete, an den Iderı mur schwach gekerbte, schwefelgelbe, schräg liegende Binde, dic rou dem schmal schwarzen Vorderrande ausgeht und hinten bis zum mittleren Vedianast reicht. Apex breit und rein schwarz, oder mit 3 Flecken, Distaland schmal schwarz. Hinterwinkel in der Grundfarbe. Schwarzer Submedianstreif verschieden breit. Unterseite wie die Oberseite, Keilfleck gröber, Wurzelstrahl abgetrennt. - Hinterflügel mit breiter schwarzer Mittelhinde. dir dureh den hinteren 'Teil der Zolle läuft, distal rorn von der vorderen Radialis abgeschnitten ist und an dem Übergang eincu stumpfen Winkel bildet. Yorderrand bis zur Subcostalis hell gelblichgrauglänzend. Distalrand mit breiter. in Apex und Hinterwinkel verschmälerter und zugespitzter Sammbinde, dic fast init der Mittelbinde zusammenfliebt und von derselben nur durch cinen schmalen trïben brïunlichen Streif oder cine Fleckemreihe in der Grumdfarbe getrenut ist. Dicht an der Flïgelwurzel ein schwarzer Wisch. Unterseits die Grundfarbe reichlicher zwischen den Binden, die Mlittelbinde hinten, tief 
gekerbt. Am Distahande kleine, etwas ron demselbeu alggerïckte. pairweise au den Adern angeordnete, weiße Flecke. For Costalis mid Subcostalis ju ein schwarzer I,ängsstreif, der letztere in der Mitte schwefelgelh unterbrocher. der erstere im Apex mit dem schwarzeu Sam zusammenhängend. - - $\subsetneq$. 7eichnnmg wie beim or, aber Vorderrandfeld des Hinterflügels rotgelb rait einem schwarzen Iängsstreif zwischen Costalis und Subcostalis. Uuterseit: nur mit einem schwarzen, unterbrochenen Längsstreif vor der Subcostalis des Hinterflïgels. Saumflecke mehr getrennt. Fleck im Apex weib.

Peru, Französisch-Guayana.

Diese Art zerfällt in 2 Unterarten:

7 a. H. gradatus gradatus Weym. 1893 H. g., Weymer in: D. ent. Z. I.t. r. 4) 1. 335 t. 5 I.9 1901 H. g., Riffarth in: Berlin. ent. Z., c. 46 p. 47.

Endzellfleck, Medianflecke und Randtfeck des Yorderflïgels fehlen wdes sind nur stiickweise angedentet. An Stelle des Randfleckes eiu hinter dem mittleren Medianast von dem schmal schwarzen Distalıande wurzelwärts vorgeschobener, schmaler, schwarzer Keil. Submedianstreif breit, proximal bis dicht an den Hinterrand ausgedebnt, allmählich verjïngt und spitz in den Hinterwinkel auslaufend. Vorderflügellänge $+1-43 \mathrm{~mm}$.

Peru (Pebas).

7b. H. gradatus thielei Riff. 1900 H. g. t. Riffarth in: Berlin. ent. Z.. r. 1 ; p. 195 | 1901 H. g., Riffarth in: Berlin. ent. Z.. v. 46 J. 47.

Wie die typische Unterart, aber Apex des Vorderflïgels mit :3 deutlichen schwefelgelben Flecken, von denen die beiden vorderen uahe aneinander liegen, der hintere etwas abgerückt ist. Vorderrand schunal schwarz: Keilfleck in der Zelle unsicher begrenzt, mit verloschenem Ausläıfer mach der Flügelwurzel. Endzellfleck nud Medianflecke ebenfalls muscburf begrenzt. zum Teil verkümmert. Randfleck schmal, hinter denselben in Hinterwinkel einige schwefelgelbe Fleckchen. Submedianstreif schual, nur etwa 1 mm breit. in der Nähe des Distalrandes erlöschend. Die auBerhalb der Zclle gelegene Querbinde breit wie bei der typischen Unterart, aber an der hinteren Radialis an der distalen Begrenzung durch das rorgeschobene Schwarz des Apex etras. eingeschnürt, die dieselbe durchquerenden Ader'u bram bestäubt. Unten im Apex des Vorderflügels 3 oder 4 kleine weiße Saumflecke, die Subapicalflecke weißlich. Schwarze Flecke schärfer. - Hinterflügel fast wie bei der typischen Unterart. Mittel- und Saumbinde nächst dem Hinterrande undeutlich getreunt, im übrigen breit zusammengeflossen, der g'rößere Flügelteil von der Zellmitte bis zum Distalrande schwarz. Fin schwefelgelbes Fleckchen im Aper. Distalrand mngefleckt. Unterseite mit dentlicher getrennten Binden, Mittelbinde hinten stärker gekerbt, zwei weiße Apicalfleckchen nnd eine Reihe rerloschener, weißer, dem Distalıande nicht aufsitzender Saumfleckchen. Vorderflügelläuge $43 \mathrm{~mm}$.

Französisch-Guayana (Cayeme).

8. H. sulphureus Weym. 189:3 H.s., Weymer in: D. ent. Z. Lep.. k. is 1.311 t. 4 f. 8 | 1901 H. s., Riffarth in: Berlin. ent. Z., $t .46$ 1. $4 \bar{i}$.

ठ․ Kopf schwarz mit weißen Punkteu. Antemnen schwarz his auf das distale Drittel, welches unterseits ockergelb ist. Tlorax schwarz mit schwefelgelben Flecken und Punkten. Abdomen ron gleicher Farbe. rentral gelb, lateral mit gelhen Jängslinien. - Vorderflügel stumpfwiuklig dreieckig. 
Vorderrand leicht gokrïmsnt. Ipex ahoromudet, Hinterand sanft gesehweift.

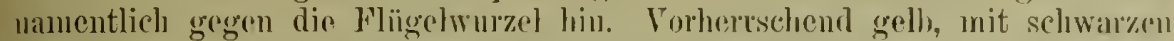

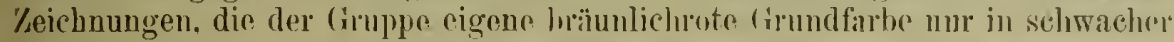
schattierung im vorderen 'Teil der \%elle. an den Radial- und Medianästen und beiderseits nachst dem Submedianstreif vorhanden. Vorderrand breit schwar\%. bindzellfleck rundlich mit anhängendem, spitz anslanfenden W Wrye]strahl. Findzellfleck rlombiselı. mit dem seliwarzen Vorderrandr: zusanmenenhängend. Medianflecke rundlich. frei liegend. Diø dureh gemaunte Flecke proximal und den schwarzen Apex distal begremzte. anberhalb der \%elle gelegene gelbe Qnerbinde von rötlichbram hestänhten Arlern dnrchschnitten, in derselben Farhe stellenweise zahn- oder stufenförmig in das sehwarze Apicalfold vortretend. In letzterem :3 schüg gestellte gelbe Flecke, Ranlfleck im hinteren Mcdianzwischenramm vom Pande rleutlich getrennt, Distalland hinter dem Randfleck schmal schwar\%. Hinterwinkel scliwar\%. Submediunstreif breit in diesen einlaufend. Enterseite noch reichlicher gell), die rötliche Bestïnhune an den Lmrissen der schwarzen Zeichmmgen gïnzlich oder fast fohlenrl. Apicalteil zrischen Querbinde und Ipicalflecken rotgelb, wit zerstreuten braunen Selmppen bestänht. Ipex distal hraun mit einer Reihe wrilice Doppelpunkte dicht am Rande. - - Hinterflïgel fast cirund, nuit breiter schwarzer Mittelbinde, die voln ziemlich gerade durch den hinteren Teil der Zolle geht. hinten gekerbt ist, sich nahe dem Apex in kurzen Bogen nach roru wendet mud durch einen zahmartigen Fortsatz an der vorderen Radialis mit dem schwarzen Distalrande rerbunden ist. Hierdmch entsteht in Apex cin isolierter, unregelmäßßiger gelber Fleck. Randbinde $6-7 \mathrm{~mm}$ hreit, rmin schwach gezälnt, am Hinterwinkel und Apex sehr verschmälert und zugespitz.t. Die den gelben Teil zwischen beiden Binden durchqnerenden Aderu schwar\%. rötlich bestänbt. Dem Distalrande sitzt eine Reilıe paarweise angeordneter kleckchen anf. Vorderandfeld hellgran gläinzend, schmal schwärzlich gesäunt. Unterseite vor Costalis und Subcostalis mit je einem sehwarzen Streif. längs des Vorderrandes ein schmaler gelher Saum: Costalis fein brïunlich bis rotgelh gesciumt, linter derselben in der Mitte cin schwefolgelber Fleck, distal vou diesen cin woißer und an Saum cin klcinerer weißer Fleck: die beiden letzten wiederholen sich im hinteren Radialzwischenraum. Sammflecke strahlenförmig verlängert. im Hinterwinkel ctw: 5 mm lang. - Torderflïgellängo $39 \mathrm{~mm}$. - - Q unbekannt.

Westliches Rrasilien (Thom:r).

\section{!). H. paraensis Riff.}

ơ. Punktierung auf Kopf.' Halskragen und 'Thorax, ebenso wie die soustige von der Grundfarbe alhweichende Keichnung und Behaarung des Körpers gell. Antennen dorsal schwarzhraun his zmr Spitze, chenso ventral auf etwa drei Viertel der Iänge, allmählich heller werdend und ockergell, endigend. Grundfarbe der Flügel gelhbraun, leicht rötlich. - Torderflügel länglich, stumpfwinklig dreicckig. Vorderrand sehwach gekrïnmut. Apex al)germat, Hinterwinkel stumpf, Hinterand sehr wenig geschwrift. Distale und mittlere Fläche bis zum Zellende und ron da etwa schräg \%um Hinterwinkel in der Grundfarbe. Fleckenzcichmmgen sehwar\%, nnd zwalr: Keilfleck in der Zclle schmal und schräg liegend, mit dïnnem Ansläufer nach der Wurzel; Endzcllfleck unregelmäßig. vorn längs der Subcostalis wurzelwärts etwas ausgeflossen und dem schwarzen Vorderrande anliegend; Medianflecke klein aber dentlich und gänzlich isolicrt. AnBertalb der Zclle gelegenc Qucrbinde schwefolgelh. die hintere Zellecks mid den vordeven 'Teil iles 
mittleren Medianzwischenraumes meist ausfüllend, hinten durch den schwarzen Randfleck zweizälınig gespalten. mit stark gezälnter, unsclıarfer, distaler Begrenzung: Apex breit schwarz mit 3 kleinen, ungewiß begrenzten, gelben Flecken, deren linterer gegen den Distalrand abgerückt ist. Distalrand schmal schwar\%. Zwischen diesem und dem Randfleck bräunliche Bestäubung: Hinterwinkel schwarz. Submedianstreif gleichmäßig breit in der ganzen Länge. Enterseite vorherrschend gelb, nur vorderer Teil der Zelle an der Mediana uud am hiuteren Medianast mit Spuren bräunlicher Bestäubung. Apex matter gefärbt, dicht am Rande einige verloschene weißliche Fleckchen. - Hinterflügel fast eirund, gelbbraun bis auf den Vorderrandteil vor der Subcostalis. Dieser hellgrau glänzend, mit einem dem Saum folgenden, dunkleren Streif dicht hinter demselben. Mittel- und Randbinde schwar\%. Erstere vollständig geschlossen, in gerader Richtung ziemlich gleichmäßig von der Mitte des Hinterrandes bis in den Apex verlaufend, dort etwas stärker und kurz nach rorn gebogen. Randbinde in der Mitte am breitesten, am Hinterwinkel oder Hinterrande und am Apex zugespitzt. Apex schwarz mit zwei gelben Flecken, ileren histerer in der braunen Grundfarbe liegt. Unter'seite mit schwefelgelbem Wurzelstrahl unmittelbar am Vorderrande. Das anschließende Feld breit schwarz bis zur Subcostalis, im Apex mit der nach vorn gebogenen Mittelbinde rereinigt. Längs der Costalis schwache bräınliche Bestäubung. Hinter der Subcostalis bis zur Mittelbinde reichlich gelb bestäubt. Mittelbinde hinten an den Adern dentlich gekerbt, nur durch eimen schmalen gelbbraunen Streif von der Randbinde getrennt. Im schwarzen Apex 2 ziemlich große, weiße Flecke, längs des Distalrandes eine Reihe paarweise in den Aderzwischenräumen angeordneter, länglicher Saumflecke bis zum Hinterwinkel. - - ․ Nur von H. p. latus bekannt (siche dort).

Unterscheidet sich von H. ethilla eucomus (S. 56) durch anderes Vorderrandfeld des Hinterflügels, andere Anlage und Gestalt der Yorderflügelbinde und Mittelbinde des Hinterflïgels.

Nördliches Brasilien.

Diese Art zerfällt in 2 Unterarten:

9 a. H. paraensis paraensis Riff. $1900 H . p$., Riffarth in: Berlin. ent. Z., v.45 p. 197 | 1901 H.. ., Riffarth in: Berlin. ent. Z., v. 46 p. 48.

Die außerhalb der Zelle gelegene Querbinde des Vorderflügels reingelb, Submedianstreif schmal, ebenso die Mittelbinde des Hinterflügels, die vorn die Zelle nicht berührt. Die Saumflecke des Hinterflügels unten dem Rande unmittelbar aufsitzend. Im übrigen mit den allgemeinen Merkmalen der Art. Vorderflügellänge $42-45 \mathrm{~mm}$.

Pará.

9 b. H. paraensis latus Riff. 1900 H. p. l., Riffarth in: Berlin. ent. Z., v. 45 p. $197 \mid 1901$ H.p. l., Riffarth in: Berlin. ent. Z., v. 46 p. 48.

o. Die außerhalb der Zelle gelegene gelbe Querbinde des Vorderflügels mit braun bestäubten Adern. Submedianstreif breiter schwarz als bei der typischen Unterart, bis etwa $4 \mathrm{~mm}$ an der breitesten Stelle. Schwarze Mittelbinde des Hinterflügels ebenfalls breiter, etwa doppelt, vor'n durch das Zellende gehend, dort etwa $5 \mathrm{~mm}$ breit, gegen den Hinterrand und den Apex bis auf etwa $1 \frac{1}{2} \mathrm{~mm}$ verjüngt. In letzterem entweder in kurzem Bogen nach rorn oder unmittelbar in der dort vorhandenen schwarzen Bestäubung endigend. Die weißen Saumfleckchen der Hinterflügelunterseite 
dem Distalrande nicht aufsitzend. der Grundfarbe abweichendem Vorderrande des Hinterflügels. Antennen in den distalen zwei Drittel ockergelb, sonst schwarz. - Vorderflügellänge $40-45 \mathrm{~mm}$.

Itaituba.

10. H. aulicus Weym. 1884 H. a., (Plötz in MS.) Weymer in: Ent. Zeit. Stettin, v. 45 p. 19 t. 1 f. 1 | 1893 H. a., Weymer in: D. ent. Z. Lep., v. 6 p. $337 \mid 1901$ H. a., Riffarth in: Berlin. ent. Z., v. 46 p. 48.

ơ. Stirnpunkte gelblich, Punkte auf Hinterkopf, Halskragen und Thorax, sowie die übrige Zeichnung und von der Grundfarbe abweichende Behaarung des Körpers gelb. Antennen vorwiegend schwarzbraun, distal gelblich. Grundfarbe der Flïgel gelbbraun, etwas diisterer als bei H. ethilla eucomus (S. 56), anf den Wurzelteil und hinteren Teil des Vorderflügels beschränkt. - Vorderflïgel stumpfwinklig dreieckig; Vorderrand leicht gekrümmt, Apex abgerundet, Hinterwinkel stumpf, Hinterland schwach geschweift. Fleckenzeichnung schwarz, und zwvar: Keilfleck in der Zelle länglich eirund, groß, mit starkem WVurzelstrahl; Endzellfleck unregelmäBig, mit dem schwarzen Vorderrande verschmolzen oder nicht; Medianflecke frei liegend, der vordere sehr klein, der hintere größer und länglich. Discale Querbinde gelb, ihre proximale Begrenzung ungewjß in die Grundfarbe übergehend an denjenigen Stellen, wo beide Färbungen zusammentreffen. Die Binde erstreckt sich im vorderen Teil der Zelle bis zum Keilfleck und füllt distal den hinteren Medianzwischenraum fast aus, umschließt also Endzell-, Median- und Randfleck; distale Begrenzung an den Adern stufenförmig abgesetzt, hinterer Teil durch den Randfleck zackenartig géspalten. Apex einfarbig schwarz, Hinterwinkel schwärzlich mit Spuren brauner Bestänbung, die sich auch zwischen Randfleck und Distalrand schieben kann. Hinterrand schmal schwärzlich, Submedianstreif $2-3 \mathrm{~mm}$ breit, unscharf begrenzt, an der Flïgelwurzel schmaler, distal breit in den Hinterwinkel auslaufend. Unterseite wie die Oberseite, aber matter in der Farbe, Apex fast schwarzgrau. - Hinterflïgel fast eirund, Apex schwach eckig, vorwiegend braun bis auf das grauglänzende Vorderrandfeld. Mittelbinde schwarz, aus länglichen, voru lose zllsammenhängenden Flecken bestehend, die dort glatt und in geschweifter Linie begrenzt sind. Die Binde entspringt dicht hinter der Flügelwurzel am Hinterrande, berïhrt vorn die Zelle, folgt distal dem vorderen Medianast und wendet sich nahe dem Apex in kurzem Bogen nach vorn, in einen dunklen Subcostalstreif ïbergehend. Apex und Distalrand schmal schwarz. Unterseite der Oberseite fast entsprechend, die Flecke der Mittelbinde noch deutlicher getrennt, Distalrand matter schwarz, ohne deutliche Binde. - - o. Wie das $\sigma^{\circ}$, nur ist der hintere Medianfleck durch einen schmalen Steg mit dem Randfleck zusammengeflossen, wodurch der distale Teil der Binde tief ausgeschnitten erscheint. Subcostalstreif des Hinterflügels kräftiger, etwas distal von der Mitte durch die Grundfarbe unterbrochen, diese Stelle auf der Unterseite gelb bestäubt. Antennen ausgedehnter gelb, nm auf etwa $1 / 3-1 / 2$ der Länge von der Wurzel aus schwarz. - - Vorderflügellänge $38-43 \mathrm{~mm}$.

Venezuela (Mérida, Tovar).

11. H. schulzi Riff. 1899 H. s., Riffarth in: Berlin. ent. Z., v. 43 p. 405 | 1901 H. s., Riffarth in: Berlin. ent. Z., v. 46 p. 49.

ㅇ. Stirnpunkte weißlich, Punkte auf Hinterkopf, Halskragen, Thorax, sowie die übrige Zeichnung und von der Grundfarbe abweichende Behaarung 
des Körpers gelb. Antennen proximal auf etwa ein Drittel schwarzbraun, daun ockergelb. Grundfarbe der Flügel bellbraun. - Vorderflügelgestalt wie bei der vorigen Art. Keilfléck klein, eirund, ohne Ausläufer nach der Flügelwurzel. Endzellfleck rundlich, doppelt so groß wie der Keilfleck, mit dem schwarzen Vorderrande verflossen. Medianflecke vorhanden, der vordere sehr klein, rundlich, der hintere eirund, doppelt so groß wie jener. Die außerhalb der Zelle gelegene Querbinde schwefelgelb, breit, beide Medianflecke einschließend und die hintere Zellecke ausfüllend, proximale Begrenzung: unscharf und allmählich in die braune Grundfarbe übergehend. Apex breit schwarz mit 4 schräg gestellten gelben Flecken, von denen die mittleren am größten sind, der hintere, nächst dem Distalrande stehende undeutlich ist. Distalrand schwarz. Randfleck bogenförmig weit in den hinteren Medianzwischenraum hineinreichend, in der Mitte mit einem fast dreieckigen oder berzförmigen, schwefelgelben Kern. Hinter dem Randfleck, zwischen dem hinteren Medianast und der Submediana, ein woiterer, manchmal verloschener, kleinerer gelber Fleck im breit scbwarzen Saum. Letzterer läuft, allmählich schwächer schattiert, zwischen diesen Adern etwa $12 \mathrm{~mm}$ nach der Flügelwurzel wischartig aus. Submediana fein schwarz, ein eigentlicher Submedianstreif feblt. Dnterseite in den Zeichnungen der Oberseite entsprechend. Das Schwarz weniger tief, Begrenzung der gelben Binde proximal sehr unscharf, nächst Apex und Distalrand 5 oder 6 weiße längliche Flecke. - Hinterflügel fast eirund, sehr ähnlich dem von H. silvana (S. 50), Vorderrand bräunlich. Zwischen Costalis und Subcostalis ein schwärzlicher Streif, in der Mitte durch die Grundfarbe breit unterbrochen. Nittelbinde nur im proximalen Teil zu erkennen, dort fleckartig, sonst mit dem breit schwarzen Distalsaum und Apex zusammengeflossen. Vordere Begrenzung dieser schwarzen Distalfläche etwa $2 \mathrm{~mm}$ hinter der Zelle, nicht gekrümmt wie bei H. silvana, sonderu gerade. Im Apex 2 oder 3 rundliche gelbe Flecke. Unterseite ähnlich der Oberseite. Mittelbinde besser abgesondert, nächst dem Hinterrande in Flecke aufgelöst. Apicalflecke weiß, am Distalrande bis zum Hinterwinkel fortgesetzt von einer Reihe weiBer wischartiger Randflecke. Subcastalstreif tiefer gefärbt, manchmal in seinem proximalen Teil zu einem länglichen isolierten Fleck verkürzt, seine Unterbrechung gelblich überstäubt. - Vorderflügellänge $42 \mathrm{~mm}$.

Nördliches Brasilien (Pará).

12. H. vetustus Butl.

○. Stirnpunkte weiß, die übrige Punktierung, sowie die von der Grundfarbe abweichende Zeichnung und Behaarung des Körpers gelb. Antennen dorsal schwarz bis zur Spitze der Keule, ventral nächst der Wurzel auf etwa ein Drittel der Länge schwar', sodann, allmählich lichter werdend, ockergelb. Grundfarbe der Flügel licht- bis dunkel-kastanienbraun. - Vorderflügel ziemlich breit, etwas gestreckter als bei der vorigen Art. Keilfleck meist sehr klein, ohne spitzen Ausläufer nach der Flügelwurzel. Endzellfleck grob, fast quadratisch, mit dem schwarzen Vorderrande leicht zusammengeflossen oder getrennt. Medianflecke mittelgroB, dicht zusammenstehend, etwa gleich groß oder der vordere kleiner als der hintere. Die außerhalb der Zelle gelegene Querbinde schmal, schwefelgelb, höchstens den vorderen Medianfleck einschließend, ziemlich scharf begrenzt, hinten bis zum mittleren oder aber bis nahe zum hinteren Medianast reichend, alsdann im mittleren Medianzwischenraum rechteckig in den schwarzen Distalteil vorspringend. Apex breit schwarz, mit oder ohne Flecke. Randfleck ähnlich dem voriger 
Art, bogenförmig, mit einem gelben, lerzförmigen oder dreieckigen Kern. Distalrand schwarz, hinter dem Randfleck zuweilen ein weiterer gelber J'leck in der schwarzen Randfürbung; diese in Hinterwinkel wurzelwärts breit ausgeflossen, namentlich vor der Submediana, daselbst in einen schmalen Submedianstreif ühergehend, der sich auf die schmal scliwarz gefürhte Submediama beschräiken kann. Unterseite ähnlich der Oberseite. Keilfleck mit Ausläufer nach der WVurzel. Endzellfleck rundlich, allseitig frei stehend, Medianflecke manchmal verschmolzen, 2-4 weißliche Apicalflecke, Füllung des Randfleckes mnd der dahinter liegende Fleck am Saum weißlich. - Hinterflügel bis auf das breit grau glänzende Vorderrandfeld fast schwarz, mit einem von der Flügelwurzel ausgehenden, länglichen, spitzen Keil in der Grundfarbe. Trenumng der mit dem verbreiterten Distalsaum völlig verflosseneu Mittelbinde zuweilen am Hinterrande durch einen undeutlichen rötlichbraunen Wisch angedeutet. Im Apex zuweilen 1 oder 2 weiBliche Fleckchen. Fransen schwarz und weiß gescleckt. Unterseite mit besser hervortretenden Zeichuungen. Vorderrand nächst der Flügelwurzel gelblich, daun schmal braun, dahinter ein breit schwarzer Costalstreif, sodann ein in der Mitte unterbrochener, mit dem distalen Teil des Costalstreifes, sowie mit dem schwarzen Apex und Distalrande zusammengeflossener Subcostalstreif. Hinter diesem ein langer, gebogener, stumpf vor dem Apex endigender Streif der braunen Grundfarbe. Mittelbinde sehr breit, nächst dem Hinterrande deutlich, sodaun undeutlich in dev Grundfarbe rom schwarzen Distalrande getrennt und schließlich völlig mit diesem rerschmolzen. Apicalflecke grob, weiß; an Distalrande eime Reibe weiBel wischartiger Saumflecke. - _ in der distalen Hälfte völlig ockergelb. Gelbe Querbinde in der Regel weiter ausgedehnt, Distalrandflecke größer. der braune Streif der Grundfarbe auf dem Hinterflïgel länger, bogenförmig der Subcostalis fast bis in den Aper folgend. Unterseite des Torderflügels vor der Submediana mit schwarzem Streif, Torderrandfeld des Hinterflügels weniger geschwärzt.

Nördliches Brasilien, Guayana.

Diese Art zerfällt in 2 Unterarten:

12a. H. vetustus vetustus Butl. $1873 H . v .$, A. G. Butler in: Cistula ent.. v.1 p. $165 \mid 1877$ H. v., W. F. Kirby, Cat. diurn. Lep., Suppl. p. $723 \mid 1893$ H. v., Weymer in: D. ent. Z. Lep., v. 6 p. 292 1901 $H$. v., Riffarth in: Berlin. ent. Z., v. 46 p. 50.

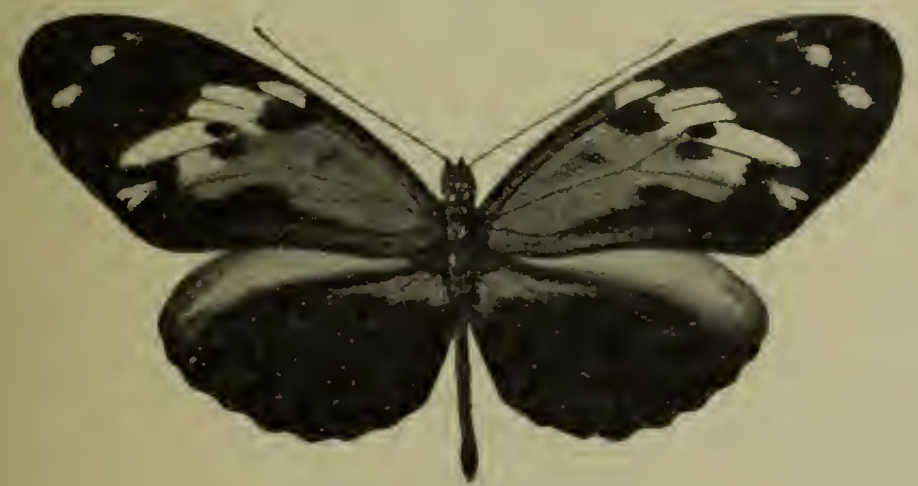

Fig. 12. H. vetustus vetustus, $\sigma^{7}\left({ }^{2} / 1\right)$.

Grundfarbe der Flügel (Fig. 12) licht kastanienbraun. Breit schwarzer Apex des Vorderflügels mit 3 oder 4 gelben, schrïg gestellten Flecken. Submedian- 
streif schmal, aber deutlich bis zur Flügelwurzel. Die breit schwarze Fläche des Hinterflügels völlig geschlossen, oder nur wenig merklich am Hinterrande durch einen undeutlichen braunen Wisch an der Trennungsstelle der Mittelund Saumbinde durchbrochen. Apex mit 1 oder 2 gelblichen Flecken. Vorderflïgellänge $45-50 \mathrm{~mm}$.

Britisch-Guayana (Demerara).

12b. H. vetustus metellus Weym. 1893 H. m., Weymer in: D. ent. Z. Lep., v. 6 p. 290 t. 4 f. $1 \mid 1901$ H. vetustus m., Riffarth in: Berlin. ent. Z., v. 46 p. 50.

Grundfarbe der Flügel dunkel kastanienbraun. Schwarzer Apex des Vorderflügels ohne Flecke, Submedianstreif fehlt, Submediana nur fein schmarz. Flecke im Discalteil größer als bei der vorigen Form. Hinterflügel etwas reichlicher braun; Mittelbinde nächst dem Hinterrande deutlicher getrennt, ibre hintere Begrenzung durch kleine Flecke der braunen Grundfarbe angedeutet. sonst aber ebenfalls mit der schwarzen Distalfäche rerflossen. Apex oberseits ungefleckt. Vorderfliigelläng*e $42 \mathrm{~mm}$.

Nördliches Brasilien (Santarem).

13. H. novatus Bates 1867 H. n., H. W. Bates in: Tr. ent. Soc. London, ser. $3 r .5$ p. $539 \mid 1871$ H. n., W. F. Kirby, Cat. diurn. Lep., p. $138 \mid 1893$ H. mirus + H. m. var. illustris + H. n. + H. leopardus, Weymer in: D. ent. Z. Lep., v. 6 p. 296 t. 4 f. 2 (forma mira); p. 298 ; p. 299 ; p. 319 t. 5 f. 11 (forma 1.) | 1894 H. l., O. Staudinger in: D. ent. Z. Lep., $v .7$ p.66 (forma l.) $\mid 1896$ H. mirus forma l. $+H$. m. aberr. illustris, 0. Staudinger in: D. ent. Z. Lep., v. 9 p. 317 (forma 1.); p. $317 \mid 1896$ H. m., Weymer in: D. ent. Z. Lep., v. 9 p. 317 (forma mira) | 1901 H. novatus (H. arethusa Plötz in IIS.) + H.n.m. + H. n. leopardus, Riffarth in: Berlin. ent. Z., v. 46 p. 51 ; p. 51 (forma mira); p. 52 (forma l.) | 1901 H. spadicarius, A. G. Weeks in: P. N. Engl. zool. Club, $v .2$ p. $72 \mid 1902$ H. s., A. G. Weeks in: Ent. News Philad., v. 13 t. 7.

§. Stirnpunkte weiß, die ïbrige Punktierung, wie auch die sonstige Zeichnung und von der Grundfarbe abweichende Behaarung des Körpers gelb. Antennen proximal gänzlich, sodann nur dorsal schwarz, ventral aber gelb. Sehr unbeständige Art. Grundfarbe der Flügel gelbbraun bis dunkel kastanienbraun. Fransen beider Flïgel schrarz und weiß gescheckt. Vorderflügel von Gestalt wie H. schulri (S. 65). Torderrand schwarz, Keilfleck rundlich, ohne oder mit, meist abgetrenntem. Spitzenausläufer murzelwärts. Endzellfleck fast rhombisch, vorn meist mit der Vorderrandfärbung verflossen. Medianflecke meist vorhanden, eirund, der hintere zureilen fehlend. Distal von der Zelle eine scbrefelgelbe schräge Querbinde, die durch den einspringenden schwarzen Randfleck distal eine stumpfe Gabel bildet; der vordere Ast derselben endet stumpf, meist etwa $2 \mathrm{~mm}$ ror dem Distalrande im mittleren Medianzwischenraum, der hintere etwas spitzer, vom hinteren Medianast begrenzt. etwa $4 \mathrm{~mm}$ ror dem Distalrande. In der Zelle zwischen Keil- und Endzellfleck häufig gelbliche Bestüubung. Apex breit schwarz, an den Adern zackig in die gelbe Binde einspringend, mit 3 oder 4 gelben, schräg liegenden Flecken, ron denen der vordere klein. die folgenden sehr gro 3 sind, der hintere oft fehlt; diese Flecke sind zuweilen weißlichgelb. manchmal auch braun umrandet. Randfleck hinter dem mittleren Medjanast stumpf zapfenförmig. weit vorspringend, rorn mit dem schwarzen Apicalteil zusammenhängend, distal, namentlich hinten, bräunlich überstäubt, zureilen ganz fehlend und durch die braune Grundfarbe ersetzt. Distalrand hinter dem Randfleck und Hinterrand schmal schwarz, im Hinterwinkel meist längs und $\mathrm{F} 0 \mathrm{r}^{\circ}$ der Submediana schwarze Bestäubung. Submedianstreif schmal, meist nur auf die schwarze Ader beschränkt. Medianflecke und Endzellfleck 
mitunter bedeutend vergröBert, derart daß sie unter sich und im äuBersten Falle stellenweise oder gauz mit dem schwarzen Apicalteil, zuerst längs der Adern, zusammenfließen. Die gelbe Querbinde wird hierdnrch stark reduziert, zerrisseu, in einzelne Flecke aufgelöst oder bis auf wenige Spuren distal von der Zelle und hinter dem mittleren Medianast durch Schwarz verdrängt. In seltenen Fällen fließt auch der lintere Medianfleck mit dem Randfleck zusammen. Unterseite matter, die gelbe Binde proximal ungewisser begrenzt und zerstäubt. Die schwarzen Zeichnungen rötlichbraun umstäubt, der Apex rötlichbraun bis auf schwarze Besäumung und proximale Begrenzung. mit 3 oder 4 weißen Fleckchen unmittelbar am Rande, die zuweilen nach oben durchschlagen. - Hinterflïgel mit einer aus fast quadratischen oder länglichen Fleckchen gebildeten, geraden Mittelbinde hinter der Zelle. die sehr rndimentär auftreten kann, sich dann etwa in der Mitte zwischen Zelle und Distalrand hält und schwach S-förmig gekrïmmt ist; doch treten die BindenHecke auch rerläıgert auf, hängen rorn zusammen und berülnen den Distalrand. Letzterer schwarz in mäBiger Breite, rorn zwisclien den Adern etwas gekerbt. Apex breit schwarz mit einem mehr oder weniger rein gelben Fleckchen. Vorderrandfeld grau, etwas dunkler umrandet. Nedian- und Radialadern fein schwarz. Cnterseite an der Flügelwurzel mit gelbem Fleck. Torderrand schmal braun, sodann ein bis nahe zur Costalis reichender schwärzlicher Streif und hinter der Costalis ein etwa in der Mitte meist gelb unterbrochener Subcostalstreif, der mit dem schwarzen Apex und Distalrande zusammenfließt. In ersterem weiße Flecke, letzterer mit einer Reihe ron paarweise in den Aderzwischenräumen stehenden, weißen, wischartigen Saumfleckchen. - - o. Im allgemeinen wie das $\sigma^{7}$. jedoch mit den Geschlechtsmerkmalen. Antennen im distalen Teil (etwa zwei Drittel) völlig ockergelb. Flecke in der Mitte des Vorderflügels meist gröBer, im Apex in der Regel von unten durchschlagende, undentliche, weißliche Randfleckchen. Auf der Enterseite des Hinterflugels in der Zelle und distal ron derselhen meist gelhe Bestäubung.

Bolivia, Peru; nördliches Brasilien?

Forma principalis. Grundfarbe der Flïgel gelbbraun. Flecke in der Mitte des Vorderflügels (Fig. 13) klein, frei liegend, etwas verwaschen. Schwefel-

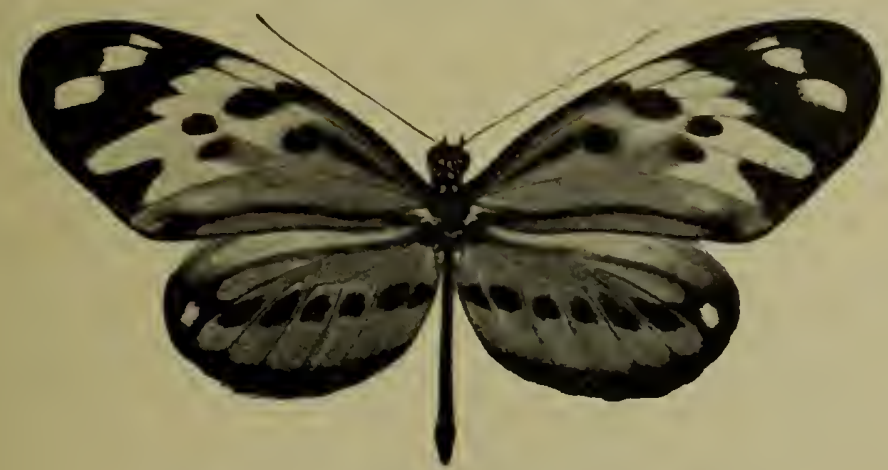

Fig. 13. H. novatus, forma principalis, $\delta(1,1)$.

gelbe Querbinde voll, nicht unterbrochen, mit deutlicher Gabelung hinten und distal. Flecke im Apex gelb. Keilfleck mit oder olne Spitzenausläufer. Schwarzer Submedianstreif nur durch die fein schwarze Submediana vertreten. 
Mittelbinde des Hinterflügels in getrennten Flecken mittlerer GröBe. In allen Übergängen mit der nächsten Form verbunden. Vorderflügellänge $41-47 \mathrm{~mm}$.

Mit dieser Form deckt sich die Abbildung ron $H$. spadicarius fast rollkommen, wähıend die Beschreibung einen Übergang zur folgenden Form erkennen läßt.

Pará?; Perı; Bolivia (Tal des Rio Songo [Y̌ungas], Coroico).

Forma mira. Grundfarbe der Flügel gelbbraun wie bei der Hauptform. Keilfleck des Vorderflügels mit getrenntem Spitzenausläufer. Endzellfleck mit dem Vorderrande, den Medianflecken und dem schwarzen Apex dergestalt zusammengeflossen, daß die gelbe Querbinde nur in 3 Fleckchen im vorderen Teil distal von der Zelle und in der Endgabel zwischen dem hinteren Median- und Randfleck erhalten ist. Vier gelbe Flecke in dem breiten, fast die ganze distale Flügelhälfte mit schräger Begrenzung von der Vorderrandmitte bis zum Hinterwinkel einnehmenden, schwarzen Apicalteil, die mittleren sehr groß. Randfleck stumpf kegelförmig, tiefschwarz. Submedianstreif sebr dünn. Hinterflïgel mit schmalem schwarzem Distalrande, ein weißlicher Fleck im Apex, Mittelbinde nur in einer schwach S-förmig gebogenen Reihe von Fleckchen rorhanden, die etwa in der Mitte zwischen Zelle und der proximalen Begrenzung des schwarzen Distalsaumes, fast näher zu letzterer, liegen.

Zu dieser Form köuneu alle Stücke der Art gerechnet werden, bei denen infolge Ausbreitung der schwarzen Zeichnungen des Vorderflügels die gelbe Querbinde eingeschränkt oder durchbrochen ist.

Bolivia (Tal des Rio Songo [Yungas] und Rio Juntas, Bueyes), Peru.

Forma leopardus. Grmudfarbe der Flügel dunkel kastanienbraun. sonst wie die Hauptform. Keilfleck des Vorderflügels ohne Spitzenansläufer, Endzellfleck frei liegend, ebenso die sehr kleinen, mnscharf begrenzten Medianflecke, deren vorderer von dem Gelb der vollen Querbinde ganz eingeschlossen ist. Distale Zone letzterer nur his in den rorderen Gabelteil reingelb, der hinter dem mittleren Medianast und dem mehr rechteckigen Randfleck gelegene Teil der Binde ungewiß gelbbraun zerstäubt. Submedianstreif sebr schmal. Distalrand und Hinterwinkel nur dunkler braun, sehr schwach schwärzlich. Mittelbinde des Hinterflügels aus fast dreieckigen Flecken gebildet, die untereinander nicht zusammenhängen und deren stumpfe Spitzen nach hinten gerichtet sind. Distalrand breiter schwarz, namentlich in der Mitte.

In allen Übergängen in Farbe und Zeichnung mit der Hauptform und der forma mira verbunden.

Bolivia (Tal des Rio Songo [Yungas] und Rio Juntas).

14. H. hecale (F.) 1774 Papilio wrania (part.) (err., non Linné 1758!), St. Iü̈ller, Naturs. Linné, v. 5 I p. 584 t. 18 f. 2 | 1893 Heliconius u., Weymer in: D. ent. Z. Lep., v. 6 p. $344 \mid 1775$ \& 76 „Pasithoé“, Papilio pasithoe (er1., non Linné 1767 !), P. Cramer, Pap. exot., v. 1 p. 25 t. 17 f.A. B; p. $154 \mid 1847$ Heliconia p., E. Doubleday (\& Westwood), Gen. diurn. Lep., v.1 p.104 1869 Heliconius p., A. G. Butler, Cat. diurn. Lep. Fabr., p. 120 1871 H. p., W. F. Kirby, Cat. diurn. Lep., p. 139 | 1880? H. p., Buchecker, Syst. Ent., Lep. t. 56 f. $16 \mid 1893$ H. p., O. Staudinger in: D. eut. Z. Lep., v.6 p.344|1901 H. p., Riffarth in: Berlin. ent. Z., v.46 p. 53 | 1777 Papilio hecale, J. C. Fabricius, Gen. Ius., p. 254 | 1779 „P. h.", Goeze, Ent. Beytr., v. 3 I p. $112 \mid 1781$ P. h., J. C. Fabricius, Spec. Ins., v. 2 p. $29 \mid 1787$ P. h., J. C. Fabricius, Mant. Ins., v. 2 p. $14 \mid 1790$ P. h., J. F. Wr. Herbst, Naturs. Ins. Schmett., v.4 p.161 t. 76 f. 1 | 1793 P. h., J. C. Fabricius, Ent. syst., v. 3 I p. $167 \mid 1816$ Ajantis $h$. . Jac. Hübner, Verz. Schmett., p. $14 \mid 1819$ Heliconia $h$., (Latreille \&) J. B. Godart in: Enc. méth., v. 9 p. 203.

ơ. Kopf schwarz, vorn mit vier weißlichen Punkten, je zwei ror und hinter den Antennenwurzeln, auf Scheitel und Halskragen ebenfalls je zwei 
Fleckchen; diejenigen auf dem Scheitel zuweilen undeutlich. Augen dunkelbraun, hinten weißlich gesäumt, oben mit je einenı sehr kleinen weiblichen Punkt. Palpen weißlich oder bräunlich, Spitze schwarz. Antennen schwar\%, Kenle unterseits bräunlich. Thorax schwarz, vorn mit vier weißlichen, quer von einer zur anderen Flïgelwurzel angeordneten, zuweilen verloschenen Punkten. Rïcken bis auf einen schwarzen Mittelstrich grauschwarz behart. Brust \%wischell den Hüften schräg gelb gestreift. Vorderbeine gelb, die übrigen Beine schwarz, leicht weißlich bestäubt. Abdomen schwarz, ventral gell, lateral mit ein oder zwei, mehr oder miuder deutlichen und meist stark unterbrochenen gelben Linien. Grund farbe der Flïgel schwarz; Fransen schwarz und weiß gescheckt. — Torderflïgel gestreckt, ziemlich breit, Vorderrand schwach gekriimmt, Apex abgerundet, Hinterwinkel stumpf. Hinterrand bedeutend kiirzer als der Vorderrand. Mit einer discalen, schräg rou der Mitte des Torderrandes gegen den Hinterwinkel ziehenden, den distalen Teil der Zelle ausfüllenden weißen Querbinde, welche in ihrem vorderen Teil durch den mit dem Torderrande verschmolzenen rhomboidalen Endzellfleck gegabelt und ron den schwarzen Adern durchquert ist. Das distale und hintere Ende ist durch den "kegelförmig rortretenden, herzförmig weiBlich gekeruten Randfleck schwarz eingekerbt, die proximale Begrenzung ungewiß, zerstäubt, die distale Grenze an den Adern durch Ausfließen des schwarzen Apicalteiles eingeschnitten. Drei ziemlich große weiße Subapicalflecke. Medianfiecke fehlen (typisch) oder stehen isoliert nächst der Zelle im mittleren und hinteren Medianzwischenraum im Teißen. Unterseite weniger scharf, her"zförmiger Kerı des Randfleckes größer, hinter ihm ein weiterer weißlicher Hleck, nächst dem Aper zuweilen kleine weibliche Saumflecke, Endzellfleck isoliert in der weißen Querbinde, diese rorn ohne Gabelbildung. - Hinterflïgel bis auf den breit gxauglänzenden Torderrandteil, schwïrlichen Apex und gescheckte Fransell einfarbig schwarz. Unterseite mit gelbem Wurzelstreif an proximalen Teil des Vorderandes, einer mehr oder weniger vollständigen Reihe weißer Randflecke und zuweilen mit Spuren rötlichbrauner Bestïubung am Hinterrande nächst dem Hiuterwinkel. - _ o. Im allgemeinen wie das $\sigma^{\pi}$, mit den Geschlechtsmerkmalen, stunupfer Färbung hinter der Mediana der Torderflügelunterseite nnd grauschwarzem Torderrindteil der Hinterflügeloherseite. Teiße Binde des Vorderflügels häutig grauschwarz iiberstäubt, Fïrbung in der Zelle rorn nud hinten lichter, so daB der spitzwinklige Keilfleck ungewib hervortritt. Im Aper des Hinterflügels verloschene weiBliche Fleckchell. auf der Unterseite der Torderrand in Verlängerung des gelben Trurzelstreifes schmal rötlichbraun. Rotbraune Färbung an Hinterrande deutlicher. - Vorderflïgellänge $46-48 \mathrm{~mm}$.

Niederländisch-Guayana, Britisch-Guayana (Demerara).

15. H. aristiona (Hew.)

o. Punktierung auf der Stirn meist weiß, selten gelblicl, Punktierung und Zeichnuug, sowie die von der Grundfarbe abweichende Behaarnng der übrigen Körperteile meist gelb, seltener bräunlich oder braungelb. Antennen in der Regel in dem proximalen Drittel schwarz oder scliwarzbraun, sonst ockergelb, seltener mit bräunlicher Keule und in rereinzelten Fällen dorsal schural geschwärzt bis zur Spitze. Grundfarbe der Flïgel hellbraun. Gestalt des Torderflügels wie bei den vorigen Arten. Proximaler Teil nuehr oder weniger gesehwärzt oder aber auch im reinen 'Ton der Grundfirbe. Keilfleck rundlich, ohne spitzen Ausläufer nacl der Flügelwurzel oder mit solchem, zusammenhängend oder getrennt, manchmal sehr breit ausgeflossen," 
die proximale Hälfte der Zelle ausfïllend, vorn jedoch stets, wenn auch nur durch einen schmalen Streif der Grundfarbe vom schwarzen Vorderrande getrennt, nach hinten zuweilen mit einer distal abgeschrägten, hinter der Mediana bis zum Hinterrande ausgedehnten schwarzen Bestäubung zusammengeflossen. Endzellfleck fast stets dentlich vorhanden, rundlich, fast viereckig, bald kleiner, bald größer, zuweilen mit dem schwarzen Vorderrande zusammengeflossen, in seltenen Fällen verkleinert oder bis auf ungewisse dunklere Bestäubung verkümmert. Medianflecke meist in charakteristischer Weise vorhanden, selten fehlt der hintere oder ist verkleinert. In einzelnen Fällen ist der vordere Medianfleck mit dem schwarzen Apicalteil oder der hintere mit dem Randfleck zusammengeflossen. Distal von der Zelle mit oder ohne schwefelgelbe Querbinde. In letzterem Falle ist die Binde durch die Lage der Discal- und Distalzeichnungen häufig in der Grundfarbe markiert. Die Binde selbst schmal, wenig gekerbt oder gezälınt, hinten nicht oder nur in ungewisser Bestäubung über den mittleren Medianast hinausreichend, distal kurz vor dem Distalrande endigend. Apex meist breit schwarz, ohne Flecke, aber auch mit gelben oder braunen, schräg gestellten Flecken unweit des Randes; letztere bisweilen derart verbreitert, daß der Apicalteil den Grundfarbenton annimmt und nur schwärzlich gerandet ist. Randfleck bis auf wenige Ausnahmen deutlich als stumpfer, ziemlich langer Zapfeu dicht hinter dem mittleren Medianast einspringend, die gelbe Binde hinten abschneidend. Distalrand hinter diesem Fleck schmal schwarz, nur bei Formen mit braunem Apex ohne eigentliche Besäumung. Hinterrand schmal schwarz. Submedianstreif meist kräftig, zuweilen stark verbreitert und, wie bei dem Keilfleck bereits erwähnt, mit letzterem zu einer breiten schwarzen Fläche verflossen. Der Submedianstreif endet meist auf der Mitte der Submediana, seltener in der Nähe des Hinterwinkels, die Ader selbst läuft schwarz in diesen aus. Fransen schwarzbraun, zuweilen weißlich gescheckt. Unterseite matter, sonst ohne wesentliche Verschiedenheiten. - Hinterflügel mit hellglänzendgrauem Vorderrandteil, mit schwach dunkler Umrandung, welche jedoch den Vorderrand selbst stets schmal grau läBt. Die übrigen Zeichnungsanlagen in allen Zusammeustellungen der charakteristischen Merkmale der Silvaniformes, und zwar vorwiegend schwarz mit braunem Apex, oder braunem Vorder- und Distalteil, vorwiegend braun mit Mittelbinde und mehr oder weniger breitem Distalrande. Beide reichen selten bis zum Apex, in dem höchstens der Saum und die. Adern fein schwarz sind, so daß dort größere braune Felder entstehen, welche zuweilen durch schwefelgelbe Flecke gekernt sind. Mittel- wie Distalrandbinde sind manchmal mehr oder weniger in Flecke aufgelöst oder fehlen mitunter gänzlich. Letztere zuweilen mit braunen Saumfleckchen, die nach dem Apex zn größer werden und dort in der Grundfarbe verlanfen. In der braunen Grundfarbe die Adern größtenteils fein schwarz. Fransen vorwiegend weiß, schmal schwarz unterbrochen, seltener grau oder bräunlich. Unterseite mit starkem, in der Nitte meist gelb unterbrochenem schwarzem Subcostalstreif, welcher ebenfalls vor dem Apex endet, meist einem minder intensiven Costalstreif, und schmal bräunlichem Vorderrande; an der Flügelwurzel meist ein gelbes Fleckchen, sonst der Oberseite entsprechend, nur zuweilen weißliche oder gelbe, dem Rande aufsitzende Saumfleckchen. _des Hinterflügels meist mitbreitem, den Apex nicht erreichendem schwarzem Subcostalstreif, der oberseits schattenhaft verkümmert sein kann, unterseits wie beim $\sigma^{\pi}$ meist unterbrochen ist. Die Lücke znweilen gelb bestänbt. Bei Formen mit vorwiegend schwarzen Hinterflügeln ist dieser Streif mit der 
übrigen schwarzen Fläche verflossen. Zeichnungen im übrigen wie beim $\sigma^{\pi}$, die schwarzen Flecke meist etwas größer, mit Neigung zum Zusammenfließen.

Sehr variable Art mit konstanten Variationsstufen, die unter sich häufig einen recht verschiedenen Eindruck machen, aber durch Zwischenformen und Übergänge verbunden sind.

Colombia, Ecuador, Peru, Bolivia, Amazonas.

Diese Art zerfällt in 13 Unterarten:

15 a. H. aristiona aristiona (Hew.) 1852 Heliconia a., Hewitson, Exot. Butt., v. 1 Heliconia t. 1 f. $4 \mid 1879$ Heliconius a., Hopffer in: Ent. Zeit. Stettin, v. 40 p. 434 1893 H. a. + H. a. var. splendidus, Weymer in: D. ent. Z. Lep., v. 6 p. 334 ; p. 334 t. 5 f. 8 (forma splendida) | 1901 H. a. + H. a. s., Riffarth in: Berlin. ent. Z., v. 46 p. 56; p. 57 (forma splendida).

Forma principalis. Stirnpunkte weib, Körperzeichnung gelb, Antennen proximal schwarz, in den distalen zwei Dritteln ockergelb, beim $\sigma^{\pi}$ indes dorsal schınal schwarz bis zur Keulenspitze. - Vorderflügel hellbraun, proximal in der Zelle leicht schwärzlich, hinter derselben stärker schwarz bestäubt. Vorderrand schwarz, proximal breiter als distal. Schwarzer Keilfleck rundlich, isoliert in der Zelle, Endzellfleck und Medianflecke verloschen, schattenhaft. Apex breit schwarz, ungefleckt. Distalrand hinter demselben und Hinterrand schmal schwarz, Randfleck nur schattenhaft angedeutet. Submedianstreif nur im proximalen Teil vorhanden, dort meist sehr breit, einerseits mit der schwarzen Wurzelbestiubung vertlossen, andererseits bis an den Hinterrand ausgedehnt, manchmal braun üherstäubt, distal etwa in der Mitte der Submediana schräg abgesehnitten. Hinterflügel sclıwarz bis auf den braunen Apex und den grauen Vorderrandteil des $\delta^{\pi}$. In ersterem gewöhnlich ein schwarzes Fleckchen und zwischen diesem und dem Distalrande 1 oder 2 schwefelgelbe Subapicalflecke. Unterseite weniger intensiv in der Färbung, aber die schwarzen Flecke des Vorderflügels deutlicher; distal an dem rorderen Nedianfleck, im mittleren Medianzwischenraum häutig leicht gelbliche Bestäubung, ein Anzeichen der gelben Querbinde. Hinterflügel mit mehr Braun, namentlich am Vorderrande, im distalen Teil und an den Adern; im Apex zwei größere weiße Wischflecke. Vorderflügellänge $37-46 \mathrm{~mm}$.

Bolivia (Tal des Rio Juntas in Höhen von $1000 \mathrm{~m}$ ), Peru (Tal des Rio Ucayali und des Chanchamayo, Pozuzo).

Forma splendida. Wie die Hauptform, aber der proximale Teil des Vorderflügels bis etwa zu den discalen Flecken und der Mitte des Submedianzwischenraumes dunkel kastanienbraun, so daB der discale hellbraune Teil zwischen Endzell- und Medianflecken und schwarzem Apicalteil sich als schräg liegende Querbinde deutlich abhebt. Keilfleck mit spitzem, aber abgetrenntem 'Ausläufer, die übrigen Flecke gröBer und schärfer als bei der Hauptform, namentlich der stumpfkegelförmige Randfleck. Hinterflügel meist vorwiegend schwarz, zuweilen bricht die braune Grundfarbe an der Trennungsstelle ron Mittel- und Randbinde durcb, und es bilden sich so Übergangsstücke zur nächsten Form.

Bolivia (Tal des Rio Juntas).

15 b. H. aristiona timaeus Weym. 1893 H. t., Weymer in: D. ent. Z. Lep., v. 6 p. 331 t. 5 f. 6 | $1901 H$. aristiona $t$, Riffarth in: Berlin. ent. Z., v. 46 p. 56.

Vorderflügel ähnlich wie bei der typischen Cuterart, Flecke meist intensiver. Keilfleck mit Spitzenausläufer nach der Wurzel, der aber häufig abgetrennt ist. Vorderand meist schwarz, manchmal nur sehr wenig; hinterer Medianfleck fehlt zuweilen, beim $o$ ist Neigung zum Zusammenfließen der 
discalen Flecke unter sich und mit dem Randfleck vorhanden. Apex zuweilen mit bräunlichen Saumpunkten, die namentlich unten dentlicher auftreten. Submedianstreif schmaler, deutlich von der Zelle und dem Hinterrande getrenut. - Hinterflügel vorherrschend hellbrauu, mit Mittel- uud Randbinde. Erstere aus einzelnen, läuglich rechteckigen oder stumpf dreieckigen, vorn meist zusammenhängenden Flecken bestehend, die Zelle fast oder ganz berührend. Beim $O$ wenden sich die distal liegenden Flecke vor dem Apex nach vorn uud vereinigen sich mit dem Subcostalstreif. Randbinde manchmal teilweise mit den Flecken der Mittelbinde zusammeugeflossen, discal am breitesten, meist mit braunen Saumfleckchen, namentlich beim o, die gegen den Apex große, häufig gelblich gekernte Subapicalflecke bilden. Auf der Uuterseite beim ơ je ein starker Costal- und Subcostalstreif und die Zeichnungsanlage des o in der bogenförmigen Vereinigung der Mittelbinde mit dem Subcostalstreif nächst dem Apex. O meist mit deutlichen, vom Distalrande schmal getrennten weißlichen Randflecken. - Torderflügellänge $43 \mathrm{~mm}$.

Yeru (Iquitos, Tal des Rio Ucayali).

$15 \mathrm{c}$. H. aristiona bicoloratus Butl. 1873 H. b., A. G. Butler in: Cistula ent., v. 1 p.167 | 1877 H.b., W. F. Kirby, Cat. diurn, Lep., Suppl. p. 721 | 1893 H.b., Weymer in: D. ent. Z. Lep., v. 6 p. $333 \mid 1901$ H. aristiona b., Riffarth in: Berlin. ent. Z., v. 46 p. $57 \mid 1879$ H. a. var. peruana, Hopffer in: Ent. Zeit. Stettin, v. 40 p. 434.

Stirnpunkte weiß, Körperzeichnung gelb. Grundfarbe der Flügel hellbraun, Zeichnung und sonstige Merkmale fast wie bei der typischeu Unterart, aber Vorderflügel proximal breit und tief schwarz bis zu einer schrägen Liuie vom Ende des Zellfleckes bis etwa zur Mitte des Hinterrandes. Die Grundfarbe erscheint als breite, discale, schräge Querbinde, distal rom schwarzen Apicalteil begrenzt, in welcher der schwarze Endzellfleck und die Medianflecke deutlich uud scharf isoliert liegen nnd die hinten durch den vom Distalrande einspring'enden, zapfenförmigen Randfleck gabelförmig gespalten ist. Hinterflügel volwiegend schwarz, Apex braun, gewöhnlich breiter als bei der typischen Uuterart, mit einem isolierten schwarzen Fleck und kleinen dreieckigen Randflecken an den Aderenden. Fransen des Vorderflügels weiß und schwarz gescheckt, die des Hinterflügels fast ganz weiß, nur in der Mitte der Aderzwischenräume ungewiß schwärzlich unterbrochen. Unterseite des Vorderflügels meist mit deutlichem Keilfleck uud davon getrenntem spitzem Ausläufer nach der Wurzel. Schwarze Bestäubung des proximalen F'lïgelfeldes weniger intensiv, proximale Begrenzung des schwarzen Apicalteiles sehr unscharf. Hinterflügel mit schmalem, rein hellbraunem Vorderrande; sonst wie oben. Vorderflügellänge $40-46 \mathrm{~mm}$.

Ecuador (Archidona, Aguamo, Sarayacu, Tal des Rio napo), Pern (Tal des Rio toro und Chanchamayo).

15d. H. aristiona phalaris Weym. $1893 H$. bicoloratus var. p., Weymer in: D. ent. Z. Lep., v. 6 p. 334 t. 5 f. 7 | 1901 H. aristiona p., Riffarth in: Berlin. ent. Z., v. 46 p. 57.

Ton der vorigen Form dadurch unterschieden, daß der schwarze proximale Teil des Vorderflügels nicht so ausgebreitet und der Keilfleck von Vordermo Hinterrand distal besser getrennt ist. Der schwar'ze Apicalteil ist mit nngewiß begrenzten braungelben Flecken durchsetzt, welche sich rorn, distal und hinten zu Reihen gruppieren, so daß von der schwarzen Bestäubung nur ein zusammenhängendes, unregelmäBig geformtes. schräg vom Vorder- zum Distalrande ziehendes Querband als Proximalgrenze verbleibt. Endzellfleck und 
Medianflecke deutlich, Randfleck wie bei der vorigen Form, vorn durch die braune Grundfarbe von der schwarzen Apicalzeichnung getrennt. Hinterflügel wie bei der vorigen Unterart. Vorderflügellänge $40 \mathrm{~mm}$.

Amazonas (Ianicoré [Rio Madeira]).

15 e. H. aristiona messene C. \& R. Felder $1862 H . m$., C. \& R. Felder in: Wien. ent. Honschr.. v. 6 p.418 | 1871 H. m., W. W. Kirby, Cat. diurn. Lep., p. $139 \mid 1890$ H. m., Weymer (\& Mrassen), Lep. Reise Stiibel, p. 21 ! $1893 H . m$., Weymer in: D. ent. Z. Lep., v. 6 p.334 | 1901 H. aristiona $m$. (H. sitinos Plötz in MS.), Riffarth in: Berlin. ent. Z., v. 46 p. 60.

Antennen in beideu Geschlechtern distal auf kurzem Verlauf gänzlich, sodanı nur dorsal schmal schwarzbraun, im übrigen ockergelb. Unterscheidet sich ron H. a. bicoloratus sonst nur dadurch, daß distal von der 7elle, der proximalen Begrenzung des schwarzen Apicalteiles folgend, scliwefelgelbe Bestäubung in Gestalt einer schrïg liegenden Querbinde mit ungewisser Begrenzung nach hinten. etwa bis zur Mitte des hinteren Mediauzwischenraumes, auftritt und der Randfleck nur als ungewisse schwarzbrauue Bestäulung rorlanden ist. Der Keilfleck ist nach hinten läugs der Mediana in der Regel deutlicher von der schwarzen Bestäubuug um die Submediana getrennt. Interseite des Hinterflügels. namentlich beim o, mit gelblichen, wisehartigen Raudfleckchen. Vorderflügellänge etwa $42-45 \mathrm{~mm}$.

('olombia (Llanos de San Martin, Kordilleren bei Bogotá in Höhe ron 1500 m).

15f. H. aristiona euphrasius Weym. 1890 H.e., Weymer (\& Iaassen), Lep. Reise Stïbel, p. 21, 116 t. 2 f. 2 1893 H. e., Weymer in: D. ent. Z. Lep., $v .6$ I. $335 \mid 1901$ $H$. aristiona e., Riffarth in: Berlin. ent. Z., $v .46$ p. 59.

Antemnen proximal auf etwa ein Fünftel der Länge schwarzbraun, sodamn ockergeth, heim ${ }^{\top}$ die Keule etwas bräunlich, sonst ungefäh wie die vorhergehende Form, aber die gelbe Querbinde des Vorderflügels schärfer, hinten von der mittleren Mediana glatt abgeschnitten, seltener in ungewisser Bestäubung stellenweise bis in den hinteren Medianzwischenraum ausgedehnt, distal stufenartig abfallend, kurz ror dem Distalrande endigeud. Keilfleck kleiner, namentlich der ron dem eigentlichen Fleck läufiger schmal getrennte Spitzenausläufer nach der Flïgelwurzel schmaler. Endzellfleck entweder isoliert oder, namentlich beim $\$$. mit dem schwarzen Torderrande zusammengeflossen. Von den meist deutlichen und isoliert liegenden Medianflecken ist der vordere zuweilen rerkümmert. Randfleck dentlicher, fast wie bei H. a. bicoloratus, Submedianstreif schmaler als bei der vorigen Form, jedenfalls den Hinterrand und einen Streif hinter der Mediana freilassend, heim o stärker und kürzer als beim 0 . Hinterflügel weniger schwarz. Diese Färbung beschränkt sich auf den proximalen Teil etwa bis zu zwei Dritteln der ganzen Fläche, nur einen Streif hinter der Subcostalis, den Apicalteil und etria die vordere Hälfte des Distalrandes freilassend. Die vordere Begrenzung dieser, mauchmal eiförmig gestalteten, schwarzeu Fläche ist z.urreilen gez:ihnt und liegt hinter der Zelle (beim ơ), zuweilen glatt und schwach gerundet und reicht in den distalen Teil der Zelle hinein (beim q), in etlichen Fällen tritt in der Mitte, der Länge nach, brïunliche Bestäubung auf, wodurch die Lage der charakteristischen Mittel- und Randbinde angedeutet wird. Frstere ist nanchmal auch in Gestalt länglicher, intensiver gefärbter Flecke iunerlall des geschwärzten Flügelteiles ohne die trennende bräunliche Bestiubung bemerkbar. Am Distalrande und im Apex an den Aderenden kleiue schwärzliche Saumflecke in Gestalt von Dreieckeu. Unterseite des 
Hinterflïgels beim ơ mit schmal braunemVorderrande, vollständigem schwarzem Costal- und in der Mitte gelb unterbrochenem Subcostalstreif, beim $o$ nur mit letzterem, die Cnterbrechung mehr oder weniger auffällig, die länglichen Flecke der Mittelbinde dentlicher, die geschwärzte Fläche weniger intensiv und kleiner. Fransen des Hinterflügels weiß. Dieselben sind an den Adern ron schwärzlichen Randfleckchen unterbrochen, und gegen den Hinterwinkel dehnt sich die weiße Färbung auf der Unterseite beim o in Gestalt länglicher Wischflecke im Flügelsaum aus. Vorderflügellänge $40-45 \mathrm{~mm}$.

Colombia (Llanos 'de San Martin in Höhen von 500-1500 m), Ecuador (Ar'chidona, Coca).

$15 \mathrm{~g}$. H. aristiona euphone C. \& R. Felder 1862 H. e., (Kollar in IIS.) C. \& R. Felder in: Wien. ent. Monschr., v. 6 p. 418 | 1871 H. e., W. F. Kirby, Cat. diurn. Lep., p. 139 | 1893 H. e., Weymer in: D. ent. Z. Lep., v. 6 p. 335 | 1900 H. e., Riffarth in: Berlin. ent. Z., v. 45 p. $214 \mid 1901 H$. aristiona e. (H. tleson Plötz in MIS.), Riffarth in: Berlin. ent. Z., v. 46 p. 58.

Antennen in beiden Geschlechtern distal auf etwa ein Sechstel bis ein Fünftel der Länge schwarzbraun, sonst ockergelb. Körperzeichnung wie die der typischen Unterart. Flügelzeichnung nächst derjenigen der vorigen Form, Fleckenbildung aber bedeutend reduziert. - Keilfleck im Vorderfliigel rundlich, mit schmalem, getrenntem oder unmittelbar anschließendem Ausläufer nach der Flügelwurzel. Endzellfleck isoliert, mäßig entwickelt, unbestimmt gestaltet. Medianflecke ebenfalls isoliert, der vordere in der Regel sehr klein, beim ơ beide Flecke manchmal verloschen und nur schattenhaft angedeutet. Gelbe Querbinde in der hinteren und proximalen Begrenzung weniger scharf, namentlich beim o, distal durch Ausfließen des. schwarzen Apicalteiles an den Adern etwas gekerbt, am mittleren Medianast stufenartig abgesetzt, gegen den Distalrand verschmälert und dort von dem mehr oder weniger intensiven, weit in den hinteren Medianzwischenraum vorspringenden Randfleck nach hinten begrenzt. - Hinterflügel vorherrschend. gelbbraun mit einer aus langen, fast strahlenförmig angeordneten, in den Aderzwischenräumen liegenden schwarzen Flecken gebildeten Mittelbinde. Die Flecke hängen vorn meist leicht zusammen, berühren die hintere Zellecke und endigen distal hinter der vorderen Radialis. Im Apex meist noch ein verloschener schwärzlicher Fleck. Ferner mit schwarzer, schmal vom Hinterwinkel ausgehender und ziemlich breit etwa bei dem hinteren Medianast endigender Randbinde, in welcher zwischen den Aderenden braungelbe, unten gelbe oder weißliche, wischartige Randflecke stehen und die vorn ungewiß begrenzt, hänfig sogar stark gezähnt erscheint. Die Binde setzt sich bis zum Apex in kleinen, an den Aderenden stehenden, dreieckigen Saumflecken fort. Unterseite entspricht im allgemeinen der Oberseite. Die Flecke der Mittelbinde des Hinterflügels sind stäriker isoliert, Costal- und Subcostalstreif des Hinterflügels in der Art wie bei der vorigen Form. Vorderflügellänge durchschnittlich $43 \mathrm{~mm}$.

Colombia, Peru (Tal des Chanchamayo und Huallaga), Ecuador (Sarayacu, Coca).

15. H. H. aristiona tarapotensis Riff. $1901 \mathrm{H}$. a. t., (O. Staudinger in MIS.) Riffarth in: Berlin, ent. Z., v. 46 p. 59.

Ähnlich H. a. euphone, aber die gesamate schwarze Zeichnung (Fig. 14) schwächer entwickelt. Keilfleck fast stets von dem Wurzelausläufer getrennt, vorderer Mediaufleck beim $\sigma^{\tau}$ zurveilen nur in bräunlicher, schwarz gekernter Schattierung angedeutet, die an der distalen Begrenzung von dem an den 
Adem ausfließenden Schwarz des Apex scharf gezähnte gelbe Querbinde hinten, im mittleren Medianzwischenraum, durch eindringende braune Grundfarbe zuweilen, namentlich beim $\circ$, getrübt, Randfleck in der Regel nur beim o deutlich vorhanden. Die Flecke der Mittelbinde des Hinterflügels scbunaler, weiter getrennt und wenig zusammenhängend, meist nur 3 oder 4 in distaler Richtung etwas länger werdende rhombische Gebilde, zurreilen

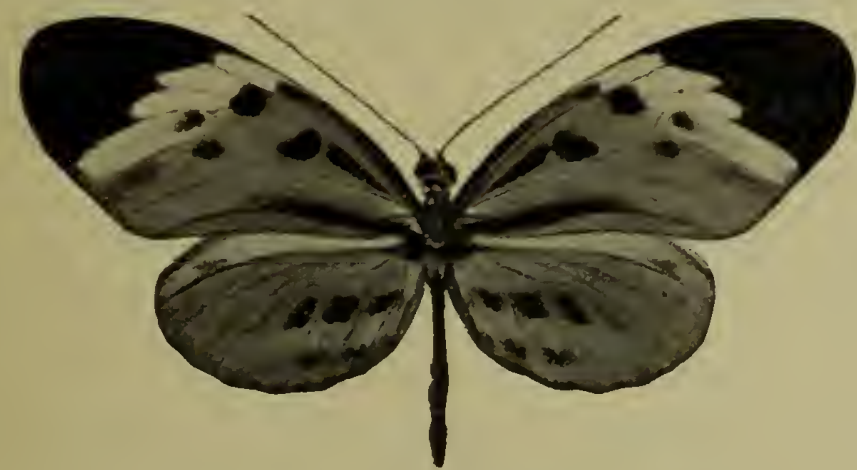

Fig. 14. H. aristiona tarapotensis, $ठ(1,1)$.

ron bedeutend kleineren Fleckchen fortgesetzt und heim o mit dem Subcostalstreif bogenförmig nach roru verbunden. Randbinde des Hinterflügels rom Hinterwinkel ausgebend, nur im proximalen Drittel des Distalrandes rorbanden, oft in Flecke aufgelöst und beim $\delta^{7}$ auch manchmal ganz fehlend, alsdann der Saum schmal" schwarz. Vorderflügellänge $45-46 \mathrm{~mm}$.

Peru (Tarapoto).

15i. H. aristiona lenaeus Weym. 1890 H.l., Weymer in: Ent. Zeit. Stettin., x. 51 p. $284 \mid 1893$ H.l., Weymer in: D. ent. Z. Lep., v.6 p.338 t. 5 f. $10 \mid 1901$ H. aristional. ( $H$. colepta Plötz in MIS.), Riffarth in: Berlin. ent. Z., v. 46 p. 58.

Unterscbeidet sich von der rorigen Form insbesondere durch fast zeichnungslose Hinterflügel. Die Mittelbinde ist bis auf etliche, bogenförmig etwa in der Mitte zwischen Zelle und Distalrand rerlaufende. rerloschene, distal etwas schärfere Fleckchen reduziert, rou der Randbinde ist nur eine Reihe spitzwinkliger, zwischen und an den Adern liegender. randständiger Dreiecke rorhanden, die sich gegen den Apex zu abflachen und in dem schmal schwarzen Saum aufgehen. Die gelbe Querbinde des Torderflügels in allgemeinen schärfer, distal weniger eingeschnitten, in der Mitte nur unwesentlich verbreitert und wie bei der vorigen Form kurz vor dem Distalrande endigend, binten vou dem hinteren Medianast abgeschnitten und ron dem in beiden Geschlechtern deutlich vorhandenen Randfleck begrenzt. Vorderflügellänge $45-46 \mathrm{~mm}$. (Cauca).

Ecuador (Loja, Archidona in Höhen ron $650 \mathrm{~m}$ ), Peru (Huarabamba), Colombia

$15 \mathrm{j} . \mathrm{H}$. aristiona idalion Weym. $1865 \mathrm{H}$. euphone var. $B$, C. \& R. Felder in: Reise Novara, v. 2 I p. $375 \mid 1893$ H. illalion, Weymer in: D. ent. Z. Lep., v. 6 p. 337 | 1900 H. $i .$, Riffarth in: Berlin. ent.Z., v.45 p.214|1901 H. aristiona i. (H. aganippe Plötz in MS.). Riffarth in: Berlin. ent. Z., v. $4 t^{\circ}$ p. 60.

Im allgemeinen wie H. a. euphone, aber im schwarzen Apicalteil 4 deutliche gelbe Flecke, von denen die äuBeren der Reihe klein 
oder undentlich, die imneren ziemlich grob, die 3 vorderen zuweilen zusammengeflossen sind. Zwischen diesen und dem Distalrande zuweilen, namentlich unterseits, Spuren weißlicher Saumfleckchen. Keilfleck und Submedianstreif meist stärker entwickelt, Randfleck nnr klein, dreieckig, und die Flecke der Mittelbinde des Hinterflügels zuweilen durch dunkelbraune Schattierung mit der Saumbinde verflossen. o mit stärker entwickelter schwarzer Zeichnung. Es kommen Übergänge zu H. a. euphone mit sehr r'eduzierten subapicalen Flecken des Vorderflügels vor: Vorderflïg'elläng*e $43-44 \mathrm{~mm}$.

\section{Colombia.}

$15 \mathrm{k}$. H. aristiona aurora Bates $1862 \mathrm{H}$. aurora, H. W. Bates in: Tr. Linn. Soc. London, v.23 p. 555 | 1871 H. a., W. F. Kirby. Cat. diurn. Lep., p. $138 \mid 1885$ H. a., O. Staudinger (\& Schatz), Exot. Schmett., v. 1 p. 75 t. $31 \mid 1893$ H. elegans + H. a. + H. floridus + H. seraphion, Weymer in: D. ent. Z. Liep., v. 6 p. 326 t. 5 f. 3 (forma e.); p. 328 ; p. 329 t. 5 f. 4 (forma florida); p. 330 t. 5 f. 5 (forma s.) | 1901 H. aristiona aurora + H. aristiona e. $+H . a . f .+H . a . s$, Riffarth in: Berlin. ent. Z., v. 46 p. 54 ; p. 55 (forma e.); p. 55 (forma florida); p. 56 (forma s.).

Forma principalis. Antennen in beiden Geschlechtern proximal auf etwa ein Fïnftel der Länge schwarzbraun, sodann ockergelb. Palpen bis anf die schwarze Spitze weiß oder weißgelb, Stirnpunkte weiß, die übrige Zeichnung und von der Grundfarbe abweichende Behaarung des Kopfes nnd Körpers gelb. Grundfarbe der Flügel wie die der typischen Unterart, ohne. gelbe Querbinde distal von der Zelle. - Fleckenbildung des Terderflïgels. im Prinzip wie bei den vorigen Formen, in der Regel aber voller, nur in Ansnahmefällen teilweise, namentlich die Medianflecke rudimentär. Endzellfleck gewöhnlich mit dem schwarzen Vorderrande verflossen, vorderer Medianfleck meist sehr groß, rhombisch, proximal die Zelle bertürend, die ganze Breite $\mathrm{zwischen}$ hinterem und mittlerem Medianast ausfüllend und distal hänfig an der vorderen Ecke mit dem schwarzen Apicalteil zusammengeflossen. In letzterem eine breite, aus zusammengeflossenen Flecken gebildete gelbe Schrägbinde, die an den Rändern hänfig bräunlich ïberstänbt ist. Randfleck schmal von dem schwarzen Apicalteil getrennt, grob, strumpf kegeloder zapfenförmig. Distalrand schmal schwar'z, Submedianstreif voll und breit, beim $\sigma^{\pi}$ meist bis zum Hinterwinkel ansgedehnt. Die schwarze Discalzeichnung beim $o$ ausgedehnter, meist leicht zusammengeflossen, die gelbe Subapicalbinde dagegen schmaler nnd die einzelnen Flecke deutlicher getrennt. - Hinterflügel schwarz, abgesehen vom Vorderrandteil, einem braunen Streif hinter der Subcostalis, Apex nud einem dort anschließenden Teil des Distalrandes. Diese fast eirınd gestaltete Fläche ist nur selten, namentlich beim $O$, in der Mitte, der Länge nach, dnrch weniger intensive, brannschwarze Schattierung; welche die Grenzfläche von Mittel- nnd Randbinde darstellt, nnterbrochen. Apex beim $\delta^{\prime}$ nur mit verloschenen, beim $o$ mit stärkeren schwärzlichen Flecken, die bei letzterem zusammengeflossen nnd nach vorn bogenförmig mit dem schwärzlichen Subcostalstreif vereinigt sind. Distalsaum, soweit die Grundfarbe reicht, schmal schwarz, an den Aderenden zu kleinen schwärzlichen Dreiecken ansgeflossen. Auf der Unterseite beim $\sigma^{\top}$ zuweilen wischartige weiße Randfleckchen. - Vorderflügellänge 39-45 mm.

Peru (Yurimaguas, Iquitos, Pebas), westliches Amazonas (São Paulo de Olireuça): Ecuador (Sarayacu), Bolivia.

Forma elegans. Unterscheidet sich von der Hauptform folgendermaßen: das Schwarz des Apicalteiles des Vorderflügels stark von der braunen 
Grundfarbe durchsetrt, meist nur schwärzliche Bestäubung an der proximalen Grenze, den Adern, in Apex und vorderen T'eil des Distalıandes. Gelbe Subapicalflecke nur schwach bindenartig verflossen, manchmal, namentlich beim $q$, die hinteren gänzlich oder teilweise braun überstänbt. Nächst dem Apex mehr oder minder dentliche Saumfleckchen. Randfleck mit dem hinteren Medianfleck zusammengeflossen. Hinterflügel mit meist deutlich getrennter Mittel- und Randbinde, erstere hinten gekerbt, beim $\delta$ zwischen den Radiales endigend, beim ㅇ nächst dem Apex bedeutend verschmälert, bogenförmig nach vol'u mit dem schwärzlichen Subcostalstreif vereinigt, unten an der hinteren Grenze an den Adern tief gekerbt, fast fleckenartig aufgelöst. Randbinde breit, voln ebenfalls stark gekerbt, unvollkommen, etwa am vorderen Medianast endigend, von da nur als schmaler, an den Adern dreieckig ausgeflossener schwärzlicher Saum fortgesetzt. Mittel- und Randbinde häufig durch schwärzliche Überstäubung des zwischenliegenden Streifes der braunen Grundfarbe an den Adern mehr oder minder zusammengeflossen. Es gibt Übergänge zur vorigen und nächsten Form.

Bolivia (Chanusi), Peru (Iquitos), Pará (Itaituba, Tal des Rio Tabajoz).

Forma florida. Vorderflügel wie bei der Hauptform, aber die gelben Subapicalflecke kleiner und einzeln mindestens durch schwarze Bestäubung an den Adern deutlicher isoliert, Apicalteil proximal mehr oder weniger stark von der braunen Grundfarbe durchsetzt, distal der Zelle im vorderen Teil des Discus der Anfang einer gelben Querbinde, die jedoch nur bis zum mittleren Medianast deutlich auftritt, also vor dem vorderen Medianfleck endet. Übergangsstücke znr Hauptform entbehren der gelben Bestäubung ganz. Nächst dem Apex eine Reihe gelber Randfleckchen im Schwarzen. Hinterflügel wie bei forma elegans, nur die Randbinde durchschnittlich etwas schmaler und näher dem Apex endigend; in derselben treten zuweilen kleine gelbliche oder bräunliche Randflecke auf.

Scheint hauptsächlich der $\&$ Form eigentürmlich und sehr unbeständig zu sein.

Bolivia (Tal des Rio Juntas), Ecuador (Sarayacu), Peru (Iquitos), Pará (Itaituba, Tal des Rio Tabajoz).

Forma seraphion. $q$. Grundfarbe dunkler braun, Apicalteil ganz. schwarz, Endzellfleck, Medianflecke und Randfleck zu einer schwarzen unregelmäBigen schräg liegenden discalen Querbinde zusammengeflossen, welche distal einen proximal an den Adern von dem Schwarz des Apex eingeschuittenen bindenartigen Streif der Grundfarbe absondert. Hinterfln̈gel wie bei forma elegans, die Mittelbinde etwas schmaler, distal nach hinten stark strahlig gezähnt. Distalrand in Fortsetzung der etwa am vorderen Medianast endigenden Randbinde etwas breiter schwarz.

Forma tempestatis?

Peru (Iquitos).

1ว̆l. H. aristiona arcuella Druce $1874 H$. arcuella, Herb. Druce in: Tr. ent. Soc. London, p. 156 | 1877 H. a., W. F. Kirby, Cat. diurn. Lep., Suppl. p. 721 | 1893 H. a., Weymer in: D. ent. Z. Lep., v.6 p. $332 \mid 1901 H$. aristiona arcuella, Riffarth in: Berlin. ent. Z., v. 46 p. 55 .

Wie H. a. aurora, aber obne gelbe subapicale Fleckenbinde des Vorderflügels. An deren Stelle braune Färbung im Tone der Grundfarbe. Diese kann so ausgedehnt sein, daB das Schwarz des Apicalteiles nur unmittelbar am Saum des Flïgels nnd in der proximalen Begrenzung als schwärzliche unregelmäßige subapicale Schrägbinde übrig bleibt; der discale und distale Flügelteil bildet also fast eine einfarbig hellbraune Fläche, in 
der nur die sehr scharf gezeichneten, mäßig großen discalen Flecke und die ungewisse schwärzliche Subapicalbinde liegen. Erstere sind beim $q$ meist von ungewisser schwärzlicher Bestäubung umgeben. Der Randfleck ist in der Regel etwas vom Distalrande abgerückt, letzterer nur schmal schwar\% oder ungesäumt (beim $q$ ). Vorderrand bis zur Hälfte ziemlich breit schwarz. Submedianstreif breit, etwa in der Mitte der Submediana schräg abgeschnitten und als schmal schwarz gezeichnete Ader mehr oder weniger deutlich bis zum Hinterwinkel fortgesetzt. - Hinterflügel wie bei forma elegans, Distalsaumbinde vorn öfters glatter begrenzt, zuweilen vom Rande etwas abgerückt, so daß dieser selbst schmal braun bleibt, namentlich beim $\sigma^{\top}$, jedenfalls aber durch braune, etwas unregelmäßig halbmondförmige Saumfleckchen zwischen den Aderenden unterbrochen. Beim o reicht dieselbe fast bis zum Apex und wird dort von den an den Aderenden stehenden schwarzen dreieckigen Saumfleckchen fortgesetzt, beim $0^{\pi}$ endet sie am vorderen Medianast. Mittelbinde beim o distal durch einen kleinen klammerartigen subapicalen Fleck mit dem breiten und tiefschwarzen Subcostalstreif leicht verbunden. Auf der Unterseite löst sich dieselbe in ähnlicher Weise wie oberseits bei H. a. euphone (S. 76) in längliche, vorn leicht zusammenhängende Flecke auf. - Vorderflügellänge $39-43 \mathrm{~mm}$.

Peru (Nauta, Yurimaguas, Iquitos, Tal des Rio Huallaga), Ecuador (Sarayacu).

$15 \mathrm{~m}$. H. aristiona staudingeri Weym. 1893 H. s. + H. s. var. pretiosus, Weymer in: D. ent. Z. Lep., v. 6 p. 324 t. 5 f. 2 ; p. 325 (forma pretiosa) | 1901 H. aristiona $s .+H$. a. p., Riffarth in: Berlin. ent. Z., v. 46 p. $59 ;$ p. 60 (forma pretiosa).

Forma principalis. Abdomen ventral beim $\sigma^{\pi}$ nur an den vorderen Segmenten und am Analteil gelb, beim 을 gänlich schwarz, sonst im allgemeinen wie die vorige Form, aber distal von der Zelle bis zu dem durch leicht schwärzliche Schattierung abgegrenzten Apicalteil mit schwefelgelber, distal stufenweise abgesetzter, schräger Querbinde, welche beim $\sigma^{\pi}$ von den fein schwarzen, beim $Q$ von rotgelb bestäubten Adern durchzogen, hinten von dem mittleren Medianast abgeschnitten ist und distal bis nnmittelbar an den schmal schwarzen Distalsaum reicht. In dem rorwiegend hell braunen Apex schwach gelbliche Flecke wie bei H. a. aurora, forma elegans. Dicht am Rande im Apex und vorderen Teil des Distalrandes stark ausgeprägte, bräunliche, winkelförmig gestaltete Saumfleckchen. Hinterflügel wie bei der vorigen Form. Vorderflügellänge $42-48 \mathrm{~mm}$.

Peru (Oberlauf des Rio Huallaga).

Forma pretiosa. $\sigma^{\star}$. Kleiner als die Hauptform (Vorderflügellänge $41 \mathrm{~mm}$ ), Keilfleck in der Zelle mit abgetrenntem Wurzelausläufer, Endzellfleck mit dem schwarzen Vorderrande zusammenhängend, schwefelgelbe Binde distal von der Zelle schmaler, ihre distale Begrenzung gegen den Apicalteil stärker schwarz bestäubt, letzterer mit 4 'schwefelgelben Flecken, stärker als bei der Hauptform. Anstatt der am Saum stehenden winkelartigen Zeichnungen oben schwefelgelbe, unten weiße Saumpunkte. Saumbinde des Hinterflügels unmittelbar dem Rande aufsitzend, unterbrochen durch eine Reihe bräunlicher Saumpunkte, die unten ron einigen weißen, dem Apex am nächsten lieg'enden Fleckchen fortgesetzt werden.

Peru (Sarayacu).

16. H. ithaka C. \& R. Felder

ठ. Die unteren Stirnpunkte weiß, die oberen meist gelblich, alle übrigen Punkte und Zeichnungen, sowie die von der Grundfarbe abweichende Behaarung 
(les Körpers gelb. Antennen proximal anf etwa ein Drittel gänzlich, von la ab nur dorsal fein scluwabrann, soust ockergelb. Gestalt der lingel wie bei den rorigen Arten. Grundfurbe der Flügel rötlich hellhraun. Vorderrand des Vorderfligels breit schwarz bis zur Hälfte, dann schmaler. Keilfleck meist groß und kräftig mit breitem, unmittelbar anschließendem Ausläufer nach der Flïgelwurel, welcher fast die proximale '/ellfläche ausfïllt und nicht selten mit dem schwarzen Vorderrande zusammengeflossen ist. Endzellfleck unregelmäBig, vorn meist breiter als hinten, isoliert, ModianHecke meist klein, eirund, dentlich getrennt. Distal von cler $\mathrm{kelle}$ eine schrvefelgelbe, schräg liegende Querbinde, deren hintere Grenze muscharf etwa in der Mitte des hinteren Medianzwischemraumes liegt, deren distale Begrenzung durch den breit schwarzen Apicalteil an den Adern unwesentlich gezähut ist. Distal endet dieselbe kurz vor den Distalrande. In Apex meist nur gelbliche. nitunter wischartig verlängerte Saumfleckchen. Snbapicalflecke fehlen oder sind wenigstens sehr nahe an deu Rand gerückt. Randfleck fehlt oder ist nur dnrch schwärzliche Schattiernng angedeutet. Distalrand hinter dem schwarzen Apicalteil schmal schwarz, im Hinterwinkel häufig stärkere schwärzliche C̈berstäubung mit Spuren eines gelben Fleckchens. Submedianstreif liräftig, meist mı längs der proximalen Hälfte der Submediana vorhanden, zuweilen sehr breit und in ganzer Länge den Hinterrand erreichend. Fransen schwärzlich, am Apex weiß gescheckt. Unterseite matter, gelbe Bestäubung der Querbinde in der Zelle bis zum Keilfleck verbreitert, Begrenzung gegen die braune Grundfarbe sehr unscharf. Subınedianstreif auch hier dentlich in der Mitte des Aderzwischenrammes hinter der Mediana, länger als oben, spitz auslaufend. Sanmfleckchen im Apex und längs des Distalrandes weiß oder gelh. - Hinterflügel schwarz his auf einen gelbbraunen Wiscl nächst der Flügelwurzel, mit einigen gelben subapicalen Fleckchen und zumeilen mit einer Reihe, dem Distalrande numittelbar aufsitzender gelblicher Flecke, oder braun mit schwarzem Sanm und vollständiger oder in Flecke aufgelöster Mittelbinde von verschiedener Form hinter der Zelle. Vorderrand dunkler grau als bei den vorhergehenden Arten, mit dunkelbrauner, ziemlich breiter Einfassung. Unterseite im allgemeinen wie die Oberseite, Vorderrand schmal gelbbraun. bei Formen mit vorwiegend schwarzen Hinterflügel deutliche weiße Randfleckehen, die sich im Apex etwas vom Rande entfermen, bei Formen mit vorwiegend braunem Hinterflügel mit einem dem Torderrande folgenden schwarzen Costalstreif nud einem damit teilweise zusammengeflossenen, bis zur Subcostalis reichenden Subcostulstreif; ersterer endet im Ipex am Rande, letzterer unweit desselben; hier deutliche Randfleckehen bis zum Apex und nächst demselben zwei subapicale weißliche Flecke. Fransen schwärzlich. weiß gescheckt. — - o. Antennen reichlicher ockergelh, im distalen Teil meist ohue schwärzliche Dorsalfürbung. Sonst im allgemeinen wie das $\sigma^{\pi}$ mit den charakteristischen Geschlechtsunterschieden: stumpfer brä̈nlichen Flügelteil hinter der Mediana der Vorderflïgelunterseite und brännlichem Vorderrandfeld der Hinterflïgeloherseite. Costalstreif fehlt anf der Unterseite des Hinterflügels. Subcostilstreif, wo er isoliert vorlanden, kürzer. Randflecke des Hinterflügels meist gelb.

Colombia.

Diese Art zerfällt in 3 Unterarten:

16a. H. ithaka ithaka C. \& R. Felder 1862 H. i., C. \& R. Felder in: Wien.

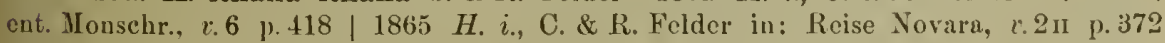
t. 47 f. 5 | 1871 H. i., W. F. Kirby, Cat. diurn. Lep., p. 138 | 1893 II. i., Weymer in: D. ent. Z. Lep., v. 6 p. 335 | 1901 H. i., Riffarth in: Berlin. ent. Z., v. 46 p. 61.

Das Tierreich. 22. Lief.: 11. Stichel \& H. Riffarth, Heliconiidae. 
Schwarzer Keilfleck kräftig, mit starker und breiter Verlängerung wurzelwärts, größtenteils mit dem schwarzen Vorderrande zusammengeflossen. Endzellfleck vorn sehr breit, an der Subcostalis schmal schwarz mit dem schwarzen Apicalteil verbunden. Medianflecke klein, aber bestimmt, der vordere von der gelben, außerhalb der Zelle gelegenen Binde eingeschlossen. Diese distal am mittleren Medianast dicht am Distalrande rundlich endigend. In der Zelle nächst dem Vorderrande häufig gelbe Bestäubung zwischen Keilund Endzellfleck. Apex oben beim ơ ohne, beim $O$ in der Regel mit Saum. fleckchen. Randfleck fehlt, Submedianstreif beim $\sigma^{\pi}$ stark verbreitert, hinten bis zum Hinterrande ausgedehnt, beim o schmaler, etwa auf der Mitte der Submediana stumpf abgerundet endigend, mitunter längs der Ader noch etwas ausgeflossen. - Hinterflügel schwarz bis auf das ganze, graue Vorderrandfeld des $\sigma^{T}$ und den distalen Teil desselben beim $\circ$, der bräunlich bleibt. Nächst der Flïgelwurzel ein bräunlicher Wisch am Hinterrande, im Apex 3 oder 4 gelbe Fleckchen. - $q$ im allgemeinen matter gezeichnet, mit weniger intensiv schwarzem, fast schwarzbraunem Hinterflügel und gelblichen Saumfleckchen, die, wie beim Typus, auch als $4-5 \mathrm{~mm}$ lange Wischfleckchen oder Streife auftreten können. - Vorderflügellänge $41-46 \mathrm{~mm}$.

Colombia (Kordilleren von Bogotá).

16b. H. ithaka vittatus Butl. 1873 H. v., A. G. Butler in: Cistula ent., v. 1 p. $166 \mid 1877$ H. v., W. F. Kirby, Cat. diurn. Lep., Suppl. p. 723 | 1893 H. v., Weymer in: D. ent. Z. Lep., v. 6 p. $338 \mid 1901$ H. ithaka v., Riffarth in: Berlin. ent. Z., v. 46 p. 62.

Vorderflügel im allgemeinen wie bei der typischen Unterart, Keilfleck in der Regel weniger breit in dem Ausläufer, im Apex 2 oder 3 wischartige gelbe Fleckchen. Submedianstreif schmaler, wie beim $ᄋ$ der typischen Unterart. - Hinterflügel braun mit $2-3 \mathrm{~mm}$ breiter, beim $\delta$ vorn ziemlich glatt begrenzter schwarzer Randbinde, in der häufig gelbliche, dem Distalrande aufsitzende Fleckchen stehen, und mit schwarzer Mittelbinde, welche meist aus mehr oder weniger länglichen, in den Aderzwischenräumen stehenden und v0rn zusammenhängenden Flecken zusammengesetzt ist. Beim $\sigma^{\star}$ ist dieselbe voller und geschlossener, nach hinten nur wenig gekerbt, ihre vordere Grenze stets ziemlich glatt, hinter der Zelle liegend oder dieselbe berührend, im Apex beim o zwischen vorderer Radialis und Subcostalis einen schmalen Bogen nach vorn bildend und beim ơ durch die schmal schwarze vordere Radialis mit dem schwärzlichen Apex verbunden. - Vorderflügellänge etwa 42-44 mm. Colombia.

16c. H. ithaka marius Weym. 1890 H. m., Weymer (\& Maassen), Lep. Reise Stübel, p. 21, 116 t. 2 f. $1 \mid 1893$ H. m., Weymer in: D. ent. Z. Lep., v. 6 p. $338 \mid 1901$ H. ithaka m., Riffarth in: Berlin. ent. Z., v. 46 p. 62.

Wie die vorige Unterart gezeichnet, aber alle schwarzen Zeichnungen schmaler, Keilfleck weiter vom Vorderrande getrennt, Distalrandbinde des Hinterflügels sehr schmal, Mittelbinde in einzelne, dreieckige Flecke aufgelöst, in einzelnem Falle in der Mitte zwischen Zelle und dem breiter schwarzen Distalrande in gerader Richtung verlaufend, distal zusammenhängend, proximal in sebr kleine Flecke aufgelöst. Vorderflügellänge $41 \mathrm{~mm}$.

Colombia (Ilanos de San Martin in Höhen von 500-1500 m, Muzo).

\section{H. pardalinus Bates}

ठึ. Stirnpunkte weiß oder gelb, Punkte auf Hinterkopf, Halskragen und Thorax, sowie die übrige Zeichnung und von der Grundfarbe des Körpers abweichende Behaarung gelb. Antennen proximal auf etwa ein Viertel der Länge und dorsal in der Regel ganz schmal bis zur Spitze schwarzbraun, 
sonst ockergelb. Grundfarbe der Flügel gesättigt rotbraun bis gelbbrann. im proximalen Teil häufig etwas dunkler. - Vorderrand des Vorderflügels bis zur Mitte ziemlich breit schwarz, Keilfleck länglich mit kräftigem, unıittelbar anschließendem Spitzenausläufer nach der Flügelwurzel. Endzellfleck groß, unregelmäBig, fast rechteckig, zuweilen mit dem schwarzen Torderrande zusammengeflossen. Medianflecke verschieden, zuweilen deutlich getrennt. fast eirund, zuweilen stärker entwickelt und leicht zusammenhängend. Distal ron der Zelle mit oder ohne gelbe Querbinde. die hinten meist vom mittleren Medianast abgeschnitten ist, zuweilen aber auch in unbestimmter Begrenzung in den hinteren Medianzwischenraum und distalen Teil der Zelle hineinreicht. Apex schwarz gesäumt, an den Adern und gegen die Querbinde schwarz schattiert oder ganz schwarz, gelbe Subapicalflecke rorlıanden oder fellend. Distalrand, soweit die braune Grundfarbe reicht, schmal schwarz. Randfleck stımpf kegelförmig, durch einen halbmondförmigen oder fast dreieckigen Fleck der Grundfarbe, der znweilen gelblich ïberstïnbt ist, von dem Distalrande getrennt. Submedianstreif verschieden breit, meist einen schmalen Streif am schmal schwarzen Hinterrande freilassend, rorn in der Mitte ziemlich scharf stumpf gewinkelt. Hinter dem Randfleck zuweilen noch eine winkelförmige Zeichnnng im Hinterwinkel, die ersteren mit dem Submedianstreif verbindet und einen braunen Fleck einschließt. Die schwarzen Discalflecke hängen zuweilen unter sich. im. weiteren auch mit dem schwarzen Apicalteil und dem Randfleck zusammen. - Vorderer Teil des Hinterflïgels seidengrau mit dunklerer Einfassung, am Vorderrande einen ganz schmalen Streif ron hellerem Glanze freilassend, mit Mittel- und Randbinde. Erstere verschieden breit, vorn ziemlich glatt begrenzt, hinten mehr oder weniger tief gezähnt, im Apex schmaler, nach vorn gebogen und mit der dunkleren Einfassung des Vorderrandteiles vereinigt. Die Randbinde wird aus meist groBen, spitzwinkligen, am Rande zusammenhängenden Dreiecken gebildet. Diese Dreiecke sind in der Mitte am gröBten, nehmen nach dem Apex zu wesentlich ab, und ihre nach vorn gerichteten Spitzen sind an den Adern zutweilen mit der Mittelbinde zusammengeflossen. - Unterseite des Vorderflïgels matter gezeichnet, meist mehr gelbe Bestäubung vorhanden. Hinterfliigel an der Wrurzel meist gelb, zuweilen auch ein Teil des sonst schmal braunen Vorderrandes gelb bestäubt. Costalstreif schwärzlich, vollkommen, Subcostalstreif meist gelb unterbrochen, Mittelbinde weniger zusammenhängend, manchmal sogar ganz in Flecke aufgelöst. im Apex meist zwei gelbe wischartige oder weißliche Flecke, am Distalrande in seltneren Fällen weiße. wischartige Saumflecke, ebenso hinter dem Subcostalstreif gelbe, bindenartig angelegte Bestäubung. - Fransen des Vorderflïgels schwärzlich, nur stellenweise gran oder weißlich unterbrochen, die des Hinterflügels schwarz und weißlich gefleckt. - - o. Antennen ockergelb bis anf ein Viertel des proximalen T'eiles. Im allgemeinen dunkler wie das $0^{\lambda}$. die schwarzen Discalflecke des Vorderflïgels meist größer, häufig verflossen, Apicalteil weniger intensiv schwarz mit mehr Neigung zum Durchbruch der Grundfarbe, wenn diese nicht so wie so vorherrscht. Vorderer Teil des Hinterflügels schwärzlich, mit der Mittelbinde nächst dem Apex sehr deutlich bogenförmig verbunden, in letzterem braune Flecke. Mittelbinde selbst meist breiter, ihr vorderer Rand dureh den hinteren Teil der Zelle lanfend. Unterseite an der Wurzel des Hinterflügels ohne oder mit nur selı geringer gelber Bestäubung, Vorderrand bis zur Costalis hellbraun, Subcostalstreif breit, nur wenig unterbrochen.

Nördliches Brasilien, Bolivin, Peru; Ecuador?

Diese Art zerfällt in $\mathbf{5}$ Unterarten: 
17 a. H. pardalinus pardalinus Bates $1862 \mathrm{H}$. encoma var, p., H. W. Bates in: Tr. Linn. Soc. London, v.23 p. $555 \mid 1871$ H. e. var. p., W. F. Kirby, Cat. diurn. Lep., p. $138 \mid$ ? 1877 H. p., A. G. Butler in: Tr. ent. Soc. London, p. $123 \mid 1885$ H. p., O. Staudinger (\& Schatz), Exot. Schmett., v. 1 p. $75 \mid 1890$ H. p., Hahnel in: D. ent. Z. Lep., v. 3 p. $264 \mid 1893$ H. p., Weymer in: D. ent. Z. Lep., v. 6 p. 321 | 1901 H. p., Riffarth in: Berlin. ent. Z.. v. 46 p. 62.

Grundfarbe der Flïgel (Fig. 15, Übergangsstiick zur nächsten Unterart, mit schwarzem Apex) gesättigt, nahezu kastanienbraun. - Keilfleck im Torderflügel vollkommen, mit anhängendem Spitzenausläufer, Endzellfleck fast quadratisch, Medianflecke rundlich, isoliert. Distal der Zelle mit schwefelgelber, schräger Querbinde, die von den fein schwarzen, leicht bräunlich schattierten Adern durchschnitten wird. Apex im Ton der Grundfarbe, an der proximalen Grenze, den Adern und dem Saum schwarz

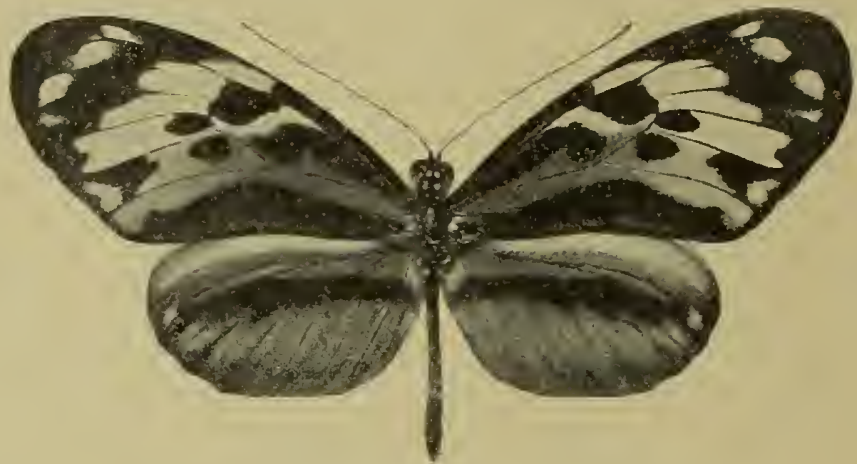

Fig. 15. H. pardalinus pardalinus, $\delta\left({ }^{1} / 1\right)$.

bestäubt, mit einer schrägen Reihe ron 4 gelben Flecken. deren mittlere größer sind als der rordere und hintere. Die gelbe Schrägbinde endet hinten am mittleren Medianast, wird dort teilweise ron dem Randfleck begrenzt und erreicht den Distalrand nicht. Das zwischen dem mittleren und hinteren Medianast vorgestreckte Ende ist distal von dem Schwarz des Distalrandes winklig eingekerbt. - Hinterflïgel mit leicht gekrümmter schwarzer, hinten stark gezähnter Mittelbinde und eimer aus großen, dreieckigen, zusammenhängenden Saumflecken gebildeten Randbinde, die kurz vor dem Apex endet, sich beim o bogenförmig nach rorn wendet und dort mit dem schwärzlichen Subcostalstreif rerbunden ist. Mauchmal laufen die Spitzen der Dreiecke, namentlich in der Nähe des Apex. bis in den Hinterrand der Mittelbinde. in anderen Fällen sind diese Randflecke reniger scharf entwickelt. Auf der Unterseite des Hinterflügels gelblichweiße. wischoder strichartige Fleckchen am Distalrande. - Torderflügellänge 42-46 mm. Ecuador:

Araazonas (São Paulo de Olivença, Fonteboa, Teffé, MIanaos), Peru (Pebas);

17 b. H. pardalinus lucescens Weym. 1893 H. p. var. l., Weymer in: D. ent. Z. Lep., v. 6 p. $321 \mid 1901$ H. p. l., Riffarth in: Berlin. ent. Z., v. 46 p. 63.

Ton der typischen Cnterart insbesondere dadurch unterschieden, daß der Apicalteil des Vorderflügels, in dem die vier gelben Flecke liegen. schwarz ist (Fig. 15) und daß die schwefel- oder weißlichgelbe Schrägbinde die nicht-schwarzen Stellen des hinteren Medianzwischenraumes bis auf den proximalen Winkel ausfüllt und in die Zelle zwischen Keil-und Endzellfleck eindringt. Die proximale und hintere Grenze der Binde ist unscharf, und 
das Gelh verliert sich allnählich in der satthramen Grundfarbe. Diese ist so düster, dab die schwarzen Streife und Flecke sich nur schwach dawon alheben. Sonstige Merkmale mit denen der vorigen Form ïbereinstimmrond. in der Regel matter gezeichnet. Torderflïgellänge $42-44 \mathrm{~mm}$.

Nördliches Brasilien (Santarem, Manicori).

16. H. pardalinus radiosus Butl. 187:3 $I$. I., A. G. Butler in: Cistula ent.,

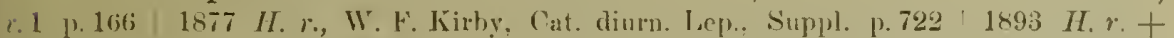

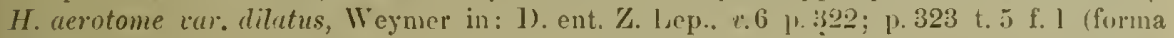

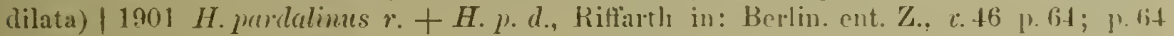
(forna dilata).

Forma principalis. Hinterkopf. Flecke und Behantums anf dem Thorax rotbram statt gelb. Gruudfarhe der Flügel lebler als bei der typischen ['nterart. gelhlichgran. ohne oder nur nit weringen spmen einer gellon s.luräghinde. Am rorderen Teil des Distahandes und im Apex cine Reihe winkelartiger. schwärzlicher Zeichungen, welche eine Reihe branner Simmfleckichen ror dem scinmal seliwarzen Saum absondern. Mittelhinde des Hinterfligels hinten wenig oder gar nicht gezilhut, zuweilen 1 oder 2 rerloschene gelbe Fleckehen im Apex. Dreiecke der Randhinde sehr grob und scharf entwickelt. gegen den Apex nit den Spitzen in die Vittelbinde ausgeflossen. O matter gezeichnet, H. p. lucescens sehr ähnlich. Vorderflügelläıge $40-42 \mathrm{~mm}$.

Wird leicht mit $H$. aristiona aurora, forma florida (S. 76) verwechselt, unterscheidet sich aber bein ơ durch den dunkleren Vorderrandteil und in beiden (ieschlechtern durch die aus langen spitzen Dreiecken gebildete Randbinde des Hinterflügcls.

Pern (Turimaguas [Kio Huallaga], Pebas, Iquitos), westliches Amazonas (Tal des Rio Jarary̆, São Paulo de Olivenȩa), Ecuador (Sarayacu), Bolivia.

Forma dilata. Cuterscheidet sich ron der Hauptform dadmeh, daßs die Grundfarbe, namentlich beim o, heller braun ist. Torderflügel in der liegel ohne in der Farhe abgesetzte. zureilen aber mit mehr lehngelher Schrägbinde. Apex in der Regel am Sam etwas schwärzlicher. Hinterflïgel mit selır schmaler Yittel- und Randhinde. Die letztere bildenden Dreieckcheu sehr kurz oder rerloschen, Mittelbinde binten schwach gezähnt. Vordertlïgellänge $\$ 41111$.

Peru (Yurimaguas, Tal des Rio Ueayali), Ecuador (Sarayacu).

17 d. H. pardalinus maeon Weym. $1890 \mathrm{H}$. m., Weymer in: Ent. Keit. Stettim, c.51 3). 287 | 1893 H. m., Weymer in: D, ent. Z. Lep., r.6 p.323|1901 H. pardalimus m., Kiffarth in: Berlin. ent. Z., $x .46$ 1. 65.

?. Ähulich H. p. radiosus. aher Grundfarbe etwas lichter, das discale Feld des Vorderflïgels dureh die rergröBerten und zusammengeflossenen Flecke eingeschrinkt und zerrissen. Apex des Vorderflügels schwarz, mit drei bramen, statt gelhen, rudimentären Flecken, Submedianstreif schniller, an del Enden spitz nnd im Hinterwinkel in einen hakenförmigen Fleck auslaufend. Mittelbinde des Hinterflïgels in dreieckige Flecke aufgelöst. die uicht zusammenluängen. rorn die hintere Ecke der Zelle heriïhren unul dort in gerader Richtung ahgeschuitten sind. Randhiude sehr sehmal. als stumpfen, nach vorn unscharf begrenzten kurzen Dreiecken hestehend. welche gergen den Apex zusammenflicßeu. Unterseite matter, Vorderflïgel mit deutlicheren Subapicalflecken und Spuren weißlicher Samiflecke im Apex. Randhinde des Hinterflügels noeh rednzierter als oben. ohne Apical- und Sauntfecke. Torderflügellänge $40 \mathrm{~mm}$.

Heimat unbekannt. 
17 e. H. pardalinus tithoreides Staud. 1900 H. $t$., O. Staudinger in: D. ent. Z. Lep., v. 12 p. $404 \mid 1901$ H. pardalinus t., Riffarth in: Berlin. ent. Z., v. 46 p. 65.

Wie H. p. radiosus (S. 85), aber gröBer und breitflügeliger. - Sämtliche schwarzen Zeichnungen des Vorderflügels breiter, unter sich teilweise zusammenhängend, namentlich der hintere Median- mit dem Randfleck; Apex meist ganz schwarz mit scharf abstechenden gelben Flecken und manchmal kleineren Saumfleckchen, selten tritt in dem Schwarz des Apex bräunliche, wischartige Bestäubung auf. Mit gelber Schrägbinde distal von der Zelle (forma prima der Übersicht), oder ohne solche (forma secunda). Die Binde in ersterem Falle nur rudimentär oder vollkommen, aber von den schwarzen Discalflecken stark unterbrochen und zerrissen. Häufig verbreitet sich das Gelb bis in den distalen Teil der Zelle und in den hinteren Medianzwischenraum. Die vor dem Hinterwinkel am schmal schwarzen Distalsaum von dem gekerbten Randfleck und einem winkelartigen schwärzlichen Streif hinter ihm abgesonderten zwei keilförmigen oder dreieckigen Flecke auch gelblich ïberstäubt. Auf der Unterseite die nicht von den schwarzen Zeichnungen eingenommenen Stellen der Flügelfläche vorwiegend gelblich bis auf den hinteren Teil. - Hinterflügel meist mit schmalerer, aber gleichmäßiger gestalteter, aus scharfen Dreiecken gebildeter Randbinde. Mittelbinde weniger intensiv und schmaler, namentlich der hintere Rand lang gezähnt und unscharf begrenzt, im Apex $1-3$ gelbe Fleckchen, die sich manchmal proximal in gelber Bestäubung verlängern. Auf der Unterseite des Hinterflügels fehlen oft die schwarzen randständigen Dreiecke, Distalrand alsdanu nur schmal schwarz mit weißlichen, wischartigen Saumfleckchen. Vorderrand von der Wurzel aus schmal gelb bis über die Mitte. Subcostalstreif scharf gelb unterbrochen, hinter demselben bis zum vor'deren Rande der Mittelbinde gelbe Bestäubung. — Vorderflügellänge $44 \mathrm{~mm}$.

Pern (Gebiet des Rio Urubamba in Höhen von $1000 \mathrm{~m}$, Tal des Ucayali, Hillapani).

18. H. fortunatus Weym.

ठิ. Stirnpunkte weiß, die andere Kopf- und Körperzeichnung gelb. Antennen im proximalen Drittel, auch etwas weiter, schwärzlich, sonst ockergelb mit schmal schwarzer dorsaler Linie. Grundfarbe der Flügel braun mit schwarzen Streifen und Flecken und gelber Schrägbinde. - Vorderflügel ziemlich schlank, aber etwas breiter als bei den verwandten Arten. Vorderrand schwarz, Keilfleck eirund, in langer schmaler Spitze in proximaler Richtung verlängert. die Flügelwurzel aber nicht erreichend. Endzellfleck unregelmäBig, meist an der proximalen Ecke mit dem Vorderrande zusammenhängend. Medianflecke in verschiedener Größe, isoliert. Distal von der Zelle mit einer schwefelgelben, ziemlich breiten Schrägbinde, welche den mittleren Medianzwischenraum fast ganz bis auf die hintere proximale Ecke ausfüllt und distal zwischen dem schmal schwarzen Distalrande und dem mehr oder weniger keilförmig ausgeschnittenen oder hakenförmig nach hinten offenen bis in die Mitte des hinteren Medianzwischenraumes vorgeschobenen Kandfleck nach hinten ausflieBt. Distaler Rand der Binde ziemlich glatt, mit einem durch das Schwarz des Apex gebildeten stumpfen Winkel ungefähr in der Mitte. Apex entweder einfarbig schwarz oder mit 4 auch 5 in einer gebogenen Reihe stehenden, gelben Flecken. Submedianstreif von verschiedener Breite, proximal und distal meist schwächer, in den schwarzen Hinterwinkel auslaufend und dort einen fast dreieckigen Fleck bildend. Hinterrand schmal schwarz. Unterseite matter, mit braunen subapicalen Fleckchen. - Hinterflügel rundlich, Saum gewellt, mit schwarzer Mittel- und Randbinde. Erstere vorn gerade begrenzt, berührt die Zelle kaum oder gar nicht und ist hinten 
mehr oder weniger stark gezähnt. Randbinde besteht aus mehr oder weniger ausgebildeten, dreieckigen, am Saum zusammenhängenden Flecken, deren Spitzen auf den Adern stehen und etwas abgestumpft sind. Vorderrandteil glänzend dunkelgrau mit etwas schwär\%licherer Einfassung, den Vorderrand selbst aber schmal grau lassend. Unterseite mit schwärzlichem Costal- und Subcostalstreif, die Binden stärker gezähnt. - - o. In der Zeiclınung dem o ihnlich, im schwarzen Apex des Vorderflügels mindestens Spuren der gelhen Flecke, Medianflecke meist größer, Hinterflügel mit schwärzlichem Torderrande, dem charakteristischen Geschlechtsunterschied, und unterseits olne Costalstreif.

Nördliches Brasilien.

Diese Art zerfällt in 2 Unterarten:

18a. H. fortunatus fortunatus Weym. $1884 H$. $f$., Weymer in: Ent. Zeit. Stettin, v. 45 p. 21 t. 1 f. $+\mid 1893 H$. f., Weymer in: D. ent. Z, Lep., v. 6 p. $308 \mid 1901$ H. f.: Riffarth in: Berlin. ent. Z., v. 46 p. 66.

Gelbe Schrägbinde des Vorderflïgels von den schwarzen Adern durchzogen und etwas braun überstäubt, an der hinteren Zellecke stark in proximaler Richtung vorgeschoben, den mittleren Medianzwischenraum fast ganz bis auf dell etwa $3 \mathrm{~mm}$ breiten schwarzen Distalrand ausfüllend und den vorderen Medianfleck einschlieBend. Medianflecke sehr klein. rundlich, isoliert. Apicalteil beim ơ einfarbig schwarz, beim o mit Spuren gelblicher, fast randständiger Flecke. Randfleck hinten ausgehöhlt, mit einer nach hinten gerichteten liakenförmigen Spitze am proximalen Ende. Der in dieser Höhlung liegende Teil gelb ausgefüllt. Submedianstreif nur schmal, in der Mitte etwa $2 \mathrm{~mm}$ breit, proximal wenig schwächer, im weiteren Verlauf, distal von der Mitte ebenfalls etwas rerschmälert, im Hinterwinkel aber stumpf dreieckig rerbreitert und mit dem Schwarz des Winkels verflossen. - Randbinde des Hinterflügels aus großen schwarzen dreieckigen Flecken bestehend, deren Spitzen auf den Adern nach vorn gerichtet und etwas abgestumpft sind, und die an ihrer Basis am Distalrande schmal zusammenbängen; in der Mitte erreichen sie die größte Ausdehmung, hängen jedoch mit der Nittelbinde nicht zusammen und fließen in den schwarzen Apex aus. In letzterem ein gelber Fleck und hinter diesem, zwischen den Basiswinkeln der nächsten Dreiecke der Randbinde zwei weitere gelbe Fleckchen. Mittelbinde vorn gerade begrenzt, die \%elle nicht berührend, hinten stark gezähnt, distal und proximal schmaler, läıgs der vorderen Radialis mit dem schwarzen Apex schmal zusammenhängend, sowie vor demselben bogenförmig nach vorn gerichtet und beim $o$ mit dem Subcostalstreif vereinigt. Unterseite mit einer Reilie, den Rand nicht unmittelbar berïhrender, weißer Saumfleckchen. - Vordertlïgellänge $44 \mathrm{~mm}$.

Östliches Amazonas (Villa Bella).

18 b. H. fortunatus spurius Weym. $1893 \mathrm{H}$. s., Weymer in: D. ent. Z. Lep., r. 6 1). 309 t. 4 f. 7 | $1901 H$. fortunatus s., Riffarth in: Berlin. ent. Z., v. 46 p. 67.

Vou der typischen Unterart folgendermaßen unterschieden: Im schwarzen Apicalteil des Vorderflïgels 4 schwefelgelhe, isolierte, in einem Bogen stehende Flecke, die in ziemlich gleichen Abständen liegen, und ron denen die mittleren größer als die distalen sind. Mediunflecke gröBer, Submedianstreif breiter, nach vorn stärker gewölht, die schwefelgelbe Querbinde breiter. Mittelbinde des Hinterflügels hinten weniger gezähnit. Dreiecke der Randbinde flacher. Im Apex. des Hinterflügels ein größerer gelber, rötlich eingefaßter Fleck. Unterseite des Vorderflügels mit weißen Saumfleckehen, 
welche im hinteren Medianzwischenraum in größere, weißlichgelbe Flecke auslaufen, die gelbe Binde in proximaler Richtung weiter ausgebreitet, his in die Mitte der Yelle.

Östliches Amazonas (Massauary).

19. H. sergestus Weym. 1893 H. s., Weymer in: D. ent. Z. Lep., v. 6 p. 334 t. 5 f. $12 \mid 1901$ H. s., Riffarth in: Berlin. ent. Z., v. 46 p. 67.

ऊ. Stirnpunkte weißlich, die sonst helle Behaarung auf Hinterkopf, Halskragen und Thorax rotbraun, nur die Punkte gelblich. Abdomen nit den gewöhnlichen gelben Streifen. Antennen proximal auf etwa ein Viertel der Länge schwarzbraun, dann ockergelb. Grundfarbe der Flïgel lebhaft hellbraun. - Vorderflügel schlank mit schwach gebogenem Vorderrande, ahgerundetem Apex und stumpfem Hinterwinkel. Hinterrand sanft geschreift. an der Wurzel beinahe gelappt. Vorderrand schmal sehwarz. Keilfleck länglich mit spitzem Ausläufer bis zur Flügelwurzel, das Ganze kommiähnlich. Endzellfleck groß, rhombisch, vorn mit dem Torderrande leicht zusammengeflossen, Medianflecke rundlich, isoliert, distal von der Zelle eine sehr schmale, schwefelgelbe Schrägbinde, deren hintere Begrenzung unscharf etwa in der Mitte des mittleren Medianzwischenraumes liegt, und die distal ziemlich spitz. manchmal in zwei Zähnen. etwa $2 \mathrm{~mm}$ vor dem Distalrande endet. Apex breit schwarz, ungefleckt. Unmittelbar hinter dem distalen Ende der gelben Binde, diese begrenzend, ein stumpfer. zapfenförmiger, mit dem Schwarz des Distalrandes völlig zusammenhängender Randfleck, der hinten etwas ausgehöhlt ist. Distalrand hinter diesem schmal schwarz, ebenso der Hinterrand. Im Hinterwinkel ein schwärzliches Fleckchen. Submedianstreif unvollständig, endet distal schräg von vorn nach hinten abgeschnitten etwas über der Mitte der Submediana. Unterseite matter in der Farbe. in der Zelle etwas gelbe Bestäubung, Randfleck durch braune Bestäubung vom Distalrande abgetrennt. - Hinterflügel im Vorderrandteil hell glänzend grau, etwas dunkler gesäumt, den Vorderrand selbst schmal grangelb lassend, im Apex rotgelb überstäubt, mit schwarzer, schmaler, distal etwas breiterer Mittelbinde, welche vorn leicht gewellt ist, die Zelle kaum berührt, bis zur vorderen Radialis reicht, dieser noch etwas folgt und so distal eine flache Biegung macht. Nächst dem Apex entsendet sie einen schmalen bogenförmigen Streif nach vorn, der sie mit dem Subcostalstreif oder der dunklen Berandung des grauen Vorderrandteiles verbindet. Hinterer Rand der Binde nnscharf, an den Adern ungewiß gezackt. Distalrand ungewiß schwärzlich bestäubt, gegen den Hinterwinkel zu beiden Seiten des hinteren Medianastes wischartige, vom Saum ausgebende Flecke. Adern schwarz, Fransen schwarz und weiß gescheckt. Unterseite matter, von der Flügelwurzel aus, proximal am Vorderrande mit gelbem Streif, Vorderrand sonst schmal braun. ein vollkommener Costalstreif und breit unterbrochener oder nur bis zur Hälfte der Flügellänge reichender schwärzlicher Subcostalstreif. Mittelbinde fast in längliche Flecke aufgelöst. Distalrand nur sehr schwach schwärzlich schattiert. - Hinterflügelunterseite ohne Costalstreif. - - Vorderflügellänge $40-43 \mathrm{~mm}$.

Die Art ändert etwas in Gestalt und Breite der Binde des Hinterflügels ab. die bald breiter ist, gleichmäßig und gerade verläuft und erst distal gebogen ist, bald proximal etwas breiter, dann schwächer und in ganzen Verlauf etwas gekrümmt erscheint, auch treten im schwarzen Apicalfelde des Vorderflügels Spuren von gelben Flecken nahe und unmittelbar am Flügelrande auf. In einem einzelnen Falle ist die Mittelbinde 
des Hinterfïgels rudinentïr und zwar nur im distalen Teil bis zum vorderen Medianast vorhanden. Auf der Linterseite des Hinterflügels erscheinen manchnal grauweiße, paarweise in den Aderzwischenräumen stehende, wischartige Sanmflecke.

Peru (Tiurapoto).

20. H. ennius Weym. 1890 H. e.. Weymer in: Kint. Zeit. Stettin, v.51 p. 283 1893 H. e. + H. e. var. nigrofasciatus, Weymer in: D. ent. '/. Lep., v. 6 p. 306 t. I I. 5 ; p. 307 t. 4 f. 6 (forma nigrofasciata) 1901 H. e. + H. e. n., Riffurth in: Berlin. cnt. \%, i. 46 1. $67 ; 1$. 68 (forma nigrofasciata).

o. Punktreihe vorn auf dem Thorax weib statt gell,. Gestalt der Flïgel ungewöhnlich breit, Grundfarbe licht kastanienliaun. - Vorderrand des Vorderfügels schmal schwar\%, an Wnde der \%elle in den großen und länglichen, unregelmäBig begrenzten Budzellfleck ïhergehend, dann weit schunaler werdend. Kieilfleck länglich eirund, vorn mit einem dicht an der Subcostalis anliegenden spitzen Ausläufer, in proxinaler líchtung. MedianHecke rerschieden, isoliert oder unter sich schmal und auch mit dem Endzellfleck breiter zusammengeflossen. Distal von der Zelle eine gelbe, verschieden breite, stark gekriimmte Schrägbinde, die an den schwarzen Aderu etwas bräunlich überstïubt und an der distalen Begrenzung mehr oder weniger gezälunt ist. Hinten reicht dieselbe his zum nittleren Medianast mud bleibt etwa $5-6 \mathrm{~mm}$ rom Distalrande entfernt. Apex breit schwar\%, mit einer gebogenen Reihe von $t$ oder 5 isolierten gelben Fleckeu und einer zweiten Reilie ron ehensolchen kleineren Saumfleckchen. Randfleck verschieden grob. distal stumpf dreieckig cingekerht und gelb ausgrefüllt, zuweilen bis zu den Medianflecken verlïngert und mit diesen und dem lindzellfleck eine die gelbe Bindeproximal begrenzende, schwarze, umregelıäBig und zackig begrenzte Binde bildend. Distalland schwarz. Submedianstreif mäBig breit, nach Verlauf von etwa zwei Drittel der Länge distal stark gekrümmt, daun verschmälert, im schwarzen Hinterwinkel wieder breiter und in einem mehr oder weniger deutlichen eckigen Fleck endigend. - Hinterflügel mit grauglänzendem, etwas dunkler gesäuntem Vorderandfelde. Vorderrand selbst schmal graubraun, ferner mit schwarzer Mittel- und Randbinde. Erstere liegt dicht hinter der linteren Zellecke, ist dort etwas eingedriickt und reicht distil his zur vorderen Radialis. Hinten ist sie an den Adern stark gezähnt, die Vorsprïnge der Zähuung liegen also zwischen den Adern. Randbindo proximal schmal, daun breiter, voru an den Adern stark gezähut, die Vorspriinge liegen lier auf den Adern und passen in die Einsclunitte der Mittelbinde. Distal endet die Randbinde in dem etwa $4-5 \mathrm{~mm}$ breiten schwar\%en Apex und ist dureh diesen nach rorn mit dem Subcostalstreif relbunden. In Apex ein oder mehrere helle Fleckchen. Distalrand mit partweise nebeneinanderstehenden, weiBen, wischartigen Saumfleckchen. Unterseite wio die Oberseite, Mittelbinde ebenfalls zusammenhängend, F'lügelwurzel und Vorderland ohne gelbe Fïrbung, mit dunklem Costal- und Subcostalstreif, Apical- und Saumflecke weiß und deutlicher. - - ․ Mit den charakteristischen Geschlechtsunterschieden, insbesondere mit schwarzgrauem Vorderrandfelde des Hinterflïgels, dem unterseits der Costalstreif fehlt. Sonst wie das $\sigma^{7}$, in der Regel jedoch die sehwarzen Flecke des Furderflügels ausgredehnter.

Forma principalis. Gelbe Querbinde des Vorderflügels selır breit, hinten, am mittleren Medianast vorwiegend vou der braunen Grundfarbe, nur distal von dem schwarzen Randfleck begrenzt. Medianflecke klein, der hintere rudimentär. Submedianstreif distal nur unwesentlich verschmälert, im schwarzen Hinterwinkel nur eine undeutliche Ecke naclı vorn abgesetzt. Randfleck 
kurz, distal stark gelb ausgefüllt. Hinterflügel in Apex mit zwei gelben Fleckchen; Mittel- und Randbinde breit, Zähnung scharf und tief. Vorderflügellänge $47-50 \mathrm{~mm}$.

Amazonas (Ega, Teffé, Fonteboa, São Paulo de Olivença).

Forma nigrofasciata. Von der Hauptform dadurch unterschieden, daß die schwarzen Discalflecke des Vorderflügels vergrößert sind und unter sich, wie mit dem schwarzen Randfleck zusammenfließen, so daß eine unregelmäßig geformte schwarze Schrägbinde entsteht, welche die bedeutend verschmälerte gelbe Binde proximal und hinten von der braunen Grundfarbe trennt. Schwarzer Apex proximal ebenfalls etwas verbreitert, Submedianstreif auch voller, aber distal stark verschmälert und dann im Hinterwinkel in einen deutlich nach vorn geeckten Fleck ausfließend. Unterseite wie die Oberseite, nur die Apicalfleckchen des Vorderflügels fast weiß mit schwach gelbem Anfluge. Sonst wie die Hauptform. Vorderflügellänge $48 \mathrm{~mm}$.

Amazonas (Manicoré).

\section{H. quitalenus (Hew.)}

ठ. Stirnpunkte meist weiß, die übrige Kopf- und Körperzeichnung gelb. Antennen ockergelb, der proximale Teil auf etwa ein Viertel der Länge schwarzbraun, zuweilen an den einzelnen Gliedansätzen dunkler geringelt oder dorsal mit fein schwarzer Linie bis zur Keulenspitze. Grundfarbe der Flügel lebhaft rötlichbraun. - Vorderflügel schlank, in Gestalt wie bei den Verwandten der Gruppe. Vorderrand ziemlich breit schwarz. Keilfleck länglich eirund, mit anschließendem, verschieden langem, spitzem Ausläufer in proximaler Richtung, der entweder dicht oder ziemlich dicht an der Subcostalis gelegen ist und nur durch schwache und schmale bräunliche Bestäubung längs dieser Ader vom Vorderrande getrennt sein kann. Endzellfleck meist groß, unregelmäßig viereckig, vorn breiter als hinten, meist mit dem schwarzen Vorderrande einerseits und zuweilen auch mit den Medianflecken und dem Randfleck andererseits zusammengeflossen, endlich auch distal verbreitert und derart mit dem breit schwarzen Apex längs der Adern verbunden, daß die distal der Zelle manchmal gelb gefärbte Binde nur als eine Reihe einzelner Flecke zu erkennen ist; von diesen Flecken ist der distal liegende am gröBten und am weitesten abgesondert. Die discalen Flecke können aber auch isoliert liegen, wenugleich die vorderen Ecken des Endzell- und vorderen Medianfleckes distal fast stets ausgeflossen sind und die Schrägbinde zerrissen erscheinen lassen. Letztere ist mitunter bräunlich ïberstäubt, nur am Vorderrande gelblich verfärbt oder überhaupt nicht in einer von der Grundfarbe verschiedenen Bestäubung. Im schwarzen Apex meist eine gebogene, fast bindenartige Reihe von 4 oder 5 schwefelgelben, oft sehr großen Flecken, die mitunter sogar größer sind als diejenigen der discalen gelben Schrägbinde, außerdem eine Reihe von mehr oder weniger deutlichen gelblichen Apical- und Saumfleckchen. Der Apex kann aber auch einfarbig schwarz sein. Randfleck distal ausgehöhlt, breit kuppenartig, nur nach vorn mit dem schwarzen Apicalteil und dem schmal schwarzen Distalrande zusammenhängend. Hinterwinkel schwarz, meist mit einem unregelmäßigen Fleck, in den der mäßig breite Submedianstreif verschmälert ausläuft. Letzterer ist zuweilen oben ungewiß zerstäubt und endet distal schon nach Verlauf von etwa zwei Dritteln der Aderlänge; die Ader setzt sich dann bis zum Hinterwinkel schmal, aber scharf schwarz fort. Fransen schwarz, stellenweise weiß unterbrochen. Unterseite matter, Apical- und Saumfleckchen weiß und deutlicher. In der Zelle zwischen 
Keil- und Endzellfleck zuweilen gelbe Bestäubnng, bei Fornen mit oben einfarbig schwarzem Apex die gelben Flecke darin meist rudimentäl oder wischartig angedentet, sonst der Oberseite entsprechend. - Hinterflügel mit griunglänzendem, scbwärzlich umzogenem Vorderrandfeld, der Vorderrand selbst schmal graurötlich, ferner mit Mittel- und Randbinde. Wirstere berïhrt mit ihrem rorderen Rande die hintere /ellecke, ist nach hiuten stark gezähnt, meist nur in rorn lose zusammenhängende Dreiecke zergliedert, endet an der vorderen Radialis nud ist dort durch einen bogenförmig nach voru gerichteten Strich oder Streif, der distal auch mit dem schwarzen Apex zusimmenfließen kann, mit der schwärzlichen Berandung des Vorderrandfeldes verbunden. Randbinde ziemlich gleichmäßig $2-3 \mathrm{~mm}$ breit, am Hinterwinkel schmaler, spitz anfangend, in der Mitte bisweilen etwas breiter, vorn ungewib begrenzt, mit schwacher Zackenbildung, distal in den schwarzen Apex einlinfend. Dort meist ein gelber Fleck. Distalsaum gewöhulich mit gelblichen oder weißen, wischartigen, paarweise nebeneinander angeordneten Saumfleckchen, die ron den weißen Stellen der schwarz und weiß gescheckten Eransen ansgehen, manchmal aber auf diese beschränkt bleiben. Unterseite meist mit vollkommenem Costalstreif und vorwiegend breit unterbrochenem, selten ebenfalls rollkommenem Subcostalstreif. Flügelwurzel nur wenig gelb bestäuht, hinter dew Subcostalstreif und in dessen Unterbrechung manchmal etwas gelh, Torderrand schmal bräunlich, Mittelbinde fast vollständig in dreieckige, voru nur schwach oder gar nicht zusammenhäng'ende Flecke aufgelöst, meist 2 weiße Apicalflecke oder Spuren solcher. _ _ o. Antennen bis auf das proximale Viertel, welches schwarz ist, ockergelb. Grundfarbe der Flügel dunkler, meist ranchbrann, Fleckenbildnng stärker. sonst nur mit den der Gruppe eigentümlichen Geschlechtsunterschieden, namentlich schwärzlichem Vorderrandfeld des Hinterflügels oben nud fehlendem Costalstreif auf der Unterseite.

Peru, Bolivia. Ecuador, nördliches Brasilien.

Diese Art zerfällt in 4 Unterarten:

21 a. H. quitalenus quitalenus (Hew.) 1852 Heliconia quitalena, Hewitson, Exot. Butt., $x .1$ Heliconia t. 1 f. $3 \mid 1871$ Heliconius q., W. F. Kirby, Cat. diurn. Lep., p. $144 \mid 1893$ H. q., Weymer in: D. ent. Z. Lep., $x .6$ p. $315 \mid 1901$ H. q., Riffarth in: Berlin. ent. Z., 2: 46 p. 69.

Schwarze Zeichmmngen des Vorderflügels sehr ausgedehnt. Keilfleck mit Spitzenausläufer nach der Flïgelwurzel vorn dicht an der Subcostalis anliegend, nur durch bräunliche Bestäubung dieser von dem schwarzen Vorderrande getrennt. Zelle des Vorderflügels nur hinten, an der Mediana und distal zwischen Keil- und dem sehr groBen, rhombischen Endzellfleck schmal braun. Discal- nnd Apicalteil ror dem mittleren Medianast, teilweise anch bis in den hinteren Medianzwischemraum, infolge Verbreiterung der Fleckenbildung eine einzige schwarze Fläche darstellend, in welcher eine schräge Reihe meist großer, gelber Subapicalflecke nnd eine ebensolche, in der Regel kleinerer, postdiscaler Flecke, den Resten der gelben Qnerbinde, steht. Beim o sind die ersteren kleiner als heim $0^{\tau}$. Die sehwarze Fläche ist proximal im hinteren Zellende an der Mediana zahuartig von der brannen Grundfarbe eingeschnitten, wodurch die Lage von Endzell- und hinterem Medianfleck angedentet ist. ebenso ist durch die in die hintere Begrenzung in der Mitte des hinteren Medianzwischemrames in das Schwar\% vortretende Grundfarbe die Grenz. des hinteren Median- und des Randfleckes bemerkbar. Hinterer Flïgelteil von der Wurzel bis zu dem schmal schwarzen Distalrande braun, an der Snbmediana Aurch den schwarzen, distal etwas ïber der Hälfte der Ader endigenden Submedianstreif geteilt. Dieser ist vorn meist unscharf begrenzt nnd hängt 
durch die fein schwarze Ader mit dem schwärzlichen Hinterwinkel und einem darin liegenden uuregelmäßigen Fleck zusammen. Beim q, dessen Grundfarbe bedentend dunkler, ranchbranu ist, erscheint der Submediaustreif etwas schmaler und länger, d. h. dentlich bis zn dem erwähuten schriarzen Fleck im Hinterwinkel. Unterseite mit einer Reihe weißer Saumfleckchen in und hinter dem Apex. in der Zelle zwischen Keil- und Endzellfleck gelhe Bestäublung, soust wie oben aber matter. - Hinterflügel, abgesehen rom Torderrandteil, mit ziemlich sehmaler. aus dreieckigen. an der nach rour gerichteteu Basis zusammenhängendeu, schwarzen Flecken gebildeten Mittelbinde. schmal schwärzlichem, ungezähntem, aher vorn unscharf begrenztem Distalraude, meist mit kleinen oder verloschenen weißen Saumflecken, die nuterseits viel deutlicher sind. Im Apex ein gelbes Fleckcheu, soust mit den hei der Art beschriebenen Einzelheiten beziiglich Lage und Anordnung: der Binden. Unterseite ohne Gelb an der Flügelwurzel, ơ mit schmal braunem Torderrande, schwärzlichem Costalstreif und breitem, mit ersterem fast znsammengeflossenem, ununterbrocheuem Subcostalstreif. Ersterer fehlt beim $ᄋ$. - Torderflügellänge $42-45 \mathrm{~mm}$.

Ecuador (Archidona, Gebiet des Rio Napo in Höhen von $450-650 \mathrm{~m}$ ).

21 b. H. quitalenus felix Weym, 1893 H. $f$. (O. Standinger in $3 \mathrm{SS}$.) $+H . f$. var. concors, Weymer in: D. ent. Z. Lep., v. 6 p.315 t. \pm f. 10 ; p. 317 t. 4 f.11 (forma c.) $1901 \mathrm{H}$. quitalena $f .+H . q$. concors, Riffarth in: Berlin. ent. Z., $v .46$ p. 69 ; p. 70 (forma c.).

Forma principalis. Meist größer als die typische Luterart. - Torderflügel vorherrschend licht rötlichbraun. Keilfleck schräg länglich mit voru anschlieBender proximal gerichteter S'pitze, die nicht an der Subcostalis anliegt und die Flügelwurzel meist nicht erreicht. Endzellfleck grob, umegeluäßig riereckig, vorn mit dem schwar"zen Torderrande rerflosseu. proximal das Zelleude ausfüllend. Vorderer Medianfleck sehr groß, distal au der rordereu Ecke bis in den schwarzen Apicalteil rorgeschobeu. Hinterer Medianfleck in der Regel kleiner, ersterer mit dem Endzellfleck und mit dem Randfleck manchmal leicht zusammengeflossen. aber ihre Gestalt mind Lage immer dentlich zu erkennen. Distal der Zelle eine schmale gelbe, rom Endzellund vorderen Mediaufleck eiugeschuürte und unterbrochene Schrägbinde, welche hinten bis zum mittleren Medianast reicht und distal etwa $5 \mathrm{~mm}$ rom schwarzen Distalrande endet. Apicalteil schwarz mit einer gebogeuen Reihe ron 4-6 gelben und einer weiteren Reihe rom Apex bis znm mittleren Mediauast sich hinzieheuder weißlicher randständiger Fleckcheu. Erstere manchmal schwärzlich überstäubt, letztere zuweilen undeutlich oder nu' nnter sichtbar. Randfleck etwa $4-5 \mathrm{~mm}$ weit rom Samm abgerüclit. nur vorn leicht mit demselben zusammenhängend. Submedianstreif schmaler als bei der typischen Cnterart, ziemlich spitz in den nnregelmäBigen Fleck im Hiuterwinkel einlaufend. - Hinterflügel mit einer in dreieckige schwarze Flecke aufgelösten Mittelbinde und breiterer, nach vorn ungewiß̈ gezähuter Randbiude. In dieser weibliche oder gelbliche, paartweise in den Aderzwischenräumen stehende längliche Saumfleckchen. In schwarzen Apex ein gelber Fleck, unterseits zwei Flecke ron weißer Farbe. das o mit sehmalem schwärzlichem Costalstreif, dem braunen Vorderraude folgend mit sta.t unterbrochenem Subcostalstreif. hiuter ihm etwas gelbe Bestäubuug; Randflecke größer, rein weiß. Sonst mit den bei der Art erwähnten Eigentïmlichkeiten. - Vorderflügellänge 44-52 mm.

Peru (Rioja), Bolivia (Tal des Rio Juntas und Rio Sougo). 
Forna concors. Linterscheidet sich rou der Hauptform dadurch, dab die schwefelgelbe Querhinde des Vordertlïgels mehr oder weniger rotbraum bestäuht oder anch ganz durch die Grundfarbe verdrängt ist. Apical-, Subapical- und Saumflecke des Vorderflïgels mehr oder weniger schwärzlich überstäubt, letztere teilweise verloschen. Mittelhinde des Hinterflügels zusammenlängend, hinten schwach zackig. Randbiude etwas breiter. Subcostalstreif des $\sigma^{\pi}$ auf der Unterseite fast zusammenhängend, nur etwas eingeschnn̈rt. Es gibt mannigfache Übergänge und Zwischenformen zn der Hauptform.

Peru (Sarayacu), Bolivia (Tal des Rio Juntas und Rio Songo). Neben der Hauptform.

$21 \mathrm{c.}$ H. quitalenus versicolor Weym. $1893 H . v$., Weymer in: D. ent. ' Z. Lep., c. 6 p. 317 t. 4 f. 12 | 1901 H. quitalena v., Riffarth in: Berlin. ent. Z., v. 46 p. 71.

Zeichnungsiunlage wie bei H. q. felix, die schwarzen Disealflecke des Torderflügels etwas kleiner, sämtlich isoliert. Randfleck auffällig hakenförmig;, die Krümmung in proximaler Richtung, distal nicht mit dem schmal schwarzen Distalrande verbunden. Das Schwarz des Apicalteiles bis auf einige wischartige Flecke an der distalen Grenze der schmalen gelben Querbinde und an Saum voll der rötlichbraumen Grundfarbe verdrängt. Distalrand schwarz. In diesem bis zum Apex gelbe Saumfleckchen. Hinterflügel wie bei der rorigen Form. nur die Mittelbinde etwas breiter, vorn durch die hintere Zellecke laufend, 3 oder 4 gelbe Subapicalfleckchen in der braunen Grundfarbe nächst der Randbinde. Saumflecke gelb, stark ausgeprägt. Torderflïgellänge etwa $48 \mathrm{~mm}$.

Amazonas (Manicoré).

21 d. H. quitalenus sisyphus Salv. 1871 H.s., O. Salvin in: Ann. nat. Hist., ser. 4 x. 7 p. $413 \mid 1877$ H. s., W. F. Kirby, Cat. diurn. Lep., Suppl. p. 722 | 1893 H. jonas + H. s., Weymer in: D. ent. Z. Lep., v. 6 p. 307 (forma j.): 1. $308 \mid 1901$ H. quitalena j. + H. q. s., Riffarth in: Berlin. ent.Z., v. 46 p. 70 (forma j.); p. 71.

Forma principalis. Nächst H. q. felix, aber Grundfarbe (Fig. 16) etwas dunkler, Vorderflügel ohne gelbgefürbte Schrägbinde, Keilfleck stark winkelförmig. Ausläufer ziemlich dicht an der Subcostalis, schmal und spitz. Apicalteil ganz schwar\% und breiter. Endzellfleck fast dreieckig,

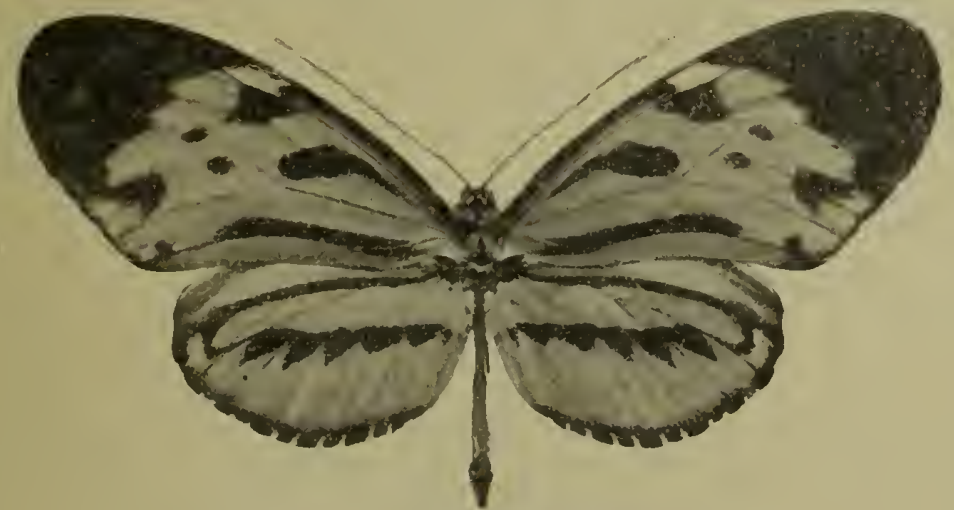

Fig. 16. H. quitalenus sisyphus, $\delta(1 / 1)$.

die stumpfe Spitze nach hinten gerichtet. vom schwarzen Vorderrande schmal getrennt, aber an der vorderen distalen Ecke fein mit dem schwarzen Apicalteil zusammenhängend. Vorderer Medianfleck klein, aber deutlich, der hintere ron gleicher GröBe, aber häufig verloschen. Randfleck rudimentär, mit dem schwarzen Apicalteil gar nicht oder lose zusammenhängend, rom Distalrande 
stets getrennt. Randbinde des Hinterflügels sehr schmal, mit weißen SaumHeckchen. Mittelbinde in einzelne Dreiecke, die vorn meist lose zusammenhängen, aufgelöst. Der nächst dem Apex nach vorn gerichtete Bogenstrich schmal durch die Grundfarbe vom Schwarz des Apex getrennt, nicht unmittelbar mit der Mittelbinde zusammenhängend, sondern an der vorderen Radjalis aufgesetzt. - Es gibt Tiere, bei denen der vordere Medianfleck des Vorderflügels größer, etwa wie bei H. q. felix, und auch der Randfleck vollkommener, kuppenartig, vorn distal mit dem Schwarz des Apicalteiles zusammenhängend, auftritt. Diese müssen auch zu dieser Unterart gerechnet werden. Auf der Unterseite des Vorderflügels zeigen sich im schwarzen Apex Spuren gelber Flecke und eine Reihe weißer, hinten bräunlicher Saumflecke. - Vorderflügellänge bis $50 \mathrm{~mm}$.

Peru (Cosnipata-Tal, Marcapato).

Forma jonas. Wie die Hauptform, aber Vorderflügel in der Regel mit verloschenen gelben, randständigen und fast randständigen Flecken im schwarzen Apicalteil. Medianflecke klein, am Vorderrande hinter dem Endzellfleck, in dem Winkel des Randfleckes, auch hinter diesem gelbliche Bestäubung, zum T'eil die Reste einer gelben Schrägbinde; Submedianstreif manchmal nur in der proximalen Hälfte oder etwas darüber hinaus vorhanden. Subapical- und Apicalflecke auf der Unterseite reiner und deutlicher. Hinterflügel wie bei H. q. felix, forma concors (S. 93), Saum etwas breiter, Subcostalstreif auf der Unterseite beim $\delta$ deutlich unterbrochen, dort zwei große weiße Apical- und eine Reihe paarweise nebeneinanderstehender weißer Saumflecke, die oben kleiner und gelblich sind.

Peru (Yurimaguas), westliches Amazonas (São Paulo de Olivença.)

22. H. anderida (Hew.)

ठ․ Stirnpunkte meist gelb, seltener weißlich, die übrige Körperzeichnung gelb; im einzelnen Falle das Abdomen dorsal im vorderen Teil weißlich. Antennen unbeständig gefärbt, schwarzbraun, wenigstens bis zur Hälfte oder darüber hinaus, sodann diese Färbung meist auf einen schmalen dorsalen Streif beschränkt, das übrige ockergelb oder bräunlich. Gestalt der Flügel wie bei den Verwandten. Färbung und Zeichnung sehr veränderlich. Vorderflügel gewöhnlich in drei verschieden gefärbte Felder geteilt, einem rotbraunen proximalen, an dessen distaler Grenze ein eirunder, selten mit Spitzenausläufer versehener Zellfleck liegt, einem schwefelgelben bindenartigen discalen Felde mit dem Endzellfleck und den Medianflecken, deren ersterer mit dem dritten, distalen oder apicalen schwarzen Felde verflossen ist. In letzterem eine gleichmäßig gebogene Reihe von schwefelgelben, selten weißen Flecken, die vorn subapical stehen und, dem Distaliande folgend, sich nahe diesem bis zum Hinterwinkel fortsetzen. Am größten sind sie in der Regel im Apex und im Hinterwinkel. Saumflecke fehlen. Zuweilen tritt proximal von dieser eine zweite Reihe gleichartiger, manchmal etwas verloschener Flecke auf, deren hinterster im mittleren Medianzwischenraum steht. In anderen Fällen ist der gelbe Discalteil oder die gelbe Schrägbinde durch Ausfließen des Schwarz des distalen Teiles und der Discalflecke stark eingeengt oder bis auf einige schräg gestellte gelbe Flecke verdrängt, auch dringt die schwarzbraune Farbe in proximaler Richtung bis auf schwach rötlichbraune Bestäubung an der Flügelwurzel und am Hinterrande vor, oder der ganze Flügel ist bis auf Rudimente gelber Fleckbildung im distalen Teil der Zelle und auf die anfangs erwähnten Fleckenreihen im Discus und Apicalteil geschwärzt. 
Endlich verbleibt außer dem sehwarzbraun gewordenen proximalen und distalen Flügelteil, letzterer mit den erwähnten zwei lleckenreihen, im Discus eine breite, vorn duich den Endzellfleck gegabelte, gelbe Binde hestehen, die proximal die Zelle bis zur Hälfte ausfüllt, die beiden isolierteu Medianflecke einschließt und distal durch den mit dem Sclıwar'z des Apex und Hintermandes zusammengeflossenen Randfleck keilförmig eingeschnitten ist. In diesen Falle ist der Hinterflïgel meist bis auf ein gelbes Fleckchen im Apex sehwarzbraun. Im anderen Falle, aber seltener, herrscht lebhaft rötichbraune Farbe, namentlich im proximalen und vorderen Teil, vor. Alsdann Saum meist breit schwarz, seltener sondert sich aus dem distalen Teil dieser Färbung eine rudimentäre Mittelbinde ab, die sich danu auf der Unterseite deutlicher zu erkemnen gibt. Vorderrandteil hellgrau, dunkler eingefaßt, den Vorderraud selbst schmal grau lassend. Unterseite im übrigen wie die Oberseite, nur sind die distalen Flecke des Vorderflügels manchmal weiß verfärbt, und am Distalrande des Hinterflügels stehen meist deutliche und intensir weiße längliche Saumfleckcheu. - o. Der Färbung und Zeichmung des O allgemeinen entsprechend. mit den charakteristischen Geschlechtsunterschieden, namentlich bräunlichem oder schwärzlichem, nicht glänzendem Vorderrandteil des Hinterflügels. Antennen nur im proximalen Drittel schwärzlich, sonst ockergelb. Grundfarbe des Hinterflügels in Fällen, in denen dunkle Färbung auf dem Vorderflügel rorherischt, dunkler, rauchbraun.

Colombia, Venezuela, Mittel-Amerika; Niederländisch-Guayana?

Diese Art zerfällt in 7 Unterarten:

22 a. H. anderida anderida (Hew.) 1852 Heliconia a., Hewitson, Exot. Butt., v. 1 Heliconia t. I f. 2 1871 Heliconius a., W. F. Kirby, Cat. diurn. Lep., p. 144|1881 H. a., F. D. Godman \& O. Salvin in: Biol. Centr.-Amer., Lep.-Rhop. v. 1 p. $150 \mid 1893$ H. a., Weymer in: D. ent. Z. Lep., v. 6 p. $294 \mid 1901$ H. clara a. (H. zagora Plötz in IIS.), Riffarth in: Berlin. ent. Z., v. 46 p. 74.

Im gauzen wie H. a. melicerta, aber die schwefelgelben Zeichnungen des Vorderflïgels gelbbraun bestäubt. In der Mitte des mittleren Medianzwischenraumes ein groBer gelber Fleck, welcher die Trennung des vorderen Medianfleckes von dem schwarzen Apicalteil andeutet. Hinterer Medianfleck größer. Keilfleck mit Spitze in proximaler Richtung, ohne die Flügelwurzel zu erreichen. Submedianstreif nur im distalen Teil vorhanden. - Hinterflügel mit schmalerer, etwa $3-4 \mathrm{~mm}$ breiter Randbinde, die vorn ziemlich. glatt begrenzt ist und in den breit schwarzen, mit zwei gelben Flecken versehenen Apex ausläuft, feruer mit etwa ebenso breiter vollständiger Mittelbinde, die vorn glatt, hinten etwas gezähnt ist, wie bei H. a. semiphorus, forma holcophora (S. 97), aber die hintere Zellecke nicht berïhrt. Es kommen abweichende Stricke mit nicht gauz durchgehender Mittelbinde vor.

Venezuela (Puerto Cabello), Colombia, Honduras.

22 b. H. anderida melicerta Bates 1793 Papilio clara (non P. clarus P. Cramer 1775!), J. C. Fabricius, Ent. syst., v. $3_{\text {I }}$ p. 161 | 1816 Melinaea c. (part.), Jac. Hiibner. Verz. Schmett., p. $11 \mid 1819$ Heliconia c., (Latreille \&) J. B. Godart in: Enc. méth.. v. 9 p. $217 \mid 1847$ H. c., F. Doubleday (\& Westwood), Gen. diurn. Lep., v. 1 p. $104 \mid 1869$ Heliconius c., A. G. Butler, Cat. diurn. Lep. Fabr., p. $123 \mid 1871$ H.c., W. F. Kirby, Cat. diurn. Lep.: p. $138 \mid 1875$ H. c., Weymer in: Ent. Zeit. Stettin, v. 36 p. 384 t. 2 f. 6 | 1880 ? H. c., Bucheeker, Syst. Ent., Lep. t. 53 f. 5 | 1884 H.c., Weymer in: Ent. Zeit. Stettin, v. 45 p. $27 \mid 18.93$ H. c., Weymer in: D. ent. Z. Lep.. v. 6 p.293| 1901 H. c. (H. etholea Plötz in MS.). Riffarth in: Berlin, ent. Z., v.46 p.72|1866 H. melicerta, H. W. Bates in: Ent. monthly Mag., v.3 p.87|1881 H. m., F. D. Godman \& O. Salvin in: Biol. Centr.Amer., Lep.-Rhop. v. 1 p. 144 t. 16 f. $12,13$. 
Stirnpunkte und Körperzeichnung gelb. Autenuen beim $\sigma^{\tau}$ proximal etwas über ein Drittel der Länge gänzlich, von da nur dor'sal schmal schwar\%bramn bis 7.11 Spitze, sonst bräunlich bis ockergelb, beim 우 im distalen Teil, etwa von der Hälfte an ganz ockergelb, sonst schwarzbrann. - Vorderflügel (Fig. 17) proximal lebhaft rotbraun, beim o etwas trïber. Diese Färbung breitet sich in der Zelle bis zu dem schwarzen eirmnden Zellfleck aus, setzt sich hinter derselben in distaler Richtung bis etwa $8 \mathrm{~mm}$ vom Distalrande und Hinterwinkel fort, rorn durch den hinteren Medianast begrenzt, beim o etwas schmaler und ungewisser. Distal von diesem Felde liegt eine breite bindenartige gelbe Fläche, in welcher der isolierte schwarze, seltener mit dem schwarzen Vorderrande zusammenhängende Endzellfleck liegt, der übrige, distale Teil des Flügels vorwiegend schwarz. Im mittleren Medianzwischenraum schiebt sich ein schwarzer stumpfer Zapfen in proximaler Richtnng fast bis zirr Zelle in die gelbe Fläche vor, es ist dies der mit dem schwarzen Distalteil zusammengeflossene vordere Medianfleck. Hinterer Medianfleck rundlich, meist klein, häufig auch fehlend. Distal endet das Gelb etwa $8-10 \mathrm{~mm}$ rom

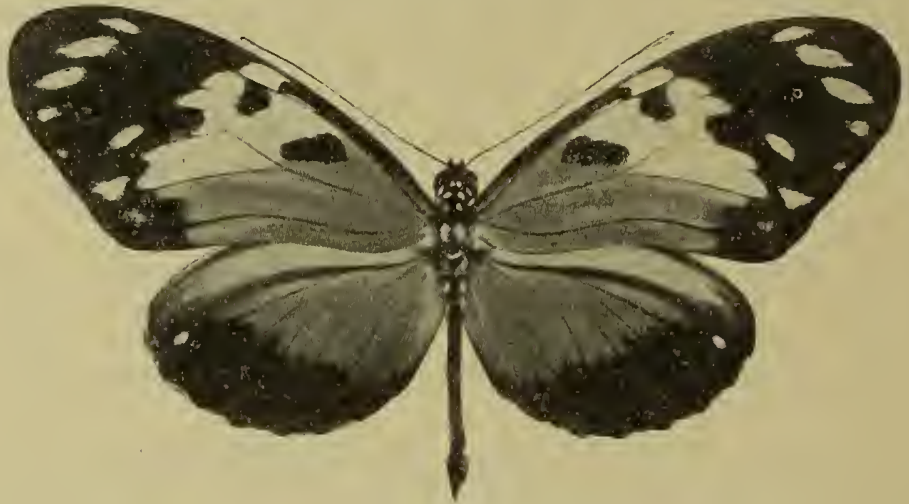

Fig. 17. H. anderida melicerta, $\delta(1 / 1)$.

Distalrande im hinteren Medianzwischenraum. Zwischen dem Ende und dem Saum erscheint jedoch im schwarzen Felde ein gelbes. fast halbmond- oder keilförmiges Fleckchen, durch welches die Lage des Randfleckes angedentet ist. Im schwarzen Apicalteil meist nur eine distale Reihe gelber Flecke schräg vom Vorder- bis zum Distalrande, die sich an diesem, nach hinten kleiner werdend, fortsetzen; selten eine zweite, proximal dieser liegende Fleckenreihe, die dann gewöhnlich schwarz ïberstänbt ist. Submediana schmal schwarz, mitunter zeigt sich, vom schwarzen Hinterwinkel ansgehend, in proximaler Richtung der Ansatz eines schwärzlichen Submedianstreifes, namentlich beim o. Fransen schwarz und weiß gescheckt. Unterseite ohne wesentliche Verschiedenheiten. - Hinterflügel proximal breit, damn allmählich schmaler und gegen den Apex ziemlich spitz auslaufend, braun wie der proximale Teil des Vorderflügels. Apex und Distalrand breit schwarz. der Gestalt der braunen Fläche entsprechend, gegen den Hinterwinkel schmaler und vor diesem am Hinterrande spitz endigend. An der breitesten Stelle, dem mittleren und vorderen Medianast, mißt der schwarze Distalteil $13-15 \mathrm{~mm}$, vordere Begrenzung uuregelmäßig, manchmal in streifenartigen Wischen in den Aderzwischenränmen ausgeflossen. Zuweilen sind, vom Apex ausgehend, namentlich beim $Q$, Spuren der Abtrennung einer Mittelbinde bemerkbar, die sich auf der Unterseite deutlicher erkennen lassen. Im Apex oberseits 1 oder 2 gelbe Fleckehen. 
auf der Unterseite deren zwei weiße. Ebendaselbst fehlen beim $\sigma^{\tau}$ und $q$ Costalnud Subcostalstreif oder sind nur in Rudimenten vorhanden; am Distalrande stehen rein weiße Silumfleckchen parweise nebeneinander, au der Flügelwirzel gelbe Bestäubung. - Vorderflügellänge bis $46 \mathrm{~mm}$.

Colombia, Panama; Niederländisch-Guayana?

22 c. H. anderida semiphorus Staud. $1896 H$. metaphorus var. s. $+H$. s. aberr. holcophorus, O. Staudinger in: D. ent. Z. Lep., v. 9 p. 284; 1. 285 (forma holcophora) $1901 H$. clıra s. + H. c. h., Riffarth in: Berlin. ent. Z., 2.46 p. 73 ; 1. 74 (forma holcophora).

Forma principalis. Vorderflïgel wie bei H. a. melicerta (S. 95), Raudbinde des Hinterflügels schmaler, vom Apex aus löst sich in proximaler Richtung in ungewissen Elecken der Ansatz einer schwarzen Mittelbinde ab, die distal mehr oder weniger noch mit der Randbinde in ungewisser Bestäubung: zusammenhängt und etwa hinter der Zellecke in der Gruudfarbe verläuft. Auf der Unterseite ist die Trennung hei weitem deutlicher und die Mittelhinde etwa his zum hinteren Medianast voll und zusammenhängend. Daselbst von der Flïgelwurzel ans proximal am Vorderrande ein gelber Wurzelstreif, beim $0^{\pi}$ der Costalstreif im distalen Drittel, der Subcostalstreif mitunter ganz allsgebildet, in anderen Fällen nuterbrochen oder r'udimentär. Saumflecke groß, leuchtend weiß. Vorderflïgellänge etwa $44 \mathrm{~mm}$.

Es gibt Übergänge zur folgenden Form.

Westliches Colombia (Tal des Rio Dagua), südliches Colombia.

Forma holcophora. Wie die Hauptform, aber die schwarze Zeichnuug des Vorderflïgels mehr ausgedehnt, namentlich der Endzellfleck, welcher mit dem schwarzen Vorderrande breit und distal an seiner vorderen Ecke mit dem schwarzen Apicalteil zusammengeflossen ist. Keilfleck mit breitem, vorn unmittelhar am schwarzen Vorderrinde auliegendem, proximal an der Flïgelwurzel spitz endigendem Ansläufer, der anf der Unterseite kürzer ist uud stımpf endet, auch ron der Snbcostalis schmal getrennt ist. Ferner oben ein proximal spitzer, allmählich stärkerer und ziemlich breit in den Hinterwinkel auslaufender Submedianstreif. Hinterflügel mit schmalerer Randbinde uud dieser folgender vollständiger schmaler Mittelbinde, welche hinten etwas gezähnt ist, vorn durch die hintere Zellecke läuft und auf der Unterseite bedeutend breiter ist. $\delta$ unterseits mit gelbem Wurzelstreif am proximalen Teil des Vorderrandes, vollständigem Costal- und schmal nuterbrochenem Subcostalstreif, beide zusammengeflossen. Saumflecke klein.

Westliches Colombia ('Tal des Rio Dagua).

22 d. H. anderida annetta Riff. $1900 \mathrm{H}$. clara var. annetta, Riffarth in: Berlin. ent. Z., v. 45 p. $187 \mid 1901$ II. c. a., Riffarth in: Berlin. ent. Z., v. 46 p. 73.

Im allgemeinen wie H. a. melicerta (S. 95), mit folgeuden Unterschieden: Mittlerer Medianzwischenraum gauz oder bis anf einen kleinen gelben Fleck schwarz ausgefïllt;; Keilfleck in der Zelle sebr breit, vor'l und linten die Zellwände berührend, in proximaler Richtnng verlängert, die Spitze dieses Ausläufers erreicht aber die Flïgelwurzel nicht; hinterer Medianfleck größer, proximal meist his zur hiuteren Zellwand ausgeflossen. Im hinteren Medianzwischenraum läuft das Schwar\% des breiten Distalrandes zuweilen in proximaler Richtming streifenartig bis etwa in die Flïgelmitte aus. - Hinterfliigel mit schmalerer Randbinde, vom Apex aus in proximaler Richtung der Ansatz einer Mittelbinde, die bis z.11 Mitte des Flügels reicht, 
dort verläuft mnd aus einzelnen Flecken besteht, welche sich fast dem schwarzen Distallande anschließen. Im Apex 1-3 schwefelgelbe Flecke. Sonst wie H. a. melicerta.

\section{Colombia.}

22 e. H. anderida albucilla Bates $1866 H$. albucilla, H. W. Bates in: Ent. monthly Mag., v. 3 p. $88 \mid 1881$ H. a., F. D. Godman \& O. Salvin in: Biol. Centr.-Amer., Lep.-Rhop. v. 1 p. 144 t. 16 f. $7-9 \mid 1893$ H. a., Weymer in: D. ent. Z. Lep., v. 6 p. $295 \mid$ 1901 H. clara a., Riffarth in: Berlin. ent. Z., v.46 p.74| 1871 H. albicilla, W. F. Kirby, Cat. diurn. Lep., p. 138.

Nächst der typischen Luterart, aber die Flecke im distalen Flügelteil und die Schrägbinde im Discus des Vorderflïgels weiß statt gelb. Letztere im proximalen Teil, selten in ganzer Ausdehnung schwärzlich überstäubt. Hinterwinkel wie bei H. a. melicerta (S. 95) breit schwarz, mit proximal gerichtetem Ansatz des Snbmedianstreifes, nahe dem Rande ein brauner Fleck. - Hinterflügel mit durchgehender, etwas schmalerer Mittelbinde als bei der typischen Unterart, Randbinde ebenfalls nicht so breit, Apicalfleck bräunlich anstatt gelb, soust wie jene.

\section{Panama (Lion-Hill-Station, Veragua).}

22f. H. anderida zuleika (Hew.) 1854 Heliconia z., Hewitson, Exot. Butt., v. 1 Heliconia t. 3 f. $10 \mid 1885$ Heliconius z., O. Staudinger (\& Schatz). Exot. Schmett., v. 1 p. $75 \mid 1900$ H. z., A. G. Butler in: Entomologist, v. 33 p. $190 \mid 1901$ H. z., F. D. Godman \& O. Salvin in: Biol. Centr.-Amer., Lep.-Rhop. v. 2 p. 667 (forma albipunctata) $1864 H$. jucundus + H. xanthicus, H. W. Bates in: Ent. monthly Mag., v.1 p. 56 (forma jucunda); p. 57 (forma xanthica) | 1870 Heliconia zudeika, Boisdural, Consid. Lép. Guatemala, p.30|1871 Heliconius zuleika + H. z. var.jucundus + H. z. var. xanthicus, W. F. Kirby, Cat. diurn. Lep., p. 139; p. 139 (forma jucuuda); p. 139 (forma xanthica) | $1881 H$. chrysantis $+H . j$. (part.) $+H . j$. var. $x .+H . z .$, F. D. Godman \& O. Salvin in: Biol, Centr.-Amer., Lep.-Rhop. v. 1 p. 146 (forma chrysantis); p. 146 t. 16 f. 10,11 (forma xanthica); p. 146 t. 17 f. 1,2 (forma jucunda); p. 147 | $1890 \mathrm{H}$. discomaculatus, Weymer in: Ent. Zeit. Stettin, v.51 p.289 (forma discomaculata)| $1893 \mathrm{H}$. jucundus + H. j. var. xanthicus + H. zuleika + H. chrysantis + H. d., Weymer in: D. ent. Z. Lep., v. 6 p. 342 (forma jucunda); p. 343 (forma xanthica); p. 343 ; p. 343 (forma c.); p. 343 (forna discomaculata) $\mid 1900 \mathrm{H} . z$. aberr. albipunctata, (O. Staudinger in MS.) Riffarth in: Berlin. ent. Z., v.45 p.199 (forma a.) | 1901 H. clara discomaculatus $+\bar{H}$. c. xanthicus + H. c. chrysantis + H. clara jucundus $+H$. c. a. + H. c. z., Riffarth in: Berlin. ent. Z., v. 46 p. 75 (forma discomacnlata); p. 75 (forma xanthica); p. 75 (forma chrysantis); p. 76 (forma jucunda); p. 77 (forma a.); p. 100.

Forma principalis. Vorderfiügel vorherschend schwarz, proximal in der Zelle schwach, hinter derselben und am Hinterrande rötlichbraun bestäubt. beim $q$ weniger und in trüberem Tone als beim $\sigma^{\top}$. Im distalen Teil der Zelle ein die Breite derselben ansfüllender, mehr oder weniger schwärzlich bestäubter oder zergliederter gelber Fleck, welcher die Trennmosstelle ron Keil- ıud Endzellfleck erkennen läßt. Nächst ihm distal von der Zelle, von del Mitte des Vorderrandes ausgehend, eine schräge. leicht gebogene Reihe ron 4 länglichen gelben Flecken, den Resten der durch das ausgeflossene Schwar\%. der Discalzeichnnng verdrängten Querbinde von H. a. melicerta (S. 95). Von diesen distal zwei parallel laufende Reihen gelber Snbapicalflecke, die sich am Distalrande nach hinten wenden und im weiteren Verlauf dicht beieinander und unweit des Distalrandes bis zllm Hinterwinliel liegen, cine Zeichnung wie sie bei einzelnen Stïcken von H. a. melicerta anch vorkommt. Im hiuteren Medianzwischenraum ein weiterer, größerer oder kleinerer. heiu 
q oft undentlicher gelher l'leck, ebenfills ain Rudiment der Querhinde. welches die Grenze zwischen dem hinteren Median- und dem Randfleck angibt. Auf der Unterseite die distal liegende Fleckenreihe weih, meist rotbraune Bestäubung proximal an der Subcostalis bis über die Zelllüilfte. Hinterflïgel rötlichbraun, beim o düsterer, mit 2-3 mu breiter, vor'n riemliclı glatt begrenzter schwarzer Randhinde, die im Apex breit ausflicht und dort 1-3 gelbe Hlecke umgibt. Tom Apex aus gehen die Anfünge einer proximal gerichteten schwärzlichen Mittelbinde in ungewiß fleckartiger Bestäubung ans, indes höchstens bis in den vorderen Medianzwischenraun. dort in die Grundfarbe ausfließend. In einem einzelnen bekanten Fallo zicht sich bei einem $q$ auf der Unterseite durch die Zelle eine gelbe Querbinde. die oben schwach durchschlägt. Costal- und Subcostalstreif aluf der Enterseite in beiden Geschlechtern vollkommen vorhanden und hreit zusammengeflossen, der Torderrand selbst schmal braun, am Distalrande weiße Saumflecke. Flecke im Apex weiB, Flügelwurzel leicht gelb angeflogen. Im übrigen wie H. m. melicerta, aber die Antennen beim ơ stärker geschwärzt. beim $ᄋ$ dorsal auch bis zu der Keule schmal schwarz. - Torderflügellänge bis $\check{0} 0 \mathrm{~mm}$.

Bei flüchtiger Betrachtung ron H. a. melicerta recht rerschieden, aber bei Zergliederung der Zeichnung an der Hand der Artmerkmale nicht von H. a. melicerta spezifisch zu trennen und mit dieser durch die Forma xanthica eng verbunden.

Nicaragua, Honduras, Panama (in Höhen ron 600-900 m), Guatemala, Costa Rica.

Forma albipunctata. Unterscheidet sich von der vorigen Form dadurch, daß sämtliche Flecke weiß anstitt gelb sind. Es kommen jedoch anch Tiere mit weißen distalen und gelben proximalen Flecken vor, welche C̈hergänge darstellen.

Pauama (Chiriqui).

Forma chrysantis. Torderfügel äbnlich der Hauptform, aber die außerhalb der Zelle gelegene, bei dieser gänzlich in Flecke aufgelöste Selıägbinde hier etwas zusammenhängender, wenngleich nicht rollständig geschlossen. Hinterflügel wie bei jener mit einer schwefelgelben Längsbinde durch die Zelle. Es kommen Übergänge zu der Hauptform vor.

Nicaragua.

Forma discomaculata. Torderfligel proximal außer bräunlicher Bestäuhung an der Mediana und Submediana bis zur schwefelgelben Querbinde dunkel schwarzbraun, Keilfleck eingeschlossen. Die Binde wie bei H. a. melicerta, nur der im mittleren Medianzwischenraum liegende gelbe Fleck größer. distal den vorderen Medianfleck deutlich isolierend und rorn und hinten mit dem übrigen Gelb lose zusammenhängend, so daß dieses mit dem Fleck ein Ganzes, und zwar ein distal winkelförmig eingeschnittenes breites Band bildet. in welchem der Endzellfleck und die Medianflecke eingeschlossen sind. Distaler und apicaler, ebenfalls schwar\%braun gefürbter Flügelteil mit zwei rollständigen, gebogenen Reihen gelber Flecke, die im Hinterwinkel sehr grob sind. Hinterflïgel wie bei der Hauptform, auf der Unterseite zwei weiße Subapicalflecke und etwas gröBere Saumflecke, Vorderrand braun, Flïgelwurzel gelb.

Honduras. 
Forma jucunda. Vorderflügel proximal in der Zelle. hinter derselben und an etwa zwei Dritteln des Hinterrandes dunkelorangebraun. Vorderrand schwarz, Keilfleck mit proxiual gerichtetem Spitzenansatz deutlich markiert, sonst wie die Hauptform gezeichnet, aber alle dort schwefelgelben Flecke rein weiß, der im Hinterwinkel stehende Fleck indes bräunlich ïberstäubt. — Hinterflügel in der Färbung wie der proximale Teil des Vorderflügels. mit vollständiger, schwarzer Mittelbinde, welche vorn ziemlich gerade, hinten zwischen den Adern stark gekerbt, in ganzer Iänge ziemlich gleich breit ist und in den Apex ausläuft. Ferner mit schwarzer Randbinde, welche voln etwals gezähnt ist.

Panama (Lion-Hill-Station, Veragua).

Forma xanthica. Vorderflïgel wie bei der vorigen Form gezeichnet, aber Bestäubung proximal hellbraun, Zelle im Discus und distalen Teil gelb. Hinterflügel im Farbtone der proximalen Bestäubung des Vorderflügels, mit schwarzer Randbinde, die vorn etwas gezähnt ist und mit unvollkommener, vom schwarzen Apex ausgehender, in Flecke aufgelöster Nittelbinde, die schmaler ist als bei der Hauptform und sich bis etwa in die Flügelmitte erstreckt, proximal also den Hinterrand nicht berührt. Auf der Unterseite ist sie etwas länger und breiter, aber verschwommener. Daselbst 3 kä̈ftige weiße Flecke im Apex und weiße, dem Distalrande aufsitzende Saumfleckchen. Beim ơ Costal- und Subcostalstreif getrennt, ersterer proximal verkürzt, letzterer voll, nicht unterbrochen.

Panama.

22 g. H. anderida fornarina (Hew.) 1854 Heliconia f., Hewitson, Exot. Butt., $v .1$ Heliconia t. 3 f. 9 | 1871 Heliconius f., W. F. Kirby, Cat. diurn. Lep., p. $144 \mid 1881$ H. f., F. D. Godman \& O. Salvin in: Biol. Centr-Amer., Lep.-Rhop. v. 1 p. $145 \mid 1893$ H. f., Weymer in: D. ent. Z. Lep., v. 6 p. 343 | 1901 H. clara f., Riffarth in: Berlin. ent. Z., v. 46 p. 77.

Beide Flügel dunkel schwarzbraun,Vorderflügel sonst wie bei H.a. melicerta (S. 95) gezeichnet, nur daß sich der Keilfleck in der Zelle nicht von der Grundfarbe abhebt und im distalen Teil zwei gebogene, vollständige Reihen gelber Flecke stehen, wie sie bei H. a. melicerta nur in seltenen Fällen auftreten, auch ist die gelbe discale Schrägbinde in der distalen Lage dadurch etwas verändert, daß der bei $H$. a. melicerta im mittleren Medianzwischenraum liegende gelbe Fleck vergrößert und distal vorn und hinten mit dem ïbrigen Gelb leicht zusammenhängt wie bei H. a. zuleika, forma discomaculata (S. 99). Die Querbinde umschließt den mit dem schwarzen Vorderrande zusammengeflossenen unregelmäßigen Endzellfleck und die beiden voneinander isolierten Medianflecke, deren vorderer stumpf dreieckig, längs gestellt, deren hinterer rundlich gestaltet ist. Die hintere Begrenzung der Binde liegt auf dem hinteren Mledianast. distal wird dieselbe durch den proximal vorgeschobenen Randfleck, der mit dem breiten schwarzen Distalrande verflossen ist, keilförmig ausgeschnitten. Flecke im Hinterwimkel kräftig und groß. Selten zeigt sich an der Mediana proximal der Schein heller brauner Bestäubung, dagegen ist die Mediana oben und unten, unten auch die Subcostalis rotbräunlich bestänbt, so daß sich der mit breitem Ausläufer nach der Flügelwurzel versehene Keilfleck in der Zelle deutlich abhebt. - Der oben fast einfarbige Hinterflügel mit einem gelben Fleck im Apex, unten mit zwei, ferner mit rotbraunem Vorderrande, einem rotbraunen Streif hinter der Snbcostalis nnd einem solchen in der Mitte zwischen Zelle und dem Distallande, diesem 
folgend, rom Hinterraude ausgehend und allmälilich, etwa bei dein vorderen Medianast in der schwar\%bramen Farbe verschwindend. Hierdurch wird sowolil die schwarze Mittelbinde als anch die Randhinde in der der Gruppe eigentïmlichen Weise in 1 ngewisser zackiger Begrenzung markiert. Nahe dem Distalrande unterseits weiße Saunfleckehen. - Fransen schwarz und weiß gescheckt. Vorderflïgellänge $50-52 \mathrm{~mm}$.

Guatemala.

H. arcuatus F. Kirby 1772, Scopoli, Annus V'. hist.-nat., 1. $113 \mid 1779$, Papilio Heliconius arcuatus", Goeze, Ent. Beytr.. v.3 I p.114 | 1877 Heliconius? arcuatus, WV. F. Kirby, (at. diurn. Lep., Suppl. 1).721, 1900 H. a., Riftarth in: Berlin. ent. \%.. r. 45 j. 194.

Rotgelb, Vorderflügel mit sehwarzem Apex und drei gelbliehen Fleeken. gelber Bincle mit schwarzen Fleeken und gebogener schwarzer Biude. - Lngenïgende Besehreibung, welche nur die Grundzüge rersehiedener Vertreter der Gruppe erkennen läßt.

Heimat unbekaunt.

H. euclea (Godart) 1819 Heliconia e., (Latreille \&) J. B. Godart in: Enc. méth.. r.9 p. $220 \mid 1871$ Heliconizs?? e., W. K. Kirby, Cat. diurn. Lep., p. $144 \mid 1900$ H. e., Riffarth in: Berlin. ent. Z., $v$. 45 p. 194.

Vorderflugel proximal und hinten bis zum Hinterwinkel rotbraun. nit zwei sehwarzen Fleeken etía in Diseus nnd mit sehwarzem Vorderrande, im iibrigen schwarz nit einer ziekzaekförmigen, gelben Querbinde. sehräg liegend zwisehen einer Reilıe gelber randständiger Punkte und dem braunen proximalen Felde des Flïgels, aber näher an diesem. - Hinterflügel gelbbraun mit zwei sehwarzen Querbiuden, von denen die hintere gerade, die rordcre nach hinten gebogen ist und sieh mit ersterer im Apex vereingt, außcrdem mit schwarzer Randbinde, die rorn ausgezaekt ist und in welcher eine Reihe gelblicher Fleckehen liegt. - Unterseite wie die obere Seite, nur die randständigen Fleekchen weiB. - Körper asehfarben unit gelben Fleeken auf dem Thorax. Antennen rotgelblich, proximal schwarz. Spannweite 54 mm.

Vielleicht eine zu H. silvana (S. 50) gehörige Form, nach der geringen (rröße zu urteilen, aber möglielıerweise auch eine Form oder Art der Neotropiden-Gattung. Mechanitis Fabrieius oder Ceratinia Hübner.

$$
\text { Antillen (?). }
$$

\section{b. Coh. Cydnoformes}

Kopf schwar\%, Punktierung weiß oder gelb wie bei den Silvaniformes (S. 38). Augen schwarzbrann, hinten weiß oder gelb eingefaßt. Palpell gelb oder weiß, Spitze oder Endglied schwarz. Antennen schwarz, etwas länger als die Zelle des Vorderflïgels. Körper schwarz. Halskagen und rorderer Teil des Thorax weiß oder gelb punktiert wie bei der vorigen Gruppe. Thorax dorsal einfarbig oder nur mit Spuren gelblicher Behaarung. Abdomen weuig über den Hinterflïgel hinausragend, lateral mit zwei, selten vollkomneueu, meist unterbrochenen, zuweilen sehr rudimentären und durch kintrocknen in eiuer Läugsfalte verborgenen, gelben Längslinien. ventral vorn wenig; hinten reichlicher gelb oder weißlich. Torderbeine ebenso, die iibrigen Beine schwalz, Brust lateral zwischen den Hüften schwach gelblich behart. -Vorderflügel gestreckt, Torderrand sehwach gekrümmt, Apex abgeruudet. Distalrand fast gerade, Hinterwinkel stumpf. Hinterrand viel kürzel als der Torderrand, leicht S-förmig gebogen. - Hinterflïgel eirund, Apex wenig hervortretend, Distalsaum schwach wellig, Hinterwinkel abgerundet. — Schwarzblaue, stark glänzende Falter mit gelben oder weißen Binden oder Flecken. o mit hell- nud dunkelgranem, his unnittelbar zur Mediana glïnzendem 
Hinterrandteil auf der Unterseite des Vorderflïgels und hellgrau glänzendem Yorderrandfelde des Hinterflügels. o mit stumpf schwärzlichem, manchmal rötlich abgesetztem Hinterrandteil auf der Unterseite des Vorderflügels und dunkelgrauem, mattem, zuweilen rötlich bestänbtem Vorderrandteil des Hinterflïgels.

3 Arten, von denen eine in 9 Unterarten zerfällt.

23. H. cydno (Doubl.)

ठ઼. Stirupunkte weiß, die ïbrige Körperzeichnung gelb. Grundfarbe der Flügel blauschwarz glänzend, seltener mit grünlichem Schimmer bis auf den stumpf schwarzen Apex und Distalrand. - Im Discus des Vorderflügels eine vom Vorderrande nach dem Hinterwinkel gerichtete, mehr oder weniger breite, vorn meist gegabelte, weiße oder gelbe Schrägbinde, welche am Zellende und im mittleren Medianzwischenraum vollkommen unterbrochen und in eine kürzere distale und längere proximale Binde zerfallen, oder aber auch vollständig in Flecke aufgelöst sein kann; zuweilen treten Apical- und Saumfleckchen oder eine gebogene Reihe Subapicalflecke auf. - Hinterflügel mit gelber oder weißer, mehr oder weniger breiter Randbinde oder einer Reihe großer, fast randständiger Flecke, auch ohne vollkommene Randbinde, sondern nur mit einigen Flecken im Apex und vorderen Teil des Distalrandes. Vorderrandfeld hell glänzend grau mit dunklerer Umrandıng, den Torderrand selbst schmal grau lassend. - Unterseite des Vorderflügels anßer dem Gruppencharakter ohne wesentliche Verschiedenheiten, die des Hinterflügels vorn und hinten mit je einer mehr oder weniger deutlichen, manchmal sehr verloschenen rötlichbraunen Binde; beide beginnen proximal und sind, dem Vorderrande, beziehungsweise dem Distalrande folgend, mehr oder weniger weit ausgedehnt. Am Hinterrande sind dieselben oft zusammengeflossen, die vordere häufig rudimentär oder ganz fehlend. Vordeñand meist rötlichbraun, Flügelwurzel schwefelgelb. — lichen Unterschieden der Gruppe. Vorderrandteil des Hinterflügels oberseits und Vorderflügel hinter der Mediana unterseits zuweilen rötlich.

Peru, Ecuador, Colombia, Venezuela, Mittel-Amerika.

Diese Art zerfällt in 9 Unterarten:

23 a. H. cydno cydno (Doubl.) 1847 Heliconia c., E. Doubleday (\& Westwood), Gen. diurn. Lep., v. 1 p. 103 t. 15 f. 3 | 1851 H. c., Chenu \& H. Lucas, Enc. Hist. nat., Pap. diurn. p. 68 t. 29 f. $2 \mid 1871$ Heliconius c., W. F. Kirby, Cat. diurn. Lep., p. 140 1874 H. c., A. G. Butler \& Herb. Druce in: P. zool. Soc. London, p. 351 | 1879 H. c., Hopffer in: Ent. Zeit. Stettin, v. 40 p. $433 \mid 1880$ ? H. c., Buchecker, Syst. Ent, Lep. t. 57 f. $21 \mid 1885$ H. c., O. Staudinger (\& Schatz), Exot. Schmett., v. 1 p. $77 \mid 1890$ H. c., Weymer (\& Mraassen), Lep. Reise Stübel, p. 9, 27 | 1896 H. c., O. Staudinger in: D. ent. Z. Lep., v. 9 p. 289 | 1901 H. c., Riffarth in: Berlin. ent. Z., v.46 p. $82 \mid 1901$ H. c., F. D. Godman \& O. Salvin in: Biol. Centr.-Amer., Lep.-Rhop. v. 2 p. 668.

Grundfarbe der Flügel blauschwarz, stark glänzend bis auf den matter schwarzen Apex und Distalrand. - Vorderflügel mit einer breiten gelbell, von den Adern schwarz durchzogenen, discalen Querbinde, welche vorn am Zellende keilförmig von der Grundfarbe eingeschnitten ist, wodurch im distalen Teil der Zelle ein länglicher, in der Mitte zusammengeschnürter Fleck abgesondert wird. Dieser ist manchmal, namentlich beim o, rudimentär oder fehlt ganz. Die Binde ist distal schwach gebogen und erreicht den Hinterwinkel. Ihre proximale Begrenzung, namentlich im hinteren Verlauf, ist ungewiß zerstäubt, allmählich in die Grundfarbe aufgehend, beim $\sigma^{\top}$ mehr als beim $Q$. 
In Hiuterwinkel und auch vor demselben ist das Gelb läufig weib ïberstäubt, oder es bildet sich ein ganz weißes bindfleckchen. - Hinterflingel mit schmal schwarzem, im Hinterwinkel spitz, im Apex breiter endigendem schwarzem Distalrande olne Schiller. Nalıe demselben eino ihn folgende breite weiße Binde, welche von den Adern nud von der längs derselben beiderseits eindringenden schwarzen Grundfarbe in längliche, abgerundet rechteckige Flecke geteilt wird. Die Binde ist am Vorderrande am hreitesten, verschmälert sich allmählich nud endet spitz in Hinterwinkel. Ihre Begrenzung ist umscharf, beiderseits tritt in den Aderzwischenräumen noch die Grundfarbe wisch-oder keilartig in das Weiß der Binde ein, vorn mehr als hinten. ơ mit hellgrau glänzendem Vorderrandteil, in dem nur ein kleiner weißer Fleck als vorderer Bindenanfang steht, beim $Q$ ist diese Fläche schwärzlich, die Binde beginnt unmittelbar am Vorderrande. - Unterseite matter, das Gelb der VorderHiigelbinde weißlich, etwas glänzend. Hinterflügel mit gelbem WTurzelstreif am Vorderrande und zwei mehr oder weniger dentlichen rotbraunen Binden, wie bei der Art beschrieben. - Fransen des Torderflügels bis gegen den Hinterwinkel schwarz, dort etwas weib abgesetzt, die des Hinterflügels weib, nur schmal schwarz an den Adern unterbrochen. - Vorderflügellänge bis $46 \mathrm{~mm}$.

Colombia (Muzo, Llanos de San Martin, Tal des Rio Dagua, Medellin), Honduras.

23 b. H. cydno eydnides Staud. 1885 H. cydho var. cydnides, O. Staudinger (\& Schatz), Exot. Schmett., v. 1 p. $77 \mid 1896$ H. cydno var.? cydnides + H. cydno var. subcydnides + H. c. var. epicydnides, O. Standinger in: D. ent. Z. Lep.. v. 9 p. 289 ; p. 289 (forma s.); p. 289 t. 6 f. 2 (forma e.) 1901 H. cydno cydnides (H. intermeta Plötz in MS.) + H. cydno s. +H. c. e., Riffarth in: Berlin. ent. Z., v. 46 p. 83 ; p. 83 (forma s.); p. 84 (forma e.).

Folma principalis. Grundfarbe wie bei der vorigen Unterart. Gelbe Querbinde des Vorderflïgels vom Yorderrande aus am Zellende und im mittleren Medianzwischenraum breit unterbrocheu, so daß. eine außerbalb der Zelle

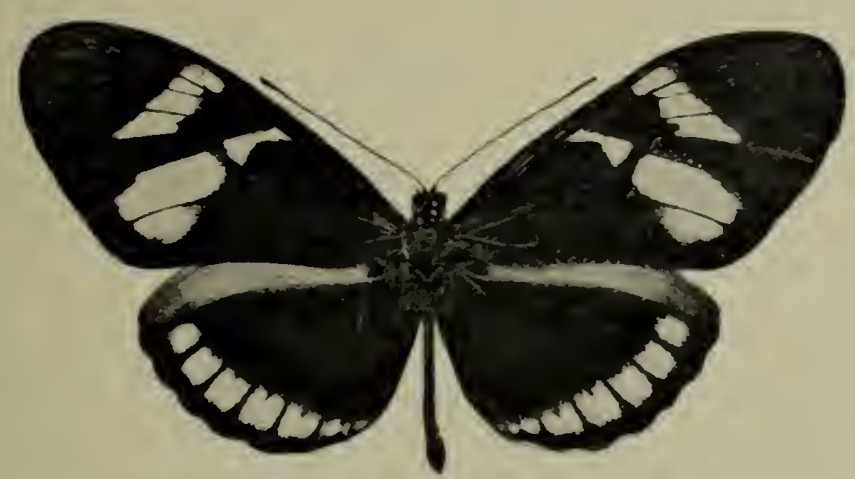

Fig. 18. H. cydno cydnides, forma subeydnides, $ठ(1 / 1)$. Vgl. S. 104.

gelegene, vom schmal schwarzen Vorderrande bis zum vorderen Medianast reichende, etwa 3-6 mm breite Schrägbinde nnd eine zweite, dieser parallellaufende Binde entsteht, welche voru, in der Zelle, schmaler, dann stark verbreitert ist, bis zum Hinterwinkel reicht und hiuten ungewiß gelb zerstäubt und in proximaler Richtnng ausgeflossen ist. Im Hinterwinkel wie bei der typischen Uuterart mehr oder weniger weibfleckig, sonst wie diese, nur die Rand- 
binde des Hinterflügels zusammenhängender, die Adern darin weniger oder gar nicht schwarz angelegt.

Colombia (Antioquia, Canca).

Forma subcydnides. Vorderflügel (Fig. 18) wie bei der Hauptform, aber die gelbe, discale Schrägbinde endet kurz vor dem Hinterwinkel und ist hinten abgerundet. Saumbinde des Hinterflügels etwa $3 \mathrm{~mm}$ vom Distalrande abgerückt, halb so breit wie bei jener und durch die stark schwarz bestäubten Adern in einzelne Flecke aufgelöst, die in der Mitte der Aderzwischenräume beiderseits schwärzlich eingeschnürt oder eingekerbt, in seltenen Fällen noch durch schwarz bestäubte Striche in der Mitte der Länge nach durchschnitten sind.

Colombia (Canca, Tal des Rio Dagua).

Forma epicydnides. Von der Hauptform dadurch unterschieden, daß die weiße Saumbinde des Hinterflügels sebr breit ist $(7-8 \mathrm{~mm})$ und unmittelbar am Rande liegt. Dort sind manchmal an und zwisehen den Adern noch Spuren des schwarzen Randes in Gestalt kleiner schwärzlicher, verwischter Dreiecke erhalten. Es kommen Übergänge in allen Stadien der Verschmälerung und Zergliederung dieser Binde vor.

Colombia (Cauca, Tal des Rio Dagua).

23 c. H. cydno alithea (Hew.) 1869 Heliconia a., Hewitson, Equat. Lep., p. 10 1871 H. a., Hewitson. Exot. Butt., v. 4 Heliconia t. 6 f. $18 \mid 1871$ Heliconius a., W. F. Kirby, Cat. diurn. Lep., p. 140 | 1900 H. cydno aberr. haenschi, Riffarth in: Berlin. ent. Z., v. 45 p. 200 (forma h.) 1901 H. c. alithea + H. c.h., Riffarth in: Berliu. ent. Z., v. 46 p. $82 ;$ p. 83 (forma h.).

Forma principalis. Vorderflügel mit gegabelter gelber Binde ähnlich wie bei der typischen Unterart, dieselbe ist aber im vorderen Teil schmaler, ihre distale Begrenzung unregelmäßig in der Form, bald flach, bald S-förmig gebogen, mitunter auch in der Mitte stumpf gewinkelt, die Ader'n in derselben stark schwarz bestäubt, der vordere Teil zuweilen rudimentär. namentlich der im distalen Teil der Zelle liegende Zweig fleckartig isoliert, teilweise oder ganz erloschen, und der distal von der Zelle liegende Zweig voll der Grundfarbe stark eingeschnitten oder unterbrochen. Die Binde reicht bis zum hinteren Medianast; hinter demselben nur unscharf begrenzte gelbliche Überstäubung: im Hinterwinkel meist wieder ein reiner gelber, mit dem hinteren Teil der Binde lose zusammenhängender Fleck, welcher namentlich beim $Q$ in proximaler Richtung am Hinterrande ansläuft. Distal von der Binde am Vorderrande etwa auf der Mitte bis zum Apex häufig Spuren gelber Fleckchen. Auf der Unterseite die Binde von weißlichem Glanz, läng's der Mediana von der Ww'zel aus schwach gelbliche Bestäubung; am Distalrande eine Reihe weißer, im Hinterwinkel großer, dann kleiner werdender und im Apex versehwindender Saunflecke. - Hinterflügel mit breiter hellgelber Saumbiude, durchzogen von schwarzen Adern, am Hinterraude breit beginnend, beim $\delta$ in einem undeutlichen Fleck im grauglänzenden Vorderrandteil am Apex endigend, beim of deutlich bis zum Vorderrande, Apex jedoch schwarz bestäubt. Der Distalrand selbst etwas heller, beim $\delta$ mitunter ganz schmal weiß, an den Aderenden stärkere schwarze Bestäubung. Vorderer Rand der Binde in den Aderzwischenräumen schwarz, mehr oder weniger tief strahlenförmig eingeschnitten. Unterseite mit gelbem Wurzelstreif am Vorderrande und rotbrauner, breit am Hinterrande nächst der Flügelwurzel beginnender und 
distal vou der Zelle spitz auslaufender. gekrümmter Mittelbinde. Randbinde weißlich oder ganz weib, Adem in derselben weniger stark schwaלz; unmittelbar ror derselben, vom Hinterrande aus, eine zweite, ersterer folgende, nurollständige, distal allmählich rerschwindende rothraune Binde oder Spuren einer solchen. Fransen weiß. - Vorderflïgellïnge lis $42 \mathrm{~mm}$.

Ecuador (Balzapamba). In Höhe ron $800 \mathrm{~m}$; Juni, Juli.

Forma lianschi. Lnterscheidet sich ron der Hauptform dadurch, daß die Zeichungen von Vorder- mo Hinterflügel milchweiß statt schwefelgelb sind.

Ecuador. Neben der Hauptform.

23 d. H. cydno hahneli Staud. 1885 H. h., O. Staudinger (\& Schatz), Exot. Schmett., p.77 t.31 | 1890 H.h., Hahnel in: D. ent. Z. Lep., v. 3 1. $261 \mid 1901$ H. cydno h., Riffarth iu: Berlin. eut. Z., c. 46 p. 82.

Vorderflügel mit gegahelter, weißer oder gelber Binde, deren in der Zelle liegender vorderer Teil voll und breit, deren distal von dieser gelegener Zweig meist schmaler ist als bei der typischen Unterart. Distal eine Reihe, manclımal zusanmenhäugender, gelber bis weißer Subapical- und Saumflecke, die selten bis zum Hinterwinkel laufen. Hinterflügel mit weißer, fast randständiger Binde, etwa 2-3 mm vom Distalrande entfernt, manchmal durch schwarze Bestäubung längs der Adern in Flecke aufgelöst oder verlosehen. Sonst wie die typische Lnterart.

Venezuela (Merida). In Höhe von $400 \mathrm{~m}$.

23e. H. cydno temerinda (Hew.) 1873 Hcliconia t., Hewitson, Exot. Butt, $v .5$ Heliconia t. 7 f. 231885 Heliconius t.. O. Staudinger (\& Schatz), Exot. Schmett., v.1 p.77| 1877 H. tamarinda, W. F. Kirby, Cat. diurn. Lep., Suppl. 1.722 | 1901 H. cydno ternerinda, Riffarth in: Berlin. ent. Z., v.46 j. 82.

Querbinde des Torderflügels weiß oder gelb, vor'n gegabelt. Das in distalen Teil der Zelle liegende Stïck fleckírtig abgesondert, distale Grenze S-förmig gebogen, von schwarzen Adern durchzogen. Zwischen Querbinde und Apex eine S-förmig gebogene Reilse weißer Subapicalflecke. die sich nach hinten nächst dem Distalrande his zum Hinterwinkel fortsetzen. Hinterflügel mit gelber, etwa $3-4 \mathrm{~nm}$ breiter und $4 \mathrm{~mm}$ rom schwarzen Distalrande entfernt verlaufender Binde. Adern in derselben schwarz bestäubt. Sonst wie die typische Cnterart. Größe wie die der rorigen Lnterart.

Colombia (Villagomes, San Augustin).

23f. H. cydno hermogenes (Hew.) 1857 Heliconia h., Hewitson. Exot. Butt., v. 2 Heliconia t. 4 f. 12 | 1871 Heliconius h., W. F. Kirloy, Cat. diurn. Lep., p. 14t|1901 H. cydro h., Riffarth in: Berlin. ent. Z., r. 46 p. 7.9.

Binde des Torderflügels rollkommen in Flecke anfgelöst, welche vorherrschend weiB. teilweise aber anch gelb sind. Lis entstehen 2 Fleckenreihen, eine discale und eime außerbalb der Zelle gelegene, ähnlich wie bei H. anderida zuleika (S. 98), nur daB hier die distale Reihe Subapicalflecke fehlt. Hinterflügel mit schwefelgelber, durch die schwarz bestüubten Adern in einzelıe Flecke aufgelöster, etwa $3-4 \mathrm{~mm}$ rom selıwarzen Distalrande entfernter Binde. Die einzelnen Flecke derselben in der Mitte vorn und hinten dureh schmal keilförmig eintretende Grundfarhe eingeschnürt. 
Unterseite mit sehr stark ausgeprägten, der Art eigentümlichen rotbraunen Binden. Sonst wie die typische Unterart. Vorderflügellänge etwa $47 \mathrm{~mm}$.

Colombia (Cauca).

$23 \mathrm{~g}$. H. cydno chioneus Bates 1864 H. chioneus, H.W. Bates in: Ent. monthly Mag., v. 1 p. $58 \mid 1871$ H. cydno var. chioneus, W. F. Kirby, Cat. dinrn. Lep., p. $140 \mid$ 1881 H. chioneus, F. D. Godman \& O. Salvin in: Biol. Centr.-Amer., Lep.-Rhop. v. 1 p. 156 t. 18 f. $7,8 \mid 1885$ H. c., O. Staudinger (\& Schatz), Exot. Schmett., v. 1 p. 77 t. 31 1890 H. c., Weymer (\& Maassen), Lep. Reise Stübel, p. 9 | 1901 H.cydno chioneus, Riffarth in: Berlin. ent. Z., v. 46.

Zeichnung wie bei der typischen Unterart, aber Querbinde des Vorderflügels r'ein weiß, der in der Zelle liegende Teil derselben zuweilen rudimentär oder ganz fehlend; zuweilen verloschene weiße Saumfleckchen, die sich im Hinterwinkel manchmal deutlicher vom hinteren Ende der Binde absonderu. Hinterrand des Vorderflïgels auf der Unterseite und Vorderiand des Hinterflügels auf der Oberseite beim o rötlich. Binde des Hinterflügels beim etwas weiter vom Distalsaum entfernt, namentlich gegen den Apex zu, sonst wie bei der typischen Cnterart. Vorderflügellänge bis $44 \mathrm{~mm}$.

Panama, Colombia (Medellin, Tal des Rio Dagua).

23 h. H. cydno galanthus Bates 1864 H. g., H. W. Bates in: Ent. monthly Mag., v. 1 p. 58 | 1874 H. g., A. G. Butler \& Herb. Druce in:' P. zool. Soc. London, p. $351 \mid 1880$ ? H. g., Buchecker, Syst. Ent., Lep. t. 57 f. 20 | 1881 H. g., F. D. Godman \& O. Salvin in: Biol. Centr.-Amer., Lep.-Rhop. v. 1 p. 155 (\& forma diotrephes) | 1901 H. g., F. D. Grodman \& O. Salvin in: Biol. Centr.-Amer., Lep.-Rhop. v.2 p. 667 (\& forma stübeli) | 1869 Heliconia diotrephes, Hewitson in: Tr. ent. Soc. London, p. 33 (forwa d.) 1871 Heliconius galanthus + H.d., W.F. Kirby, Cat. diurn. Lep., p. 140; p. 140 (forma d.) | 1900 H. cydno aberr. stübeli, Riffarth in: Berlin. ent. Z., v.45 p. 199 (forma s.) | 1901 H.c. galanthus (H.piera Plötz in MS., err., non Papilio (H.) p. Linné 1758!) + H.c. diotrephes + H. c.s., Riffarth in: Berlin. ent. Z., v. 46 p. 80 ; p. 81 (forma d.); p.81 (forma s.).

Forma principalis. Querbinde des Vorderflügels milchweiß, von den schwarzen Adern durchschnitten, gegabelt, breiter als bei der typischen Unterart. Distale Grenze vor'n näher zum Apex, als zum Zellende, fast gerade oder schwach gebogen, in schräger Richtung bis zum vorderen Medianast laufend, hinter demselben scharf winklig in der Richtung des Distalrandes abgesetzt und dann wiederum schräg oder gebogen in den Distalrand am mittleren Medianast auslaufend. Der von dem keilförmigen schwarzen Fleck am Vorderrande in der Zelle abgesonderte Teil meist sehr groß, proximale Begrenzung der Binde hinter der Zelle unscharf und ungewiß zerstäubt, am hinteren Medianast stumpfwinklig abgesetzt. schräg in den Hinterwinkel einlaufend und hier längs des Hinterrandes etwas in proximaler Richtung ausgeflossen. Manchmal sind beim o vor dem distalen Ende der Binde verloschene Saumfleckchen vorhanden, die auf der Unterseite in beiden Geschlechtern meist deutlicher auftreten und bis zum Apex reichen. - Hinterflügel fast einfarbig blauschwarz, nur im Apex einige nach hinten zu kleiner werdende weiße Flecke, die sich zuweilen auf der Unterseite weiter fortsetzen und in seltenen Fällen eine vollständige Reihe von Saumfleckchen bilden, welche als Rudimente der der Art eigentümlichen Randbinde zu betrachten sind. Solche Stücke stellen das Bindeglied mit H. c. chioneus dar, und läßt sich vorliegende Form deswegen spezifisch nicht von der Art abtrennen. Unterseite des Hinterflügels mit schmal rotbraunem, nicht gelbem Vorderrande und zwei ziemlich schmalen und weiter als bei der typischen 
Unterart voneinauder stehenden Binden von gleicher Farbe, deren vordere manchmal nur im proximalen Teil erhalten ist. -- Fransen des Vorderflügels schwarz und weib, die des Hinterflügels vorherrschend weils, schmal schwarz unterbrochen. - Vorderflügellänge bis $45 \mathrm{~mm}$.

Honduras, Guatemala, Costa Rica, Chiriqui, Peru.

Forma diotrephes. Von der Hauptform dadurch unterschieden, dab auf Ober- und Unterseite des Vorderflügels eine Reihe sehr dentlicher, weiber Sirumflecke steht und am sonst rotbraunen Vorderrande des Hinterflügels auf der Unterseite ein gelber Wurzelstreif auftritt.

Nicaragua, Guatemala.

Forma stübeli. Die weiße Querbinde des Vorderflügels gleichmäßiger breit als bei der Hauptform, der sonst in der Zelle stehende, am Vorderrande fleckartig abgesonderte proximale Teil derselben fehlt; ferner außer der randständigen Fleckenreihe der vorigen Form eine zweite Reihe weißer Fleckchen nahe dem Distalrande des Vorderflügels.

Costa Rica.

23i. H. cydno zelinde Butl. 1869 H.z., A. G. Butler in: Ann. nat. Hist., ser. 4 v. 3 p. 17 t. 9 f. $1 \mid 1871$ H.z., W. F. Kirby, Cat. diurn. Lep., p. $144 \mid 1893$ H.z., Weymer in: D. ent. Z. Lep., v. 6 p. $344 \mid 1901 H$. $z$, Riffarth in: Berlin. ent. Z., v. 46 p. 80.

Nächst H. c. galanthus, aber die weiße Querbinde des Torderflïgels kürzer und breiter, fast fleckartig. Sie endet nngefähr kurz hinter dem hinteren Medianast, so daß der Hinterwinkel schwarz bleibt. In diesem und zureilen auch im Apex mehr oder minder deutliche Spuren weißer Fleckchen. Hinterflügel ohne Sammbinde, im Apex ebenfalls Spuren weißer Fleckchen. - Unterseite auf beiden Flügeln mit weißen rundlichen Saumfleckchen, etwa $1 \mathrm{~mm}$ vom Distalrande entfernt und in der Mitte der Aderzwischenräume liegend. Dieselben nelımen nächst dem Apex des Hinterflügels und dem Hinterwinkel des Vorderflügels zu und sind dort am größten. Rotbraune Bindenzeichunng des Hinterflügels sehr intensiv nnd vollkommen. Vorderflügellänge etwa $44 \mathrm{~mm}$.

Westliches Colombia (Tal des Rio San Juán. Rio Dagua und Rio Juntas).

24. H. weymeri Staud. $1896 H . w .+H, w$, aberr, gustavi, O. Staudinger in: D. ent.Z.Lep., v.9 p. 287 t. 6 f.5; p. 287 t. 6 f. 1 (forma g.) | 1901 H. cydno w. + H.c.g., Riffarth in: Berlin. ent. Z., v. 46 p. 84 ; p. 84 (forma g.).

ণ̃. Vorderflügel etwas schlanker als bei der vorigen Art, Apex stïrker abgerundet. Grundfarbe blansehwarz, wenig glänzend, fast matt, Apex und Distalrand stumpf schwarz. Torderflügel mit zwei weißen, selten gelben, schräg liegenden Querbinden oder Fleckenbinden, einer discalen vollständigen, welche jedoch den Hinterwinkel nicht erreicht, und einer außerhalb der Zelle gelegenen nnvollständigen, mehr oder weniger in Flecke aufgelösten, welche an dem vorderen Medianast endet. Beide Binden können fehlen nnd nur stellenweise durch matt bläuliche Punkte angedeutet sein. Unterseite matter, sonst ohne Unterschiede außer dem Gruppencharacter: - Hinterflügel mit hreiter gelber Mittelbinde, die nur einen kleinen proximalen Teil der Zelle frei läßt, sonst diese ganz ausfüllt, vorn dicht an der Subcostalis entlang zieht und etwa 80-100 mm vom Apex entfernt stumpf endet. Vorderrandfeld hellglänzend grau, Apex und eine Umrandung des ersteren dunkler, der Vorderrand selbst schmal grau. Unterseite matter, Binde weißlich, Vorder- 
land mit einem gelben Wurzelstreif, 2 oder 3 weißliche Subapicalflecke. - . . Tie das $\sigma^{\pi}$, mit den unterschiedlichen allgemeinen Geschlechtscharakteren. Hinterrand des Vorderflügels anf der Cnterseite und Vorderrand des Hinterflügels oberseits rötlich. Auf der Unterseite des letzteren hinter der gelben Binde manchmal Spuren der der vorigen Art eigentümlichen rotbraunen Binde.

Colombia.

Forma principalis. Querbinden des Vorderflügels deutlich, weiß, selten gelh. Anlage ähnlich wie bei H. cydno cyduides (S. 103), die distale Binde heginnt schmal an der Subcostalis etwa im distalen Drittel der Zelle und bildet hier einen länglichen, in der Mitte zusammengeschnürten, hinten an der Mediana ziemlich breit durch die Grundfarbe von dem übrigen Teil der Binde abgetrennten Fleck. Hinter diesem setzt sich die Binde in einem verbreiterten länglichen Fleck schräg gegen den Hinterwinkel fort. diesen nicht erreichend, ron dem hinteren Medianast begrenzt oder denselbeu nur wenig überschreitend und distal von rorn nach hinten abgeschrägt. Die zweite, distal von der Zelle liegende Binde ist kürzer und schmaler, sie endet am vorderen Medianast, ist an den Adern fleckartig zerteilt nud verläuft etwas steiler als erstere. Zuweilen erscheinen am Vorderiande etwa nächst dem 4. Subcostalast ein auch zwei verloschene bläulichweiße Fleckchen, welche auf der stumpf schwarzbraunen Unterseite deutlicher zu bemerken sind. Beim $o$ ist die Mittelbinde des Hinterflïgels etwas breiter als beim o und stumpfer am Ende, die hintere Begrenzung in beiden Geschlechtern weniger scharf als die vordere, die darin liegenden Aderu im hinteren und distalen Teil scharf schwarz. sonst gelb bestänbt. Fransen schwarzbraum, am Vorderflügel stellenweise schwach weißlich, am welligen Saum des Hinterflügels reichlicher weiß unterbrochen. Vorderflügellänge etwa $43 \mathrm{~mm}$.

Südliches Cauca-Tal nächst Popayan, Tal des Rio Dagua.

Forma gustavi. Eine Abänderung der vorigen Form. bei der die Binden und Flecke des Vorderflügels soweit verkleinert sind, daß höchstens am Vorderrande und am hinteren Medianast Spuren derselben in Gestalt kleiner. lichtblauer oder weißlicher Flecke vorlianden sind. Zuweilen fehlen auch diese. Dagegen treten sowohl anf Oher- wie Unterseite mehr oder minder deutliche Spuren ron Saumfleckehen auf. Mittelbinde des Hinterflügels teilweise etwas schmaler als bei der Hauptform, sonst wie diese. Fs kommen C̈bergänge mit weniger eingeschränkten Binden vor.

Neben der Hauptform.

25. H. pachinus Salv. 1871 H. p., O. Salvin in: Ann. nat. Hist., ser. $t$ v.7 p. $414 \mid 1875$ H. p., O. Standinger in: Verh. Ges. Wien, v. 25 Abh. p. 98 | 1881 H. p., F. D. Godman \& O. Salvin in: Biol. Centr.-Amer., Lep.-Rhop. v. 1 p. 158 t. 18 f. 11 1885 H. p., O. Staudinger (\& Schatz), Exot. Schmett., v. 1 p. 80 t. $32 \mid 1875$ Heliconia p., Hewitson, Exot. Butt., v. 5 Heliconia t. 8 f. $26 \mid 1877$ Heliconius pochinus, W. F. Kirby, Cat. diurn. Lep., Suppl. p. 722 | 1880 ? H. pachynus, Buchecker, Syst. Ent., Lep. t. 55 f. 14.

Ђ. Punktierung und ron der Grundfarbe des Körpers abweichende Behaarung gelb. - Vorderflügel schlank. schmaler als bei der vorigen Art. Grundfarbe blauschwarz, etwas glänzend bis auf den stumpf schwarzen Apex und Distalrand. Torderflügel mit einer discalen und einer subapicalen schrägen Querbinde. Erstere beginnt etwa in der Mitte des Torderrandes, berührt proximal den Zellabschluß und zieht in ziemlich gleicher Breite und ganz flacher Krïmmung gegen den Hinterwinkel, etwa in einer Entfermung von 
$2 \mathrm{~mm}$ von demselben abgerundet endigend, selten in ungewisser Bestäubung denselben erreichend; ihre Breite heträgt $3-6 \mathrm{~mm}$. Die zweite, subapicale Binde reicht rom Vorderrande bis nahe zum Distalsaum im hinteren Radialzwischenramn und ist etwa $2-3 \mathrm{~mm}$ breit. Die Ränder beider Binden, namentlich die der letzteren nnd die distale Begrenzung der ersteren, etwas mnscharf, an den Adern etwas eingeschnïrt, diese selbst dïnn schwarz. Unterseite matter, Grundfarbe stumpf schwarzbramn, manchmal mit weiBlichen, verlosehenen Simmfleckchen, sonst ohne wesentliche Verschiedenheiten anßer dem Gruppencharakter. - Hinterflügel mit einer etwa $5 \mathrm{~mm}$ breiten gelben Binde, die $4-5 \mathrm{~mm}$ vom Distalrande entfernt liegt, rorn in den Aderzwischenräumen etwas wellig eingeschnitten ist und von den fein schwarzen Adern durchzogen wird; sie endet vorn kurz hinter dem granen Vorderrandteil. Unterseite matter, im Apex einige verloschene weiBliche Fleckchen, die sich auch längs des Distalrandes hinziehen und oben schwach durchscheinen können. Proximal rote. wischartige Flecke, deren vorderer als Wurzelstreif längs des Vorderrandes verlängert ist. - $-o$. Wie das $\sigma^{\top}$, aber mit den charakteristischen Geschlechtsunterschieden, sonst die Discalbinde des Vorderflügels in der Regel etwas schmaler. Hinterrand des Vorderflïgels auf der Unterseite rötlich, Saumfleckchen beider Flügel ebendaselbst deutlicher ausgeprägt. - - - Fransen beider Flügel schwarz. Vorderflügellänge etwa $40 \mathrm{~mm}$.

Chiriqui, Costa Rica.

\section{c. Coh. Melpomeneformes}

Kopf schwarz, Pnnktierung wie bei den Silvaniformes (S. 38). Augen schwarzbraun, hinten weißlich oder gelb eingefaßt. Palpen gelb oder weiß, Spitze oder Endglied schwarz. Antennen schwar\%, länger als die Hälfte des Vorderrandes des Vorderflügels. Halskragen und vorderer Teil des Thorax weißlich oder gelb punktiert wie bei den Silvaniformes. Thorax meist mit Spmen gelblicher Behaarung, namentlich hinten. Abdomen wenig ïber den Hinterflügel hinansreichend, lateral mit je einer einfachen, darunter mit je einer feinen doppelten gelben Längslinie, die mehr oder weniger deutlich nnd durch Zusammenschrumpfen des Leibes unkenntlich geworden sind, ventral in ganzer Iänge gelb, ebenso die Vorderbeine, die übrigen Beine schwarz, bei frischen Stücken leicht weißlich bestäubt. - Vorderflügel gestreckt, zuweilen etwas breiter, stumpfwinklig dreieckig: Vorderrand schwach gekrümmt, A pex abgerundet, Distalrand gerade, Hinterwinkel stumpf, mehr oder weniger abgerundet, Hinterrand kürzer als der Vorderrand, schwach S-förmig gebogen. - Hinterflügel eirund. Apex wenig hervortretend und abgesetzt, Distalsaum schwach gewellt, Hinterwinkel abgerundet. - Schwarzbraune, selten bläulich glänzende Falter mit roten, gelbroten bis schwefelgelben oder weißen oder in diesen Furben zusimmengesetzten discalen Zeichnungen des Vorderflügels, proximal häufig rot bestäubt; Hinterflïgel einfarbig schwarzbraun oder mit roten bis gelben Qnerbinden allein oder mit Strablenzeichnung. $\sigma^{\pi}$ mit hellgrau glänzendem Vorderrandteil des Hinterflïgels und größtenteils zeichnungslosem, granem. bis unmittelbar zur Mediana glänzendem Hinterrandteil der Vorderflügelunterseite. o mit schwïrzlichem, wenig von der Grundfarbe abweichendem Torderrandteil des Hinterflügels nnd stumpfem, etwas leller als die Grundfurbe bestïultem Hinterrandteil der Vorderflügelunterseite, in dem anch farbige Zeichnungen in gewissen Fällen anftreten. 
26. H. rubellius Grose Sm. \& F. Kirby 1892 H. r., Grose Smith \& Wr. F. Kirby, Rhop. exot., v. 1 Helicon. t. 1 f. 1, $2 \mid 1901$ H. r., Riffarth in: Berlin. ent. Z., $v .46$ p. 87.

Grundfarbe bläulichschwarz, ohne Schiller. — Vorderflügel mit einem großen roten Discalfleck. der sich bindenartig und etwas gebogen distal von der Zelle bis in den hinteren Medianzwischenraum zieht, dort in der Nähe des Hinterwinkels verschmälert und zipfelförmig endet. Seine distale Begrenzung von dem an den Adern einfließenden Schwarzbraun der Grundfarbe, namentlich im vorderen Teile, tief eingeschnitten, fast fleckartig aufgelöst, Adern im Fleck schwarz, distaler Teil namentlich am Vorderrande und hinter der Zelle stark gelb angeflogen. - Hinterflügel, außer dem Gruppenmerkmal der $\delta$ im vorderen Teil. mit einer Reihe ron 5 fast quadratischen Flecken unweit des Distalrandes von weißgrauer Farbe. Unterseite matter, der Fleck des Torderflügels distal noch tiefer an den Adern eingeschnitten. proximal breiter gelb, Torderrand an der Flügelwurzel mit kurzem rotem Wisch. Hinterflügel mit gelbem Wurzelstreif am Vorderrande, einem kleinen roten Fleck an der Wurzel hinter der Mediaua und einem größeren braunroten Fleck etwa in der Mitte des Hinterrandes. Distalsaum breit bindenartig aufgehellt. - Vorderflügellänge $35 \mathrm{~mm}$.

Colombia.

27. H. heurippa (Hew.) 1854 Heliconia h., Hewitson, Exot. Butt., v. 1 Heliconia t. 2 f. 7 | 1871 Heliconius h., W. F. Kirby, Cat. diurn. Lep., p. $140 \mid 1890$ H. h., Weymer (\& Maassen), Lep. Reise Stübel, p. 21 | $1901 H . h$. , Riffarth in: Berlin. ent. Z.. v. 46 p. 87 .

ठ઼. Grundfarbe tief schwarzbraun. Vorderflügel ziemlich breit. stumpf dreieckig, im Discus eine vorn am Zellende gegabelte, schräge gelbe Querbinde, welche hinten nur wenig über den hinteren Medianast reicht. den mittleren Medianzwischenraum fast ausfüllt und distal etwa $4-5 \mathrm{~mm}$ rom Distalrande entfernt endet. Ihr proximaler vorderer Teil liegt in der Zelle als länglicher, in der Mitte etwas eingeschnürter Fleck, der distale vordere Teil jenseits der Zelle, diese berührend. Distal von dieser Binde, derselben anliegend, rote Bestäubung, die vorn längs der Subcostalis meist tief gespalten ist, sodann bis zum vorderen Medianast in ziemlich gleicher, etwa $10-11 \mathrm{~mm}$ betragender Breite reicht, von dort nach hinten gewendet. bedeutend rerschmälert ist und meist uahe bis zum Hinterwinkel läuft. Dieser hintere Zipfel der roten Bestäubung ist distal stark gezackt, vorn ist die Begrenznng unscharf und zerstänbt. Die Adern in der gelben und roten Zeichnung schwarz. Unterseite viel matter, das Gelb weißlich, die rote Fläche bräunlich, längs der Mediana proximal ein gelblicher Wisch, Vorderrand an der Flügelwurzel rot. - Hinterflügel einfarbig schwarzbraun bis auf den hellgrauen Torderrandteil. Zuweilen finden sich am Distalrande Spuren weißlichgelber Saumfleckchen. Cnterseite dunkelbraun, am Vorderrande ein gelber Tirzelstreif. proximal 2-4 rote Wurzelfleckchen. - Fransen des Vorderflügels dunkelbraun. die des Hinterflügels leicht weißlich gescheckt. — — o. Wie das $\sigma^{2}$. jedoch mit den charakteristischen Geschlechtsunterschieden. - - Torderflïgellänge bis $44 \mathrm{~mm}$.

Südliches Colombia (Lianos de San Martin).

28. H. melpomene (L.) 1903 H. m., Riffarth in: Berlin. ent. Z., v.47 p. 157, 163.

ठ․ Punktierung des Kopfes und sonstige ron der Grundfarbe des Körpers abweichende Behaarung gelb; alle gelben Flecke und Zeichnungen können aber mehr oder weniger trübe sein. Grundfarbe der Flügel tief 
schwarzbraun. - Vorderflügel ziemlich breit, stumpf dreieckig, der schwach gekrümmite Vorderand als Basis gedarlıt, Apex abgermudet. Mit roter oder gelber his weiBer, oder aus zwei dieser Farben, meist Rot und Gelb, zusannengesetzter Discalzeichnung oder mehr oder weniger zersprengter Fleckengruppe, einem einzelnen Fleck in distalen T'eil der Zelle nnd einer unregelnäBigen, manchmal sehr rerloschenen Rleckenbinde distal ron derselben. Bisweilen proximal nächst dem Vorderrande, in der Zelle und hinter derselhen rote Bestïubung von gröBerer oder geringerer Ansdelnung. welche daun den rorderrand meist schmal schwarz läßt und im mittleren Teil der Zelle den ron den Silvaniformes (S. 38) bekannten Keilfleck ganz oder teilweise zeigt. Dieser fast immer kreis- oder eirund, manchmal mit einer proximal gerichteten Spitze. Seltener längs der Mediana beiderseits gelbe wischartige Bestiubung. Unterseite der oberen Seite bis auf den glänzend granen, fast zeichnungslosen Hinterrandteil entsprechend aber bedeutend matter, die Grundfarbe dunkelbraun, die auf der Oberseite grell aufgetragenen Farbentöne weniger intensiv und meist unsicherer begrenzt. Vorderrand an der Flïgelwmrel mit einem kmren, seltener länglich ansgezogemen, schmal roten Streif. - Hinterflügel einfarbig schwarz bis auf den granglänzenden Vorderrandteil oder mit roter Wrurzelbestäubung, die sich zn einer; die Zelle durchquerenden. der Subcostalis folgenden Binde oder zu rinem bindenartigen Streif verlängern kann und dann meist ron einer Reihe hinter derselben isoliert liegender, roter, in der Regel nagelförmiger Strahlen in der Richtnry der Medianäste und zwischen diesen und den Radiales begleitet ist. Seltener ist dic ersterwähnte Binde gelblich und liegt den Strahlen vorn an oder ist ganz gelb und ohne Strahlenbildung, oder endlich die vordere Querbinde fehlt und die Strahlen entspringen frei hinter der Zelle ans der Grundfarbe, roru mehr oder weniger zusammenhängend. Lnterseite mit gelbem WTurzelstreif am Vorder'rande, der stark reduziert spin kann, und selten fehlenden roten Punkten, Flecken oder Wischen an der Wurzel. Sonst in der Regel mit stark reduzierter oder ungewisser und verwaschener Zeichnung der Oberseite, hälfig nur mit länglichen roten Streifon hinter der Zelle. Distalrand schwach gewellt. - - o. Dem $\sigma$ entsprechend gezeichnet, meist etwas matter in der Farbe, mit den charakteristischen Geschlechtsunterschieden, namentlich schwärzlichem Torderrande des Hinterfliggels ohne Glanz. - - Fransen meist schwarzbraun, seltener weißlich gescheckt.

Nördliches Süd-Amerika (Gruayana, Amazonas, Peru, Bolivia); nicht aber Colombia, Venezuela.

Diese Art zerfällt in 15 Unterarten:

28 a. H. melpomene melpomene (L.) 1702, Petiver, Gazoplyyl., v. 1 t. 4 f. 2 1761, Rösel, Insecten-Belustig., $v .4$ p. 27 t. 3 f. 6 | 1765 , Seba. Thesaurus, $v .4$ t. 13 f. $15,16 \mid 1758$ Papilio (Heliconius) m., Jinné, Syst. Nat.. ed. 10 p. $467 \mid 1764$ P. m., Limné, Mlus. Ludnx. Ulr., p.332|1772 P. m., P. melpemone, Scopoli, Annus V. hist.-nat., p.111

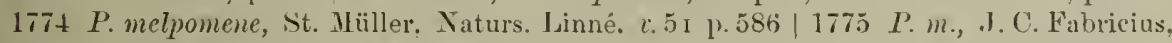
Syst. Ent., p. 462 | 1777 „Melpomene", P. m., P. Cramer, Pap. exot.. r.2 p. 143 t. 191 f. C.; p. 149 | 1779 "P. m.", Goeze, Ent. Beytr.. $x .31$ p. 103 1781 P. m, .J. C. Fabricius,

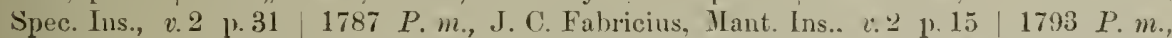
J. C. Fabricius, Ent. syst., v. 3 I j). 171 | 1804 P. m., 'Thunberg. Mus. Ac. Upsal., v. 23 p.9 | ?1818 P. m., J. Sepp, Surin. Vlinders, $v .1$ t. +1820 Laparns m., Billberg, Lnum. Ins., 1. 77 182.2-26 Phlogrism., Jac. Hübuer, Exot. Schmett. v.2 t.[5] | 1835 Heliconirm., H. Lueas, Hist. Lép. exot. p. 93 t. 49 f. 2 | 1844 H. m., E. Doubleday, Iist Lep. I3rit. ILus., v. 1 p. $54 \mid 1851$ H. m. (part.), Chenu \& H. Lucas, Enc. Hist. nat., Pap. diurn. 1. tis f. 159 1887 H. m. (part.?), P. Snellen in: Tijdsehr. Ent.. $x .30$ p. $15 \mid 1893$ H. m., C. Oberthür in: Feuille Natural., $x .24$ p. $4 \mid 1840$ Heliconius m., F. Blanchard in: Hist. An. artic., 
v. 3 p. 436 Lep. t. 10 f. 3 | 1866 H. m., H. W. Bates, Naturf. Amazonenstr, p. 139| 1867 H. m., H. W. Bates in: Tr. ent. Soc. London, ser. 3 v. 5 p. 5381869 H. m., A. G. Butler, Cat. diurn. Lep. Fabr., p. $122 \mid 1877$ H. m., W. F. Kirby, Cat. diurn. Lep., Suppl. p. 721 | 1878 H. m., Möschler in: Ent. Zeit. Stettin, v. 39 p. $426 \mid 1881$ H. m. (part.), F. D. Godman \& O. Salvin in: Biol. Centr.-Amer., Lep.-Rhop. v. 1 p. $154 \mid 1882$ H. m., Chr. Aurivillius in: Srenska Ak. Handl., n. ser. v. 19 nr. 5 p. 48 | ?1899 H. m., W. J. Kaye in: Ent. Rec., v.11 p. $56 \mid 1900$ H.m. (part.), W. F. Kirby, Exot. Schmett. Hübner, p. $12 \mid 1781$ \& 82 „Lucia“, Papiliolucia, P. Cramer, Pap. exot., v. 4 p. 117 t. 350 f. E, F; p. 250 (forma l.) | 1790 P. nelpomene + P. l., J. F. W. Herbst, Naturs. Ins. Schmett., $v .4$ p. 132 t. 72 f. 3 ; p. 134 t. 72 f. 4,5 (forma l.) | 1816 Sunias $m .+$ S. $l$., Jac. Hübner, Verz. Schmett., p. 12; p. 12 (forma l.) | 1819 Heliconia m. + H. l., (Latreille \&) J. B. Godart in: Enc. méth., v. 9 p. 208 ; p. 208 (forma 1.) 1847 H. l. + H. m., E. Doubleday (\& Westwood), Gen. diurn. Lep., v. 1 p. 103 (forma l.); p. 1041862 Heliconius $m .+H$. m. var. l., H. W. Bates in: Tr. Linn. Soc. London, v. 23 p. 557 ; p. 558 (forma l.) | 1871 H. m. (part.) +H. m. var. l., W. F. Kirby, Cat. diurn. Lep., p. 142 ; p. 142 (forma 1.) | 1877 H. m. + H.l., A. G. Butler in: Tr. ent. Soc. London, p. 125 ; p.126 (forma l.) | 1885 H.m. (part.) + H.l., O.Staudinger (\& Schatz), Exot. Schmett., v. 1 p.78 t. 32 (?); p.78 (forma l.) | 1900 H. m. aberr. atrosecta $+H$. m. aberr. melpomenides $+H$. melpomene var. lucinda $+H$. m. aberr. karschi, Riffarth in: Berlin. ent. Z., v. 45 p. 202 (forma a.); p. 203 (forma melponenides); p. 203 (forma l.); p. 203 (forma k.) | $1901 \mathrm{H}$. melpomene + H.m.a. + H.m.melpomenides + H. melpomene l. + H.m. $k .+H$. m.lucia Riffarth in: Berlin. ent. Z., v. 46 p. 88 ; p. 89 (forma a.); p. 89 (forma melpomenides); p. 89 (forma lucinda); p.90 (forma k.); p.90 (forma lucia) | 1902 "Heliconia thelxiope-melpomene" + „H.t.-m. var." + "H. t.-lucia var.", C. Oberthür, Étud. Ent., v. 21 t. 4 f.37-39, t. 4 f. 40 , t. 4 f. 43 , t. 4 f. 47 , t. 5 f. 49 ; t. 4 f. 42 (?), 48 (forma atrosecta); t. 4 f. 46 , t. 5 f. 50 (forma melpomenides); t. 5 f. $51,52,59$ (forma lucinda); t. 5 f. $54-56$ (forma lucia).

2 Forma principalis. Dunkelschwarzbraun, Vorderflügel mit einem geschlossenen, biudenartigen, ziegel- bis hochroten Fleck im Discus, der nächst dem schmal schwarzen Vorderrande in etwas geringerer als durchschnittlicher Breite beginnt und den distalen Teil der Zelle ausfüllt, so daß das Zellende etwa in der Mitte des vorderen Teiles des Fleckes liegt. Die proximale Begrenzung zieht sich in schräger Richtung ohne wesentliche Einschränkung des scharfen Randes bis kurz über den hinteren Medianast, wo der Fleck in voller Breite

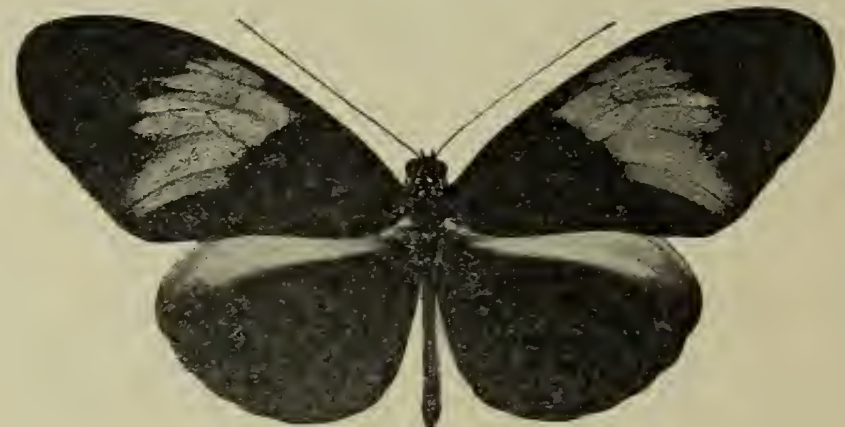

Fig. 19. H. melpomene melpomene, forma principalis, $\delta(1 / 1)$.

endet. Distale Begrenzung weniger scharf, an den Adern mehr oder weniger zerrissen und gezähnt, namentlich am mittleren Medianast, und im hinteren Teile zahnartig nach dem Distalraude rorgeschoben. Vorderer Teil des Fleckes von der Subcostalis schmal, mehr oder weniger deutlich, abgetrennt. Bei typischen Stücken sind die Adern in der roten Fläche bis auf ein kleines, distal eindringendes Stückcheu schwärzlicher Bestäubung ebenfalls rot, es bildet sich aber bäufig, namentlich am Zellende, schwarze Beschmppung auf den Adern, welche den Anfang der Teilung der Discalzeichnung andeutet 
und Übergänge zur näclisten Form bildet. - Hinterflïgel einfarbig schwarzbraun, beim ơ his auf den glänzend silbergrauen, beim o bis auf den etwas lichter schwärzlichen Vorderrundteil. - Lnterseite matter, discale IBinde des Vorderflügels im allgemeinen verloschener, heller, fast gelblichrot, manchmal weiblich, meist weniger ausgedehnt und namentlich distal eingreschränkt. Vorderrand proximal kurz und schmal rot. Hinterflügel mit 3 oder 4 groben roten Wurzelpunkten und einem gelben Wurzelstreif am Vorderande. Vorderflügellänge bis $45 \mathrm{~mm}$.

Französisch-, Niederländisch- und Britisch-Gruayana, Trinidad(?), Süd-Uyfer des unteren Amazonen-Stroms (ausschließlich Pará) rom Rio Tocantins bis Rio Madeira, Gebiet des oberen Amazonen-Stroms (Peru), Ecuador (östlich der Anden).

Forma atrosecta. Ton der Hauptform dadurch unterschieden, daB die rote Binde im Discus des Torderflügels durch stark schwarze Bestäubung auf und an deu Adern eingeschränlit und in einzelne Flecke aufgelöst ist. Im rorderen Teil sind diese nur schmal, rudimentär, schwärzlich überstänbt oder fehlen ganz. so daß die rote Zeichnung erst an den Radiales deutlich beginnt. Die Zelle bleibt in der rorderen Ecke, manchmal auch distal ganz, frei ron roter Bestäubung. Auf der Enterseite ist die Binde sehr schmal, mattrot und sehr ungewiß begrenzt.

Obidos.

Forma melpomenides. Rote Binde des Vorderflügels proximal bedeutend verkümmert, daher sclumaler als bei der Hauptform, etwa halb so breit und distal auffällig konver. Sonst wie die Hauptform.

Niederländisch-Guayana (Villa Bella).

Forma lucinda. Rote Vorderflügelbinde in ganzer Ausdehnung fast gleichmäßig breit, distal stark konvex gewölbt, proximal stark gelb angeflogen, besonders in der Zelle. Die gelbe Bestäubung nimmt dort etwa ein Drittel der ganzen Breite ein. AuBerdem bildet sich gelbe Färbnng im hinteren Medianzwischenraum.

Östliches Amazonas (Mlassauary).

Forma lucia. Mittelbinde des Vorderflügels der Länge nach breit schwarz geteilt und im hinteren proximalen Teil verkümmert. Fs bleibt ein ambosförmiger, zuweilen schwärzlich überstäubter, gelber Fleck im distalen Drittel der Zelle in ganzer Breite derselben übrig. Das Zellende bleibt schwarz. Außerdem distal von der Zelle, am Vorderrande beginnend und schräg etwas stufenförmig bis zum mittleren Medianast gestellt, eine schmale, durch die schwarz bestäubten Adern mehr oder weniger in einzelne längliche Flecke zerlegte Binde, wie sie bei H. m. thelxiope (S. 117) in ähnlicher Weise vorhanden ist, aber ron roter, proximal mehr oder weniger gelb angeflogener Farbe. Der hinterste Fleck dieser Binde ist meist stärker isoliert und distal etwas vorgeschoben, meist ist auch noch im binteren Medianzwischenraum ein in proximaler Richtung zurücktretendes gelbes isoliertes Fleckchen rorhanden, das rund herum, namentlich aber distal, ron roter oder rötlicher Bestüubung umgeben ist, die sich bis gegen den Hinterwinkel erstrecken kann. In seltemeren Fällen tritt das Rot in der Fleckenbinde stark zurïck, und diese ist bis auf die rote distale Kante oder die distalen Spitzen der schmalen Fleckchen leuchtend gelb. - Unterseite bedeutend matter. Sonst wie die Hauptform.

Niederländisch-Guayana, nördliches Brasilien (Pará, am-Rio Tahajoz, Massauary).

Das Tierreich. 22. Lief. : H. Stichel \& Riffarth, Heliconiidae. 
Forma karsehi. Etwas kleiner als die DurchschnittsgröBe der Hauptform. Ähnlich der vorigen, aber ohne gelben Fleck in der Vorderflügelzelle, auch die distal der Zelle liegende Fleckenbinde nur in Spuren schwefelgelber Bestäubung vorhanden, die sich etwa in der Mitte zwischen Zellende und Distalrand im mittleren Medianzwischenraum ganz verlieren. Im hinteren Medianzwischenraum und im Hinterwinkel schwache rote Bestäubung und im proximalen Teil des ersteren nahe der Zelle ein kleiner eirunder rerschwommener rötlicher Fleck, der mit der anderen roten Bestäubung durch vereinzelte rote Schuppen verbunden ist. Die Zeichnung der vorderen Flügelhälfte vervollkommnet stellt H. m. thelxiope (S. 117), die der hinteren Hälfte die typische Unterart vor.

Pará, Niederländisch-Guayana.

28 b. H. melpomene aphrodyte Staud. $1896 H$. a., O. Staudinger in: D. ent. Z. Lep., v. 9 p. 299 t. 6 f. 4 | 1901 H. melpomene a., Riffarth in: Berlin. ent. Z., v. 46 p.101| 1902 "Heliconia vesta-a.", C. Oberthür, Étud. Ent., v. 21 t. 9 f. $103($ (?).

Vorderfiügelbinde ähnlich derjenigen der typischen Unterart vorhernschend rot, nur ein in der Zelle liegender, etwas durch schwarze Aderbestäubung abgetrennter Fleck mehr oder weniger gelb oder gelblichweiß bestäubt. Gelbe Bestäubung auBerdem am Vorderrande und an der proximalen Begrenzung der Binde hinter der Zelle. Die Binde im allgemeinen etwas verkleinert, namentlich proximal, so daß der Winkel an der Zelle im hinteren Medianzwischenraum, zuweilen auch die hintere Zellecke, schwarz bleibt. Distal ist die Binde stark zersetzt und unregelmäßig gespalten, ähnlich wie bei Forma atrosecta (S. 113). Zuweilen proximal längs der Mediana ein gelber Streif. - Hinterflügel entweder einfarbig schwarzbraun oder seltener mit Spuren einer gelben Querbinde, auf der Unterseite deutlicher wie oben, wie sie bei H. m. amandus (S. 127) in vollendetem Maße erscheint. Fast alle bekannten Stiucke zeigen diese Binde blind auf der Unterseite, d. h. es markiert sich die Gestalt derselben in matter abgetönter dunkelbrauner Färbung, namentlich bei schräger Beleuchtung: Unterseite des Vorderflügels im Hinterwinkel mit eimem roten, von der Submediana durchschnittenen Fleck, sonst mit der Zeichnung der Ober'seite, aber das Rot matter und weniger Gelb vorhanden. - Vorderflïgellänge etwa $43 \mathrm{~mm}$.

Bolivia (Bueyes, Gebiet des Rio Juntas). In Höhen von $300 \mathrm{~m}$.

28c. H. melpomene funebris MIöschl. 1777 „Cybele", Papilio cybile (laps.) (non P. cybele J. C. Fabricius 1775!). P. Cramer, Pap. exot., v. 2 p. 139 t. 188 f. A; p. 148 (forma cybele) 1779 „P. cybele", Goeze, Ent. Bejtr., v. 3i p. 118 (forma c.) | 1790 P. c., J. F. W. Herbst, Naturs. Ins. Schmett., $v .4$ p. 144 t. 74 f. 2 (forma c.) $\mid 1847$ Heliconia c., E. Doubleday (\& Westwood), Gen. diurn. Lep., v.1 p. 104 (forma c.) | 1871 Heliconius melpomene var. c., W. F. Kirby, Cat. diurn, Lep., p. 142 (forma c.) 1896 H. c., O. Staudinger in: D. ent. Z. Lep., v.9 p.304 (forma c.) | $1862 \mathrm{H}$. melpomene var. c. + H. $m$. var. 4, H. W. Bates in: Tr. Linn. Soc. London, v. 23 p. 558 (forma c.); p. 558 (forma deinia) | $1877 \mathrm{H}$. funebris $+H$. deinia (Plötz in MSS.), Möschler in: Verh. Ges. Wien, v. 26 Abh. p. 314 t. 3 f. 8; p. 315 (forma d.) | 1877 H. thelxiope var. mutabilis, A. G. Butler in: Cistula ent., v. 2 p. 151 (forma deinia) | 1877 H. m. + H. cybelc, A. G. Butler in: Tr. ent. Soc. London, p. 125 (forma d.); p. 126 (forma c.) | 1877 H. deinia + H. $n .+H$. funebris, W. F. Kirby, Cat. diurn. Lep., Suppl. p. 847,847 (forma d.); p. 847 $1883 \mathrm{H}$. erato forma cybele $+H$. e. forma $d .+H$. e. forma $f$., Höschler in: Terh. Ges. Wien, v.32 Abh. p.316 (forma c.); p. 316 (forma d.); p.316|1885 H.c. + H. faustina, O. Staudinger (\& Schatz), Exot. Schmett., v. 1 p. 78 (forma c.); p. 78 (forma f.) | 1900 H. melpomene aber\%. diana, Riffarth in: Berlin. ent. Z., v. 45 p. 204 (forma d.) 1901 $H$. m. funebris $+H . m$. diance $(H$. gaea Plötz in MS. $)+H . m$. deinia $+H$. m. funstina (H. justina Boisduval in IIS.) $+H$. m. cybclc, Riffarth in: Berlin. ent. Z., v. 46 p.91; 
p. 91 (forma diana); p. 91 (forma deinia); p. 92 (forma faustina); p. 92 (forma c.) 1902 "Hcliconia thelxiope-cybele var.", C. Oberthür, Étud. Ent., $v .21$ t. 5 f. 60. t. 6 f. $61-63$ (forma diana); t. 6 f. $64-67$ (forma deinia); t. 6 f. 68,69, t. 7 f. 74,75 (forma faustina); t. 7 f. $76-78$ (forma cybele); t. 7 f. $79-81$.

Forma principalis. Oberseite der Flügel bei typischen Stiicken schwarzbraun, nur Proximalteil des Vorderflügels hinter dem schmal dunklen Vorderrande bis zur Submediana rot; in diesem Felde Subcostalis und Mediana streifenartig schwarzbrann angelegt. Nahe dem Distalrande in den Aderzwischenräumen etwas rötliche, ungewisse Bestäubnng. Hinterflügel mit einem dicht hinter der Subcostalis liegenden, dieser folgenden, knrzen roten Wurzelstreif, der bis zum Ende der Zelle oder etwas weiter reicht und von der schwarzbraunen Gabel des hinteren Medianastes durchschnitten wird. Sonst ohne Zeichnung. Es kommen Übergangsstïcke zn Forma deinia mit geteilter roter Discalbinde und zn Forma diana mit einem der Forma cybele ähnlichen aber verloscheneren großen roten Discalfleck vor.

Niederländisch-Guayana.

Forma diana. Vorderflügel proximal loot wie bei der Hanptform; distal dieser Bestäubnng eine geschlossene rote breite Binde in Gestalt wie bei der typischen Unterart (S. 111). Diese Binde ist in einem bekannten Falle verkürzt, fleckartig; so daß der Hinterwinkel breiter schwarzbraun ist. Hinterflügel wie bei der vorigen Form. Zeichnung entspricht derjenigen ron H. m. tyche (S. 116), aber Hinterflügel ohne Strahlen.

Niederländisch-Guayana; Französisch-Guayana?

Forma deinia. Vorderfügel im proximalen Teil hochrot bestäubt wie bei der Hauptform. gewöhnlich anch noch hinter der Snbmediana, znweilen fehlt jedoch das hintere Drittel der ganzen Breite. Zelle distal von der roten Bestänbung znweilen mit verloschenen Spuren eines gelben Fleckes, seltener ein solcher in dentlicher Gestalt vorhanden. Distal von der Zelle eine meist schmale, manchmal rudimentäre Fleckenbinde in der Lage wie bei Forma crbele, aber nicht von gelber, sondern hochroter Farbe; der hinterste, isolierte Fleck im hinteren Medianzwischenranm gut ansgebildet oder aber rerkümmert, mitunter anch ganz fehlend, der vorderste Fleck manchmal gelb angeflogen. Es kommen Stücke, namentlich $q$, vor, welche ron dieser Fleckenbinde keine Spur zeigen, aber im mittleren Medianzwischemranm nächst dem Hinterwinkel ganz zerstrent rot überstäubt sind. Cnterseite matter, der im distalen Teil der Zelle liegende gelbe Fleck in der Regel deutlicher ansgebildet. - Hinterflügel wie bei der Hauptform, der rote Wrnzelstreif meist etwas kräftiger, unterseits in der Regel aber sehr verkïmmert, manchmal ganz fehlend.

Niederländisch- und Französisch-Guayana, östliches Amazonas (Serpa).

Forma cybele (non Papilio c. F.). Vorderflügel mit einer Fleckengruppo ähnlich wie bei Forma lucia (S. 113), aber rein gelb nnd etwas mehr ausgebreitet, und zwar: ein isolierter, in der Mitte eingeschnürter, ambosförmiger Fleck im distalen Teil der Zelle, diese rorn nnd hinten bern̈hrend, eine hinter dem schmil schwarzen Vorderrande beginnende, schräg bis zum vorderen Medianast reichende, von den schwarz bestäubten Adern durchschnittene Halbqnerbinde, hinter derselben in unmittelbarem AnschlnB ein kleinerer, distal rorgeschobener Fleck im mittleren Medianzwischenraum und ein isolierter größerer eirunder Fleck im hinteren Medianzwischenranm, sümtlich schwefelgelb. 
Proximaler Teil des Flügels hinter dem schmal schwarzen Vorderrande bis zur Submediana rot in ähnlicher Weise wie bei der Hauptform. Die rote Bestäubung erstreckt sich voln und binten bis zu dem gelben Fleck in der Zelle, ist in derselben konkav ausgeschnitten und hinter ihr in ungewisser Begrenzung in proximaler Richtung abgeschrägt. Hinter der Submediana noch einzelne Spuren roter Bestäubung, zuweilen auch distal von der gelben Halbbinde, dieser unmittelbar angeschlossen. Wurzel des Vorderflügels schwach gelb beschuppt. Hinterrand stets schmal oder breiter schwarz hinter dem roten Felde. Hinterflügel mit einem dicht hinter der Subcostalis liegenden, dieser folgenden, kurzen, bis zum Ende der Zelle oder etwas weiter reichenden roten Wurzelstreif wie bei der Hauptform. - Unterseite matter, nächst der Wurzel mit einem kurzen roten Streif am Vorderrande, die gelben Flecke des Torderflügels weißlich, an den Rändern ungewiß schwärzlich angeflogen, die rote Färbung im proximalen Teil sehr verringert, nur in je einem Streif hinter der Subcostalis und vor der Mediana erhalten. Hinterflügel mit grellroten Wurzelpunkten, aber verloschenem, bedeutend verküiztem Wurzelstreif und schmal gelb gefärbtem Vorderrande bis auf etwa die Hälfte seiner Länge. - Fransen schwarzbraun, weiß gescheckt, am Saum des Vorderflügels auffälliger als an dem des Hinterflügels und namentlich am Aper des ersteren rein weiß. Vorderflügellänge etwa $42 \mathrm{~mm}$. - In Anlage der Zeichnung des Vorderflügels ziemlich genau mit H. m. thelxiope (S. 117) übereinstimmend, die Hinterflügel aber ohue Strahlenbildung.

Niederländisch-Guayana (Berg en Dal), Französisch-Guayana, Brasilien (am Rio Negro, Rio Madeira und unteren Amazonen-Strom).

Forma faustina. Wie Forma cybele gezeichnet, aber die gelbe Fleckengruppe außerhalb der Zelle meist schmaler und am distalen Rande rot angeflogen. Gewöhnlich dringt dort die schwarzbraune Grundfarbe an den Adern zahnartig in die Binde ein, diese fast in Flecke auflösend, und die nach dem Distalrande gerichteten Spitzen dieser Flecke sind zackenförmig rot angeflogen. - Hinterflügel wie bei Forma cybele.

\section{Niederländisch-Guayana (Berg en Dal), Französisch-Guayana.}

28 d. H. melpomene tyche Bates 1862 H. m. var. $t .+H$. m. var. hippolyte, H. W. Bates in: Tr. Linn. Soc. London, v. 23 p. 559; p. 559 (forma h.) 1871 H. m. var. $t .+H . m$. var. h., W. F. Kirby, Cat. diurn. Lep., p. 142 ; p. 142 (forma h.) | 1901 H. m.t. + H. m. h., Riffarth in: Berlin. ent. Z., v. 46 p. 92 ; p. 92 (forma h.) 1902 Heliconia thelxiope var., C. Oberthür, Étud. Ent., v. 21 t. 9 f. 98,99 (forma h.); t. 9 f. $100,101$.

Forma principalis. Vorderflügel mit proximaler roter Bestäubung und roter Discalbinde wie bei H. m. funebris, forma diana (S. 115), Hinterflügel mit einem am Hinterrande unmittelbar an der Flügelwurzel entspringenden, anfangs etwa $3 \mathrm{~mm}$ breiten, dann schmaler werdenden und im letzten Drittel der Flügellänge in stumpfer Spitze endigenden, roten Streif, welcher der Subcostalis folgt und die Zelle durchschneidet. Hinter diesem Streif in gleichmäßigem Abstande eine Reihe von 7 roten Strahlen, welche wie bei $\mathrm{H}$. m. thelxiope gebildet und angeordnet sind. Die Färbung der Zeichnungen ist mehr orangerot. - Unterseite matter und die Zeichnungen des Hinterflügels verloschener oder verkleinert. - Vorderflügellänge etwa $41 \mathrm{~mm}$.

Östliches Amazonas (Serpa, Massauary). 
2 Forma hippolyte. Vorderflügel mit roter Bestäubung des proximalen Feldes wie bei der Ḣauptform und einer Discalzeiclnnung, die der Anlage derjenigen vou Forma lucia (S. 113) entspricht. Im distalen Teil der Zelle ein selten deutlicher, meist verkïmmerter oder schwärzlich iilherstäubter, in der Mitte eingeschniirter länglicher Fleck von gelber Farbe, distal vou der Zelle eine orangerote Binde oder Fleckenbinde, die an Breite und innerem Zusammenliang wechselt und nicht selten gänzlich in Flecke aufgelöst ist. Proximal und am Vorderrande tritt manchmal gelbe Bestäubung auf; ist sie sehr breit, so sind ihre Ränder unscharf und verlosehen. Der hinterste Fleck der Binde ist, wie bei der genamnten Form und entsprechend der Zeichnung der Forma deinia (S. 115), weiter ron dem rorderen Teil abgetrennt, etwas in proximaler Richtung abgerückt und liegt im hinteren Medianzwischemraum. Hinterfluggel wie bei der Hauntform. Bildet C̈bergänge zu dieser. ,

Östliches Amazonas (Serpa, Massauary, Maués, an Rio Tabajoz).

28 e. H. melpomene thelxiope (Hb.) $1806-19$, Yerëis festiva Thelxiope", Jac. Hübner, Exot. Schmett. v. 1 t. 12 f. $1-+\mid 1816$ Migonitis thelxiope, Jac. Hübner. Verz. Schmett., p.12 1847 Heliconia t., E. Doubleday (\& Westwood), Gen. diurn. Lep., v. 1 p. 103 | 1893 H. t., C. Oberthür in: Feuille Natural., v. 24 p. $4 \mid 1896$ H. t., C. Oberthür, Étud. Ent., v. 20 p. $15 \mid 1902$ H. t., C. Oberthür, Etud. Ent., v. 21 t. 8 f. 88,$89 ;$ t. 7 f. 83,84 1862 Heliconius t., H. W. Bates in: Tr. Linu. Soc. London, v. 23 p. 559 | 1866 H.t., H. W. Bates. Naturf. Amazonenstr., p. 139 | 1867 H.t., H. W. Bates in: Tr. ent. Soc. London, ser. 3 v. 5 p. $538 \quad 1883 H$. erato forma $t$., Möschler in: Yerh. Gres. Wien, $v .32$ Abh. p. $316 \mid 1885$ H.t., O. Staudinger (\& Schatz), Exot. Schmett., v. 1 p. 78 t. $32: 1896$ H. t., O. Staudinger in: D. ent. Z. Lep., v. 9 p. $305 \mid 1900$ H. t., W. F. Kirby, Exot. Schmett. Hübner, p. $12 \mid 1901$ H. melpomene t., Riffarth in: Berlin. ent. Z., $x .46$ p. 93 1880? H. telxiope, Buchecker, Syst. Ent.. Lep. t. 58 f. 23.

Vorderflügel (Fig. 20) proximal hinter dem schmal schwarzen Vorderrande gelblich- bis orangerot, von der Subcostalis und Mediana schmal, von der

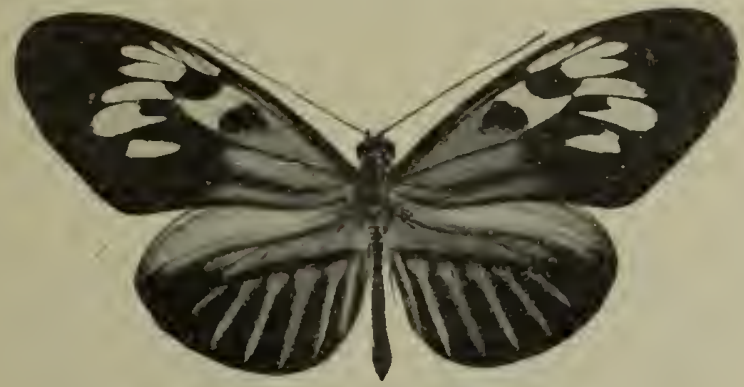

Fig. 20. H. melpomene thelxiope $(1 / 2)$.

Submediana breiter sehwarz durchschnitten, Hinterrand stets schmal schwarz. Die rote Bestäubung reicht vorn und hinten in der Zelle bis zu einem im distalen Teil derselben liegenden schwefelgelben, über die ganze I3reite ersterer ausgedehnten, in der Mitte eingeschnürten Fleck, etwa ron Gestalt eines Amboß, der verkümmert sein oder ganz fehlen kann. Zwisehen diesem und dem proximalen Rot ein rundlicher Fleck der Grundfarbe, welcher proximal ausgeflossen sein kann, dann einen Ausläufer in der Richtung der. Flügelwurzel entsendet und so die Gestalt des Keilfleckes der Vertreter der Silvauiformes (S. 38) erkemnen läßt. Fehlt der gelbe Fleck in der Zelle, so ist das Rot im distalen Teil ruudlich von der Grundfarbe ausgeschnitten. Hinter der Zelle setzt sich die Begrenzung der roteu Fläche nngewiß zerstäubt 
durch den Winkel am Ursprunge des hinteren Medianastes bis nahe zur Submediana in ziemlich senkrechter Richtung fort, um hinter letzterer meist etwas weiter nach dem Hinterwinkel zu streifenartig auszufließen. Distal von der Zelle, diese mindestens an der vorderen Ecke berïhrend, eine gebogene, gelbe, quer liegende Fleckenbinde, welche namentlich am distalen Rande von der au den Adern eindringenden Grundfarbe stark eingeschnitten ist. Die vorder'en länglichen Fleckchen nächst dem schwarzen Vorderrande treten in proximaler Richtung zurtick, und hinter der Subcostalis, uumittelbar an der vorderen Zellecke wendet sich die Binde bogenförmig nach hinten. Der vor dem vorderen Medianast liegende Fleck ist häufig so weit in proximaler Richtung ausgeflossen, daß er die hintere Zellecke berührt oder fast berührt; der nächste, im mittleren Medianzwischenraum liegende Fleck ist von eirunder Gestalt, meisteus in distaler Richtung vorgeschoben, zuweilen proximal zipfelartig längs des mittleren Nedianastes ausgeflossen und meist kürzer als die übrigen. Meistens tritt hinter demselben, im hinteren Medianzwischenraum. ein weiterer, etwas abgerïckter, ei- oder kreisrunder Fleck auf, der wiederum in der Richtung der hinteren Zellwand zurüektritt und dem hinteren Medianast anliegt. Die Anordnung und Gestalt dieser um das Zellende gruppierten Flecke oder Fleckenbinde ist sehr rariabel. Zuweilen sind die einzelnen Flecke, namentlich im vorderen Teil, fester zusammenhängend, zuweilen stärker getrennt, der hinterste Fleck fehlt öfters gänzlich. - Unterseite matter, Grundfarbe dunkelbraun, die proximale rote Färbung zurücktretend, nur als tief aus distaler Richtung her keilförmig eingeschnittene Gabel in der Zelle erhalten. Vordèrand mit einem kurzen, intensiver roten schmalen Wurzelstreif. Das Gelb des Zellfleckes und der Fleckenbinde weißlich. - Hinterflügel mit einem am Hinterrande, dicht an der Wurzel in einer Breite von etwa $3 \mathrm{~mm}$ entspringenden, der Subcostalis folgenden, aber schmal schwarz von dieser getrennten roten Streif, welcher die Zelle durchquert, von den Adern schmal schwarz durchschnitten wird und in stumpfer Spitze etwa am letzten Drittel der Flügellänge endet. Diese Spitze ist mauchmal durch stärker schwarze Bestäubung an der vorderen Radialis als längliches Fleckchen abgetrennt. Hinter diesem Streif in ziemlich gleichmäßigem Abstande von etwa 1-1.5 mm, der sich nur am Hinterrande verringert, eine Reihe von 7 roten Strahlen zwischen den Adern, von denen der erste, dicht am Hinterrande liegende, kurz und wischartig ist, der zweite gleichmäßig schmal bis zum Hinterwinkel reicht, die nächsten 4 vorn ähnlich der Gestalt eines Nagels kopfartig verdickt sind und sich mit den Spitzen allmählich von dem Distalrande entfernen, sowie endlich der letzte als länglicher Wisch auftritt und am weitesten vom Saum entfernt endet. Beim o bilden sich zuweilen in Fortsetzung dieser Strahlen bis zum Vorderrande rötliche Wische in den Aderzwischenrärmen. - Unterseite matter, mit gelbem oder rötlichem Wurzelstrahl am Vorderrande, 2 oder 3 roten Wurzelflecken und erheblich verringerter Zeichnung der Oberseite. Der vor den Strahlen liegende Streif schmaler, manchmal verkümmert und dann im distalen Teil verloschen, ebenso die Strahlen selb̧st, welche selten die nagelförmige Gestalt der Oberseite erkennen lassen. In einzelnen Fällen sind ganz feine, dem Distalrande aufsitzende Saumfleckchen vorhanden. - Fransen dunkelbraun. Vorderflügellänge bis $41 \mathrm{~mm}$.

Nördliches Brasilien (Pará, Manaos; Itaituba?, Mlaués?).

28f. H. melpomene thelxiopeia Staud. $1896 \mathrm{H}$. thelxiope aberr. thelxiopeia + H. thelxiope var. aglaopeia, O. Staudinger in: D. ent. Z. Lep., v. 9 p. 305 ; p. 305 (forma a.) | 1900 H. melpomene var. augusta (Maassen in MS.) + H. m. var. melanippe, Riffarth in: Berlin. ent. Z., v. 45 p. 204 (forma a.); p. 204 (forma melanippe) | 1901 H. melpomene 
melanippe $+H$. melpomene angusta $+H . m$. aglaopeia $(H$. judith, $H$. milesia Maassen in IIS.) + H. melpomene thelxiopeia, Riffarth in: Berlin. ent. Z., v. 46 p. 90 (forma melanippe); p. 93 (forma augusta); p.93 (forma aglaopeia); p. $94 \mid 1902$ "Heliconia thelxiope-lucia var." + H. t. var. + H. thelxiopeia $+H . t$. var. + "H. t.-aglaopeia", C. Oberthür, Étud. Ent., v. 21 t. 5 f. 57,58 (forma melanippe); t. 7 f. 82 , t. 9 f. 97 (forma aglaopeia): t. 8 f. $93-96$ (forma augusta); t. 8 f. $85-87,90$.

Forma principalis. Torderflïgel im proximalen Felde wie bei der vorigen Unterart rot bestäubt; diese Bestäubung läBt jedoch den Hinterteil hinter der Submediana häufig frei und ist lebhafter, dunkler rot, rotbraun bis violettrot. Fleck im distalen 'Teil der Zelle und discale Fleckenbinde wie bei H. m. thelxiope (S. 117), nur im hinteren 'Teil meist verkümmert und die Abstände der Elecke unter sich wie rom Zellende beträchtlicher, üherhaupt mit Neigung zur Reduktion dieser Fleckengruppe und Übergänge zmr Forma aglaopeia (S. 120) bildend. Hinterflügel mit kürzerem rotem Streif hinter der Subcostalis, dieser nur deutlich bis zum Zellende, darüber hinaus nur zerstäubte Spuren. Hinter demselben meist nur 6 Strahlen von Gestalt wie bei der vorigen Unterart, aber meist kiirzer, derjenige am Hinterrande sehr klein verloschen oder ganz fehlend, selten zwischen den Radiales ein weiterer, nur wischartiger Streif in Fortsetzung der Strahlen. Diese Zeichnungen also bedentend weniger reich als bei der vorigen Form und von lebhafterem Rot, entsprechend dem des Vorderflügels. - Unterseite des Vorderflïgels fast wie die Oberseite, die rote Wurzelbestäubung aber geringer als bei der vorigen Unterart, aber dicht am Vorderrande von der Flügelwurzel aus ein etwas längerer roter schmaler Streif als bei dieser. Die gelben Flecke scharf und deutlich, aber etwas natter in der Farbe. Hinterflügel fast einfarbig, nur selten sind die roten Strahlen in den Aderzwischenräumen teilweise als rote Streife angedeutet; der rote Querstreif binter der Subcostalis stark verkleinert, meist nur in ungewisser Bestiubung im proximalen Teil erhalten. 2 oder 3 hochrote Wurzelfleckchen, Wurzelstreif am Vorderrande gelb. - Vorderflügellänge $37-42 \mathrm{~mm}$.

Niederländisch- und Französisch-Guayana.

Forma augusta. Zeichnung des Vorderflïgels (Fig. 21) analog derjenigen der Hauptform, aber die gelbe Fleckengruppe oder Binde schmaler und am distalen Rande rot angeflogen in der Weise wie bei H. m. funcbris,

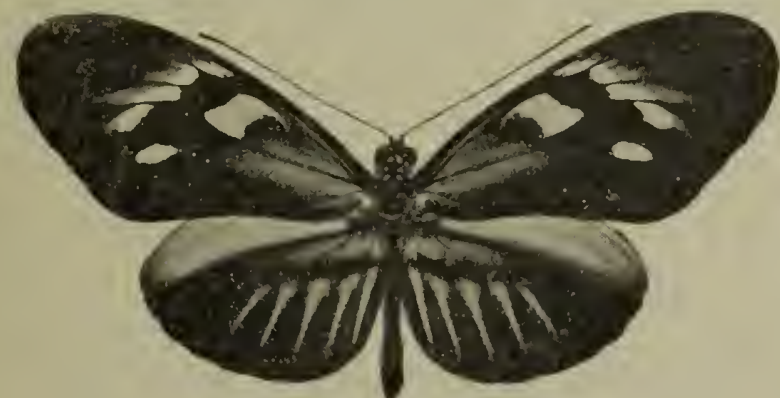

Fig. 21. H. melpomene thelxiopeia, forma augusta. $\delta(1 / 1)$.

forma faustina (S. 116). Rote proximale Bestäubung weniger intensiv und im hinteren Teil eingeschränkt, so daß das Randfeld hinter der Submediana, ausgenommen einen kleinen Wisch dicht an der Flügelwurzel, und auch noch ein Teil vor demselben schwarz bleibt; auch im rorderen Teil der Zelle 
weniger Rot, und die schwarze Grundfarbe in Gestalt eines langen spitzen Keiles gegen die Flügelwurzel eingeschoben. Hinterflügel wie bei der Hauptform. Auf der Unterseite die rote Berandung der discalen Fleckenbinde weniger deutlich, sonst matter und die Zeichnungen, namentlich die des Hinterflügels, geringer, proximale rote Bestäubung des Vorderflügels fast ganz fehlend.

Niederländisch- und Französisch-Guayana.

- Forma aglaopeia. Die gelbe Fleckengruppe oder Binde des Torderfügels und der Fleck im distalen Teil der Zelle mehr oder weniger schwarz bestäubt, kleiner, teilweise oder ganz fehlend. Sonst wie die Hauptform.

Niederländisch- und Französisch-Guayana.

Forma melanippe. Vorderflügel proximal ohne rote Bestäubung; Discalzeichnung gelb wie bei der Hauptform, zuweilen mit Spuren roten Anfluges am distalen Rande der Fleckenbinde. Hinterflügel oben einfarbig schwarzbraun ohne rote Zeichnung. nur im einzelnen Falle der Querstreif hinter der Subcostalis schwach angedeutet. Unterscheidet sich von H. m. funebris, forma faustina (S. 116) dadurch, daß sowohl die rote Bestäubung des proximalen Feldes auf dem Vorderflügel als auch der rote Wurzelstreif des Hinterflügels fehlt.

Niederländisch-Guayana (Berg en Dal).

28g. H. melpomene bari (C. Oberth.) 1902 Heliconia b., C. Oberthür, Étud. Ent., v. 21 p. 23 t. 11 f. 129, $130 \mid 1903$ Heliconius melpomene b., Riffarth in: Berlin. ent. Z., v. 47 p. 165.

Oberseite tief schwarzbraun. Vorderflügel an der Wurzel mit einem gelben Fleckchen, proximales Feld rotgelb, Vorderrand schmal schwarz, Costalis, Subcostalis, Mediana ebenfalls schmal, Submediana breiter schwarz, namentlich distal in dem roten. Felde. Letzteres reicht in der Zelle bis zu einem die Breite derselben im distalen Teil ausfüllenden gelben Fleck, welcher in der Mitte zusammengeschnürt ist, so daß sich ein rundlicher schwarzer Fleck zwischen ihm und dem angrenzenden Rot bildet. Distal von der Zelle, in kurzem Abstande von dem Fleck, eine gebogene gelbe Fleckenbinde rom schmal schwarzen Vorderrande bis zum mittleren Medianast. Im hinteren Medianzwischenraum und im Hinter'winkel je noch ein weiterer kleinerer eirunder Fleck, ebenso ein vom hinteren Medianast durchschnittener gelber Wisch dicht am Distalrande und endlich einer Reihe von 5 länglichen schmalen Apicalflecken derselben Farbe. Hinterflügel wie bei der typischen Unterart, nur der vor den roten Strahlen liegende Querstreif etwas schmaler, distal durch die vordere Radialis in zwei Zipfel gespalten. - Unterseite matter, die rote Färbung des proximalen Vorderflügelfeldes geringer, sämtliche Flecke weißlichgelb, Hinterflügel mit rotem Wurzelstreif am Vorderrande und einem weiteren gelblichen Streif dicht hinter der Costalis; roter Quer'streif hinter der Subcostalis schmaler, von den Adern durchbrochen, Strahlen fast wie oben. Am Distalrande einige weißliche Punkte. - Vorderflügellänge $40 \mathrm{~mm}$.

Französisch-Guayana.

28h. H. melpomene elevatus Nöldner 1901 H. e., Nöldner in: Berlin. ent.Z., v.46 p.5 | 1901 H. melpomene aglaope (err., non H. a. C. \& R. Felder 1862!), Riffarth in: Berlin. ent. Z., v. 46 p. 95 | ? 1902 „Heliconia thelxiope-aglaope var.", C. Oberthür, Étud. Ent., v. 21 t. 11 f. 121. 
Punktierung des Kopfes weißlich, Thoraxzeichnnng gelb, Anteunenkeule unterseits bräunlich. - Flügeloberseite schwarzbraun, Vorderflügel proximal hell orangerot; Costalis, Subcostalis, Mediana und Submediana sowie Vorder- und Hinterrand in und an dem roten Wurzelfelde fein schwarz. An der Flïgelwurzel ein gelbes Fleckchen. Distal von der Zelle in unmittelbarem Anschluß eine proximal abgerundete, an den Adern mebr oder weniger eingekerbte und von diesen schwarz durchschnittene schräge, ziemlich breite Halbbinde ron schwefelgelber Farbe, welche an dem mittleren Medianast endet. Der rorderste, durch die fein schwarze Subcostalis abgeschnittene, schmale Streifenfleck etwas in proximaler Richtung zurücktretend, distal abgeschrägt. Der hinterste Teil proximal etwas verkürzt und in ganzer Breite dem nittleren Medianast anliegend. Hinter demselben, im hinteren Medianzwischenraum wie auch im distalen Teil der Zelle, an das rote Wurzelfeld ansehließend, mehr oder weniger deutliche Überreste gelber Flecke in der Lage wie bei H. m. thelxiope (S. 117), oder diese Flecke sind wie dort vollkommen ausgebildet, aber seltener. Im Hinterwinkel vor der Submediana ein weiterer, kleinerer gelber Fleek. Hinterflïgel des $\sigma^{\top}$ mit hellgranem, breit dunkler umrandetem Yorderrandfeld, ein konstantes Merkmal, welches im wesentlichen diese von der folgenden, sehr ähnlichen Form mit breitem hellgrauem Vorderrandteil trennt. Hinter der Subcostilis, dieser folgend und schmal schwarz davon getrennt, ein hellorangeroter Streif, welcher die Zelle durchquert, sich allmählich verschmïlert und vor der vorderen Radialis ziemlich spitz, ausläuft. Die Adern in diesem Streif schmal schwarz. Hinter dem Streif 7 starke Strahlen ron derselben Farbe, welche vorn in fast gleichmäBigem, schmalem Abstande von ersterem dicht an der Zelle beginnen und nahezu den Distalrand erreichen. Der nächst dem Hinterrande liegende Stralıl etwa von halber Länge des folgenden. beide ohne wesentliche Verstärkung; während die nächsten 4 vorn nagelförmig verstärkt sind und sich fast berïhren. - Unterseite matter mit verringerten Zeichnungen, Vorderflügel am Vorderrande nicht mit einem kurzen, breit abgeschnittenen roten Wurzelstrich, sondern mit einem lang auslaufenden, sich allmählich im Schwarzen verlierenden orangefarbenen Streif, der noch eine sclımal scliwarze Kante des Vorderrandes freilïBt. Die Strahlen des Hinterflügels fast in gleicher Stärke wie oberseits, während der Querstreif bis auf einen schmalen, an der Mediana fast winkelig gebogenen Strich verkleinert ist. Vorderrand mit orangerotem Wurzelstreif. hinter der Costalis ein gelblicher, etwas kürzerer Streif, an der Wurzel der Mediana ein roter Punkt. - Fransen schwarzbraun, am Distalrande des Vorderflügels zwischen den Adern fein weiß gescheckt, am Hinterflügel jederseits der Ausläufer der rotgelben Strahlen feine weiße Randfleckehen bildend. Vorderflïgellänge $39 \mathrm{~mm}$.

Bildet Übergänge zur nächsten Form, zu H. m. thelxiope und zu H. m, vicinus (S. 117 und 122).

Gebiet des Amazonen-Stroms.

- 28i. H. melpomene aglaope C. \& R. Felder 1862 H. a., C. \& R. Felder in: Wien. ent. Monschr., v. 6 p. $79 \mid 1862 H$. thelxiope var. a., H. W. Bates in: Tr. Linn. Soc. London, v. 23 p. 559 ! 1877 H. a., A. G. Butler in: Tr. ent. Soc. London, p. 126 | 1879 H. a., Hopffer in: 'Ent. Zeit. Stettin, v.40 p. $432 \mid 1885$ H. thelxiope var. a., O. Standinger' (\& Schatz), Exot. Schmett., v. 1 p. $78 \mid 1869$ Heliconia unimaculata, Hewitson. Equat. Lep., p. 10 (forma u.) ! 1871 H. u., Hewitson, Exot. Butt., v. 4 Heliconia t. 6 f. 19 (forma u.) | 1877 Heliconius u., W. F. Kirby, Cat. diurn. Lep., Suppl. p. 721 (forma u.) ) $1871 H$. thehxiope var, aglaope $+H$. u., W. F. Kirby, Cat. diurn. Lep., p. $142 ;$ p. 143 (forma u.) | $1900 \mathrm{H}$. melpomene aberr. nirabilis, Riffarth in: Berlin. ent. Z., v. 45 p. 205 
(forma mirabilis) $\mid 1901 H$. melpomene aglaope (part.) $+H$. m. mirabilis $+H$. melpomene unimaculata (H. radiatus Plötz in MIS.), Riffarth in: Berliu. ent. Z., v. 46 p. 95 ; p. 96 (forma mirabilis); p.96 (forma u.) | 1902 „Heliconia thelxiope-a. var.", C. Oberthür, Etud. Ent., v. 21 t. 10 f. $113-115,118$; t. 11 f. 122, 123.

Forma principalis. Vorderflügel ähnlich dem der vorjgen Unterart, aber der distale 'Teil der Zelle entweder ganz fleckenlos oder nur mit einem gelblichen Wischfleck hinter der Subcostalis, im Hinterwinkel ohne Fleckenbildung. Die distal von der Zelle liegende schwefelgelbe Binde in analoger Form wie bei der vorigen Unterart, in mehr oder weniger weitem Abstande von der Zelle, also nicht ganz konstant in der Anlage. - Hinterflügel beim $\delta^{\pi}$ mit dem der Art charakteristischen breiten, bis zur Subcostalis reichenden, nicht auffällig dunkler umrandeten Vorderrandfelde, welches nur im Apex schwärzlich wird; beim o mit schwärzlichem vorderem Teil, in dem sich, von der Wurzel entspringend, ein rötlicher, ungewiß begrenzter Wisch nächst dem Vorderrande, etwa in halber Länge derselben, bildet; dieser Wisch ist bis hinter die Costalis verbreitert und wird von ihr schwarz durchschnitten. Im übrigen mit einem der Subcostalis folgenden, von dieser schmal schwarz getrennten, allmählich spitz auslaufenden orangegelben Querstreif und 7 hinter demselben liegenden Strahlen von derselben Farbe in der Weise wie bei der vorigen Unterart, nur daß der hinterste dieser Strahlen sehr kurz und wischartig, manchmal nur verkümmert oder verloschen auftritt. - Unterseite des Vorderflügels matter, das Rot des proximalen Teiles in der Zelle tiefer ausgeschnitten. Hinterflingel am Vorderrande mit schwefelgelbem, manchmal, namentlich beim o, sehr reduziertem Wurzelstreif und einem zweiten, unmittelbar hinter der Srbcostalis liegenden, meist etwas kürzeren rötlichen Streif; die übrjge Zeichnung verringert, aber alle Strahlen deutlich, wenn auch schmaler, am. Distalrande kleine, verloschene weiße Saumflecke. - In Übergängen zu den benachbarten Formen vorhanden. - Fransen schwarzbraun. Vorderflügellänge bis $42 \mathrm{~min}$.

Nördliches Marajo, Pará?, Amazonas (Santarem, Manaos, Fonteboa, São Paulo de Olivença), Peru (Yurimaguas, Chanchamayo, Ucayali, Pozuzo Cuzco), am Rio Negro, Ecuador (Arehidona).

Forma mirabilis. Vorderflügel schwarzbraun, auch das Wurzelfeld, nur mit der schwefelgelben Discalfleckenbinde, die der Hauptform eigentümlich ist. Im Hinterwinkel etwas rotgelbe Bestäubung. Hinterflügel einfarbig: schwarzbraun.

Peru (Yurimaguas).

Forma unimaculata. Wie die vorige Form, aber die gelbe Vorderflügelbinde an der distalen Kante rot angeflogen.

Niederländisch-ờuayana; Ecuador?

- 28j. H. melpomene vicinus (Ménétr.) 1857 Heliconia vicina, Ménétriés, Lép. Ac. St.-Pëtersb., v.2 p. $114 \mid 1862$ Heliconius thelxiope var. vicinus, H. W. Bates in: Tr. Linn. Soc. London, v.23 p. $560 \mid 1871$ H. t. var. vicina, W. F. Kirby, Cat. diurn. Lep., p. 142 | 1873 H. rufolimbatus, A. G. Butler in: Cistula ent.. v. 1 p. 169 (forma rufolimbata) | 1877 H.r., W.F. Kirby, Cat. diurn. Lep., Suppl. p. 722 (forma rufolimbata) 1885 H. amor, O. Staudinger (\& Schatz), Exot. Schmett., v.1 p.78 t.32 (forma a.) $\mid 1890$ H. a., Hahnel in: D. ent. Z. Lep., v. 3 p. 260 (forma a.) | 1901 H. melpomene vicina + H. m. a. + H. m. rufolimbatus, Riffarth in: Berlin. ent. Z., v.46 p.96; p. 97 (forma a.); p. 100 (forma rufolimbata) | 1902 Heliconia thelxiope var. + "H. t.aglaope var.", C. Oberthür, Étud. Ent., v. 21 t. 8 f. 91 , t. 10 f. 116 ; t. 8 f. 92 (forma rufolimbata). 
Forma principalis. Nächst der vorigen Unterart und derselhen sehr ähnlich, mit gelbroter Proximalbestïubung des Vorderflügels und discaler gelber Fleckenbinde, die aber in proximaler Richtung erweitert ist, dicht am Zellende liegt und vorn und hinten wurzelwärts zurï̈cktritt, so daß letzteres davon eingeschlossen ist; sie reicht außerdem bis in den hinteren Medianzwischenraum, dort einen stärlker isolierten eirunden Fleck bildend. Ferner im distalen Teil der Zelle ein breiter, in der Mitte eingeschnïrter gelber Fleck, der vou der roten Wurzelbestäubung vermöge dieser Gestalt durch einen ei- oder kreisrunden schwarzbraunen Fleck der Grundfarbe und von der Fleckenbinde dureh schmalere schwarze Färbnng am Zellende getrennt ist, im ïbrigen aber die ganze Breite der Zelle einninimt und vorn sowie hinten an der distalen Ecke von der Fleckenbinde nur durch die schmal schwarze Subcostalis nud Mediana geschieden ist. - Hinterflügel wie bei der Hauptform der vorigen Unterart, der rotgelbe Querstreif vor den Strahlen zuweilen etwas schmaler. Unterseite matter, das rote Wurzelfeld des Vorderflügels von geringerer Ausdehnung. Fleck am Zellende zuweilen verkümmert, Querstreif und Strahlen des Hinterflügels schmaler und kürzer, am Distalrande manchmal weiße wischartige Saumfleckchen. - Fransen schwarzbraun, am Apex des Vorderflügels weiß und im n̈brigen stellenweise weiß gescheckt. Vorderffügellänge etwa $40 \mathrm{~mm}$.

Bildet in Gestalt und Ausbreitung der gelben Flecke Abänderungen in analoger Weise wie H. m. aglaope (S. 121). Vielleicht Zeitformen.

Westliches Amazonas (Teffé, São Paulo de Olivença), Peru (Pebas).

Forma amor. Kleiner als die Hauptform, ohne Rot im proximalen Felde des Vorderflügels, aber die schwefelgelbe Fleckengruppe distal der Zelle proximal in ganzer Länge etwa $2 \mathrm{~mm}$ breit rot gerandet. Diese rote Färbung setzt sich nach hinten bis in den Hinterwinkel fort, und wird der letzte Teil dort durch den hinteren Medianast fleckartig abgesondert. Hinterfligel einfarbig schwarzbraun; auf der Unterseite drei rote Wurzelpunkte.

Östliches Amazonas (Massauary).

Forma rufolimbata. Rotgelbe Zeichnung auf Vorder- nnd Hinterflügel wie bei der Hauptform, gelbe Discalzeichnung, $d$. h. Fleck im distalen Ende der Zelle und Fleckengrnppe distal hiervon, besser zusammenhängend, eine volle, nur von den feinschwarzen Adern durchschnittene breite gelbe Binde bildend, welche distal an den Adern schwarz eingeschnitten, unregelmäßig gezähnt, schmal, aber scharf rot gerandet ist und mit dem hinteren Medianast abschneidet. Gestalt der Binde im ganzen wie bei H. m. penelope (S. 124). AnBerdem im Hinterwinkel vor dem hinteren Medianast ein rot bestäubter Fleck. Vorderflïgellänge $45 \mathrm{~mm}$.

Nördliches Brasilien (am Rio Tabajoz).

28k. H. melpomene eulalia Riff. 1900 H.m.aberr.e., Riffarth in: Berlin. ent.Z., c. 45 p. $20 \pm$ | 1901 H. m. e., Riffarth in: Berlin. ent. Z., v. 46 p.96 | 1902 "Heliconia thelxiope-cybelc var.", C. Oberthür., Étud. Ent., $v .21$ t. 6 f. 70, 72, 71; t. 7 f. 73.

Vorderffügel wie H.m. vicinus, Hinterflügel ohne rote Strahlenzeichnung, aber mit rotgelbem Querstreif hinter der Subcostalis in der Weise wie bei der erwähnten Unterart, sonst von dieser nicht unterschieden.

Niederländisch- und Französisch-Guayana. 
- 281. H. melpomene peñelope Staud. 1894 H.p. + H. p. aberr. penelamanda + H. m. aberr. pelopeia, O. Staudinger in: D. ent.Z.Lep., v. 7 p. 67 ; p. 67 (forma penelamanda); p. 67 (forma penelopeia) | 1896 H. penelope $+H$. p. aberr. penelamanda $+H$. m. aberr. penelopeia + H. penelope aberr. pluto, O. Staudinger in: D. ent. Z. Lep., v. 9 p. 303 t. 7 f. 1 ; t. 7 f. 3 (forma penelamanda); p. 303 (forma penelopeia); p. 303 t. 7 f. 4 (forma pluto) | 1900 H. m. aberr. margarita, Riffarth in: Berlin. ent. Z., v. 45 p. 205 (forma margarita) | $1901 \mathrm{H}$. melpomene penelope $+H$. m. margarita $+H$. melpomene pluto + $H$. m. penelamanda + H. m. penelopeia, Riffarth in: Berlin. ent. Z., v.46 p. 97 ; p. 98 (forma margarita); p. 99 (forma pluto); p. 100 (forma penelamanda); p. 100 (forma penelopeia) | 1902 , "Heliconia thelxiope-penelope" + "H. t.-p. var. ${ }^{+}+$"H. t.-penelamanda", C. Oberthür, Etud. Ent., v. 21 t. 9 f.108; t. 10 f. 110 ; t. 9 f. 106 (forma penelopeia); t. 10 f. 112 (forma margarita); t. 10 f. 111 (forma penelamanda).

Forma principalis. Grundfarbe tief schwarzbraun. Vorderflügel proximal in der Zelle, hinter derselben (weniger auch vor ihr) und am Hinterrande dunkel, fast bräunlich rot, hieran anschließend, in der Mitte aber rundlich schwarz getrennt, ein gelber, die Breite der Zelle und den distalen Teil dieser ausfüllender, schwefelgelber Fleck, der mit einer distal liegenden, durch die Adern fein schwarz geschnittenen, gelben Fleckengruppe mehr oder weniger zusammenhängt und mit dieser meist eine breite, vom schmal schwarzen Vorderrande bis zum hinteren Medianast reichende Binde bildet, welche distal an den Adern, namentlich am mittleren Medianast zahnartig eingeschnitten ist, an der proximalen Grenze aber meist ohne wesentliche Einschnürung oder nur durch einen kleinen, hinter der Zelle eingerückten Winkel unterbrochen, vollrandig abgeschrägt ist. Im Hinterwinkel öfters ein rotes Fleckchen. Hinterflügel wie bei H. m. thelxiope (S. 117), aber auch hier die rote Färbung bedentend intensiver und nicht in gelblichem Ton. - Unterseite matter in der Färbung. Vorderflügel mit kurzem rotem Costalstreif, die rote Wurzelbestäubung sehr verringert, mitunter ganz verkümmert oder verwaschen vorn und binten in der Zelle. Die gelbe Binde am Zellende breiter schwarz unterbrochen, so daß der eingeschnürte Fleck im distalen Teil der Zelle deutlicher isoliert steht. Hinterflügel mit 2 oder 3 roten Wurzelpunkten, gelbem, kurzem, häufig ganz rudimentärem Wurzelstreif längss des Vorderrandes, Querstreif und Strahlenzeichnung bedeutend verschmälert und teilweise rerloschen. - Fransen schwarzbraun, Saum des Hinterflügels - schwach gewellt. Vorderflügellänge bis $40 \mathrm{~mm}$.

Bolivia (Yungas, Bueyes, am Rio Juntas).

Forma margarita. Vorderffügel wie bei der Hauptform, jedoch mit Spuren eines gelben Streifes in der Zelle vor der Mediana. Hinterflügel mit der roten Strahlenzeichnung der Hanptform, aber vor derselben, dicht an den nagelkopfförmigen vorderen Enden der Strahlen und nur durch eine ganz schmale wellenförmige schwarze Linie getrennt, gelbe Bestäubung, welche sich fast über den ganzen, hinter der Subcostalis verlaufenden, roten Querstreif ausbreitet und diesen bis auf den äußersten proximalen Winkel gelblich rot färbt. - Unterseite matter, gelber Medianstreif in der Zelle des Vorderflügels etwas deutlicher, proximale rote Bestäubung stark verringert. Hinterflïgel mit rein gelbem Wurzelstreif am Vorderrande bis zur Hälfte seiner Länge; 3 oder 4 rote Wurzelpunkte, der gelbrote Querstreif und die Strahlen schmaler und breiter getrennt, ersterer weißlich, fast rosa verfärbt, nur proximal und auf den Adern sowie am hinteren Rande schmal rein gelb. In einem bekannten Falle die gelbe Discalzeichnung des Vorderflügels schwärzlich bestäubt, fast verloschen.

Bolivia (Gebiet des Rio Juntas). 
Forma penelopeia. Von der Hauptform dadurch unterschieden, daß der große gelbe Discalfleck oder die Discalbinde distal von der Mitte an stark rot augeflogen ist. Diese rote Bestäubung setzt sich im Schwarzen fort und bildet dort eine Zeichnung, die derjenigen der roten Binde der typischen Unterart (S. 111) entspricht. Sonst wie die Hauptform.

Es liegt hier ein ausgeprägter Übergang der hochroten Binde der typischen Unterart in die schwefelgelbe Binde oder den gelben Discalfleck der Hauptform von H. $\mathrm{m}$. penelope vor.

Bolivia (Gebiet des Rio Juntas).

-Forma penelamanda. Torderflügel proximal mit roter Trurzelbestäubung wie bei der Hauptform, in derselben aber vor der schwarzen Mediana ein rein gelber, schmaler Streif. Distal von diesem Wurzelfelde, schmal schwarz getrennt, eine breite rote Schrägbinde, die den distalen Teil der Zelle ausfüllt, nur von den Adern schmal schwarz geschnitten wird, vorn etwas gelb angeflogen ist und in Gestalt derjenigen der typischen Unterart (S. 111) entspricht. - Hinterflügel mit Strablenbildnng wie bei der vorigen Form, vor den Strahlen jedoch ein breiter, entweder rein gelber oder rötlicher, stark gelb bestänbter Querstreif, welcher sich vorn unmittelbar den breiten Strahlenenden anschließt und am distalen Ende, sowie in der äußersten proximalen Ecke deutlich rot ist. Anlage analog derjenigen der Forma margarita. - Unterseite matter, Vorderflügel proximal mit kurzem rotem Costalstreif, die rote Wurzelfärbung sehr verringert, Discalzeichnung rötlich weiß. Hinterflïgel mit gelbem kurzem Wurzelstreif am Vorderrande, 2 oder 3 roten Wurzelpmnkten, Querstreif weißlich gelb, Strahlen schmaler und kürzer.

Bolivia (Bueyes, Gebiet des Rio Juntas).

Forma pluto. Intensiv schwarzbraun, Vorderflügel mit gelber Discalzeichnung wie bei der Hauptform, im Hinterwinkel anf dem Ende des hinteren Medianastes ein rundlicher hochroter Fleck. Rote Wurzelfärbung fehlt, ebenso die Strablen des Hinterflïgels. Dort nur ein schwefelgelber, schwärzlich überstänbter Querstreif hinter der Snbcostalis, der sich bis etwis über die Mitte des Flügels erstreckt. - Unterseite matter, das Gelb des Vorderflïgels weißlich: proximal ein kurzer roter Costalstreif, der rote Fleck im Hinterwinkel verloschener. Hinterflügel mit 3 roten Wurzelpunkten, der gelbliche Qnerstreif schmaler und kürzer.

Bolivia (Gebiet des Rio Juntas).

- $28 \mathrm{~m}$. H. melpomene timareta (Hew.) 1867 Heliconia t., Hewitson in: Tr. ent. Soc. London, ser. 3 v. 5 p. 563 | 1871 H. t., Hewitson, Exot. Butt., v. 4 Heliconia t. 6 f. $21 \mid 1871 \& 77$ Heliconius t., W. F. Kirby, Cat. diurn. Lep., p. 140; Suppl. p. $721 \mid 1903$ $H$. melpomene t., Riffarth in: Berlin. ent. Z., v.47 p. $157 \mid 1890$ H. contigurs, Weymer (\& Mraassen), Lep. Reise Stübel, p. 118 t. 2 f.6 (forma contigua) | $1900 H$. timareta aberr. richardi, Riffarth in: Berlin. eut.Z., v. 45 p. 201 (forma r.) | 1901 H. melpomene $r .+$ H. $m$. contiguus + H. m. $t$., Riffarth in: Berlin. ent. Z., v.46 p. 97 (forma r.); p. 98 (forma contigua); p. 99| 1902 H.m.t. + H. m. t. aberr. virgata + H. m. t. aberr. c. + $H$. m. t. aberr. $r$., Stichel in: Ins.-Börse, $v .19$ p. 355; p. 355 (forma v.); p. 355 (forma contigua); p. 355 (forma r.) | 1903 H.m.t. + H. m.t.aberr. v. + H. m.t. aberr. c. + H. m. t. aberr. r., Stichel in: Berlin. ent. Z., v.48 p. 14; p. 14 (forma v.); p. 14 (forma contigua); p. 14 (forma r.) | 1902 "Heliconia vesta-aphrodyte var.", C. Oberthür, Étud. Ent., v. 21 t. 9 f. 104.

Forma principalis. Oberseite tiefschwarz, Vorderflügel mit einem schwefelgelben bindenartigen unregelmäBigen Fleck im Discus, welcher sich aus einem die Breite der Zelle in distalen Teil ausfüllenden, in der Mitte 
eingeschnïrten kleineren Fleck und einer um das Zellende lagernden Fleckengruppe zusammensetzt. Diese letztere beginnt voru hinter der Costalis mit einem der Subcostalis anliegenden schmalen länglichen Fleckchen und setzt sich hinter der vorderen Radialis in zwei weiteren, nur durch die fein schwarze hintere Radialis getrennten, kleinen, unregelmäßig geformten Fleckchen fort, verbreitert sich alsdann im mittleren und hinteren Medianzwischenraum und wird an dem mittleren Medianast distal zahnartig stark eingeschnitten. Selten erscheint hinter dem hinteren Medianast ein kleiner gelber Wischfleck. Am Zellabschluß ist diese Discalzeichnumg melu oder weniger, meist winkelförmig, schwarz gekernt. Die Zeichnung ist rariabel und durch die sowohl von vorn, als auch distal eindringende Grundfarbe mehr oder weniger zerrissen, der proximale Fleck in der Zelle zuweilen nur unvollkommen, namentlich fehlt der vordere Teil. Im übrigen zeichnungslos, nur der hellgraue, glänzende Vorderrandteil auf dem Hinterflügel des $\sigma^{\pi}$ augenfällig ron der tiefschwarzen Grundfarbe abstechend. - Unterseite in matterem Farbton, Vorderflügel proximal mit kurzem rotem Costalstreif, Hinterflügel mit gelbem Wurzelstreif am Vorderrande und 3 oder 4 wischartigen Wurzelfleckchen. Frausen schwarz, Saum des Hinterflügels gewellt. Vorderflügellänge bis $44 \mathrm{~mm}$.

Ecuador (Santa Inéz). In Höhe ron $1250 \mathrm{~m}$; Oktober bis Norember.

Forma virgata. Vorderflügel (Fig. 22) wie bei der Hauptform, Hinterflügel mit 6 schmalen hochroten strahlenförmigen Streifen in den Aderzwischenräumen, welche vol'n nagelkopfartig erweitert sind, dort lose zusammen-

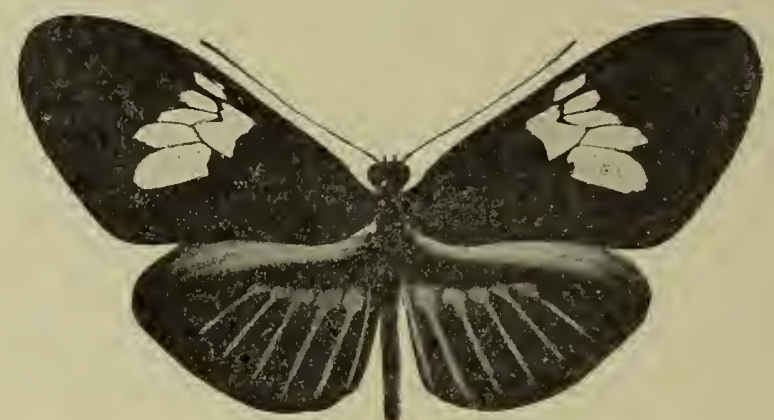

Fig. 22. H. melpomene timareta, forma virgata, $\delta(1 / 1)$.

hängen, in einer ziemlich gerade abgeschnittenen Linie kurz hinter der Zelle beginnen und auf der Unterseite nur in ganz schmalen, fast strichförmigen Streifen von weniger intensiver Färbung zu erkennen sind. Übergangsform zur folgenden.

Ecuador. Neben der Hauptform.

- Forma contigua. Vorderflügel wie bei der Hauptform. Im Hinterwinkel bilden sich zuweilen $1-3 \mathrm{mehr}$ oder weniger große, rote, rundliche Flecke, auch erscheint oberseits manchmal ein subapicaler rötlicher Wischfleck (forma secunda). Hinterflügel mit einer Reihe von 7 oder 8 breiten hochroten Strahlen, die vorn in gerader Iinie dicht hinter der Zelle, zuweilen noch die hintere Ecke derselben ausfïllend, abgeschnitten sind, bis reichlich zm* Hälfte ihrer Länge zusammenhängen und nur durch die fein schrarzen Aderu durchschnitten sind, sich alsdam verschmälern und in kurzer Entfermung rom Distalrande spitz auslaufen. Der proximal liegende Streif fïrbt 
den Hinterrand bis nahe an den Hinterwinkel rot, der distale, vor der vorderen Radialis liegende, ist manchmal verwischt oder verkiirzt. -- Unterseite matter gefärbt, sonst im allgemeinen der oberen Seite entsprechend. Bei solchen Stricken, welche oben mehrere rote Flecke im Hinterwinkel des Vorderflïgels tragen, entsteht unten zuweilen eine dem Distalrande folgende, fast randständige und mehr oder minder deutliche Fleckenbinde von rötlichbrauner Farbe. Strahlen des Hinterflügels bedeutend schmaler, matter und meist ganz zusammenhanglos.

Ecuador (Agoyan, Santa Inéz).

-Forma richardi. Vorderflügel proximal mit hochroter, von der Subcostalis nnd Mediana schmal, von der Submediana breit schwarz durchschnittener Bestäubung; Vorder- nnd Hinterrand bleiben schmal schwilrz. Diese rote Färbung erstreckt sich in der Zelle und hinter derselben bis zu einer schwefelgelben Discalzeichnung, welche derjenigen der Hauptform entspricht. Auf der Grenze beider im distalen Teil der Zelle ein rundlichdreieckiger Fleck der Grundfarbe, im Hinterwinkel ein rotes Fleckchen. Hinterflügel ähnlich demjenigen der vorigen Form, aber vor den breit zusammenhängenden Strahlen, nur durch einen schmalen, eine Wenigkeit nach hinten gekriimmten schwarzen Streif getrennt, ein roter, die Zelle durchschneidender und diese fast ganz ansfüllender Querstreif, der am Hinterrande nächst der Flïgelwurzel etwa $3.5 \mathrm{~mm}$ breit beginnt, sich allmählich verschmälert und ziemlich spitz etwa in der Flügelmitte vor der vorderen Radialis endet. - Unterseite matter, Vorderflügel mit sehr verringerter rötlicher Wurzelfärbung, welche nur in zwei, an der Wurzel einen spitzen Winkel bildenden Streifen vorn und hinten in der Zelle ïbrig geblieben ist. Discalzeichnung fast weiß. Strahlen und Querstreif des Hinterffügels schmaler, kürzer und verwaschen. Sonst wie die Hauptfor'm.

\section{Ecuador (Santa Inéz).}

$28 \mathrm{n}$. H. melpomene erebius Riff. $1900 \mathrm{H}$. timareta aberr? erebia, (Maassen in MIS.) Riffarth in: Berlin. ent. Z., v.45 p.201 | 1901 H. melpomene e., Riffarth in: Berlin ent. Z., v. 46 p. 99.

Schwarzbraun, Torderflügel mit einem gelben Discalfleck wie H. m. timareta (S. 125), nur im hinteren Medianzwischemraum proximal etwas verschmälert, so daß der Winkel an der Mediana nicht ausgefüllt wird, auch der in der Zelle liegende, durch die schwarze Bestäubung am Ende derselben abgetrennte Fleck in der Mitte nnterbrochen, und die verbleibenden Rudimente kleiner als die analogen Teile bei der erwähnten Unterart. Diese Eleckbildung ist, wie sicher anzunehmen. Veränderungen unterworfen, wie sie bei H. m. timareta und den nächst verwandten Unterarten auftreten. Distal dieser Fleckengruppe liegt eine schmale, stellenweise unterbrochene, rote Binde, von welcher erstece fast berührt wird. Die ungewisser bestäubte distale Kante nimmt die Lage der roten Binde der typischen Unterart (S. 111) ein und geht bei dem hinteren Medianast bis nahe zmon Distalrande.

\section{Französisch-Guayana?, wahrscheinlicher Ecuador.}

28 o. H. melpomene amandus Grose Sm. \& F. Kirby $1892 \mathrm{H}$. a., (O). Staudinger in MS.) Grose Smith \& W. F. Kirby, Rhop. exot., v. 1 Helicon. t. 1 f. 3 ; $1894 H$. a., O. Staudinger in: D. ent. Z. Lep., v. 7 p. $68 \mid 1901$ H. melpomene a., Riffarth in: Berlin. ent. Z., v. 46 p. 101.

Schwarzbraun, Vorderflügel mit einem dicht vor der Mediana, etwas zerștäubter auch hinter dieser liegenden, schmalen sclıwefelgelben Streif bis zu 
einer breiten, derjenigen der typischen Unterart (S. 111) ähnlichen roten Binde, in deren Mitte etwa die Discocellulares liegen, welche in der Regel schwarz sind. Diese Binde von hoch-mennigroter Farbe füllt den distalen Teil der Zelle auf etwa ein Drittel der Länge aus, wendet sich in der proximalen Begrenzung in flachem Bogen von der Subcostalis bis zu dem Ursprunge des hinteren Medianastes und endet in unverminderter, bis nahe zum Distalrande reichender Breite etwa 1.5-2 mm hinter dieser Ader. Vorn tritt dieselbe teilweise, einen durch die Subcostalis fein schwarz abgeschnittenen schmalen Streif bildend, bis zur Costalis vor; Vorderrand selbst aber schmal schwarzbraun. Ihre distale Begrenzung ist zerstäubt, stark zerrissen und namentlich an den Adern tief eingeschnitten. Die allgemeine Richtung ist schräg und flach gebogen, vom Vorderrande gegen den Hinterwinkel jedoch ist der Teil hinter dem mittleren Medianast stufenartig abgesetzt und bildet einen distal vorspringenden stumpfen Zahn. Vorn, in dem vor der Subcostalis liegenden abgesonderten Streifchen, mitunter etwas gelbe Bestäubung. Hinterflügel mit breiter schwefelgelber Querbinde, welche in einer Breite von etwa $3 \mathrm{~mm}$ am Hinterrande dicht an der Flügelwurzel beginut, die Zelle durchquert und dieselbe bis auf den proximalen spitzen Winkel an der Wurzel ausfüllt, dann der Subcostalis folgt und etwas jenseits der Mitte der Flügellänge endet. Das Ende ist durch die an der vorderen Radialis eindringende Grundfarbe kurz gespalten, ebenso ist der letzte Teil der Binde hinten an der hinteren Radialis etwas eingekerbt, im übrigen aber riemlich ganzrandig; die sie durchschneidenden Adern auch gelb bestäubt. - Unterseite matter in der Farbe, das Rot der Vorderflügelbinde weißlich, Querbinde des Hinterflügels gelblichweiB. Sonst wie die typische Unterart. - Vorderflügellänge etwa $43 \mathrm{~mm}$.

Bolivia (Bueyes, Gebiet des Rio Juntas), Peru.

\section{H. amaryllis C. \& R. Felder}

ऽ. Wurzel- und Mittelglied der Palpen, Stirupunkte und hintere Augeneinfassung weiß oder gelb, die übrige von der Grundfarbe des Körpers abweichende Behaarung oder Zeichnung stets gelb. Grundfarbe der Flügel schwarzbraun, zuweilen mit blauem Glanz. - Vorderflügel schlank, mit sehr stark abgerundetem Apex und stumpfwinkligem, ebenfalls abgerundetem Hinterwinkel. Distalrand flach konvex, Hinterrand bedeutend kürzer als der Vorderrand, schwach S-förmig geschweift. Mit einer schmaleren oder breiteren roten Binde im Discus, die schräg vom Vorderrande, das Zellende etwa in der Mitte lassend, bis zum Hinterwinkel zieht, distal gewöhnlich im hinteren Verlauf etwas stufenartig abgesetzt ist und in einem stumpfen Zipfel dicht am Distalrande an dem hinteren Medianast endet. Unterseite mit kurzem rotem Wurzelstreif an Vorderrande, der zuweilen auch fehlt, sonst der oberen Seite entsprechend gezeichnet, in der Farbe matter, die rote Binde viel heller, fast weiBlich und die Begrenzung ungewisser. Hinter der Mediana granglänzend ohne Zeichnung, nur im distalen, Teil hinter dem hinteren Medianast rötliche Färbung. - Hinterflügel mit hellgrau glänzendem mehligem Vorderrandfelde bis zur Submediana, im Apex allmählich in die schwarzbraune Grundfarbe übergehend. Vorderrand selbst etwas dunkler und blanker. Im übrigen einfarbig oder mit gelber Querbinde, welche den hinteren Teil der Zelle ausfüllt und ziemlich spitz hinter der Subcostalis in einiger Entfernung rom Apex endet. Unterseite mit gelbem, mehr oder weniger ausgedehntem Wurzelstreif am Vorderrande, ohne oder mit 1-4 roten Wurzelpunkten, sonst wie die Oberseite oder, falls diese einfarbig, mit verloschener, nur schwach erkennbarer gelber Querbinde. - - o. Dem on entsprechend, nur 
mit den charakteristischen Geschlechtsunterschieden, namentlich schwärzlichem Torderrandfelde des Hinterfügels. - Fransen schwarzhraun.

Nordwestliches Brasilien, Peru, Venezuela, Trinidad, Colombia, Mittel-Amerika.

Diese Art zerfällt in 3 Unterarten:

- 29 a. H. amaryllis amaryllis C. \& R. Felder 1862 H. a., C. \& R. Felder in: Wien. ent. Monschr., v. 6 p. $80 \mid 1871$ H. a., W. F. Kirby, Cat. diurn. Lep., p. $143 \mid 187$ ? H. a. (part.?), Hopffer in: Ent. Zeit. Stettiu, v.40 p. $131 \mid 1901 H$. a., Riffarth in: Berlin. ent. Z., $x .46$ p. 102.

Mittleres und proximales Glied der Palpen, sowie Stirnpunkte und die hintere Augenbesäumung weiß, sonstige Kopf- und Körperzejchnung gelb. Oberseite der Flügel tief schwarzbraun mit mattem Sammetglanz aber ohne blauen Schiller. Im Discus des Jorderflügels eine mennigrote breite Binde, welche hinter dem schmal schwarzen Vorderande beginnt, deren vorderer Teil schmal streifenartig durch die schwarze Subcostalis abgeschnitten ist. und welche in schräger Richtung bis etwa $1 \mathrm{~mm}$ hinter dem linteren Medianast verläuft. Ihre proximale Kante läuft durch den distalen Teil der Zelle schräg bis zum hinteren Medianast, den Winkel am Ursprunge desselben freilassend, alsdann ist dieselbe stufenartig in distaler Richtung abgesetzt, so daß die Biude in ihrem letzten schmalen Teil mehr oder weniger an Breite verliert. Die distale Kante ist etwas unscharf und zerstäubt, zieht in schräger Richtung vom Vorderrande bis zum vorderen Medianast, ist dort stumpfwinklig schräg nach hinten gebogen und endet in einem etwas distal vorgeschobenen stumpfen Zipfel bei dem hinteren Medianast etwa $1 \mathrm{~mm}$ rom Distalrande. In letzten Verlauf meist einige unscharfe zahnartige Einschnitte der Grundfarbe. Hinterer Medianast fast ganz, mittlerer Medianast nur im distalen Verlauf fein schwarz das Rot schneidend, die übrigen Adern in der Binde, namentlich die Discocellulares, rot. Hinterflügel mit breiter gelber Querbinde, die kurz hinter der Flügelwurzel am Hinterrande etwa $3-3.5 \mathrm{~mm}$ breit beginnt und in schräger Richtung durch den linteren und distalen Teil der Zelle läuft. in ihrem vordereu Rande den Winkel der vorderen Discocellularis und Radialis schneidet und, der Subcostalis in kurzem Abstande folgend, etwa $5-6 \mathrm{~mm}$ vom Apex entfernt ziemlich spitz endet. Der hintere Rand, welcher außerhalb der hinteren Zellecke verläuft, ist an den Adern, namentlich an den Radiales, etwas zahmartig eingeschnitten; letztere selbst sind teilweise fein schwarz bestäubt, die übrigen, die Binde durchquerenden Adern indes gelb. - Unterseite in der hauptsächlichen Zeichnung der oberen Seite entsprechend, die oben rote Binde des Vorderflügels weißlich, an den Rändern gelblichrot. Torderrand ohne roten Wurzelstreif. Hinterflügel mit kurzem gelbem Wurzelstreif am Vorderrande und 2 roten Wurzelpunkten, welche manchmal fehlen. - Im ganzen dem bekannteren H. a. rosina (S. 130) sehr ähnlich, von diesem unterschieden durch die breitere rote Binde des Vorderflügels, den fehlenden Wurzelstreif der Unterseite des Torderflügels am Vorderrande und die geringere Anzahl der roten Wurzelpunkte des Hinterflügels unterseits. Es kommen Übergangsstücke ror. Vorderflügellänge $38-40 \mathrm{~mm}$.

Gebiet des Rio Negro, Peru (Cumbase, Huayabamba, Tarapoto).

29 b. H. amaryllis euryades Riff. 1900 H. a. var. e., Riffarth in: Berlin. ent. Z.. $v .45$ p. $205 \mid 1901$ H. a. e., Riffarth in: Berlin, ent. Z., $v .46$ p. 103.

Punktierung des Kopfes, proximale Glieder der Palpen und sonstige Körperzeichnung gelb. - Vorderflügel ähnlich dem der typischen Unterart, 
die Binde aber meist breiter. Die proximale Kante der Binde läuft etwa dureh die Mitte der Zelle oder etwas distal von diesér, ist dort meist ein wenig eingeschnürt und füllt den Winkel am Lrsprunge des hinteren Medianastes ganz oder fast ganz aus. Hinter demselben ist kein Absatz rorhanden, sondern die Binde endet gleichmäßig in voller Breite; zuweilen findet sich etwas ungewisse rote Bestäubung stellentreise hinter derselben bis zur Submediana. Die distale Kante der Binde entspricht ungefähr der Anlage bei der typischen Unterart, ist aber im vorderen Verlauf etwas gebogen und der stumpfe Winkel am vorderen Medianast, sowie der distal vorgeschobene Zipfel des hinteren Teiles ist weniger deutlich. Das Zellende liegt etwa in der Nitte der Binde. Form und Breite der Binde ist etwas wechselnd, mindestens entspricht dieselbe aber an Breite derjenigen der typischen Unterart. - Hinterflügel bis auf die Geschlechtsmerkmale oben einfarbig schwarz, in einem bekannten Falle ist die Querbinde in zerstreuter roter Bestäubung angedeutet. Auf der Unterseite erscheint dieselbe zuweilen blind, d. h. in einem ihrer Form entsprechenden helleren Ton der Grundfarbe, namentlich bei schräger Beleuchtung; daselbst $1-3$ rote Wurzelpunkte. Sonst wie die typische Unterart. - Vorderflügellänge etwa $40 \mathrm{~mm}$.

Leicht mit H. melpomene melpomene (S. 111) zu verwechseln, ist aber beständig kleiner und die rote Discalbinde des Vorderflügels voller, oben meist mehr orangefarben, unten gelblich, bis auf die Stücke aus Venezuela, bei welchen die Binde oben dunkelrot, unten rosafarben ist.

Peru (Vilcanota in Höhe von etwa $940 \mathrm{~m}$ ), Venezuela (Gebiet des Rio Iguapo und Rio Cassiquiari, Mérida), Trinidad; Colombia?

229 c. H. amaryllis rosina (Boisd.) $1862 \mathrm{H}$. melpomene (part.), H. W. Bates in: Tr. Linn. Soc. London, v. 23 p. 557 (forma .euryas) | ?1880 H. m., F. D. Godman \& O. Salvin in: Tr. ent. Soc. London, p. 122 (forma e.) | ?1881 H. m. (part.), F. D. Godman \& O. Salvin in: Biol. Centr.-Amer., Lep.-Rhop. v. 1 p. 154 (forma e.) | 1870 Heliconia euryas + H. rosina, Boisduva], Consid. Lép. Guatemala, p. 29 (forma e.); p. $79 \mid 1871$ Heliconius e. + H. r., W. F. Kirby, Cat. diurn. Lep., p. 647 (forma e.); p. $647 \mid 1890$ H. $r$. + H. e., Weymer (\& Maassen), Lep. Reise Stübel, p. 18; p. 97 (forma e.) | 1901 H. amaryllis $r .+$ H.a.e., Riffarth in: Berlin. ent. Z., v.46 p. 103 ; p. 104 (forma e.) | 1874 Heliconia $r$, A. G. Butler \& Herb. Druce in: P. zool. Soc. London, p. $351 \mid 1876$ H. amarallis (err., non C. \& R. Felder 1862!), Distant in: Tr. ent. Soc. London, p. xIv | 1885 Heliconizus a., Staudinger (\& Schatz), Exot. Schmett., v. 1 p. 79 t. $32 \mid 1881$ H. petiveranus (err., non Helicmia petiverana Doubleday 1847!), F. D. Godman \& O. Salvin in: Biol. Centr.Amer., Lep.-Rhop. v.1 p. 153 | 1901 H. euryas, Therese von Bayern in: Berlin. ent.Z., v. 46 p. 253 (forma e.).

Forma principalis. Flügeloberseite schwarzbraun, meist mit blauem Glanz (bei colombischen Stïcken), oder ohne Glanz (bei mittelamerikanischen Stücken). Binde des Vorderflügels schmaler als bei der typischen Unterart (S. 129), ihre distale Kante annähernd gleichmäßig schräg bis etwa zum mittleren Medianast, dort stufenartig abgesetzt und rechtwinklig bis dicht an den Distalrand vortretend. Der hierdurch gebildete Zipfel der Binde also deutlicher ausgeprägt. Hinterflügel wie bei der typischen Unterart, die gelbe Binde variiert etwas in der Breite. - Unterseite des Torderflïgels mit kurzem rotem Wurzelstreif am Vorderrande; Hinterfügel meist mit 3 roten Wurzelpunkten und kräftigem gelbem Wurzelstreif am Vorderrande. - Sonst wie die typische Unterart. Vorderflügellänge etwa $38 \mathrm{~mm}$.

Colombia (Chiquinquira, Zipaquira), Costa Rica, Panama (Chiriqui). 
2 Forma euryas. Forderflügel (Fig. 23) wie bei der Hauptform. Hinterflïgel ohen ohne gelbe Querbinde. welche aber auf der Linterseite meist blind rorhanden ist. Beide Flügel in der Regel nit starkem blauem Glanz, nur

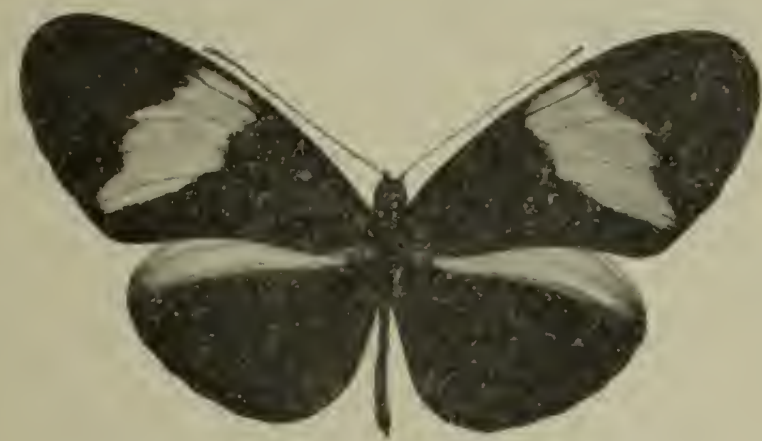

Fig. 23. $/ H$. amaryllis rosina, forma euryas, $\delta(1 / 2)$.

selten stumpf schwarzbraun in der Grundfarbe. Es kommen Übergänge zur Hauntform vor mit blind angedeuteter Hinterflügelbinde anf der Oberseite oder schwach roter oder gelber Bestäubung an deren Stelle.

Guatemala, Colombia, Venezuela(?)

\section{H. vulcanus (Butl.)}

Wurzel- und Mittelglied der Palpen, Punktierung des Kopfes, Halses und des vorderen Thorax weiß. Vorderbeine cbenfalls weißlich. Seitenlinien. soweit erkennbar, und Unterseite des Abdomen gelb. Thorax oben meist ohne Zeichnung. Flügelform wie die der vorigen Art. - Vorderflügel oben stark glänzend schwarzblau nit roter schräger Discalbinde, welche proximal weib begrenzt sein kann. Die Form der Binde variert; diese ist entweder breit, den distalen Teil der Zelle ausfüllend, reicht bis etwa $1 \mathrm{~mm}$ über den hinteren Medianast und ist im hinteren Teil zipfelartig gegen den Distalrand rorgeschoben oder ist schmaler, liegt gauz außerhalb der Zelle, ist mehr oder minder an den Adern zerschuitten und endet ror dem hinteren Medianast. Ihre Farbe ist auf der Unterseite matter, gelblichrot oder weißlich. - Hinterflügel außer den Geschlechtscharakteren einfarbig schwarzblan oder mit mehr oder weniger ausgebildeter rreißer Saumbinde, oben stets ohne, dagegen unterseits mit leuchtend weiBlichgelber, gerader Querbinde, starkem gelbem Wurzelstreif am Vorclerrande und 1 oder 2 sehr kleinen roten Wurzelpunkten. Die auf der Oberseite erscheinenden rreißen Saumflecke oder Fleckenbinde auch unten vorhanden. - Fransen weiß, nur an den Adern schwarz unterbrochen, an dem Hinterflügel häufig ganz weiß.

Ecuador, Colombia, Panama; Guayana?

Diese Art zerfällt in 2 Unterarten:

30 a. H. vulcanus vuleanus (Butl.) 1865 Heliconia v., A. G. Butler in: P. zool. Soc. London. p. 433 t. 25 f. 5 | 1871 Heliconius v., W. F. Kirby, Cat. diurn. Lep., p. 143 1901 H. v., Riffarth in: Berlin. ent. Z., r. 16 p. 104.

Flïgeloberseite schwarz mit starkem Blauglanz. Torderflügel mit breiter roter Disealbinde, deren proximale Grenze unweit des Zellendes schräg durch den distalen Teil der Zelle verläuft, etwas unregelmäBig abgesetzt nächst 
dem Ursprunge des hinteren Medianastes diesen schneidet und etwa $1 \mathrm{~mm}$ hinter ihm endet. Thre distale Grenze ist unscharf, zwischen den Adern gezähnt, verläuft in schräger Richtung distal von der Zelle hinter dem schwarzen Torderrande flach gebogen bis etwa zum hinteren Medianast, ist dort stufenartig abgesetzt und bildet einen in distaler Richtung vorgeschobenen Zipfel. der etwa $1 \mathrm{~mm}$ rom Distalrande endet. Die hintere Grenze der Binde liegt etwa in derselben Entfernung hinter dem hinteren Medianast, die Binde ist dort etwas verschmälert. Der vordere Teil ist ebenfalls schmaler und durch die fein schwarze Subcostalis als schmaler Streif abgeschnitten. Hinterflïgel, außer dem Geschlechtscharakter des $\sigma^{\pi}$, einfarbig blauschwarz. - Unterseite des Torderflügels mit Spuren eines gelben Wurzelstreifes an der Mediana, ohne roten Wurzelstreif am Vorderrande. Das Rot der Discalbinde matter; weißlich. Hinterflügel mit starkem hellgelbem seidenglänzendem Wurzelstreif am Vorderrande auf etwa $2 / 3$ seiner Länge und ebensolcher Querbinde. welche unweit der Flügelwurzel am Hinterrande etwa $4 \mathrm{~mm}$ breit beginnt und in gerader Richtung nach dem Apex rerläuft, diesen jedoch nicht erreicht, sondern, allmählich keilförmig schmaler werdend, spitz im vorderen Radialzwischenraum etwa $5-6 \mathrm{~mm}$ rom Apex entfernt endet. Ihre rordere Grenze läuft durch den Ursprung der Submediana, durchquert die Zelle. schneidet den Ursprung der rorderen Radialis und nähert sich in ihrem Terlauf der Subcostalis bis auf etwa $1 \mathrm{~mm}$. Die hintere Grenze liegt in gerader Linie etwa $1-2 \mathrm{~mm}$ hinter der hinteren Zellecke. Rote Wurzelpunkte in der Regel sehr klein, meist nur einer vorhanden. - Frausen beider Flïgel leuchtend weiß. nur an den Adern schmal schwarz unterbrochen. Vorderflügellänge etwa $39 \mathrm{~mm}$.

H. amaryllis rosina, forma enryas (S. 131) im allgemeinen sehr ähnlich, auf der Oberseite kaum ron ihm zu unterscheiden, aber vermöge der ganz anderen Zeichnungsanlage der Hinterflügelunterseite und der weißen Fransen spezifisch von demselben getrennt.

Colombia (Gebiet des Rio Dagua und Rio San Juan). Panama; Guayana (Demerara)?

30 b. H. vulcanus cythera (Hew.) 1869 Heliconia c., Hewitson, Equat. Lep., p. $9 \mid 1871$ H.c., Hewitson, Exot. Butt., 2.4 Heliconia t. 6 f. $17 \mid 1871 \& 77$ Heliconius c., IV. F. Kirby, Cat. diurn. Lep., p. 141; Suppl. p. 721 | 1900 H. vulcanus aberr. modesta, Riffarth in: Berlin. ent. Z., v. 45 p. 206 (forma m.) | 1901 H. v. cythera $+H . v$. modestus (H.7iypna Plötz in MIS.), Riffarth in: Berlin. ent.Z., $v .46$ p. 105 ; p. 105, 178 (forma modesta).

Forma principalis. Flügeloberseite schwarzblau mit starkem Seidenglanz. Vorderflügel bei typisch gezeichneten Stücken distal von der Zelle nit roter, proximal weiß begrenzter schmaler Querbinde, die hinter dem schmal schwarzblauen Vorderrande beginnt und in schräger Richtung bis zum hinteren Medianast zieht. Der vorderste Teil, ein schmaler von der fein schwarzen Subcostalis abgesonderter Streif, tritt bis zur rorderen Zellecke zurück und ist fast ganz weiß; die Binde ist im übrigen Verlauf beiderseits etwas zerrissen, mindestens von den fein schwarzen Adern durchschnitten oder auch stellenweise, namentlich am vorderen Medianast, etwas gekerbt. Im anderen, häufigeren Falle ist die Binde in proximaler Richtung mehr oder weniger verbreitert und reicht bis in die Zelle derart hinein, daß die beiden distal vorspringenden Ecken ausgefüllt werden. Alsdann sind nur geringe Spuren des weißen Anfluges vorhanden, meist nur ein kleiner weißer Fleck oder Wisch proximal im vordersten Teil, unmittelbar ror der Subcostalis. Die Binde kann auch voller, die Adern weniger geschwälzt sein. und hinten bildet sich meist ein an dem hinteren Medianast distal rorspringender Zahn, der etwa $1-2 \mathrm{~mm}$ rom Distalrande endet. Die Anlige hat dann Ähnlichkeit mit der Binde ron H. amarỵllis rosiua (S. 130), ist aher' 
intensiver rot. Gewöhnlich bildet der hintere Radialast auch die hintere Begrenzung, jenseits desselben treten nur zerstäubte rote Spuren auf, aber es kann auch eine Reduktion der Länge dergestalt auftreten. dab das Ende in ungewisser Zerstäubung schon im hinteren Medianzwischenraum liegt. In seltenen Fällen ist die proximale Begrenzung gelb statt weiß, und es bildet sich im Hinterwinkel schwache gelbe Bestäubung. Hinterflügel außer dem hellgelbgrau glänzenden Vorderandfelde des ò mit einer weißen. an den Adern meist ron der Grundfarbe durchbrochenen Saumbinde. Es bilden sich hierdurch fast quadratische oder rechteckige Flecke, die auch rorn etwas ron der Grundfarbe eingekerbt sind und durch deren Vitte sich, dem Distalsaum folgend, meist ein schwach bestäubter blauschwär?licher Schattenstreif zieht, der in der Mitte jedes Fleckes wiederum einen dunkleren Keru bildet. Mauchmal setzen sich diese Flecke anf dem Torderfligel in verkleinertem Maßstabe als Verbreiterung der weißen Stellen der Fransen fort. - Cuterseite matter, Torderflügel mit kurzem rotem Trurzelstreif am Vorderiande oder ohme solchen, Querbinde weißlich oder rosa gefärbt. Hinterflügel mit starkem gelbem Wurzelstreif am Vorderrande. 1-3 mehr oder weniger deutlicheu roten Tirurzelpunkten, weißlich gelber schmaler Querbinde wie bei der typischen Interart; die Flecke der Randbinde mehr isoliert, in der Form abgestumpfter Dreiecke, und im Apex verkleinert, häufig von den weiBen Fransen abgerückt. Torderflïgellänge etwa $39 \mathrm{~mm}$.

Ecuador (Paramba, Balzapamba in Höhe von $800 \mathrm{~m}$, Palmar in Höhe von $1000 \mathrm{~m}$ ).

Forma modesta. Färbung wie bei der Hanptform. Binde des Torderflügels stets so breit, daß die Zellecken distal ausgefüllt sind, nu mit Spuren eines weißen Fleckchens proximal im vorderen Teil oder ganu rot. Hinterflügel ohne Saumbinde oder Saumflecke oder nur mit rerloschenen Spuren letzterer, namentlich auf der Lnterseite.

Ecuador (Paramba).

31. H. batesi Riff. 1900 H. b., Riffarth in: Berlin. ent. Z., $x .45$ p. 207 | 1901 H. b., Riffarth in: Berlin. ent. Z., v. 46 p. 105.

ठ․ Punktierung auf Kopf und Hals, sowie die übrige, ron der Grundfarbe abweichende Zeichnung oder Behaarung des Körpers und seiner Anhänge gelb. Flügelform wie die der vorhergehenden Arten. Oberseite der Flügel schrarzbraun. ohne blauen Glanz. - Torderflügel mit einem großen roten Fleck im Discus, der hinter der schwarzbrannen Subcostalis im distalen Teil der Zelle etwa $5 \mathrm{~mm}$ breit beginnt, schräg durch die Zelle läuft, hinter der Mediana bedeutend rerbreitert ist und sich gegen den Hinterwinkel wiederum rerschmälert. Der vordere, in der Zelle liegende Teil ist beiderseits eingeschnürt, die distale Begrenzung hinter der Zelle läuft bogenförmig durch den proximalen Teil des mittleren Medianzwischenraumes, wendet sich von dem mittleren Medianast gestreckt in schiefer Richtung bis kurz vor den hinteren Medianast und bildet dort einen distal etwas ansgeflossenen kleinen Zapfen. Hinten geht, die Binde in flachem Bogen bis etwa an die Submediana und ist an dieser Begrenzung ungewiß zerstäubt; letztere rereinigt sich mit dem distalen Zapfen der erst beschriebenen Begrenzung stumpf hinter dem hinteren Medianast in der Nähe des Hinterwinkels. Der Fleck hat annähernd die Gestalt eines bauchigen Gefäßes mit weitem Halse (Line), ist jedoch Veränderungen unterworfen und namentlich im hinteren und distalen Verlauf ron der Grundfarbe manchmal weniger regelmäßig begrenzt. Außerdem distal vou der Zolle mit einem weiteren, halbbindenatigen, breiten Fleck, der hinter dem schmal schwarzbraunen 
Torderrande beginnt, von der fein schwarzen Subcostalis durchschnitten wird und flach gekrümmt bis zum vorderen Medianast reicht. In seltenen Fällen ist dieser Fleck proximal in den Radialzwisehenräumen ausgeflossen und auch der Fleck im Discus distal zerstäubt verbreitert, so daß beide zu einer nur in der Mitte, am Zellende, schwärzlich gekernten oder wischartig bestäubten, breiten roten Fläche zusammenfließen. Unterseite matter dunkelbraun. mit kurzem rotem Basalstreif am Vorderrande; das Rot der Flecke blasser. - Hinterflügel schwarzbraun, mit dem Nerkmal der Gruppe, dem mehligen hellgrauglänzenden Torderrandteil mit etwas dunklerem seidenglänzendem Saum; der Apex sehwärzlich. Unterseite mit starkem gelbem Wurzelstreif am Vorderrande und 1-4 roten Wurzelpunkten. - . . . Dem o in Farbe und Zeichnung gleich, nur durch den sexuellen Charakter, d.h. hauptsächlich schwarzbraunes Vorderrandfeld der Hinterflügeloberseite unterschieden. - Leicht mit H. xenoclea (S. 188) zu rerwechseln, meist indes dureh den im rorderen Teil halsartig eingeschnürten Discalfleck, sicher aber nur durch den Gruppencharakter zu unterscheiden. - Vorderflügellänge etwa $40 \mathrm{~mm}$.

Ecuador, Peru (Gebiet des Chanchamayo).

32. H. nanna Stich. 1899 H. n., Stichel in: Ent. Z. Guben, v. 12 p. $143 \mid 1899$ H. n., Stichel in: Ent. Tachr., v.25 p.28 1901 H. n. (H. bidentatus Staudinger in IIS.). Riffarth in: Berlin. ent. Z., v. 46 p. 106.

7. Punktierung auf Kopf und Hals sowie die übrige von der Grundfarbe abweichende Zeichnung und Behaarung des Körpers gelb. Gestalt der Flïgel wie die der vorigen Art, Oberseite tief schwarzbraun. - Vorderflügel mit gelbem Wurzelstrahl längs der Mediana, welcher sich zurveilen bis über den Winkel am Ursprunge des hinteren Medianastes erstreckt und dort in unmittelbarem Zusammenhange mit einer breiten tiefroten Discalbinde steht. Diese beginnt distal von der Zelle binter dem schmal schwarzbraunen Vorderrande, zieht in voller Breite, die vordere und hintere Ecke ersterer berührend, schräg bis etra $2 \mathrm{~mm}$ hinter den hinteren Medianast und bildet distal 2 oder 3 starke, gegen den Distalrand rorspringende Zacken, namentlich an dem mittleren und hinteren Medianast. Die Spitzen dieser Ausläufer berühren fast den Distalrand. Die Begrenzung der Binde ist allseitig unscharf, und das Rot geht in ungerwisser Beschuppung in die Grundfarbe über. Manchmal erscheint vorn proximal in der Binde ein kleiner gelber Fleck. Unterseite matter braun, mit kurzem rotem Turzelstreif am Vorderrande, die Binde weniger intensiv, fast weißlich. - Hinterflügel im Vorderrandfelde breit leuehtend silbergrau mit sehwefelgelber, gerade und gestreckt rom vorderen Teil des Hinterrandes bis in die Mitte des rorderen Radialzwischenraumes, zuletzt in kurzem Abstande von der Subcostalis verlaufender, rundlich endigender Querbinde. Ihre rordere Kante rerläuft etwa durch den Ursprung des hinteren Medianastes, die hintere liegt auf oder wenig hinter dem hinteren Zellwinkel. Cnterseite mit gelbem ITurzelstreif am Vorderrande bis etwa zu dessen Mitte, zwei großen roten Trurzelpunkten hinter der Costalis und der Mediana, aber ohne Apicalfleckehen; Grundfarbe matter schwarzbraun, gelbe Querbinde wie oben. - - o. Nur dureh die Geschlechtscharaktere unterschieden. - Leicht mit H. erato phyllis (S. 208) zu rerrtechseln. aber von diesem außer durch die Gruppenunterschiede durch die distal doppelzahnartig ausgeflossene, bis hinter den hinteren Medianast reichende, unscharf begrenzte Disealbinde des Vorderflügels und fehlende A picalfleckchen des Hinterflügels unterseits spezifisch zu trennen. - Torderflügellänge $39-40 \mathrm{~mm}$.

Südliches Brasilien (Espirito Santo, Minas Geraes). 
33. H. besckei (Jénétr:) 1857 Heliconia b., Ménétriés, Lép. Ac. St.-Pétersb., v. 2 p. 114 t. 8 f. 3 | 1871 Heliconius b., W. F. Kirby. Cat. dium. Lep., p. 143 | 1885 H. b., O. Staudinger (\& Schatz), Exot. Sehmett., v. 1 p. $79 \mid 1890$ H. b., Seitz in: Ent. Zeit. Stettin, $v 51$ p. $93 \mid 1901$ H.b. (H. epiphyllis Plötz in MIS.), Riffarth in: Berlin. ent. Z.,

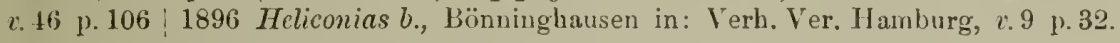

ô. Punktierung des Kopfes nnd auf Halskragen, sowie die ron der Grundfarbe abweichende Zeichnung und Behaarung des Körpers gelb. Gestalt der Flügel wie die der vorigen Arten. - Oberseite des Vorderflügels schwarzbraun mit gelbem Wurzelstreif ror der Mediana bis etwa zum Ursprunge des hinteren oder mittleren Medianastes. Distal von der Zelle eine hinter dem schmal schwarzbraunen Vorderrande beginnende breite rote Binde, die vorn ron der fein schwarzen Subcostalis durchschnitten ist, die rordere und hintere Zellecke in ihrer proximalen Begrenzung berïhrt und schräg: bis zum hinteren Medianast läuft. Distal bildet sie im mittleren Medianzwischenraum einen langen, gegen den Distalvand vorspringenden, an der Spitze manchmal gespaltenen Zahn und einen kürzeren vor dem hinteren Medianast, diesem anliegend. Torn, dicht am Vorderrande, an der proximalen Leke der Binde ein gelbes Fleckchen. Unterseite matter, das Rot der Binde weißlich, der im mittleren Medianzwischenranm gebildete Zahn erreicht den Distalrand und ist gelb. - Hinterflügel mit gelblichgrau glänzendem Torderrandfelde bis zur Subcostalis, welches indes den Apex schwärzlich läßt, und einer gelben Querbinde; diese beginnt am Hinterrande unweit der Flïgelwurzel, durchschneidet in ihrer vorderen Grenze den Crsprung des hinteren Medianastes, durchquert die Zelle und wendet sich kurz ror der vorderen Radialis in flachem Bogeu gegen den Apex, der Subcostalis in kurzem Abstande folgend. Sie endet, sich allmählich verschmälernd, ziemlich spitz etwa $5-6 \mathrm{~mm}$ vom Distalrande im vorderén Radialzwischenraum und erreicht in der Nitte eine Breite ron $3-4 \mathrm{~mm}$. Unterseite mit rotem, seltener in proximalen Teil gelblichem. Wurzelstreif am Vorderrande, der in der Regel liurz und rudimentär, wischartig ist, und rahe dem Rande mit einer roten Linie, welche ror dem Hinterwinkel dicht am Hinterrande beginut, uahe dem Distalsaum entlang zieht und im Apex in 3 oder 4 gelben länglichen Fleckehen endet. Die gelbe Querbinde heller, proximal mit rerflosseuen roten Wurzelpunkten oder Wischen. - - - ㅇ. Wie das $\sigma^{2}$, jedoch mit den charakteristischen Geschlechtsunterschieden, namentlich schwarzbraumem mattem Vorderrandfelde des Hinterflügels. Iu einem bekannten Falle ist die rote Binde des Vorderflügels proximal gelb angeflogen. - Vorderflügellänge $38-40 \mathrm{~mm}$.

Sïdliches Brasilien (Espirito Santo, Santa Catharina).

\section{d. Coh. Atthidiformes}

Kopf schwarz, Punktierung wie bei den Melpomeneformes (S. 109), weiß und gelb. Augen schwarzbraum, hinten weiß eingefaßt. Palpen weiß, Endglied schwarz. Antennen schwarz, sehr lang, über $2 / 3$ der Flügellänge. Halskragen und rorderer Teil des Thorax gelblich punlitiert wie bei der rorigen Gruppe. Thorax mit Spuren gelblicher Beharung. Abdomen etwas über den Hinterflügel hinausreichend, lateral mit drei, bei getrockneten Tieren teilweise durch Zusammenschrumpfen des Leibes unkenntlichen oder unterbrochenen Längslinien, ventral in ganzer Länge gelb. Vorderbeine gelblich, die übrigen Beine schwarz. teilweise leicht weißlich bestäubt. Torderflügel stumpfwinklig dreieckig, mit schwach gekrümmtem Torderrande, 
Apex abgerundet, Hinterwinkel stumpf, rundlich, Hinterrand flach geschweift, kï̈rzer als der Vorderrand, Distalrand flach konvex. Hinterflügel eirund, Distalrand schwach gewellt, Hinterwinkel abgerundet. - Flügel tiefschwarz mit gelben und weißen Zeichnungen. $\sigma^{\star}$ mit grauglänzendem Vorderrandfelde des Hinterflügels. dieses dunkler als in der vorigen Gruppe, schwärzlich gerandet, aber der Forderrand wieder schmal hell seidenglänzend nnd mit bis auf den Hiuterwinkel zeichnungslosem, grauglänzendem Hinterrandfelde des Vorderflügels unterseits. o mit schwärzlichem, wenig von der Grundfarbe abweichendem Vorderrandteil des Hinterflügels und stumpfem grauem Hinterrandteil auf der Unterseite des Vorderflügels.

1 Art.

34. H. atthis (Doubl.) 1847 Heliconia a., E. Doubleday (\& Westwood), Gen. diurn. Lep., v. 1 p. 102 t. 14 f. $3 \mid 1871$ Heliconius a., W. F. Kirby, Cat. diurn. Lep., p. $141 \mid 1885$ H. a., O. Staudinger (\& Schatz), Exot. Schmett., v. 1 p. $76 \mid 1901$ H. $а$. (H. bourcieri Plötz in MS.), Riffarth in: Berlin. ent. Z., v.46 p. 107.

o. Oberseite der Flügel tiefschwarz (Fig. 24). - Vorderflügel an der Mediana, vor und hinter derselben, mit einem trübgelben Wurzelstreif bis zur Abzweigung des hinteren Medianastes; dieser Streif hängt dort mit einem reingelben Fleck zusammen, der quer über der Zelle liegt, vorn spitz zuläuft, von der Mediana schwarz durchschnitten und hinten vom genannten Medianast begrénzt wird. Distal von der Zelle, die vordere Zellecke berührend, 3 kleine schräg gestellte, durch die schwarzen Adern getrennte weiße Flecke. Ein weiterer,

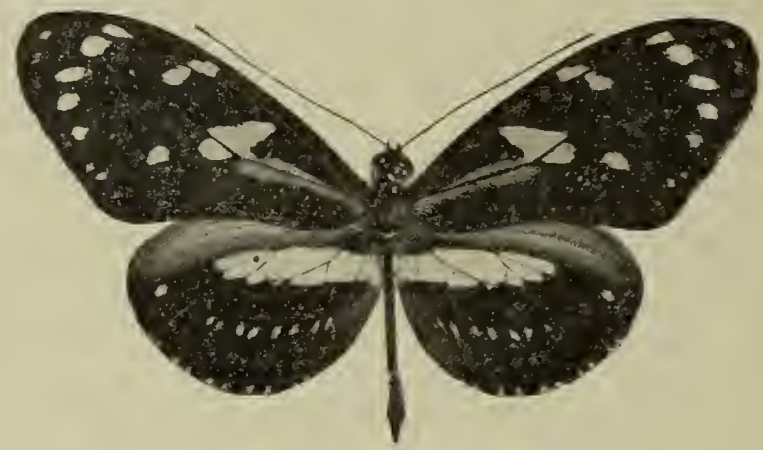

Fig. 24. H. atthis, $\delta^{\star}\left({ }^{1} / 1\right)$.

etwas größerer, manchmal feblender Fleck in der Mitte des hinteren Medianzwischenraumes, ferner eine subapicale gebogene Reihe von 4 rundlichen weißen Flecken, die sich am Distalrande nahe dem Saum bis zum Hinterwinkel fortsetzt, und endlich einige, meist verloschene weiße Apicalfleckchen, welche auch fehlen können. Unterseite matter schwarzbraun, mit kurzem braunrotem Wurzelstreif am Vorderrande; der gelbe Wurzelstreif kïrzer, nur vor der Mediana. Fleck in der Zelle weißgelb, subapicale und nahe dem Rande gelegene weiße Fleckenreihe meist deutlicher, ebenso eine völlige Reihe apicaler und randständiger, paarweise in den Aderzwisehenräumen bei einander stehender weißer Wischfleckchen. Zwischen je zwei dieser Randflecke auf und an den Adern ein rotbrauner Wisch; diese Wische oder Flecke rerlängern sich im Apex entsprechend dem Abstande der weißen Fleckchen. Der oberseits im hinteren Medianzwischenraum zuweilen fehlende weiße Fleck stets vorhanden. Hinterflügel mit gelblich grauem Vorderrandfelde, welches den Apex schmärzlich 
läßt und, bis auf den selmual hellgrauen seidenglänzenden Vorderand selbst, etwas dunkler gesäunt ist, und mit breiter, von den schwarzen Adern durclizogener gelber (querbindle. Diese beginnt am Hinterrande dicht hinter der Flügelwurzel, richtet sich etwas nach vorn, füllt die Zelle bis auf den proximalen spitzen Winkel aus und folgt der Subcostalis in kurzem Abstande bis etwa in die Mitte des vorderen Radial\%wischenraumes, wo sie rundlich und bedeutend verschmälert endet. Ihre hintere Grenze liegt hinter der Zellecke und wird an den Adern, namentlich an den Radiales, schwarz eingekerbt. In der Mitte enreicht dic Binde ihre größte Breite, etwa $4-5 \mathrm{~mm}$. Auf der Mitte des Abstandes derselben rom Distalrande eine nächst dem Hinterande begiunende und dem Distalrande folgende Reihe von kleinen, weißen oder gelblichen Flecken, die gegen den Apex an Intensität abnehmen und verschwiuden. Im Apex selbst wiederum ein größeres weißes rundliches Fleckchen. am Distalrande weiße, paalweise in den Aderzwischenräumen stehende Saumfleckchen in Verlängerung der weißen Stellen der Fransen. Unterseite mit kurzem gelbem Wurzelstreif am Vorderrande und einem rotbraunen Wurzelpunkt linter der Mediand. Querbinde weißlich, zwischen den beiden weißen Punktreihen eine Reihe von rothraunen schiefquadratischen Flecken, die sich nach rorn in proximaler Richtung verlänger'n und deren letater vor der Costalis einen langen Streif im Apex bildet. - - o. Entsprechend dem ơ, mit den charakteristischen Geschlechtsunterschieden und häufig schmalerer Binde des Hinterflügels, deren vordere Begrenzung schräg vom Hinterrande durclr den Ursprung der vorderen Radialis zieht und sich dann erst. dem Terlauf dieser Ader entsprechend, in distaler Richtung krümmt. In einem bekannten Falle sämtliche Flecke und Binden weiß. _ - Fransen schwarz und weiß gescheckt. Vorderflügellänge bis $38 \mathrm{~mm}$.

Ecuador (Balzapamba in Höhe von $800 \mathrm{~m}$; Palmar in Höhe von $100 \mathrm{~m}$; Guayaquil).

\section{Sect. Opisorhypari}

Unterseite des Vorderflügels beim ơ hinter der Zelle abweichend von der Grundfarbe heller oder dunkler grau, meist ohne farbige Zeichnung, in der Regel matt mehlig oder sammet-, seltener seidenglänzend, alsclann bleibt jedoch ein schmaler Streif von $0.5-1 \mathrm{~mm}$ Breite unmittelbar hinter der Jediana gliuzlos und matt beschuppt (bei vereiuzelten Ausnahmen bleiben die folgenden Merkmale entscheidend). Torderer Teil des Hinterflügels beim o dunkelgrau, häufig, wie beim o, nur wenig heller als die Grundfarbe; bis zur vorderen Radialis oder etwas weiter matt mehlig oder sammetartig bestäubt oder schwach glänzend bis zur Subcostalis.

\section{a. Col. Hecalesiformes}

Kopf schwar\%, vorn mit vier, vor und hinter den Antemen paarweise nebeneinander stehenden Fleckehen oder Punkten zwischen den Augen, ron denen die unteren länglich, streifenartig und voll den Palpen teilweise rerdeckt sind. Antenuenwmzel ventral gelblich oder weiß. Augen schwarzbraun, hinten gelb oder weiß gesäumt, oben hänfig noch mit je einem kleinen hellen Punkt. Palpen weiß oder gelb, ihre Spitze oder das distile Glied schwar\%. Antenuen von der Länge der Vorderflïgelzelle, meist schwarzbraun, beim $q$ etwas heller, zuweilen jedoch mit hellbrauner Keule, und beim o lateral fast in ganzer Länge hellbraun, nur proximal schwarz. Körper schwarz bis schwarzbraun. Halskragen oben mit 2, vorderer Teil des Thorax mit 
4 nebeneinander ron einer zur anderen Flügelwurzel angeordneten, gelben, gelblichen oder weißen Punkten. Thorax dorsal mit zwei seitlich geneigten Fleckchen ron gleicher Farbe, hinten schmal gelb gesäumt. Abdomen gar nicht oder nur wenig über den Hinterflügel himausragend, rentral gelb, rorn lateral fleckartig gelb behaart, seitlich mit je einer, bei getrockneten Tieren undeutlich wahrnehmbaren, feinen Doppellinie und über derselben mit einem an den lateral gelb oder weißlich gesäumten Segmenteinschnitten mehr oder weniger unterbrochenen Streif ron gelber oder weißlicher Farbe. Tibia der Torderbeine an der nach außen gekehrten Seite mit gleicher Behaarung; die ührigen Beine schwarz, Tibia und Femur meist etwas weiß bestäubt. Thorax lateral zwischen und hinter den Hüften gelb. Alle gelbe oder gelbliche Zeichnung nnd Behaarung des Kopfes und Körpers kann verdunkelt oder abgeschwächt auftreten. manchmal auch teilw eise in Braun ïbergehen. - Vorderflügel gestreckt. Vorderrand schwach gekrümmt, Apex abgerundet, Hinterrand bedeutend kiirzer als der Vorderrand. Hinterflügel abgerundet dreieckig. - Meist schwarz gefärbte Falter mit gelben oder weißen Flecken des Vorderflügels und rorherrschend rotbrauner Färbung des Hinterflügels oder vorwiegend braun mit schwarzen Binden und gelben Flecken, etliche gewissen Vertretern der Gattung Tithorea Doubledas in Gestalt und Färbung ähnlich. - C. Mit braun- bis dunkelgrauem glänzendem Hinterrandteil auf der Unterseite des Torderflügels, dessen vorderer Streif etwa $1 \mathrm{~mm}$ breit hinter der Mediana matt beschuppt ist. nnd dmmkel- oder braungrauem, etwas glänzendem Vorderrandteil des Hinterflügels. — ○. Mit stumpfem. wenig heller als die Grundfarbe gefärbtem hinterem Teil auf der Unterseite des Vorderflügels und mattem bräunlichem oder schwärzlichem Vorderrande des Hinterflügels.

7 Arten, von denen eine in 3 Unterarten zerfällt.

35. H. crispus Staud. 1885 H. c., O. Staudinger (\& Schatz), Exot. Schmett., $v .1$ p. $76 \mid 1901$ H. $c$., Riffarth in: Berlin. ent. Z., v. 46 p. 110.

Gestalt der Flügel ähnlich derjenigen ron H. atthis (S. 136), Apex stark abgerundet. Oberseite der Flügel schwarz, Vorderflügel mit schmalem gelbem rudimentärem Wurzelstreif längs der Mediana; distal ron der Zelle eine Reihe gröBerer gelber Flecke, am Distalrande eine weitere Reihe kleinerer Flecke derselben Farbe, die sich nach hinten zu rerdoppeln. Hinterflügel mit breiter gelber Mittelbinde und einer doppelten Reihe gelber randständiger und fast randständiger Flecke, ron denen die distale Reihe auf der Lnterseite weif ist. Daselbst ror den Randflecken eine breite braune Binde. welche sich in einem bekannten Falle im Aper nach rorn umbiegt und, dem Vorderrande folgend, bis zur Flügelwurzel verläuft. Die Unterseite im iibrigen der Oberseite entsprechend, aber matter gefärbt, auch einzelne distale Randflecke des Vorderflügels weiß. - Ähnlich H. atthis, aber größer, Hinterrandteil der Vorderflügelunterseite beim $\sigma^{x}$ sehr matt und stumpf und Abdomen nicht über den Hinterflügel hinausreichend.

Colombia (Antioquia, Cauca).

36. H. hecuba (Hew.) 1857 Heliconia h., Hewitson, Exot. Butt., v. 2 Heliconia t. 4 f. $11 \mid 1871$ Heliconius $h .$, W. F. Kirbs, Cat. diurn. Lep., p. $141 \mid 1885$ H. h., O. Staudinger (\& Schatz), Exot. Schmett., v. 1 p. $76 \mid 1901$ H. h., Riffarth in: Berlin. ent. Z., v. 46 p. 170.

Grundfarbe der Flügel blauschwarz. - Torderflügel an der Mlediana mit rudimentärem weißlichem Wurzelstreif. Distal rou der Zelle, etra ron der Mitte des Vorderrandes ausgehend bis zur Mitte des Distalrandes eine 
teilweise unterbrochene Reihe ron länglichen weiben Flecken, zwei weitere Flecke nebeneinander im hinteren Medianzwischenraum. ron denen der distal liegrende in der Regel kleiner ist, manchmal auch ganz, fehlt. Nächst dem Apex eine Reihe kleiner weifer schräg gestellter Flecke und im Hinterwinkel kleine weiße Saumflecke. die sich nach ror'n his zur subapicalen Fleckenreihe fortsetzen. Unterseite im allgemeinen eutsprechend der Oberseite, Trurzolstreif an der Mediana breiter, Tordenand proximal kurz braumot, nalie dem Distalrande ron dessen Mitte his zum Hinterwinkel eine zweite Reihe vou Saumflecken (nach Hewitson). - Hinterflügel mit einer umegelmäBig hegrenzten. etwa 6-8 $\mathrm{mm}$ breiten. gelben Querhinde, die zicmlich genan durch die Mitto des Flügels gelit, sich gegen den Torderrand lin weiß färbt nud dureh die scliwarzen Adern fast in Flecke geteilt wird. Nahe dem Distalrande eine Reihe partreise nebeneinander stehender weißlicher Sammfleckchen: Unterseite ror der gelben Querbinde mit Spuren einer braunen Binde, an die sich ein rom Hinterande durch die Zelle gehender grangelber Streif anschlicßt. der aher den Torderrand nicht erreicht. Wurzelstreif an letzterem weiß. Die nilhe dem Distalrande stchenden Saumfleckchen nach rorn lang, streifenartig ausgezogen. - Vorderflïgellänge $43 \mathrm{~mm}$.

Colombia (Bogotá?).

37.H. choarinus (Hew.) 1872 Heliconia choarina, Hewitson in: Ent. monthly Mag., v.. p. $83 \mid 1873$ H.c., Hewitson, Exot. Butt., $v .5$ Tithorea \& Heliconia t. 7 f. 24, 25 | 1877 Heliconius c., W. W. Kirby, Cat. diurn. Lep., Suppl. p.722! 1901 H. c., Riffarth in: Berliu. ent. Z., v.46 p. 111 1880? Blanchatdia dismorphia, Buchecker, Syst. Ent., Lep. t. 51 .

Stirnflecke, Palpen, Vorderbeine weißlich, sonstige Körperzeichnung gelb. Grundfarbe der Fliigel schwarz. - Vorderflügel mit gelhem, schwach anfgetragenem Wurzelstreif in der Zelle längs der Mediana. Distal ron der Zelle, etra von der Mitte des Vorderrandes bis zur Mitte des Distalrandes eine in ihrem distalen Verlauf stärker unterbrochene Reihe ron unregelmäßigen gelben bis weißen Flecken, die in der Mitte längliche Wische und nächst dem Distalrancle einen kleinen Doppelfleck bilden. Im hinteren Medianzwischenraum außerdem cin einzelner, manchmal undeutlicher gelber oder weißlicher Wischfleck und eine leicht gekrümmte Reihe kleiner golber bis weißer Flecke, anfangend etwa hinter dem rorber erwähnten Doppelfleck und endigend nahe dem Distalrande im Hinterwinkel nud nächst demselben am Hinterrande; endlich eine subapicale golbe Fleckenreihe, welche sich am Distalrande nach hinten in mehr oder weniger deutlichen Saumflecken fortsetzt. Unterseite matter. proximal am Vorderrande ein kurzer rotbramer IV urzelstreif; der Streif in der Zelle breiter, weißlich gelb, sämtliche Discal- und Saumflecke ganz oder fast ganz weiß. Zwischen den heiden Fleckenreihen eine ungewisse rötlichbraúne Binde. die sich durch die Unterbrechung der discalen Fleckenreilie, proximal ron dem letyten Doppelfleck. zieht und damn in halbmondförmigen Flecken bis zum Hinterrande fortsetzt. Die Sammflecke am Distalrande sebr deutlich, parrweise an den Aderenden.- Hinterflügol etwa in der Mitte zwischen Zelle und Distalrand mit einer breiten gelben Fleckenbinde, die etwas schmaler nächst dem Hinterwinkel an Hinterrande beginnt, dem Distalrande folgt, in der Nitte am stärksten ist und sich. wiederum schwächer werdend, nächst dem Apex gegen den Torder'and biegt und dort endet. Die cinzelnen Flecke sind meist rolu und hinten noch eingekerbt. teilmeise fast gespalten, liegen bis zur binteren Radialis ziemlich dicht zusammen. dahinter jedoch weiter getrennt. Am Distalrande eine Reihe gelber Fleckchen. Enterseite unit gelbem Trurzelstreif am Torderrande; demselben folgt eine rotbrinne Binde, 
die am Hinterrande dicht an der Flügelwurzel beginnt, allmählich schwächer wird, sich meist bis zu dem vordersten Fleck der auch oben vorhandenen Fleckenbinde hinzieht, dort nach hinten wendet und, jener Fleckenbinde folgend und dieselbe vorn begrenzend, wiederum in den Hinterrand verläuft. In dem durch dieselbe abgeschlossenen Medianteil eine vom Hinterrande ansgehende, kurze, stark gekrümmte, gelbe Binde, welche die Mediana am Ursprunge des binteren Medianastes schmeidet und die Zelle fast ganz ausfüllt. Distal von letzterer zwei weißliche, keilförmige Wischflecke. Die Querbinde nmr schwach gelblich, proximal und distal weiß, Saumflecke größer wie oberseits, ebenfalls weiß. - Vorderflügellänge etwa $40 \mathrm{~mm}$.

Ecuador (Baiza). In Höhen ron $1500 \mathrm{~m}$; im Januar.

38. H. cassandra C. \& R. Felder 1862 H. c., C. \& R. Felder in: Wien. ent. Monschr., v. 6 p. 419 | 1865 H. c., C. \& R. Felder in: Reise Norara, v.2 Ir t. 47 f. $3,4 \mid$ 1871 H. c., W. F. Kirby, Cat. diurn. Lep., p. $141 \mid 1885$ H. c., O. Staudinger (\& Schatz), Exot. Schmett., v. 1 p. $76 \mid 1901$ H. c., Riffarth in: Berlin. ent. Z., v. 46 p. 112.

Punktierung des Kopfes weiß, Thorax dorsal fast einfarbig schwarz. Gestalt der Flügel wie die der vorigen Arten, Grundfarbe schwarz. Torderflügel distal von der Zelle mit einer schräg liegenden Fleckenbinde von weißer Farbe. Diese beginnt hinter dem schmal schwarzen Torderrande, ist aus 4 länglichen, in den Aderzwischemräumen liegenden Flecken zusammengesetzt und endet am vorderen Medianast. Nächst dem Apex eine zweite schräge Reihe kleinerer weißer Flecke, die sich am Distalrande nahe dem Saum in einer etwas unregelmäBigen Reihe fortsetzen und am Hinterrande nächst dem Hinterwinkel endigen. Fin fernerer kleiner Fleck in der Mitte des hinteren Medianzwischenraumes. Unterseite der Oberseite entsprechend, aber ohne Saumfleckchen. - Hinterflügel nahe dem Distalrande mit gelber Fleckenbinde, etwa in der Weise wie bei $H$. choarinus (S. 139). Dieselbe beginnt kurz vor dem Hinterwinkel, liegt etwa in der Mitte zwischen Zellende und dem Distalrande und verläuft nächst dem Apex in den Vorderrand. Die einzelnen, in den Aderzwischenräumen liegenden Flecke sind im allgemeinen von länglich eirunder Gestalt, nehmen nach rorn an Breite und Länge zu und 'werden dort herzförmig. Nahe dem Distalrande ferner eime Reihe rerloschener weißer Saumfleckchen. Unterseite ohne gelben Wurzelstreif am Vorderrande, statt dessen dicht an letzterem ein grauer Wisch bis zur Mitte, ein zweiter, halb so langer Wisch zwischen Costalis und Subcostalis. Im vorderen Radialzwischenraum, nächst der vorderen Discocellularis ebenfalls ein kleiner grauer Wischfleck, in der Zelle, diese fast ganz ausfüllend und die Mediana nach hinten teilweise überschreitend, ein großer unregelmäßiger gelblich grauer Fleck, der in proximaler Richtung hinter der Zelle schmal zum Hinterrande verläuft. Zwischen diesem Fleck nnd der hier teilweise weiß verfärbten Fleckenbinde, von der Costalis ausgehend, eine unvollständige braune Binde, die im hinteren Medianzwischemraum aufhört nnd schmal schwarz von dem grauen Fleck in der Zelle und der Fleckenbinde abgesetzt ist. - Vorderflügelläng*o etwa $44 \mathrm{~mm}$.

Colombia (Kordilleren ron Bogotá).

39. H. hecalesia (Hew.)

§̋. Vorderflügel gestreckt, Vorderrand schwach gekrümmt, Apex spitzwinklig abgerundet, Distalrand leicht gewellt, Hinterwinkel stumpf, Hinterrand schwach S-förmig gebogen, bedeutend kürzer als der Vorderrand. Hinterflïgel fast dreieckig, mit schwächer abgerundetem Apex und stärker abgerundetem 
Hinterwinkel, Distalrand wellig. Grundfarbe der Flügel schwarz. - Vorderflïgel nahe dem Distalrande mit einer Reihe rundlicher gelber oder weißre Flecke, mehreren unregelmäßig geformten, schräg vom Vorderrande zur Fleckenreihe am Distalrande verlanfenden Flecken distal von der Zelle, einigen weiteren Flecken oder Wischen distal hierron nächst dem Vorderrande und einem isolierten linglichen Fleck im hinteren Medianzwischenranm; alle Flecke gelh oder weib, proximal hinter der Zelle manehmal hraunrot ïberstäubt. Hinterflügel mit grauem mattglänzendem Vorderrandteil. sonst schwarz, vom Hinterrandteil ansgehend mehr oder weniger rotbraun bestänbt, mitunter so intensir, daß diese Farbe vorherrscht und nur den Apex und einen schmalen Distalrandstreif freiläßt: ferner meist nahe dem Distalrande eine aus großen herzförmigen gelben Flecken bestehende Binde, die stets hinter dem grauen Vorderrandfeld beginnt, aber in einigen Fällen stark reduziert ist, so daß ron ihr nur etliche weißliche Flecke, namentlich im Apex, zurïckbleiben. - Unterseite matter, Hinterflügel mit gelhem Wisch an der Wurzel und rotbraunem Wurzelstreif am Vorderrande oder mur mit einem gelben Wurzelstreif daselhst. - - o. Flïgelform etwas weniger schlank, sonst wie das $0^{t}$, abgesehen von den charakteristischen Geschlechtsunterschieden der Gruppe, namentlich schwärzlichem Vorderrandteil des Hinterflügels, anf dem die gelbe Fleckenbinde bis zum Vorderrande ausgedehnt ist.

Ilittel-Amerika und Colombia.

Diese Art zerfällt in 3 Unterarten:

39 a. H. hecalesia hecalesia (Hew.) 1853 Heliconia h., Hewitson, Exot. Butt., そ. 1 Heliconia t. 2 f. 6 | 1871 Heliconius h., W. F. Kirby, Cat. diurn. Lep., p. $141 \mid 1885$ $H$. h., O. Staudinger (\& Schatz), Exot. Schmett., $v .1$ p. $75 \mid 1893$ H. h., Weymer in D. ent. Z. Lep., v. 6 p. $345 / 1901$ H.h., Riffarth in: Berlin. ent. Z., v. 46 p. 113.

Torderflügel (Fig. 25) sclıwarz; distal von der Zelle eine schräg gestellte Reihe gelber Flecke, vom Vorderrande ausgehend und dort in der Regel mit einem Doppelffeck anfangend. Diesem folgen zwei weitere längliche, manchmal

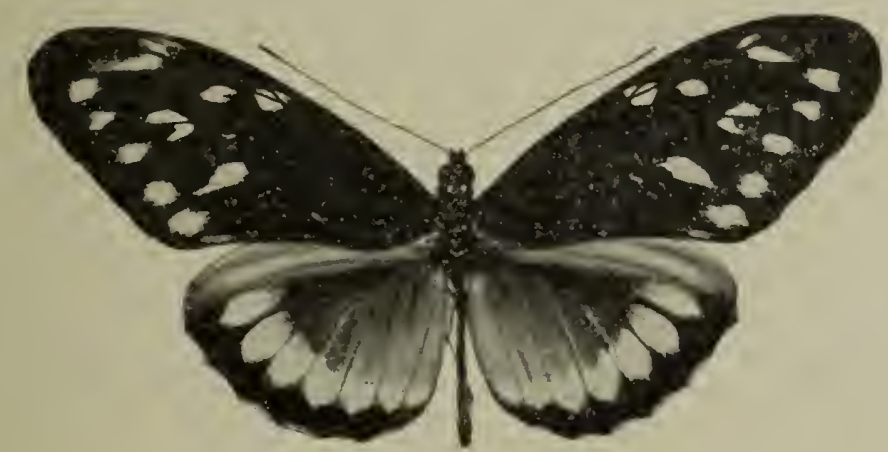

Fig. 25. H. hecalesia hecalesia, $\delta\left({ }^{2}, 1\right)$.

wischartige Flecke, deren zweiter durch den rorderen Medianast gespalten oder geteilt ist. Hinter diesem Doppelfleck, etwas in proximaler Richtung zurückgestellt, im hinteren Medianzwischenraum an den hinteren Medianast angelehnt, ein weiterer länglich riereckiger Fleck. Distal ron der ersterwähnten schrägen Fleckenreihe nahe dem Apex hinter dem Vorderrande ein durch den 4. Subcostalast gespaltener Fleck, der distal weiß wischförmig ausfließt und bis nahe zu dem vordersten einer unweit des Distalrandes 
rerlanfenden Reihe gelber rundlicher Flecke reicht. Der dritte oder rierte dieser letzteren bildet zugleich den Beschluß der schrägen Discalfleckenreihe. - Hinterflügel schwarz mit einer aus länglich herzförmigen, gelben Flecken gebildeten Binde nahe dem Distalrande. Das zwischen dieser und der Flügelwurzel liegende Feld mehr oder weniger rotbraun bestäubt, namentlich binten. Mitunter überwiegt diese Färbung und der ganze Abschnitt von der W'urzel bis kurz zur Fleckenbinde ist rotbraun, nur einen schmalen Keil an der Wurzel selbst und vorn hinter der Subcostalis und vorderen Radialis schwarz lassend. Diese Erscheinung überwiegt beim $ᄋ$, nur ist die Färbung hier etwas trüber. Unterseite mit den Zeichnungen der Oberseite, aber matter. Grundfarbe fast schwarzbraun, Flecke heller. Hinterflügel prosimal am Vorderrande mit gelbem Wischfleck und einem hiervon ausgehenden rotbraunen Wurzelstreif. - Fransen beider Flügel weiß, an den Aderenden schwarz unterbrochen, am Saum des Vorderflügels breiter als an dem des Hinterflügels. Vorderflïgellänge bis $46 \mathrm{~mm}$.

Colombia (Cauca, Medellin, Gebiet des Rio Magdalena).

39 b. H. hecalesia formosus Bates $1863 \mathrm{H}$. $h$. (err., non Heliconia $h$. Herritson 1853!), H. W. Bates in: P, zool. Soc. London, p. 247 | 1866 H. formosus, H. W. Bates in: Ent. monthly Mag., v. 3 p. 87 ! 1871 H. f., W. F. Kirby, Cat. diurn. Lep., p. 144 1881 H. f., F. D. Godman \& O. Salvin in: Biol. Centr.-Amer., Lep.-Rhop. v. 1 p. 148 t. 17 f. $7,8 \mid 1885$ H.f., O. Staudinger (\& Schatz), Exot. Schmett., v. 1 p. $75 \mid 1893$ H. f., Weymer in: D. ent. Z. Lep., v. 6 p. $345 \mid 1901$ H. hecalesia f., Riffarth in: Berlin. ent. Z., v. 46 p. 113.

Vorderflügel ähnlich demjenigen der vorigen Unterart, die Medianflecke meist gтößer und mehr zusammenhängend, leicht schwärzlich überstäubt. Subcostalfleck nächst dem Apex und die Fleckenreihe nächst dem Distalrande meist weißlich oder weiß, letztere in der Regel aus kleineren Flecken bestehend. Von der Flügelwurzel aus hinter der Mediana ein hänfig ungewiß. endigender rotbrauner Streif, namentlich beim ơ. - Hinterflügel bis auf einen kleinen schwarzen Keil an der Turzel, den breiten schwarzen, nach hinten verschmälerten Apical- und Distalteil rotbraun, nach vorn bis zur Subcostalis; die distale Begrenzung dieses Feldes ungewiß, manchmal an den Adern von der schwarzen Färbung eingeschnitten. Der vor demselben liegende Teil beim ơ dunkelgran, mattglänzend, beim $ᄋ$ stumpf schwärzlich. Im schwarzen Distalteil des Apex und am Distalrande eine Reihe ron 4 oder 5 fast randständigen, weißen, nach hinten allmählich kleiner werdenden Flecken. Unterseite matter, Zeichnnng wie oben, nur an der Wurzel des Hinterflügels ein gelber Wisch, der sich läng's des Vorderrandes als ein braunroter, allmählich zugespitzter Wurzelstreif fortsetzt. Das oben rotbraune Feld trüber mit leicht riolettem Schimmer. Fleckenreihe am Distalrande deutlich bis zum Hinterwinkel rerlängert. - Fransen schwarz und weiß. Vorderflügellänge bis $45 \mathrm{~mm}$.

Guatemala, Nicaragua, Costa Rica, Panama (Chiriqui, Veragua, Lion-Hill-Station).

39 c. H. hecalesia gynaesius (Hew.) 1875 Heliconia gynaesia, Herritson iu: Ent, monthly Mag., v. 11 p. $182 \mid 1875$ H.g., Hewitson, Exot. Butt., v. 5 Heliconia t. 8 f. 28 1877 Heliconius g., W. F. Kirby, Cat. diurn. Lep., Suppl. p. 722 | 1893 H. g., Weymer in: D. ent. Z. Lep., v. 6 p. $345 \mid 1901$ H. hecalesia g.: Riffarth in: Berlin. ent. Z., v.46 p.114.

- Vorderflügel wie bei der typischen Unterart gezeichnet, aber alle Flecke sehr groß und dentlich. Hinterflügel in der schwarzen Grundfarbe mit einer breiten orangefarbenen Binde, welche sich etwa in der Mitte zırischen der Fliigelwurzel und der nahe dem Distalrande gelegenen gelben Fleckenbinde 
befindet; letztere hesteht hier aus etwas kleineren herzförmigen Flecken. Hinterflügelunterseite mit gelbem Wrmelstreif am Vorderande. Soust wie die typische Cuterart. Vorderflügellänge etwa $44 \mathrm{~mm}$.

Heimat unbekannt.

40. H. octavia Bates 1866 H. o., H. W. Bates in: Ent. monthly Mag., $v: 3$ p. $86 \mid 1871$ H. o., W. F. Kirby, Cat. diurn. Lep., p. 1 Ht 1881 H. o., F. D). Godman \& O. Salrin in: Biol. Centr.-Amer., Lep.-Rhop. $v .1$ p. 148 t. 17 f. $9,10 \mid 1893$ H. o., Weymer in: D. ent. Z. Lep., $\iota .6$ p. $345 \mid 1901$ H. o., Riffarth in: Berlin. ent. Z., $v .46$ p. 114.

Punktierung des Kopfes und auf dem Halskragen weißlich, die übrige, ron der Grumdfarbe abweichende Körperzeichnmmg gelb. Antenuen proximal schwarz anf etwa $1 / 4-1 / 3$ der Länge. dann gelb. Flïgelform wie die der vorigen Art. - Vorderflügel am Vorderrande und Hinterrande breit schwarz, ebenso der distal ron der Zelle liegende Teil bis zum Apex und hinten bis zur Mitte des hinteren Medianzwischenranmes. Ein Streif beiderseits der Mediana und des hinteren Medianastes rotbram. Im übrigen der rorigen Art ähnlich gezeichmet: distal ron der Zelle eine ron den schwarzen Aderu durchschnittene. unregelmäBig begrenzte und eingeschnittene gelbe Schrägbinde vom Torderande bis zu dem dritten Fleck einer nahe dem Distalrande gelegenen Fleckenreihe in gleicher Farbe. Distal von dieser Schrägbinde, etwa in der Mitte zwisehen ihr und dem Apex, ein rom 3. Subcostalast zerschnittener gelber Fleck, an den sich ein zwischen dem 4. und 5. Subcostalast liegender länglicher gleich gefärbter Fleck anschlieBt, der bis nahe zum Distalrande reicht. Im hinteren Medianzwischenraum, vom hintereu Medianast begrenzt, ein länglich riereckiger, ebenfalls gelber Fleck. Flïgelwurzel leicht gelhlich aufgehellt. Unterseite der Oberseite entsprechend, aber matter gefärbt, die Zeichmungen verwaschen. - Hinterflügel gelbbramn bis auf einen schmalen Keil an der Trurzel und einen etwa $5 \mathrm{~mm}$ breiten schwarzen Saum am Distalrande. Das braune Feld erstreckt sicl vorn bis zur Subcostalis nnd wird beim ơ rom grauen mattglänzenden Forderrandteil, heim 아 ron einem breiten schwärzlichen Streif begrenzt, dem wiederum ein schmaler rötlichbramner Saum am Torderrande folgt. In der schwarzen Besäummng des Distalrandes eine Reihe gelblicher Flecke, die vor'n deutlicher sind, nach hinten kleiner und trüber werden. Lnterseite fast wie die Oberseite; an der Trurzel ein gelber Wisch, Torderrand sonst brann. Der diesem folgende schwarze Streif zwischen Costalis und Subcostalis sebueidet am letzten Drittel der Flügellänge ab, geht also nicht in den schwarzen Distalrand über, sondern wendet sich schattenhaft nach hinten, etwa bis zul rorderen Radialis. Das braune Feld, namentlich im mittleren Teil, aufgehellt und violett glänzend. Distalrandbinde an ihrer proximalen Begrenzung stark wellenförmig, Saumflecke deutlicher. - Fransen schwarz, am Samm des Hinterflügels stellenweise fast unmerklich weißlich. Samm des Hinterflïgels stark gewellt. Torderflügelläng*e bis $49 \mathrm{~mm}$.

Guatemala, Honduras.

41. H. longarenus (Hew.) 1875 Heliconia longarena, Hewitson in: Ent. monthly Mag., v. 11 p. 182 | 1875 H. l., Herritson, Exot. Butt., v. 5 Heliconia t. 8 f. $39 \mid 187$ i Heliconius l., W. F. Kirby. Cat. diurn. Lep., Suppl. p. 722 | 1893 H. l., Weymer in: D. ent, Z. Lep., v. 6 p. $345 \mid 1901$ H. l., Riffarth in: Berlin. ent. Z., v. 46 p. 115.

Grundfarbe der Flïgel schwarz. - Torderflïgel schlank und schmal, Apex abgerundet. Hinterwinkel sehr stumpt, Hinterrand etwa von $2 / 3$ der Länge des Torderrandes. Tou der Flïgelwurzel ausgehend beiderseits der 
fein schwarzen Mediana ein zuerst schmaler, dann breiterer roter Streif, dessen hintere Begrenzung etwa in gerader Richtung bis zur Mitte des hinteren Medianastes läuft. Vorn verbreitert sich der Streif in der Zelle dergestalt, daß er etwa vor der Abzweigung des hinteren Medianastes seine größte Breite, $6 \mathrm{~mm}$, erreicht; von hier ist er in distaler Richtung bis zum Endpunkt ziemlich steil abgeschrägt. Die das Rot schneidenden Adern fein schwarz. Distal ron der Zelle eine schräg liegende Reihe gelber, etwas unregelmäßig gestalteter Flecke, von denen die mittleren verkümmert sind. Nächst dem Apex eine weitere gelbe unregelmäßige, schräg liegende Fleckenbinde, die sich am Distalrande nach hinten in einer Reihe länglicher, meist schmaler und in unregelmäßiger Zwischenfolge gestelltel Flecke von gleicher Farbe bis zum Hinterwinkel fortsetzt. Unterseite am Vorderrande mit kurzem rotgelbem $W$ urzelstreif, sonst wie die Oberseite. - Hinterflügel rundlich, Vorderrand etwas abgeflacht. Vom Hinterrande ausgehend eine breite rote Querbinde, die den hinteren und distalen Teil der Zelle ausfüllt und etwa um 2-3 $\mathrm{mm}$ das hintere Ende derselben überschreitet. Zwischen dieser Binde und dem Distalrande eine Reihe von 7 länglichen, eine Binde bildenden, in den Aderzwischenräumen liegenden, gelben Flecken. von denen jeder der Länge nach ron der Grundfarbe tief eingeschnitten oder fein schwarz geteilt ist. Unterseite mit einem gelben, im distalen Verlauf rotgelben Tirzelstreif am Vorderrande. - Vorderflügellänge etwa $49 \mathrm{~mm}$.

Colombia.

\section{b. Coh. Aoediformes}

Kopf schwarz, sehr kräftig, Zeichnung und Punktierung desselben wie bei der vorigen Gruppe. Augen schwarzbraun, hinten weißlich gesäumt, oben mit je einem kleinen weißen Punkt. Palpen an der nach außen gekehrten Seite weiß, seltener gelb, bis auf die Spitze. diese und das übrige schwarz. Antennen etwa so lang wie die Zelle des Vorderflügels, aber kürzer als die Hälfte des Vorderrandes, schwarzbraun bis braun mit ockergelber Keulenspitze oder hellbräunlicher Keule, die beim o distal meist reichlicher aufgehellt ist; Wurzel nicht weiß gefärbt. Körper schwarz bis schwarzbraun. Halskragen oben mit 2 und rorderer Teil des Tborax mit 4 Punkten wie bei der vorigen Gruppe. Thorax dorsal mit zwei seitlich geneigten gelben Flecken, hinten ebenfalls gelb gefleckt. Abdomen nicht über den Hinterflügel hinausragend, ventral gelb, an den Segmenteinschnitten meist unterbrochen, fleckartig gezeichnet, vorn lateral fleckartig behaart, seitlich mit einer gelben unterbrochenen Doppellinie; über dieser meist auf jedem Segment ein kräftiges gelbes rundes Fleckchen. Diese Zeichnungen durch Zusammentrocknen des Leibes manchmal undentlich und teilweise in Falten rerborgen. Tibia der Vorderbeine außen weißlich oder gelb, die übrigen Beine schwarz, zuweilen an Tibia und Femur heller bestäubt. Thorax lateral und hinter den Hüften weißlich. - Vorderflügel annähernd stumpfwinklig dreieckig, beim $\sigma^{\pi}$ schlanker als beim $ᄋ$. Vorderrand flach gekriimmt, Apex abgerundet, Distalrand flacb konvex, Hinterwinkel sehr flach, Hinterrand bedentend kürzer als der Vorderrand, flach S-förmig geschweift. Hinterflügel fast eirund, Vorderrand abgeflacht, Apex abgerundet, Distalrand ohne merkliche Tinkelung rundlich in den Hinterrand übergehend. Vorderrandfeld beim $\sigma^{\star}$ breit sammetartig oder mehlig, schwach glänzend bis zur Zelle und der vorderen Radialis, auch darüber hinaus, aber nicht bis unmittelbar zum Apex. - Falter von schwarzer oder schwarzbrauner Grundfarbe. Vorderflügel gelb gefleckt, proximal meist 
rot bestäubt. Hinterflügel einfartig. mit weißlichen Saumwischflecken oder roter Strahlenzeichnung, seine Unterseite stets olne rote Wurzelpunkte, dagegen fast immer mit roter, in der Zelle und in den Aderzwischenrïumen liegender Strahlenzeichnung.

3 Arten, von denen eine in 4 Unterarten zerfällt.

42. H. godmani Staud. 1882 II. g., O. Staudinger in: P. zool. Soc. London, p. 397 t. 24 f. 3 | 1893 H. g., Weymer in: D. ent. Z. Lep., v. 6 p. 345 | 1901 H. g., Riffiurth in: Berlin. ent. Z., $x .46$ p. 116.

Palpen außen weiß. Punktierung des Kopfes weiß, die n̈brige Körperzeichmung gelh. - Vorderflügel schwarz. im mittleren Teil der \%elle ein schwefelgelber Fleck und ror dem Ende derselben nächst dem Vorderiande ein gelbes Doppelfleckchen. Distal hierron drei schräg gestellte, fast zusammenliängende Flecke ron gleicher Farbe, deren letzter sich an eine rorn subapicale. dann nahe dem Distalrande gelegene Reihe gelber Flecke anschließt. Diese letztere beginnt am Vorderrande klein und schmal, die Flecke vergrößern sich dam allmählich und der letzte, im Hinterwinkel gelegene, ist zu cinem dieht am Hinterrande liegenden wischartigen Streif in proximaler Richtung ausgeflossen. Im hinteren Medianzwischenraum ein unregelmäßiger. gleichfarbiger Fleck, der mit dem Fleck in der Zelle und dem distal liegenden Saumfleck etwa in einer geraden Linie liegt. Die discale und distale Zeichnung des Vorderfliigels ähnlich wie bei H. hecalesia gynaesius (S. 142). Unterseite matter, in der Zelle proximal zureilen ein gelber Längsstreif, die Flecke stärker entwickelt. - Hinterflügel mit breiter. vom Hinterrande ausgehender roter Querbinde, deren hintere Begrenzung anBerhalb der Zelle gelegen ist und beim $\delta^{T}$ rom in etwa $1 \mathrm{~mm}$ breitem Abstande ron der Subcostalis und der rorderen Discocellularis endet, woselbst das breite, nur den Apex freilassende, mehlig grau bestäubte Vorderrandfeld beginnt, welches fïl die Gruppe charakteristisch ist. Im schwarzen Distalrandteil eine Reihe gelber, länglicher Flecke nahe dem Rande. Cuterseite am Vorderrande mit gelbem Wurzelstreif, der von einem gelben Wurzelfleck ausgeht. - Vorderflingellänge etwa $37 \mathrm{~mm}$.

\section{West-Colombia (Gebiet des Rio San Juan).}

43. H. metharme (Er.) 1848 Heliconia m., Erichson in: Schomburgk. Guiana, r. 3 p. 595 | 1862 Heliconius m., H. W. Bates in: Tr. Linn. Soc. London, v. 23 p. 557 1901 H. m. (H. anaclia Plötz in JIS.), Riffarth in: Berlin. ent. Z., v. 16 p. 117 | 1870 Heliconia thetis, Boisdural, Consid. Lép. Guatemala, p. $29 \mid 1871$ Heliconius t., W. F. Kirby, Cat. diurn. Lep., p. $647 \mid 1896 \mathrm{H}$. doris aberr.t., O. Staudinger in: D. ent. Z. Lep., r. 9 p. 316 | 1871 H. methame, W. F. Kirby, Cat. diurn. Lep., p. 142 | 1881 H. erato (err., non Papilio e. Linné 1758!), F. D. Godman \& O. Salvin in: Biol. Centr.-Amer., Lep.-Rhop. v. 1 p. 160.

ơ. Punktierung des Kopfes und die ïbrige Körperzeichnung bis auf die des Abdomen weiß oder weißlich. Thorax dorsal fast zeichnungslos. Abdomen ventral gelb, lateral gelb liniiert. Grundfarbe der Flügel tiefschwarz, leicht blaugrüı glänzend. - Vorderflïgel (Fig. 26) mit einem durch die Mediana geschnittenen gelben länglichen Fleck, der in distalen Teil der Zelle hinter der Subcostalis schmal ansetzt. kurz darauf etras eingeschnürt ist. sich dann rerbreitert und am Schnittpunkt der Mediana wiederum beiderseits eingekerbt ist. Er endet bei dem hinteren Medianast. Distal daron eine subapicale, schräge, liurze und schmale Binde ron gleicher Farbe, die hinter der Subcostalis beginnt und im vorderen Medianzwischenraum endet. 
Unterseite von matterer Färbung; in der Zelle hinter der Subcostalis ein gelber Wurzelstreif, Hiuterrandfeld von der Mediana und dem hinteren Iedianast an auffällig von der matten Grundfarbe abstechend, sammetartig glänzend, dunkelgraul. Nächst dem Distalrande im hinteren Teil manchmal Spuren weißlicher Wischflecke. - Hinterflïgel mait zu je zweien in deu Aderzwischenräumen liegenden, weißlichen, randständigen oder fast randständigen, streifenartigen Wischen, die von vorn aus fast in ganzer Läng'e bläulich ïberstäubt sind. Sie sind am Hinterwinkel und in der Mitte des Distalrandes am breitesten, werden nach dem Apex zu allmählich kleiner und verschwinden schließlich. Der ganze vordere Teil des Flügels, bis in den vorderen Teil der Zelle und etwa bis zur vorderen Radialis sammetartig* glänzend duukelgrau mit leichtem gelblichem Anfluge. Unterseite mit den randständigen

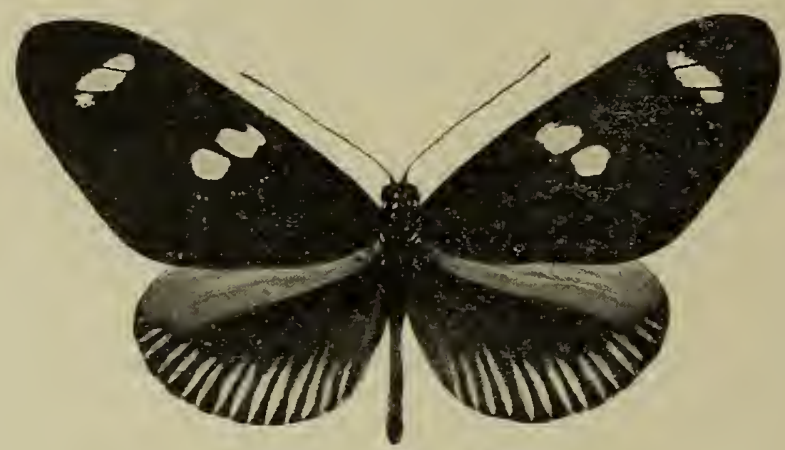

Fig. 26. H. metharme, $\delta(1 / 1)$.

Wischen der Oberseite, ferner mit einem gelben Wurzelstreif am Vorderrande und folgendermaßen angeordneter roter Strahlenzeichnung: von der Wurzel ans ein langer Streif zwischen Costalis und Subcostalis, ein weiterer längs verlaufend in der Zelle, sodann 3 Streife zwischen dem hinteren Medianast, der Submediana, der Hinterrandader und dem Hinterrande, endlich 5 kiirzere, um die Zelle gruppierte Streife in den übrigen Aderzwischenräumen. Sämtliche Streife endigen vor dem Distalrande etwa da, wo die randständigen Wische beginnen und stehen in ihrer gesamten Richtung zwischen letzteren. - ․ Größer als das $\sigma^{\pi}$, sonst mit denselben Zeichnungen, aber ohne die der Gruppe eig๋entümlichen männlichen Charaktere, also nameutlich der Vorderrandteil des Hinterflügels nur wenig von der ïbrigen Grundfarbe abweichend. Am Distalsaum des Vorderffügels bilden sich auch oberseits im hinteren Teil nicht selten weißliche randständige Wischflecke, diejenigen des Hinterflïgels sind meist länger und reiner weiß. - - Fransen des Vorderflügels schwarz, die des Hinterflügels weiß gescheckt. Vorderflügellänge etwa, $40 \mathrm{~mm}$, beim 오 ausnahmsweise bis $\mathrm{zu} 47 \mathrm{~mm}$.

Nördliches Brasilien (Ega, Fonteboa, São Paulo de Olivença), Peru (Iquitos, Pebas), Colombia, Britisch-Gnayana; Nicaragua (?).

\section{H. aoede (Hb.)}

$0^{7}$. Punktierung des Kopfes, Färbung der Palpen meist weiß, im übrigen die von der Giundfarbe abweichende Zeichmung des Körpers gelb. Abdomen lateral über der Doppellinie mit sebr dentlichen, anf den einzelnen Segmenten isoliert stehenden rundlichen gelben Fleckchen. Torderflügel mit 
schwach gekrümutem Vorderande, abgerundetem Apex; Hinterrand beträchtlich kürzer als der Vorderrand, leicht S-förmig geschweift. Hinterflügel fast eirund, Vorderrand abgeflacht. Grundfarbe der Flügel dunkel schwarzbraun. - Vorderflügel proximal breit rot oder rotgelb bestäubt, discal mit einer meist distal von der Zelle liegenden, mehr oder weniger deutlich zusammenhängenden gelben Fleckenbinde, auBerdem meist mit cincu Fleck im distalen Teil der Zelle und einem weiteren im hinteren Medianzwischenraum. Diese ganze Zeichnungsanlage in seltnerem Falle zusammengerïckt und eine nur durch die Adern zerschnittene und am Schluß der Zelle schwarz geliernte Fleckengruppe bildend. Unterseite der Oberseite entsprechend, aher matter, die rote Wurzelbestäubung verringert und nicht bis hinter die Zelle reichend. - Hinterflügel einfarbig schwarz, nur mit kleinen roten Wischflecken au der Trurzel oder mit roter bis rotgelber Strahlenzeichnung, und zwar ill den Aderzwischemäumen mit 6 oder 7 Streifen, vou denen die ersten drei, rom Hinterrande aus gezählt, an der Flügelwurzel entspringen, die übrigen hinter der Zelle beginmen und von einem weiteren, in der Zelle liegenden Iängsstreif an der Mediana mehr oder weniger breit schwarz getrennt sind. Der siebente, im hinteren Radialzwischemaum liegende Streif ist meist verkümnert. Torderer Teil des Flügels ron der Zelle und vorderen Radialis bis zum Torderrande, jedoch ausschließlich des Aper, mehlig braungrau, schwach sammetartig glüuzend. Cnterseite ohne diese mehlige K'läche, matter gefürbt, aher sofern die Oberseite gezeichnet ist, mit vollkommener rotgelber Strahlenzeichnung, und zwar einem breiten, allmählich verjüngten Streif hinter der Costalis und je einem weiteren distal von der Zelle im vorderen und hinteren Radialzwischenraum; im übrigeu wie oben, aber alle Streife schmaler, öfters nach dem Distalraude zu keulig rerdickt (tränen- oder tropfenförmig). Torderrand mit gelbem Wurzelstreif, der manchmal undeutlich ist und auch rötlich sein kann. - - O. Im allgemeinen wie das $\sigma^{2}$, Antennen distal meist etwas weiter hellbraun, sonst mit den charakteristischen Geschlechtsunterschieden, namentlich ohne den mehlig grauen vorderen Teil des Hinterflügels. Hierdurch die Strahlenzeichnung, wo sie vorhanden, nach vorn ausgedehnter in der Weise wie beim $\delta$ auf der Unterseite, der Subcostalstreif jedoch weniger deutlich und intensiv.

Xördliches Brasilien, Guayana; Yenezuela, Bolivia, Peru, Ecuador.

Diese Art zerfällt in 4 Unterarten:

4 a. H. aoede aoede (Hb.) 1816 Migonitis a., Jac. Hübner, Verz. Schmett., p. 12 | 1818 M. a., Jac. Hübuer, Zutr. exot. Schmett., v. 1 p. 23 | 1817 Heliconia a., E. Doubleday (\& Westwood), Gen. diurn. Lep., $v .1$ p. $103 \mid 1862$ Heliconius a., H. W. Bates in: 'Tr. Linn. Soc. London, v. 23 p. 561 | 1871 H. a., W. F. Kirby, Cat. diurn. Lep., p. $141 \mid 1885$ H. a., O. Staudinger (\& Schatz). Exot. Schmett., v. 1 p. $78 \mid 1890$ H. a., Weymer (\& Maassen), Lep. Reise Stübel, p. $87 \mid 1901$ H.a., Riffarth in: Berlin. ent. Z., i. 46 p. 118.

Vorderflügel proximal rotgelb. Diese Färbung beginnt hinter dem schmal schwarzen Torderrande, ist ron den schwarzen Aderu durehschnitten, erstreckt sich in der Zelle und ror derselben bis nahe zu einem im distalen Teil der Zclle liegenden, die ganze Breite letzterer ausfüllcuclen gelben Fleck, der in der Mitte beiderseits eingeschnürt ist. Hinter der Zelle tritt die rote Bestäubung beim $\sigma^{x}$ in proximaler Richtuug schräg zurück. ist ungewisser hegrenzt und bildet hinter der Submediana einen ron dieser Ader mehr oder weniger weit abgetrennten, gekrümmten Streifenwisch, während sie beim $\varnothing$ meist noch weiter in distaler Richtung ausläuft und einen nur von der fein schwarzen 
Submediana in der Länge geschnittenen, breiten, distal ungewiß zerstäubten Streif bildet, der etwa $2 / 3$ der ganzen Hinterrandlänge erreicht. Vor dem gelben Fleck in der Zelle ein schmaler langer gelber Streifenfleck, an den sich distal von der Zelle eine durch die Adern mehr oder weniger in unbestimmte längliche Flecke zerlegte, schräg liegende Binde anschließt. Diese ist distal bis zum vorderen Medianast ziemlich gerade abgeschnitten und dann nach hinten gewinkelt, proximal aber infolge Rückbildung des mittleren Teiles schwach gekrümmt oder im hinteren Verlauf etwas eingerückt und winkelig abgesetzt. Sie endet hinten am mittleren Medianast. Im hinteren Medianzwischenraum, proximal von dem letzten 'Teil jener Binde eil mehr oder weniger eckiger, großer, isolierter gelber Fleck, der manchmal nach hinten etwas ausläuft und distal meist mit einem spitzen Zapfen an der hinteren Ecke versehen ist. - Hinterflügel mit der bei der Art geschilderten Strablenzeichnung von rotgelber Farbe. - Unterseite im ganzen wie Oberseite, nur mit den bei der Art erwähnten Abweichungen der roten Wurzelbestäubung des Vorderflügels und mit ausgedehnterer Streifenbildung des Hinterflügels; letzterer mit gelbem Wurzelstreif am Vorderrande, beim 오, seltuer auch beim $\sigma^{\top}$, mit kleinen, parweise in den Aderzwischenräumen stehenden weißlichen Saumfleckchen. - Fransen schwarzbraun. Vorderflügellänge $37-42 \mathrm{~mm}$.

Nördliches Brasilien (Pará, Santarem, Itaituba, Villa Bella, Massauary), FranzösischGuayana.

44 b. H. aoede astydamia (Er.) 1818 Heliconir astydamia, Erichson in: Schomburgk, Guiana, v. 3 p. 595 | 1871 Heliconius aoede var. astydamia, IV. F. Kirby, Cat. diurn. Lep., p. $144 \mid 1901$ H. aoede astydamia, Riffarth in: Berlin. ent. Z., v.46 p.118| 1902 Heliconia emmelina, C. Oberthür, Étud. Ent., v. 21 p. 24 t. 11 f. 132.

Vorderffügel wie bei der typischen Unterart gezeichnet, nur die distal vou der Zelle liegende gelbe Fleckenbinde meist etwas stärker an den Aderu unterbrochen und die Wurzelbestäubung nicht rotgelb sonder'l hochrot, nach hinten in der Regel etwas weniger ausgedehnt, in beiden Geschlechtern etwa wie beim $\sigma^{\pi}$ der vorigen Form. Hinterflügel fast einfarbig dunkel schwarzbraun, nur an der Wurzel mit $1-3$ kleinen roten Wischflecken, welche als Überbleibsel der von der Flügelwurzel ausgehenden Strablen der typischen Unterart betrachtet werden müssen. Geschlechtscharaktere wie bei der Art beschrieben. - Unterseite der Oberseite entsprechend, aber matter, die proximale rote Bestäubung des Vorderflügels reicht beim $\delta$ nur bis zur Mediana, beim $O$ ist noch ein abgetrennter Streif hinter derselben vorhanden. Wischflecke an der Wurzel des Hinterflügels meist länger, derjenige hinter der Costalis mitunter streifenartig verlängert. Gelber Wurzelstreif am Vorderrande fehlt mitunter; er ist dann zu einem kleinen gelben Wischfleck verkümmert. Vorderflügellänge etwa $38-40 \mathrm{~mm}$.

Britisch-Guayana (Demerara), nördliches Brasilien (Obidos, Manaos, Manicore bis São Paulo de Olivença), Peru.

44c. H. aoede lucretius Weym. $1890 H . l$., Weymer in: Ent. Zeit. Stettin, $v .51$ p. $290 \mid 1896 H$. bartletti forma l., O. Staudinger in: D. ent. Z. Lep., v.9 p.307 $190 \mathrm{l}$ $H$. aoede l., Riffarth in: Berlin. ent. Z., v. 46 p. 118.

Von der typischen Unterart dadurch unterschieden, daß die distal von der Zelle liegende gelbe Fleckengtuppe oder Binde (Fig. 27) geschlossener ist, in proximaler Richtung bis dicht an die Zelle herantritt und mit dem in derselben liegenden etwas verkleinerten Fleck eine fast zusammenhängende 
Fläche bildet, welche nur am Zellende schwarz gekernt und ron den Adern fein schwarz durchzogen ist. Der im hinteren Medianzwischemaum vorhandene Fleck schließt sich im abzweigenden Winkel des mittleren Medianastes dieser

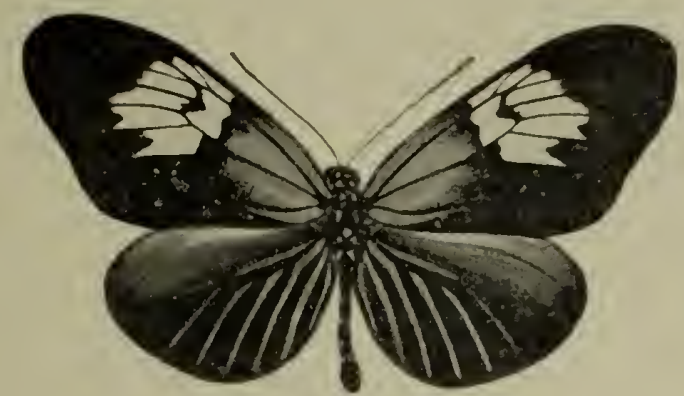

Fig. 27. H. aoede lucretius, $\delta(1 / 1)$.

Fläche ebenfalls an, ist aber in der Regel kleiner. In übrigen wie die typische Unterart. Vorderflügellänge etra $36-38 \mathrm{~mm}$.

Nördliches Brasilicn (Thomar, São Paulo de Olivença), Peru (Pebas), Bolivia, Venezuela (Atahapo-Yarito).

44 d. H. aoede bartletti Druce 1876 H. b., Herb. Druce in: ['. zool. Soc. London, p. 219 t. 18 f. $2 \mid 1877$ H. b., W. F. Kirby, Cat. diurn. Lep., Suppl. p. $721 \mid 1896$ H. b., O. Staudinger in: D. ent. Z. Lep., v. 9 p.307 | $1901 \mathrm{H}$. aoede b., Riffarth in: Berlin. ent. Z., v.46 p. $119 \mid 1885$ H. vedius, O. Staudinger (\& Scliatz), Exot. Schmett., $x .1$ p. 78.

Unterscheidet sich von der vorigen Form hauptsächlich dadurch, daß der gelbe Fleck im distalen Teil der Zelle stets und derjenige im hinteren Medianzwischenraum fast immer fehlt; letzterer ist zuweilen als ein feiner Streif an mittleren Medianast angedeutet. Der Vorderflügel trägt außer der rotgelben W urzelbestäubnug distal ron der Zelle eine nehr oder weniger verschmälerte gelbe sehräge Halbbinde rom Torderande bis zum mittleren Medianast, die nur voll den Adern fein seliwarz durchschuitten ist. Im übrigen wie die typische Cnterart. Das o dieser Form ist demjenigen ron H. xanthocles unelior (S. 153) so außerordentlich ähnlich, daß es fast nur durch die Körperzeichnung (Abdominalflecke ohne markierte Segmenteinschnitte) und die kürzeren Antemen zu erkennen ist. Torderflïgellänge etwa $40 \mathrm{~mm}$.

Gebiet des oberen Amazonen-Stroms (Pebas, São Panlo de Olivença, Santa Cruz), Ecuador (Coca, im Järz).

\section{c. Coh. Xanthocledoformes}

Kopf sehwarz. Punktierung wie bei den vorigen Gruppen, aber die unteren Stirnpunkte nicht streifenartig verïungert, sondern rundlich. Augen schwarzbraun, hinten gelblich oder weiß gesäumt, ohen meist je noch mit einem weißen Pünktchen. Palpen schwarz, nur proximal an der nach außen gekehrten Seite etwas weiß. Antemnen schwarz oder schwarzbraun, distal, namentlich an der Unterseite de Keule, bräunliclı, länger als die Zelle. Körper schwarz, kräftig. Punlitierung des Halskragens und Fleckenbildung auf dem Thorax wie bei der vorigen Gruppe, aber meist reichlicher entwickelt. Abdomen nicht ïber den Hinterflïgel hinausragend, rentral gelb gefleckt, vorn an den Seiten fleckartig gelb behaart, lateral ferner mit einer mehr oder weniger 
unterbrochenen und durch Znsammentrocknen des Leibes in einer Längsfalte rerborgenen Doppellinie, darüber mit einer selten fehlenden oder nur teilweise vorhandenen Reibe rmudlicher oder länglicher Fleckchen. Alle Segmenteinschnitte dorsal und lateral scharf gelb markiert. Thorax und Beine wie bei der vorigen Gruppe. - Vorderflügel ziemlich breit, stumpfwinklig dreieckig, mit schwach gekrümmtem Torderrande und abgerundetem Aper. Hinterflïgel fast eirund, mit abgeflachtem Vorderrande und wenig hervortretendem Hinterwinkel. Vorderer Teil des Hinterflügels beim $\delta$ fast so dunkel wie die Grundfarbe, mit schwachem Sammetglanz, beim o etwas heller, stumpf, an der Wurzel mit hellerem rötlich gelbem Längsstreif hinter dem Vorderrande. - Falter von schwarzer Grundfarbe mit roter Wurzelfïrbung und gelber Fleckenbildung im Discns, manchmal auch im Apex des Torderflügels, einfarbigem oder mit roter Strahlenzeichnung versehenem Hinterflügel, sämtlich den Vertretern der vorigen Gruppe mehr oder weniger ähnlich, aber vermöge längerer Antennen und spezifisch unterschiedener Körperzeichung mit jenen nicht zu vereinigen.

$1 \mathrm{Art}$, die in 6 Unterarten zerfällt.

45. H. xanthocles Bates.

Ђ. Punktierung der Stirn und proximales Glied der Palpen meist weiß, die übrige Körperzeichnung vorwiegend gelb. Grundfarbe der Flügel schwarz oder schwarzbrann. - Vorderflügel proximal bis gegen die Hälfte der Fläche rot oder rotgelb; im distalen Teil der Zelle häufig ein gelber Fleck, der rudimentär auftreten kann. Distal von der Zelle eine mehr oder weniger breite oder zusammenhängende, stets ron den schwarzen Adern geschnittene gelbe Binde, Fleckenbinde oder Fleckengruppe, die in gewissen Fällen dem Zellende so nabe gerückt ist, daB sie ron dem Fleck in der Zelle nur durch einen mehr oder weniger breiten schwarzen, manchmal winkelförmig gestalteten Kern getrennt ist und mit ihm eine fast geschlossene große fleckförmige Discalzeichnung mit unregelmäßig eingeschnittener Begrenzung bildet. Distal von dieser Fleckengruppe zuweilen mehrere, fast zusammenhängende subapicale gelbe Fleckchen. Unterseite mit derselben Zeichnung, aber matter. das Rot der Flügelwurzel nicht über die Mediana ausgedehnt. — Hinterflügel einfarbig schwarz, nur mit Spuren kleiner roter wischartiger Flecke an der Turzel oder mit vollständig ausgebildeter roter oder rotgelber Strablenzeichung wie bei der rorhergehenden Art, nur mit dem Unterschiede, daß auch beim $\sigma^{\pi}$ der Streif im vorderen Radialzwischenraum meist vollständig ausgebildet ist, weil der vordere Teil des Flügels nicht von der der vorigen Gruppe eigenartigen mehlig grauen Beschupping bedeckt, sondern nur sammetartig schwärzlich ist. Unterseite in der Regel der Oberseite entsprechend, aber matter. Da, wo auf letzterer keine vollständige Strahlenzeichmung vorhanden ist, in der Regel ohne oder nur mit verwaschenen Spuren roter Streife. An der Flügelwurzel in der Regel nur ein gelber Fleck. seltener ein kurzer roter Wurzelstreif längs des Vorderrandes. Die Strahlenzeichmung, wenn vorhanden, meist schmaler als oben, die einzelnen Streife gegen den Distalrand wenig oder gar nicht verdickt und nicht kenlen- oder tränenförmig wie zuweilen bei der vorigen Art. Nahe dem Distalrande häufig kileine weiße Flecke. - - o. In der Zeichnung dem ơ im allgemeinen entsprechend. jedoch mit den bei der Beschreibung der Gruppe herrorgehobenen Geschlechtsunterschieden.

Nördliches Süd-Amerika.

Diese Art zerfällt in 6 Unterarten: 
45a. H. xanthocles xanthocles liates. 1862 H. $x$, H. W. Bates in: 'Tr. Linn. Soc. London, $x .23$ p.j61 | $1871 H . x$, W. F. Kirby, Cat. diurn. Lep., p. 144 | 1901 H. $x$, Riffarth in: Berlin. ent. K., $v .46$ p. 120.

Grundfarbe der Flügel tiefsehwarz. - Torderflügel am Vorderrande schmal schwarz, sodann proximal bis etwa zur Mitte der Zelle zinnoberrot. Oiese Bestäuhung ist in der Zelle ansgehöhlt nad tritt linter derselben in ungewisser Begrenzung in distaler Richtung etwa bis zur Abzweigung des bintereu Medianastes oder etwas weiter vor. Alle das Rot schmeidenden Ideru fein schwarz. Distal von dem Rot, uur schmal schwarz getrennt, in der Zelle cin die ganze Breite derselben ausfüllender gelher Fleck, der proximal, dem Einschnitt in der Wurzelfärbung entsprechend, kouvex, an der anderen Seite konkar ist. Tor demselben, getrennt durch die schwarze Subcostalis, hinter dem schmal schwarzen Torderrande ein langer schmaler gélber Streif, an welchen sich distal ron der Zelle nach hinten eine ron den schwarzen Adern durchschnittene gelbe Fleckenquerbinde anschließt. Diese beginnt in mäßiger Breite, rerschmälert sich im weiteren Verlanf mehr oder weniger, um sich hinter dem vorderen Medianast nach beiden Seiten beträchtlich auszudehnen. Die im mittleren nnd hinteren Medianzwischemraum liegenden Flecke der Binde treten proximal ganz odel fast ganz bis an die Zelle heran und sind von dem in dieser liegenden Fleck häufig nur durch die schmal schwarze Mediana getreunt. Auf diese Treise entsteht eine um das Zellende angeordnete, fast zusammenhängende, schwarz gekernte Fleckengruppe, die ron den schwarzen Adern durchschnitten und einen umregelmäßigen stumpfen Zahn in mittleren Medianzwischenraum gegen den Distalrand vorschiebt. Distal ron dieser Fleckengruppe 3 oder 4 lïngliche gelbe subapicale Fleckchen oder eine ron den Aderu schwarz durchschnittene kurze Binde, in der sich der" Winkel des 4 . und 5. Subcostalastes deutlich markiert. - Hinterflïgel cinfarbig schwarz bis auf 2 oder 3, häufig undentliche rote kurze Tischflecke an der Flügelwurzel, die Anfänge cimer Strihlenzeichnung. Unterseite der Oberseite in allgemeinen entsprechend gezeichnet, Farbentöne sämtlich matter, die rote Trurzelfürbung des Vorderflügels reicht beim $\delta$ nur bis zur Mediana. Hinterflügel meist mit deutlicheren Wischflecken an der Wurzel, die manchmal kurz streifenartig rerlängert sind, einem gelben Fleckchen dicht an der Wurzel und kurzen rotem Wurzelstreif am Torderrande; nahe dem Distalrande Spuren weiBlicher Saumfleckchen. - Vorderflïgelläinge etwa $37 \mathrm{~mm}$.

Britisch-Guayana (Demerara), Französisch-Guayana.

45b. H. xanthocles vala Staud. 1885 H. v., O. Staudinger (\& Schatz), Exot. Schmett., $v .1$ p. 78 ! $1896 \mathrm{H}$. paraplesits forma v., O. Staudinger in: D. ent. Z. Lep., v.9 p. $306 \mid 1901$ H. xanthocles v., Riffarth in: Berlin. ent. Z., v. 46 p. 120 | 1902 Heliconia caternaulti, C. Oberthür, Etud. Ent., v. 21 p. 24 t. 11 f. 131.

Der vorigen Form ähnlich, aber Wurzelfeld des Torderflögels (Fig. 28) nicht hochrot, sondern gelbrot. der hinterste Fleck der distal ron der Zelle liegenden gelben Binde rerkleinert. proximal nicht his zur Zelle reichend, modurch der Charakter der Bindenzeichnung besser gewahrt ist; der Fleck im mittleren Medianzwischenraum distal weit vorspringend. - Hinterflügel mit teilweise verkümmerter rotgelber Strahlenzeichnung, und zwar mit 3 von der Wrurzel ausgehenden Streifen vom Hinterande bis zum hinteren Medianast und einem Streif in der Zelle, der diese fast ganz ausfïllt. Hinter der Zelle zwischen den Medianästen und vor ihmen 3 oder 4 weitere, in vorderen Terlauf meh oder weniger undeutliche schmale Streife. - Auf der Lnter- 
seite sind diese Streife deutlicher und es treten zwei weitere Strahlen im vorderen Radialzwischenraum nud hinter der Costalis auf. An der Wurzel ein gelbes Fleckchen, nächst dem Yorderrande ein kurzer rotgelber Wurzelstreif,

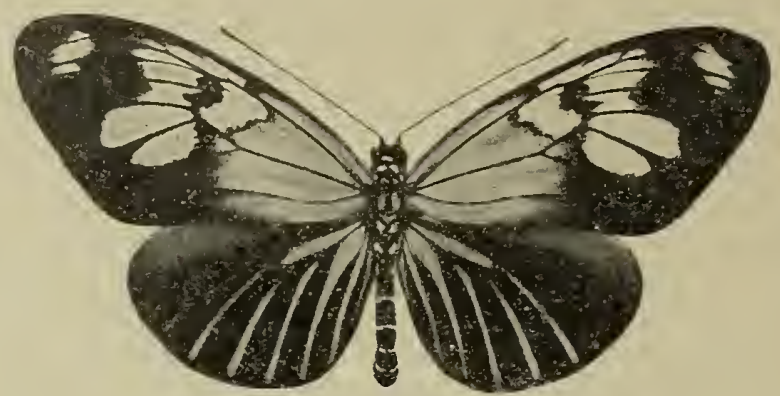

Fig. 28. H. xanthocles vala, $\sigma^{\prime \prime}(1 / 1)$.

sowie Spuren weißlicher Saumfleckchen. - Sonst wie die vorige Lnterart, von der sie vielleicht nur eine Aberration darstellt. Vorderflügellänge etwa $37 \mathrm{~mm}$.

Niederländisch-Guayana (Berg en Dal), Französisch-Guayana.

45 c. H. xanthocles paraplesius Bates $1867 H . p_{.,}$H. W. Bates in: Tr. ent. Soc. London, ser. 3 v.5 p. $540 \mid 1871$ H. p., W. F. Kirby, Cat. diurn. Lep., p. $144 \mid 1901$ H. santhocles p. (H. olede Plötz in IIS.), Riffarth in: Berlin. ent. Z., v. 46 p. 120.

Ähnlich der vorigen Cnterart. Wurzelfeld des Vorderflügels. rotgelb, schräg vom schmal schwarzen Vorderrande bis zum Hinterrande abgeschnitten, hinter der Zelle ungewiß begrenzt. Gelber Fleck in der Zelle proximal wenig: oder gar nicht konvex. Fleckenbinde distal von der Zelle bedeutend breiter, namentlich im hinteren Radial- und vorderen Medianzwischenraum weit gegen den Distalrand vorspringend. Fleck im hinteren Medianzwischenraum dagegen stark verkleinert, völlig isoliert, distal spitz ausgezogen. Subapicalflecke kleiner. - Hinterflügel zwischen den Adern mit 7 oder 8 starken, vor'n von dem Streif in der Zelle und unter sich an den Adern nur schmal schwar' getrenuten, rotgelbeu Strahlen, das o außerdem mit einem schwach rotgelben Subcostalstreif, der auch beim $\sigma^{\frac{\pi}{2}}$ proximal angedeutet ist. Unterseite des Hinterfiügels außerdem mit kleinem gelbem Fleck an der Wurzel und gelhrotem Wurzelstreif am Vorderrande, sowie deutlichen weißen Saumpunkten, die zurveilen auch oben schwach sichtbar sind. — Vorderflïgellänge bis $40 \mathrm{~mm}$.

Nördliches Brasilien (Pará, Jaues, Itaituba, Cameta).

- 45̃ d. H. xanthocles melete C. \& R. Felder 1865 H. m., C. \& R. Felder in: Reise Novara, v. 2 II p. 376 | 1871 H. m., W. F. Kirby, Cat. diurn. Lep., p. $144 \mid 1879$ H. m., Hopffer in: Ent. Zeit. Stettin, v. 40 p. $432 \mid 1901$ H. xanthocles m., Riffarth in: Berlin. ent. Z., v. 46 p. 121.

Trurzelfeld des Vorderflügels wie bei der vorigen Unter'art, aber hochrot. Der Fleck im distalen Teil der Zelle und die distal ron der Zelle gelag'erte Fleckengruppe bilden eine große einheitliche, nur von den schwarzen Adern fein durchschnittene gelbe Discalfäche, die rorn rom schmal schwarzen Torderrande begrenzt, am Zellende vermöge stärkerer schwarzer Bestäubung auf 
den Discocellulares winklig gekernt und distal an den Medianästen stark zahnartig eiugeschnitten ist. Die hintere Begrenzung dieser Fläclie liegt am hinteren Mediauast, der Winkel, den dieser mit der Mediana bildet, bleiht indes schwarz. Im Apex keine Flecke. - Hinterflügel wie bei der rorigen Unterart, aber die Strahlen nicht gelb, sondern zinnoherrot. Bei ơ und $ᄋ$ ein mehr oder weniger ausgeprägter rötlicher Streif hinter der Costalis. Unterseite des Hinterflïgels nur mit scliwach angedeutetem rötlichgelbem oder gelbem Wurzelstreif am Vorderrande, aber stets mit cinem deutlichen gelben Wurzelfleck. Die roten Strahlen sehr schmal, zuweilen mit Gelb rermiseht; deutliche weiße Saumfleckchen rorhanden. - Es gibt Aberrationen mit verringerter roter Bestäubung des Wurzelfeldes des Torderflügels und teilweise rerkímmerter Strahlenzeichnung des Hinterflügels. Vorderflügellänge bis $41 \mathrm{~mm}$.

Colombia, Bolivia (Gebiet des Rio Juntas, Rio Suapi und Rio Songo).

4ว๊e. H. xanthocles melior Stuud. $1896 \mathrm{H} . \mathrm{m} ., \mathrm{H}$. bartletti var.?, O. Staudinger in: D. ent. Z. Lep., $v .9$ p. 307 | $1901 H$. xanthocles $m$., Riffarth in: Berlin. ent. Z., v. 46 p. 122.

Wrurzelfeld des Torderflügels rotgelb bis über die Hälfte der Zelle und ron da bis zum letzten Drittel des Hinterrandes abgeschrägt. In der Zelle in der Regel kein gelber Fleck, zuweilen aber Spuren eines solchen. Distal ron der \%elle, in der Regel dicht anschließend, eine kurze, mehr oder weniger schmale schräge Halbbinde, welche hinter dem schmal schwarzen Vorderrande beginnt, bis znm vorderen Medianast reicht und ron den schwarzen Adern durchschnitten wird. Selten erscheinen im mittleren Medianzwischenraum Spuren eines gelben Fleckes. Apex ungefleckt. - Hinterflügel mit rotgelber Strahlenzeichnung, wie bei der Art beschrieben, aber die einzelnen Streife hängen roln unter sich und mit dem die Zelle vollständig ausfüllenden Streif oft zusammen und bilden dann eine rote Discalfläche, welche nur ron den fein schmarzen Adern durchschnitten ist. Die Trennung der einzelnen Strahlen erfolgt erst etwas ror der Mitte der Aderzwischenräume, die einzelnen Zilcken rerlaufen dann ziemlich spitz am Distalrande. - Unterseite matter. Hinterflügel ohne oder nur mit schwach angedeutetem rotgelbem Wurzelstreif am Torderrande, aber stets mit gelbem Wurzelfleck und deutlich sichtbaren Saumfleckchen. - Das o ist demjenigen ron H. avede bartletti (S. 149) so außerordentlich ähnlich. daß es fast nur durch die Körperzeichnumg und die längeren Antennen sicher von diesem zu unterscheiden ist. - Vorderflügellänge etwa $39 \mathrm{~mm}$.

Peru (Gebiet des Chanchamayo), Ecuador (Archidona, im Januar, Februar und Juni, in Höhe ron $640 \mathrm{~m}$ ).

recutitit.

45f. H. xanthocles melittus Staud. $1896 \mathrm{H} . \mathrm{m}$., $\mathrm{U}$. Staudinger in: D. ent. Z. Lep., $t .9$ p. 307 | $1901 H$. xanthocles m., Riffarth in: Berlin. ent. Z., $\iota .46$ p. 121.

Cnterscheidet sich ron H.x. melior dadurch, daß im distalen Teil der Zelle im hinteren Winkel ein kleiner dreieckiger Fleck auftritt und die distal rou der Zelle liegende Fleckengruppe oder Fleckenbinde rerbreitert und verlängert ist. etwa in der Art wie bei H. x. melete; der letzte Fleck dieser Binde liegt also im hinteren Medianzwischenraum. - Diese Form bildet eine Zwischenstnfe ron $H . x$. melete zu H. x. melior. ist in der Ausdehnung der gelben Zeichnung des Vorderflïgels und im Farbton der roten 
Strahlen des Hinterflügels unbeständig und tritt in der typischen Gestalt nur rereinzelt anf.

Peru (Rioja). In Höhen ron $800-900 \mathrm{~m}$.

\section{d. Coh. Egeriformes}

Kopf schwarz mit 2 länglichen weißen Stirnfleckchen und 4 parrweise zwischen den Augen stehenden gelblichen Punkten. Augen schwarzbraun, hinten weiß gesäumt, oben meist noch mit je einem ganz lileinen weißen Punkt. Palpen weiß, proximaler Teil des Mittelgliedes und Spitze sowie die Innenseite schwarz. Antennen schwarzbraun, distal unterseits rötlich braun, länger als die Zelle. Körper sehwarz, Punktiermng des Halskragens und Fleckbildung auf dem Thorax wie bei der vorigen Grippe. Abdomen wenig über den Hinterflügel hinausragend, rentral bis auf die rorderen Segmente gelb, lateral mit zwei meist unrollkommenen schwefelgelben Linien und über diesen mit einer Reihe meist unregelmäBiger Strichpunkte. die von den gelben Segmenteinschnitten unterbrochen werden. Thorax gelbfleckig. Torderbeine schwarz, an den Gelenken weiß gefleckt. Vorderflügel mit stärker ausgezogenem Apex. Torderrand schwach gekrümmt, Distalrand leicht konkav, Hinterwinkel stumpf, Hinterrand etwa von derselben Länge wie der Distalrand oder nur wenig länger, leicht S-fölmig gebog'en. Hinterflügel etwa dreieckig mit konvexen Seiten oder elliptisch, rorn abgeflacht. Apex beim $\sigma^{*}$ in eimigen Fällen auffällig spitz herrortretend, im allgemeinen schmal abgerundet. Distalrand stark gewellt, Hinterwinkel abgerundet. Torderrandfeld des Hinterflïgels beim ơ dunkel braungrau, sammetartig glänzend, beim o wenig heller als die Grundfarbe, nur der Torderrand schmal gelblichgrau mit schwachem Glanz und proximal etwas breiter in demselben Farbenton oder rötlich aufgehellt. - Giößere, kräftige Falter von schwarzer Grundfarbe mit roter Wurzelbestäubung, gelber discaler Fleckengruppe, teilweise auch subapicalen Flecken des Vorderflïgels, sowie roter, zu Spitzen, Zacken oder Strablen ausgeflossener Wurzelfärbung des Hinterflïgels.

2 Arten, die in 8 tinterarten zerfallen.

46. H. egeria (Cram.)

๑๋. Grundfarbe der Flïgel schwarz. Torderflügeì an der TTurzel hinter der Mediana mit einem gelben Fleckchen. Proximales Feld hinter der Subcostalis reichlich rot oder gelbrot bestäubt. Vorderrand selbst schwarz, aber hinter ihm noch ein mehr oder weniger langer roter Streif. Die rote Fläche wird ron den schwarzen Adern geschnitten, füllt entweder die Breite der Zelle aus oder beschränkt sich auf den hinteren Teil derselben und endet in nngewisser Begrenzung an der Abzweigung des hinteren Medianastes. Der Hinterrand bleibt frei. Im Discus des Flügels eine schwefelgelbe Fleckengruppe. bestehend aus einem Fleck in der Zelle und einer bindenartig angeordneten Reihe ron Flecken distal derselben, deren hinterster in proximaler Richtung verschoben ist und der Mediana im hinteren Medianzwischenranm anliegt. Der Fleck in der Zelle ist manchmal rerkümmert oder fehlt zurreilen, die distal liegende Fleckenbinde ist enger; nur rou den schmal schwarzen Adern geschnitten. zusammengerïckt und derart rerkürzt, daß sie beim mittleren MLedianast abschneidet oder nur etwas über denselben ausläuft. Unterseite braun, seidenartig glänzend, die rote Turzelbestänbung feblt oder ist nur schwach durchscheinend, am Torderrande ein kürzerer oder längerer gelber Trurzelstreif, ein zweiter gelber Streif zuweilen an der Mediana in der Zelle. Fleckenbildung 
in Discus wie oben, aber gelhlichweib, meist schwärlich überstiubt. Hinterflügel in der Zelle bis auf einen sehmalen rorderen Streif rot. Diese Färbung verbreitert sich nach hinten und distal mehr oder weniger und liuft in Zacken oder Spitzen aus, oder setzt sich hinter der Zelle in schmalen roten Streifen bis zum Iistalrande fort. Unterseite graubram, seidenglänzend, manchmal violett abgetönt. Am Vorderrande ein kurzer gelber Wurzelstreif; Strahlenzeichumg, wemn oben vorhanden, in derselben Weise aber matter, sonst uur sehwach angedeutet. - - o. Tie das $\sigma^{\pi}$ gezeichnet, Apex des Hinterflïgels mehr ahgerundet, Torderrandfeld nur wenig beller als die Grundfarbe.

Nördliches Brasilien, Guayana.

Diese Art zerfällt in 4 Unterarten:

46 a. H. egeria egeria(Cram.) 1775\& 76 ,Egeria“, Papilioe., P. Cramer, Pap.exot., $v .1$ p. 54 t. 34 f. B, C; p. 152 i 1790 P. e., J. F. W. Herbst. Naturs. Ins. Schmett., $v .4$ p. 142 t. It f. 1862 Heliconius e., H. W. Bates in: Tr. Linn. Soc. London, r.23 p. 561 | 1896 H. e.. O. Staudinger in: D. ent. Z. Lep., $v .9$ p. $311 \mid 1901$ H. e., Riffarth in: Berlin. ent. Z., r. 46 p. 123 | 1816 Migonitis isaea, Jac. Hübner, Verz. Sclnnett., p. 12 | 1571 Helieonius i., W. F. Kirby, Cat. diurn. Lep., p. 143 | 1819 Helieonia ergatis, (Latreille \&) J. B. Godart in: Enc. méth., v.9 p. $207: 1847$ H. e., E. Doubleday (\& Westwood), Gen. diurn. Lep., $x .1$ p. 104.

Grundfarbe der Flügel schwarz. Wurzelbestäubung des Torderflügels gelblichrot, in der Zelle auf einen schmalen Streif ror der Mediana heschränkt; die Fläche zwischen Mediana uud Submediaua ist ganz rot ausgefüllt, hinter letzterer liegt wiederum ein schmalerer Streif, welcher den Hinterraud in etwa gleicher Breite freiläBt. Distale Begrenzung des Rot unscharff ron der Abzweigung des hinteren Medianastes in schräger Richtung gegen die Submediana. Hinter der Costalis mitunter noch ein roter Streif. Im distalen Teil der Zelle ein schrrefelgelher Fleck, der die Breite derselben ausfüllt. proximal wenig, distal scharf spitzwinklig eingekerbt ist. Distal voul der ZClle ein länglicher schnaler Śbbostalfleck, linter demselben zwei langgezogene Streifenflecke, im mittleren Medianzwischenraum ein die Zelle nicht berïhrender kürzerer und breiterer Fleck und ein ähnlicher im hinteren Medianzwischenraum: dieser ist in proximaler Richtung abgerïckt und kann als Fortsetzung des Zellfleckes gedacht werden. Alle diese Flecke schmefelgelb. - Hinterfügel von der Wurzel aus hinter der Subcostalis bis auf etra ${ }^{2}$ des Flügels gelblichrot, die hintere Begrenzung dieser Bestäubung unscharf zackevartig zwischen den Adern ausgeflossen. Apex heim $\sigma^{\pi}$ scharf und eckig, beim o rundlicher. - Unterseite graubraun. stark seidenglänzend. Vorderflügel mit schwachem gelbem Wurzelstreif am Vorderande, die discale Fleckengruppe weißlich, graubraun überstäubt. Hinterflügel mit weißgelhem Wurzelstreif am Vorderrande, weiBlichem Subcostalstreif; an der II urzel Anfänge roter Streifenbildung; in den Aderzwischenräumen verloschene rötliche Strahlen. - Frausen des Vorderflügels schwarz, die des Hinterflügels schwarz und weiß gescheckt. Vorderflügellänge $4 t-46 \mathrm{~mm}$.

Gebiet des unteren Amazonen-Stroms (Santarem, Itaituba), Niederländisch-Gua yana.

46 b. H. egeria egerides Staud. $1896 \mathrm{H}$. egeria var. eyerides, O. Standinger in: D. ent. Z. Lep., v. 9 p. 311 | 1901 H. egeria egerides, Riffarth in: Berlin. ent. Z., v. 46 p. 124. 
Vorderflügel (Fig. 29) wie bei der typischen Unterart. Rotes Feld des Hinterflügels bindenartig verschmälert und verkürzt. Dasselbe reicht distal nur bis zum Zellende und ist dort sowie an der hinteren Grenze schwach

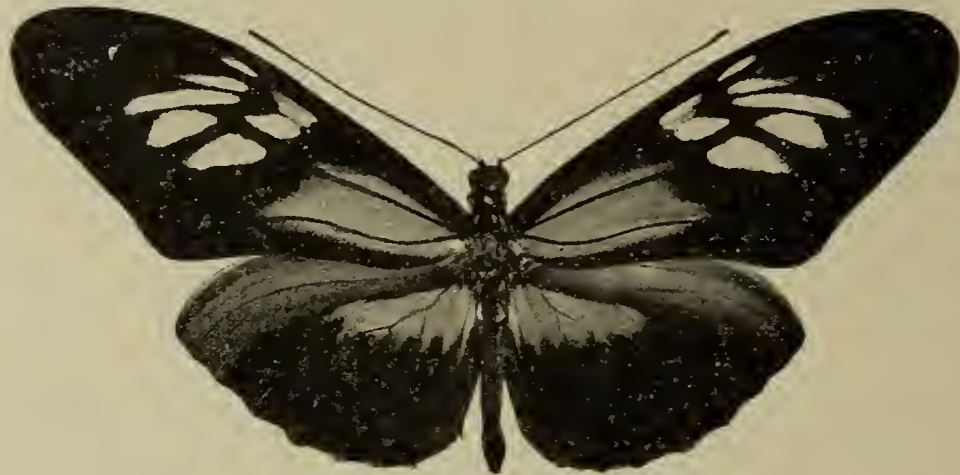

Fig. 29. H. egeria egerides, $ठ(1 / 1)$.

ausgezackt. Im übrigen wie die typische Unterart, nur die rote Zeichnung etwas lebhafter, zinnoberfarben.

Niederländisch-Guayana (Berg en Dal), Amazonas (Manaos).

46 c. H. egeria hyas Weym. $1884 H$. $h$. , Weymer in: Ent. Zeit. Stettin, v. 45 p. 26 t. 1 f. $5 \mid 1885$ H. $h$., O. Staudinger (\& Schatz), Exot. Schmett., v. 1 p. $78 \mid 1901$ H. egeria $h_{.,}$Riffarth in: Berlin. ent. Z., v. 46 p. 124.

Kleiner als die vorige Unterart. Wurzelbestäubung des Vorderffïgels nach vorn verbreitert, rotgelb, Zellfleck kleiner, die distal ron der Zelle liegende Fleckengruppe voller und die einzelnen Flecke nur durch die schwarzen Adern getrennt. Das ebenfalls gelbliche Rot des Hinterflügels zwischen den Adern zu langen, kurz vor dem Distalrande spitz endigenden strahlenartigen Streifen ausgezogen. Der zwischen Submediana und hinterem Medianast liegende Streif gespalten oder in seinem vorderen Verlauf schlitzartig schwarz gekernt. Die Streife unterseits weniger deutlich, aber bis zum Distalrande reichend, der rote Wurzelteil nur als schlingenförmiger Streif in der Zelle erhalten. Zwischen Costalis und Snbcostalis ein weiterer verloschener, roter Streif. Sonst wie die typische Unterart. Vorderflügellänge $42-43 \mathrm{~mm}$.

Südufer des unteren Amazonen-Stroms (Massauary, Santarem, Itaituba).

46 d. H. egeria astraea Staud. 1896 H. e. var.? a., O. Staudinger in: D. ent. Z. Lep., v. 9 p. $311 \mid 1901$ H. e. a., Riffarth in: Berlin. ent. Z., v. 46 p. 125.

Flïgelform etwas weniger spitz als bei den vorigen Unterarten, namentlich Apex des Hinterflügels auch beim ơ rundlich. Wurzelbestäubung des Vorderflügels rotgelb, vorn bis zur Costalis rerbreitert, ron der Subcostalis schwarz durchschnitten, der vordere Streif am längsten. Zellfleck rerkleinert, meist nur als vorderes Stück erhalten, mitunter in zwei Teile geteilt. Fleckenteil distal von der Zelle bindenartig zusammengerïckt, rerbreitert und proximal die Discocellulares berübrend. Adern schwarz. Der bei der typischen Unterart im hinteren Medianzwischenraum liegende Fleck fehlt meist oder ist nur vorn teilweise erhalten. Hinterflügel mit rotgelber Strahlenbildung ähnlich wie bei der vorigen Unterart, aber die einzelnen Streife bis zum Ausgangspunkt unmittelbar hinter der Zelle deutlich getrennt, der zwischen Submediana und hinterem Medianast liegende Streif im rorderen Verlauf sehr 
breit, mit einem eirunden schwarzen Kern. Dieser Kern auf der Lnterseite bedeutend größer, die Ränder verschmälert. so daß der Streif wie ein Nadelöhr gestaltet ist. In der Zelle nur ein schlingenförmiger rötlicher Streif. Sonst wie die typische Cnterart. Torderflügellänge $40-49 \mathrm{~mm}$.

Vestliches Amazonas (São Paulo de Olivenģa).

47. H. burneyi (Hb.)

ơ. Grundfarbe der Flïgel sehwar\%. - Vorderflügel mit roter Trurzelbestäubung, welche hinter dem schmal schwarzen Torderande oder deutlich erst hinter der Subcostalis begimnt, ron den Adern schwarz durchschnitten wird und distal etwa bis zur Mitte der Zelle reicht, von da in ungewisser Begrenzung gegen die Mitte oder das letzte Drittel der Submediana abgeschrïgt ist und hinter derselben bis zum Hinterrande meist etwas zurïcktritt. Dicht an der Flïgelwurzel am Hinterrande ein gelbes Fleckchen. Im distalen Teil der Zelle eine Gruppe ron 3 gelben Flecken, die entweder eng bindenartig zusammengerïckt und hur ron den Adern fein schwarz geschnitten sind oder mehr oder weniger isoliert liegen, und zwar ein groBer, die Breite der Zelle ausfüllender, beiderseits winklig eingekerbter Fleck im distalen Teil letzterer, ein kleinerer meist elliptischer oder dreicckiger Fleck im proximalen Teil des mittleren Medianzwischenraumes, der stets den rorderen Tinkel an dem Ursprunge des mittleren Medianastes ausfüllt, und hinter diesem ein etwas gröBerer, meist die ganze Breite des hinteren Mediauzwischenraumes ausfüllender Fleck von verschiedener Gestalt, der meist vor"n der Mediana anliegt, aber auch isoliert sein kann. Hinter diesem zuweilen noch etwas gelbliche Bestäubung. Torn, distal rom Zellende, fast ummittelbar an den Zellfleck angeschlossen oder nur in mäßiger Entfernung rou demselben ein kleiner länglicher Costalfleck ron gleicher Farbe und im distalen Teil des Flügels 3 oder 4 ebeusolche subapicale, schräg gestellte Fleckchen, die dicht hinter dem Vorderrande begimnen. Unterseite matter, Grundfarbe graubraun, rote Wurzelbestäubung in der Regel anf einen ITurzelstreif am Torderrande und einen Wischfleck in der Zelle beschränkt. Das Gelb der Discal- und Subapicalflecke weißlich, Hinterrandfeld nächst einem Streif matter Bestäubung an der Mediana grau, an der Wurzel rötlich mit schrachem Seidenglanz. Am Distalrande manchmal weiße Saumfleckchen, namentlich gegen den Hinterwinkel. - Hinterfliigel mit meist ganz rot ausgefüllter Zelle, roter Strahlen- oder Zackenbildung hinter und distal von derselben; die Strahlen beginnen vorn meist in voller Breite der Aderzwischenränme und sind daun nur durch die schwarzen Adern ron dem Rot der Zelle und unter sich getrennt, verschmäleru sich indes kurz darauf wesentlich und endigen spitz dicht an dem Distalrande. Im rorderen Teil des zwischen Submediana und dem hinteren Medianast liegenden Streifes manchmal ein länglicher schwarzer Keru. Im selteneren Falle sind die Strahlen schon von voru an weiter getrennt. im anderen Falle sind diesclben sehr verkürzt, wischartig und auf den hinteren Flïgelteil beschränkt. Unterseite meist matter, ohne Wurzelstreif am Vorderrande, die Strahlenbildung rednziert, wenn oben rorhanden: sonst nur mit roten wischartigen Wrurzelfleckeu, Distalrand mit mehr oder weniger lang gezogenen, weißen oder gelblichen Streif- oder Wischtlecken, welche ron den weiß gescheckten Fransen ausgehen. Torn an der Flügelwurzel ein gelbes Fleckchen. - - . Meist $^{-}$ etwas größer, Flügel breiter. soust wie das $\sigma^{*}$, jedoch mit den charakteristischen Geschlechtsunterschieden.

Guayana, nördliches Brasilien, Peru, Bolivia. Colombia.

Diese Art zerfällt in 4 Unterarten: 
47 a. H. burneyi burneyi (Hb.) 1816 Migonitis $b$. (nom. nud.), Jac. Hübner, Terz. Schmett., p. $12: 1825$ M. b., Jac. Hübner, Zutr. exot. Schmett., v. 3 p. 7 t. f. 401, $402 \mid 1847$ Heliconia b., E. Doubleday (\& Westwood), Gen. diurn. Lep., v.1 p. $104 \mid$ 1862 Heliconius b., H. W. Bates in: Tr. Linn. Soc. London, v. 23 p. $561 \mid 1871$ H. b., W. F. Kirby, Cat. diurn. Lep., p. $143 \mid 1880$ ? H. b., Buchecker, Syst. Ent., Lep. t. 58 f. $24 \mid 1885$ H. b., O. Staudinger (\& Schatz), Exot. Schmett., v. 1 p. $78 \mid 1896$ H. b., O. Standinger in: D. ent. Z. Lep., v. 9 p. $312 \mid 1901$ H. b.. Riffarth in: Berlin. ent. Z., v. 46 p. 126 .

Oberseite der Flügel schwarz oder tief schwarzbraun. - Vorderflügel mit gelbroter von den schwarzen Adern durchschnittener Wurzelbestäubung, gewöhnlich auch am Vorderrande, während der vordere Teil der Zelle mehr oder weniger schmal keilförmig frei bleibt. Die distale Begrenzung dieser Bestäubıng unscharf von der Mitte der Zelle bis gegen das letzte Drittel der Submediana abgeschrägt, hinter derselben bis zum Hinterrande etwas wurzelwärts zurücktretend. Distal des Roten, in fast unmittelbarem AnschluB, in der Zelle eiu die ganze Breite der'selben ausfïllender schwefelgelber Fleck, der beiderseits, namentlich aber distal, winklig eingeschnürt ist und das Zellende höchstens an der hinteren Ecke erreicht. Im mittleren und hinteren Medianzwischenraum je ein weiterer länglicher Fleck von gleicher Farbe: der vordere füllt den Winkel an der Mediana aus und ist hier nur durch letztere von dem Zellfleck getrennt, während der hintere gewöhnlich isoliert steht, aber auch so vergröbert sein kann, dab er proximal mehr oder weniger breit die Mediana berïhrt, vorn in den hinteren Winkel des mittleren Medianastes ausläuft und hinten in voller Breite dem hinteren Medianast aufsitzt. In diesem Falle sind indes die beiden Flecke distal durch die keilartig eindringende Grundfarbe mehr oder weniger breit getrennt und bilden zwei gegen den Distalrand gerichtete stumpfe Zipfel. Hinter dem hinteren Medianast zuweilen ein weiterer schmaler Fleck oder Wischfleck von gleicher Farbe. Distal von der Zelle, nächst dem Vorderrande, zwischen dem 1. und 2. Subcostalast ein schmales längliches Fleckchen und darauf, vorn zwischen dem 3. und 4. Subcostalast ausgehend, eine schräg gestellte Reihe von 3 kleinen ebenfalls schwefelgelben Subcostalflecken. - Hinterflügel mit kleinem gelbem Wurzelfleck und rotgelber Strahlenzeichnung. Zelle bis auf einen schmalen vorderen Streif ausgefüllt, um dieselbe gruppiert 7 lange, bis nahe zum Distalrande reichende Strahlen, die vorn und an der Wurzel in der Breite der Aderzwischenräume beginnen, dort unter sich und von der Zelle nur durch die schwarzen Adern getrennt sind, sich gleich darauf verschmälern und spitz endigen. Beim 0 tritt in der Regel ein mehr oder weniger vollkommener achter Streif zwischen der Subcostalis und der vorderen Radialis auf. Zeicbnung und Grundfarbe der Unterseite matter, rote Wurzelbestäubung des Vorderflïgels auf einen Wurzelstreif am Vorderrande und in der Zelle verringert. Das Gelb der Discal- und Subapicalflecke weiBlich. Hinterflügel unten mit einem schlingenartigen roten Streif in der Zelle und schmalen Streifen von gleicher Farbe in den Aderzwischenräumen, von denen der zwischen Submediana und dem hinteren Medianast liegende der Länge nach gespalten ist und nur vorn und hinten zusammenhängt. - Fransen beider Flügel schwarz und weiß. Streifenförmige Verlängerumg der weißen Stellen unterseits des Hinterflügels beim $\delta$ fast gar nicht, beim $Q$ deutlicher bemerkbar. Die übrigen Merkmale wie bei der Art beschrieben. Vorderflügellänge bis $48 \mathrm{~mm}$.

Französisch-Guayana, Pará, Amazonas (Mlassauary, Manicore, Villa Bella), Bolivia (Gebiet des Riv Juntas). 
47 b. H. burneyi huebneri Staud. $1896 H . b . v a r h$., O. Staudinger in: D. ent. Z. Lep., v.9 p. 312 1901 H. b. h., Riffarth in: Berlin. ent. Z., v. 46 p. 126.

Yon der rorigen Unterart dadurch unterschieden, dab die discale Fleckengruppe rerkleinert und die 3 Flecke meist dichter aneinander liegen und nur durch die fein schwarzen Adern geschnitten werden. Der Zellfleck meist derart rerkürt, daß er ron dem roten Wurzelfelde weiter getrennt ist; hinter dem hinteren Medianzwischenraum niemals gelbe Bestäubung und der Fleck im hinteren Medianzwischenraum zuweilen ganz rerkümmert. Subapicalflecke sehr klein oder fehlend. Hinterflügel wie bei der rorigen Cnterart, aber die Streife teilweise meist etwas schmaler rou vorn an und der zwischen Hinterrandader und dem ersten Medianast liegende Streif im rorderen Verlauf öhrörmig oder eirund schwarz gekernt. Die weißlichen Saumfleckehen auf der Unterseite des Hinterflügels bis zum Apex sehr deutlich und meist streifenartig nach vorn fortgesetzt. Sonst wie die typische Cnterart, neben welcher sie auch als therration auftritt und mit der sie durch zahlreiche Zwischenformen nud Übergänge verbunden ist. Torderflïgellänge $46-49 \mathrm{~mm}$.

Französisch-Guayana, westliches Amazonas. Peru, Bolivia.

47 c. H. burneyi catharinae Staud. 1885 H.c., O. Staudinger (\& Schatz), Exot. Schmett., $v .1$ p. $79 \quad 1896$ H. c., O. Staudinger in: D. ent. Z. Lep., v.9 p. 313 | 1901 $H$. burneyi c., Riffarth in: Berlin. ent. Z., v. 46 p. 127.

Torderflügel (Fig. 30) wie bei der typischen Unterart, die in den Medianzwischenräumen liegeuden gelben Flecke isoliert, nur der vordere distal die Zelle berührend. Der hintere Fleck in seinem distalen Teil häufig schwärzlich bestäubt. Turzelteil des Torderflügels mehr zinnoberrot. Hinterflügel rorherrschend schwarz, nur ron der Wurzel aus in der Zelle und hinter derselben 3 rote kurze wischartige Strahlen, ron denen der mittlere mehr oder

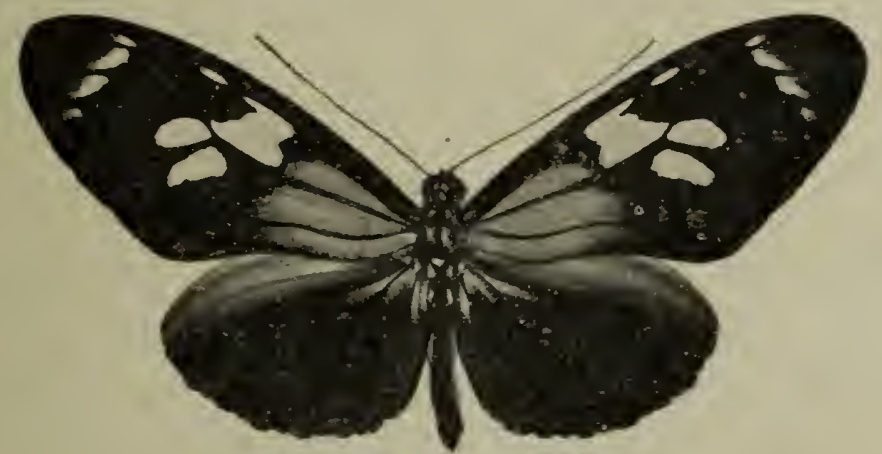

Fig. 30. H, burneyi catharinae, $\sigma^{\pi}\left({ }^{1}{ }_{1}\right)$.

weniger gespalten ist. Hinterrand ebenfalls mit kurzem rotem Wurzelstreif. Zuweilen rerlängert sich der in der Zelle liegende Strahl bis zum Ende derselben und füllt sie bis auf einell schmalen vorderen Streif aus. Alsdann bilden sich hinter der Zelle einige weitere, mehr oder weniger deutliche und lange, wischförmige, zugespitzte Strahlen. - Unterseite matter, wenngleich noch intensir braunschwarz, Vorderflügel mit längerem rotem Trurzelstreif am Vorderrande; beim $\sigma^{*}$ ein weiterer roter Wisch oder Streif in der Zelle, beim of meist breite rote Bestäubung in letzterer bis nahe zum Zellfleck. Dieser und die übrigen Flecke weißlich. Hinterflïgel rorı mit 
gelbem Wurzelfleck, einem nicht sehr deutlichen, kurzen roten Wurzelstreif am Vorderrande und 4 oder 5 zum Teil kurz streifenartig verlängerten ebensolchen Wurzelflecken. Nahe dem Distalrande meist deutliche weißliche oder seltener gelbliche, zum Teil wisch- oder streifenartig verlängerte Saumfleckchen. - In allen Übergängen zur typischen Unterart vorhauden, der sie sonst gleicht. Vorderflügellänge bis $48 \mathrm{~mm}$.

Niederländisch- und Französisch-Guayana, am unteren Amazonen-Strom (Obidos, Massauary).

47 d. H. burneyi lindigii C. \& R. Felder 1865 H. l., O. \& R. Felder in: Reise Novara, v.2 II p. 377 t. 47 f. 1, 2 | 1871 H. l., W. F. Kirby, Cat. diurn. Lep., p. 143|1877 H. l., A. G. Butler in: Tr. ent. Soc. London, p. 126 | 1885 H. l., O. Staudinger (\& Schatz), Exot. Schmett., v. 1 p.79 | 1890 H.l., Weymer (\& Naassen), Lep. Reise Stübel, p. $27 \mid 1901$ H. burneyi l., Riffarth in: Berlin, ent. Z., v. 46 p. 127.

Von der vorigen Unterart dadurch unterschieden, daß die drei gelben Discalflecke eng aneinander gerückt sind und ein einheitliches Ganzes in Gestalt einer breiten knrzen Biude bilden, die nur von den Adern fein schwarz geschnitten "wird. Der in der Zelle liegende Fleck nder Teil der Binde bedeutend vergrößert, der distal, im mittleren Medianzwischenraum liegende Teil dagegen klein, dreieckig, proximal den vorderen Winkel am mittleren Medianast ansfüllend, der dahinter liegende wiederum mehr oder minder verbreitert rnd in der Regel sowohl vorn an der schräg schneidenden Mediana als auch hinten am wagerechten hinteren Medianast breit anliegend, vorn, am mittleren Medianast, mehr oder weniger zahnartig eingeschnitten. Subapicalflecke klein, meist deren nur zwei. Hinterffügel wie bei der vorigen Unterart, in der Regel wohl etwas reichlicher rot an der Wurzel. Fransen beider Flügel sehr deutlich schwarz und rreiß gescheckt. Hinterflügel unten, beim o auch stellenweise der Vorderflügel, mit weißen oder bläulichweißev, meist, namentlich beim $ᄋ$, sehr kräftigen, streifenartig verlängerten Saumflecken, die von den weißen Stellen der Fransen ausgehen. Sonst wie die typische Unterart, aber durchschnittlich größer.

Colombia (Muzo, Llanos de San Martin).

\section{e. Coh. Doridiformes}

Kopf schwarz mit zwei weißen Stirnflecken, oben mit vier paarweise zwischen den Augen stehenden, weißlichen oder gelben Punkten. Augen schwarzbraun, hinten weiß gesäumt, oben meist mit je einem kleineu weißen Punkt. Palpen schwarz, außen proximal und am Mittelglied weiß gefleckt. Antennen schwarzbraun, an der Keule meist bräunlich aufgehellt, nur wenig länger als die Zelle. Körper schwarz, Halskragen mit zwei, Thorax vorn mit $4 \mathrm{zn}$ einer Reihe angeordneten, weißlichen oder gelben, manchmal etwas undeutlich erkennbaren Fleckchen. Thorax in der Mitte und hinten gelblich gefleckt. Abdomen liräftig, wenig länger als die Breite des Hinterflügels, ventral gelb, lateral mit einer meist undeutlichen oder unvollkommenen gelben Doppellinie und über dieser mit ebensolchen Strichflecken auf den gelb geteilten Segmenten. Thorax ventral gelb oder weißlich gefleckt. Vorderbeine schwarz, weiß gefleckt. - Vorderflügel schlank, Vorderrand sehr flach gebogen, Apex deutlicher hervortretend als bei den vorigen Gruppen, wenngleich nicht eckig, Distalrand leicht konvex, Hinterwinkel stumpf, leicht abgerundet, Hinterrand schwach S-förmig gebogen, etwa von der Länge des Distalrandes. Hinterflügel nahezu eirund, Vorderrand etwas abgeflacht, Apex nur wenig herrortretend, 
beim ơ etwas spitzer als beim $Q$, Hinterwinkel ahgermndet, Distalrand gewellt. Falter verschiedener Größe, von schwarzer bis schwarzbranner Grundfarbe. Vorderflingel mit oder obne rote Wurzelbestïubung, mit discaler gelber bindenartiger Fleckengruppe, häufig mit subapicalen gelben Flecken oder solcher Fleckenbinde. Hinterfliggel mit rotem, blauem oder griinem Wurzelfelde und meist mit mehr oder weniger ausgeprïgter Strahlenzeichnung, selten ganz zeichnungslos. Vorderrandfeld des Hinterflügels beim ô dunkel braungrau mit schwachem Glanz, beim $Q$ nur wenig heller als die Grundfarbe, proximal nächst dem Vordertande indes weißlich gelbgrau, seidenglänzend.

2 sichere Arten, von denen eine in 4 Unterarten zerfällt, und 1 unsichere Art.

\section{H. doris (L.)}

§. Grundfarbe der Flïgel schwarzbraun. - Vorderflügel proximal hinter der Subcostalis zuweilen mehr oder weniger rot bestäubt. Dieses von den schwarzen Adern durchschnittene W'urzelfeld distal etwa von der Nitte der Zelle in ungewisser Begrenzung bis gegen das letzte Drittel des Hinterrandes abgeschrïgt. Nitunter statt dessen nur 1 oder 2 rote Längswische meist hinter der Mediana und am Hinterrande. Bei ganz schwarzem Wurzelfelde längs der Mediana ein mehr oder weniger deutlicher schmaler gelber Streif. Im Discus eine gelbe bindenartige, meist nur von den schwarzen Adern fein geteilte Fleckengiruppe, bestehend aus 1 oder 2 kleinen Subeostalflecken vor dem Zellende und einem das Ende der Zelle ausfïllenden, mehr oder weniger breiten Fleck, an den sich zwei weitere in sclıäger Richtung gegen den Hinterwinkel gerichtete Flecke, ohne diesen indes zu erreichen, im mittleren und hinteren Medianzwischenraum anschließen. Mitunter ist der Zellfeck sehr verkleinert oder fehlt auch gänzlich, alsdann tritt distal von der Zelle, dieser unmittelbar anliegend, ein weiterer kleiner, von der hinteren Radialis mehr oder weniger dentlielı zerschnittener Fleck auf, so daß die als Binde gedachte Fleckengruppe vorn stark verschmälert ist, sich hiuter der Zelle rerbreitert und distal im mittleren und hinteren Medianzwischenraum zwei stımpfe Zapfen oder Zipfel bildet. Distal von dieser Binde eine subapicale schmale, schriig liegende Fleckenbinde ron gleicher Farbe. In seltenen Fällen sind die gelben Zeichnungen schwärzlich überstäubt, oder die discale Fleckenzeichnung fehlt gänzlich. Unterseite matter, sonst im allgemeinen der Oberseite entsprechend, Vorderrand stets mit einem roten Wurzelstreif. das Rot im proximalen Felde, wenn oberseits vorhanden, nnr schwach angedentet, längs der Mediana in der Zelle ein mehr oder weniger deutlicher gelber Streif. Das Gelb der Discalflecke weißlich, Subapicalflecke mehr oder weniger verkleinert, am Distalrande zuweilen weißliche Wische zwischen den Adern, namentlich gegen den Hinterwinkel. Hinterrandfeld etwas heller als die Grundfarbe, schwach glänzend. - Hinterflïgel selten einfarbig sclıwarz, meist aber von der Turzel aus bis z.nm Zellende oder darüber hinaus rot, blau oder grïn, diese Bestäubung hinter und distal der Zelle entweder uninittelbar oder erst in weiterem Abstande strahlenförmig ausgeflossen. Die Strahlen entweder in den Aderzwischenrïumen nochmals längs gespalten oder voll, von verschiedener Länge, zuweilen fast den Distalrand erreichend. In gewissen Fällen treten mehrere der genannten Farben kombiniert auf. Am Distalrande zuweilen deutliche weiße oder bläulichweiße Saumpunkte, Frausen schwarz und weiß gescheckt. Unterseite mit rotem Wrurzelstreif am Torderrande, roten Wurzelflecken, die sich mitunter, namentlich in der Zelle und hinter derselben, streifen- oder wischartig rerlïngern. Außerdem hinter der Zelle oft schmale strahlenförmige rote Streife. Im distalen Teil der Zelle, auch 
hinter derselben zuweileu weißliche wischartige Flecke, die Saumflecke nach rorn und in proximaler Richtung zu schmalen weißlichen Streifen von verschiedener Länge und Intensität ausgeflossen. - - o. Meist etwas größer. die Saumflecke des Hinterflügels in der Regel reichlicher und intensiver, sonst wie dås $0^{*}$, abgesehen von den Geschlechtsunterschieden.

Nördliches Brasilien, Guayana, Venezuela, Ecuador, Bolivia, Peru, Colombia, Mittel-Amerika.

Diese Art zerfällt in 4. Unterarten:

48a. H. doris doris (L.) ?1764 Papilio ricini ㅇ (err., non Linné 1758!), Linné, Mus. Ludov. Ulr., p. 227 (forma delila?) | ?1775 P. r. ठૈ, J. C. Fabricius, Syst. Ent., p. 461 (forma delila?) | ?1781 P.r. o,, J. C. Fabricius, Spec. Ins., v.2 p.29 (forma delila?) | ?1793 P. r. ot. J. C. Fabricius, Ent. syst., v. 3i p. 167 (forma delila?) | 1764 P. erato (err., non Linné 1758!), C. Clerck, Icon. Ins., v. 2 t. 40 f. 1 (forma delila) | 1774 P. e., St. Müller, Naturs. Linné, v. 5 I p. 586 t. 18 f. 3 (forma delila) | 1837 Heliconia e., Jam. Duncan, Foreign. Butt., p. 135 t. 11 f. 1 (forma amathnsia) | 1851 H. e., Chenu \& H. Lucas, Enc. Hist. nat., Pap. diurn. p. 68 t. 23 f. 1 (forma delila)! 1877 Heliconizes e., IV. F. Kirby, Cat. diurn. Lep., Suppl. p.721 (forma delila) | 1879 H. e., Hopffer in: Ent. Zeit. Stettin, v.40 p. 433 (forma principalis, forma amathusia, forma delila) $\mid 1881 \mathrm{H}$. e., F. D. Godman \& O. Salvin in: Biol. Centr.-Amer., Lep.-Rhop. v. 1 p. 160 (forma principalis, forma delila, forma amathusia) | 1771 Papilio (H.) doris, Linné, Mant. Plant. II. p. 536 | 1781 „Doris", P. Cramer, Pap. exot., v. 4 p. 92 t. 337 f. C. 1787 P. d., J. C. Fabricius, Mant. Ins., v. 2 p. $17 \mid 1807$ P. d., Mechanitis (part.), (J. C. Fabricius in:) Illiger in: Mag. Insektenk., v. 6 p. 284 | 1820 Laparus d., Billberg, Enum. Ins., p. 77 | 1840 Heliconius d., E. Blanchard in: Hist. An. artic., v. 3 p. 436 (ठ); p. 436 (早: forma delila) 1877 H. $d$. , A. G. Butler in: Ann. nat. Hist., ser. 4 v. 20 p. $119 \mid 1890$ H. $d$., Hahnel in: D. ent. Z. Lep., v. 3 p. $256 \mid 1890$ H. erato var. d., Weymer (\& Maassen), Lep. Reise Stübel, p. $78 \mid 1775 \& 76$ "Quivina", Papilio quirina, P. Cramer, Pap exot., v.1 p.101 t. 65 f. A, B; p. $154 \mid 1775$ P. doris + P. ricini o, J. C. Fabricius, Syst. Ent., p. $461 \mid 1781$ P. d. + P.r. o, J.C. Fabricius, Spec. Ins., v. 2 p. $29 \mid 1793$ P.d. + P.r. o, J.C. Fabricius, Ent. syst., v. 31 p. 166, 167 | 1777 „Amathusia", P. amathusia, P. Cramer. Pap. exot., v. 2 p. 124 t. 177 f. F; p:147 (forma a.) | 1779 "P. doris" + "P. a.", Goeze, Ent. Beytr., v. 3 I p. 107; p. 117 (forma a.) $\mid 1790$ P. erato + P. a. + P. d., J. F. W. Herbst, Naturs. Ins. Schmett., $v .4$ p. 138 t. 73 f. 5 (forma delila); p. 149 t. 74 f. 4 (forma a.); p. 155 t. 75 f. $3,4 \mid 1806-19$ "Nereis festiva Delila", Jac. Hübner, Exot. Schmett., v. 1 t. [13] (forma delila) | 1816 Migonitis crenis (part.) + Sicyonia doris, Jac. Hübner, Verz. Schmett., p. 12 (forma amathusia); p. 13 | 1819 Heliconia d. + H. erato, (Latreille \&) J. B. Godart in: Enc. méth., v. 9 p. 204 ; p. 205 (forma delila) $1844 H . d .+H$. e. (part.), E. Doubleday, List. Lep. Brit. Mlus., v. 1 p. 54 ; p. 54 (forma delila) | 1847 H. $d .+H$. e., E. Doubleday (\& Westwood), Gen. diurn. Lep., v.1 p.104; p.104 (forma delila) | 1862 Heliconius e. + H. e. forma rubra, H. W. Bates in: Tr. Linn. Soc. London, v. 23 p. 557 ; p. 557 (forma delila) | 1867 H.doris + H. e., H. W. Bates in: Tr. ent. Soc. London, ser. 3 v. 5 p. 537 ; p. 537 (forma delila) | 1869 H. $d .+H$. l. var. e., A. G. Butler, Cat. diurn. Lep. Fabr., p. 121; p. 121 (forma delila)| 1871 H. e. + H. e. var. d., W. F. Kirby, Cat. diurn. Lep., p. 141 (forma delila); p.141 | $1877 H$. d. var., A. G. Butler in: Tr. ent. Soc. London, p. 124 (forma delila) | 1877 H. $l$. var. delila (non Papilio delila J. C. Fabricius 1775!), Möschler in: Verh. Ges. Wien, v.26 Abh. p. 313 (forma delila) | $1882 \mathrm{H}$. doris forma delila (part.), Chr. Aurivillius in: Svenska Ak. Handl., n. ser. v. 19 nr. 5 p. 18 (forma delila) | 1902 H. doris delila, Stichel in: Berlin. ent. Z., v.47 p.152 (forma delila) 1885 H. erato + H. e. var. doris + H. e. var. mars, O. Staudinger (\& Schatz), Exot. Schmett., v. 1 p.77 (forma delila); p. 77; p. 79 t. 32 (forma delila) | 1896 H. e. + H. e. var. \& aberr. doris $+H$. e. aberr. amathusia $+H$. e. aberr. metharmina, O. Staudinger in: D. ent. Z. Lep., v. 9 p.313, 316 (forma delila); p.313, 315, 317; p.316 (forma amathusia); p. 315 (forma metharmina) | 1900 H. e. aberr. tecta (MIaassen in MIS.), Riffarth in: Berlin. ent.Z., v. 45 p.207 (forma tecta) 1901 H. e. + H. e. amathusia $+H$. . c. doris (H.d. cacrulea Staudinger in MS.) + H. e. $t .+H$. e. mctharmina, Riffarth in: Berlin. ent. Z., v. 46 p. 129 (forma delila); p. 130 (forma amathusia); p. 131; p. 132 (forma tecta); p. 132 (forma metharmina). 
Forma principalis. Grundfarbe der lilügel schwar\% - Vorderflügel ron der Wurzel aus mit einem dünn gelb bestäuhten Streif beiderseits der Mediana bis zum hinteren Medianast. Im Discus eine von den fein schwarzen Adern geteilte. scliwefelgelbe, sehr selten weiße, schräg liegende Binde. Dieselbe beginnt dicht hinter dem Torderrande bei der Abzweigung des 1. Subcostalastes in Gestalt eines kleinen Doppelfleckes. Das Ende der Zelle ist breit ausgefüllt, manchmal erscheint distal ron derselben noch etwas gelbliche Bestäubung. Der große, fast quadratische Zellfleck setzt sich in voller Breite im hinteren Medianzwischemaum mit schräg gegen den Hinterwinkel gerichteter distaler Begrenzung fort. und ror diesem lünglichen liegt ein fast dreieckiger Fleck, welcher den proximalen Teil des mittleren Medianzwischenraumes ausfüllt. Die letaten beiden Flecke der Binde sind distal, am mittleren Medianast mehr oder weniger ron der schwarzen Grundfarbe eingeschnitten. Hintere Begrenzung der Biude stets am hinteren Medianast. Distal von derselben eine schräg liegende, schmale subapicale Fleckenbinde, die hinter dem Torderrande beginnt, durch die schwarz markierte Gabel des 4 . und 5. Subcostalastes läuft, an den übrigen sie durchschneidenden Adern schwarz geteilt ist und im hinteren Radialzwischenraum endet. - Hinterflügel vou der Wurzel aus hinter der Subcostalis blau bis zum Ende der Zelle, hinter dieser und distal ron derselben kurze, höchstens etwa bis zur Flügelmitte reichende strahlenförmige, in der Mitte der Länge nach gespaltene Streife in den Aderzwischenräumen, die am Hinterrandteil im rorderen Verlauf gewöhnlich etwas roller sind und dort breit zusammenhängen. Nächst dem Distalrande eine Reihe bläulichweißer, paarweise in den Aderzwischemäumen stehender Samipunkte. Cnterseite matter, Vorderflügel mit kurzem rotem Wurzelstreif am Vorderrande, die gelben Zeichnungen weißlich, in den Radialzwischemäumen und nächst dem Hinterwinkel am Distalrande weißliche Wischflecke oder Streife. Hinterflügel ebenfalls mit rotem Wurzelstreif am Vorderrande, roten Wurzelflecken, die sich in der Zelle und hinter ihr streifenartig fortsetzen. Hinterrand ebenfalls schmal rot, in den übrigen Aderzwischenräumen meist bis zur hinteren Radialis schmale rote isolierte Strablen. Saumfleckchen weiß, streifenartig nach vorn und in proximaler Richtung verlängert, am meisten die vorderen in den Radialzwischenräumen, dagegen wenig oder gar nicht diejenigen im Apex selbst. - Fransen des Hinterflügels schwarz und weiß gefleckt, die des Vorderflügels rorwiegend schwarz, nur undentlich weißlich unterbrochen. Torderflügellänge $43-46 \mathrm{~mm}$.

Niederländisch- und Französisch-Guayana, nördliches Brasilien (Pará, Amazonas), Peru, Bolivia, Venezuela.

Forma amathusia. Vorderflügel wie bei der typischen Cnterart. indes proximal in der Zelle und hinter derselben neben dem gelben Medianstreif mehr oder weniger schwach rote Streife oder Wische. Hinterflügel mit der blauen Strablenzeichnung der Hauptform, aber die Zelle länglich rot gekernt und zwischen den gabelartig gespaltenen blauen Streifen in den Aderzwischemräumen spitz auslaufende rote Strahlen eingeschoben, welche die ersteren beiderseits in der Regel wesentlich einengen, so daß das Blau nur als schmale rordere Berandung dieser roten Streife anzusehen ist.

Seltene Zwischenform zwischen der Hauptform und der folgenden Form, in den sonstigen llerkmalen mit ersterer übereinstimmend und auch als Aberration bei H. d. viridis und H. d. transiens (S. 165) rorkommend.

Xiederländisch-Guayana, Ecuador (Archidona in Höhe ron $650 \mathrm{~m}$ ). 
Forma delila. Vorderflügel (Fig. 31) proximal hinter der Subcostalis bis etwa zur Mitte der Zelle rot bestäubt. Distale Begrenzung dieses von den schwarzen Adern durchschnittenen Wurzelfeldes ungewiß zerstäubt und bis zum distalen Drittel des Hinterrandes abgeschrägt. Distal ron demselben in ummittelbarem Anschluß oder schmal schwarz getrennt eine breite gelbe Fleckenbinde und darauf eine schmale subapicale Fleckenbinde, beide wie bei der Hauptform, die subapicale Binde indes öfters auf die 2 oder 3 vorderen Fleckchen reduziert. Das Rot des Wurzelteiles meist sehr intensiv, zuweilen tritt längs der Mediana und Submediana vermehrte schwarze Bestäubung auf, wodurch das Rot auf zwei Längswische zurückgedrängt wird, zuweilen ist der Ansatz. eines gelben Medianstreifes von der Wurzel aus bemerkbar. - Hinterflügel mit rot ausgefüllter Zelle und langen roten Strahlen in den Aderzwischenräumen, die fast bis zu ihrem Ausgange hinter der Zelle gut, mindestens aber durch die schwarzen Adern getrennt sind. Die ersten 2 oder 3 Strahlen, vom Hinterrande gerechnet, füllen vorn meist die Breite des Aderzwischenraumes aus, die ïbrigen sind schon voru etwas schmaler; der vorterste

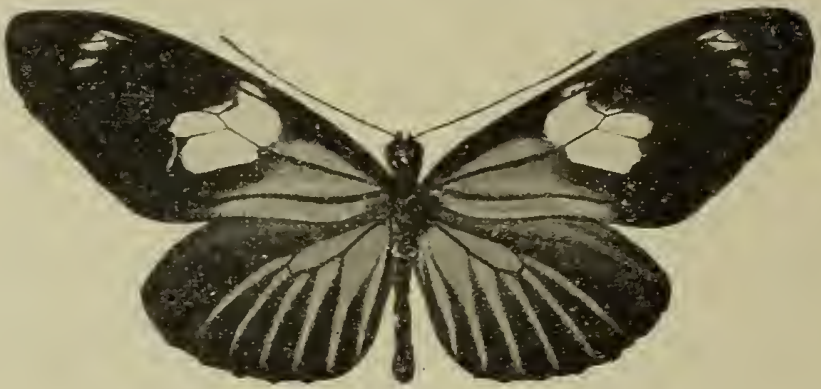

Fig. 31. H. doris doris, forma delila, $\delta(1 / 1)$.

liegt im hinteren Radialzwischemraum, nur seltener erscheint vor ihm noch eim Rudiment. Sämtliche Strahlen verschmäler'n sich allmählich und laufen fast bis zum Distalrande. Fransen schwarz und weib gescheckt. - Unterseite matter, rauchbraun, Vorderflügel mit schwach bestäubtem gelblichem Medianstreif. kurzem rotem Wurzelstreif am Vorderrande, nur schwach rötlichbraun angedeutetem IV urzelfelde. Discalflecke gelblichweiß. Subapicalflecke sehr verkleimert. Hinterrandfeld bräunlichgrau, schwach glänzend. Hinterflügel mit rotem Wurzelstreif am Vorder'rande, einem starken roten Fleck in der Krümmung: der Praecostalis und zwei weiteren roten Wurzelflecken hinter der Costalis und Mediana, ron denen der letztere zu eimem langen schmalen roten Streif ausgeflossen ist. Ebensolche Streife am Hinterrande und in den übrigen Aderzwischenräumen, denen der Oberseite entsprechend, aber schmaler. Immitten der Zelle ein mehr oder weniger intensiver roter Längsstrahl, nächst dem Distalrande kleine, seltell oben durchscheinende, weiße, nicht verlängerte Saumflecke. Im übrigen wie die Hauptform, deren Fluggebiet sie teilt.

Niederländisch- und Französisch-Guayana, nördliches Brasilien (Amazonas), Peru, Bolivia, Ecuador.

Forma tecta. Wie die Hauptform, aber die gelben Discal- und Subapicalflecke derart schwärzlich überstäubt und verdunkelt, daß sie sich nur wenig von der Grundfarbe abheben.

Peru, Colombia. 
Forma metharmina. Torderflïgel wie bei der Hauptform, Hinterflügel einfarbig schwarz oder nur mit geringen Rudimenten blauer Strablenzeichnung an der Wrurzel. Im übrigen wie erstere, namentlich auch mit den roten Strahlen auf der Lnterseite des Hinterflïgels.

Nördliches Brasilien (Amazonas), Peru, Bolivia, Ecuador, Venezuela, Colombia.

48b. H. doris transiens Staud. 1881 \& 1901 H. erato (part.), F. D. Godman \& O. Salrin in: Biol. Centr.-Amer., Lep.-Rhop. v. 1 p. $160 ; v .2$ p. 669 1896 H. c. var. transiens, O. Staudinger in: D. ent. Z. Lep., c.9 p. 314, 317 | 1901 II. e. t., Kiffarth in: Berlin. ent. Z., $v .46$ p. 130.

Torderflïgel proximal schwarz oder nur mit Spuren ron Rot am Hinterrande, zuweilen mit gelbem Medianstreif. Fleckengruppe in Discus rorı bedentend rerschmälert. auch die hinter der Zelle liegenden Flecke rerkleinert. - Hinterflügel mit roter Strahlenzeichnung ähnlich H. d. rl., forma delila (S. 164), aber die einzelnen Streife rorn, am Lrsprunge hinter der Zelle, breiter und nur durch die fein schwarzen Adern ron letzterer und unter sich getrennt, auch kürzer als bei der genaunten Form, daher fast keilförmig gestaltet. Die spitzen Enden sind $3-4$ mm rom Distallande entfernt. Zuweilen tritt an den Spitzen, namentlich au den vorderen Strahlen, blaue oder griüne Saumbestäubung auf. Am Distalrande deutliche weiße Saumfleckchen, die unten nach rorn und in proximaler Richtung streifenartig ausfließen. Auf der Cnterseite fehlt die rote Strahlenzeichnung häufig ganz oder ist nur hinten erbalten, dagegen sind 3 deutliche rote Wurzelflecke vorhanden. - Sonst wie die typische Unterart, aber kleiner. Torderflügellänge $38-40 \mathrm{~mm}$.

Mexiko. Honduras, Colombia.

$48 \mathrm{c} . \mathrm{H}$. doris viridis Staud. ?1874 H. erato (err., non Papilio e. Linné 1758!), A. G. Butler \& Herb. Druce in: P. zool. Soc. London, p. 351 (forma eratonia) | 1880 H.e., F. D. Godman \& O. Salvin in: Tr. ent. Soc. London, p. 122 (forma eratonia) | 1881 H. e., F. D. Godman \& O. Salrin in: Biol. Centr.-Amer., Lep.-Rhop. v. 1 p. 160 (forma principalis \& eratonia) ? 1890 H. e., Weymer (\& Massen), Lep. Reise Stiibel, p. 12. 17, 27. 33 (forma eratonia) 1885 H.e.var. viridis, O. Staudinger (\& Schatz), Exot. Schmett., r. 1 p. 77 t. $32 \mid 1890$ H. obscuves, Weymer in: Fnt. Zeit. Stettin, v. 51 p. 290 (forma obscura) | $1896 \mathrm{H}$. erato var. viridis $+H$. e. var, eratonius $+H$. erato var. obscurus, O. Standinger in: D. ent. Z. Lep., 1.9 p.313, 317; p. 314, 317 (forma eratonia); p. 315,317 (forma obscura) $1901 \mathrm{H}$. erato eratonius $+H$. eratoluminosus + H.e.v. + H. e. obseurus, Riffarth in: Berlin. ent. Z., $v .46$ p. 130 (forma eratonia); p. 132 (forma luminosa); p. 132; p. 133 (forma obscura).

Forma principalis. Größer als die vorige Unterart. Torderflügel schwarz ohne rote Wurzelbestäubung. meist mit gelbem Medianstreif. Discale Fleckengruppe ühnlich wie bei H. d. transiens, rorn ganz schmal, der Fleck in der Zelle auf den rorderen Eckwinkel beschränkt oder ganz fehlend, die beiden Flecke binter der Zelle in der Regel distal etwas länger ausgezogen. Subanicale Fleckenbinde meist stark rerbreitert. Hinterflügel ron der Wrurzel aus hinter der Subcostalis grün, in den Aderzwischenräumen binter der Zelle und distal ron dieser mit Strahlen, die dev Länge nach gespalten sind. Die grüne Farbe ist vorn meist etwas intensiver und in den Strahlen häufig weißlich anfgehellt. Anlage der Strahlen wie bei der tṛpischen Unterart in Blau, aber meist etwas länger, seltener selır verkürzt, ramentlich im mittleren Teil. Hinterflügelunterseite außer dem roten Wurzelstreif am Vorderrande nur mit drei roten $\Pi$ urzelpunkten, meist ohne rote Strahlenbildung oder diese in der hinteren Fläche nur angedeutet. Auf Ober- und Unterseite deutliche weiße Saumfleckchen, die unten wie bei Forma 
eratonia streifenartig ausfließen. Im übrigen wie letztere und hauptsächlich in demselben Fluggebiet vorkommen.

Tenezuela, Colombia, Panama, Honduras.

Forma eratonia. Ähnlich der Forma delila (S. 164). Vorderflügel wie bei der Hauptform, aber proximal selten ganz schwarz, meist mindestens am Hinterrande, öfters auch noch vor der Submediana rot bestäubt. Ein gelber Medianstreif fast immer vorhanden. Hinterflügel hinter der Subcostalis ron der Wurzel aus breit zinnoberrot, strahlig ausgezackt. Die einzelnen Strahlen etwas länger als bei H. d. transiens (S. 165), aber nicht so lang wie bei H. d. d., forma delila (S. 164), rorn breit unter sich und mit dem Rot der Zelle zusammenhängend, auch die Adern meist mehr oder weniger rot bestäubt. An den Spitzen, namentlich denen der vorderen Zacken, manchmal grüne oder blaue Saumbestäubung. Am Distalrande deutliche weiße Saumpunkte, die unten stärker als bei der vorigen Unterart zu langen weißen Streifen ausfließen. Die roten Strahlen fehlen auf der Unterseite oder sind nur am Hinterrande und in zwei oder drei folgenden Aderzwischenräumen vorhanden. Subapicalflecke des Vorderflügels unten zu langen weißlichen Wischen ausgeflossen, ebensolche Wischflecke am Distalrande nächst dem Hinterwinkel. Sonst wie die typische Unterart. Vorderflügellänge bis $45 \mathrm{~mm}$.

Venezuela, Colombia, Panama, Costa Rica.

Forma obscura. Vorderflügel schwarz bis auf die sehr verkleinerten gelblichen Subapicalflecke und einen mehr oder weniger deutlich gelben Medianstreif, der sich in schwacher Bestäubung manchmal auf dem hinteren Medianast fortsetzt. Hinterflügel mit roter, blauer oder griiner Strahlenzeichnung, in der Form. Anlage und Ausdehmung wie bej der Hauptform, der Forma eratonia und bei der typischen Unterart. Unterseite einfarbig: schwarzbraun bis auf Spuren der Subapicalflecke des Vorderflügels, einem kurzen roten Wurzelstreif am Vorderrande beider Flügel, vier roten Wurzelflecken des Hinterflügels und den weißen Saumpunkten ebenda, die auch oben teilweise auftreten. Sonst wie Forma eratonia.

Colombia (Antioquia, Cauca).

Forma luminosa. Vorderflügel wie bei der Hauptform, Subapicalflecke meist bedeutend vergrößert. Hinterflügel mit blaner, namentlich distal von der Zelle reichlich weißlich überstäubter Strahlenbildung; diese Strahlen in der Art wie bei der vorhergehenden Form, also jeder Strahl gabelförmig' gespalten. Unterseite des Hinterflügels ohne rote Streife oder nur am Hinterrande mit solchen, dagegen mit roten Wurzelflecken; am Ende der Mittelzelle weißliche Wischflecke, die Saumflecke zu langen weißen Streifen ausgeflossen. Sonst wie die Hauptform.

Colombia, Panama (Chiriqui).

48 d. H. doris aristomache Riff. ?1890 H. erato var, d. (err., non Papilio d. Linné 1771!), Weymer (\& MIaassen), Lep. Reise Stübel, p. 12 | 1901 H. d. aristomache, Riffarth in: Berlin. ent. Z., v. 46 p. 131.

Unterscheidet sich von der typischen Unterart dadurch, daß die gelbe discale Fleckenbinde wie bei der vorigen Unterart schmaler und besonders vorn bis zur hinteren Ecke der Zelle infolge Verkleinerung oder Ausscheidung: des Fleckes im Zellende verkïmmert ist. Zuweilen treten dort nur Spuren gelber Bestäubung auf, oder der vordere Teil der Binde fehlt ganz. Der im hinteren Medianzwischenraum stehende Fleck proximal rerkürzt. so daß er 
vorn gat nicht, oder nur mit dem vorderen Zipfel die Mediaua berübrt. Gelber Medianstreif meist deutlich, weun auch nicht sehr intensiv gefärbt, Subapicalflecke wie bei der: typischen Cnterart. - Hinterflügel oberseits wie bei dieser, die blauen, gabelförnnig gespalteneu Strahleu vou verschiedener Ausdehnung, manchmal stark verkürzt, namentlich in der Elügelmitte. Unten fehlt jede Spur der der typischen Cnterart eigentümlichen roten Strahlenzeichnung. nur ein kurzer roter Wnrzelstreif am Vorderrande, 3 ebensolehe Wrurzelflecke vor, in und hinter der Zelle und ein kurzer Wisch an der Trurzel des Hinterrandes sind vorhanden, Saumfleckehen weiß, oben mindestens im hinteren Teil des Distalrandes deutlich, unten mebr oder weniger zu weißlichen Streifen nach rorn und in proximaler Richtung ausgeflossen. - Fransen beicler Flügel schwarz und weiß gefleckt, am vorderen weniger deutlich als am hinteren Flügel. - Charakteristische Vertreter sind aus Ecnador bekannt, woselbst die drt ausschließlich in der blauen Form vorzukommen scheint, in Colombia erscheinen Übergänge znr typischen Cnterart als Aberation ron H. d. transiens (S. 165). Im übrigen ersterer gleichend. Vorderflügelläuge $36-42 \mathrm{~mm}$.

Ecuador (Balzapamba, in Höhe ron $860 \mathrm{~m}$; Palmar, in Höhe ron $100 \mathrm{~m}$ ).

49. H. hierax (Hew.) 1869 Heliconia h., Hewitson, Equat. Lep., p. 11 | 1871 H.h., Hewitson, Exot. Butt., v. 4 Heliconia t. 6 f. $20 \mid 1871$ \& 77 Heliconius h., W. F. Kirby. Cat. diurn. Lep., p. 141; Suppl. p. 721 | 1890 H. h., Weymer (\& Maassen), Lep. Reise Stübel, p. $35 \mid 1901$ H. h., Riffarth in: Berlin. ent. Z., v. 46 p. 133.

ऽ. Kopf, Augen, Körper wie bei der vorigen Art. Palpen rorwiegend schwarz, nur außen an der Wurzel nnd am Mittelgliede ein kleiner weißer Fleck. Antennen etwas länger als die Zelle, völlig schwarz. Vorderbeine schwarz, nur wenig weißlich überstäubt. Flügelform etwas gedrnngener, Apex des Vorderflügels stärker abgerundet, der des Hinterflügels wenig hervortretend. Grundfarbe der Flügel schwarz. - Vorderflügel proximal hinter der Mediana bis etwa zur Mitte mebr oder weniger hochrot bestäubt, Submediana hierin und Hinterand schmal schwarz. Im Discns eine schwefelgelbe Querbinde, deren vorderer Teil als kleiner länglicher, hinter dem Vorderrande am Zellende liegender Fleck von der Subcostalis abgeschnitten ist, die sich nach hinten allmählich verbreitert, nur von den teilweise fein schwarzen Adern durchschnitten wird und am linteren Medianast endet. Die proximale Begrenzung nur wenig von der Grundfarbe eingeschnitten, fast seukrecht von der vorderen Zellecke znm hinteren Medianast verlaufend, distale Begrenzung mehr oder weniger zackig und hinter dem mittleren Medianast eingeschnürt, so dab sich vor diesem nnd dem hinterell Medianast zwei kleine nach dem Distalrande rorspringende Zipfel bilden, deren hinterer distal am weitesten rorgern̈ckt ist. Die gröBte Breite der Binde ist hier etwa $10 \mathrm{~mm}$. An der Spaltung des 4. und 5. Snbcostalastes und hinter letzterem zwei kleine gelbe Subapicalflecke. Unterseite matter, schwarzbranu, mit kurzem rotem Wnrzelstreif am Vorderrande, proximal ohne rote Bestäubung, das Gelb der Binde und Flecke weißlich, am Distalrande nächst dem Hinterwinkel ungewisse weißliche Streife. Hinterrandfeld etwas heller als die Grundfarbe, proximal schwach rötlich, leicht glänzend. - Hinterflügel hinter der Subcostalis vou der Wurzel und dem Hinterrande breit rot bis über die Flügelmitte, unter allmählicher Verschmälerung der hinteren Berandung. Diese zwischen den Adern leicht gekerbt und auf letzteren schwach gezacht. ohne Strahlenbildung: Adern im Roten nnr teilweise fein schwarz. Unterseite mit gelbem Wurzelstreif am Vorderrande: in der Zelle ein rotes Streifchen, hinter derselben ein roter Fleck, Hinterrand an der Wurzel rot bestäubt. 
Fleckbildung an der Flïgelwurzel manchmal rerschwommen, zumeilen reitere ron derselben ausgehende Spuren ron Strahlenbildung, die rote Wurzel- und Discalfläche der Oberseite schwach dmrchscheinend: zwischen den Adern paar\#еise, zum Teil ron den weißlichen Saumfleckchen ansgehende, reißgraue Streife. welche dunklere, rorn spitze. gegen den Distalrand rerbreiterte Strahlen in der Grundfarbe begrenzen und absondern. Vorderrandfeld ror der Submediana einfarbig. - - o. Flïgel etwas gedrungener, Distalrand des Hinterfliigels stark gewellt. Grundfarbe meniger intensir, schwarzbramn, sonst wie das ऊ. jedoch mit den Geschlechtsunterschieden. - - Torderflügellänge etwa $39 \mathrm{~mm}$.

Ecuador (Kiobamba-Banos und Jiraria del Pintuc; Santa Inéz; in Höhe ron $1200 \mathrm{~m}$, im Oktober).

H. cinereofuscus F. Kirby 1765, Seba. Thesaurus, 2.4 Inclex p. 17 t. 29 f. 11 , $12 \mid 1779$ "Papilio Heliconius cinereofuscus", Goeze, Ent. Beytr., 2.3 I p. $122 \mid 1877$ H.c., W. F. Kirby, Cat. diurn. Lep., Suppl. p. 722.

Torderfï̈gel schlank, Vorderrand schwach gekrümmt. A pex ziemlich spitzwinklig aber abgerundet, Hinterwinkel stumpf, Hinterrand etwa ron ${ }_{3}$ der Länge des Vorderrandes. Hinterflügel elliptisch, rorn etwas abgeflacht, ohne herrortretenden Apex und mit abgerundetem Hinterwinkel. Schwarzbraun, Yorderflügel mit zwei weißeu Querbinden, deren eine etwa $4 \mathrm{~mm}$ breite dicht hinter dem Vorderrande, der distale Rand etra in der Hitte der Zelle, beginnt und schräg bis zum letzten Drittel des Hinterrandes zieht. Die zweite ist schmaler und liegt subapical. Hinterflügel ron der Trurzel aus rostrot bis auf einen breiten schwarzbraunen Distalsaum, dessen Begrenzung etwas wellig ist. Unterseite wie die Oberseite. jedoch der Hinterflügel einfarbig, ohne rot abgesetztes Wurzelfeld. [Nach Seba.] - ̈̈hnlich Eneides ricini (S. 243), aber die Lage der Discalbinde anders und Antennen länger.

Niederländisch-Guayana.

\section{f. Coh. Wallaceiformes}

Kopf schwarz, Stirn mit zmei länglichen, teilweise ron den Palpen rerdeckten weißen Flecken. Hinterkopf mit rier, parrmeise zwischen den Augen stehenden, weißen oder gelben Punkten. Augen schmarzbraur, hinten reiß oder gelb gesäumt. Palpen schwarz, Turzel außen und das Mittelglied пeiß oder gelb. Antennen schwarz, länger als die Zelle, bis über die Abzweigung des 2. Subcostalastes reichend. Körper schmarz $z_{z}$ Halskragen mit 2, Thoras rorn mit 4 in einer Reihe stehenden weißen oder gelben Punkten, Thorax oben ohne eigentliche Fleckbildung, beiderseits nur schwach gelblich kurz behaart. Abdomen beim ơ den Hinterflïgel etwas überragend. beim o etwa ron der Länge des Hinterrandes, ventral gelb oder weiß, lateral mit drei Längslinien, deren untere in der Regel deutlicher. wenngleich auch öfters rudimentär ist, deren obere $z$ mei selten rollkommen erhalten sind und meist nur als unregelmäBige Strichfleckchen auftreten. Thorax unten gelb oder weiß gefleckt, Torderbeine schwarz, ebenfalls hell gefleckt. - Torderflïgel schlank. Torderrand schwach gekrümmt, Apex ziemlich lang ausgezogen. abgerundet, Distalrand fast gerade. in schräger Richtung abfallend. Hinterwinkel stumpf. Hinterrand leicht S-förmig gebogen, etwa ron der Länge des Distalrandes. Hinterflügel elliptisch, rorn etwas abgeflacht, Apex renig hervortietend, Hinterwinkel abgerundet, wenngleich weniger als bei der rorhergehenden Gruppe. Vorderrandfeld des $\sigma$ dunkelgrau, proximal etras heller. schwach glänzend, die C'ostalis ron der Wurzel ans bis etwa zur Hälfte schmal gelblich oder тeiß bestäubt, Torderrandfeld des $ᄋ$ dunkler. ohne Glanz 
und nur wenig ron der Grundfarbe abgehoben. - Meist größere Arten von sehwarzhlau glänzender Grundfarbe, Vorderflïgel mit gelber oder weißer Discalbinde oder solchen Flecken und ebenso gefürbter schmaler Subapicalbinde. Hinterflügel stets einfarbig mit gewelltem Distallande und schwarz und weiß gescheckten Fransen dergestalt, daß zwischen je 2 Adern zwei weiße und in deren Mitte eine schwarze Stelle erseheint, die Aderenden selhst aber auch schwarz bleihen. Hierdurch leicht von ähulichen Vertretern anderer Gruppen zu unterscheiden.

1 Art, die in 3 Unterarten zerfällt.

50. H. wallacei Reak.

ठ․ Grundfarbe schwarz bis schwarzbraun, auf beiden Flügch proximal und auch discal in verschieden weiter Ausdehunng, jedoch nie bis in den Apex und in den distalen 'Teil, mit starkem stahlblanem oder grünlichblauem Glanz. Torderflügel im Discus mit einem großen gelben oder weißen Fleck, der hinter der Subcostalis beginnt, sich gegen die Mediana verbreitert, ron dem durch letztere und dem hinteren Nedianast gebildeten Winkel fein sehwarz durchschnitten wird und hinten vor der Submediana flach abgerundet endet. Dieser Fleck ist mitunter sehr verschmälert und läuft dann als Querbinde schräg von der Mitte der Zelle längs des hinteren Medianastes bis nahe zum Iistallande, dort ziemlich spitz endigend; in anderen Fällen erscheinen im nittleren Teil der Zelle und im proximalen Teil des hinteren Medianzwischenraumes zwei rundliche isolierte Flecke, vou denen der hintere meist größer ist, zuweilen die Mediana und den hinteren Medianast berïhr't oder auch über letzteren hinausreicht. Distal cine schräge, dicht hinter dem Vorderrande heginnende und fast bis zum Distalrande im vorderen Medianzwischenraum reicheude. schmale gelbe oder weiße Subapicalbinde, die von den Aderu schwarz durehschnitten wird. Unterseite matter, die Flecke und die Subapicalhinde weiß oder gelblichweiß, Hinterrandfeld nur wenig aufgehellt, mur hinter der Submediana glänzend, am Vorderrande ein ku'zer, hochroter Wurzelstreif. - Hinterflügel einfarbig, der Blauglanz in der Regel bis nahe zuin Distalrande reichend, ohne bestimmte Begrenzung, im Vorderrandfelde fehlt derselbe. Fransen schwarz und weiB gescheckt, wic bei der Gruple beschrieben. Lnterseite grauschwarz, an der Wurzel ein gelbes oder weißes Eleckchen, am Hinterande und hinter der Subcostalis je ein mehr oder weniger langer roter Streif, in der Zelle und hinter derselben drei ebensolche Wurzelflecke, dereu hinterer zwischen Submediana und Hinterrandader auch mitunter streifenartig verlängert ist. $\mathrm{Vor}^{\circ}$ dem Distalrande mitunter mehr oder weniger lange, paarweise in den Aderzwischemrüumen stehende, weißgraue, strahlenartige Streife, die von den weißen Stellen der Fransen ausgehen. - - o. In der Regel ron etwas matterer Grundfarbe und größer; oberseits ohme Unterschiede, auf der Unterscite des Hinterflügcls die weißlichen Strahlen meist besser ausgebildet. In allgemeinen etwas größer und wenig gedrungener, sonst wie das ơ, jedoch mit den charakteristischen Geschlechtsunterschicden, Abdomen meist kürzer.

Guayana, nördliches Brasilien, Perı, Bolivia. Ecuador, Colombia, Venezuela.

Diese Art zerfällt in 3 Unterarten:

50 a. H. wallacei wallacei Reak. 1862 H. clytia var., H. W. Bates in: Tr. Linu. Soc. London, v. $\{3$ p. $556 \mid 1866 \mathrm{H}$. wallacei, (H. W. Bates in MS.) Reakirt in: P. Ac. Philad., p. 242 | 1871 H. clytia var. w., W. F. Kirby, Cat. diurn. Lep., p. 140 | 1877 $H . w$., A. G. Butler in: Tr. ent. Soc. London, p. $124 \mid 1899$ II. clytia var, elsa, Riffarth in: Berlin. ent. Z., v. 43 p. 407 (forma e.) | 1901 H. c. wallacei + H. c. e., Riffarth in: Berlin. ent. Z., v. 46 p. 135 ; p. 136 (forma e.). 
Forma principalis. Zeichnung des Vorderflügels schwefelgelb wie bei Forma flavescens (S. 172), Discalfleck des Vorderflügels bindenartig rerschmälert. Der in der Zelle liegende, von der fein schwarzen Mediana abgetrennte Fleck etwa wie bei jener, manchmal vorn in proximaler Richtung längs der Subcostalis mit einem mehr oder weniger langen, spitzen Ausläufer. Der Fleck setzt sich schräg gegen den Hinterwinkel hinter der Mediana in einer vorderen Breite von etwa $5 \mathrm{~mm}$ fort, verschmälert sich dann und endet ziemlich spitz am hinteren Medianast unweit des Distalrandes. Gewöhnlich tritt hinter dem Medianast in der Mitte, in unmittelbarem Anschluß, noch ein längliches gelbes Wischfleckchen auf. Subapicalbinde etwa 2-3 mm breit, ziemlich voll, nur von den Adern fein schwarz geschnitten in derselhen Weise wie bei H. w. colon. Unterseite matter, die gelbe Zeichnung weißlich, der von dem Zellfleck an der Subcostalis rücklaufende schmale Streif deutlicher, vor der Mediana ebenfalls ein schmaler gelblicher Streif. Im übrigen wie H. w. colon, in allen Übergängen zu Forma flarescens (S. 172) vorhauden. Torderflügellänge $36-44 \mathrm{~mm}$.

Colombia, Niederländisch- und Französisch-Guayana, Gebiet des unteren AmazonenStroms (Santarem, Massauary).

Forma elsa. Wie die Hauptform, aber die Binden des Vorderflügels rein weiß anstatt gelb. Im einzelnen Falle die discale Binde in der Mitte des Verlaufes zwischen Mediana und Spitze schwarz unterbrochen. Hinterflügel unterseits ohne oder nur mit verloschenen Saumstreifchen.

Niederländisch-Guayana.

50 b. H. wallacei mimulinus Butl. 1873 H. m., A. G. Butler in: Cistula ent,, $v .1$ p. $168 \mid 1877$ H. m., W. F. Kirby, Cat. diurn. Lep., Suppl. p. $722 \mid 1901$ H. clytia m., Riffarth in: Berlin. ent. Z., v. 46 p. 136.

Nächst der typischen Unterart, jedoch der Blauglanz in geringerer Ausdehnung. Der vordere Teil der Discalbinde in der Zelle gleichmäBiger breit, fast rhombisch mit wenig eingeschnürten Seiten, an der rorderen proximalen Ecke mit einem langen schmalen, längs der Subcostalis rïcklaufenden Fortsatz, mitunter fast bis zur Flügelwurzel. Auch zwischen Costalis und Subcostalis reichlicher gelb bestäubt. Hinter der Zelle verbreitert, sich die Binde etwas, füllt in der Regel den rorderen Winkel am hinteren Medianast bis auf den Scheitel aus und liegt hinten breiter auf letzterem auf. Im ïbrigen gegen die typische Unterart ohne unterschiedliche Charaktere, auch in deren Größe.

Colombia.

50 c. H. wallacei colon Weym. $1775 \& 76$ „Clytia", Papilio clytia (non Linné 1758 !) P. Cramer, Pap. exot., v. 1 p. 103 t. 66 f. C, D; p. 152 (forma c.) | 1779 „P. c.", Goeze, Ent. Beytr., v.3 1 p. 11 ( wood), Gen. diurn. Lep., v.1 p. 103 (forma flarescens)। 1871 Heliconius c., W. F. Kirby, Cat. diurn. Lep., p. 140 (forma c.) 1874 H. c., Capronnier in: Ann. Soc. ent. Belgique, v. 17 p. 23 (forma c.) | 1877 H. c., A. G. Butler in: Tr. ent. Soc. London, p. 124 (forma c.) | 1885 H.c., O. Staudinger (\& Schatz), Exot. Schmett., v. 1 p. 76 (forma flarescens) $\mid 1890$ H. c., Weymer (\& Maassen), Lep. Reise Stübel. p. 76, 87 (forma c.) | 1790 Papilio antiocha (err., non P. antiochus Linné 1767!), J. F. W. Herbst, Naturs. Ins. Schmett., v. 4 p. 157 t. 75 f. 5, 6 (forma c.) | 1806-19 „Nereis caerulea sara“, Jac. Hübnè, Exot. Schmett., v. 1 t. 16 f. 1-4 (forma flavescens) | 1816 Sicyonia sara (err., non Papilio s. J. C. Fabricius 1793!), Jac. Hübner, Verz. Schmett., p. 13 (forma flarescens) | 1819 Heliconia s. + H. s. var., (Latreille \&) J. B. Godart in: Enc. méth., v. 9 p. 204 (forma flavescens); p. 224 (forma e.) | 1844 H. s., E. Doubleday, List. Lep. Brit. IIus.. v. 1 p. 54 (forma 
flavescens) | 1890 Heliconius clytia var. colon $+H$. clytia var. flavescens (O. Staudinger in MS.), Weymer in: Ent, Zeit. Stettin, v.51 p.291; p. 292 (forma flarescens) $\mid 1896$ H. clytia + H. c. var. sulphurea (err., non H. sulphureus Weymer 1893!), O. Staudinger in: D. ent. Z. Lep., v. 9 p. 295 (forma c.); p. 295 (forma flarescens) | 1900 H. hagar, W. F. Kirby, Exot. Schmett. Hiibner, p. 11 (forma Harescens) | $1900 \mathrm{H}$. clytia aberr. parvimaculata (O. Staudinger in MS.), Riffarth in: Berlin. ent. Z., v.45 p.207 (forma p.) 1901 H. c. + H. c. flavescens + H. c. p. + H. c. colon, Riffarth in: Borlin. ent. Z., v. 46 p. 135 (forma clytia); p. 135 (forma f.); p. 136 (forma p.); p. 136.

Forma principalis. Oherseite der Flügel schwarz, mit Blauglanz, der minchmal auf das Wurzelfeld beschränkt ist. Zwisehen Costalis und Subcostalis des Vorderflügels ein schmaler langer gelblicher Streif, im Discus zwei isolierte Fleckchen von weißer (typisch) oder gelber Farbe, von denen der eine mitten in der Zelle, der andere im proximalen Teil des hinteren Medianzwischenraumes liegt. Beim Original ferner ein kleiner weißer Punkt vor der Submediana, etwa in der Mitte des Aderzwischenraumes. Subapicalbinde wie bei Forma flavescens (S. 172), aber schmaler, auch am Ende etwas konkar gekrümmt. Unterseite matter, Discalflecke des Vorderflügels in der Regel noch mehr verkleinert, längs der Subcostalis und Mediana ein weiBlicher schmaler Streif. Im übrigen, auch der Hinterflügel, wie Forma clytia.

\section{Am unteren Amazonen-Strom (Santarem).}

Forma elytia (non Papilio c. L.). Grundfarbe der Flügel schwarz. Torderflïgel (Fig. 32) proximal mit starkem stahlblauem Glanz, der sich nach dem Apex und Distalrande hin allmählich verliert, ohne den einen oder anderen zu erreichen. Zwischen Costalis und Subcostalis schwach weißliche Bestäubung. im Discus ein schräg liegender, fast elliptischer, rein weißer Fleck, der vorn in der Mitte der Zelle der Subcostalis anliegt und dort etwas abgestumpft ist, proximal durch den Winkel des ersten Medianastes läuft, hinten flach abgerundet ist und auf dem hinteren Medianast distal etwas zugespitzt ist. Die ihn durchschneidende Adergabelung fein schwar\%. Distal eine schmale

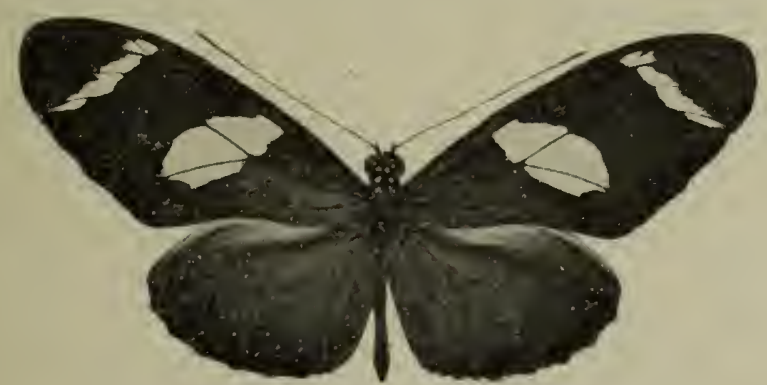

Fig. 32. H. wallacei colon, forma elytia: $\sigma^{7}\left(\begin{array}{l}1 / 1 \\ 1\end{array}\right)$.

schräge weiße Subapicalbinde, die hinter dem 3. Subcostalast beginnt, durch die Gabel des 4. und 5. Subcostalastes läuft und im vorderen Medianzwischenraum ziemlich dicht am Distalrande endet. - Hinterflügel mit grauem, am Vorderrande und proximal stïrker aufgebellten und schwach glänzendem rorderrandfeld bis zur Subcostalis. Costalis voll der Flügelwurzel aus bis etwa zur Mitte weißlich bestäubt. Hinter diesem Felde, von der Wurzel aus, reichlich stahlblau glänzende Bestäubung, die den Hinterrand freiläBt und sich gegen den Apex und Distalrand allmählich verliert. Fransen schwarz und weiß gescheckt, wie bei der Gruppe beschrieben. - Unterseite matter, graubraun. Vorderflügel am Torderrande mit kurzem rotem Wurzelstreif, 
die weißliche Bestäubung zwischen Costalis und Subcostalis deutlicher, zuweilen anch schmal bis hinter letztere ausgedehnt und in den Discalfleck übergehend, Zeichnung sonst wie oben, Hinter'andfeld hinter der Submediana hellgrau glänzend bis auf den distalen Teil. Hinterflügel mit weißem Fleck rorn an der Wurzel, einem roten Wurzelstreif hinter der Costalis und am Hinterrande, und 3 roten Wurzelflecken zwischen den iibrigen Adern, von denen der hintere, zwischen Hinterrandader und Submediana liegende, streifenartig verlängert ist. Distaler und apicaler Flügelteil ohne weißliche Streife in den Aderzwischenräumen. - Vorderflügelläng'e $38-46 \mathrm{~mm}$.

Niederländisch- und Französisch-Guayana, nördliches Brasilien (Pará, Amazonas), Peru.

Forma flavescens. Unterscheidet sich ron Forma clytia dadurch, daß die Zeichnungen des Vorderflïgels oben schwefelg'elb statt weiß sind.

Niederländisch-Guayana, Venezuela, nördliches Brasilien (Pará, Amazonas), Peru, Bolivia, Ecuador.

Forma parvimaculata. Unterscheidet sich von Forma flavescens dadurch, daß der Discalfleck durch die stärker schwarz bestäubten Adern zerteilt und in 2 oder 3 mehr oder weniger isolierte Flecke, die selbst außerdem oft verkleinert sind, aufgelöst ist. Sonst wie Forma clytia, zu der sie in allen Übergängen vorkommt, sie selbst steht zwischen dieser und der Hauptform.

Nördliches Brasilien (Obidos, Santarem, Faro, Yuruty).

\section{g. Coh. Sapphoformes}

Kopf schwarz, Stirn mit zwei kräftigen, teilweise von den Palpen verdeckten länglichen Flecken von weißer oder gelber Farbe. Punktierung auf Kopf und Halskragen wie bei der vorigen Gruppe, häufig weniger intensir. Augen schwarzbraun, hinten gelb oder weiß gesäumt. Palpen an der nach innen gerichteten Seite schwarz, außen meist vorwiegend weiß oder gelb bis auf die Trennungsstelle der Wurzel- und Mittelglieder und die Spitze, oder nur an der Wurzel und dem Mittelgliede weiß gefleckt. Antennen schwarzbraun, etwas länger als die Zelle. Körper schwarz bis schwarzbraun, Thorar vorn mit einer Reihe von vier meist nicht sehr deutlichen weißlichen oder gelben Punkten, sonst nur trübe gefleckt, oft mit blauem Glanz. Abdomen kürzer als die Breite des Hinterflüg'els, ventral mehr oder weniger gelb oder weiß, lateral mit je 3 oft undeutlichen oder verkürrzten Längsstreifen. Thorax ventral gelb oder weiß gefleckt, Vorderbeine an der Tibia reichlich weiß bestäubt. - Vorderflügel ziemlich breit, Apex breit abgerundet, Distalrand fast gerade, Hinterwinkel stumpf, Hinterrand etwa von der Länge des Distalrandes oder wenig länger, an der Flügelwurzel etwas geschweift. Hinterflïgel fast elliptisch, vorn etwas abgeflacht, Apex wenig oder gar nicht hervortretend, Hinterwinkel flach abgerundet. Vorderrandfeld beim on dunkel braungrau, schwach glänzend, beim o schwärzlich braun, proximal nnd dicht am Torderrande etwas aufgehellt und schwach glänzend. - Falter ron schwarzblauer Grundfarbe, mehr oder weniger glänzend, mit ein oder zwei Teißen oder gelben Querbinden des Vorderflügels und meist mit einer gleichgefürbten Binde am Distalrande des Hinterflügels oder nahe demselben.

3 Arten, von denen eine in 5 Unterarten zerfällt.

51. H. sapho (Drury)

ठ․ Grundfarbe der Flïgel schwarzbraun mit mehr oder weniger starkem stahlblauem, seltener blaugrünem Glanz, der sich im Vorderflügel auf den Wurzelteil beschränkt, im Hinterflügel, allmählich schwächer werdend, sich 
vor dem Distalrande oder der Sammbinde verliert. - Vorderflügel über die ganze Breite mit breiter weißer oder schwefelgelber, von den fein schwarzen Adern durehschnittener Querhinde, deren breiterer Teil distal ron der Zelle liegt, deren schmalerer jedoch noch dureh das \%ellende läuft. Der in der Zelle liegende Teil der Binde durch die von vorm am \%ellende keilförmig eindringende Grundfarbe zuweilen fleckartig ahgetrennt. Nanchmal verbreitert sich die Binde in distaler Richtung bis nahe zum Apex und bildet in binteren Verlauf am rorderen Medianast einen bis dicht zum Distallande vorspringenden Zahn. In anderen Fällen ist dieselbe längs geteilt, so daß zwei isolierte Bänder entstehen, ron denen das proximal gelegene durch den distalen Teil der Zelle bis zum Hinterwinkel, das distal gelegene schräg vom Vorderrande bis zum vorderen Medianast läuft und längs desselben analog der vorher erwähnten Zipfelbildung bis dicht zum Distalrande reicht. Unterseite matter, schwärzlich braun, glanzlos; am Vorderrande ein kurzer roter Trurzelstreif. Zeichnung sonst wie oben, indes, wenn dort gelb, hier weißlich gelb. Zuweilen entsendet der in der Zelle liegende Bindenteil oder Fleck von der proximalen vorderen Feke aus einen schmalen streifenartigen Ausläufer längs der Subcostalis bís zur Fliigelwurzel. - Hinterflügel einfarbig; eine schmale weiße Sammbinde nur am Apex fleckartig angedeutet, oder auch der Distalrand mit mehr oder weniger breitem weißem oder weißlichem Saum, der zuwoilen die Hälfte der Flügelbreite einnimmt. Unterseite mit meist kräftigen roten Wrurzelflecken, von denen der zwischen Costalis und Subcostalis gelegene Fleck meist wischartig verlängert ist, auch der vordere mitunter in eimen liurzen Streif längs des Vorderrandes ausläuft. - Fransen des Vorderflügels grau oder schwarz, stellenweise weiß unterbrochen, seltener vorherrschend weiß, die des Hinterflïgels weiß, nur manchmal an den Aderenden fein schwarz unterbrochen. $--o$. Vorderflïgel etwas breiter, Apex flacher abgerundet, sonst ohne Unterschiede gegen das $\sigma^{\pi}$ auBer deu charaliteristischen Geschlechtsmerkmalen.

Peru, Ecuador, Colombia, Mittel-Amerika; Jamaica?

Diese Art zerfällt in 5 Unterarten:

51 a. H. sapho sapho (Drury) 1782 Papilio s., Drury, Ill. nat. Hist., v.3 p. 54 t. 38 f. 4 ; Index | 1790 P. s., C. Stoll, Suppl. Pap. exot., p. 137 t. 30 f. 2,2 b | 1819 Heliconiu s., (Latreille \&) J. B. Godart in: Enc. méth., v.9 p. 203 | 1879 Heliconius s., Hopffer in: Ent. Zeit. Stettin, v. 40 p. $434 \mid 1790$ Papilio sappho (non Pallas 1771!), J. F. W. Herbst, Naturs. Ins. Schmett, v. 4 p. 159 t. 75 f. 7 1793 P. s., J. C. Fabricius, Ent. syst., v.3I p.165 | 1816 djantis s. (part.), Jac. Hübner, Verz. Schmett., p. $13 \mid 1844$ Heliconia s., E. Doubleday, List. Lep. Brit. Mus., v. 1 p.53| 1817 H. s., E. Doubleday (\& Westwood), Gen. diurn. Lep., v. 1 p. 102 | 1869 Heliconius s., A. G. Butler, Cat. diurn. Lep. Fabr., p. $120 \mid 1871$ H. s., W. F. Kirby, Cat. diurn. Lep., p. $140 \mid 1880$ ? H. s., Buchecker, Syst. Ent., Lep. t. 57 f. 22 | 1881 H. s., F. D. Godman \& O. Salvin in: Biol. Centr.-Amer., Lep.-Khop. v. 1 p. 157 t. 18 f. $5,6 \mid 1901$ H. s., Riffarth in: Berlin. ent. Z., v.46 p. 137.

Palpen außen bis auf die Spitze, Punktierung auf Stirn, Kopf und Hals weiß. Thorax fast zeichnungslos, licht blauschwar\% gläuzend. Abdomen rentral weiß, lateral mit Rudimenten weißlicher Längsstreife. - Vorderflügel von der TTurzel aus bis zu einer breiten weißen Querbinde stark glänzend blauschwarz, distal ron letzterer mit geringerem oder fast ohne Glanz, namentlich beim 0 ; Apex und Distalrand matt sehwärzlich. Die Querbinde liegt zum breiteren T'eil distal ron der Zelle, ist ron den Adern fein schwarz durehzogen und beginnt dort dicht linter dem selımal sehwarzen Torderrande. Der durch den distalen Teil der Zelle laufende schmalere T'eil begiunt dagegen erst hinter der Subcostalis und ist durch melur oder 
minder stark schwarze keilartige Bestäubung auf den Discocellulares fleckartig abgesondert, oder die Binde ist vorn in zwei ungleiche Zipfel gespalten. Sie richtet sich in ganz flachem Bogen in einer durchschnittlichen Breite ron etwa 4-5 mm gegen den Hinterwinkel. Die Besäumung dort und am Distalrande bleibt schmal schwarz. Die proximale Begrenzung ziemlich scharf, die distale etwas zerstäubt und leicht gezackt. - Hinterflügel mit leicht glänzendem dunkelgrauem Vorderrandfelde und matt schwarzem Hinterrande, sonst stark schwarzblau glänzend bis zu einer breiten weißen Saumbinde, welche spitz im Hinterwinkel oder kurz vor ihm beginnt, sich allmählich auf $5\left(\sigma^{T}\right)$ bis $7(q) \mathrm{mm}$ verbreitert und bis zum Vorderrande geht. Sie wird durch die Adern fein schwarz geschnitten, ist vor'n nicht scharf begrenzt und wird sowohl an den Adern, als in der Mitte zwischen denselben von der schwarzen Grundfarbe fein und kurz strahlig eingeschnitten. Zuweilen, namentlich beim $ᄋ$, ist sie stellenweise leicht schwärzlich überstäubt. Diese Bestäubung teilt sich den sonst rein weißen, nur an den Aderenden fein schwärzlich unterbrochenen Fransen mit. - Unterseite matt schwarzbraun. Vorderflügel mit kurzem rotem Wurzelstreif am Vorderrande, mit schmaler, leicht weißlicher, streifenartiger Bestäubung an der Subcostalis. Hinterflügel mit großen roten Wurzelflecken, von denen sich der vordere am Vorderrande und der hinter der Costalis gelegene kurz wischartig fortsetzt, sonst wie oben. - Vorderflügellänge $40-42 \mathrm{~mm}$.

Colombia (Hedellin, Antioquia), Ecuador, Peru; Jamaica?

51 b. H. sapho leuce (Doubl.) 1825 Ajantis sappho (err., non Papilio sapho Drury 1782 !), Jac. Hübner, Zutr. exot. Schmett., v. 3 p. 36 t. f. $565,566 \mid 1847$ Heliconia leuce, E. Doubleday (\& Westwood), Gen. diurn. Lep., v. 1 p. $102: 1871$ Heliconius $l$. , W. F. Kirby, Cat. diurn. Lep., p. 139 | 1880? H. l., Buchecker, Syst. Ent., Lep. t. 56 f. $18 \mid 1881$ H. l., F. D. Godman \& O. Salvin in: Biol. Centr.-Amer., Lep.-Rhop. v. 1 p. 156 t. 18 f. $3,4 \mid 1885$ H. l., O. Staudinger (\& Schatz), Exot. Schmett., v. 1 p. 77 | 1901 H. sappho l., Riffarth in: Berlin. ent. Z., v. 46 p. 138.

Vorderflügel (Fig. 33) proximal schwarzblau glänzend bis zu einer breiten weißen, von den Adern fein schwarz durchschnittenen Querbinde.

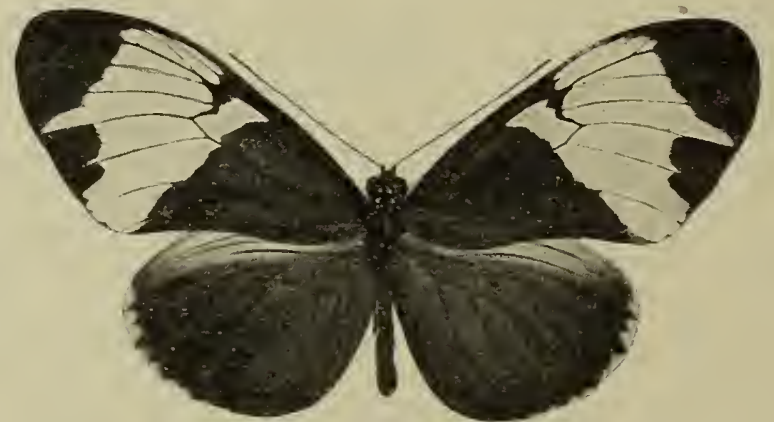

Fig. 33. H. sapho leuce, $\delta(1 / 1)$.

deren schmalerer Teil proximal, deren breiterer distal vom Zellende liegt. Torn ist dieselbe am Zellende etwas breiter keilartig eingeschnitten, als bei der typischen Unterart, so daß der in der Zelle liegende vordere, fleckartig abgesonderte Zipfel etwas schräger liegt. Dieser Teil beginnt hinter der Subcostalis, und die proximale Begrenzung der Binde zieht ron hier in gerader Linie schräg bis gegen den Hinterwinkel, während der jenseits der Zelle liegende Arm dicht hinter dem Vorderrande anfängt, und die distale Grenze 
rom Scheitel des dnrch den 3. Subcostalast gebildeten Winkels schrïg bis dicht zım Distalrande an den vorderen Medianist läuft, hinter demselben, einen spitzen Zipfel bildend, in proximaler Riclitung zuriicktritt und sich kı% doppelbogenförmig wiederum zmm Distalrande wendet. Sie endet dort kurz, rol dem Hinterwinkel, der Saum bleibt ganz schmal schwarz. Der distal vou der Binde liegende Apical- und Distalrandteil matt schwarz. - Hinterflügel bis auf das Torderrandfeld und den mattschwarzen Hinterrand schwarz, stahlblan glänzend. Der Glanz verliert sich allmählich gegen den Apex und Distalrand. Vou crsterem aus einige bogenartig an letrterem mehr oder weniger writ fortgesetzte weiße Saumfleckchen. die Anfïnge cincl Simmbinde. - Unterseite matter, Vorderflügel an der Subcostalis olne oder mit nur ganz geringer gelblicher Bestänbung. Sonst wie die typische Unterart, abcr die roten Wurzelflecke beim of ron geringerel Ausdehnung. - Vorderfliigellïnge $31-45 \mathrm{~mm}$.

Guatemala, Honduras, Costa Rica.

51 e. H. sapho eleusinus Staud. 1885 H. c., O. Staudinger (\& Sehatz), Exot. Schmett., v. 1 p. 76 t. $31 \mid 1901$ H. sappho e., Riflarth in: Berlin. ent. Z., v. 46 p. 138.

Der rorigen Unterart ähnlich, aher die weiße oder leicht gelbliche Binde des Vorderflügels etwas schmaler, der am vorderen Medianast distal vorspringende Zipfel kürzer, der hinter demselben einspringende Teil der Grundfarbe keilartig bis nahe zur hinteren Ecke vorgeschoben, so daß beinahe eine Längsspaltung der Binde eintritt. Auch der vorn eintretende schwarze Keil am Vorderrande verbreitert, wodurch der in der Zelle liegende Fleck fast dreieckig wird. Hinterflïgel ohne Apicalfleckchen, einfarbig schwarzblau bis auf die weißen Fransen. Unterseite wie die Oberseite, indes die vordere Ecke des weißen Zellfleckes schmal streifenartig längs der Subcostalis bis zur Flügelwurzel ausgeflossen; der distal vorspringende Zipfel der Binde erreicht beinahe den Distalrand. Sonst wie die typische Unterart. Vorderflügellänge etwa $37 \mathrm{~mm}$.

Colombia (Gebiet des Rio San Juan).

51d. H. sapho primularis Butl. 1869 H. p., A. G. Butler in: Ann. nat. Hist., ser. $4 v .3$ p. 18 t. 9 f. 2 | 1871 H. p., W. F. Kirby, Cat. diurn. Lep., p. $140 \mid 1901$ H. sappho p., Riffarth in: Berlin. ent. Z., v. 46 p. 139.

Auf dem Vorderflingel ist die bei der vorigen Unterart angedeutete Längsspaltung der Binde vollendet. Proximaler Teil schwarz mit starkem Blauglanz, sodann eine gelbe schräg liegende Binde im Discus und eine ebensolche Subapicalbinde. Erstere entspricht dem schmaleren 'Teil der Binde der rorigen Unterarten, beginnt wie dort hinter der Subcostalis im distalen 'Teil der' Zelle und zieht in schräger Richtung, die vordere Zellecke freilassend, bis zum Hinterwinkel. Der vordere Teil ist mehr oder weniger fleckartig an der Mediana abgetrennt, entweder schief rechteckig oder dreieckig; Binde hinter der Mediana etwa 5-6 mm breit, aber veränderlich, dehnt sich nach vorn manchmal bis in den proximalen Teil des mittleren Medianzwischenraumes aus nnd ist damn nur ganz schmal von der Subapicalbinde getrennt. Letztere schmaler, läuft, kurz hinter dem Vorderrande anfangend, durch den Raum zwiselren dem 2. und 3. Subcostalast schrïg zum rorderen Medianast, verschmälert sich ziemlich plötzlich und ist an letzterem in distaler Richtung spitz ansgez.ogen. - Hinterflïgel nur im proximalen Felde, welches distal etwa ron der Mitte des Hinterrandes bis zum letztell Drittel der Costalis begrenzt ist, blauschwarz, der übrige Teil des Flïgels wird rul 
einer breiten hellgelben Saumbinde eingenommen, welche ron den fein schwarzen Adern durchzogen und rorn ungewiß begrenzt ist. Zwischen den Adern springt strahlenartig schwärzliche Bestäubung von vorn her mehr oder weniger weit in die Binde ein. - Die gelben Zeichnungen auf der Unterseite weißlich. Grundfarbe matter, der Zellfleck längs der Subcostalis schmal streifenartig bis zur Flügelwurzel ausgeflossen. Begrenzung der Saumbinde des Hinterflügels noch ungewisser, der proximale Teil ersterer schwärzlich überstäubt. - Sonst wie die typische Unterart, aber kleiner nud die Fransen des Hinterflügels rein weiß. Torderflügellänge bis $40 \mathrm{~mm}$.

Ecuador (Guayaquil; Gebiet des Rio Napo; Paramba, in Höhe ron $3500 \mathrm{~m}$, im IIärz; Balzapamba, in Höhe von $800 \mathrm{~m}$; Zaruma; Chimbo).

51 e. H. sapho eleuchia (Hew.) 1854 Heliconia e., Hewitson. Exot. Butt., v. 1 Heliconia t. 3 f. 8 | 1871 Heliconius e., W. F. Kirby, Cat. diurn. Lep., p. 140 | 1879 H. e., Hopffer in: Ent. Zeit. Stettin, v. 40 p. $434 \mid 1880$ H. e., F. D. Godman \& O. Salvin in: Tr, ent. Soc. London, p. 122 | 1880 ? H. e., Buchecker, Syst. Ent., Lep. t. 56 f. 17 | 1885 H. e., O. Staudinger (\& Schatz), Exot. Schmett., v.1 p. 77 1890 H. e., Weymer (\& Maassen). Lep. Reise Stübel, p. 33 | 1901 H. sappho e., Riffarth in: Berlin. ent. Z., v. 46 p. 139.

Vorderflügel dem der vorigen Unterart ähnlich. Zwei gelbe, schräg liegende Querbinden, eine discale und eine subapicale. Erstere beginnt in der Zelle wie bei H. s. primularis (S. 175), bildet aber hinter der Mediana einen stumpfen Winkel dadurch, daß sie einen größeren proximalen dreieckigen Teil im Medianzwischenraum freiläßt und dafür nach rorn in den mittleren Medianzwischenraum eintritt. Der rordere, fleckartig in der Zelle abgesonderte Teil derselben hängt infolgedessen nur schmal am Crsprunge des mittleren Medianastes mit dem Hauptteil der Binde zusammen. Lage der Subapical. binde wie bei der genannten Unterart, der vor dem rorderen Medianast gebildete spitze Zipfel in der Regel länger, dicht am Distalrande endigend. - Hinterflügel mit breiter weißer Saumbinde: welche etwa ein Drittel der Flügelbreite einnimmt, von den fein schwarzen ddern durchzogen und rorn etwas schärfer begrenzt ist als bei der vorigen Unterart. Auch hier kleine ron rorn her in das Weiß einspringende zapfenartige Spitzen. - Unterseits der distal vorspringende Zipfel der Subapicalbinde des Vorderflügels am Distalrande breit abgestumpft. - Sonst wie die vorige Unterart auch in der Größe.

Colombia (Cerro Pelado, im November-Dezember; Gebiet des Rio Dagua; Sierra Nevada de Santa Marta; Cauca; Tal des oberen Magdalenen-Stroms).

52. H. hewitsoni Staud. 1875 H. $h$., O. Staudinger in: Verh. Ges. Wien, v. 25 Abh. p. $98 \mid 1877$ H. h., W. F. Kirby, Cat. diurn. Lep., Suppl. p. 722 | 1881 H. h., F. D. Godman \& O. Salrin in: Biol. Centr.-Amer., Lep.-Rhop. $v .1$ p. 158 | 1885 H. $h$, O. Staudinger (\& Schatz), Exot. Schmett., v. 1 p. $80 \mid 1901$ H. h., F. D. Godman \& O. Salvin in: Biol. Centr.-Amer., Lep.-Khop. v. 2 p. 669 | 1901 H. h., Riffarth in: Berlin. ent. Z., v. 46 p. $140 \mid 1875$ Heliconia h., Hewitson, Exot. Butt., v. 5 Heliconia t. 8 f. 27.

ठ․ Punktierung des Kopfes und sonstige Körperzeichnung gelb. Grundfarbe der Flügel schwarz. - Proximales Feld des Vorderflügels mit schwachem blauem Glanz, im Discus eine schräg liegende Querbinde und distal von derselben eine schmalere subapicale Binde, beide schwefelgelb. Erstere beginnt hinter der Subcostalis im distalen Teil der Zelle, läuft, die rordere Ecke der Zelle freilassend, schräg bis kurz an den Hinterwinkel und wird ron den fein schwarzen Adern geschnitten. Distal ist dieselbe hinter der Mediana und dem hinteren Medianast stufenartig abgesetzt, proximal im flachen Bogen ohne wesentliche Einschränkung begrenzt. Sie läuft dort durch den Scheitel des vorderen Winkels am Ursprunge des mittleren Medianastes und ist an 
ilırem Ende fast rechtwinklig abgeschnitten. Die Subapicalbinde heginnt dicht binter dem Vorderrande, durchsehneidet den Winkel an der Abzweigung des dritten Medianastes, verschmälert sich dann etwas und endet in kurzem Abstande vom Distalrande ohne Zipfelbildung vor dem vorderen Medianast. Unterseite matter, Grundfarbe schwarzbraun, Bindenzeichnung wie oben, weißlichgelb. Längs der Subcostalis ein schmaler gelber Streif rou der Flïgelwurzel bis zur discalen Querbinde. Hinterrandteil grau, ganz schwach glänzend, am Vorderrande ein kurzer roter Wurzelstreif. - Hinterflïgel schwarz mit dunkelgrauem Vorderrandfelde, schwärzlichem Hinterrande, proximal mit schwachem Blauglanz bis zu einer breiten gelben, von den fein schwarzen Adern durehzogenen Querbinde. Diese beginnt am distalen Teil des Hinterrandes in einer Breite von etwa $4-5 \mathrm{~mm}$ und läuft in flacher Krümmung, dem Distalrande folgend, bis nahe zum Vorderrande unweit des Apex. Vordere Begrenzung ziemlich scharf, hintere etwas zerstäubt, in jedem Aderzwischenraum kurz doppelt gekerbt. Unterseite mit kurzem Wurzelstreif am Vorderrande, einem etwa gleichen Streif zwischen Costalis und Subcostalis und drei roten Wurzelflecken hinter jenem. Das Gelb der Binde weißlich. - - 2 . Wie das $\sigma^{\top}$, meist etwas größer, sonst nur mit den Geschlechtsunterschieden. - - Fransen schwarz. Vorderflügellänge bis $40 \mathrm{~mm}$.

Chiriqui, Costa Rica.

53. H. congener Weym. 1890 H.c., Weymer (\& Maassen), Lep. Reise Stübel, p. 117 t. 2 f. 5 | 1896 II. apseudes var. paranapurae, O. Staudinger in: D. ent. Z. Lep., v. 9 p. $293 \mid 1901 H$. congenor, Riffarth in: Berlin. ent. Z., $v .46$ p. 141.

ণ. Kopfpunltierung und Körperzeichnung gelb. Grundfarbe der Flügel schwarz. - Vorderflügel proximal mit starkem Blauglanz und zwei sehräg liegenden Querbinden, discal und subapical. Erstere beginnt wie bei der vorigen Art hinter der Subcostalis im distalen Teil der Zelle mehr oder weniger schmal, verbreitert sich dann wesentlich und ist gegen den Hinterwinkel gerichtet. Ihre proximale Grenze zieht in ziernlich gerader Richtung schräg bis zum hinteren Medianast, dort ist sie abgesetzt und hierdurch der letrte hinter jener Ader liegende Bindenteil wesentlich verschmälert. Die distale Begrenzung läuft durch den vorderen Winkel am Ursprunge des mittleren Medianastes und sodann ziemlich steil gegen den hinteren Medianast, unweit des Distalrandes. woselbst die Binde spitz aber unscharf begrenzt endigt. Subapicalbinde schmaler, vorn durch die breit schwarz bestäubten Adern mehr oder weniger in Flecke aufgelöst. Sie beginnt dielit hinter dem Torderrande zwischen dem 2. und 3. Subcostalast, näher dem letzterell, und läuft schräg bis zum vorderen Medimast nahe an Distalrande. Der letzte Teil wesentlich verschmälert und nngewiß zerstäubt. Unterseite wie die Oberseite, aber matter, Grundfarbe braunschwarz, das Gelb der Binden weißlich, Subapicalbinde in ihrem distalen Verlauf deutlicher bis zum Ende, längs der Subcostalis von der Turzel bis zur Discalbinde schmale, streifenartige Bestäubung und am Vorderrande ein kurzer roter Wurzelstreif. Hinterrandfeld grau, schwach glänzend. - Hinterflïgel außer dem braungrauen Vorderrandfelde und schwärzlichen Hinterrande schwarz mit starkem stahlblauem Glanz, der sich gegen den Apex und Distalrand verliert. Unterseite matt schwarzbraun mit 5 roten Wurzelflecken, deren vordere zwei kurz wischartig ausgezogen sind. - - - . Außer den Geschlechtsunterschieden vom ơ nicht verschieden. - - Frausen des Vorderflügels schwärzlich, stellenweise 
undeutlich weißlich nnterbrochen, die des Hinterflügels weiß, an den Aderenden schwarz. Vorderflügellänge $32-44 \mathrm{~mm}$.

Ecuador (Baños; Jivaria del Pintuc, in Höhen von 900-1500 m, im Januar und Februar; Santa Inéz; Rosario, in Höhe von $1200 \mathrm{~m}$; Canelos, in Höhe von $700 \mathrm{~m}$. im Oktober bis Dezember); östliches Peru (Balsapuerto, in Höhe von $220 \mathrm{~m}$; Gebiet des Rio Paranapura).

\section{h. Coh. Antiochiformes}

Kopf schwarz, Flecke auf der Stirn, Punktierung oben und auf dem Halskragen wie bei der vorigen Grinpe, meist gelb. Augen dunkelbraun, hinten weißlich oder gelb gesäumt. Palpen entweder vorwiegend schwarz, außen an der Wurzel und am Mittelglied weiß gefleckt, oder gelb bis auf die Spitze. Antennen schwarzbraun, etwa von der Länge der Zelle bis zur vorderen Ecke oder um weniges länger. Körper wie bei der vorigen Gruppe mit oder ohne blauen Schimmer. Abdomen nicht über den Hinterflügel hinausieichend, ventral gelb, lateral mit 2 oder 3 meist undeutlichen oder nur stellenweise erhaltenen Längsstreifen. Thorax ventral gelb geffeckt, dicht an der Wurzel des Vorderflügels häufig ein karminroter Fleck. Vorderbeine an der Tibia und am Tarsus mehr oder weniger reichlich gelb bestäubt. - Vorderflügel schlank, wie bei den Wallaceiformes (S. 168), Hinterflügel ebenfalls wie dort abgeflacht elliptisch. Vorderrandfeld beim $\delta$ dunkelbraungrau, schwach glänzend, beim o schwärzlichbraun, proximal vorn etwas heller. - Falter von mehr oder weniger glänzender blauschwarzer Grundfarbe, Vorderflügel mit zwei schrägen, gelben oder weißen Querbinden, manchmal mit starkem Medianstreif, Hinterflügel meist einfarbig, selten mit gelber Querbinde. Auf der Unterseite rote Wurzelflecke, von denen der hinter der Costalis liegende meist lang streifenartig ausgezogen ist. Fransen weiß, nur an den Aderenden kurz schwarz unterbrochen, ein sicheres Unterscheidungsmerkmal von den Wallaceiformes, deren Vertreter den folgenden Formen zum Teil ähnlich sind.

3 Arten, die in 14 Unterarten zerfallen.

\section{H. antiochus (L.)}

ণ. Grundfarbe der Flïgel schwarz bis schwarzbraun mit tiefblanem Glanz von verschiedener Ausdehnung meist bis auf den Apex und Distalrand beider Flügel und den Vorderrandteil des Hinterflügels, in selteneren Fällen auf den Wurzelteil beschränkt. — Vorderflügel meist mit mehr oder weniger kräftigem gelbem Streif längs der Mediana und zwei schräg liegenden weißen oder gelben Querbinden, von denen die eine hinter dem Vorderrande am distalen Drittel der Zelle anfängt und bis nahe zum Ende der Submediana zieht, die zweite subapical gelegen ist, dicht hinter dem Vorderrande vor der Gabel des 4. und 5. Subcostalastes anfängt und nahe am Distalrande beim vorderen Medianast aufbört. Zuweilen ist erstere an der Mediana mehr oder minder breit unterbrochen. Unterseite mit langem gelbem Subcostalstreif und Medianstreif von der Flügelwurzel aus und kur'zem rotem Wrurzelstreif am Vorderrande; Grundfarbe matter, schwarzbraun, ohne Glanz, die oben gelben Binden weißlich; Hinterrandfeld grau glänzend hinter einem schmalen vorderen Streif mattschwarzer Bestäubung. - Hinterflügel einfarbig. selten mit einer gelben Querbinde vom vorderen Teil des Hinterrandes bis auf etwa $2 / 3$ der Flïgellänge. Unterseite matt schwarz bis schwarzbraun. mit 4 hochroten Wurzelflecken, von denen der vordere etwas über die Praecostalis ausfließt, der folgende hinter der Costalis zu einem mehr oder weniger langen 
Streif rerlängert ist. Dicht an der Flügelwurzel auf der Spaltung der Costalis und Mediana ein kleiner, aber deutlicher weißlicher Flock. - Fransen beider Flügel weiß, an den Aderenden schmal schwarz unterbrochen.

Guayana. Brasilien, Peru, Ecuador, Colombia, Venezucla.

Diese Art zerfällt in 5 Unterarten:

5ła. H. antiochus antiochus (L.) 1767 Papilio (H.) a., Linné, Syst. Nat., ed. 12 ห. 2 p. 1068 | 1869 H. a., A. G. Butler, Cat. diurn. Lep. Fubr., p. $120 \mid 1871$ H. a., IV. F. Kirby, Cat. diurn. Lep., p. 139 | 1901 H. a., Riffarth in: Berlin. ent. Z., v. 16 p. 142 1775 Papilio antiocha, J.C. Fabricius, Syst. Ent., p. $464 \mid 1775$ \& 76 „A.". P.a., P.Cramer, Pap. exot., v.1 p.62 t. 38 f. E, F; p. $151 \mid 1779$,P.a.", Goeze, Ent. Beytr., v.3I p. $106 \mid 1781$ P. a. (part.), J. C. Fabricius, Spec. Ins., v. 2 p. $32 \mid 1787$ P. a., J. O. Eabricius, Mant. Ins., $v .2$ p. $16 \mid 1793$ P.a., J. C. Fabricius, Ent. syst., v.31 p. $173 \mid 1816$ Ajantis a., Jac. Hübner, Verz. Schmett., p. 14 | 1819 Heliconia a., (Latreille \&) J. B. Godart in: Enc. méth., c. 9 p. $209 \mid 1844$ H. a., E. Doubleday, List. Lep. Brit. Mlus., v. 1 p. $53 \mid 1847$ H. a., E. Doubleday (\& Westwood), Gen. diurn. Lep., v. 1 p. $102 \mid 1865$ H. a., Prittwitz in: Ent. Zeit. Stettin, v. 26 p. 136 | 1862 Heliconius a., H. W. Bates in: Tr. Linn. Soc. London, v. 23 p. 556 | 1877 H. a., d. G. Butler in: T'r. ent. Soc. London, p. $124 \mid 1805$ H. anthioca, Latreille, Hist. Crust. Ins., v. 14 p. 108 | 188 o H. antiochus + H. a. var. aranea (non Papilio a. J. C. Fabricius 1793!), O. Staudinger (\& Schatz), Exot. Schmett., $x .1$ p. 75 (forma alba); p. 75 t. $31: 1896 \mathrm{H}$. antiochus $+H$. a. var. araneides, O. Staudinger in: D. ent. Z. Lep., v. 9 p. 294 (forma alba); p. $294 \mid 1900 \mathrm{H}$. antiochus aberi: alba (O. Staudinger in MS.), Riffarth in: Berlin. ent. Z., v. 45 p. 208 (forma alba) $\mid 1901 \mathrm{H}$. antiochus alba, Riffarth in: Berlin. ent. Z., $v .46$ p. 143 (forma alba).

Forma principalis. Palpen außen, Punlitierung der Stirn und auf dem Kopf sowie Torderbeine gelb oder gelblich. Grundfarbe der Flügel schwarz. - Vorderflügel blauglänzend bis nahe zum Apex und Distalrande. Von der Flïgelwurzel bis etwa zur Abzweigung des hinteren Medianastes beiderseits der Mediana streifenartig schmale gelbe Bestäubung, ferner zwei weiße schräg liegende Querbinden, eine discale, welche von der Mediana und distal vom hinteren Medianast, und eine subapicile, welche von dem vorderen

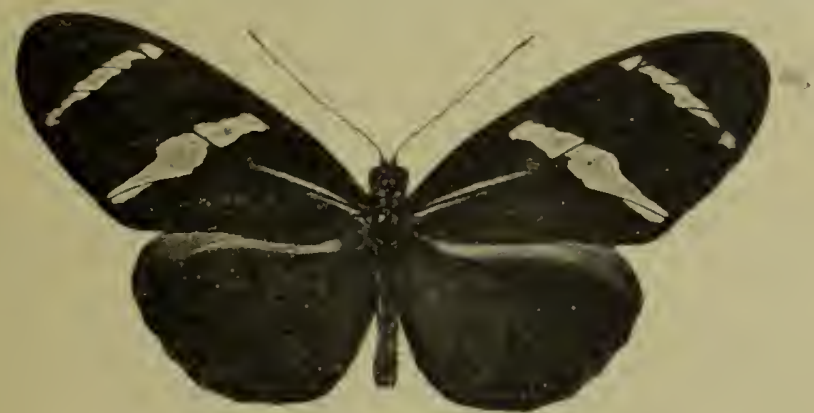

Fig. 34. H. antiochus antiochus, $\delta\left({ }^{1} / 2\right)$.

Geäder fein sehwarz durchschnitten wird. Erstere beginnt hinter der Subcostalis etwa in der Mitte der vorderen Zellwand und ist schräg gegen den Hinterwinkel gerichtet. Der in der Zelle liegende Teil ist beiderseits etwas eingeschnürt; am breitesten, etwa $4-5 \mathrm{~mm}$, ist sie hinter der Mediana und verschmälert sich dann ziemlich plötzlich auf $1-2 \mathrm{~mm}$. Im distalen Verlauf liegt sie dem hinteren Medianast an, iiberschreitet diesen zuletzt und endigt nahe dem Distalrande im Hinterwinkel. Die zweite, schmalere Binde beginnt kurz hinter dem Vorderrande, durchschneidet den Basiswinkel des 3. Subcostalastes und endet ror dem vorderen Medianast dicht am Distalrande. - Hinter- 
flügel schwarz mit Blauglanz bis nahe dem Distalrande, auBer im Costalfeld und an dem mattschwarzen Hinterrande. - Unterseite des Torderflügels mit schmalem gelbem Subcostalstreif von der $W$ urzel bis nahe zum Ende der Zelle und einem zweiten gelben Streif an der Mediana bis zur weißen Discalbinde, welcher sich an den Berïhrungsstellen, namentlich vor'n, das Gelb etras mitteilt. Hinterflügel zuweilen mit schwach gelb bestäubtem Torderrande, einem roten Fleck voru an der Wurzel bis zur Praecostalis, einem mitunter bis etwa zur Hälfte des Flügels reichenden, spitz auslaufenden roten Streif hinter der Costalis und zwei weiteren roten Wurzelflecken hinter demselben. Am Hinterrande nächst der Flügelwurzel manchmal wischartig gelbliche Bestäubung, die Anfäng'e einer Querbinde, wie sie bei H. a. salvinii (S. 181) auftritt. - Fransen beider Flügel weiß, an den Aderenden schmal schwärzlich unterbrochen. Vorderflügellänge etwa $41-42 \mathrm{~mm}$.

Niederländisch-Guayaua, Venezuela (Puerto Cabello, Valencia), Brasilien (Rio de Janeiro, Itaituba, Mlassauary, Mlanaos, Manicore, São Paulo de Olivença), Peru (Sarayacu, Iquitos).

Forma alba. Vorderflügel oben ohne gelben Streif an der Mediana. also nur mit den beiden weißen Querbinden der Hauptform, welcher sie im übrigen gleicht. Kommt in Übergängen mit melr oder weniger starker Andeutung dieses Streifes ror.

Neben der Hauptform.

54 b. H. antiochus zobeide Butl. 1869 H. z., A. G. Butler in: Ann. nat. Hist., ser. 4 v. 3 p. 18 t. 9 f. 3 | 1871 H. $z$., W. F. Kirby, Cat. diurn. Lep., p. 139 | 1877 H. z., A. G. Butler in: Tr. ent. Soc. London, p.124|1901 H. antiochus z., Riffarth in: Berlin. ent. Z., v, 46 p. $143 \mid 1880$ ? H. a. (err., non Papilio a. Linné 1767!), Buchecker, Syst. Ent.: Lep. t. 55 f. 13 | 1896 H. a. aberr. divisus, O. Staudinger in: D. ent. Z. Lep., v. 9 p. 294.

Von der typischen Unterart dadurch unterschieden, daß die Discalbinde schmaler, namentlich an dem hinteren Medianast sehr eng zusammengeschnürt und hinter der Mediana durch die blauschwarze Grundfarbe breit getrennt ist. Der vordere Teil wird hierdurch als Zellfleck in Gestalt eines Parallelogrammes abgetrennt. An der Subcostalis und Mediana selten Spuren gelber Bestäubung: Sonst wie die typische Unterart. In Übergängen rorkommend.

Neben der typischen Unterart.

54c. H. antiochus aranea (F.) 1793 Papilio aranea (non J. C. Fabricius 1793, Satyridae!), J. C. Fabricius, Ent. syst., v. 3 I p. $168 \mid 1814$ Heliconia a., E. Doubleday, List. Lep. Brit. Ilus., v. 1 p. 53 | 1817 H. a., E. Doubleday (\& Westwood), Gen. diurn. Lep., v. 1 p. 102 | 1869 Heliconius a., A. G. Butler, Cat. diurn. Lep. Fabr., p. $121 \mid 1880$ H. a., F. D. Godman \& O. Salvin in: Tr. ent. Soc.London, p. $122 \mid 1880$ ? H. a., Buchecker, Syst. Ent., Lep. t. 55 f. 12 ! 1890 H. a., Hahnel in: D. ent. Z. Lep., v.3 p. 153 | 1901 H. antiochus aranea, Riffarth in: Berlin. ent.Z., v.46 p.143 | 1819 Heliconia arane, (Latreille \&) J. B. Godart in: Enc. méth, v. 9 p. 209.

Durchschnittlich etwas größer als die typische Unterart, das $\circ$ meist mit geringem Blauglanz, die Querbinden schwefelgelb anstatt weiß, davon die discal liegende manchmal schmaler und an der Mediana eingekerbt oder unterbrochen. An der letzteren von der Flügelwurzel aus meist beiderseits reichliche, einen starken Streif bildende und an der Subcostalis manchmal spärlichere gelbe Bestäubung. Soust wie die typische Unterart. Fs kommen Kombinationen mit der typischen Unterart vor, bei denen die discale Querbinde gelb, die Subapicalbinde weiß ist. Vorderflügellänge bis $44 \mathrm{~mm}$.

Colombia, Venezuela (Puerto Cabello), Ecuador, am unteren Amazonen-Strom (Santarem), Niederländisch-Guayana. 
54d. H. antiochus ocannensis Stich.*) $1885 \mathrm{H}$. ocamms (non $\mathrm{H}$. ocamna Buchecker 1880 !), H. antiochus var.?, O. Staudinger (\& Schatz), Exot. Schmett., v. 1 p. 75 1901 H. a. o., Riffarth in: Berlin. ent. 'J., v. 46 p. 143.

Wie die vorige Unterart. aber die schwefelgelhe Querbinde in Discus wie bei $H$. a. zobeide rerschmälert und an der Mediana breit unterbrochen und, wie letztere, ohne oder mit nur geringen Spuren rou Streifenbildung längs der Subcostalis und Mediana. Hinterflügel unterseits ohne roten Streifenwisch hinter dem Vorderrande, sondern dort nur mit einem roten Wurzelfleck in der Größe des vorderen.

Nördliches Colombia (Ocaña).

54 e. H. antiochus salvinii Dewitz $18 \bar{i}$ H. s., H. Dewitz in: Mlt. Miinch. ent. Ver., $v .1$ p. 861901 H. antiochus s., Riffarth in: Berlin. ent. Z.: $x .46$ p. 143.

Torderflügel wie bei der typischen Lnterart. Binden weib, Medianstreif schwach entwickelt. Hinterflügel mit schwefelgelber Querbinde, welche vorn am Hinterrande etra $3 \cdot 5 \mathrm{~mm}$ breit begiunt und hinter der Subcostalis etwa 2-3 mm rom Apex entfernt spitz endet. Das Ende der Zelle liegt genau in der Mitte der Breite dieser Binde. Wurzelfleck am Torderrande unterseits etwas über die Praecostalis ausgeflossen. Sonst wie die typische Unterart.

Venezuela (Gebiet des Orinoco). - Vielleicht nur Aberration.

55. H. leucadia Bates

ठ. Punktierung des Kopfes und Körperzeichunng weiß. Cnter der Elügelwurzel jederseits des Thorax ein roter Achselfleck. Grundfarbe der Flügel schwarz. Beide Flïgel mit starkem, manchmal leicht grïnlich schimmerndem Blauglanz, der sich im Vorderflügel auf das Wurzelfeld heschränkt, im Hinterflügel unter allmählicher Verringerung auf etwa $\% / 3$ der Flügelfäiche auschehnt, den Distal- und Hinterrand schwarz lassend. - Torderflïgel im Discus mit einem großen gelben Fleck, der von der Mediana fein geschnitten wird und am hinteren Medianast endet. Der vordere Teil liegt distal in der Zelle ohne die Ecken anszufüllen, ist meist trapezförmig oder stumpf dreieckig gestaltet, der hintere Teil füllt den proximalen Teil des linteren Medianzwischenraumes bis auf einen kleinen Winkel am Crsprunge des hinteren Medianastes aus. Die hintere Begrenzung reicht etwa bis zul Hälfte des letzteren oder wenig weiter. Torn ist der Fleck schmaler und wird meist rom mittleren Medianast hegrenzt. dessen hinteren Winkel an der Mediana el ausfüllt. Der Gesamtfleck liegt schräg. ist breit und kurz bindenartig und wird an der Mediana meist jederseits etwas eingekerbt. Distal ron ihm eine kurze, etwa $3-4$ mu breite, gelhe subapicale Binde. Sie beginnt in dem Trinkel des 3. Subcostalistes und zieht in schräger Richtung bis zur hinteren Radialis, wo sie in etwa 4-5 mm weiter Entfernung vom Distalrande in ganzer Breite endet. Unterseite matter, an der Flügelwurzel ein kurzer roter Streif, längs der Subcostalis schwache gelbliche Bestäubung bis zum Disculfleck. Dieser und die Subapicalbinde weißlich gelb. Hinterrandfeld nächst einem schmalen Streif mattschwärzlicher Beschuppung graubraun, schwach glänzend. - Hinterflügel einfarbig mit braungramem Vorderrandfelde oder mit unscharf begrenzten, parweise in den Aderzwischenräumen stehenden reißen Saumflecken, die am Hinterwinkel und nächst ihm am gröBten sind und gegen den Apex abnehmen. Unterseite matter, an der Flügelwurzel ein roter wischartiger kurzer Costal- und Subcostalstreif, hinter

*) Nom. nov. 
letzterem zwei rote Wurzelflecke, Hinterrand proximal ebenfalls rot und ron ihm ausgeliend eine gebogene, dem Distalrande folgende rote Fleckenbinde, die sich allmählich verschmälert und in der Grundfarbe etwa im rorderen Medianzwischenıaum verläuft. Proximal hängen die Flecke fast zusammen, in der Mitte und distal sind sie an den Adern stärker getrennt. Randflecke, wenn oben vorhanden, stärker, mitunter ungewiß streifenartig ausgezogen. Fransen des Torderflügels schwarzbraun, die des Hinterflügels weiß, an den Aderenden schwarz unterbrochen.

Nördliches Brasilien, Peru, Ecuador, Boliria.

Diese Art zerfällt in 2 Unterarten:

55 a. H. leucadia Ieucadia Bates 1862 H. l., H. W. Bates in: Tr. Linn. Soc. London, v. 23 p. 556 | 1871 H. l., W. F. Kïirby, Cat. diurn. Lep., p. 140 | 1901 H. l., Riffarth in: Berlin. ent. Z., v. 46 p. $1 \pm 5$.

Discalfleck des Torderflügels meist zusammenhängend, nur durch die fein schwarze Mediana geschnitten, indes an derselben beiderseits mehr oder weniger eingekerbt. Hinterflügel mit weißer Randfleckenbinde, die aus paarweise in den Aderzwischenräumen stehenden länglichen Flecken ron ungewisser Begrenzung besteht, als Fortsetzung der weißen Stellen der Fransen in die Flügelfläche. In seltenen Fällen treten auf dem Hinterflügel hinter der Zelle kleine gelbliche Wischflecke als Anzeichen einer Bindenbildung auf. Vorderflügellänge bis $37 \mathrm{~mm}$.

Westliches Amazonas (São Paulo de Olivença), Peru (Yurimaguas), Bolivia (Tal des Rio Juntas).

55 b. H. leucadia pseudorhea Staud. 1896 H. p., O. Staudinger in: D. ent. Z. Lep., v. 9 p. $291 \mid 1901$ H. leucadia p.. Riffarth in: Berlin. ent. Z., v. 46 p. 145.

Von der typischen Unterart dadurch unterschieden, daß die weißen Saumflecke des Hinterflïgels fenlen; auch sind die roten Zeichnungen auf dessen Unterseite manchmal weniger stark ausgeprägt, die rote Fleckenbinde endet dann schon im mittleren Medianzwischemraum. Größe wie bei der typischen Unterart.

Nördliches Brasilien (Thomar, São Paulo de Olivença), Ecuador (Archidona in Höhe ron $640 \mathrm{~m}$, im Februar; Sarayacu), Peru (Pebas, Yurimaguas, Tal des Rio Ucayali), Bolivia (Tal des Rio Juntas).

56. H. sara (F.)

07. Punktierung auf Stirn und Kopf gelb oder weiß, Körperzeichnung gelb. Nahe der Wurzel des Vorderflügels lateral am Thorax ein rotes Fleckchen. Palpen außen bis auf die Spitze vorwiegend gelb, seltener weißlich, innen schwarz. Grundfarbe der Flügel schwarz, proximal mit starkem Blauglanz, der sich auf dem Hinterflügel bis etwa zur Flügelmitte erstreckt und allmählich in mattes Schwarz übergeht. Das Vorderrandfeld bleibt grau. Hinterrand matt schwarz. - Vorderflügel mit einer gelben, selten weißen. scbräg liegenden, von der Mediana und dem hinteren Medianast schmarz geschnittenen Querbinde, deren vorderer Teil hinter der Subcostalis im distalen Felde der Zelle liegt, ohne die Ecken an den Discocellulares auszufüllen, und die sich schrïg gegen den Hinterwinkel wendet, ohne ihn zu berühren. Zuweilen ist die Trennung an der Mediana beträchtlicher, so daß zwei mehr oder weniger große Flecke entstehen, deren rorderer zumeilen ganz rudimentär ist, oder die Binde ist vorn und binten verkürzt, fleckartig. Nahe dem Apex eine zweite, sehr schräg liegende schmalere gelbe, selten weiße Binde, welche von den Adern mehr oder weniger zerschnitton ist. Sie 
beginut dicht linter dem Vorderrunde, geht durch den Winkel an dor Abzweigung des 3. Subcostalastes und endet in der Mitte des vorderen Hedianzwischemraumes dicht am Iistalrande. Cnterseite der Oberseite cntsprechend, aber matter. An der Flügelwurzel längs des Vorderrandes ein kurzer, häufig nur als Rudiment vorhandener roter Wisch. Iängs der Subcostalis von der Trurzel bis zur Discalbinde schmale gelbliche Bestäubung, die indes fehlen oder unvollkommen auftreten kaun. - Hinterflügel meist olne Zeichnung. seltener verbreitern sich die weißen Stellen der an den Aderu suhwarz unterbrochenen Fransen, so daß ungewiß bestäubte weißliche Randfleckchen entstehen, oder aber es treten schwefelgelbe, hindenartig angeordnete gröBere Saumflecke auf. Unterseite mit roten Wurzelflecken, je einem nächst dem dem Vorderrande, in der Zelle, in jedem Ader\%wischenram und am Hinterlande. sowie mit einem weiteren gleichen Fleck in der proximalen Hälfte des letzteren; dieser setzt sich zuweilen in einer quer über den Fln̈gel laufenden, geschwungenen Reihe weiterer ebensolcher Flecke (1-4) fort. An der Wurzel der Mediana auf dieser Ader bei der Abzweigung der Subcostalis ein gelbliches Fleckchen. - - $\supsetneq$. Wie das $\sigma^{\pi}$, abgesenen von den charaliteristischen Geschlechtsunterschieden.

Colombia, Mittel-Amerika, Venezuela, Guayana, Brasilien, Peru, Ecuador.

Diese Art zerfällt in 7 Unterarten:

56 a. H. sara sara (F.) 1793 Papilio s., J. C. Fabricius, Ent. syst, v. 3 r p. 167 1820 Laparus s., Billberg, Enum. Ins., p. 77 | 1869 Heliconius s., A. G. Butler, Cat. diurn. Lep. Fabr., p. 121 | 1876 H. s., Distant in: Tr. ent. Soc. London, p. XILI | 1900 H. s., Riffarth in: Berlin. ent. Z., v. 45 p. 208 | $1864 H$. magdalenu, H. W. Bates in: Ent. monthly Jlag., $v .1$ p. $57 \mid 1881$ H. m., F. D. Godman \& O. Salvin in: Biol. Centr.-Amer., Lep.-Rhop. $v .1$ p. 159 t. 18 f. 13 | 1901 H. m., F. D. Godman \& O. Salvin in: Biol. Centr.-Amer., Lep.-Rhop. $v .2$ p. $669 \mid 1871$ H. rhea var. m. + H. sara, W. F. Kirby; Cat. diurn. Lep., p. $140 ;$ p. 647 | 1874 H. r. (err., non Papilio r. P. Cramer 1775!), A. G. Butler \& Herb. Druce in: P. zool. Soc. London, p. 351 1890 H. apsendes (err., non Sicyonia a. Jac. Hübner 1818!), Weymer (\& Maassen). Lep. Reise Stübel, p. 17 | 1896 H. a. var. magdalena + H. a. var. m. aberv. albimaculata, O. Staudinger in: D. ent. Z. Lep., v.9 p. 292; p.292 (forma albimaculata) | 1901 H. sara + H. s. albimaculata, Riffarth in: Berlin. ent. Z., $v .46$ p. 146 ; p. 146 (forma a.).

Forma principalis. Palpen außen gelblich, Stirnflecke und die vorderen Kopfpunkte weiß, die übrige Körperzeichunng gelb. - Discalbinde des Torderflïgels (Fig.35) in ihrem rorderen Teil, der schräg rechteckig in der Zelle liegt,

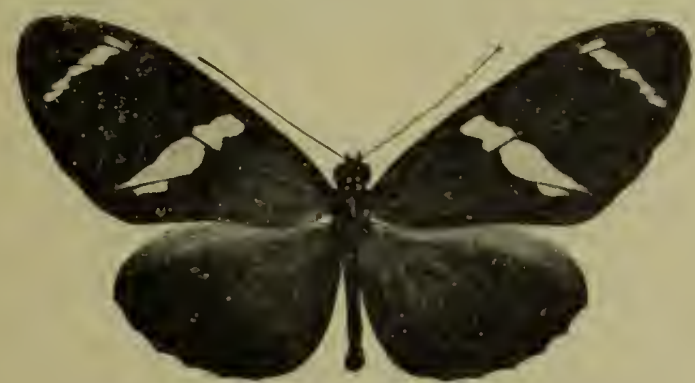

Fig. 35. H. sara sara, forma principalis, $\delta^{2}(i 1)$.

beiderseits etwas eingeschnürt, an der Mediana häıfig auch auf beiden Seiten eingekerbt. Die Binde richtet sich schräg gegen den Hinterwinkel. ohne den Scheitel des vorderen Basiswinkels am hinteren Medianast zu berühren, ist dort stufenartig abgesetzt, üherschreitet distal letzteren etwas und erdet spitz, 
hinten ungewiß zerstäubt, auf demselben in kurzem Abstande vom Distalrande. Snbapicalbinde bedeutend schmaler, von den Adern fein schwarz geschnitten, knrz hinter dem Vorderrande an der Wurzel des 3. Subcostalastes beginnend, schräg bis in den vorderen Medianzwischenraum laufend und in knrzem Abstande vom Distalrande endigend; die distale Begrenzung ungewisser zerstäubt, die proximale ziemlich scharf. - Hinterflïgel oben zeichnungslos. Unterseite schwarzbraun, roter Wurzelstreif am Vorderrande des Vorderffügels kaum bemerkbar, längs der Subcostalis schmale gelbliche Bestäubung bis zur Discalbinde. Hinterflügel mit roten, bei der Art näher gekennzeichneten Wurzelflecken und einem einzelnen Fleck im vorderen Teil des Hinterrandes, ohne Fleckenbinde. - Fransen des Vorderflügels schwarzbraun, stellenweise weißlich unterbrochen, die des Hinterflïgels weiß, nur an den Aderenden schwarz. Vordertlügellänge bis $37 \mathrm{~mm}$.

Costa Rica, Panama (Chiriqui), Colombia, Venezuela (Puerto Cabello, Merida),

Forma albimaculata. Binden des Vorderflügels weiß statt gelb. Sonst wie die Hauptform.

Colombia.

56 b. H. sara apseudes (Hb.) 1816 Sicyonia a. (nom. nud.), Jac. Hübner, Verz. Schmett., p. 13 | 1818 S. a., Jac. Hübner, Zutr. exot. Schmett., v.1 p. 25 t. f. 141,142 | 1847 Heliconia a., E. Doubleday (\& Westwood), Gen. diurn. Lep., v. 1 p. 103 | 1871 Heliconius a., W. F. Kirby, Cat. diurn. Jep., p. $140 \mid 1885$ H. a., O. Staudinger (\& Schatz), Exot. Schmett., v. 1 p. 75 t. $31 \mid 1886$ H. a., G. W. Yüller in: Zool. Jahrb., v. 1 p. 428 | 1890 H. a., Seitz in: Ent. Zeit. Stettin, v. 51 p. 93 | 1890 H. a., Weymer (\& Maassen), Lep. Reise Stübel, p. $90 \mid 1896$ H. a., O. Staudinger in: D. ent. Z. Lep., v. 9 p. $292 \mid 1896$ Heliconias a., Bönninghausen in: Verh. Ver. Hamburg, v. 9 p. $32 \mid 1835$ Heliconia sara (err., non Papilio s. J. C. Fabricius 1793 !), H. Lucas, Hist. Lép. exot., p. 93 t. $49 \mid 1900$ Heliconius s. aberr. albula, Riffarth in: Berlin. ent. Z., v.45 p. 208 (forma a.) | $1901 \mathrm{H}$. s. apseudes + H. s. albula, Riffarth in: Berlin. ent. Z., v.46 p. 146 ; p. 146 (forma albula).

Forma principalis. Discalbinde des Vorderflügels breiter und voller als bei der typischen Unterart, rorn in der Zelle zuweilen etwas verschmälert, an der Mediana wenig oder gar nicht eingeschnitten und anch hinter dem hinteren Medianast oft weniger plötzlich abgesetzt. Proximal berührt dieselbe fast den Scheitel des vorderen Basiswinkels an letzterem. Die normale Gestalt im ganzen ist annäher"nd die eines verschobenen Rechteckes. Hinterflügel unten in der Regel mit einer von dem Hinterrandfleck ausgehenden, ziemlich geraden oder nur leicht geschwungenen Reihe von 4 oder 5, selten weniger Flecken von roter Farbe. Fransen schmaler, nndeutlicher weiß. Sonst wie die typische Unterart.

Eier werden in großer Anzahl an den Spitzen der Zweige einer Passiflora-Art abgelegt. - Raupe zuerst gelb mit schwarzen kurzen Borsten, später mit längeren Dornen. Körper vorn mit schwarzem Anfluge. Kopf braun, später glänzend schwarz mit zwei Hörnern. - Puppe (G. W. Mäller l. c. t. 15 f. 2) hängend, schlank, mit weit rorgezogener Flïgelscheide, dorsal entsprechend eingedrückt, dornig und höckerig, mit zwei wellig gerandeten stark divergierenden Hörnern und drei rein seitlich bewegbaren Segmentverbindungen; die einzelnen Antennenglieder in Dornen ausgezogen. Grundfarbe weiß mit zerstreuten schwarzen Punkten und silberglänzenden Flecken; Dornen, Hörner und Flügeladern schwarz. [Nach G. W. Müller.]

Brasilien (Santa Catharina, São Paulo, Espirito Santo, Pernambuco).

Forma albula. Binden des Vorderflügels weiß mit schwach rötlicher Bestäubung. Sonst wie die Hauptform.

Venezuela (La Guayra). 
$56 \mathrm{c} . \mathrm{H}$. sara brevimaculatus Staud. $1896 \mathrm{H}$. apscudes aberr. brevimaculata, 0. Staudinger in: D. ent. \%. Lep., v.9 p. $292 \mid 1901$ H. sara b., Riffarth in: Berlin. ent. Z., v. 46 p. 147.

Discalbinde des Vorderflïgels verschmälert und verkürzt, durch breitere Unterbrechung an der Mediana in zwei mehr oder weniger isolierte eirunde Flecke anfgelöst, deren vorderer, in der Zelle liegender, nanchmal verkümmert ist. Hinter dem hinteren Medianast nm selten Spuren gelber Bestäubung. Der diesem Ast anliegende hintere Bindenfleck reicht distal nicht oder nur wenig über die Mitte der Ader. Die Subapicalbinde ebenfalls meist verkürzt, an der hinteren Radialis endigend. Unterseite des Hinterflügels entweder mit der roten Fleckenreihe oder nur einem einzelnen Fleck am Hinterrande. Sonst wie die typische Unterart, zu der Übergänge in allen Stadien rorkommen.

Vielleicht nur Aberration der typischen Unterart.

Colombia (Gebiet des Rio Dagua).

56 d. H. sara sprucei Bates 1864 H. sprucei, H. W. Bates in: Ent. monthly IIag., v. 1. p. $57 \mid 1871$ H. s., W. F. Kirby, Cat. dinrn. Lep.. p. 140 | 1901 H. sara sprucei, Riffarth in: Berlin. ent. Z., v.46 p. $147 \mid 1901 \mathrm{H}$. sprucci, Therese von Bayern \& Rebel in: Berlin. ent. Z.. v. 46 p. 252,297 t. 5 f. 11.

Wurzelfeld des Vorderflügels und der gröBere Teil des Hinterflïgels mit sehr starkem, tief grünblauem Glanz. Discalbinde sehr schmal, verschieden gebildet, in der Regel entweder wie bei der typischen Cnterart, aber schmaler hinter der Snbcostalis anfangend und dann im vorderen Teil beiderseits eingeschnürt, oder erst in der Mitte der Zellenbreite oder hinter derselben dreicckig einsetzend, an der schwarzen Mediana beiderseits mehr oder weniger stark eingekerbt, seltener ïber den hinteren Medianast hinausreichend, manchmal aber läng's desselben in stumpfen Winkel und in mehr oder weniger ungewisser Zerstäubung gegen den Distalrand ausgeflossen. Subapicalbinde wie bei der typischen Unterart, aber schmaler. Beide Binden untell fast weiß. Hinterflügel unten mit sebr lebhaft gefärbten Wurzelflecken, ohne Fleckenreibe, nur mit dem einzelnen roten Fleck am vorderen Teil des Hinterrandes. Fransen des Vorderflügels weiß, an den Adern schwarz unterbrochen, die des Hinterflügels meist breit rein weiß; in manchen Fällen verbreitert sich das Weiß auf dem Distalrande, so daß in den Aderzwischenränmen mugewiß begrenzte, parweise beieinander stehende Saumflecke entstehen, die fast den Eindruck einer weißen, schmal schwarz unterbrochenen Sammbinde machen. Torderflïgellänge $30-36 \mathrm{~mm}$.

Westliches Ecuador (Balzapamba, in Höhe von $800 \mathrm{~m}$, im Nai und Juni; Palmar, in Höhe ron $100 \mathrm{~m}$; Chimborazo, in Höhen rou $900-1000 \mathrm{~m}$ ).

56 e. H. sara thamar (Hb.) $1775 \& 76$, ,Rhca“, Papilio rhea (non Poda 1761 !), P. Cramer, Pap. exot., v.1 p. 85 t. 54 f. C, D; p. $154 \mid 1779$ „P.r.", Goeze, Ent. Beytr., v.3 I p.117 | 1781 P.r., J. C. Fabrieius, Spec. Ins., v.1 p.29| 1862 Heliconius r., H. W. Bates in: Tr. Linn. Soe. London, v. 23 p. $556 \mid 1869$ H. r., A. G. Butler, Cat. diurn. Lep. Fabr., p. $121 \mid 1871$ H. r., W. F. Kirby, Cat. diurn. Lep., p. $140 \mid 1877$ H. r., A. G. Butler in: Tr. ent. Soc. London, p. $124 \mid 1879 H$. $r$, Hopffer in: Ent. Zeit. Stettin, v. 40 p.433 | 1885 H.r., O. Staudinger (\& Schatz), Exot. Schmett., v. 1 p. $76 \mid 1890$ H. r., Weymer

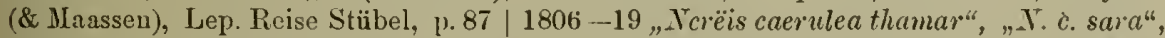
Jac. Hübner, Exot. Schmett., $v .1$ Index; t. [15] | 1816 Sicyonia t., Jac. Hübner, Verz. Schmett., p. 13 | 1900 Heliconius t., W. F. Kirby, Exot. Schmett. Hübner, p. 11 | 1899 $H$. sara aberr. albinea, Riffarth in: Berlin. ent. Z., v. 43 p. 408 (forma a.) | $1901 H . s$. rhea + H. s. a., Riffarth in: Berlin. ent. Z., v. 46 p. 147 ; p. 148 (forma a.). 
Forma principalis. Discalbinde des Vorderflügels fleckartig verbreitert, von fast elliptischer Gestalt, vorn an der Subcostalis etwas abgestumpft und hinten etwas voller gerundet, so daß sie in flachem Bogen etwas über den hinteren Medianast reicht. Der Scheitel des vorderen Basiswinkels des letzteren wird fast ausgefüllt, und der hintere Teil der Binde ist nur wenig abgesetzt. Bisweilen ist diese distal im hinteren Medianzwischenraum etwas eingedrückt. Subapicalbinde kürzer und breiter als bei der typischen Unterart, anch etwas steiler stehend. Unterseite des Hinterflïgels nicht immer mit vollständiger Fleckenreihe, statt dessen häufig nur mit 2 oder 3 Punliten nebeneimander am Hinterrande. Zwischen dem ersten und dem vor ihm liegenden Wurzelfleck manchmal ein gelbes Wischfleckchen. Sonst wie die typische Unterart. Vorderflügellänge bis $37 \mathrm{~mm}$.

Nördliches Brasilien (Tal des Rio Tocantin, Itaituba, Santarem, Villa Bella, Maues, São Paulo de Olivença, Gebiet des Rio Madeira), Niederländisch- und FranzösischGnayana, Ecuador (Archidona, im Januar und Februar), Peru (Nauta, Tal des Rio Ueayali, Pozuzo), Colombia.

Forma albinea. Wie die Hauptform, aber die Zeichnungen des Vorderflügels weiß statt gelb.

Niederländisch-Guayana.

56f. H. sara veraepacis Bates $186+H . v$., H. W. Bates in: Ent. monthly Mag., v. 1 p. $57 \mid 1871$ H. rhea var. v., W. F. Kirby, Cat. diurn. Lep., p. $140 \mid 1881$ \& 1901 H. v., F. D. Godman \& O. Salvin in: Biol. Centr.-Amer., Lep.-Rhop. v. 1 p. 159 t. 18 f. $12 ; v .2$ p. $669 \mid 1901$ H. sara v., Riffarth in: Berlin. ent. Z., v. 16 p. 148.

Discalbinde des Vorderflïgels weißlich, in der Mitte gelb, breit und eckig, der vordere, in der Zelle liegende Teil fast quadratisch, vorderer Basiswiukel des mittleren Medianastes gelb ausgefüllt. Die Binde läuft auf dem hinteren Medianast nahe dem Distalraude in eine verlosehen begrenzte stumpfe Rundung aus und hat nach hinten noch einen Spitzenansatz. Subapicalbinde weißlich, schmal, an den Adern unterbrochen, etwas konver gekrüimmt.

Guatemala (Vera-Paz in Höhe von etwa $300 \mathrm{~m}$; Tal des Polochic).

56 g. H. sara theudela (Hew.) 1874 Heliconia t., Hewitson in: Ent. monthly Hag., v. 10 p. 224 | 1877 Heliconius t., IV. F. Kirby, Cat. diurn. Lep., Suppl. p. 722 | $1881 \& 1901$ H. $t$., F. D. Godman \& O. Salvin in: Biol. Centr.-Amer., Lep.-Rhop. v. 1 p. 157 t. 18 f. 9,$10 ; v .2$ p. $669 \mid 1901$ H. sara t., Riffarth in: Berlin. ent. Z., v. 46 p. 148.

Discalbinde intensiv schwefelgelb, fast wie bei der typischen Unterart aber etwas breiter und längs des hinteren Medianastes bis dicht an den Distalrand ausgedehnt, namentlich auf der Unterseite. Gewöhnlich ohne beträchtliche seitliche Finschnürungen, manchmal indes in ihrem vorderen Teil in der Zelle eingeschränkt, an der Mediana eingekerbt und hinten in ungervisser Bestäubung zuweilen zipfelartig bis zur Submediana ausgeflossen. Subapicalbinde von derselben Farbe wie bei der typischen Unterart. Hinterflügel mit einer Saumbinde von gelben Flecken, die schmal an Hinterwinkel und Hinterrande beginnen, sich allmählich verbreitern, gegen den Apex wiederum abnehmen und undeutlicher werden. Dieselben stehen parweise, nur durch einen schmalen Schattenstrich getrennt, in den Aderzwischenräumen. divergieren vorn in ungewisser Bestäubung und sind an den Aderu schwarz getrennt. Hinterflügelunterseite gewöhnlich ohne mittlere rote Fleckenbinde, sondern meist nur mit einem einzelnen Punkt am Hinterrande. Die Saumbinde 
breiter aber weniger intensiv. Sonst wie die typische Lnterart. auch in deren Größe.

Venezuela (Merida, Puerto Cabello), Colombia (Medellin), Panama (Chiriqui).

\section{i. Coh. Eratoformes}

Kopf schwarz, Augen dunkelbraun, hinten weißlich oder gelb gesiumt. Stirn mit zwei gelben, meist etwas länglichen Flecken, die teilweise von deu Palpen verdeckt sind. Kopf oben mit 4 paarweise zwischen den Angen stehenden gelben Punkten, auf den Augen je noch ein gelbes Pünktchen. Palpen schwarz, an der nach außen gerichteten Seite mehr oder weniger gelh, hïufig bis auf die Spitze. Antennen schwarzbraun, manchnal distal an der Keule brännlich aufgehellt, an der Wurzel unterseits wenig weib, länger als die Zelle. Körper schwarzbraun, Halskragen mit vier in einer Reilıe stehenden gelben Flecken, Thorax mit jederseits zwei, häufig obsoleten gelbell Flecken. hinten meist gelb gesüumt. Abdomen nicht oder nur wenig ïher den Hinterflügel hinausreichend, ventral mehr oder weniger gelb, lateral unten mit mehr oder weniger deutlich erkenubarer Doppellinie, dariiber mit einer an den Segmenten durch zuweilen undeutliche Querstreifchen unterbrochenen gelben Fleckenlinie, die selbst auch oft rulimentär ist. Thorax ventral gelb gefleckt, jederseits nächst der Flügelwurzel ein häıfig undeutlicher oder kaum bemerkbarer roter Fleck, der, wenn vorhanden, ein untrïgliches Merkmal der Zugehörigkeit der Art zur Abteilung der Opisorhypari darstellt. Vorderbeine, vamentliclı an der Tibia, stark, die übrigen Beine clort ebenfalls ganz oder zum Teil gelblich bestäubt. - Vorderflügel schlank, mit schwach gekrümmtem Vorderrande und abgerundetem Apex. Distalrand fast gerade, Hinterwinkel stumpf, Hinterrand schwach S-förmig gebogen, etwas länger als der Distalrand. Hinterflügel elliptisch, roru abgeflacht. Apex beim $0^{T}$ etwas merklicher hervortretend als bein $q$, Distalrand leicht gewellt. Hinterwinkel abgerundet. Vorderrandfeld beim o dunkelgrau, etwas gelblich, beim $q$ einen Ton heller als die Grundfarbe. - Falter von schwarzbrauner bis schwarzer, mitunter blauglänzender Grundfarbe. in seltenen Fällen ohne hemerkliche Zeichnung, meist mit lebhaften roten oder gelben Binden wenigstens auf einem beider Flügel, häufig beide Farben in verschiedenen Zeichnungsanlagen nebeneinander oder in einer Anlage kombiniert, auch mit roter W' Wrzelbestäubung oder gelbem Medianstreif des Vorderflingels und roten Strahlen auf dem Hinterflügel.

Die Vertreter dieser Gruppe sind ebenso unbeständig und die Formen so reichhaltig wie die der Melpomeneformes (S. 109) und unterliegen leicht der Verwechselung mit den dorthin gehörigen Arten.

9 sichere Arten, von denen 5 in 25 Unterarten zerfallen, und 1 unsichere Art.

57. H. himera (Hew.) 1867 Heliconia h., Hewitson. Exot. Butt., $v .4$ Heliconia t. 5 f. 16 | 1871 Heliconius h., W. F. Kirby, Cat. diurn. Lep., p. 141 | 1901 H. h., Riffarth in: Berlin. ent. Z., v. 46 p. 150.

0. Palpen schwarz, an der nach außen gekehrten Seite gelh bis auf das Endglied und einem 'Trennungsstreif zwischen Wurzel- und Mittelglied. Punktierung auf Stirn und Kopf, sowie Zeichnung des Leihes gelb. Grundfarbe der Flügel schwarzbritun. - Vordertlügel im Discus mit einer schräg liegenden gelben Querbinde, die vor"l in Gestalt von zwei durch die Submediana abgeschnittenen Fleckehen an der Wurzel des 1. Subcostalastes beginnt. den distalen Teil der Zelle vollständig ausfüllt und in geringem Maße sich bis jenseits des Zellschlusses ausdehnt; hinter der Mediana ist 
dieselbe in ihrer proximalen Begrenzing etwas abgesetzt und läuft beiderseits in paralleler schräger Richtung bis zum hinteren Medianast, den sie nur in geringen Spuren überschreitet und auf dem sie distal mit abgestumpfter Spitze in der Nähe des Distalrandes endet. Distal wird der proximale Teil des mittleren Medianzwischenraumes ansgefüllt. Die das Gelb durchschneidenden Adern fein schwarz. Cnterseite matter, die Binde fast weiB, sonstige Zeichnung fehlt. - Hinterflügel mit breiter, unscharf begrenzter, roter Querbinde, welche vom Hinterrande in der Nähe der Flügelwurzel schräg nach vorn bis nahe zur Subcostalis zieht. Vor derselben bleibt nächst dem grauen Vorderrandfelde nur ein schmaler kurzer keilförmiger Streif der Grundfarbe, die bintere Begrenzung schneidet hinter der Zelle ab, so daß diese zum größten Teil in der Binde liegt. Die Adern in derselben ebenfalls zum größten Teil rot bestäubt. Unterseite braun mit gelbem Wurzelstreif am Vorderrande, drei roten Wurzelflecken, einem roten Wurzelwisch am Hinterande und einem gelben kleinen Tupf auf der Mediana an deren Wurzel. Die rote Binde der Oberseite nnr schwach dnrchschlagend. - - - . Mit den charakteristischen Geschlechtsmerkmalen, die Binde des Hinterflügels nach vor'n weiter ausgedehnt, sonst wie das $\sigma^{\star}$. - - Fransen schwarzbraun. Vorderflügellänge ois $37 \mathrm{~mm}$.

Ecuador.

58. H. xenoclea (Hew.)

Ђ. Palpen all der nach außen gerichteten Seite bis auf die Spitze, Punktierung auf Stirn und Kopf, sowie die übrige Körperzeichnung gelb. Grundfarbe der Flïgel schwarzbraun. - Vorderflügel mit zwei roten oder weißen, rot gesäumten Flecken, von denen der eine breit bindenartig im Discus, der andere, kleinere, von annähernd elliptischer Form, subapical liegt. Unterseite matter, Grundfarbe braun, die roten Flecke weißlich, sonst keine weitere Zeichnung: - Hinterflïgel oben einfarbig, nur das Vorderrandfeld dunkelgrau, schwach glänzend. Unterseite mit langem gelbem Wnrzelstreif am Torderrande, 3 roten Wurzelflecken zwischen den Adern nnd rotem Wischfleck rorn am Hinterande, sonst einfarbig braun. _ — -0 . Wie das $\sigma^{3}$, Vorderrandfeld des Hinterflïgels nur wenig heller als die Grundfarbe, Vorderrand selbst schmal gelbgrau glänzend.

Ecuador, Peru.

Diese Art zerfällt in 2 Unterarten:

58a. H. xenoclea xenoclea (Hew.) 1852 Heliconia x., Hewitson, Exot. Butt., v. 1 Heliconia t. 1 f. $1 \mid 1871$ Heliconius $x$., W. F. Kirby, Cat. diurn. Lep., p. 143 | 1879 $H . x$., Hopffer in: Ent. Zeit. Stettin, v. 40 p. $432 \mid 1885$ H. x., O. Staudinger (\& Schatz), Exot. Schmett., v. 1 p. $79 \mid 1901$ H. $x$., Riffarth in: Berlin. ent. Z., v.46 p. 150.

Vorderflügel mit zwei roten Flecken. Der eine, discal gelegene. ist breit bandartig, in seinem allgemeinen Umriß etwa fïnfeckig. Er beginnt hinter der Subcostalis und füllt vorn etwa den distalen Teil der Zelle zur Hälfte bis auf den vorderen Winkel aus. Die distale Begrenzung läuft fast ganzrandig oder nur wenig gezackt, steil schräg bis zur Submediana, die proximale Grenze zieht sich von der binteren Zellecke flach schräg bis zum mittleren Medianast und wendet sich hier fast senkrecht ebenfalls bis zur Submediana, welche die hintere Grenze des Fleckes bildet. Hinter dem mittleren und am hinteren Medianast ist derselbe distal in der Regel etras eingekerbt und schließlich auch etwas verschmälert, so daß er im hinteren Medianzwischenraum einen mehr oder weniger deutlichen. gegen den Distal- 
rand vorgeschobenen Zapfen oder Zahn bildet. Der andere, subapicale Fleck ist kleiner, fast elliptisch, distal scharf- und ganzandig. proximal mehr oder weniger eingeschnitten. Er beginnt hinter dem schmal schwarzbraunen Yorderande zwischen dem 2. und 3. Subcostalast, in der Regel näher an letzterem und den Basiswinkel desselben einschließend, ist schräg gegen den Distaliand gestellt und endet hinten dicht vor dem vorderen Medianast. Beim o nächst dem Apex des Vorderflügels unten manchmal weißliche, wischartige Bestäubung. Yorderflügelläuge his $37 \mathrm{~mm}$.

Jeicht mit H. batesi (S. 133) zu rerwechseln, aber spezifisch durch die Jerkmale der Selition unterschieden.

Peru (Gebiet des Chanchamayo), Ecuador.

58b. H. xenoclea notabilis Salv. \& Godm. 1868 H. n., O. Salvin \& F. D. Godman in: Ann. nat. Hist., ser. 4 v. 2 p. 145| 1871 H. n., WT. F. Kirby, Cat. diurn. Lep., p. 143 | 1901 H. xenoclea n., Riffarth in: Berlin. ent. Z., v.46 p. 151.

ㅇ. Discalfleck des Vorderflügels schmaler und kürzer als bei der vorigen Unterart, der vordere, in der Zelle liegende Teil etwa quadratisch, distal winklig eingeschnürt, weiß, proximal rot gerandet. Der Fleck setzt sich zunächst weiß ïber die Mediana fort. füllt den vorderen Basiswinkel des mittleren Merianastes aus und ist dort distal rot angelegt; der dahinter liegende Teil im hinteren Medianzwischenraum, der nur den Scheitel des vorderen Basiswinkels am hinteren Medianast freiläBt und sich distal bis nahe zur Hälfte des Aderzwischenraumes ausbreitet, sowie ein schmaler Streif hinter letzterem rot. bis auf einige Spuren weiBer Beschuppung an der Mediana. Die den Fleek schneidenden Adern fein schwarz. Subapicalfleck ebenfalls kleiner. anü̈hernd elliptisch, rein weiß. an der proximalen Begrenzung schmal rot gerandet. Unterseite der Oberseite entsprechend, aber matter.

Östliches Ecuador (Canelos, Ashpiyaco).

ј9. H. cyrbia (Godart)

o. Palpen an der nach außen gerichteten Seite weiß oder gelb bis auf die Spitze und das Gelenk 2 wischen Wurzel- und Mittelglied, dort schwarz. Punktierung des Kopfes und Körperzeichnung meist weiß oder weißlich, seltener gelb. Grundfarbe der Flügel schwarz bis schwarzbraun, meist stark blauglänzend. - Vorderflügel mit mehr oder weniger breiter, schräg liegender, oft fleckartig verbreiterter. roter Querbinde, die zum größeren Teil distal von der Zelle liegt, nur die Ecken oder ein kurzes Stück des Endteiles derselben ausfüllt und rom hinteren Medianast abgeschnitten wird. Unterseite matter. braunschwarz. stets olne Blauglanz. die Binde oft weißlich. namentlich im medianen Teil. keine weitere Zeichnung, nur im einzelnen Falle ein kurzer roter Wurzelstreif am Vorderrande; Hinterrandfeld nächst einem schmalen matt beschuppten Streif an der Mediana und dem hinteren Medianast grauglänzend. - Hinterflügel, abgesehen ron dem grauen, schwach glänzenden Torderrandfelde und schwarzen Hinterrande, cinfarbig oder nit weißlichen, bindenartig angeordneten Randflecken. Unterseite mit gelbern Wurzelstreif am Vorderrande, vier manchmal teilweise undeutlichen oder sehr kleinen. l'oten Wnrzelflecken, meist einer rom vorderen Teil des Hinterrandes in gerader Richtung nach dem Apex laufenden und dort etwas nach vorn gebogenen gelben Querbinde von verschiedener Breite, die in einem Falle ganz verloschen und nur bei schräger Belichtung wahrzunehmen ist. Randbinde, wenn rorhanden, fast geschlossen und rein weiß. _ _- 
૧. Vou etwas rundlicherem Flügelschnitt, mit den charakteristischen Geschlechtsmerkmalen, insbesondere schwarzgranem, nur sammetartig beschaffenem Vorderrandfelde des Hinterflügels. Sonst wie das $0^{\pi}$. — - Fransen beider Flügel meist weiß, uur schwarzbraun, wenn der Blauglanz fehlt.

Ecuador, Colombia, Bolivia.

Diese Art zerfällt in 3 Unterarten:

59 a. H. cyrbia cyrbia (Godart) 1819 Heliconia c., (Latreille \&) J. B. Godart in: Enc. méth., v. 9 p. 203 | 1844 H. c., E. Doubleday, List. Lep. Brit. Mus., v. 1 p. 55 1847 H.c., E. Doubleday (\& Westwood), Gen. diurn. Lep., v. 1 p. 103 | 1871 Heliconius c., W. F. Kirby, Cat. diurn. Lep., p. $140 \mid 1901$ H. c., Therese von Bayern in: Berlin. ent. Z.. v.46 p. $253 \mid 1900$ H.c.aberr. diformata, Riffarth in: Berlin. ent.Z., v.45 p.209 (formad.) 1901 H. c. + H. c. d., Riffarth in: Berlin. ent. Z., v. 46 p. 151; p. 152 (forma d.).

Forma principalis. Oberseite mit starkem Blauglanz. Rote Querbinde des Vorderfiügels schmal, $2-3 \mathrm{~mm}$ breit. Sie beginnt dicht binter dem Vorderrande zwischen der Abzweigung des 1. und 2. Subcostalastes, füllt proximal die äußersten Ecken der Zelle aus und länft schräg, in gauz flach konvexer Krümmung bis zum hinteren Medianast. Umriß ziemlich scharf, nur distal etwas weniger, im großen und ganzen auch ganzrandig, nur ab und zu wenig gezackt. Hinten verschmälert sich die Binde etwas oder ist abgerundet, so daB der hintere Medianast unter Umständen nur eben berühırt wird. - Hinterflügel mit weißer, beim o bläulichschwarz überstäubter Saumbiude, bestehend aus länglichen Doppelflecken, die am Distalrande nur von den fein schwarzen Adern und unter sich der Länge nach durch je einen -schwärzlichen Schattenstrich getrennt sind, vor'n aber spitzbogenartig divergieren. Die Binde beginnt breit am Hinterwinkel, nimmt gegen den Apex zu ab und verschwindet dort allmählich. - Unterseite schwarzbraun, Vorderflügel ohne Wurzelstreif am Vorderrande, das Rot der Binde weißlich bis auf die intensivere Berandung und den Streif längs der Adern. Hinterflügel mit langem schmalem gelbem Costalstreif, deutlichem rotem Wurzelfleckchen und einer schmalen gelben Mittelbinde, welche vom vorderen Teil des Hinterrandes in gerader Richtung durch das Zellende bis zur Subcostalis zieht und dort dicht am Apex gewöhnlich in kurzer Biegung zipfelartig nach vor'n gerichtet ist. Zuweilen aber ist sie in ihrem distalen Verlauf etwas weniger intensiv gefärbt und verschwindet allmählich ohne merkliche Zipfelbildung. Saumfleckenbinde reiner weiß, auch beim $\wp$, und vorn bestimmter begrenzt. - Fransen beider Flügel rein weiß ohne Uuterbrechung. Vorderflügellänge bis $36 \mathrm{~mm}$.

Ecuador (Balzapamba in Höhe von $800 \mathrm{~m}$; Palmar in Höhe ron $100 \mathrm{~m}$ ).

Forma diformata. Rote Querbinde des Vorderflügels verbreitert, sie füllt die Endecken der Zelle reichlich aus und schließt deu von den Discocellulares gebildeten Winkel proximal ein. Ihre proximale Begrenzung: zieht schräg und ohne merkliche Krümmung, oder vorn nur wenig eingeschnürt, durch den Ursprung des mittleren Medianastes bis zum hinteren Medianast, dem die Binde breit aufsitzt; distale Begreuzung mehr oder weniger konvex aufgebauscht und im letzteu Teil, im hinteren Medianzwischenraum, etwas nach dem Distalrande herausgerückt. Die Binde beim $q$ im ganzen in der Regel etwas breiter als beim $\sigma^{\top}$. Randbinde des Hinterflügels undeutlich, schwarzblau überstäubt und reichlicher in Flecke aufgelöst. Wurzelflecke der Unterseite kleiner, punktartig, manchmal teilweise fehlend.

Ecuador (Paramba; Quito?). 
$59 \mathrm{~b} . \mathrm{H}$. cyrbia venus Staud. $1882 \mathrm{H} . v$., O. Staudinger in: P. zool. Soc. London, p. 396 t. 24 f. 2 | 1885 H. $v$, O. Staudinger (\& S'chatz), Exot. Schmett., v. I p. $79 \mid 1901$ H. cyrbia v., Riffartl in: Berlin. ent. Z., $v .46$ p. 152.

Palpen und Körperzeichung gelb. - Binde des Vorderflügels zinnoberrot mit leicht gelblichem Ton, etwa 8-9 mm breit, vorn etwas schinaler. Proximale Begrenzung etwa wie bei Forma diformata, distale Grenze beträchtlich gegen den Apicalteil herausgeriickt, ohne eigentliche Krüımung schrïg von der Mitte des Ursprunges des 2. nud 3. Subcostalastes bis zum vorderen Medianast lanfend, dort mehr oder weniger stnfenartig nach hinten abgesetzt und darauf wiederum schräg gegen den Distalrand gerichtet, in dessen mmittelbarer Nähe die Binde stumpf abgeschnitten endet. Hinten liegt diese breit dem hinteren Medianast auf. Hinterflügel obne Zeichnung, nur bei schräger Belichtung die Querbinde der Unterseite schwach durchscheinend. - Binde des Vorderflügels unten rotgelb. Hinterflügel unten mit starkem gelbem Costalstreif und gelber Querbinde, die am Hinterrande und in der Mitte etwa $4 \mathrm{~mm}$ breit ist und sich distal allmählich verschmälert. Lage wie bei den rorigen Formen, der im Apex gebildete nach rorn gerichtete Zipfel sehr deutlich. Wurzelflecke fehlen oder sind rudimentär. - Sonst wie die typische Unterart. Torderflügellänge bis $37 \mathrm{~mm}$.

Colombia (Gebiet des Rio Dagua, Rio San Juan), Bolivia (Gebiet des Rio Juntas).

59c. H. cyrbia juno Riff. 1900 H.c.var. $j$., Riffarth in: Berlin. ent. Z., v. 45 p. 209 | 1901 H.c.j., Riffarth in: Berlin. ent. Z., v. 46 p. 153.

ð. Palpen und Körperzeichnung' gelb. - Oberseite der Flügel schwarzbraun mit schwachem Blauglanz, der nur bei ganz schräger Beleuchtung bemerkbar ist. Binde des Torderflügels wie bei der vorigen Unterart. Hinterflügel ohne Zeichnung. - Unterseite matter. Vorderflügel mit kurzem rotem Wurzelstreif am Vorderzande. Binde weißlich rotgelb, Ränder stärker rot. Hinterflügel mit gelbem Costalstreif und schwachen roten Wurzelflecken. Mittelbinde blind, namentlich bei schräger Beleuchtung in schwach hellerer Schattierung bemerkbar. - Fransen beider Flügel schwarzbraun. Sonst wie die vorhergehende Unterart. Vorderflügellänge iiber $37 \mathrm{~mm}$.

Heimat unbekannt.

60. H. favorinus Hopff. $1874 H$. $f$., Hopffer in: Ent. Zeit. Stettin, $v .35$ p. $348 \mid$ 1877 H. f., W. F. Kirby, Cat. diurn. Lep., Suppl. p. $722 \mid 1879 H$. f., Hopffer in: Ent. Zeit. Stettin, v.40 p. 431 | 1890 H. f., Weymer (\& Maassen), Lep. Reise Stübel, p. 78 | 1901 H.f.. Riffartl in: Berlin. ent.Z., v.46 p. 153 | 1896 H. amaryllis var. pseudamaryllis, O. Staudinger in: D. ent. Z. Lep., v. 9 p. 297.

${ }^{*}$. Palpen an der nach außen gekehrten Seite bis auf die Spitze und das Gelenk zwischen Wurzel- und Mittelglied gelb oder gelblich, sonst schwarz. Stirnflecke und Kopfpunkte, sowie hintere Besäumung der Augen weiß. Punkte auf dem Halskragen und die übrige Körperzeichnung gelb. Gestalt der Flügel wie die der vorigen Arten, Apex flach abgermndet. Grundfarbe schwarzbraun obne blauen Glanz. - Vorderflïgel mit breiter fleckartiger schräg liegender zinnoberroter, schwach gelblich getönter Querbinde. Diese beginnt dicht hinter dem Torderrande etwa il der Breite der Entfernung des 1. vom 2. Subcostalast, verbreitert sich vorn derart, daß der distale T'eil der Zelle ausgefïllt wird und etwa das Doppelte dieser Breite jenseits der Zelle liegt. Die proximale Begrenzung läuft nicht sehr scharf und etwas zackig schräg bis zum hinteren Medianast, den rorderen Basiswinkel desselben freilassend. Die distale Begrenzung wendet sich in flachem 
Bogen, der am rorderen Medianast in der Regel etwas abgestuft ist, bis zum mittleren Medianast etwa $2-1.5 \mathrm{~mm}$ vom Distalrande und von da in paralleler Richtung zu letzterem bis zum hinteren Medianast, dem die Binde meist in voller Breite aufliegt; nur selten erscheint ein schmaler kürzerer Streif hinter demselben. Die die Binde durchschneidenden Adern mit Ausuahme der Snbcostalis und eines Teiles der hinteren Discocellularis, welche schwarz bestäubt sind, rot. Unterseite matter, das Rot der Binde gelblich, namentlich die Adern teilweise schwefelgelb bestäubt. Hinterrandteil nächst einem schmalen Streif mattbrauner Bestäubung an Mediana nud hinterem Medianast grau, schwach glänzend. Sonst ohne Zeichnung. - Hinterflügel mit dunkelgrauem, leicht glänzendem Vorderrandfelde bis etwa $1 \mathrm{~mm}$ hinter der Snbcostalis und einer breiten schwefelgelben Querbinde. Diese beginnt nächst der Flügelwurzel am Hinterrande in einer Breite von etwa $2-3 \mathrm{~mm}$. verbreitert sich in der Mitte etwas, schließt das Zellende ein und endet in einer stumpfen Spitze dicht hinter der Subcostalis, $3-4 \mathrm{~mm}$ weit vom Apex entfernt. Die vordere Begrenzung läuft im flachen Bogen durch den Basiswinkel des hinteren Medianastes und der vorderen Radialis, von dort dicht dem grauen Vorderrandfelde folgend. Die hintere Begrenzung verlänft gestreckt und ist an den Adern ein wenig gekerbt, die vordere Radialis in der Regel fein aber intensiv schwarz bestäubt. Unterseite mit gelbem Wurzelstreif am Vorderrande, Wurzelflecke fehlen oder sind nur rudimentär, Querbinde wie oben, aber bleichgelb, die Spitze distal etwas näher dem Distalrande gerückt. Bei der Spaltung der Mediana und Costalis an der Flügelwurzel ein weißgelbes Tüpfchen. - - - . Wie das $\sigma^{\pi}$, mit den unterschiedlichen Geschlechtscharakteren, das Rot der Vorderflïgelbinde in der Regel etwas gelblich getönt. Auf der Unterseite des Hinterflügels bilden sich distal nächst dem Apex mitunter gelbliche Streifenwische, der Costalstreif ist oft sehr verkürzt. _- Fransen schwarzbraun. Vorderflügellänge $34-36 \mathrm{~mm}$.

Peru (Moyobamba, Tarapoto, Naxos), Gebiet des oberen Amazonen-Stroms.

\section{H. petiveranus (Doubl.)}

ऽ. Palpen an der nach außen gerichteten Seite, Stirnflecke, Kopfpunkte und Körperzeichnung gelb. Gestalt der Flügel wie bei der vorigen Art, die rorderen ein wenig schmaler. Grundfarbe der Flïgel schwarzbraun. - Vorderflïgel mit schräg liegender roter Querbinde im Discus, die dicht hinter dem Vorderrande vor dem Zellende beginnt, an der Subcostalis etwas breiter wird, proximal schräg durch den distalen Teil der Zelle bis zum hinteren Medianast läuft, den vorderen Basiswinkel desselben freilassend. Distal zieht ihre Begrenzung in fast gerader Linie schräg bis zum vorderen Medianast, ist dort eingeschnürt oder stufenartig bis dicht zum mittleren Medianast abgesetzt und bildet hinter letzterem einen mehr oder weniger spitzen oder abgestumpften, gegen den Distalrand bis auf $1-2 \mathrm{~mm}$ vorspringenden Zahn oder Zipfel; ihre proximale Begrenzung liegt breit auf dem hinteren Medianast. kann jedoch beiderseits etwas abgerundet sein. Die die Binde schneidenden Adern meist rot, die Subcostalis jedoch in der Regel schwarz. Unterseite braun mit kurzem rotem Wurzelstreif am Vorderrande, die Querbinde meist schmaler, schärfer begrenzt, weißlich, namentlich im mittleren Teil. Hinterrandfeld wie bei der vorigen Art. - Hinterflïgel meist mit schmaler gelber Querbinde, die sich in gestreckter, beiderseits geradlinig begrenzter Richtung vom vorderen Teil des Hinterrandes, das Zellende einschließend, bis etwa 4-5 mm vom Apex erstreckt und hinter der Subcostalis endet. Der distale Teil wird durch das dunkelgraue, schwach glänzende Vorderrandfeld rorn 
etwas zugespitzt. Die Binde fellt zuweilen. Unterseite mit mehr oder minder gut alusgeprägtem gelhein Costalstreif, meist 4, aber auclı weniger, roten Wurzelpunkten; die gelbe Querbinde heller, distal in schwacher Krümmung bis zun Yorderrande ausgedehut, zuweilen nur blind vorlanden mind nur bei schräger Beleuchtuug wabrzunehmen. - $-q$. Yon etwas breiterem Sehuitt des Vorderflügels. auch der Hinterflügel mit flacher gerundetem Apex. Vorderflügel oben wie beim $\delta^{*}$ gezeichnet, Hiuterflügel oben mit etwas aufgehelltem Vorderrandfelde, in dem die nach vorn gerichtete Fortsetzung der Binde von der Cnterseite meist etwas durchseblïgt und ror der Subcostalis etras gelbliche Bestäubung auftritt. Sonst wie das O charakteren. - - Frausell sebwarzbraum.

Colombia, Venezuela, Nittel-Amerika.

Diese Art zerfällt in 2 Unterarten:

61a. H. petiveranus petiveranus (Ioubl.) 1702-11 "P(q)ilio nigricans". Petiver, Gazophyl., $x .1$ t. 4 f. $2 \quad 1847$ Heliconia petiverana, (Boiscluval in ISS.) E. Doubleday (\& Westwood). Gen. dium. Lep. v. 1 p. $103 \mid 1874$ Heliconius p., A. G. Butler \& Herb. Druce in: l'. zool. Soc. London. p. 351 | 1885 H. p., O. Staudinger (\& Schatz), Exot. Schmett., $r .1$ p. $79 \mid 1896$ H. p., O. Staudinger in: 1). ent. Z. Lep., v. 9 p. 295 | 1901 H. p. (H. petiverea l'lötz in MS.), Riffarth in: Berlin. ent. Z., v. 46 p. $153 \mid 1881$ \& 1901 H. petiverunus (part.), F. I). Godman \& O. Salvin in: Biol. Centr.Anrer., Lep.-Khop. $v .1$ p. $153 ; v .2$ p. 667 | 1863 H. demophoon (err., non Heliconia d. Ménétriés 1857!), H. W. Bates in: P. zool. Soc. London, p. 247| 1876 H. l., Distant in: Tr. ent. Soc. London, p. XIJI 1870 Heliconia mexicane (part.), Boisduval, Consid. Lép. Guatemala, p. $28 \mid 1871$ Heliconius petiverana + H. m., W. F. Kirby, Cat. diurn. Lep., p. $143 ;$ p. 647.

Yorderflügel mit roter, vorher beschriebener Binde, die in ihrer gröBten Ausdehnumg etwa $10 \mathrm{~mm}$ breit wird. Gelbe Hinterflügelbinde $1-2 \mathrm{~mm}$ breit, oben distal etwas zugespitzt, $4-5 \mathrm{~mm}$ rom Apex entfernt hinter der Subcostalis endigend. unten diese übersehreitend, nach vorn gewendet und in den Vorderrand unweit cles distalen Endes der Costalis auslaufend. Hinterflügel nuten mit $t$ dentlichen roten Wurzalfecken und einem ebensolchen Wischfleck am Hinterrande; Costalstreif kurz, nnr in schwacher gelber Bestäubung vorhainden. Sonst wie bei der Art beschrieben. Vorderflïgellïnge bis $37 \mathrm{~mm}$.

Venezuela, Colombia. I'anama, San Salrador, Honduras, Hexiko.

61 b. H. petiveranus demophoon (Ménétr.) 1857 Heliconia d., Ménétriés, Lép. Ac. St.-Pétersb., v. 2 p. 86 t. 2 f. $4 \mid 1901$ Holiconius petiverana d., Riffarth in: Berlin. ent. Z., v. 46 p. $154 \mid 1881$ \& 1901 H. petiveranus (part.), E. D. Godman \& O. Salvin in: Biol. Centr.-Amer., Lep.-Khop. v. 1 p. $153 ;$ v. 2 p. 66 T (forma tristis) 1900 H. petiverana, A. G. Butler in: Entomologist. v. 33 p. 190 1900 H. p. var. demophoon (H. p. var. chiriquensis Stichel in MS.) + H. p. aberr. tristis, Riffirth in: Berlin. ent. Z... l. 45 p. 20 ; ; p. 210 (forma t.).

Forma principalis. Vorderflïgel wie bei der rorigen Lnterart. Hinterflügel mit doppelt so lreiter gelber Qnerbinde, die am Hinter'ande etwas scbmaler beginnt nud distil in stumpfer Spitze endet. Die rordere Begrenzung läuft wie bei der typischen Lnterart dureh den Lrsprung des hintereu Medianastes und der vorderen Radialis, die Binde selbst ist aber etwas rerkürzt und scheint hierdurch etwas steiler zu stehen; ihre bintere Begrenzung etwas zackig. Verlauf der Binde unten genau in derselben IV eise wie bei der typischen Unterart. mitunter ist sic. namentlich beim $O$, an Vorderende beiderseits etwas ansgeflossen oder rerdickt. Sonst wie die tỵpiscbe Interart. Vorderflügellänge his $37 \mathrm{~mm}$.

Colombia (Gebiet des Rio Putumayo), Costa Riea (Puerto Limon), Panama.

Das Tierreich. 22. lief.: II. Stichel \& H. Riffarth, Heliconijdae. 
Forma tristis. Hinterflügel oben einfarbig schwarzbraun, ohne Querbinde. Unten ist diese blind angedeutet, namentlich bei schräger Beleuchtung wahruehmbar. Sonst ohne Unterschied gegen die Hauptform.

Panama (Bugaba, Chiriqui).

62. H. hydarus (Hew.)

ठ. Palpen an der mach anßen gerichteten Seite bis auf die schwarze Verbindung von Wurzel- und Mittelglied und die Spitze, sowie Stirnflecke, Punktierung des Kopfes und Körperzeichnung meist gelb, seltener weiß. Flügelform wie die der vorigen Art. Grundfarbe der Flügel schwarzbraun mit oder ohne blauen Schiller oder ganz blauschwarz. stark glänzend. - Vorderflügel in der Regel mit breiter roter schräg liegender Querbincle, die bis über den hinteren Medianast reicht. seltener, alsclann auf blauschwarz glänzendem Grunde, verschwindet, mehr oder weniger zerstäubt oder in Rudimenten fleckartig vorhanden ist oder endlich ganz fehlt. Unterseite dunkelbraun, im letzteren Falle ganz einfarbig, meist jedoch mit kurzem rotem Wurzelstreif am Vorderrande und der matter gefärbten, manchmal weißlichroten Querbinde, sehr selten mit Rudimenten letzterel in Gestalt von einzelnen weißen Fleckchen. Hinterrandfeld dunkelgrau, nächst einem Streif matter, braun oder rötlich getönter Bestäubuug an Mediana und hinterem Medianast leicht glänzend. - Hinterflügel mit gelber, ziemlich breiter Querbinde oder Rudimenten einer solchen am Hinterrande, sonst einfarbig. Vorderrandfeld dunkel braungrau, leicht glänzend, Apex natt braunschwarz oder schwarz. Unterseite dunkelbraun bis mattschwarz mit manchmal fehlenden oder verkümmerten roten Wurzeipunkten, mehr oder weniger dentlichem gelbem Costalstreif und der etwas hellereu gelben Binde der Oberseite, die auch nur blind oder zerstäubt auftreten kann, wenn sie oben fehlt oder rndimentär ist, oder nur im Anfange als gelber Fleck am Hinterrande angedeutet sein kann. - - $Q$. Dem $\sigma^{\pi}$ entsprechend, mit den charaliteristischen Geschlechtsunterschieden, namentlich nur wenig hellerem Vorderrandfelde des Hinterflügels. durch das sich die gelbe Binde, weun vorbanden, in leichter Zerstäubuug bis zum Vorderrande fortsetzt. - - Fransen schwarz bis schwarzbraun.

Venezuela, Colombia. 'Trinidad, Mittel-Amerika.

Diese Art zerfällt in 6 Unterarten:

62 a. H. hydarus hydarus (Hew.) 1867 Heliconiahydara, Hewitson, Exot. Butt., $x .4$ Heliconia t. 5 f. $14 \mid 1871$ Heliconius h., IV. F. Kirby, Cat. diurn. Lep., p. $143 \mid 1901$ $H . h$, Riffarth in: Berlin. ent. Z.. v. 46 p. $155 \mid 1901$ H. $h$., Therese ron Bavern in: Berlin. ent. Z., v. 46 p. 253 | ?1890 H. melpomene, Weymer (\& IIaassen), Lep. Reise Stübel, p. $9,13,27$.

Gruudfarbe der Flügel schwarzbraun, ohne blauen Schiller. Vorderflïgel mit hochroter, breit fleckartiger Querbinde, die hinter dem schmal schwarzbraunen Vorderrande etwas schmaler beginut und sich an der fein schwarzen Subcostalis derart ausbreitet, daß der Zellschluß etwa in der Mitte der Bindenbreite liegt. Die Begreuzung ziemlich scharf, proximal in schräger Richtung; manchmal etwas gezähnt. ohne wesentliche Biegung oder Krümmung gegen den hinteren Medianast gerichtet, ohne den vorderen Winkel am Ursprunge desselben auszufüllen, darauf in distiler Richtung stufenartig abgesetzt und in breiterem abgerundetem oder in schmalem abgekürztem Streif hinter jenem Aste endigend. Distale Begrenzung am vorderen Medianast mehr oder minder deutlich stumpfwinklig gebogen, sodaun schräg bis zum hinteren Medianast in etwa $1-2 \mathrm{~mm}$ weiter Entfermung vom 
Distalrande verlaufend. Die Binde bildet dort init der hinteren Begreuzung einen mehr oder weniger scharfen Winkel oder aber einen etwas rorgeschobenen stumpfen Zahn. Breite in der Regel $7-8 \mathrm{~mm}$, jedoch auch gröber oder geringer. Unterseite hraun, init kurzem rotem Wurzelstreif am Vorderrande; das Rot der Binde weißlich, namentlich im mittleren Teil, die Ränder lebhafter rot. - Hinterflügel oben einfarbig; der Typus zeigt in der Nähe des Vorderiandes in der Witte ein rotes Fleckchen, welches sonst fehlt. Unterseite mit schmalem gelbem Costalstreif und kräftigen roten Wurzelfleckchen, die manchmal auf der Oberseite zum Teil und rerkleinert durchschlagen, selten mit blinder Andeutung einer Querbinde, wie sie bei H. h. colombinus ausgebildet vorhanden ist. und auch im eimzelnen Falle an der Stello des Anfanges derselben am Hinterrande mit einem gelben Fleck. Häufig mit H. melpomene (S. 110) verwechselt, durch die Merkmale der Sektion und auch durch die Gestalt der roten Binde unverkenmbar zu tremmen. In Ïbergängen mit schwachem blauem Glanz zur nächsten Form vorhanden. Vorderflügellänge his $39 \mathrm{~mm}$.

Venezuela (Puerto Cabello), 'Trinidar, Colombia (Cauca, Muzo), Panana.

62b. H. hydarus guarica Reak. 1868 H. g., Reakirt in: P. Ac. Philad., [1.91 | 1871 H. g., W. F. Kirby. Cat. diurn. Lep., p. 143 | 1901 H. hydara g. (H. guayana Plötz in MS.), Riffarth in: Berlin. ent. Z., t. 46 p. 155.

Wie die typische Cnterart, aber mit mehr oder minder reichlichem blauem Schiller auf der Grundfarbe. In seltenen Fällen tritt vorn im proximalen Teil der Torderflïgelhinde etwas gelbe Färbung auf. Binde auf der' Unterseite weißlich rot, seltener gelblich, zuweilen rudimentär vorhanden in Übergangsstücken zn Forma nocturna (S. 196), denen in der Regel, namentlich bei weiter rorgeschrittener Reduzierung der Binde, die Wurzelstreife am Vorderrande heider Flügel unterseits und die Wurzelfleckchen daselbst fehlen.

Venezuela, Colombia (cauca, Medelliu)

62 c. H. hydarus molina Grose Sm. $1898 \mathrm{H} . m$., Grose Smith in: Ann. nat. Hist., ser. 7 r. 2 1. 70.

Oberseite beider Flügel stark blauglänzend. Rote Binde des Torderflügels in der Lage wie hei der rorigen Unterart, aber beträchtlich schmaler, rorn verkürzt und das crste, ror der Subcostalis liegende Stück fleckartig abgetrennt und getrübt. Beim Typus schieht sich im binteren Medianzwischenraum ein schnaler Schattenstreif der schwarzhlauen Grundfarbe über das Rot der Binde. Hintere Discocellularis inmitten der Binde vorn etwas schwarz bestäubt. - Vorderflügel unten mit kurzem rotem Wurzelstreif. Die Binde vou der hier bramen Grundfarbe doppelt unterbrochen, auch sonst etwas trübe. Hintertiügel mit 3 roten Wurzelfleckchen, schwach angedeutetem gelbem Wurzelstreif am Vorderrande und einer hlinden Querbinde. — Sonst wie die typische Interart. Torderflïgellänge $31 \mathrm{~mm}$.

(Colombia (Valdivia).

62 d. H. hydarus colombinus Staud. $1896 \mathrm{H}$. petireranus var.? colombina, $\mathrm{O}$. Staudinger in: D. ent. \%. Lep., r. 9 p. 295 | 1901 H. hydara c., Riffarth in: Berlin, ent. Z., $\imath .46$ p. 156.

Vorderflügel wie bei der typischen Lnterart. Gelbe Binde des Hinterflügels weniger scharf hegrenzt, ihre hintere Begrenzung an den Adern gekerht. Sie heginnt schmal vorn am Hinterrande, rerbreitert sich ror und 
in der Zelle auf etwa $4 \mathrm{~mm}$ und nimmt dann wieder etwas ab. Das Zellende liegt etwa in der Mitte der Bindeubreite. Das letzte Stück ist durch die fein schwarze vordere Radialis abgeschnitten und bildet in der Regel einen schräg nach vorn gerichteten, verloschenen, mehr oder weniger spitzen Zipfel, der etwa 4-5 mm rom Apex entfernt liegt. Cnterseits schneidet sie etras trübe, aber noch deutlich und breit an der Costalis ab. Beim o ist dieser Verlauf in schwacher Bestäubung auch oben angedeutet. Sonst wie die typische Unterart.

Colombia (Gebiet des Rio Dagua, Cauca, Medelliu, Muzo).

62 e. H. hydarus antigona Rift. $1900 \mathrm{H}$. hydara var. a., Riffarth in: Berlin. ent. Z., v. 45 p. $210 \mid 1901$ H. h. a., Riffarth in: Berlin. ent. Z., v. 46 p. 156.

Unterscheidet sich von der typisehen Cnterart dadurch, daß die Grundfarbe tiefbliu glänzt. Gelbe Hinterflïgelbinde hinten besonders stark gekerbt; sie endet unten in der Nähe des Apex am Vorderrinde und ist im letzten Verlauf etwas zerstäubt. Costalstreif unterseits des Hinterflügels fehlt oder ist nur ungewiß angedeutet.

Colombia (Medellin, Gebiet des Rio Dagua).

$62 \mathrm{f}$. H. hydarus chestertonii (Hew.) 1872 Heliconia c., Hewitson. Exot. Butt., $v .5$ t. Helicon. f. 22 1884 Hcliconius c., Weymer in: Eut. Zeit. Stettin, v.45 p. $27 \mid 1885$ H. c., O. Staudinger (\& Schatz), Exot. Schmett., v. 1 p. $\varepsilon 0$ t. $32 \mid 1890$ H. c., Weymer (\& Maassen), Lep. Reise Stübel, p. 36|1880? H. chestertoni, Buchecker, Syst. Ent.. Lep. t. 55 f. $15 \mid 1874 H$. damysus, Hopffer in: Ent. Zeit. Stettin, v. 35 p. $349 \mid 1879 H$. $d$., Hopffer in: Ent. Zeit. Stettin, v.40 p. $431 \mid 1877$ H. chestertonii $+H$. d., W. F. Kirby, Cat. diurn.Lep., Suppl. p. 722 | 1900 H. hydara aberr. nocturna, Riffarth in: Berlin. ent. Z., $v .45$ p. 210 (forma n.) | 1901 H. h. chestertonii $+H . h . n$. , Riftarth in: Berlin. ent. Z., v. 46 p. 156 ; p. 156 (forma n.).

Forma principalis. Grundfarbe schwarz mit tiefblauem. bei schräger Beleuchtung blaugrünem Glanz auf dem sonst zeichnungslosen Vorderflügel; am schmal schwarzen Vorderrande, dem Apex und Distalrande, verliert sich der Glanz allmällich. Hinterflügel mit grauem, beim ơ schwach glänzendem Vorderrandfelde, Grundfarbe in übrigen blauschillernd bis anf Hinterrand. Hinterwinkel und Distalland; in der Mitte mit einer ziemlich breiten schwefelgelben Querbinde, die proximal am Hinterrande beginnt und schräg gegen den Apex bis zur Subcostalis verläuft, auch jenseits derselben vou unten her schwach durchschlägt. Beim o verbreitert sich vorn das Gelb in ungewisser Zerstäubung streifen- oder wischartig bis zum Vorderrande. - Cuterseite schwarzbraun. Vorderflïgel nur im discalen Teil mit schwachem Blauglanz, sonst völlig einfarbig bis auf den etwas helleren Hinterrandteil. Hinterflügel ohne. selten mit eimzelnen Resten roter Wurzelflecke, ohne oder nur mit Spuren eines gelben Costalstreifes, aber mit kräftig, wenngleich in heller gelbem Ton als oben, entwickelter Querbinde, welche sich vorn etwas rerschmälert. aber deutlich und scharf bis zum Vorderrande unmittelbar am Apex läuft. Abdomen ventral in der Regel schwarz oder uu mit Spuren gelblicher

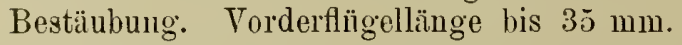

Colombia (Cauca; Gebiet des Rio Dagua; Antioquia; Sau Augustiu. im Januar und Februar).

Forma nocturna. Vorderflügel wie bei der Hanptform, nur an der vorderen Ecke der Vorderflügelzelle ein gelbliches Fleckchen. Hinterflügel nur am Hinterrande mit zerstäubtem Anfange einer gelben Querbinde. die unterseits zwar in ganzer Länge, aber sehr verloschen und ungewiß auftritt. 
An der Wurzel des Hinterfliigels unten manchmal ein roter Tunkt hinter der Mediana, am Vorderande ein kimzer und sclmaler gelber Wurzelstreif. Sonst wie die Hauptform. Bildet Übergänge mit mehr oder weniger verloschener roter Bindenbestiubung des Vorderflügels zu H. h. guilrical (S. 195).

Venezuela.

\section{H. erato (L.)}

ठ․ Grundfurbe der Flïgel schwar\% his schwarzhraun. - Wurzelfeld des Vorderflügels rot auBer auf deu Adern, oder mit roten Streifen oder" Wischen 7.wischen denselben, all.h ganz schwarz nder endlich mit cinem gelben Streif an der Mediana. In I)iscus, ansgebreitet bis in den apicalen Teil, eine gelbe oder rote Fleckengruppe. deren Lage hej den einzelnen Formen beschrieben ist. oder eine melı oder weniger schwarz gekernte oder z'klüftete, auclı ganz geschlossene rote oder gelhe Binde, welche entweder his in den distalen T'eil der Zelle reicht oder distal rou derselben in nehr oder weniger bescluänkter oder rerkürzter Gestalt. dann aber um grelb, liegt. Dic rote Binde ist entweder ron einem roten Wurzelfelde oder gelben Medianstreif begleitet. kann aber auch als einzige Zeichmmg anftreten. In letzterem Falle nimut die Grundfarbe selten einen tiefhlanen Schiller an. Dic übrigen Zeichnungen treten in rerschiedenen Komhinationen anf, und zwar: roter Wrurzelteil. gelbe Fleckengruppe: roter Wruzelteil, rote Fleckengruppe; roter Turzolteil, gelbe Binde oder geschlosserter Fleck. Sehr selten treten die zwei Farben. Rot und Gelb, in einer Zeichnungsanlage, so in der Discalbinde auf. Unterseite der oberen Seite in allgemeinen entsprechend. Grundfurbe matter, die gelben und roten Discalzeichnungen blasser oder weiBlich, rote Wurelbestüubung, wenn rorhanden. auf Streife am Torderrande und in der Zelle heschräulit. Hinterrandfeld nächst einem schmalen Streif matter Bestäubung gr.u, leicht glänzend, läutig proxiunal etwas rötlich. - Hinterflïgel mit roter Strahlenhildung. deralt. daß rou der Wurzel aus ein Streif lä̉ngs in der Zelle liegt und 6 oder 7 rorm breitere. hinten spitzere Streife 1 m dieselbe gruppiert sind. Die Strahlen manchmal mehr oder weniger reduziert oder auch ganz fehlend. seltener werden dieselben von miner gelben, vom Hinterrande uach dem Apex laufenden gelben Binde durchquert, oder diese tritt allein auf. Cuterseite mit mehr oder weniger ansgebildetem gelbem Wurzelstreif am Vorderiande, \pm oder 5 roten, zum Teil zusammengeflossenen Trurzelflecken. ron denen der rordere und der in der Zelle liegende häufig mehr oder reniger strahlenförmig auslanfen. Die ïbrigen Streife, wenn oben ror-

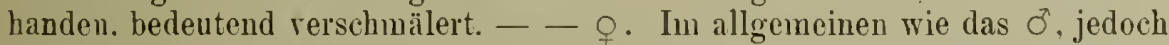
mit stärker gerundetem Apex des Hinterflügels und den sonstigen charaktelistischen Geschlechtsunterschieden. Strahlenzeichnung des Hinterflïgels vermöge des feblenden grauen Vorderrandfeldes weiter nach vorn ausgebreitet, so daß (der kurze, am Hinterrande liegende Streif mitgerechnet) stets 7 Strahlen vorhanden sind, mituntel auch das Rudiment eines achten im rorcieren Radialzwischenraum.

Der außerordentliche Formenreichtum der Art und die noch recht mangelhafte grenauere Kenntnis der Verbreitung und Erscheinungszeit erschwert die systematische Gliedernng. Bei der folgendeu Aufstellung der Luterarten ist insbesondere das Verbreitungsgebiet als ansschlaggebend erachtet und es sind zweifelhafte Formen als Formzustände betrachtet worden, namentlich wenn dieselben, soweit bekannt. unter gleichen Lebensbedingungen rotkonmen. Nach Beobachtungen ron Bates und anderen Reisenden (J. Nichaelis, von dem sich zahlreiche interessante Formen in der Sammlung des Herrn H. Riffarth befinden) sind die direkt von der typischen Unterart abzuleitenden Formen mit roten Strahleu des Hinterflügels und solche ohne Strahlen zwei neben- 
einander, aber unter sehr verschiedenen Lebensbedingungen (erstere in feuchten und nasseu Niederungeu, letztere in trockeneren Gegenden) auftretende Variationsreihen, die sich an den Berührungsstellen vermischen, von dencn die eine Reihe, mit einfarbigem Hinterflügel, sich stellenweise im nördlichen Brasilien (Unterer Amazonen-Strom) abzusondern scheint und deshalb als Unterarten betrachtet werden darf, wenngleich sich sämtliche Formen beider Reihen durch Übergänge in unmittelbarer Folge aneinander reihen lassen. Die an die Hauptform der typischen Unterart angereihten Formen können auch in analoger oder ähnlicher Weise bei H. e. amazona (S. 201) von der Südseite des untereu Amazonen-Stroms vorkommen.

Brasilien, Guayana, Peru, Bolivia, Paraguay, Ecuador.

Diese Art zerfällt in 12 Unterarten:

63a. H. erato erato (L.) 1758 Papilio (H.) e., Linné, Syst. Nat., ed. 10 p. 467 1764 P. e., Linné, Mus. Ludov. Ulr., p. 231 | 1767 P. (H.) e., Linné, Syst. Nat., ed. 12 v. 2 p. $757 \mid 1775$ P. e., J. C. Fabricius, Syst. Ent., p. $465 \mid 1788$ P. (H.) e. (part.), J. F. Gmelin, Syst. Nat., v. 5 p. 2255 | 1877 H. e., Möschler in: Verh. Ges. Wieu, v. 26 Abh. p. 313 | 1902 H.e., Stichel in: Berlin. ent. Z., v.47 p.150| 1777 „Vesta“, Papilio vesta + "Erythrea", P. erythrea, P. Cramer, Pap. exot., v.2 p.33 t.119 f. A, p.151; p. 140 t. 189 f. A, p.148 (forma e.) | 1869 Heliconius v. + H. e., A. G. Butler, Cat. dimn. Lep. Fabr., p. 122 ; p. 122 (forma e.) | 1779 "Papilio erato" + „P. v.", Goeze, Eut. Beytr., v. 3 I p. 103; p. $118 \mid 1780 \& 82$ „Andremona", P. andremona + „Udalrica", P. uddalrica, P. Cramer, Pap. exot., v.4 p. 16 t. 297 f. A. p. 247 (forma a.); p. 16 t. 297 f. B, p. 252 (forma u.) 1781 P. erythrea + P. erato, J. C. Fabricius, Spec. Ins.. v. 2 p. 34 (forma erythrea); p. $34 \mid 1787$ P. erythrea $+P$. crato, J. C. Fabricius, Hant. Ins., $x .2$ p. 17 (forma erythrea); p. $17 \mid 1793$ P. erythrea + P. erato (part.), J. C. Fabricius, Ent. syst., v. 3 I p. 179 (forma. erythrea): p. 179 $\mid 1790 P$. andremona $+P$. udalrica + P. erythrea + P. vesta, J. F. W. Herbst, Naturs. Ins. Schınett., v. 4 p. 128 t. 71 f. 7 (forma a.); p. 129 t. 71 f. 8 (forma u.); p. 137 t. 73 f. 4 (forma e.); p. 141 t. 73 f. 6 | 1816 Migonitis erato (part.) $+M$. andremone $+M$. ulrica $+M$. erythrea, .J ac. Hübner, Verz. Schmett., j. 12 ; p. 12 (forma a.); p. 12 (forma u.); p. 12 (Lorma erythrea) 1819 Heliconia cynisca + H. andremona + H. erythraea, (Latreille \&) J. B. Godart in: Enc. méth., v. 9 p. 205; p. 206 (forma a.); p. 206 (forma erythrea) i 1837 H. c., Jam. Duncan, Foreign Butt., p. 137 t. 11 f. $2 \mid 1844 H$. c. + H. erythraea, E. Doubleday, List. Lep. Brit. Mus., $2: 1$ p. 54 ; p. 54 (forma erythrea) $\mid 1847$ H.e. + H. vesta + H. andremona + H. a.var. udalrica, E. Doubleday (\& Westwood), Gen. diurn. Lep., v.1 p. 103 (forma erythrea); p. 103; p.104 (forma a.) ; p. 104 (forma u.) | 1862 Heliconius melpomene var. a. + H. m. var. e. + H. $m$. var. u. + H. v., H. W. Bates in: Tr. Linn. Soc. London, v. 23 p. 558 (forma a.); p. 558 (forma erythrea); p. 559 (forma u.); p. 560 | 1871 H. m. var. a. + H. m. var. c. + $H . m . v a r . u .+H . v$., W. F. Kirby, Cat. diurn. Lep., p. $1+2$ (forma erythrea); p. 142 (forma a.); p. 142 (forma u.); p. $143 \mid 1877$ H. v., A. G Butler in: Tr. ent. Soc. London, p. 126 1880? H. v. + H. aoede (err., non Migonitis a. Jac. Hübner 1818!), Buchecker, Syst. Ent., Lep. t. 58 f. $25,26 \mid 1883 H$. erato $+H$. e. forma andremona $+H$. e. forma erythraea, Möschler in: Verh. Ges. Wien, v. 32 Abh. p. 315 ; p.316 (forma a.); p. 316 (forma erythrea) | $1885 H$. vesta $+H . a .+H$. udalrica $+H$. erythrcaea, O. Staudinger (\& Schatz), Exot. Schmett., v. 1 p. 78 ; p. 78 (forma a.); p. 78 (forma u.); p. 78 (forma erythrea) $1896 H . v .+H . v$. aberr. leda, O. Standinger in: D. ent. Z. Lep., v. 9 p. 306; p. 306 (forma l.) | 1896 Heliconia v., C. Oberthüir, Étud. Ent., v.20 p. 15 | 1901 Heliconius phyllis leda + H.p. andremona + H. p. udalrica + H.p. erythraea + H. p. v., Riffarth in: Berlin. ent. Z., v. 46 p. 161 (forma l.); p. 161 (forma a.); p. 161 (forma u.); p. 161 (forma erythrea); p.162|1902 „Heliconia vcsta-andrcmona var." + ,H.v.-udalrica var." + "H. v.-erythraea var." + H. vesta tellus (Boisduval in MS.) $+H . v .+$..H. v.-anuzona var." + "H. v.-lella" + H. xanthoceras, C. Oberthür, Étud. Ent., v. 21 t. I f. $8-13$ (forma a.); t. 2 f. $14-18,21,22$ (forma u.); t. 2 f. 19, $20,23,24$, t. 3 f. 25 (forma erythrea); t. 3 expl. f. 26 (forma t.); t. 3 f. 30,34 (forma 1.); t. 3 f. 35 (forma oberthüri); t. 3 f. $27,31-33$; p. 24 t. 3 f. $36 \mid 1903$ Heliconius erato oberthüri + H. e. tellus, Riffarth in: Berlin. ent. Z.. v. 47 p. 162 (forma o.); p. 162 (forma t.).

Forma principalis. Wurzelteil des Vorderflügels (Fig. 36) rot, seltener gelbrot, vorn breiter als hinten, von dell schwarzen Adern durchschnitten und 
distal an diesen meli oder weniger tief gespalten und unscharf begrenzt. Im Discus und distal von demselben eine schwefelgelbe Fleckengruppe, bestehend aus einem, nur schmal von dem roten Wurzelfleck getremuten, groBen F'leck im distalen 'T'eil der Zelle, welcher die ganze Breite derselben ausfïllt, proximal meist rechtwinklig abgeschnitten, distal tief spitzwinklig eingekerbt ist und die Zellecken nicht ganz erreicht. Vor ihm und distalwärts, von den Adern mehr oder weniger deutlich geteilt. eine Anzahl länglicher, schmaler Fleckchen, die sich ror und längs der Subcostalis.linziehen, an der vorderen Zellecke schräg nach hinten fortsetzen und vergrößern und sich schlieblich hogen-

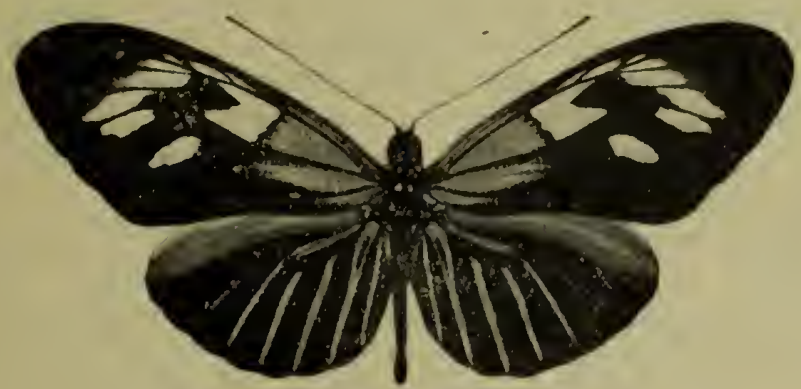

Fig. 36. H. erato erato, forma principalis $\left({ }^{2} / 1\right)$.

förmig wieder der Zelle nähern. Der im mittleren Medianzwischenraum gelegene Fleck ist im Vergleich zu den vor ilım stehenden etwas verkïrzt, der hinter iln gelegene eirund, weiter abgetrennt und der Zelle nahe gerïekt, selten erscheint hinter ihm noch ein weiteres Fleckchen. Größe der Flecke veränderlich, die an weitesten gegen den Listalrand vorgeschobenen in der Regel beiderseits zugespitzt. die übrigen von einer durch die Lage der Adern bedingten schmal rechit- oder dreieckigen Gestalt oder zugespitzt elliptisch. - Hinterflïgel mit ausgehildeter loter Strahlenzeichnung, wie bei der Art beschrieben, der zwischen Submediana und dem hinteren Medianast gelegene Streif vor'u länglich schwarz gekernt, alle Strahlen schmal, vorn vou dem Zellstreif an der Mediana moln oder weniger isoliert, nach hinten spitz auslaufend, obne den Distalrand selbst z.n berübren. - Unterseite matter, das Rot des Wurzelfeldes des Vorderflïgels auf Vorderraud und \%elle beschränkt, nur beim q etwas ausgelehnter. die Fleckengruppe weißlicl. Hinterflügel mit schmalem gelbem C'ostalstreif, drei roteu, zu langen Streifen ausgeflossenen Wurzelflecken, von denen der hinter der Mediana gelegene häutig isoliert steht oder mit dem dort ausgelıenden, vorn tief gespaltenen Streif nur unsicher zusammenhängt. Strahlenbildung im ührigen wie oben, aber die einzelnen Streife schmaler, fast strichartig. Beide Flügel an der Wrurzel, an dem Winkel der Costalis und Mediana, mit einem gelbell Tupffleckiben. Vorderflügelläuge bis $40 \mathrm{~mm}$.

Französisch-Guayana. Niederländisch-Guayana.

Forma leda. Vorderflïgel wie bei der typischen Cuterart mit rotem, leicht gelblich getöntem Wurzelfeld. welches häufig nur rou den Aderı fein schwarz geschintten wird. Von der discalen Fleckengruppe fehlt der mittlere Teil distal von der Zelle. Vorhanden ist der mehr oder weniger reduzierte, zuweilen ganz gespaltene Fleck in der Zelle und ein durch den ersten Subcostalast gespaltenes schmales Fleckchen ror denselben, ferner zwei isolierte, manchual schwärzlich 
bestäubte längliche Flecke im mittleren und hinteren Medianzwischenraum. Selten erscheinen vor diesen Spuren der übrigen Flecke der Hauptform.

Französisch-Guayana. Niederländisch-Guayana (Berg en Dal).

Forma oberthüri. Gelbe Fleckengruppe des Vorderflügels fehlt bis auf Rudimente des Zellfleckes in vorderen Teil ersterer und vor dem Zellende am ersten Subcostalast. Distal von der Zelle gar keine Fleckenbildung oder nur ganz schwache Spuren solcher.

Niederländisch-Guayana (Berg en Dal), Französisch-Guayana.

Forma andremona. Vorderflügel wie bei der Hauptform, die discale Fleckengruppe aber rot anstatt gelb und in ihrem vorderen Teil inniger zusammenhüngend, die durchschneidenden Adern nur fein schwarz oder auch rot. Der im hinteren Medianzwischenraum isoliert stehende längliche Fleck ziemlich groß, hinter ihm in der Regel noch ein kleinerer roter Fleck. Das Rot der Fleckengruppe unten weißlich, oben zuweilen gelblich oder etwas gelb überstäubt in Übergängen zur Hauptform.

Französisch-Guayana, Niederländisch-Guayana (Berg en Dal), östliches Amazonas (Massauary, Maues).

Forma udalrica. Rote Fleckengruppe des Vorderflügels verdichtet, die hinteren Elecke proximal verlängert, die Zelle berübrend und mit den vorderen, distal von jener liegenden, zusammenhängend, nur von den Adern fein schwarz geschnitten. Es entsteht eine in der Mitte, am Zellende, mehr oder weniger stark schwarz gekernte und in ihrem vorderen, distalen Teil etwas zersprengte, unregelmäßige, fast bindenartige Zeichnung wie bei H. e. callycopis (S. 202). Der hintere Teil derselben besteht aus einem mehr oder minder regelmäßig rechteckigen Fleck über die Breite des hinteren Medianzwischenraumes, welcher den vorderen Winkel am Ursprunge des Medianastes frei läßt, mit der vorderen proximalen Ecke an die Zelle und den Zellfleck anstößt und distal bis nahe zum Distalrande. hinten gewöhnlich etwas ausgeflossen, reicht. Der vordere, distal von der Zelle liegende Teil der Zeichnung häutig rudimentär und von der aus der Mitte her sich ausbreitenden Grundfarbe eingeengt und verdrängt. Farbe der Fleckengruppe meist blaßrot. Zuweilen tritt am Vorderrande, distal ron der Zelle, etwas gelbe Bestäubung auf. Sonst wie die Hauptform, mit der sie in Copula angetroffen ist (Stichel in: Berlin. ent. Z., v. 47 (1902) p. (19)).

Französisch-Guayana, Niederländisch-Guayana (Berg en Dal).

Forma erythrea. Vorderflügel (Fig. 37) mit rotem bis rotgelbem Wurzelfelde wie die Hauptform. Im Discus anstatt der roten Fleckengruppe

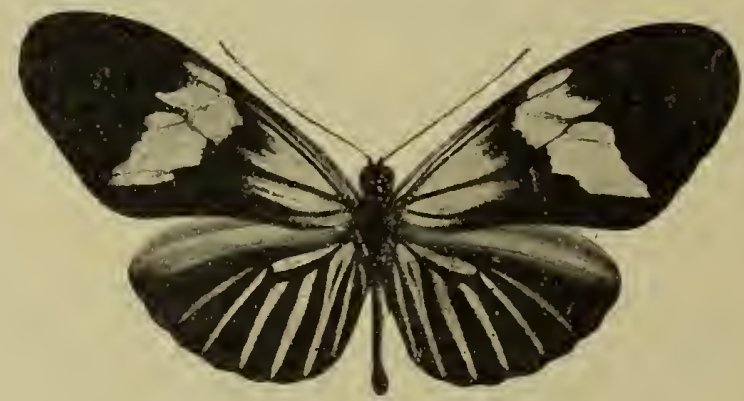

Fig. 37. H. erato erato, forma erythrea $(1 / 1)$.

eine ebensolche schräg liegende Querbinde, welche hinter dem schmalen Vorderrande am Ende der Zelle beginnt, sich an der Subcostalis etwas [weiter 
ausbreitet und schräg bis zum binteren Medianast länft. Beide Begrenzungen etwas zackig, namentlich die distale znweilen an rorderen Medianast tief gespalten. Das Zellende liegt etwa in der Mitte del vorderen IBindenbreite, hinten ist der distale 'Teil der Biude fast bis zum I)istalrande ripfelartig vorgeschoben. Die gauze Anlage wie bei H. e. callycopis, forma viculata (S. 204). Hinterflügel und sonstige Beschaffenlieit wie bei der Hauptforin.

Niederlindisch- und Französisch-Guayana, Gebiet des unteren Amazonen-Stroms. (Santarem).

Forma tellus. Wie die vorige Form, aber die Querbinde des Vorderflügels schwefelgelb anstatt rot. In C̈bergängen mit roter, vorn gelb bestäubter Binde obne Strahlenbildung des Hinterflügels z,u H. e. callycopis. forma dryope (S. 204) rorkommend.

Französisch-Guayana.

63 b. H. erato amazona Staud. $1806-19$ "Nerëis festiva vesta", .Jac. Hübner. Exot. Schmett., $v .1$ t. 11 f. $1-4 \mid 1816$ Migonitis erato (part.), Jac. Hübner, Verz. Sclımett., p. $12 \mid 1896$ Heliconius vesta var. amazona, O. Staudinger in: D. ent. \%. Lep... ¿.9 p. 306 । 1901 H. phyllis a., Riffarth in: Berlin. ent. Z.. v. 46 p. $163 \mid 1902$ „Heliconia vesta-a.", C. Oberthïr, Étud. Ent., v. 21 t. 3 f. $29 \mid 1900$ Helieoniues philadelphus, IV. F. Kirby, Exot. Schmett. Hiibner, p. 12.

Wrurzel des Vorderflïgels und Strahlen des Hinterflügels rotgelb. Discale Fleckengruppe wie bei der typischen Unterart schwefelgelb, aber inniger zusammengeschlossen, der ror und distal der Zelle liegende Teil bindenartig, und von den fein schwarzen Adern durchzogen, etwa in der. Art wie bei $H$. e. e., forma andremona, aber gelb statt rot. Distal ist diese Bindenzeichnung ziemlich gerade schräg begrenzt, proximal tief eingebuchtet, der bintere Fleck im hinteren Medianzwischenraum isoliert, elliptisch; seltener binter demselben ein weiteres kleineres gelbes Fleckchen. Der vorlere Teil der Zeichunng bildet mit dem Fleck in der Zelle einen gewölbeartigen Bogen, der sich auch hinten beinahe schließt. Strahlen des. Hinterflügels breiter und stumpf, vorn näher an den Zellstreif gerückt und teilweise, namentlich die hinteren, in den Distalrand einmündend, auch die. vorderen kräftiger und länger entwickelt als bei der typischen Unterart. Unterseite matter. der gelbrote Wurzelteil des Torderflügels beim $\sigma^{\top}$ auf Vorderrand und Zelle beschränkt, das Gelb der Flecken- und Bindengruppe heller. Hiuterflügel wie bei der typischen Unterart, die Strablen aber etwas. breiter und stumpf, der Oberseite entsprechend. besonder's kräftig der binter der Costalis mit dem betreffenden Wurzelfleck völlig verschmolzene Streif, der oben fehlt. Vorderflügellänge $25-40 \mathrm{~mm}$.

Purá (im März, Oktober, Dezember). östliches Amazonas.

$63 \mathrm{c}$. H. erato cybelinus Staud. $1896 \mathrm{H}$. cybele aberr. cybelina, O. Staudinger in: D. ent. Z. Lep., $x .9$ p. 304 t. 7 f. 2 ! 1900 H. phyllis aberr, amalfreda (O. Staudinger in US.) + H. vesta cybclina, Riffarth in: Berlin. ent. Z.. v.45 p.212 (forma a.); p. 2141 1901 H. phyllis a. +H.p.c., Riffarth in: Berlin. ent. Z., v. 46 p. 160 (forma a.); p. 160.

Forma principalis. Vorderfliigel mit breitem rotem Wurrelfelde und einer distal rou der Zelle gelegenen gelben subapicalen Fleckeubinde, welche an Zellende, etwas proximal eingeriickt, nüchst dem Vorderrande beginnt, dort mit dem Rot des Wurzelfeldes zusammenliängt und sich etwa an der Abzweigung des 3. Subcostalastes in schräger Riclitung gegen den Distalrand wendet, obue diesen zu ereichen. Der letzte. rom mittleren Medianast abgeschnittene Fleck ist proximal gegen das Zellende etwas rorgeschoben, so daß die Binde bier einen konvexen Halbbogen oder Trinkel bildet. Im. 
hinteren Medianzwischenraum tritt zuweilen noch ein weiterer isolierter, verwaschener gelber Fleck auf. Im distalen Teil der Zelle keine Fleckenbildung. Hinterflügel oben einfarbig; unten mit roten Wurzelflecken, deren vorderster strichartig verlängert ist, und mit kleinem gelbem Costalstreif. Unterseite im iibrigen matter, das Rot des Wurzelfeldes des Vorderflügels auf Torderrand und Zelle beschränkt, die Fleckenbinde bleicher. Sonst wie die typische Unterart. Vorderflügellänge $38 \mathrm{~mm}$.

Ö́stliches Amazonas (Manaos).

Forma amalfreda. Wie die Hauptform, aber im distalen Teil der Telle ein schwefelgelber Fleck wie bei der typischen Unterart, der hinterste, isolierte gelbe Fleck der subapicalen Binde meist größer, elliptisch, die Binde selbst mitunter stark in kleinere Flecke aufgelöst (Fig. 7 S. 6). Die Zeichnungsanlage des Vorderflügels entspricht derjenigen der ty pischen Unterart. Hinterflügel oben einfarbig, unten mit schmalem gelbem Costalstreif und roten Wurzelflecken.

Gebiet des unteren Amazonen-Stroms (Obidos, Manaos, Furo, Manicoré), Niederländisch-Guayana (Berg en Dal).

63d. H. erato callycopis (Cram.) 1777 „C.", Papilio c., P. Cramer, Pap. exot., v. 2 p. 143 t. 190 f. E, F; p. 148 | 1779 „P.c.", Goeze, Ent. Beytr., v.31 p. 118 | 1781 P. melpomene (err., non Linné 1758 !), J. C. Fabricius, Spec. Ins., v.2 p.31 | ?1887 Heliconia m., P. Snellen in: Tijdschr. Ent., v. 30 p. 15 (forma viculata) 1790 Papilio callicopis, J. F. W. Herbst. Naturs. Ins. Sclımett., v. 4 p. 130 t. 72 f. 1 | 1816 Sunias c., Jac. Hiibner, Verz. Schmett., p. 12 | 1819 Heliconia c., (Latreille \&) J. B. Godart in: Enc. méth., v.9 p. 207 1847 H. c., E. Doubleday (\& Westwood), Gen. diurn. Lep., v. 1 p. $103 \mid 1885$ Heliconius melpomene var. c., O. Standinger (\& Schatz). Exot. Schmett., v. 1 p. $78 \mid 1848$ Heliconia elimaea, Erichson in: Schomburgk, Guiana, v.3 p.595 (forma e.) | 1862 Heliconius melpomene var. callycopis $+H$. m. var. e., H. W. Bates in: Tr. Linn. Soc. London, v. 23 p. 558 ; p. 558 (forma e.) | $1871 H . m$. var. c. + H. m. var. e., W. F. Kirby, Cat. diurn. Lep., p. 142 ; p. 142 (forma e.) 1877 H.coralii, A. G. Butler in: Cistula ent., $v .2$ p. 151 (forma c.) | 1877 H. c., W. F. Kirby, Cat. diurn. Lep., Suppl. p. 847 (forma c.) | 1877 H. callicopis + H. coralii + H. erythrea var., A. G. Butler in: Tr. ent. Soc. London, p. 125 ; p. 125 (forma coralii) ; p. 125 (forma dryope) | $1883 \mathrm{H}$. melpomene var, callycopis + $H$. erato forma palantia, Möschler in: Verh. Ges. Wien, v. 32 A bh. p. $315 ;$ p. 316 (forma coralii) | $1900 \mathrm{H}$. phyllis aber. callista $+H . p$. var. viculata $+H . p$. aberr. dl.yope, Riffarth in: Berlin, ent. Z., v. 45 p. 212 (forma c.); p. 188, 212 (forma r.); p. 212 (forma d.) 1901 H. p. callycopis $+H . p . v .+H . p$. corallii $(H$. palantes Plötz in MIS.) $+H . p$. callista + H. p. d. + H. p. elimaea, Riffarth in: Berlin. ent. Z.. v. 46 p. 158 ; p. 158 (forma v.); p. 159 (forma coralii); p. 159 (forma callista); p. 159 (forma d.); p. 160 (formu e.) | 1902 "Heliconia vesta-melpomene" + ,H. . -callycopis" + ,H.v.-c.var." + "H.thelxiopc-m.var.", C. Oberthür, Étud. Ent., v.21 t.1 f. 1, 2. t. 4 f. 41 (forma viculata); t. 1 f. 3. 4, t. 4 f. 44.45 ; t. 1 f. 7 (forma corulii); t. 5 f. 5,6 (forma callista); t. 5 f. 53 (forma dryope) | 1902 Heliconius callycopis $+H$. c. forma viculata, Stichel in: Berlin. ent. Z., r.47 p.149; p. 149 (forma v.).

Forma principalis. Grund farbe der Flügel (Fig. 6 S. 6) schwarzbraun. Vorderflügel mit einer unregelmäßig schwarz gekernten. breiten. fleckartigen, roten Querbinde im Discus, welche gewöhnlich durch die sich ron dem dunklen Kern am Zellende nach hinten und in distaler Richtung ausbreitende Grundfarbe in eine unregelmäßige Fleckengruppe zersprengt ist, welche eine ähnliche Anlage besitzt, wie die gelbe Discalfleckengruppe der typischen Unterart. hinten aber mehr oder weniger geschlossen ist. Im distalen Teil der Zelle ein die Breite derselben ausfüllender großer Fleck. der proximal ziemlich gerade abgeschnitten. distal spitzwinklig eingekerbt ist. rorn rerbunden 
mit einigen längs der Subcostalis in distaler Richtung herausgeschobenen schmalen Fleckchen, die sich, mehr oder weniger zerklinftet nnd meist etwas verbreitert, bogenförmig oder schräg nach hinten und gegen den Distalrand wenden, in einigem Abstande ron letaterem im mittleren Medianzwischenraum wiederum in proxinnaler Richtung zuriicktreten und mit ihrem Fnde ganz oder fast die hintere Zellecke erreichen. Hinter dieser bogenförmigen Grupue ein oder zwei weitere, meist mit den rorderen und nnter sich zusammenhängende. längliche Flecke, rou denen der vordere hedeutend gröBer als der hintere. der auch fehlen kann, ist und proximal meist bis zur Mediana reicht, ohne indes den rorderen Basiswinkel des hinteren Medianastes auszufïllen. Die Verteilung ron Rot nnd Schwarzbraun im Bereich der Discalzeichnung außerordentlich unbeständig, zuweilen ersteres so leduziert. dab der distal rou der Zelle gelegene rordere Teil des Bogens teilweise oder ganz verschwindet. Es kommen C̈hergänge zur Fornal viculata und Forma callista (S. 204 und 203) in allen erdenklichen Stufen der Zusammensetzung der Iiscalzeichnung vor. Hinterflügel zeichnungslos. jedoch mit deu Geschlechtscharakteren der Grnppe am Vorderrande. - Unterseite matter. Vorderflügel mit kurzem rotem Wurzelstreif am Vorderrande. Hinterflügel mit schmalem gelbem Costalstreif. roten Wmzelflecken und einem gelblichen Fleckchen an der Wurzel der Mediana. - Torderflïgellänge his $43 \mathrm{~mm}$. Niederländisch-Guayana, Gebiet des unteren Amazonen-Stroms (Pará, Santarem,
Obidos).

Forma elimaea. Vorderflügel mit rotem Wurzelfeld wie die typische Unterart und einer discalen Fleckengruppe in der Form und Anlage wie bei dieser, aber rot statt gelb. You der Hauptform abzuleiten dadurch. dab die discale Fleckengruppe ron innen her nach hinten durch die Grundfarbe mehr oder meniger anseinandergetrieben ist und rote Wurzelfürbung hinzutritt. Die Form entspricht auch der Vorderflügelaulage ron H. e. e., forma andremona (S. 200), aber Hinterflïgel einfarbig. höchstens mit ganz kleinen roten Pünktchen an der Wurzel.

Britisch-Guayana. Niederländisch-Guayana (Berg en Dal), am unteren AmazonenStrom (Obidos).

- Forma coralii. Vorderflügel mit loter Wurzelfäbung wie bei der typischen Unterart und einer discalen Fleckengruppe ähulich derjenigen der Forma callista, aber hinten geschlossen in der Weise wie hei der Hauptform. Zuweilen tritt in dem distal rom Zellende sich aushreitenden schwarzen Kern im vorderen Medianzwischemram ein isolierter. länglicher roter Fleck anf, und oft sind die subcostalen Fleckchen rorn gell hestäubt. auch fehlt zuweilen die distale Verbindung dieser Fleckehen mit dem hinteren Teil der Fleckengruppe. Hinterflügel einfurbig oder mur mit winzigen roten Strichfleckelien an der Wurzel. Sonst wie die Hauptform.

Niederländisch-Guayana. Pará (Cameta. im Dezember), (rebiet des unteren Amazonen-Stroms (Ubidos. Serpa).

Forma callista. Wurzel des Torderflügels ohne Rot. Discale Fleckengruppe rot. in der Anlige wie bei Forma elimalea Die Subcostalfleckehen mitnnter proximal etwas gelb hestäuht. Hinterflügel zeichuungslos. Sonst wie die Hauptform.

Niederländisch-Guayana (Berg en Dal). 
Forma viculata. Vorderflügel mit vollständig geschlossener, roter bis rotgelber discaler Binde (Fig. 5 S. 6). Diese beginnt schmal dicht hinter dem Vorderraude vor dem Zellende, verbreitert sich hinter der Subcostalis derart, daß das Zellende in der Regel in dem distalen Drittel der Bindenbreite liegt. der im Zellende liegende Teil also breiter ist als der außerhalb der Zelle gelegene. Sie verläuft dann schräg bis zun hinteren Medianast, überschreitet denselben um ein Weniges und bildet dort distal einen bis dicht an den Distalrand rorspringenden Zapfen oder Zahn. Die Begrenzung ziemlich scharf, aber meist unregelmäßig gezackt. Die proximale Begrenzung läßt den vorderen Basiswinkel des hinteren Medianastes frei und ist an letzterem wie auch an der Mediana meist etwas stufenartig abgesetzt. Hinterflügel zeichnungslos, Vorderl’and des $\sigma^{\pi}$ dunkelgrau, schwach glänzend, der des o bräunlich grauschwarz, etwas heller als die tief schwarzbraune Grundfarbe. Im übrigen auch unterseits wie die Hauptform. - Leicht mit H. melpomene melpomene (S. 111) zu rerwechseln, aber durch die verschiedenartigen Merkmale der Sektion und auch dadurch von jenem zu unterscheiden, daß die Begrenzung der roten Binde schärfer, ihre Breite im allgemeinen auch gleichmäBiger ist; ferner ist sie nach hinten häufig bis zur Submediana zipfelartig ausgeflossen, ein Umstand, der bei $H$. melpomene $\mathrm{m}$. nie vorkommt.

Niederländisch-Guayana, Venezuela (Puerto Cabello), Curaçao (?), Gebiet des unteren Amazonen-Stroms (Santarem, Obidos).

Forma dryope. Vorderflügel mit hochroter Discalbinde wie die rorige Form und ebenso wie bei der typischen Unterart gefärbter Wurzelbestäubung, die aber im hinteren T'eil voller, indes distal ungewiß zerstäubt ist. Im einzelnen Falle tritt vorn und im vorderen Stück des in der Zelle liegenden Teiles der Binde gelbe Bestäubung auf, eine Erscheinung, die auf Übergang zu H. e. e.. forma tellus (S. 201) hinweist, und andererseits erhält die Grundfarbe bei einzelnen Stücken aus Britisch-Guayana blauen Schiller, woraus der Zusammenhang mit der nächsten Unterart gefolgert werden muß. Hinterflügel zeichnungslos oder mit roten Fleckchen an der Wurzel.

Niederländisch-Guayana, Britisch-Guayana (Omai), Gel,iet des unteren AmazonenStroms (Obidos).

63 e. H. erato magnificus Riff. $1900 H$. phyllis var. magnifica, Riffarth in: Berlin. ent. Z., v. 45 p. $211 \mid 1901$ H. p. m., Kiffarth in: Berlin. ent. Z., v. 46 p. 157.

Vorderflügel schwarzbraun, tief blauglänzend bis auf Vorderrand, Apex und Distalrand, woselbst sich der Glanz allmählich verliert. Im Discus eine wie bei H. hydarus guarica (S. 195) und ähnlich der vorigen Unterart gebildete tief- oder blaßrote, schräg liegende, breite Querbinde, welche ebenfalls in schwach bläulichem Ton schimmert. Der vordere, dicht hinter dem Vorderrande gelegene Teil der Binde vor der fein schwarzen Subcostalis ist schmaler und geht distal ohne merklichen Absatz in die schräg gegen den vorderen Medianast gerichtete Grenze über, dort wendet sich diese in stumpfem Winkel etwas steiler schräg nach hinten bis zum hinteren Medianast in unmittelbarer Nähe des Distalrandes. Proximal ist der hinter der Subcostalis gelegene breitere Teil der Binde gegen den schmalen Anfangsstreif etwas abgesetzt, die Grenze verläuft schräg durch die Zelle bis zum hinteren Medianast mit schwacher Abstufung an der Mediana, hierauf erfolgt ein stärkerer Absatz, aher die Binde überschreitet den erwähnten Ast nur in einem schmalen Streif, der mit der distalen Begrenzung nächst dem Distalrande einen mehr oder weniger spitzen Winkel bildet. Letzterer kann aber auch so abgestumpft sein. daß die distale Grenze im hinteren Medianzwischenraum parallel zum Distalrande 
vorlüuft. Begren\%ung im allgeneinen scharf und nicht wesentlich zackig, las Zellende liegt etwa in der Mitte der Bindenbreite. Hinterflïgel nächst dem heim ơ dunkelgran glänzenclen, beim of schwäl\%lichen Vorderrandfelde ebenfalls tief blanscbillernd mit Ansuahme des Hinter- nud Distalrandes sowie des Apex, sonst zeichnmingslos. - Enterseite matter, las Rot der Binde weiblich, Wurzelstreif an Vorderande des Vorderflügels felılt. Hinterflïgel digegen mit kräftigem gelbem Costalstreif nud 4 roten Wurzelflecken. rou denen die drei vorderen rundlich sind uncl isoliert liegen, der vierte als Doppelfleck und wischartig am Hinterande auftritt. sonst ohne weitere Zeichnung. Die übrigen Merkmale wie bei der typischen Unterart. - Vorkerflügellänge bis $43 \mathrm{~mm}$.

Britisch-Guayana, Ecuador, Peru.

633. H. erato estrella Bates $1862 \mathrm{H}$. estrella, H. W. Bates in: Tr. Linn. Soc. London. $v .23$ p. $560 \mid 1871$ H. e., W. F. Kirby, Cat. diurn. Lep.. p. $142 \mid 1877$ H. e., A. (7. Butler in: Ann. nat. Hist., ser + r. 20 p. 119 18:16 H. vesta forma e., O. Staudinger in: D. ent. Z. Lep.. v.9 p. 306 | 1871 H. elylus, O. Salvin in: Ann. nat. Hist., ser. 4 r. 7 p. 414 (forma e.) 1877 H. e., W. F. Kirby, (Cat. diurn. Lep., Suppl. p. 722 (forma c.) $1885 H$. vesta var. vestalis, O. Staudinger (\& Schatz), Exot. Schunett., $r .1$ p. is 1901 H. pliyllis estrella + H. p. etylus $+H . p$. emma ( $\bar{H}$. augusta $\mathrm{O}$. Staudinger in IIS.), Riffarth in: Berlin. ent. Z.. v. 16 j. 163: p. 164 (forma etvlus); p. 164 (forma emma) | 1902 "Heliconia resta-estrella var.", C. Oberthür, Étud. Ent.. «. 21 t. 10 1. 119 , 120 ; t. 11 f. $124,125,127,128$; t. 11 f. 126 (forma etylus).

Forma principalis. Vorderflïgel mit ziegelroter. ron den schwarzen Adern durchschnittener Wurzelfiache, die distal unscharf zerklüftet begrenzt ist. meist aher in voller Breite bis zum Hinterrande auftritt. Der gelbe Fleck der typischen Unterart im distalen Teil der \%elle fehlt. Lis folgt eine nur durch die fein schwarzen Adern geschnittone. qner gelagerte Halbbinde. welche der Lage der Fleckenbinde der typischen Enterart entspricht, aber breiter mod nannentlich in hinteren 'Teil voller ist. Sie beginnt rorn hinter dem schmal schwarzen Torderrande in einer Breite etwa ron der vorderen Zellecke oler dem Crsprunge des 1. Subcostalastes bis nahe zmm 3. Subcostalast und endet hinten im mittleren Medianzwischenranm. Die proximale Begrenzung ist an der Subcostalis mnd im rorderen Medianzwischenram mehr orler weniger eingebuchtet. namentlich an letaterer Stelle. Die Bincle nimmit hierdnrch eine bogen- oder winkelförmige Gestalt an mul ist clementsprechend an der distalen Begrenzmng ror dem vorderen Medianast stumpf gewinkelt. Gewölnnlich ist die Begrenznng scharf nnd ganzandig, zntreilen jedoch. namentlich an den Arlern, etwas zackig. Seltener tritt hinter der Binde. im hinteren Medianzwischenranm noch cin einzelner gelber Fleck auf. länfig aber finclen sich Überoangstiïcke zur typischen T'nterart und zu H. e. amazona (S. 201) mit mehr orler weniger beträchtlich entwickelten Rudimenten ies gellen Endzellfleckes. - Hinterflïgel mit Strahlenzeichnung wie bei der typischen Cnterart, die einzelıen Streife aber ziegelrot, vorn meist hreiter und bis dicht zur Mediana reichend. - Es finden sich anch Übergangsstücke z.u H. e. phyllis (S. 20S) mit Andeutung der gelben Querbinde in Gestalt cines gelben Fleckchens binter dem Vorderrandfelde etwa in der Mitte des Hinterflügels. - - Sonst wie die typische Interart. Vorderflügellänge lis 431 mu.

Grebiet des Amazonen-Stroms (Manaos, Jnnicore an Rio Jadeira, Sĩo Paulo de Olivença. Pebas, Iquitos, Fonteboa), Gebiet des Huallaga, Ecuador (Coca in Höhe ron $260 \mathrm{~m}$; Gebiet des Rio Napo in Hölse ron $450 \mathrm{~m}$; Archidona in Höhe von $640 \mathrm{~m}$ ). 
Forma etylus. Unterscheidet sich von der Hauptform dadurch, daß die gelbe Binde distal von der Zelle des Vorderflïgels im proximalen und hinteren Teil soweit recluziert ist, daß nur ein länglicher, proximal in der Mitte etwas winklig austretender Subcostalfleck übrig hleibt, der etwa in der Mitte zwischen Zellende und Apex liegt. Er wird von der Subcostalis und vorderen Radialis fein schwarz geschnitten.

Eeuador (Gualaquiza).

Forma e'mma. Wie die Hauptform, aber kleiner, die roten Zeich"ñungen heller, gelblich, und die distal von der Zelle des Vorderflügels gelegene, gelbe, quer verlaufende Halbbinde sehr schmal, stets nur bis in die Mitte des mittleren Medianzwischenraumes reichend. Im einzelnen Falle der Hinterflügel mit weißen Saumfleckchen. ein Umstand, der auf die Zusammengehörigkeit mit der folgenden Unterart hinweist, zu welcher Übergänge auch in der anderen Zeichnungsanlage vorkommell. Vorderflügellänge bis $37 \mathrm{~mm}$.

Ecuador (Archidona in Höhe von $640 \mathrm{~m}$, im Februar), Peru (Yurimaguas, Sarayacu, Gebiet des Rio Pachitea).

$63 \mathrm{~g}$. H. erato demeter Staud. $1896 H$. d., O. Staudinger in: D. ent. Z. Lep., $v .9$ p. 310 t. 7 f. 6 | 1901 H. phyllis d., Riffarth in: Berlin. ent. Z., v. 46 p. 164.

$\sigma^{\pi}$. Wurzelfeld des Vorderflügels rotgelb, Vorderrand und Submediana schmal schwarz. Hinterrand nnd Subcostalis etwas breiter schwar', namentlich ersterer. Distal von der Zelle eine schwefelgelbe, von den fein schwarzen Adern durchzogene, kurze und breite Binde, ähnlich wie bei H. e. estrella (S. 205). Dieselbe beginnt hinter dem schmal schwarzen Vorderrande an der vorderen Zellecke, proximal etwas vorgeschoben, und endet am mittleren Medianast. Distal ist dieselbe in ungewiß schwärzlicher (graugrüner) Überstäubung zackenförmig begrenzt, ebenso ist die proximale und hintere Seite leicht schwärzlich angeflogen. Hinter der Binde, im hinteren Medianzwischenraum, ein isolierter, länglicher, gelber, völlig schwärzlich überstäubter und hierdurch graugrün erscheimender Fleck. Vorn im distalen Teil der Zelle meist noch ein einzelnes gelbes Fleckchen. Hinterflügel mit rotgelber Strahlenzeichnung. Die einzelnen Streife dünn, mindestens die drei dem Hinterrande zunächst liegenden. oder alle rorn plötzlich rerbreitert, unter sich zusammengeflossen und ron der ganz rot ausgefüllten Zelle nur durch die fein schwarze Mediana abgesondert. Die ersten drei Strahlen enden nahe dem Distalrande. die übrigen werden nach vorn zu allmählich kïrzer und bilden in den Radialzwischenräumen schmale Streifenwische stets in unmittelbarem Zusammenhange mit dem Rot der Zelle. - Unterseite mit ziemlich intensiv braunschwarzer Grundfarbe. Das Rot des Wurzelfeldes des Vorderflügels verringert auf einen Streif ror und in der Zelle. Die Querbinde schmaler und scharf begrenzt, ohne in die Grundfarbe übergehende Bestäubung. Der Fleck im hinteren Medianzwischenraum fehlt. Hinterrandfeld grau, proximal rötlichgrau, leicht glänzend, am Distalrande hinten einige verloschene weiße Saumfleckchen. Hinterflïgel mit gelbem schmalem Costalstreif, die Strahien schmaler als oben, vorn unter sich und ron dem roten Zellstreif getrennt; vor der Subcostalis erscheint ein weiterer, oben fehlender, langer Streif. Am Distalrande eine Reihe parrweise in den Aderzwischemräumen stehender, runder, weißer Saumfleckchen, die nach rorn $\mathrm{zu}$ allmählich rerschwinden. -- — $q$. Außer durch die Geschlechtscharaktere rom $\sigma^{\pi}$ dadurch unterschieden, daß die Querbinde des Vorderflügels oben und unten bestimmt begrenzt und ohue grangrüne 
Bestäubnug an der Kante ist. Dieselbe ist an den Adern leicht gezackt, die einzeluen Flecke sind distal auBerdem in der Mitte der Ader\%wischenränme etwas. eingeschürt. Der hintere Fleck etwas rerkürzt, der in hinteren Medianzwischemrann bein $\sigma^{\pi}$ vorhandene grangrïne Fleck fehlt. Hinterflügel mit schmalen strahlenförmigen, rotgellen Streifen, welche länger sind als die des $\sigma^{\top}$, in ganzer Ausdehnumg annälıernd von gleicher Breite bleiben und vorn weder unter sich, noch mit dem Streif der Zelle eng zusammonfießen. Distalrand leicht wellig. Unterseite und die übrigen Merkmale wie heim O. - - Bildet Übergänge zu H. e. estrella, forma principalis und forma emnia (S. 205 und S. 206). Vorderflügellänge his $37 \mathrm{~mm}$.

Pern (Iruitos).

63 h. H. erato bouqueti Nöldner $1901 H$. demeler var. b., Nöldner in: Berlin. ent. Z., a.45 H. 7 | 1901 H. phyllis buqueti, Riffarth in: Berlin. ent. Z., v. 46 p. 165.

c. Der vorigen Unterart älnlich, aher die gelhe Querbinde des Vorrerflïgels in Flecke aufgelöst, etwas weiter vou der Yelle abgerückt, der Fleck in distalen Teil letzterer vergrößert. Ls entsteht eine um den schwarzen Zellschlub als Kern gelagerte Fleckengruppe, bestehend aus dem in seiner Mitte eingeschnïrten oder geteilten \%ellfleck und einer schwach gebogenen Reihe ron 5 oder 6 sclıwäızlich oder graugrüı gerandeten länglichen Flecken distal von der Zelle, von denen die vorderen enger zusammenstehen, der lintere stärker isoliert ist. Diese Flecke unten kleiner, weißlich, bestimmt begrenzt. Hinterflügel nit rotgelb ausgefüllter \%elle und damit verflossenen of oder 7 Strahlen, von denen die dem Hinterrande zunïchst liegenden nahe dem Saum endigen, die ïbrigen, wie anch der Hinterrandstreif selhst stark verkïrrt sincl. Sonst wie die vorliergehende Form. Vorderflügellänge $35 \mathrm{~mm}$.

Cayana.

b3 i. H. erato lativitta Butl. 187 i H. l., A. (G. Butler in: Cistula ent., $v .2$ p. 150 | 1877 H.l., A. G. Butler in: Tr. ent. Soc. London, p. $126 \mid 1890$ H.l., Weymer (\& IIassen). Lep. Reise Stübel, p. 76. 99| 1901 H. phyllis $l$. . Riffarth in: Berlin. ent. Z., x.46 p. 165 | 1902 "Heliconia vesta-estrella var.", C.Oberthür, Étud. Ent.. v.21 t.10 f. 117.

Wurzelfeld des Vorderflügels rotgelb, Vorderrand. Aderu und Hinterrand fein schwarz; distal in der Zelle, von dem ungewiß endigenden Rot nu sehmal getrennt. ein großer. distal winklig eingeschnürter gelher Fleck, der rorn den spitzen Winkel des Zellschlusses ganz ausfüllt. Distal von der Zelle, das Fnde derselben rorn nnd hinten nmfassend, eine Fleckenbinde ron gleicher Fiube wie bei H. e. estrella (S. 20\%), die ron den Adern fein schwarz geschnitten ist, distal in schräger Richtung his zum mittleren Medianast zieht unrl dort fast rechtwinklig bis zum hinteren Medianast abscheidet. Derhinterste 'Teil ist in Gestalt eimes elliptischen Fleckes stïrker isoliert. Die ganze Zeichnungsanlage bildet einen nm vou den Adern fein schwarz gesclinittenen, im vorderen Teil des Discus liegenden großen gelben Fleck mit schwarzem Kern am Zellende. Hinterflügel mit rotgelber Strahlenzeichnung wie H. e. estrella, dem sie auch in den übrigen Eigenschaften gleicht. Torderflügellänge etwa $36 \mathrm{~mm}$.

Peru (Rioja, Mloyabamba, Pebas), Bolivia (Yungas), Amazonas (São Paulo dle Olivença, Maues, 'Thoinar).

63j. H. erato anactorie (Doubl.) 1847 Heliconia a., E. Joubleday (\& Westwood), (ien. diurn. Lep., v. 1 p. 103 t. 15 f. 4 | 1871 Heliconius a., W. F. Kirby. Cat. dinrn. Lep., p. 143 | 1879 H. a., Hopffer in: Ent. Zeit. Stettin, v. 40 p. 431 | 1871 H. venustus, O. Salvin in: Aun. nat. Hist., ser. 4 v. 7 p. 413 (forma venusta) 1877 H. v., W. F. Kirby, 
Cat. diurn. Lep., Suppl. p. 223 (forma renusta) | 1894 H. anactorie aber $v .+H$. a. aberr. sanguineus, O. Staudinger in: D. ent. Z. Lep.. v.7 p. 66 (forma venusta); p. 66 (forma sanguinea) $; 1901$ H. phyllis v. (H. locris Plötz in MS.) +H.p.s. +H. p. a., Riffarth in: Berlin. ent. Z., v. 46 p. 165 (forma renusta); p. 166 (forma sunguinea); p. $166 \mid 1902$ "Heliconia venustus-a." + "H. thelxiope-venustus var." + „H. vesta-venustus", C. Oberthür, Étud. Ent., v. 21 t. 9 f. 105 ; t. 9 f. 107 ; t. 10 f. 109 (forma venusta).

Forma principalis. Vorderrand des Vorderflügels proximal in der Regel wenig oder gar nicht rot bestäubt. In der Zelle und hinter derselben, sowie nächst dem Hinterrande rote, distal zugespitzte und ungewiß endigende Wische. Discale Fleckengruppe um das Zellende zu einem bindenartigen. nur an der Basalwinklung der Radiales etwas schwarz gekernten, geschlossenen Eleck zasammengerückt, der gelb gefärbt, vorn und distal nehr oder weniger rot überstäubt ist. Der Fleck beginnt schmal dicht ninter dem Vorderrande. füllt proximal das Zellende und läuft dort schräg bis zum hinteren Medianast. Seine distale Begrenzung zieht, mehr oder weniger gezackt, schräg bis zum vorderen Medianast und wendet sich, am mittleren Médinnast winkelförmig eiugeschnitten, nach hinten, ebenfalls am hinteren Medianast endigend. Die den Fleck schneidenden Adern rot bestiiubt, außer der Subcostalis, die fein schwarz ist. Unterseite matter, mit kmrzem rotem Wurzelstreif am Vorderrande, geringer oder gar keiner roten Wurzelbestäubung. Farbe des Discalfleckes gelblichweiß mit rötlichem Ton. - Hinterflügel mit roter Strahlenzeichnung; die einzelnen Strahlen ziemlich kurz, deutlich getrennt, der zwischen der Submediana und dem hinteren Medianast gelegene vorn länglich schwarz geschlitzt. Anlage im allgemeinen wie bei der typischen Unterart, aber auf der Unterseite wesentlich reduziert, die einzelnen Streife schmal und undentlich, dagegen mit isolierten, deutlichen roten Wurzelfleckchen. Am Vorderrande ein kurzer gelber Wurzelwisch. - Vorderflügellänge etwa $37 \mathrm{~mm}$.

Bolivia (Cocapata, Tunampaya, Gebiet des Rio Juntas).

F orma venusta. Im allgemejnen wie die Hauptform, aber der Discalfleck rein gelb, häufig bis über den hinteren Medianast hinausreichend; der schwarze Kern am Zellende fehlt öfters ganz, die das Gelb schneidenden Adern fein schwarz. Rote Bestäubung im proximalen Teil des Vorderflügels und Strahlenzeichuung des Hinterflügels in intensiverem dunklem Ton, die Strablen meist etwas länger. Im übrigen wie die Hauptform, zu der Übergänge mit den Anfängen roter Bestäubung des Vorderflügelfleckes vorkommen, auch deutet das Auftreten von Spuren eines gelben Medianstreifes des Vorderflügels und von Rudimenten eiwer gelben Querbinde des Hinterflügels auf die Zusammengehörigkeit mit H. e. phyllis, andererseits sind Übergänge zu H. e. lativitta (S. 207) nicht selten. Meist etwas größer als die Hauptform.

Bolivia (Apolobamba, Iungas, La Paz).

Forma sanguinea. Wie die vorige Form und die Hauptform, aber der Vorderflügelfleck völlig rot, und zwar zinnober- bis orangerot. Das Rot des proximalen Vorderflügelfeldes zuweilen zu einer breiten geschlossenen Fläche verbreitert.

Bolivia (Gebiet des Rio Juntas).

63 k. H. erato phyllis (F.) 1775 Papilio p., J. C. Fabricius. Syst. Ent., p. 463 1781 P.p., J. C. Fabricius, Spec. Ins., v. 2 p. 31 i787 P. p., J. C. Fabricius, Mant. Ins., $v .2$ p. $15 \mid 1790$ P. p., J. F. W. Herbst, Naturs. Ins. Schmett., v. 4 p. 135 t. 73 f. $1 \mid 1793$ P. p., J. C. Fabricius, Ent. syst., v. 3 I p. $171 \mid 1807$ P. p., Mechanitis (part.), (J. C. Fabricius in:) Illiger in: Jlag. Insektenk., v.6 p.284| 1806-16 Sunias p., Jac. Hübner, 
Exot. Schmett., 2.2 t. [t] 1816 S.p., Jac. Hübner, Verz. Schmett., p. $12 \mid 1819$ Heliconia p., (Latreille \&) J. B. (Godart iu: Enc. méth.. 2.9 p. 208 | 1844 H.p., E. J)oulsleduy, List Lep. Brit. Mus., $v .1$ p. jõ $18+7 H . p$., E. Doubleday (\& Westwood), (Ben. diurn. Lep., $v 1$ p. 103 $187+\& 81$ H.p., Capronmier in: Amn. Soc.ent. Be]gique, r. 17 p. $23 ; v .25$ p. 991820 Laparusp., Billberg, Enum. Ins., p. 77 | 183\% "Heliconiep. ", H. Lucas, Hist. Lép. exot., p.94; t. 49 f. 3 (forma urtifex) | $18 \pm 0$ Heliconius p., F. Blanchard in: Hist. An. artic., $v .3$ Lep. t. 10 f. ") 1869 H. p., A. G. Butler, Cat. diurn. Lep. Fubr., p. 122 | 1871 \& 77 H. p., W. F. Kirby, Cat. diurn. Lep., p. 143; Suppl. p. 721 | 188 a H.p., O. Staudinger (\& Scliatz), Exot. Schnett., v. 1 p. 79 | 1888 H.p., B. P. Mann in: P.ent. Soc. Washington, $\iota .1$ p. $41 \mid 189+H . p$. Weymer in: Ent. Zeit. Stettin, $r$. 5 p. 321 | 1900 H. p., W. F. Kirby. Lixot. Sehmett. Hübner, p. 12 | 1896 Heliconias p., Bönningluasen in: Verh. Ver. Hamburg, v. 9 1. 32 1775 \& 76 "Roxane*, P'upilio roxane, P. Cramer, Pap. exot.. v. I p. 71 t.45 f. E, E; p. 154 $1779, P$. phyllis" $+. P . r . "$, Goeze, Ent. Beytr., v. 3 I p. 110 : p. $116: 1845$ Heliconia phyllus, Prittwitz in: Ent. Zeit. Stettin, v. 26 p. 136 | 1892 Heliconius phyllidis, Grose Smith \& IV. F. Kirby, Rhop. exot., r.1 Helicon. t. 1 f. 4, p.2 (forma p.) 1894 H. phyllis forma phyllides, 0 . Staudinger in: 1). ent. Z. Lep., $x .7$ l. 68 (forma phyllidis) 1896 H. amalus, H. amanulus aberr.?, O. Stuudinger in: D. ent. Z. Lep., c.9 p.301 (forma anata) | 1900 H. phyllis aberr. amatus, Riffarth in: Berlin. ent. Z., 2.45 1. 213 (forma amata) | 1899 H. p. aberr. artifex, Stichel in: Ent. Nachr., v. «5 p. 30) (forma a.) 190] H. p. +H.p.a. +H.p. amatus +H.p.phyllides, Rifarth in: Berlin. ent. Z., r.46 p. 168; p. 169 (forma artifex); p. 169 (forma anata); p. 169 (lorma phyllidis).

Forma principalis. Flügel mit tief schwarzbranner Grundfarbe wie bei den rorigen Unterarten und ron gleicher Gestalt. Ton der Wurzel des Vorderflïgels aus längs der Mediana in der Zelle ein schmaler gelber Streif, der am Ursprunge des hinteren Medianastes durch erstere Ader schmal unterbrochen ist und sich an letzterem, jedoch nur in Gestalt eines den Aderwinkel ausfüllenden länglichen Endfleckehens, fortsetzt. Distal von der Zelle eine breite rote Querbinde, welche hinter dem schmal schwarzen Vorderrande beginnt, proximal die vordere Zellecke meist ausfüllt und sich an der hinteren Zellecke in kurzer Biegung in der Richtung der Mediana bis zum hinteren Medianast, der die Grenze bildet. wurzelwärts wendet. I) distale Begrenzung verläuft in großen und ganzen in meist flach konvexem Bogen, ist jedoch im hinteren Terlauf zweimal melı oder weniger eingekerbt, so daß 2 oder 3 zackenartige, gegen den Distalrand gerichtete Vorsprüuge entstelıen, von denen der vordere auf dem vorderen Medianast liegt, ganz liurz bleibt, zuweilen sogar kaum wahruehmbar ist, der hintere etwas schärfer auftritt, der mittlere indes bis nahe zum Rande reicht. Zuweilen tritt das Rot proximal in mehr oder weniger dicliter Bestäubung in die Zelle oder verbindet sich hinten mit dem lindHeck des Mediaustreifes. In selı seltenen Fällen treten nocl linter dem hinteren Medianast verloschene Spuren rötliclıer Bestäubung auf. - Hinterflügel mit gelber Querbinde, die an Hinterrande dicht bei der Flügelwurzel heginnt, rorn in flachem Bogen durch die Wrurzel des linteren Medianastes und der rorderen Radialis läuft und, der Subcostalis in liurem Abstande folgend, in einer lang ansgezogenen, mehr oder weniger scharfen Spitze etwa $4-5 \mathrm{~mm}$ rom Apex entfernt endet. Beim $\sigma^{\pi}$ grenzt dieser letzte T'eil unmittelhar an das dunkelgrau gläuzende Vorderrandfeld. In seltenen Fällen die das Band durchschneidenden Adern schwarz. - Unterseite matter, Grundfarbe dunkelbraul, Medianstreif meist weniger ausgedehnt. Farbe der hier schmaleren Binde weißlich rot, die Begrenzung stärker rot. der Zahn auf dem mittleren Medianast sclımaler, gleichmäßiger zapfenartig;, bis dicht an den Distalrand rorspringend. Am Torderrande ein liurzer roter Wurzelstreif. Hinterflügel mit kurzem gelben Costalstreif, dentlichen roten Wurzelflecken. Farbe der Binde gelblichweiß, im Apex mit geringen Ausnahmen einige gelbliche Randfleckchen, mit denen sich die weiter als oben 
ausgedehnte Querbinde manchmal vereinigt; hinter letzterer, namentlich am Hinterrande, ein oder mehrere rote Fleckehen, von denen der proximal liegende, seltener mebrere, punktartig nach oben durchschlagen. - Vorderflügellänge $2 \tilde{j}-40 \mathrm{~mm}$.

Paraguay: südliches und mittleres Brasilien. Peru, Bolivia.

Forma artifex. Wie die Hauptform, aber auf dem Hinterflügel hinter der gelben Querbinde 4 oder 5 rote, längliche, vom Hinterrande ausgehende Fleckchen, die Rudimente der roten Strahlenzeichnung der typischen Unterart.

Paraguay, Brasilien (Espirito Santo).

Forma phyllidis. Wie die Hauptform, aber die gelbe Querbinde des Hinterffügels schwärzlich überstäubt und von den stark schwarz gefärbten Adern durchschnitten. Bei extrem gebildeten Stücken die Binde völlig überstäubt, der Flügel also einfarbig schwarz. In diesem Falle die rote, wie bei der Hauptform variable Querbinde des Vorderflügels den distalen Teil der Zelle ausfüllend und auf den Discocellulares schwarz gekernt, der gelbe Medianstreif in der Regel verkümmert. Die Saumfleckchen im Apex der Hinterflügelunterseite fehlen meist.

Bolivia (Bueyes), Paraguay.

Forma amata. Gelber Medianstreif des Vorderfiügels meist fehlend. Rote Querbinde wie bei der Hauptform. sehr variabel. Gelbe Querbinde des Hinterflügels mehr oder weniger schwarz überstäubt, ohne abgesetzte Schwarzfärbung der Adern. Hinterflügel im einzelnen bckannten Falle ( $Q$ ) nur mit dem Anfange der Binde in Gestalt eines gelben Fleckchens am Hinterrande. Apicalfleckchen der Unterseite des Hinterflügels meist rorhanden.

Bolivia (Bueyes, Chiquitos).

631. H. erato anacreon (rrose Sm. \& F. Kirby 1892 H. a., Grose Smith \& W. F. Kirby, Rhop. exot.. v. 1 Helicon. t. 1 f. 5 p. 3 1894 H. a. (hybr.: H. anactorie (H.amandus) $\times H$. phyllides), O.Staudinger in: D. ent. \%. Lep., $x .7$ p.68 | 1900 H. phyllis aberr. ottonis, Riffarth in: Berlin. ent. Z., v.45 p. 212 (forma o.) |.1901 H.p.o. + H. $p$. anacreon, Riffurth in: Berlin. ent. Z.. x. 46 p. 167 (forma o.); p. 169.

Forma principalis. Wurzelfeld des Vorderflügels (Fig. 38) neben dem etwas undeutlicheren gelben Medianstreif mit mehr oder weniger

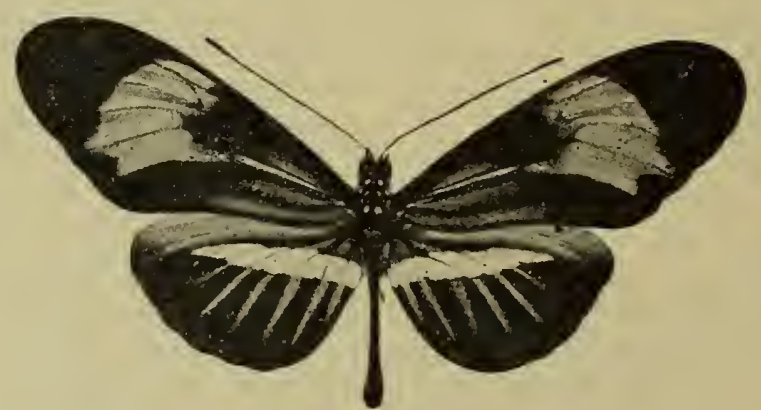

Fig. 38. H. erato anacreon, forma principalis, $\delta\left(1_{1}\right)$.

starken roten Wischen in der Zelle und hinter derselben in der Art wie bei H. e. anactorie, forma principalis und forma renusta (S. 208). Rote Querbinde wie bei H. e. phyllis (S. 208) und auch, wie dort. proximal bisweilen 
mit dem Medianstreif an der hinteren licke zusanmenhängend. - Hinterflügel mit der gelben Querbinde, wie bei H. e. phyllis, und der der Art eigenen roten Strallenzeichumng dergestalt. dab die roten Streife, wo sie in das Gelh bineinragen, anf diesen Untergrund anfgelegt zu sein scheinen. Hs ist vorhanden: ein zuweilen schleifenartig gebildeter Streif von der Wurzel aus längrs gelagert in der \%elle, ein kurzer Wisch am Hinterrinde, der auch fehlen kann, ein kurzer, proximal voller, darauf folgend ein längerer, proximal in der gelben Binde länglich gespaltener Streif, beide ebenfalls von der ITurzel ausgehend, und vier hinter der Zelle beginnende, allmählich wieder etwas kürzer werdende Stroife nebeneiuander, sämtlich proximal ziemlich schmal, daun etwas rerbreitert und spitz auslaufend, ohne den Rand zu berïhren. Unterseite des Vorderflügels wie bei H. e. phyllis, Strahlenbildung des Hinterflügels viel schwächer, proximal zuweilen ganz undeutlich und durch rote Wurzelfleckchen ersetzt, Es gibt Übergänge zu H. e. anactorie (S. 207) mit rudimentärer Ausbildung der gelben Hintertlügelbinde und teilweiser Gelbfürbung der Vorderflügelbinde, oder zur folgenden For'm mit letzterer Figenschaft allein.

Bolivia (Bueyes, Chiquitos), Peru.

Forma ottonis. Querbinde des Vorderflügels gelb statt rot. Sonst wie die Hauptform, aucl mit der variablen Formation der Binde der Hanptform.

Bolivia (Chiquitos, Bueyes).

64. H. amphitrite Riff. 1901 H. phyllis a., Riffarth in: Berlin. ent. Z., v. 46 p. 157 ? 1902 "Heliconir vesta-melpomene“, C. Oberthür, Étud. Ent., v. 21 t. 9 f. 102

\%. Palpen an der nach auBen gerichteten Seite his anf die schwarze Spitze gelb. Antenuenwurzel unten weiß, Kopf nnd Körperzeichnung gelb. Gestalt wie die der vorigen Arten. - Grundfarbe tief schwarzhraun ohne Blauglanz. Vorderflügel mit breiter. fast die ganze discale Breite des Flügels ausfüllender, schräg gestellter, fleckartiger Binde von orangeroter Farbe. Der vordere. linter dem schmal schwarzen Torderrande beginneude Teil derselben schmaler und ron der schwarzen Subcostalis abgeschnitten. Dis Zellende liegt etwa in der Mitte der Bindeubreite, und diese ist an der Winklung der Discocellulares mehr oder weniger schwarz gekernt. Die proximale Grenze der Binde verläuft von der Subcostalis schrïg durch die Zelle zum hinteren Medianast, ohne den vorderen Basiswinkel des letzteren auszufüllen. ist damn in der Regel etwas abgesetat und endet. stumpf oder rundlich in die hintere Begrenzung n̈bergehend, an der Submediana. Die distale Begrenzung läuft bis etwa zum mittleren Medianast mit der proximalen parallel, ist aber ctwas gezackt und wendet sich ron da etwas steiler schräg gegen den hinteren Medianast, um sich in stumpfer Ecke nächst dem Hinterwinkel des Flügels mit der hinteren Begrenzung zu rereinigen. Im großen und ganzen bildet die Zeichnung ein schräg gestelltes Rechteck, mit zicmlich scharfer Begrenzung. dessen schmalere Seiten vorn parallel dem Torderrande. linten schräg rom Hinterrinde gegen den Distallaind stehen, ohne den einen oder anderen zu erreichen. Unterseite matter. Querbinde gellhlich. an den Rändern rot, nuregelmäBiger, namentlich distal stärker gezackt. alm hinteren Medianast zapfenartig gegen den Distalland vorspringend und wenig über den ersteren hinausreichend. - Hinterffügel mit dunkelgrau glänzendem Torderrandfelde, sonst zeichnungslos. Unterseite matter, mit ziemlich langem, intensiv gelbem Costalstreif, 3 oder 4 roten Wurzelflecken und einem gelblichen Tupf an der Spaltung der Mediana und Subcostalis. - - ․ Gleicht dem $\sigma^{\pi}$, abgesehen ron den clarakteristischen 
Geschlechtsunterschieden. - - Unterscheidet sich von dem ähnlichen H. erato callycopis, forma viculata (S. 204), hauptsächlich durch Farbe und Größe der Vorderflïgelbinde, in der die Adern übrigens in der Regel fein aber tief schwarz angelegt sind. Torderflügellänge etwa $41 \mathrm{~mm}$.

Peru (Hillapani).

65. H. hermathena (Hew.) 1853 Heliconia h., Hewitson, Exot. Butt., v.1 Heliconia t. 2 f. 5 | 1862 Heliconius h., H. IV. Bates in: Tr. Linn. Soc. London, v. 23 p. $556 \mid 1871$ $H . h$. W. F. Kirby, Cat. diurn. Lep., p. 141 | 1877 H. h., A. G. Butlor in: 'Tr. ent. Soc. London, p. $125 \mid 1901$ H. h., Riffarth in: Berlin. ent. Z., v. 46 p. 171.

ठ․ Palpen an der nach außen gekehrten Seite schwefelgelb, innen weißlich bis auf das schwarze Endglied. Stirnflecke, Punktierung auf Kopf und Halskragen, sowie Körperzeichnung gelb. Form der Flügel wie die der vorhergehenden Arten, ziemlich breit, Apex des Vorderflügels abgerundet, der des Hinterflïgels nur wenig hervortretend. Grundfarbe schwarzbraun. Vorderflügel mit gelbem, etwas schwärzlich überstäubtem Wurzelstreif in der Zelle längs der Mediana, welcher sich bis zum binteren Medianast erstreckt. dort von der fein schwarzen Mediana zerschnitten wird und sich, allmählich zugespitzt, an dem genannten Ast bis zu dessen Mitte oder etwas kürzer in proximaler Richtung fortsetzt. Distal von der Zelle, deren Endecken fast beriihrend, eine gelblichrote breite, schräg liegende Querbinde, die vorn hinter dem schmal schwarzbraunen Vorderrande beginnt und in hinteren Medianzwischenraum endet. Begrenzung ziemlich bestimmt und nur an der proximalen Seite etwas gezackt. Diese ist an der vorderen Zellecke etwas abgesetzt, läuft schräg bis kurz über den mittleren Medianast hinaus, obne den vorderen Basiswinkel des letzteren ganz auszufüllen. Die distale Grenze zieht sich schrïg bis zum vorderen Medianast, wendet sich dort in kurzem Abstande vom Distalrande nach binten und rereinigt sich mit der hinteren Begrenzung in einem fast rechten Winkel. Unterseite matter in der Grundfarbe. Der Medianstreif reiner gelb, die Querbinde gelblichweiß überstäubt bis auf die etwas intensivere Begrenzung. Hinterrandfeld nächst einem schmalen Streif mattbramer Bestäubung dunkel graubraun mit schwachem Glanz. - Hinterflügel mit eben solchem, etwas stärker glänzendem Vorderrandfelde und einer vom vorderen Teil des Hinterrandes atusgehenden, von den schwarzen Adern durchschnittenen gelben Querbinde, deren distale Begrenzung durch die Wurzeln des hinteren Medianastes und der hinteren Radialis läuft, deren proximale Begrenzung kurz hinter der Zellecke verläuft, und welche an der Subcostalis, etwa $+-5 \mathrm{~mm}$ vom Apex entfernt, stumpf endet. Sie ist ziemlich ganzrandig, au der Umgrenzung, namentlich hinten und distal, etwas schwärzlich überstäubt. Am Distalrande eine Reihe kleiner, vorn verloschener und im Apex allmählich verschwindender Saumfleckchen, und eine Reibe größerer und kräftigerer Fleckchen von gelber Farbe nahe dem Saum. Die Flecke beider Reihen liegen parrweise zwischen den Adern, beginnen gemeinsam am Hinterrande kur' vor dem Hinterwinkel. entfernen sich sodann beträchtlich voneinander dadurch, daß die proximale Reihergerade läuft. die distale der Biegung des Saumes folgt, und nähern sich gegen den Apex wiederum. Unterseite mit denselben Zeichnungen, die Saumfleckchen bis zum Apex deutlich, die Mittelbinde distal noch die Subcostalis überschreitend. Ferner ein gelber kurzer Wurzelstreif am Vorderrande, 3 rote Wurzelflecke zwischen den Adern und ein kleiner weißlicher Fleck auf der Wurzel der Mediana. - - $Q$. Im allgemeinen wie das $\sigma^{2}$, jedoch mit den charaliteristischen Geschlechtsunterschieden. Vorderflügel im Apex auf den Aderı rötlich 
bestäubt, ebenso der an hinteren Meclianast liegende spitze Ausläufer des Wurzelstreifes. Zwischen Querbinde und der proximalen Sanmfleckenreile am Hinterrande mitunter ein roter Fleck. - - Vorderflïgellänge bis $42 \mathrm{~mm}$.

Gebiet des unteren Amazonen-Stroms (Santarem, Thomar, Mlassauary, Tabajoz).

H. carolina (Herbst) 1790 P'upilio c., .I. F. W. Herbst, Naturs. Ins. Schmett., ¿. 4 p. 131 t. 72 f. 2 1900 Heliconius c., Riffarth in: Berlin. ent. Z.. v. 45 p. 195.

Scheint, soweit ans der Abbildung und der (ieäderzeichnung zu schließen, ein gefälschtes Stiick zu sein. zusamnengesetzt aus den Vorderflïgeln inn II. e. callycopis, forma principalis und forma viculata (S. 202 und 204) dergestalt, daß die der letzteren Form rundlich zugeschnitten als Hinterfligel verwendet worden sind.

Heimat unbekannt

\section{j. Coh. Charithoniformes}

Kopf schwarz. Augen dnukelbraun, hinten weiblich oder gelb gesïumt. Stirn mit zwei gelblichen orler weißen. teilweise von den Palpen verdeckten Flecken. Kopf oben mit vier paarweise zwischen den Augen stehenden gelben Fleckchen. am oberen Samm der Augen noch je ein kleiner gelher P'mkt. Palpen heiderseits gelb oder gelblich, nur oben distal schwarz behart oder mit schwarzer Spitz. Endglied innen schwarz. Antenuen schwarzbran. die Spitze der Kéule beim o etwas brännlich anfgehellt, etwa von der Länge der Zelle, an der Wurzel unterseits etwas weib. Körper schwarzbraun, Halskragen. Thorax und Abdomen mit gelbeu Zeichunngen wie bei der vorigen Gruppe. Abdomen wenig oder nicht ïber den Hinterffügel hinausragend. Lnterseite des 'Thorax und Torderbeine reichlich gelb, nächst der Flügelwurzel beiderseits ein roter Fleck, dessen Vorlandensein sich bei einigen Form. en nicht mit Sicherheit nachweisen läBt. - Vorderflügel schlank, schmaler als bei den Vertretern der rorigen Gruppe, Vorderrand flach gekrüınmt, Apex scharf algerundet. Distalrand vorm leicht konvex, sodann zicmlich gerade oder ganz flach konkar schräg zurïcktretend. Hinterwinkel stumpf, Hinterrand leicht S-förmig geschweift, etwa ron $\frac{2}{3}$ der Länge des Vorderrandes. Hinterflügel abgerundet dreieckig. die Seiten leicht konrex. Apex ziemlich scharf hervortretend. Distalrand wellig, Hinterwinkel abgerundet. Torderrandfeld beim o dunkelgrau, kaum glänzend, beim o nur wenig heller als die Grundfarbe. - Falter von schwarzer bis schwarzhrauncr Grundfarbe. Torderflügel mit gelhem Medianstreif und gelben oder weißlichen Schräghinden. oder im proximalen und hinteren 'T'eil rotbraun mit breit schwarzem, gelb geflecktem Apex. Hinterflügel mit gelber Querbinde und gelber oder weißer Fleckenreille unweit des Distalrandes, oder rorwiegend gelb oder ockergelb, dunkel gesümınt.

3 Arten, von denen eine in 2 Unterarten zerfällt.

66. H. charithonia (L.)

o. Punktiermug und Zeichnung des Kopfes und Körpers schwefelgelb. Grundfarbe ticf schwarzbraun. - Vorderflügel mit gelbem Medianstreif, der sich an der Abzweigung des hinteren Medianastes gegen den Distalrand wendet, entweder in der Mitte dieses Astes spitzwinklig endet odler bis nahe zum Saum ansläuft. Distal rou der \%elle eine scliwefelgelbe Sclurïghinde. die längs des vorderen Medianastes his dicht zum Distalıande zicht, oder verkürzt an diesem Ast unweit der hinteren Zellecke endet und dann weißlich gelb oder weiß ist. Endlich eine subapicale schmale aber kräftige, gellse oder 
weiße, dann weniger volle und hinten verloschene, schräge Querbinde. Unterseite mit den Zeichnungen der oberen Seite, die Binden meist weiter ausgezogen, deren Färbung, sowie die Grundfarbe matter. Hinterrandteil nächst einem schmalen gelben Streif an der Mediana grau, etwas glänzend bis auf den weißlich gefleckten dunkelgrauen Hinterwinkel. - Hinterflügel mit rotem, manchmal undeutlichem Wurzelpunkt vor der Subcostalis, zuweilen mit einem zweiten solchen hinter der Mediana und mit gelber, flach gekrümmter Querbinde, die am Hinterrande vorn beginnt, mit ihrer vorderen Begrenzung durch den Winkel des hinteren Medianastes, zuweilen auch etwas weiter vor demselben, und den Winkel der vorderen Radialis läuft, dann der Submediana in schmalem Abstande folgt und mehr oder weniger weit vom Apex in stumpfer Spitze endet. Hinter derselben eine im Anfang ziemlich gerade, sodann nach vorn gekrümmte und dort subapical gestellte, in den Vorderrand laufende Reihe von gelben oder weißen Fleckchen, je zwei paarweise in den Aderzwischenräumen, und endlich etliche, zuweilen obsolete gelbe oder weißliche Saumpunkte vom Hinterwinkel aus. Unterseite matter, mit derselben Zeichnung, außerdem einem kurzen weißlichen Wurzelstreif am Vorderrande, 2 oder 3 roten isolierten Wurzelfleckchen, zwei weiteren, nebeneinander stehenden roten Flecken am Hinterrande zwischen Querbinde und Punktreihe und zwei rötlichen, subapicalen dreieckigen Fleckchen. Saumflecke gröBer und bis zum Apex deutlich. - - o. Wie das 0 , mit den charakteristischen Geschlechtsunterschieden. - - Fransen des Vorderflügels schwarzbraun, auch stellenweise weißlich unterbrochen, die des Hinterflügels weißlich, schwarzbraun unterbrochen, oder an beiden Flügeln vorwiegend weiß.

Chile, Peru, Ecuador, Colombia. Venezuela. Mittel-Amerika, südliches NordAmerika, Antillen.

Diese Art zerfällt in 2 Unterarten:

66 a. H. charithonia charithonia (L.) 1767 Papilio (H.) c., Linné, Syst. Nat.. ed. 12 v. 2 p. $757 \mid 1871$ H. c., W. F. Kirby, Cat. diurn. Lep., p. $41 \mid 1874$ H. c., A. G. Butler \& Herb. Druce in: P. zool. Soc. London, p. $351 \mid 1881$ H. c., J. Gundlach, Contr. Ent. Cubana, $v .1$ p. 20 | 1881 H. c., F. D. Godman \& O. Salrin in: Biol. Centr.-Amer., Lep.-Rhop. v. 1 p. 151 | 1890 H. c., Weymer (\& Maassen), Lep. Reise Stübel, p. 27, 36 | 1901 H. c., Riffarth in: Berlin. ent. Z., v. 16 p. 171 1901 H. c., F. D. Godman \& O. Salvin in: Biol. Centr.-Amer., Lep.-Rhop. v. 2 p. $667 \mid 1875$ Apostraphia c., S. H. Scudder in: Bull. Buffalo Soc., v. 2 p. 247 1902 A. c., Dyar in: Bull. U. S. Mus., v. 52 p. $32: 1770$ Papilio charitonia, J. C. Fabricius, Syst. Ent., p. $462 \mid 1777$ „Charitonia", P.c., P. Cramer, Pap. exot., v. 2 p. 145 t. 191 f. F.; p. $148 \mid 1779$,P. c.", Goeze, Ent. Beytr., c.. 3 r p. 101 1781 P.c., J. C. Fabricius, Spec. Ins., v. 2 p. $130 \mid 1787$ P. c., J. C. Fabricius, MIant. Ins., v. 2 p. $15 \mid 1790$ P. c., J. F. W. Herbst, Naturs. Ins. Schmett., v. 4 p. 163 t. 76 f. $2 \mid 1793$ P. c., J. C. Fabricius, Ent. syst., $v .3$ I p. $170 \mid 1816$ Apostraphia c., Jac. Hübner, Verz. Schmett., p. 13 | 1819 Heliconia c., (Latreille \&) J. B. Godart in: Enc. méth.. v. 9 p. 210 1833 H. c., Boisduval \& .J. E. Leconte, Lép. Amér. sept., v. 1 p. 140 t. 41 | 1844 H.c., E. Doubleday, List Lep. Brit. Mus., v. 1 p. $53 \quad 1847$ H.c., E. Doubleday (\& Westwood). Gen. diurn. Lep., v. 1 p. $102 \mid 1870$ H. c., Boisduval, Consid. Lép. Gruatemala, p. 28|1877 H. c., H. Dewitz in: Ent. Zeit. Stettin. v. 38 p. 237 | 1882 H. c., W. H. Edwards, Butt. N.-Amer., v. 2 Heliconia t. $1 \mid 188+$ H. c., W. H. Edwards in: Tr. Amer. ent. Soc., v. 11 p. $266 \mid 1835$ Heliconius c., H. Lucas. Hist. Lép. exot., p. 95 t. $50 \mid 1869$ H. c., A. G. Butler, Cat. diurn. Lep. Fabr., p. $123 \mid 1877$ H. c., W. H. Edwards in: Tr. Amer. ent. Soc., $x .6$ p. $18 \mid 1880$ H.c., F. D. Godman \& O. Salvin in: Tr. ent. Soc. London, p. $122 \mid 1881$ $H$. c.. W. H. Edwards in: Canad. Ent., $v .13$ p. $157 \mid 1881$ H. c, W. H. Edwards in: Papilio, v. 1 p. $209^{\circ} 188$ I $^{\circ}$ H. c., O. Staudiuger (\& Schatz), Exot. Schmett., v. 1 p. 76 1886 H. c., G. W. Müller in: Zool. Jahrb., v. 1 p. $430 \mid 1886$ \& 87 H. c., Möschler iu: Abh. Senckenb. Ges., v. 14 III p. 27; v.15I p. 95 | 1899 H. c., W. J. Kaye in: Ent. Rec., v. 11 p. 1451900 H. c., A. G. Butler in: Entomologist, v. 33 p. 1901893 H. charitonius, W. J. Fox \& C. W. Johnson in: Ent. News Philad., v. 4 p. 3. 
Oben alle Zeichnuıgen außer den Wurzelflecken des Hinterflïgels schwefelgelb. Medianstreif sehmal, heiderseits der fein schwarzen Mediana, distal allnählich verbreitert, am hinteren Medianast stumpfwinklig gegen den Distalramd gerichtet, dem geninuten Ast vorn unmittelbar aufliegend und allmählich wieder verjüngt in nächster. Nähe des Distalrandes mit stumpfer Spitze endigend. Zwischen letzterer und den Rande indes noch ein gelbes Fleckchen. Discalbinde heginnt hinter dem fein schwarzen Vorderrande. berührt die vordere Zellecke, läuft schräg bis zum vorderen Medianast und längs desselbeu, allmählich versehmälert, bis dicht zum Distalrande. Die Subapicalbinde beginnt ebenfalls dicht linter dem fein sehwarzen Vorderrande, beriihrt die Gabel des 4. und 5. Subcostalastes und läuft schräg bis zur vorderen Radialis, überschreitet diese ein wenig und wendet sich hinter ihr his nahe zmm Distalrande. - Querbinde des Hinterflügels leicht gekrümmt, vom Winkel der vorderen Radialis der Subcostalis folgend und in stumpfer Spitze nahe dem Apex endigend. Die einzelnen Punkte der hiuter ihr, etwas näher dem Distalrande verlaufenden Reilıe in der Mitte etwas größer als in der Nähe des Apex, dort manchmal verloschen, zwischen letrterem und der Bindenspitze nach vorn gebogen. 1 oder 2 rote Wurzelfleckchen, vom Hinterwinkel aus mehr oder weniger deutliche Saumpunkte. - Vuterseite matter. Vorderflügel wie oben gezeichnet, alle drei Binden distal bis nnmittelbar an den Saum reichend, dort manchmal etwas rötlich bestänbt, die discale und subapicale Binde weißlich, zwisehen heiden und binter den Streif an Medianast etliche weißliche Saumfleckehen, am Vorderrande ein kurzer roter Wurzelstreif. Hinterflügel anßer den matter gefärbteu Zeichnungen der Oberseite mit kurzem weißlichem Wurzelstreif am Vorderrande, 2 oder 3 roten Wnzelflecken, zwei weiteren, nebeneinander stehenden roten Flecken zwischen der Binde und der Punktreihe am Hinterrande; am Distalrande dentliche Saumfleckelien, die Flecke der Pnnktreihe in Apex schärfer. zwischen diesen und der Bindenspitze zwei rötliche keilförmige Fleckehen. - Fransen vorwiegend schwarzbraun, am welligen Samm des Hintertlïgels stellenweise weiblich oder grau unterbrochen. Stücke aus Mittel- und Nord-Amerika bäufig mit verbreiterten, der Abbildnng von Cramer entsprechenden Binden. diese zuweilen rötlich angeflogen. Vorderflügellänge his $47 \mathrm{~mm}$.

Variiert selten. Aus Nord-Amerika (Edwards) sind einzelne individnelle Aberrationen bekannt, so eine Form, bei welcher auf dem Vorderflügel zwisehen den beiden gelben Jändern im distalen Teil, etwa in der Mitte zwischen Zelle und Distalrand, noch ein großer gelber Wischfleek steht, und eine andere mit weißer, statt gelber Punktreilıe hinter der Binde des Hinterflügels; auch sind die gelben Binden zuweilen teilweise rötlieh angehaueht oder bestäubt.

Fi gelb, zuekerhutförmig, oben abgestnmpft, Basis flach. Senkrecht und wagerecht gerippt, derart, daß die erluabenen Längs- und Querrippen vertielte, list rechtwinklige Zellen mit abgernudeten Ecken einschließen, die im oberen 'Teil des Kegels größer, besser gewinkelt und tiefer sind. - Raupe walzentörmig, in der .lugend falıl braunrot bis hellh)raun, anfangs mit if Reihen Warzen, auf jeder derselben eine sehwarze Borste; die oberen Reihen, seitlich je 2. länger als die unteren; später Dornen anstatt der Borsten. Erwachsene Raupe grünlich-gläsern weiß, $31-38 \mathrm{~nm}$ lang. Kopf lundlieh. abgestumpft, rorn etwas eingedrüekt. seitlich gewölbt; Mandibeln seitlich schwarz. mit stumpfen Borsten. Kö̈rper sehlank, walzenförmig. an den Segmenteinschnitten fahl weißlieh, unbehaart. sehwarz order braun gefteckt. Flecke iiber Kreuz in parallele Reihen gestellt und zwar in einer dorsalen und zwei seitlielıen Reilen. Über der unteren ventralen Reihe des $4 .-11$. Segmentes ein brzmer Wisel, ein anderer auf jedem Stigma. Unterseite rötlichbraun nit grïnlichem Ton. Auf dem 2. Seguent dorsal eine elitinöse Erhöhung, welehe in der Mitte geteilt ist nnd auf jeder der so entstehenden beiden Kuppen zwei schwarze, behaarte Wrarzen trägt. Körper jederseits mit 3 lieihen schwarzer 
spitzer verzweigter Dornen, einer subdorsalen, einer mittleren lateralen und einer infrastigmalen Reihe; die Dornen der obcren beiden Reihen gerade und aufrecht, die der unteren abwärts gerichtet und etwas gekrümmt. Beine braun, schwarz gefleckt. Auf Passiflora coerulea L. und anderen Passifloren. - Puppe schlank, seitlich zusammengepreßt, 'Thoraxsegmente mit den Flügelscheiden rentral stark konvex hervortretend, die letzteren durch eine rertiefte Rille getrennt, beiderseits dieser eine Reihe kleiner, knopfartiger Warzen, jede mit einer kurzen Borste. Die Rille erweitert sich vorn und schließt die Antennenscheiden ein, die Warzen setzen sich an der Kopfscheide bis zum Scheitel an der dorsalen Seite fort, dort aber ohne Borsten. Kopfscheide gewölbt, der Länge nach zusammengepreßt, der Scheitel eckig, mit zwei langen, blattähnlichen, flachlanzettlichen, wenig divergierenden Fortsätzen. Mesonotum kielartig zusammengedrückt, vorn doppelt konkav eingebuchtet, dann eine sclarfe Spitze bildend und hinten abschüssig gesenkt, hierauf in eine rundliche Einbuchtung auslaufend. Abdomen valzenförmig, die beiden vorderen Segmente mit einem langen subdorsalen flachen Fortsatz, der an den Rändern unregelmäßig gewellt ist. Auf dem nächsten Segment ein kleiner scharfer rundlicher Fortsatz, das folgende mit einem kleinen unregelmäßigen Höcker und einer zuweilen verlängerten spitzen Warze. An den Spitzen aller dieser Fortsätze Dornen, je einer auf den kleineren, zwei auf den größeren. Auf der Einbuchtung und an den Seiten des Mesonotum viel kleine kegelförmige bedornte Warzen. 9., 10. und 11. Segment ventral an den Kanten aufgebogen und in zwei divergierende Spitzen auslaufend. An der Basis der Kopfscheide dorsal ein großer glänzender goldener Fleck, und die IVarzen hinter dem Mesonotum ebenfalls goldig. Farbc im allgemeinen braun, die vorderen 'Teile, Kopf, Mesonotum und die Hälfte der Flügelscheiden, lichter oder gelblich. Das übrigc dunkelbraun oder braun und grau gestreift. Fortsätze auf dem Kopf und Antennenscheiden braun. Puppenruhe 6-7 Tage. [Nach Edwards.]

Colombia, Venezuela, Mittel-Amerika, Texas, Kalifornien. Florida, Georgia, South (arolina, Antillen (Cuba, Porto Rico, Jamaica).

66b. H. charithonia peruvianus (C. \& R. Felder) 1859 Heliconia peruviana, C. \& R. Felder in: Wien. ent. Monschr., v. 3 p.396 | 1871 Heliconius p., W. F. Kirby, Uat. diurn. Lep., p. 141 | 1879 H. peruvicnus, Hopffer in: Ent. Zeit. Stettin. v.40 p.434| 1885 H. peruviana, O. Staudinger (\& Schatz), Exot. Sehmett., $v .1$ p. 76 | 1890 H. p., Weymer (\& Maassen), Lep. Reise Stübel. p. $65 \mid 1901$ H. charithonia p. (H. aganice Plötz in MS.), Riffarth in: Berlin. ent. Z., $v .46^{\circ}$ p. 172.

Kleiner als die typische Unterart, Flügel etwas kürzer und gedrungener. - Medianstreif hellgelb; er zieht sich bei der Abzweigung des hinteren Medianastes in schmalem Streif auch binter demselben entlang und endet, dreieckig zugespitzt, etwa in der Mitte der Ader. In der Verlängerung. unweit des Saumes, ein trübes gelbes Fleckchen. Discalbinde gelblichweiß oder weiß, verschmälert und bedeutend verkürzt; sie endet am vorderen Medianast, ohne längs desselben in distaler Richtung wesentlich auszufließen. Subapicalbinde schmaler, weiß. an den Adern mehr oder weniger eingeschnitten oder zerteilt, im hinteren Verlauf verloschen. Mittelbinde des Hinterflügels schmaler, beim ㅇ kürzer, weißlichgelb. Die hinter ibr liegende Punktreihe weiß, die Punkte kJeiner. - Unterseite des Vorderflügels beim o meist wie die Oberseite, matter gefärbt, hinter der Subapicalbinde und nächst dem Hinterwinke] weißliche Saumfleckchen, beim o fast der Zeichnung der typischen Unterart entsprechend, Medianstreif längs des hinteren Medianastes mehr oder minder deutlich bis zum Distalrande fortgesetzt, ebenso die aiscale Binde längs des vorderen Medianastes, beide distal rötlich bestäubt. Hinterflügel in beiden Geschlechtern wie bei der typischen Unterart gezeichnet, nur die Mittelbinde schmaler, die Punkte kleiner. - Fransen des Vorderflitgels schwarzbraun, weißlich gescheckt, die des Hinterflügels weiß, nur an den Aderenden schwarz. Vorderflingellänge bis $35 \mathrm{~mm}$.

Chíle, Peru (Lima, Callao), Ecuador (Balzapamba). 
67. H. nattereri ('. \& R. Felder 1865 $H . u$, C \& R. Felder in: Reise Novara, v. 2 II p. 375 t. 47 f. 8 | 1871 H. n., W. F. Kirby, Cat. diurn. Lep., p. 141 | 188: H. n., O. Staudinger (\& Schatz), Exot. Schmett.. $v .1$ p. 76 ; 1901 H. n., Riffarth in: Rerlin. ent. Z., v. 46 p. 172.

ช. Palpen gelb, Spitze schwar\%, an der Innenseite das ganze Eudglied schwar\%. Stirnflecke und Iüngs\%eichnmng am Abdomen weiblich. Halspunkte, Thoraxflecke und die n̈brige Körperzeichumng gelb. - Vorderflïgel (Fig. 39) gestreckt und schmal, Vorderrand, Apex. Distal- und Hinterrand und die auschließende Flïgelfïche bis auf die im folgenden beschriebene schwefelgelhe Zeichnung scliwarzbraun. Vou der Wurzel aus schmal anfangend, zielt ein allmählich verbreiterter Streif in der Zelle. unr einen vorderen schinalen Strich freilassend, bis gegen das Ende derselben und wendet sich hier stumpfwinklig

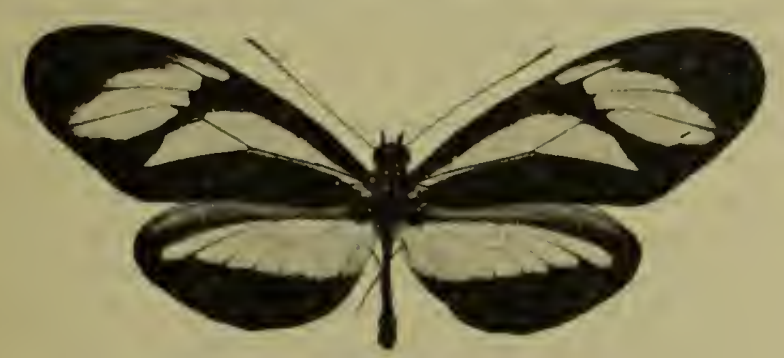

Fig. 39. H. nattereri. $\delta(\%)$.

gegen den Distalrand. zunächst in ganzer Breite des hinteren Medianzwischenraumes, dann plötzlich ron rorn nach hinten abgeschüigt und an letzten Drittel des hinteren Medianastes endigend. Hinter der fein schwarzen Mediana nur Spuren schmaler gelblicher Bestäubung, im distalen Teil bildet der hintere Medianast die Grenze. Distal von der Zelle ein bindenartiger, von den fein schwar\%en Adern durchschnittener gleichgefärbter Fleck; derselbe beginnt dicht hinter dem Vorderande schmal, ist hinter der Subcostalis in distaler Richtung abgesetzt und zicht sich schräg bis dicht an den Distalrand. Die hintere Begrenzung ist abgerundet und liegt im mittleren Medianzwischenraum so, daB der mittlere Medianast in der Mitte noch berïhrt wird. Seitlich ist der Fleck an den Adern etwas eingeschnitten. [ntere Seite mit den Zeichnungen der oberen, aber riel nutter in der Farbe, Hinterrandteil kamn heller braungrau als die Grundfarbe, stumpf, am Vorderrande ein kinrzer roter Wurzelstreif. -- Hinterflügel mit breitem bindenartigen Mittelfelde, rom Hinterrande sich alluällich verjüngend bis nalıe zum Apex und in einer abgerundeten Spitze endigend. Die rordere Grenze liegt dicht hinter dem bräunlichgrauen Vorderrandfelde, nur schmal schwarzbraun von ihm getrennt und in flacher Krïmmung der Subcostalis folgend. Die hintere Grenze verläuft fast grerade etwa in der Mitte zwischen der hinteren \%elleche und dem Distalrande und ist an den kürzer oder länger fein schwarz gefärbten Adern, namentlich distal. etwas eingekerbt. Die iibrige Flügelflüche im Apex und ror dem Distalraude schwarzhriun. Unterseite ehenso aber matter, am Torderrande ein kurzer gelblicher Wurzelstreif. hinter der Costalis ein gröBerer. linter der Medianc ein kleinerer roter Wurzelfleck. Vorder'andfold wie die matt schwärzlichbrame Grundfarbe. in Apex weiBliche wischartige Flecke. Vorderflügellänge $39 \mathrm{nmm}$. - - o. Cubekannt, wenn es etwa nicht mit der nächstell Art identisch ist.

Brasilien (Rio Grande do Sul, Bahia). 
68. H. fruhstorferi Riff. 1899 H. f., Riffarth in. Berlin. ent. Z., v. 43 p. 406 ! 1901 H. f., H. nattereri \&?, Riffarth in: Berlin. ent. Z., v. 46 p. 173.

Q. Antennen distal unterseits der Keule rötlichbraun aufgehellt. Körperzeichnung, auch die Längstreife des Abdomen lebhafter gelb als bei H. nattereri (S. 217). Etwas größer als diese Art, im Flügelschnitt derselben gleichend. Vorderrand, Apex, ein Steg von ersterem durch das Zellende bis zum Distalrande schwarzbraun, letzterer ebenfalls schmal schwarz, Hinterrand rotbraun. Ton der Flügelwurzel aus ein breiter rotbrauner Streif, der nur einen schnualen Strich vorn in der Zelle freiläßt, hinten bis über die Mediana hinaus reicht und durch einen schwarzbraunen Submedianstreif begrenzt wird. Er erreicht seine größte Breite an der Wurzel des hinteren Medianastes, wendet sich dort, dessen Richtung annehmend; in stumpfem Winkel und allmählich etwas schmaler werdend bis zum schmal schwarzen Distalraude. Distal von der Zelle ein ähnlicher, etwas schmalerer schwefelgelber Fleck oder fleckartige Binde, die proximal die vordere und hintere Zellecke leicht berïhrt und schräg bis nahe zum Distalrande läuft. Die hintere Begrenzung etwas kürzer bogenförmig im mittleren Medianzwischenraum. Unterseite matter und verwaschen, in dem rötlichbraunen Zellteil und ror dem hiuteren Medianast gelblich überstäubt, am Vorderrande ein kur\%er roter Wurzelstreif. - Hinterfiugel mit schwarzbraunem Vorderrandfeld bis zur Subcostalis, ebensolchem Apex und Distalrandteil. Mittelfeld vom Hinterrande bis in die Nähe des Apex ockergelb bindenartig wie bei der vorigen Art. der distale Teil an der vorderen Radialis stärker eingeschnürt und zipfelartig vorspringend. Zwischen dieser Binde und dem Distalrande in der schwarzbraunen Grundfäche eine letzterem folgende rothraune schmale Binde, die am Hinterrande beginnt, sich allmählich verjüngt und in ungewisser Bestäubung etwa an der hinteren Radialis endet. Unterseite mit denselben Zeichnungen, aber matter und verwaschen gefürbt. Vorderrand schmal rotbraun, an der Wurzel gelblich; 2 rote Wurzelflecke, je einer vor der Subcostalis und hinter der Mediana. - Vorderflügellänge $\$ 1 \mathrm{~mm}$.

Brasilien (Espirito Santo).

\section{k. Coh. Clysonymoformes}

Kopf schwarz, Stirn mit zwei starken, länglich fleckartigen, gelben oder weißen, zum Teil von den Palpen bedeckten Haarbüscheln. Yor der Antennenwurzel vier zwischen den Augen nebeneinander stehende, gelbe oder weiße Haarflecke. Antennenwurzel rentral weiß. Augen schwarzbraun, hinten weiß oder gelb gesäumt, oben beiderseits mit je einem kleinen weißen Punkt am Rande. Palpen an der nach außen gerichteten Seite gelb oder weiß. am Einschnitt des Wurzel- und Mittelgliedes schwarz, ebenso das Endglied und die nach innen gekehrte Seite. Antennen schwarzbraun, länger als die Torderflügelzelle, nit einer Ausnabme (H. hortense), dort so lang wie die Zelle. Körper schwarz bis schwarzbraun. Halskragen oben mit zwei gelben oder gelblichen, vorderer Teil des Thorax mit vier, manchmal teilweise undeutlichen, nebeneinander von der einen zur anderen Flügelwurzel angeordneten gelben Fleckichen. Thorax dorsal gar nicht oder beiderseits triibe gelb gefleckt. ofler hinten gelb gesäumt. Abdomen ventral in ganzer Länge gelb, lateral unten mit öfters undeutlicher oder rudimentärer Doppellinie, darüber mit einfachem, an den meist gelb markierten Segmenteinschnitten unterbrochenem, zuweilen nur punktiertem, schmalem Streif, sämtlich gell. Vorderbein schwarz. weiß oder gelblich gefleckt. Thorax rentral zwiscben 
den Hüften gelb oder weißlich, in der Achsel ein rotes Fleckehen. - Vorderflügel schmal und schlank, Vorderrand distal flach gekrīmmt, Apex scharf abgerundet, Distalrand hinter demselben in fist stumpfen Winkel proximal schräg zurïcktretend oder dentlich geeckt und stark gewellt. Hinterrand flach S-förmig gekrümmt, etwas länger als der Distalland. - Hinterflïgel abgerundet dreieckig, fast elliptisch, mit ziemlicl eckigem Apex, welligem Distalrande und meist stumpf gewinkeltem, etwas ahgerundetem Hinterwinkel. - Falter rou schwarzbrauner Grundfurhe. Torderflügel nit gelber oder roter unregelmäßiger Discal-, seltener mit Subapicalbinde, Hinterflügel nit roter. rotgelber oder weißer, meist breiter Querbinde. on mit dunkelgrau glänzendem Vorderrandfelde des Hinterflügels oherseits und ähnlichen, etwas beller grauem Hinterrandfelde des Torderflügels nächst einem schınalen Streif matterer, dunkler Bestänbung hinter der Mediana unterseits. o an diesen Stellen mit nur wenig lichterem Ton der Grundfarbe, Forderrand des HinterHingels schmal gelbgrau.

3 Arten, von denen 2 in is Unterarten zerfallen.

69. H. clysonymus Latr.

Ђ. Kopf und Körperzeichunng gelb. Grundfarbe tief schwar.hraun. Yorderflïgel mit gelber schrïg liegender schwefelgelber Querbinde in Discus, deren vorderer schmaler Teil von der Subcostilis fleckartig abgesondert ist. welche durch den distalen Teil der Zelle läuft, deren Endecken vollständig ansfïllt, sich hinter der Zelle banchig verbreitert, zuweilen am mittleren Medianast einen distal vorspringenden Zahn bildet und längs des hinteren Medianastes in einem langen schmalen Zipfel bis nahe zum Distalrande läuft. Manchmal ist die Binde verschmälert und von hinten her an der Mediana hinter der \%elle stark eingeschnitten, so dab der in letzterer liegende Teil fleckartig abgesondert wird; es tritt dann an der Gabel des 4 . und 5. Sul)costalastes eine kleine Gruppe gelber subapicaler Fleckchen auf und längs der Mediana ein gelber Wurzelstreif. Cntere Seite in allgemeinen der oberen entsprechend, matter in der Farbe, am Vorderrande ein kur"er loter Wurzelstreif und weißliche Bestänbung in Apex. - Hinterflügel mit melı oder weniger breiter, roter bis rotgelber Mittelbinde, die distal zugespitzt ist nnd in einigem Abstande vom Apex im vorderen Radialzwischenraum endet. Lnterseite matter, mit oder ohne gelblichen Wurzelstreif am Vorderrande und mit roten Wurzelflecken. Die Binde schwach rötlich markiert, distal in scharfer Krüımmng nach ror'n bis zur Snbcostalis oder zum Torderrande in weiblicher Bestänbung fortgesetzt. Vom Distalrande her, auf und in der Mitte zwischen den Adern, dunkler als die Grundfarbe schattierte branne, strahlenartige Streife, welehe rorn spitz auslaufen und bis in das trïbe Rot der Querhinde hineinreichen. - - o. Im allgemeinen wie das $\sigma^{2}$. nnit den (harakteristischen Geschlechtsunterschieden. die Binde des Hinterflügels ähnlich wie unten, auch oberseits bis zur Subcostalis oder darïber hinaus fortgesetat und breit oder flach abgerundet endigend.

Eenador, Colombia, Tenezuela, Mittel-Amerika.

Diese Art zerfällt in 3 Unterarten:

69 a. H. clysonymus clysonymus Latr. 1817 H. c., Jatreille in: Humboldt \& Bonpland, Voy. Anér., $v .2$ p. 128 t. 42 f. 1,2 1871 H. c., W. F. Kirby, Cat. diurn. Lep., p. $141 \mid 1880$ H. c., F. D. Godman \& O. Salrin in: Tr. ent. Soc. London, p. 122 $1 \times 85$ H. c., O. Staudinger (\& Schatz). Exot. Schmett., $t .1$ p. 76 | 1901 H. c., Therese von Bayern in: Berlin. ent. Z., v. 46 p. $253 \quad 1819$ Heliconia clysonyma, (Latreille \&) 
J. B. Godart in: Eue. méth., v. 9 p. $210 \mid 1844$ H. c., E. Doubleday, List. Lep. Brit. Mlus., v. 1 p. $53 \mid 1847$ H. c., E. Doubleday (\& Westwood), Gen. diurn. Lep., $x .1$ p. $103 \mid 1890$ Heliconius clysonimus, Weymer (\& Maassen), Lep. Reise Stïbel, 1. 27, 33, 53 | 1901 H. c., Riffurth in: Berlin. ent. Z., $\iota .46$ p. 174.

Schwefelgelbe Querbinde des Vorderflügels beginnt gleich binter dem Vorderrande vor dem Zellende in einer Breite von etwa $2-3 \mathrm{~mm}$. Der vor der Subcostalis liegende schmale Teil durch schwarze Bestäubung der Ader fleckartig abgetrennt. Die Binde läuft dann durch das Ende der Zelle, ist beiderseits, distal durch die Lage der Discocellulares, winklig eingeschnürt, verbreitert sich hinter der Zelle derart, daß nach vorn der proximale Teil des mittleren Medianzwischenraumes, andererseits der hintere Medianzwischenraum mit Ansnahme des vorderen spitzen Winkels am Ursprunge des hinteren Medianastes ausgefüllt ist, verschmälert sich dann plötzlich durch Einschnürung oder Absetzung der distalen Begrenzung ond läuft in einem langen schmalen Zipfel längs des hinteren Medianastes bis nahe zum I)istalrande. Selten erscheinen distal vou der Zelle in numittelbarem Anschluß Spureu gelber Bestänbung, zuweilen bildet die Binde in ihrer bauchigen Verbreiterung distal vor dem mittleren Medianast einen kurzen, gegen den Distalrand vorspringenden Zahı. Die das Gelb schneidenden Adern fein schwar\%. - Hinterflügelbinde hochrot bis gelblichrot; sie beginnt am Hinterrande nächst der Flügelwnrzel, verläuft vorn ziemlich gerade und gauzrandig, hiuten flach konvex gekrümmt und an den Adern etwas eingekerbt schräg nach vorn, beim $\sigma^{\pi}$ bis in die Mitte des vorderen Radialzwischemraumes, legt sich dort an den granglänzendev Vorderrandteil an und endet zugespitzt etwa $6-7 \mathrm{~mm}$ vom Apex eutfernt, während sie beim $q$ bis zur Subcostalis reicht und meist vor derselben breit kuppenartig absclineidet. Die hinter der Binde liegende schwarzbraune Distalrandzone verbleibt etwas breiter als die Binde. - Unterseite mit den matteren Zeichnnngen der Oberseite auf fast brauner bis graubrauner Grundfarbe, Vorderflügel mit kurzem rotem Wurzelstreif am Vorderrande, Hinterflügel ebenfalls matter gefärbt, mit 3 roten Wurzelflecken, der am Hinterrande liegende wischartig, am Vordertande ein gelblicher Wurzelstreif. Die Binde schwach rötlich markiert, sie setzt sich distal in scharfer Krümmnng, etwas verminderter Breite und weißlicher Bestäubung nach vorn deutlich bis zur Costalis und in ungewisserer Begrenzung bis zum Torderrande selbst fort. Im hinteren Flügelteil lange braune strahlenartige Streife wie bei der Art erwähnt. — Vorderflügellänge bis $42 \mathrm{~mm}$.

Columbia (Llanos de San Martin; Neiva, im Norember-Dezember; Gebiet des Rio Dagua : Mlediacion, in Höhen ron 2000-2300 m; Zentral-Kordillere; Sierra Nevada de Santa Marta; Mruzo), Ecuador (Baños; Pintuc; Santa Inéz, im Oktober, in Höhe von $1200 \mathrm{~m}$ ). Venezuela (Caracas, Merida, Puerto Cabello).

69 b. H. clysonymus montanus Salv. 1871 H. m., O. Salvin in: Ann. nat. Hist., ser. $4 \quad v .7$ p. $41+\mid 1874$ H. m., A. (T. Butler \& Herb. Druce in: P. zool. Soc. London, p. $351 \mid 1877$ H. m., W. F. Kirby, Cat. diurn. Lep., Suppl. p. 722 | $1881 \& 1901$ H. m., F. D. Godman \& O. Salrin in: Biol. Centr.-Amer., Lep.-Rbop. v. 1 p. 152; v. 2 p. $667 \mid 1901$ H. clysonimus m., Riffarth in: Berlin. ent. Z., $v .46$ p. 175.

Im allgemeinen kleiner als die typische Cnterart. Rote Binde des Hinterflügels breiter als bei dieser, so dab eime bis zum Hintertande reichende mittlere lote Flügelfläche entsteht, welche breiter ist als der hinter ihr liegende schwarzbraune Distalrandteil. Sonst wie die typische Unterart.

Mittel-Amerika (Costa Rica, Panama). 
69) c. H. clysonymus hygiana (Hew.) 1867 Meliconia h., Hewitsou, Exot. Butt., v. 4 Heliconia t.j f. 15 | 1871 Heliconius h., W. F. Kirby, Cat. diurn. J.ep., 1). 111 1885 H. h., O. Staudinger (\& Sclatz), Exot. Schmett.. r. 1 p. 76 : 1901 H. clysonimus h., Riffarth in: Berlin. ent. / $/ ., v .46 \mathrm{j}$ ). $17 \mathrm{j}$.

Kleiner als die typische Unterart. - Vorderflïgel nit schnalen scliwefelgelbem Medianstreif vor und linter der Mediana. Querbinde verschmälert, vor'n schwär\%lich überstäubt, das vor der Subcostalis liegende Fleckchen öfters kaum bemerkbar, der in der Zelle liegende Teil beiderseits flach eingeschnürt, die Zellecken werden nicht ausgefüllt, der hinter der Zelle liegende Teil durch die von hinten an der Medinna keilförmig eindringende Grundfarbe abgesondert und rol'n. im hinteren Winkel des nittleren Medianzwisclienraumes mit dem Zellfleck, nur durch die Medianil fein schwarz getrennt, mittelbar zusammenlı̈ngend. Der Endzipfel in hinteren Medianzwischenraun vorn und distal fast rechtwinklig abgestuft, proximal und hinten in scharfer Kı̈̈mmung an den hinteren Medianast angeschlossen und längs desselhen verschmälert bis nahe zum Distalrande verlaufend. I)istal ron der Binde, an der Gabel des 4. und 5. Subcostalastes ein durch diese in 3 T'eile gespaltener kleiner gelber Subapicalfleck. - Hinterflügel mit rotgelber Querbinde in der Form wie bei der typischen Lnteritrt. Untere Seite matter, nuit dell Zeichnungen der oberen, der Medianstreif des Vorderflïgels nur vor der Ader bemerkbar, der Wrumelstreif am Vorderrande des Hinterfliigels felılt, dagegen in der Krümmung der Praccostalis ein großer roter Fleck außer den übrigen Wurzelpunkten vorhanden. — Sonst wie die typische Enterart. Vorderflügellänge $35--37 \mathrm{~mm}$.

Ecuador (Balzapamba, in Höhe von $800 \mathrm{~m}$; Gebict des Rio Chimbo).

70. H. hortense (Guér.) 1829-38 Heliconica h., (iuẹrin-Héneville, Iconogr. liègne an., v.3 [ns. p. 469 i 1847 H. hortensia, F. Doubleday (\& Westwood), (ien. diurn. Lep., v. 1 p. 103 t. 15 f. 1 : 1870 H. h., Boistluval, ('onsill. Lép. Guatemalia, p. $29: 1871$ Heliconius h., W. F. Kirby, Cat. diurn. Lep.. p. 144 1881 H.h., F. 1). Godman \& O. Salvin in: Biol. Centr-Amer, Lep-Khop. v. 1 p. 151 | 1901 H. h., Riffartis in: Berlin. ent. Z., v.46 p. $175 \quad 1901$ H. h., F. 1). Godman \& O. Salvin in: Biol. Centr.-Amer., Lep.-Rlop. v. 2 p. $66 \%$.

ơ. Palpen fast schwarz. nur das Wrurzelglied und ein Teil des Nittelgliedes an der nach auben gerichteten Seite weiß oder weiblich. Stirnlıar-

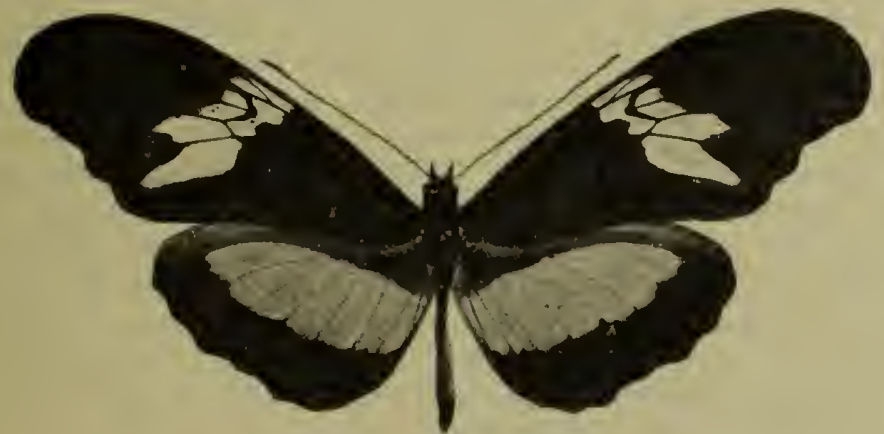

Fig. 40, H. hortense, $\delta(1 / 4)$.

büschel, Punktierung des Kopfes weiß, Halspunkte weißlich oder gelb, die übrige Körperzeichnung gelb. Vorderbeine vorwiegend schwarz, weiß läng's gestreift oder gefleckt. Grundfarbe der Flïgel schwarz his scliwarzbrauı. Vorderflügel (Fig. 40) schmal, gestreckt, Vorderrand distal Harh gekrïmmt, 
Apex abgerundet. Distalrand hinter demselben an der hinteren Radialis geeckt, dann konkav und bis zum Hinterwinkel stark gewellt. Letrterer stumpfwinklig, abgeschrägt, Hinterrand flach S-förmig geschweift, etwa von $2 / 3$ der Länge des Vorderrandes. Discal mit einer durch die sie schneidenden Adern fast in Flecke zerteilten schwefelgelben Querbinde, die binter dem schmal schwarzen Vorderrande vor dem Zellende beginṇt, über dasselbe bis in den hinteren Medianzwischenraum läuft und in der Nähe des Distalrandes endet. Der vor der Subcostalis liegende Teil ist durch diese Ader abgesondert und an der Abzweigung des 1. Subcostalastes in zwei weitere Teile zerlegt. Hinter demselben ist die Zeichnung durch starke Bestäubung: auf den Discocellulares winklig schwarz gekernt oder gespalten. Es steht ein beiderseits eingeschnürter schmaler Fleck im Ende der Zelle und ein unregelmäßiger, mitten dmeh die hintere Radialis geschnittener Fleck distal von der Zelle. Hinter diesen Flecken sind zwei weitere, durch den mittleren Medianast geteilte längliche Flecke zu unterscheiden. deren vorderer den proximalen Teil des mittleren, deren hinterer denselben Teil des hinteren Medianzwischenraumes ausfüllt, jedoch den Winkel am Ursprunge des Medianastes freiläßt. Beide Flecke laufen distal vermöge der sich dort keilartig einsehiebenden Grundfarbe in stumpfe Zipfel aus, deren hinterer der längere ist, dem hinteren Medianast anliegt und sich bis auf $3-4 \mathrm{~mm}$ gegen den Distalrand vorschiebt. Unterseite lebhaft sammetbraun, im distalen Teil weißlich gewässert. Fleckenbinde weißlichgelb. Hinterrandteil grau, fast ohne Glanz, am Vorderraude ein kurzer roter Wurzelstreif. - Hinterflügel mit stark welligem Distalrande. Mittelfeld bindenartig rom Hinterrande ausgehend, allmählich etwas rerschmälert, bis in die Nähe des Apex rot, leicht gelblich getönt. Vorn verbleibt nächst dem graubraunen. etwas glänzenden Vorderrandfelde ein langer spitzer Keil der Grundfarbe, der Distalrandteil ist schmaler als das bindenartige Mittelfeld. Die Grenze dieses Feldes zieht vorn glatt und in flacher Krümmung durch die Wurzel des hinteren Medianastes nnd der vorderen Radialis schräg bis in den vorderen Radialzwischenraum, legt sich dort an das graue Vorderrandfeld und endet in stumpfer Spitze etwa $4-5 \mathrm{~mm}$ rom Apex entfernt. Hinten ist die Begrenzung weniger scharf, an den Adern etwas eingeschnitten nud flach gekrümmt. Unterseite mit schmalem gelbem Wurzelstreif am Vorderrande und drei roten Wrirzelflecken. Grundfarbe braun, auf und zwischen den Aderu vom Distalrande her einspringende dunklere, strahlenförmige, vorn spitz auslaufende Streife, die am Distalrande stellenweise beiderseits noch durch weißliche Wische dentlicher markiert sind, vorn bis in die fahlrote Binde hineinreichen, in derselben seitlich ausfließen und in ihrer Nitte eine mehr oder wenjger deutliche Schattenbinde hervorrufen. Die rötliche Mittelbinde setzt sich nach vorn in ungewiß rötlich- und weißgrauer Schattierung in kurzem Bogen bis zum Torderrande fort. - o. Meist größer. sonst wie das $0^{\circ}$, mit den charakteristischen Geschlechtsunterschieden. Binde des Hinterflügels indes in der Regel etwas fahler gefärbt, rorn und distal nicht dmrch das fehlende graue Torderrandfeld abgeschrägt, sondern in wenig verminderter Breite bis zur Subcostalis reichend und dort breit abgeschnitten; mitunter auch noch Spuren roter Bestäubung ror dieser Ader: - Vorderflügellänge bis $46 \mathrm{~mm}$.

Eenador, Colombia, Guatemala, Honduras.

71. H. telesiphe (Doubl.)

ऽึ. Palpen weiß gefleckt, Stirnflecke und Punktierung des Kopfes weiß, die übrige Körnerzeichuung gelb. Form der Flügel schlank, Distalrand rorn 
nur schwach konvex. sonst gerade und nicht gewellt, Hinterflügel mit rienlich schallf hervortretendem Apex und fast eckigem Hinterwinkel, Distalland etwas gewellt. Gruudfurbo der Flügol tief schwarzbrann. - Vorderflügel mit zwei vou der Mediana getrennten, fast lose zusammenhä̈genden roten Flecken, von denen der eine im distalen Teil der Zelle, der andere hinter der Zelle, sthräg gegen den Hinterwinkel vorgeschioben, liegt. Letzterer Fleck füllt die Breite des mittleren und hinteren Medianzwischenraumes ans, läBt jedoch den vorderen Basiswinkel des mittleren Medianastes sowie den proximalen Teil des letrtgenannten Raumes frei und ïberschreitet etwas den hinteren Medianast. Außerdem distal ron der Zelle eine unregelmäbige, von den Adern durchschnittene und zerlegte, schmale, rote Subapicalbinde. Unterseite dunkelbriun mit denselben Discalflecken, diese aber weißlichrot. Subapicalbinde nur rudimentär, vor'n und hinten fleckartig. weißlichıot, erlalten, sußerdem hinter derselben und auch nächst dem Hinterwinkel am Distallande weißliche, wischartige Bestäubung. Hinterrandteil dunkelgran. - Hinterflügel mit weißer oder gelber, vom proximalen 'Teil des Hinterrandes schräg gegen den distalen Teil des Vorderrindes gerichteter Querhinde, die von den schwarzen Adern geschnitten wird und vorn an dem gelblichgrauen Vorderrandfeld im vorderen Radialzwischeuramm endet. Unterseite mit matter brauner Grundfarbe, weiBlichem Wurzelstreif am Vorderrande, roten. am Hinterrande wischartigen Wurzelflecken, langen, vom Distalrande nach vorn bis in die Binde spitz auslaufenden, dunkelbramnen, strahlenartigen Streifen auf und zwischen den Adern, die durch anliegende weißliche Bestäubung zum T'eil selı deutlich narkiert sind. - - o. Dem $\sigma^{\sigma}$ ähnlich, nit den charakteristischen Geschlechtsunterschieden. Die Binde des Hinterflïgels setzt sich nach roln mitunter auch oben in ungewisser Bestäubung bis zmm Vorderande fort.

Bolivia, Peru, Ecuador.

Diese Art zerfällt in 2 Unterarten:

71 a. H. telesiphe telesiphe (Noubl.) $18+7$ Heliconia t., E. Doubleday (\& Westwood), Gen. diurn. Lep., v. 1 p. 103 t. 15 t. 2 | 187 L Heliconius t., W. F. Kirby, Cat. diurn. Lep., p. 143 1879 H.t., Hopffer in: Ent. Zeit. Stettin, v. 40 p. $431 \mid 1885$ H.t., O. Staudinger (\& Schatz), Exot. Schmett., v. 1 p. $79 \mid 1901$ H.t., Riffarth in: Berlin. ent. Z., v. 46 p. 176.

Vorderer Teil des in der Zelle liegenden. schmalen, roten Fleckes des Vorderflügels durch die Subcostalis abgeschnitten, der Vorderand hleibt schmal schwarz. Hinterer, von ersterem in schrïger Richtung gegen den Hinterwinkel gelegener Fleck unregelmäBig begrenzt. Derselbe häugt an der vorderen, proximalen Ecke fast mit dem Zellfleck zusammen, ist rorn und hinten flach abgerundet, füllt die Breite des mittleren und hinteren Medianzwischenıumes ans, läßt indes ein etwa gleichschenkliges Dreieck im proximalen Teil des letzteren und den Scheitel des rorderen Bisisminkels am mittlereu Medianast frei und überschreitet den hinteren Medianast nur wenig. Distal steht die hintere, abgerundete Ecke etwa 2 mo vom Distalraude entfernt. In der roten Subapicalbiude die fein schwarz bestäubte Gabel des 4. und 5. Subcostalastes deutlich markiert. Binde sellost vorn leicht weißlich angeflogen, an der vorderen Radialis melı oder weniger deutlich abgestuft und in der Nähe des Distalrandes an der hinteren Radialis endigend. - Hinterflügel mit weißer, vou den Adern schwar' geschnittener Querbinde. Sie beginnt in einer Breite von 3-4 mm am Hinterande nächst der Flügelwurzel. Ton den ungewissen zerstämbten Begrenzungen zieht die vordere durch den distalen Teil der Zelle, etwa den Ursprung der hinteren 
Radialis berührend, die hintere lüuft parallel zur ersten unweit der hinteren Zellecke. Distal endet die Binde stumpf im vorderen Radialzwischenraum. etwa $7-8 \mathrm{~mm}$ vom Apex entfernt, und legt sich beim $\sigma^{7}$ im letzten Teil vorn an den dunkelgranen Vorderrandteil, während beim $\circ$ zuweilen vor dem Finde zwischen Costalis und Subcostalis noch ein beller Wischfleck steht. Torderflïgellänge bis $43 \mathrm{~mm}$.

Peru (Canchamayo), Bolivía (Bueyes, Huasampilla, Huiro. Santana).

II b. H. telesiphe sotericus Salv. 1871 H. s., O. Salvin in: Ann. nat. Hist., ser. $t$ v. 7 p. +13 | 1877 H. s., W. F. Kirby, Cat, diurn. Lep., Suppl. p. 722 | 1890 H. telesiphe var. s., Weymer (\& llaassen), Lep. Reise Stübel. p. 53 | 1901 H. t. s., Riffarth in: Berlin ent. Z., v. 46 p. 177.

Torderflügel wie bei der typischen Unterart, nur die Zeichnung etwas voller und intensiver karminrot. Hinterflügel mit schwefelgelber anstatt weißer Querbinde. Sonst wie die typische Unterart, auch in der Größe.

Ecuador (Gebiet des Rio Allpayacu; Riobamba; Pintuc, in Januar und Februar; Huamboya: Guaymay; Baños, in Höhe ron $2000 \mathrm{~m}$, in Oktober; Santa Inéz, in Höhe von $1200 \mathrm{~m}$, im Oktober), Peru.

\section{Gen. Eueides $\mathrm{Hb}$.}

1758 Papilio, [Subgen.] Heliconius (part.), Linné, Syst. Nat., ed. 10 p. 458,465 1816 Eueides (part.) + Migonitis (non Rafinesque 1815, Mollusca!) (part.) + Apostraphia (part.) + Coluen is (part.), Jac. Hübner, Ver\%. Schmett., p.11, 12, 13, $32 \mid 1819$ Heliconia (part.) + Cethosia (part.), (Latrcille \&) J. B. Godart in: Enc. métl., v. 9 p. 202, 245 | 1820 Epimetes (part.), Billberg, Enum. Ins., p. 77 | 1822-26 Eieides, Jac. Hübner, Exot. Schmett., v. 2 t. [3] | $18+4$ Heliconia (part.) + Eueides + Semelia (Boisdural in MS.). E. Doubleday, List. Lep. Brit. Mus., v. 1 p. 53. 57, 64 | 1848 E., E. Doubleday (\& Westwood), Gen. diurn. Lep., v. 1 p. $143 \mid 1851$ E., Chenu \& H. Lucas, Enc. Hist. nat., Pap. diurn. p. $80 \mid 1862$ E., H. W. Bates in: Tr. Linn. Soc. London, r. 23 p. 562 $1862 \& 64$ E., Herrich-Schäffer in: CB. Ver. Regensburg, v. 16 p. 28,$146 ; v .18$ p. 97 1875 E., S. H. Scudder in: P. Amer. Ac., v. 10 p. $169 \mid 1877$ E., Fritz Müller in: Ent. Zeit. Stettin, v. 38 p. $492 \mid 1881$ E., F. D. Godman \& O. Salvin in: Biol. Centr.-Amer., Lep.-Rhop. v. 1 p. $161 \mid 1887$ E., (O. Standiuger \&) Schatz, Exot. Schmett., v. 2 p. 107 1896 E., E. Reuter in: Acta Soc. Sci. Fenn., v. 22 p. $49 \mid 1900$ E., W. F. Kirby, Exot. Schmett. Hïbner, p.12|1903 E., Stichel in: Berlin. ent.Z., v.48 p. $1 \mid 1870$ Semelia + Eveirles, Boisdural, Consid. Lép. Guatemala, p. $35 \mid 1874$ S., Capronnier in: Ann. Soc. ent. Belgique, $v .17$ p. $24 \mid 1875$ Epinetes, S. H. Scudder in: P. Amer. Ac., $v .10$ p. $16 t$ 1880 Eurides, F. D. Godman \& O. Salvin in: Tr. ent. Soc. London, p. 130.

Kopf ziemlich breit, Augen elliptisch. gewölbt, nackt. Körper schlank. kurz nnd dicht beschuppt. Palpen etwas über den Kopf hervorragend, dicht beschuppt, etwas weniger reichlich behaart; Wurzelglied liurz, aufwärts gebogen. Mittelglied etwa dreimal so lang wie ersteres, schwach gebogen. distal verjüngt, Endglied kürzer als das Wurzelglied, etwas nach vorn gerichtet. zugespitzt. Die Behaarung des Mittelgliedes bildet dorsal einen der Stirn anliegenden schopfartigen Büschel. Antennen gerade, unter halber Länge des Torderrandes des Torderflügels, distal mit deutlich abgesetztem Kolben. dorsal bis auf das letzte Glied dicht beschuppt. Beine ohne Cnterschiede gegen die Gattung Heliconius (S. 2). - Torderflügel (Fig. 41 a, $41 \mathrm{c}$ ) länglich oder stumpfwinklig dreieckig, der schwach gekrümmte Vorderrand als Basis betrachtet. Apex abgerundet, Distalrand vorn bis etwa zum vorderen Medianast konvex, sodann in mehr oder weniger scharfer Krümmung schräg: in proximaler Richtung abfallend. Hinterwinkel stumpf, leicht abgerundet. 
Hinterrand schwach s-förmig gebogen, etwa von ${ }_{3}^{2}$ der Länge des Vorderrandes. Aderbildung im allgemeinen wie bei der Gattung Helironius, jedoch teilweise in der Ausilebnung der Zelle nud der dadureb bedingten Isage der ersten beiden Subcostalïste abweichend. Hieruach sind zil unterscheiden: ./ucrostuner (\$. 231): Zelle (Mittellinie) länger als die Hälfte des Vorderrandes, 1. Subcostalast entspringt in mäßigem Abstande proximal ron der vorleren Zellecke, 2. Subcostalast etwa in gleichem Abstande distal ron dieser (Fig. 41 a); Bracliyscepna (S. 24t): Zelle (Mittellinie) von balher Länge des Vorderraudes oder unter dieser. 1. Subcostalast entspringt an vorderen Zellende oder in nnmittelbarer Nähe desselben. 2. Subcostinlast in hetrïchtlichem Abstande distal ron demselben (Fig. 4 Ic). Die Lage des 1. 1nnd 2. Subcostalastes ist bei verschiedenen Arten ein und derselben Gruppe nicht beständig und selhst innerhalb ein und derselben Art kleinen Scliwankungen unterworfen. - Hinterfliigel (Fig. $41 \mathrm{~b}$ ) eirmu, vorn algeflacht. oder dreieckig mit konvex gekrümmten Seiten. Apex stumpf. wenig herrortretend. Hinterwinkel alogerundet. Geäder wie bei der Gattung Heliconius. Im übrigen ohne clurchgreifende Unterschiede gegen letztere.
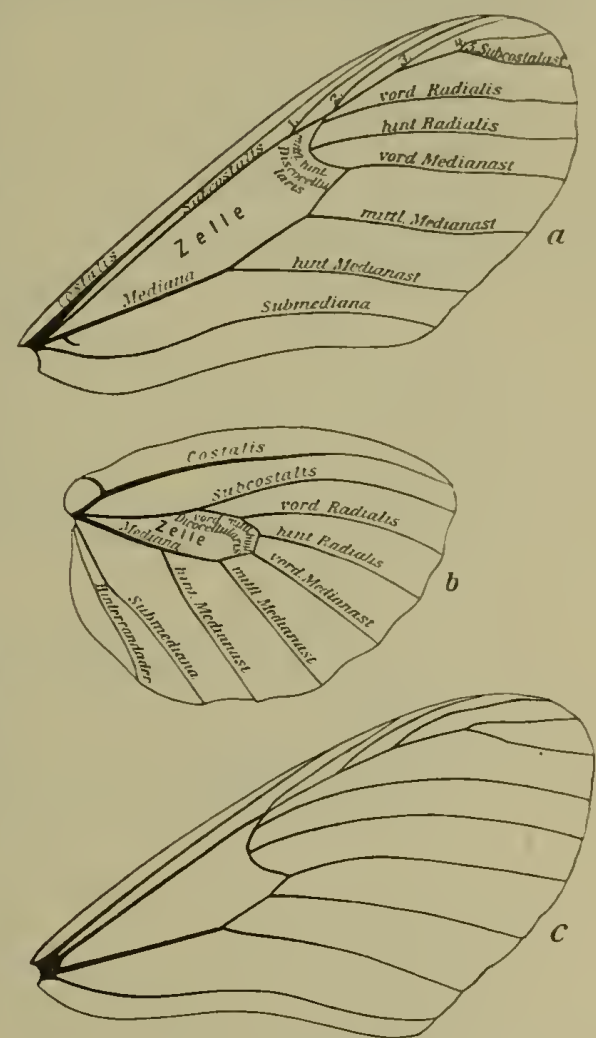

Fig. 41. Flügelgeäder.

a Vorderflügel ron E. dianassa. $\zeta$;

b Hinterflügel ron E. dianassa, ठす:

$c$ Vorderflïgel von E. heliconioides, $\delta$.

Die Arten der Dianassiformes und Thaletoformes ähnelı ungemein solchen der Gattung Heliconius, mit deuen sie auch die außerordentliche Variabilität gemeinsam haben. Andere Arten (Vibiliformes) erinnern au südamerikanische Vertreter der (Gattung Acracs F. (Actinote $\mathrm{Hb}$.). ron denen sie sich durch Bildung der Beine und andere Kichtung der Praecostalis des Hinterfiigels unterscheiden; wieder andere (Lybiiformes) gleicheu in Zeichnung und Flügelschnitt auffällig Vertretern der Gattung Colaenis Hb., die aber eine offene \%elle des Hinterflügels haben. Von den Heliconius-älınlichen Eueides-Arten haben diejenigen der Dianassiformes auch gewisse Ähnlichkeit mit einigen Ithomiiden- und Danaiden-Gattungen (z. B. Mechanitis F.. Lycorea Doubl.), sind aber leicht an der proximal ungegabelten Submediana des Vorderflïgels und an den Antenmen zu erkennen.

Raupen, soweit bekannt, an Passifloren. Gestalt wie Lei der Gattung Heliconius, mit langen Dorneu und Kopfhörneru. - Puppe hängend, zuerst lotrecht, später wagerecht oder parallel zum Anheftungskörper, ventrale Seite diesem zugckeh.t; höckerig und dornig, einige bekannte Arten dorsal mit selı langen Fortsätzen.

Süd-Amerika sïdlich etwa bis zum 32. Breitengrad, Mittel-Amerika und Antillen. - Gewohnheiten wie bei den Heliconius-Arten, der Flug wohl etwas lebhafter.

16 Arten, von denen 11 in 35 Luterarten zerfallen.

Das Tierreich. 22. Lief.: H. Stichel \& H. Riffarth, Heliconiidae. 
Ïbersicht der Arten und Unterarten:

Grundfarbe der Flïgel gelb- bis rotbraun,

1 dunkelbraun oder gelbgrau (durchscheinend) -2.

Grundfarbe schwarz oder tief schwarzbraun -42 .

Hinterflügel mit mittlerer schwarzer Querbinde oder Fleckenbinde oder vorwiegend schwarz -3.

2 Hinterflügel ohne Mittelbinde, aber mit mehr oder weniger schwarzem Distalrande $\mathbf{- 2 3}$.

Distalrand des Hinterflügels ober- und unterseits mit meist schmaler, schwarzer, wenig gewellter oder an den Adern gekerbter Saumbinde - 4.

Distelrand des Hinterflügels unterseits mit spitzdreieckigen, leicht zusammenhängendeu Saumflecken - 20.

Hinterflügel nit einem bis zum Apex durchgehenden schwarzen Subcostalstreif (beim 0 entscheidet die Unterseite) -5 .

4 Hinterflügel mit unvollkommenem, meist in der Hitte oder kurz distal von derselben endigendem Subcostalstreif (beim $\sigma$ ist die Unterseite maßgebend) - 9 .

$\left\{\begin{array}{c}\text { Vorderflügel mit einem subapicalen Fleck } \\ \text { oder Doppelfleck - } 6 .\end{array}\right.$

5 Vorderflïgel mit einer subapicalen Fleckenbinde (mitunter teilweise verloschen) - $\mathbf{7}$.

$6\left\{\begin{array}{l}\text { Hinterflügel vor der Mittelbinde gelb . . } \\ \text { Hinterflügel vor der Mittelbinde braun. . }\end{array}\right.$

1. E. dianassa, forma $R=$ ? principalis . . . p. 233

1. E. dianassa, forma decolorata ... p. 234

Vorderfliigel mit discaler geschlossener schwefelgelber Schrägbinde... . . .

7 Vorderflügel mit discaler Fleckenbinde oder 3a. E. cleobaea cleobaea . p. 242 2 oder 3 schräg gestellten Flecken in
schwarzer Begrenzung - 8 .

$8\left\{\begin{array}{c}\text { Subapicalflecke des Vorderfligels schwefel- } \\ \text { gelb. } \\ \text { Subapicalflecke des Vorderflügels bräunlich }\end{array}\right.$

3 b. E. cleobaea zorcaon, forma principalis . . p. 242

3 b. F. cleobaea zorcaon, forma adusta. . . p. 242

$9\left\{\begin{array}{c}\text { Apex des Vorderflügels oberseits schwarz, } \\ \text { ungefleckt }-10 . \\ \text { Apex des Vorderflügels gefleckt }-12 .\end{array}\right.$

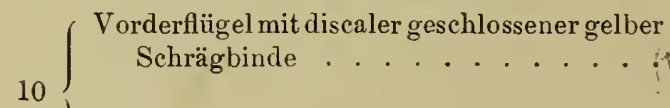

Vorderflügel ohne gelbe Schrägbinde im

2 b. E. isabella hippolinus, forma margaritifera . p. 236 Discus - 11. 
Schwarzes A picalfeld des Vorderflügels breit von Keil- und Medianfleck getrennt. .

Schwarzes Apicalfeld mit dem Keilfleck und distalen 'f'eil des Submedianstreifes stellenweise zusammengeflossen . . .

Vorderfligel vorherrschend rauchbraun, mit einzelnen gelblichen Flecken....

Vorderflïgel wenigstens im proximalen 'Teil mit abgesetzter schwarzer Zeichnung in der Grundfarbe - 13.

Vorderflügel mit discaler gelber schräg liegender Binde oder Fleckenbinde - 14 .

Vorderflügel ohne ron der braunen Grundfarbe verschiedene Binde oder Fleckenbinde in Discus - 19.

14

Hinterflügel mit geschlossener schwarzer Mittelbinde - 15.

Hinterflügrel mit schwarzer Fleckenbinde -- 17.

Discale Schrägbinde des Vorderflügels geschlossen, Medianfleck isoliert ... .

Discale Schrägbinde des Vorderflügels in Flecke aufgelöst. Medianfleck längs des mittleren Medianastes mit dem schwarzen Distalrande und Apicalteil mehr oder weniger zusammengeflossen -16 .

Subrpicalflecke des Tordertlügels klein, isoliert . . . . . . . . .

Subapicalflecke des Vorderflügels vergrößert, - mit den discalen flecken mehr oder weniger zusammengeflossen .....

$2 a,-E$. isabella isabella . p. p. 235

$2 \mathrm{f}$. E. isabella hübneri, forma principalis . . p. 239

2g. E. isabella arquatus . p. 240

Vordertliigel mit discaler geschlossener Schrägbinde; Medianfleck isoliert oder nur leicht mit deen Keilfleck zusammenhängend . . . . . . . . . .

Schrägbinde des Vorderfligels melır oder weniger in Flecke aufgelöst; Mediantleck längs des mittleren Medianastes nit dem schwarzen Apical- und Distalrandfelde verflossen -18.

Fleckenzeichnung im Discus und Apex des Yorderflïgels schwefelgelb . . . . .

Fleckenzeichnung in Discus und Apex des Vordeıflïgels ockergelb oder weißlich .

Mittelbinde des Hintertlügels gesehlossen . Mittelbinde des Hinterflügels in Flecke aufgelöst ..........
2 6. E. isabella hippolinus,

forma principalis . . p. 236

2 b. - E. isabella hippolinus, forma personata . p. 236

2 f. E. isabella hübneri, forma spoliata . . p. 240
2d.-E. isabella dissolutus . p. 237

2e. E. isabella pellucidus, forma regetissima. . p. 239

2 e. E. isabella pellucidus, forma principalis . p. 238

2 c.-E. isabella seitzi . . p. 237

2 b.-E. isabella hippolinus, forma brunnea ... p. 236 
Apex des Vorderflügels schmal schwarz. Endzell- und Randfleck deutlich von - denselben getrennt - 21.

Apex des Vorderfügels breit schwarz, mit Endzell- und Randfleck mehr oder minder zusammengeflosseu - 22 .

Hinterflügel mit schwarzer Mittelbinde aus länglicheu Flecken........

Hinterflügel mit geschlossener, nur von den braunen Adern durchschnittener, zuweilen bis gegen den Distalrand verbreiterter Querbinde.......

Hinterflügel mit schwarzer Mittelbinde aus länglichen Flecken ........ .

Hinterflügel mit geschlossener, vom Saum mehr oder minder breit getrennter Mittelbinde ..........

Hinterflügel bis auf den Apex und die Wurzel gänzlich schwarz.....

Apex des Vorderflïgels bis zum discalen Flügelfelde oder der helleren Discalzeichnung breit schwarz, nur sclten mit verloschenen Flecken - 24.

Apex des Vorderflügels schmal schwarz gerandet oder breiter schwarz mit helleren Flecken oder solcher Fleckenbiude - 25 .

Vorderflügel mit einel aus 3 weißlichen Flecken zusammengesetzten discalen Schrägbinde; Wurzelteil vorherrschend dunkelbraun wie die übrige Flügelfläche

Vorderflügel mit bräuulichen oder gelblichen, bindenartigen Flecken; Wurzelteil braun. nur mit schwarzem Keilfleck und Submedianstreif ........

Vorderflügel mit Keilfleck in der Zelle und vorherrschend verdunkeltcm Wurzelfelde -26.

Vorderflügel ohne Keilflcck in der Zelle - 36.

Hinterflügel an der Wurzel mit kurzem keilförıuigem Subcostalstreif - 27.

Hinterflügel an der Wurzel ohne Subcostalstreif -30 .

Wurzel des V'orderflügels völlig verdunkelt, einfarbig dunkelbraun; Keilfleck mit Submedianstreif und Vorderrand gänzlich verschmolzen, im Discus uud Apex einige hellere Flecke. . . . . . . .

Keilfleck und Submedianstreif durch einen helleren Streif im hintereu Teil der Zelle getrennt $\mathbf{- 2 8}$.
5 a. E. lampeto lampeto - p. 246

5 b. E. lampeto fuliginosus, forua principalis . . p. 246

5. E. lampeto acacates - p. 247

5b. E. lampeto fuliginosus, forma amoena . . p. 217

5̋. E. lampeto fuliginosus, forma carbo . . P. 247

7. E. procula . . . . p. 252

$8 \mathrm{~d}>$ E. vibilia unifasciatus [). 256

6 c-F. edias vulgiformis . p. 251 
Vorderflïgel im Discus mit drei hellen gelbliehen Flecken, unten ohne Saun. flcekchen . . . . . . . . .

Vorderflïgel mit verlosehenen rotbraunen oder ungewib durchseheincuden Ëlccken. oder vorwiegend durchscheinend unit spärlicherer dunkler Zeichnung, unten mit deutlichen wcißen Saumfleckchen - 29.

Keilfleck des Vorderflïgels längs der Mlediana mit dem dunkelbraunen Apicalteil und Endzellfleck zusanmengeflossen. Hinterfliigel mit sehmalerer, im Hinterwinkel zicmlich spitz anfangender Saumlinde.

Keilfleck und Endzellfleck getrennt, Die Saumbinde des Hinterfliigels beginnt breit am Hinterrande . . . . . . .

Hinterflügel mit langen. rom schwärzlichen Distalrande bis nalie zur Zelle rücklaufenden schwarzen Strahlen in den Aderzwischeuräunen; beim o die hellen Fliigelstellen durchscheinend . . . .

Randbinde des Hinterflïgels ungewiß begrenzt oder mit kleinen Spitzen oder Kegeln in den Aderzwischenräumen - 31 .

Grund farbe des Hinterflïgels bleich ockergelb oder in dieser Farbe leicht rötlich angetlogen -32 .

Grundfarbe des Hinterflügels lcbhal't rotbraun -33 .

Submedianstreif des Vorderflïgels breit und voll schwarz; helle Grundfurbe beider Flügel bleich ockergelb . . . . . .

Gelbliche Grundlarbe des Hinterflügels in der Regel lebhafter als die Fürbung der Discal- und Subapicalflecke des Vorderflïgels; Submedianstreif des Vorderflïgels ungewiß schattiert. . . . . . .

Vorderflügel gleichnäßig rotbraun mit schwarzen Binden.........

Vorderflügel im Discus und Apex mit Flecken, die ockergelb oder heller als die brannen Streife an der $1 \mathrm{~T}$ urzel und am Hinterrande gefärbt sind - 34 .

Submedianstreif des Vorderflügels inmitten der Länge nach braun überstäult; Hinterflïgel mit breitem schwarzem, in ungewisser Schattierung bis etwa in die Flügelmitte ausgeflossenem Saum . . .

Submedianstreif des Vorderflügels voll schwarz oder nur wenig zerstäubt; Hinterfliigel mit schmalerem, bestimmter begrenztem schwarzem Saum - 35. 6b. E. edias_luminosus . . p. 250

6a. E. edias edias . . p. 249

6d. E. edias eurysaces . . p. 251

9. E. pavana . . . p. 257

8a. E-vibilia vibilia, forma pallens . . . . p. 255

8b. E. vibilia vicinalis - p. 256

8a.-E. vibilia vibilia, forma principalis, o . . . p. 254

8 c. E. vibilia vialis, 우 - p. 256 
Vorderrand des Hinterflügels breit grauglänzend . . . . . • . . . . Vorderrand des Hinterflïgels hellbraun.

Hinterflügel unten mit rein weißen Saumflecken - 37.

Hinterflügel unten ohne weiße Saumflecke - 38 .

Der Submedianstreif des Vorderflügels erreicht den Hinterwinkel nicht. Hinterflügel unten mit roten Wurzelfleckchen Der Submedianstreif des Vorderflïgels reicht bis zum Hinterwinkel. Hinterflügel unten ohne rote Wurzelflecke. . . . . . .

Hinterflügel unten ohne Saumbinde - 39 .

Hinterflügel unten mit Saumbinde -40 .

Submedianstreif des Vorderflügels kräftig, Saum breit schwarz, Grundfarbe satt rotbraun . . . . . . . . . .

Submedianstreif des Vorderflügels schmal, häufig nur auf die Aderstärke beschränkt, Saum schmaler schwarz, Grundfarbe blasser rotbraun. . . . . . . .

Hinterflïgel unten mit roten Wurzelpunkten.

$40\{$ Apicalfeld des Vorderflügels oben nicht \{ verschieden von der Gruudfarbe ... Hinterflügel unten ohne rote Wurzelpunkte $\mathbf{- 4 1}$.

11 a. E. aliphera aliphera . p. 261 $\mathrm{B}_{2} \cdot 36$

11 b. E. aliphera gracilis . p. 262

12a. E. lybia lybia . . . p. 262

8c. E. vibilia vialis, $\delta$. p. 256

8 a. E. vibilia vibilia, forma principalis, + . . p. 254

10b. E. lineatus libitina - p. 260

10 a. E. lineatus lineatus . p. 259

12 b. E. lybia 1ybioides . - p. 263

13. E. olympia . . . p. 263

A picals die Grundfarbe, namentlich beim 우

Zeichnung des Vorderflügels in einer Farbe - 43.

42

Zeichnung des Vorderflügels in mehreren Farben -48.

43

f Vorderflügel mit gelber Zeichnung -44 .

\{ Vorderflügel mit roter Fleckengruppe - 47 .

(Vorderflügel mit zwei gelben, discal und subapical gelegenen Binden; Hinterflügel bis auf einen breiten schwarzen Rand rot.

Vorderflügel mit einer discalen gelben Fleckengruppe - 45 .

Hinterflügel mit roten Strahlen ....

Hinterflügel ohne rote Strahlen - 46. forma farragosa . . p. 271

Die Fleckengruppe des Vorderflügels liegt 46

Die Fleckengruppe liegt distal von der Zelle..........

Hinterflügel einfarbig schwarz . . . . 16 c. E. eanes felderi, forma

Hinterflügel wit roten Strahlen zwischen den Adern . . . . . . . .
$16 \mathrm{~b}$.

E. eanes eanides, pluto..... p. 271

4. E. ricini . . . . p. 243

$16 \mathrm{~b}$. E. eanes eanides, forma aides .... p. $2\lceil 1$

16 c. E. eanes felderi, forma principalis . . . p. 271 
(Hinterflügel einfarbig schwarz oder nur mit schwachen Rudimenten roter Streif'nzeiclnung an der Wurzel $\mathbf{- 4 9 .}$

Hinterflügel nit Strahlenzeichnung hinter der Zelle oder mit rot umrandeter Zelle - 50 .

Vorderflügel mit zerstreuten gelben Flecken im Discus. von denen ein in den Radial. zwischenräımen liegender DoppelHeck nur wenig länger als der vor ihm liegende Subeostalfleck ist ........

Vorderflügel mit gleich angelegte: Fleckengruppe. aber der Doppelfleck in den Radialzwischenräumen distal in zwei langen Zipfeln ausgeflossen. . . . .

1)ie Strah len des Hinterfliigels liegen zwischen den Adern - 51.

Die Strahlen des Hinterflügels liegen auf den Adern - 52.

Vorderflïgel mit zusammenlı̈̈ngender gelber Fleckengruppe, die distal ron der Zelle liegrt ............ Vorderflügel init zusammenhängender Fleckengruppe, die zum Teil in der Zelle liegt

16. E. eanes eanes . . 2. 269

14c. E. tales surdus, forma aquilifer . . . p. 267 $16 \mathrm{~b}$. E. eanes eanides,

Vorderflïgel mit zerstrenten gelben Flecken formal principalis . . p. 270 im Discus - 53.

Vorderflïgel mit einer zusammenhängenden Fleckengruppe im Discus - $\mathbf{5 4}$.

Ein in den hadialawischenräumen liegender Doppelfleck nicht wesentlich länger als der vor ihm lagernde Subcostaltteck.

Doppelfleck zwischen den Radiales distal zu zwei langen Zipfeln ausgeflossen. .

14a. E. tales tales ... p. 265

14b. E. tales pythagoras - p. 266

Die Fleckengruppe des Vordertlügels liegt distal ron der Zelle. . . . . .

$15 \mathrm{~b}$. E. heliconioides xenophanes . . p. 268

Die Fleckengruppe des Yordertlügels liegt zum Teil in der Zelle...... 15a.

heliconioides
heliconioides... p. 268

\section{Sect. Macroscenae}

Zelle des Torderflügels länger als die Hälfte des Vorderrandes, der 1. Subcostalast entspringt in mäBigem Abstande proximal ron der vorderen Zellecke, der 2. Subcostalast etwa in gleichem Abstande distal von derselben. Falter von meist gelb- bis rothranner Grundfarbe mit einer anf eine bestimmte Einheit zurïckzuführenden, bei den Dianassiformes erlänterten, schwarzen Zeichnung oder von schwarzhanner Farbe mit farhigen Binden.

\section{a. Coh. Dianassiformes}

Kopf schwarz. voru mit zwei weißen, teilweise von den Palpen verdeckten länglichen Flecken an der Antennenwurzel, oben mit vier kleineren weißlichen oder gelblichen. panrweise zwischen den Augen gelegenen I'nnkten. Angen 
schwarzbraun, hinten weiß oder gelblich gesäumt, oben häufig noch mit je einem kleinen weißlichen Punkt. Palpen weiß, schmal schwarz gesäumt, Spitze schwarz. Antennen unter halber Länge des Vorderflügels, beim $\sigma^{\tau}$ schwarzbraun mit mehr oder weniger deutlich ockergelbem Kolben, beim o ockergelb bis etwa auf das proximale schwarzbraune Drittel. Körper schwarz oder schwarzbraun. Halskragen oben mit zwei gelblichen Flecken, Thorax oben schmal schwarz, seitlich und hinten gelb gefleckt. Abdomen wenig über, den Hinterflïgel hinausragend, ventral gelb, lateral unten mit einer Doppellinie, darïber mit einem einfachen, manchmal unterbrochenen, gelben Streif. Diese Zeichnungen bei getrockneten 'Tieren häufig undeutlich und nur stïckweise zn erkennen. Tibia und Tarsus des Vorderbeines gelb, dieses sonst schwarz wie auch die übrigen Beine, letztere indes etwas weißlich bestäubt, an der Coxa weiß gefleckt. Thorax unten lateral und zwischen den Hüften gelb. Die gelbe Behaarung des Körper's und Kopfes manchmal bräunlich. - Vorderflügel gestreckt, Vorderrand flach gekrümmt, Apex abgermudet, Hinterrand bedeutend kürzer als der Vorderrand.

Grundfarbe der Flügel rot bis gelbbraun mit folgender schwarzer, den Silvaniformes (S. 38) der Gattung Heliconius ähnlicher Zeichnung: Vorderrand, ein Fleck im mittleren Teil der Zelle, der vorn stets der Subcostalis anliegt und in proximaler Richtung keilförmig verlängert ist (Keilfleck); ein Streif auf oder vor der Submediana (S ubmedianstreif); ein rundlicher Fleck zwischen dem mittleren und hinteren Medianast (Medianfleck); der Apex, meist. bis zum Zellende und von da in unregelmäbiger Begrenzung bis etwa zur Mitte des Distalrandes; zwischen dem vorderen und hinteren Medianast in der Nähe des Distalrandes ein Fleck, der mit dem schwarzen distalen Teil verflossen ist und nur als vorspringender Keil oder Kegel kenntlich bleibt ( $\mathrm{R}$ andfleck). Im discalen Teil des Vorderflügels tritt meist gelbe Färbung in Gestalt einer schräg liegenden Binde auf, die aber durch Verbreiterung und Zusammenfließen der schwarzen Zeichnungen in Flecke aufgelöst sein kann. Oder der schwarze Apicalteil ist mehr oder weniger braun oder gelb gefleckt, und die Flecke fließen in proximaler Richtung bis in den discalen Teil aus. Danu entsteht distal von der Zelle ein unregelmäBiger schwarzer Fleck, der nur an den Adern mit dem übrigen Sclıwarz des Apex in Verbindung steht. Iu vereiuzelten Fällen verdrängt die dunkle Zeichnung, die dann aber nicht schwarz, sondern rauchbraun gefärbt ist, die Grundfarbe bis auf etliche hellere Streife und Flecke. - Hinterflügel fast eirund, vorn abgeflacht, Apex stumpf, in der Farbe wie der Vorderflügel, oberseits mit einem schwarzen Subcostalstreif, geschlossener oder in Flecke aufgelöster Mittelbinde hinter der Zelle und schwarzern Distalsaum. -- đ. Unterseite des Vorderflügels hinter der Mediana, nächst einem sehr schmalen Streif matter bräunlicher Beschuppung am hinteren MLedianast, grau- und hinter der Submediana grangelb-glänzend. Vorderrandteil des Hinterflügels auf der Oberseite grau-, nach der Wurzel zu etwas gelblich-glänzend. - 오. Hinterrandfeld des Vorderflügels uuten, sowie Vorderrandfeld des Hinterflügels oben nicht wesentlich anders gefärbt wie die übrige Fllügelfläche; an beiden Stellen die etwa vorhandenen Zeichnungen der entsprechenden Gegenseite des Flïgels matt durchschlagend.

3 Arten, von denen 2 in 9 Unterarten zerfallen.

1. E. dianassa Hb. 1806-16 "Nerëis fulva dianasa", Jac. Hübner, Exot. Schmett., v. 1 t. [8] 1816 Eueides dianassa (part.), Jac. Hübner, Verz. Schmett., p. 11 1844 E. dianasa, E. Doubleday, List. Lep. Brit. Mus.. v. 1 p. $57 \mid 1848$ E. d., E. Doubleday (\& Westwood), Gen. diurı. Lep., v. 1 p. $147 \mid 1862$ E. isabella var. $l .$, H.W. Bates iu: Tr. Linn. Soc. London, v. 23 p. $562 \mid 1871$ E. d., W. F. Kirby, Cat. diurn. Lep., p. 146 1885 E. d., O. Standinger (\& Schatz), Exot. Schmett., v.1 p. $81 \mid 1890$ E. d., E. dionasa (laps.). Seitz in: Ent. Zeit. Stettin, v. 51 p. $94 \mid 1896$ E. dianasa, Bönninghausen in: Verh. Ver. Hamburg, v.9 p. $33 \mid 1900$ E. d., W. F. Kirby, Exot. Schmett. Hübner, p. 13 1903 E. d. + E. d. aberr. decolorata, Stichel in: Berlin. ent. Z., a. 48 p. 3 ; p.3 (forma d.).

ठ. Vorderflügel gestreckt, Apex abgerundet, Distalrand bis zum vorderen Medianast konvex, alsdann in ziemlich scharfer, fast stumpfwinkliger Krïmmung 
in proximaler Richtung alogeschràgt, Hinterwinkel stumpf. Hiuterand etwa von $.2 \%$ der Flügellänge. Oberseite rot- bis gelbbraun mit schmal schwar\%em Vorderrande und folgender schwarzer Zeichunug: Keilfleck schü̈g in der Mitte der Zelle, vorn der Subcostalis anliegend und dort in proximaler Richtung etwas ausgeflossen; im hinteren Mediauzwischemaum, dicht au der Zelle, ein rundlicher Medianfleck; ein breiter Submedianstreif dicht vor der Submedialla, von der Flügelwurzel bis z.um Hinterwinkel reichend, in letzten Verlauf die Ader berülırend. I)istal des Keilfleckes eine schwefelgelbe schräg liegende Querbinde, welche distil an den bis zum Kellende breit schwarzen Apex grenzt und vor dem mittleren Medianast durch einen einspringenden schwarzen Zapfen. Randfleck, stufenartig abgesetzt ist. Her hintere 'Teil der Binde fiillt den hinteren Medianzwischenraum vom Medianfleck bis zum schmal schwarzen Distalrande aus. Im schwarzen Apicalteil ein gelber, bräunlicher oder schmutzigweißer Fleck oder ein an der vorderen Radialis durchschuittener Doppelfleck. Die das Gelb. durchschneidenden Adern leicht schwarzbrauu bestäubt. Unterseite matter, nächst dem Anex und dem Hinterwinkel einige weiße Saumfleckchen. - Hinterflügel fast eirund, vorn abgeflacht, mit wenig hervortretenden Apex, braun mit schwarzer, hinter der Zelle liegender Mittelbinde und breitem schwarzem Distalsaum mit trïhe weißlichen Fleckelen. Subcostalstreif keilförmig, nur an der Flügelwurzel bomerkbar und in dem graugläuzenden Vorderrandteil verschwindend. Tor der schwarzen Mittelbinde in der Regel mehr oder weuiger intensiv gelbe Bestäubnug. Unterseite mit breitem schwarzem Costal- und gestrecktem deutlichem Subcostalstreif. der von der gelb gefärbten Flügelwurzel bis z.nm Apex reicht und sich dort mit dem Saum vereinigt. Mittelbinde häufig in eirunde Flecke aufgelöst; der schwarze Distalsaum proximal bogenattig gekerbt, mit deutlichen weißen Flecken. die rom Hinterwinkel bis z.ur linteren Radialis paarweise, sodann bis zum Apex einzeln in den Aderzwischenräumen stehen. - - o. Im allgemeinen wie das $\sigma^{*}$, aber Torderflügel oberseits im Apex meist mit einigen weißen Fleckchen, die unterseits deutlicher und größer sind und sich am Distalrande bis zum Hinterwinkel fortsetzen. Hinterflügel auch oben mit vollkommenem Subcostalstreif und deutlicheren weißen Fleckchen im schwarzen Distalsaum, unterseits meist mit reicherer gelber Bestäubung vor der Mittelbinde und dem Subcostalstreif. In übrigen mit den bei der Gruppe erwähnten Geschlechtsuntersehieden.

Südliches, mittleres und nördliches Brasilien (Santa Catharina, Santos, Rio de Janciro, Bahia, Pará), I’araguay.

Forma principalis. Zeichnumgscharaktere (Fig. 42) wie bei der Art

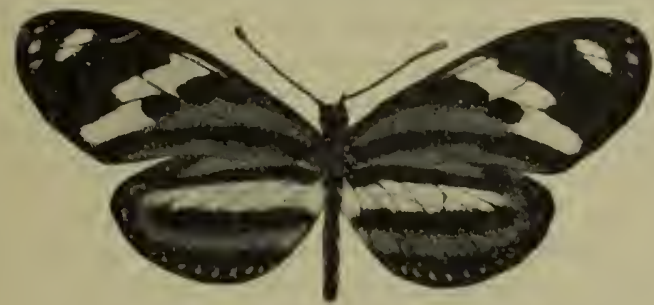

Fig. 42. E. dianassa, forma principalis, $2(1 / 2)$.

beschrieben, Hinterflügel mit deutlicher gelber Bestäubung zwischen Subcostalstreif und Mittelbinde. Torderflügellänge $30-35 \mathrm{~mm}$.

Verbreitungsgebiet wie bei der Art angegeben. 
Forma decolorata. Hinterflügel auf Ober- und Unterseite ohne Gelh vor der Mittelbinde, sondern dort in dem Ton der Grundfarbe. Sonst wie die Hauptform.

Brasilien (Bahia).

\section{E. isabella (Cram.)}

ऽ. Stirnflecke meist weiß, Punktierung des Hinterkopfes und die sonstige Körperzeichnung gelb oder bräunlich. Form der Flügel wie bei der vorigen Art. Grundfarbe der Flügel rot- bis gelbbraun, in seltenen Fällen weißlich oder dunkelbraun. In letzterem Falle mit einzelnen gelblichen Flecken und Streifen, sonst mit der charakteristischen schwarzen Zeichnung: - Vorderrand des Torderflügels schwarz, Keilfleck rundlich oder länglich, in der Mitte der Zelle schräg gestellt, vorn der Subcostalis anliegend und längs derselben in proximaler Richtnng mehr oder weniger in einem spitzen Ansläufer endigend. Meist 1, seltener 2 rundliche Medianflecke, Apex stets breit schwarz bis zum Zellende. Zwischen letzterem und dem Median- und Keilfleck meist eine schwefelgelbe schräg liegende Querbinde, im Apicalteil häufig ein länglicher Subcostalfleck und hieran anschließend eine schräg gestellte Reihe von 3 mehr oder weniger großen, länglichen Flecken von weißlicher, gelber oder bräunlicher Farbe. Submedianstreif kräftig, in kurzem Abstande vor der Submediana von der Flügelwurzel bis zum Hinterwinkel laufend oder kurz vor diesem endigend. Randfleck meist in Gestalt eines in proximaler Richtung rom Distalrande her einspringenden Zapfens erkemubar. Keilfleck und Medianfleck zuweilen zusammengeflossen, beide, oder letzterer alleiu auch läng's des mittleren Medianastes durch den Randfleck mit dem schwarzen Distalrande und dem Apicalteil vereinigt. Die discale Querbinde dann in melr oder weniger stark isolierte Flecke aufgelöst. Lnterseite matter, hinter der Mediana stark glänzend grau und gelbgrau ohne eigentliche Keichnung. Im Apex und hinten am Distalrande einige weiße Saumfleckchen. - Hinterflügel hinter dem glänzenden Vorderrandfelde mit dentlichem Subcostalstreif, der jenem unmittelbar anliegt, aber den Apex nicht erreicht, sondern auf etwa $2 \%$ der Flügellänge endigt. Vittelbinde geschlossen oder in mebr oder weniger stark isolierte Flecke aufgelöst. Distalsanm stets schwarz, proximal meist etwas gekerbt, mitunter mit verloschenen weißlichen Saumpunkten; Flügelfeld vor der Mittelbinde selten etwas gelblich angeflogen. Unterseite mit schwarzbramuem Costalstreif. der Subcostalstreif deutlicher in der etwas matteren Grundfarbe, Flügelwurzel, mitunter anch eiu Streif vor der Mittelbinde gelb; letztere stets in Flecke anfgelöst. die Saumbinde proximal stärker bogenförmig gekerbt. mit rein weißen, am Apex eiuzeln, sonst parweise in den Aderzwischenräumen stehenden Fleckcben. - - $\supsetneq$. Im allgemeinen wie das $\sigma^{2}$. mit den bei der Gruppe erwähnten Geschlechtsunterschieden. Vorderflügel meist allch oben mit weißlichen Sammfleckchen im Apex und stärkerer Neigung zul Gelhfärbung. Der subapicale Fleck im vorderen Medianzwischenraum manchmal in proximaler Richtung ansgeflossen und mit der discalen gelben Zeichnung leicht vereinigt, so daß am Ende der Zelle ein unregelmäßig begrenzter schwarzer Fleck a.bgesondert wird. Subcostalstreif des Hinterflügels infolge Fehlens des glänzenden Costalfeldes dentlicher von der Grundfarbe abgehoben. Auch hier vor der Mittelhinde mitunter gelbliche Bestäıbung: — — Torderflügellänge bis $40 \mathrm{~mm}$.

Ei einzeln an der Unterseite ron Passiflora edulis Sims. - Erwachsene Racipe: Kopf schwarz mit 2 Hörnern; Körper schwarz, hinten orangefarben, seitlich unten blaßgelb mit langen, an der Wurzel schwarzen. sonst blaßgxauen Dornen. In der 
Jugend mit spitzen Borsten, zum T'eil auf größeren W'arzen; Körper griulich, später braun, hell gefleckt. - Puppe hängend, anfangs lotrecht, bald wagerecht aufgebogen, Bauchseite nach oben oder parallel zum Anheftunrrskörper. Bauchseite eingedrückt, Flïgelscheide wenig rorgeschoben, Rücken stark höckerig und mit Hörnern sowie 2 langen dünnen Fortsätzen auf dem 6. und 7. Segment. Kremaster mit lang ausgezogener Anheftungsfläche. Körper grau und weiß mit zwei weißen Längsstreifen, Dornen weißgelb (G. W. Müller, 1. c., t. 1i f. 3).

Mittleres und nördliches Brasilien, Französisch-(iuayana, Venezuela, Bolivia, Peru, Ecuador, Colombia, Yanama.

Diese Art zerlällt in 7 Unterarten:

2 a. E. isabella isabella (Cram.) $1781 \& 82$ „Isabella", Papilio i., P. Crumer, Pap. exot., v.t p.117 t.350 f. C, 1); p. 250 i 1819 Heliconia i., (Latreille \&).1. B. Godart in: Enc. méth., v. 9 p. $220: 1820$ Epimetes i.. Billberg, Euum. Ins., p. $77: 1848$ Eucides i., F. Doubleclay (\& Westwood), Gen. diurn. Lep., v. 1 p. 147 | 1851 E. $i$., Chenu \& H. Lucas, Enc. Hist. nat., Pap. diurn. p. 81 f. 180 | 1862 E. i., H. W. Bates in: Tr. Linn. Soc. London, v. 23 p. 563 | 1870 Eveilles i., Boisdural, Consid. Lép. Guatemala, p. 35 | 1871 Eueides i., W. F. Kirby, Cat. diurn. Lep., p. $146 \mid 1878$ E. i., Hritz Müller in: Ent. Zeit. Stettin, v. 39 p. $296 \mid 1885$ E. i., O. Staudinger (\& Schatz), Exot. Schmett., v. 1 p. 81 | 1886 E. i., G. W. Müller in: Zool. Jahrb., v. 1 1. 430 (Jetamorph.) | 1903 E. i. typica, Stichel in: Berlin. ent. Z., v. 48 p. 4 i. 1 f. 1.

Grundfarhe der Flügel rothraun, zuweilen etwas hlasser. Vorderflüged mit schwarzem Vorderrande und schwarzer Fleck- und Streifzeichnung, und zwar: Keilfleck länglich, in schräger Richtung in der Zelle gelagert, vorn längs und rumittelbar an der Subcostalis mit spitzem Ausliufer in proximaler Richtung; im hinteren, selten auch in mittleren Medianzwischenlaum nahe dem Zellende ein rundlicher isolierter Medianfleck. Apex breit schwarz his zum Zellende. Zwischen diesem und den Discalflecken eine sthräg liegende schwefelgelhe Binde, deren distale Begrenzung häutig etwas unregelmäbig ist. Meist tritt das Gelh hinter dem Zellende etwas in den rorderen Medianzwischenraum ror und ist distal im mittleren Medianzwischenram dureh einen vorspringenden schwarzen Zapfen (Randfleck) stufenartig algesetzt. Der hintere Medianzwischenraum ist rom Mediantleck bis auf den schmal sehwarzen Distalrand gelh ausgefüllt. Distal von der rorderen Ficke der golben Binde ein kleiner länglicher gelher Subcostalfleck. daran anschließend 3 schräg gestellte subapicale Fleckchen in gleicher Firhe, ron denen der hintere etwis aus der geraden Richtung distalwärts gerïclit ist. Submedianstreif roll und hreit, von der Flügelwurzel ans der Submediana in etwa 1 mm Ahstand folgend und distal diese herührend. Hinterrand im distalen 'Teil ganz. fein schwarz. Unterseite in derselben Zeichnung. aber matter, nächst dem Apex einige. heim $Q$ auch auf der Oberseite matt durchsedlagende. weiße Saumfleckchen. - Hinterthïgel mit unvollkommenem, etwa il $\% / s$ der Flïgellänge endigendem schwarzem Subcostalstreif, der beim or unmittelhar dem gläuzenden Vorderrandteil anliegt, beim o ron der Grundfarbe deutlicher ahgesetzt ist. Der Streif ist gerade und gestreckt oder etwas geschweift. distal entweder in stumpfer Spitze endigend. oder hinten leieht eingekerht oder gespalten. Mittelhinde hinter der Zelle. rom Hinteraude ausgehend. schwarz, geschlosseu, höchstens an den Aderu hogenförmig gekerht, ziemlich gestreckt, nur distal etwas nach rorn gekrümmt, all der rorderen Radialis endigend. Schwarzer Distalsaum ctwa 2-3 $\mathrm{mm}$ breit, heim $Q$ am Apex längs des Torderrandes allınählich auslaufend, mit verlosehenen. heim o dentlicheren, weißen Fleckchen. Cnterseite in heiden Geschloditern nit schwarzhamem, his znm Apex reichendem und dort in den Distalrand übergehenden Costalstreif und unrollkommenem, heim $\sigma^{\pi}$ in der Regel deutlichà als heim ? 
erkenubarem Subcostilstreif. Flügelwurzel gelb oder gelbbraun gefleckt, das Q häufig mit einer rou dort ausgehenden gelben Bestäubung vor dem Subcostalstreif. Mittelbinde stets mehr oder weniger in längliche oder eirunde Flecke aufgelöst. Saumflecke weiß, sehr deutlich, im Apex einzeln, alsdann paarweise nebeneinander in den Aderzwischenräumen stebend. Der schwarzbraune Saum proximal bogenförmig gekerbt. - Vorderflügelläng*e $30-35 \mathrm{~mm}$.

Bahia, Pará, östliches Amazonas, Französisch-Guayana.

2 b. E. isabella hippolinus Butl. 1873 E.h., A. G. Butler in: Cistula ent., v.1 p. $169 \mid 1877$ E. h., W. F. Kirby, Cat. diurn. Lep., Suppl. p. $723 \mid 1903$ E. isabella h. + E. i. h. aberr. margaritifera $+E$. i. h. aberr. personata $+E$. $i . h$. aberr. brunnea (O. Staudinger in MS.), Stichel in: Berlin. ent. Z., v.48 p.4 t. 1 f. 2 ; p. 5 t. 1 f. 3 (forina m.); p. 5 t. 1 f. 4 (forma p.); p. 6 t. 1 f. 5 (forma b.).

Forma principalis. Grundfarbe etwas dunkler rotbraun (lohfarben), Torderrand, Keil-, Medianfleck und Submedianstreif wie bei der typischen Unterart. Zwischen den Discalflecken und dem schwarzen Apicalteil keine gelbe Querbinde, sondern die braune Grundfarbe. Subcostal- und Subapicalflecke fehlen, oder ron letzteren ist nur der vordere schwach angedleutet. Mittelbinde des Hinterflügels meist auch auf der Oberseite mehr oder weniger in einzelne Flecke aufgelöst, sonst wie bei der typischen Unterart. Auf der Unterseite des Torderflügets ist der Anfang der gelben Binde am Vorderrande und der distal davon im Schwarzen liegende Subcostalfleck schwach angedeutet. Vorderflügellänge etwa $33 \mathrm{~mm}$.

Östliches Peru.

Forma margaritifera. Yorderflügel wie bei der typischen Cnterart, aher der schwarze Apicalteil ungefleckt. Hinterflïgel mit mittlerer Fleckenbinde wie bei der Hauptform. Unterschieden ron letzterer durch die gelbe Querbinde des Tordeiflügels.

Peru.

Forma personata. Ton der Hauptform dadurch auffällig abweichend, daß der Keilfleck mit dem Medianfleck, und dieser einerseits nach rorn an der hinteren Zellecke, andererseits distal längs des mittleren Medianastes mit dem schwarzen Apicalteil und Distalrande zusammengeflossen ist. Der schwarze Apex selbst auch verbreitert. so daß der vordere Medianzwischenraum ganz. der mittlere bis auf ein braunes Fleckchen ausgefüllt ist. Endlich auch der Subcostalstreif am Hinterwinkel nach vorn bis zu dem Schwarz des Apicalteiles und dem Steg zwischen Median- und Randfleck ausgeflossen, wodurch ein weiteres brauneres Fleckchen im Hinterwinkel abgesondert wird. Diese ganze Zeichnung etwa wie bei F. i. hübneri (S. 239), aber ohne Gelb und ohne Flecke im Apex. Hinterflügel mit mittlerer Fleckenbinde. Saumflecke der Unterseite scheinen schwach durch. - Auf der Unterseite des Vorderflügels die Begrenzung der Grundfarbe und des schwarzen Apicalteiles ungewisser. die isolierten Fleckchen ersterer rauchig iuberstäuht, dagegen ein deutliches gelbliches Subcostalfleckchen distal von der Zelle und etliche weiße Saumfleckchen im Apex rorhanden.

Peru (Tarapoto).

Forma brunnea. Torderflïgelzeichnung wie bei der typischen Lnterart, aber ohne schwefelgelbe Querbinde zwischen den discalen Flecken und dem schwarzen Apicalteil. Die Fläche dort wie die Grundfarbe. Das Schwarz des Apex im mittleren Medianzwischenraum meist in distaler Richtung etwas 
zurücktretend, so dals ler Randtleck zapfenartig frei liegt. Subrostal- und Subapicalflecke briunlich statt gelh. Zuweilen im mittleren Meclianzwischenraum nächt dem Distalrande ein vierter kleiner Flock von gloichre Farhe. Ansläufer des Keilfleckes in seltenen Fällen dergestalt gespalten, daß sich rom Beginu lesselhen cin inmitten der \%elle in proximaler Richtung varlanfender besonderer Striclı ablöst. Medianfleck mitunter längs der Mediana und des mittleren Merliamastes bis zum seliwarzen Apicalteil stegartig ausgeflossen (C̈bergang zur Forma personata). Hinterflügel mit mittlerer Fleckenbinde wie bei der Hauptform: beim \& meist die ainzeluen Flerke kleinel und in weiterem Abstando vomeinander. Cnterseite des Vorderflïgels im Discus und distalen Teil mehr olev weniger rauchbraun überstäuht, in cinzoluen Fällen am Torderande distal rom Keilfleck und im distalen Eude des mittleren Medianzwischenraumes mit schwal her gelblicher Bestäubung, den Resten der golben Querbinde der typischem [nterart. Sonst wio diese.

l'erı.

t. 1 f. 6.

2 c. E. isabella seitzi Stich. 1903 E. $i$. s., stichel in: Berlin. ent. \%., r. 48 p. 6

Stirnpunkte weißlich, Punktierung des Hinterkopfes und Thoracalflecke bräunlich, die übrige Körperzeiclunung ockergelb. - Vorterflïgel ähnlich deu der rorigen Form. also ohne gelbe Querhiude oder uur mit Spuren gellher Bestäubung roln in der Zelle und im distalen knde des hintereu Mredianzwischeuraumes. Keilfleck zuweileu mit gespaltenem Ausläufer. Rantfleck anf dem mittleren Medianast iu der Regel aufällig in proximaler Richtung als stumpfer Zapfen ans dem schwalzen Apical- und Distalrandteil hervortretend. wodurch die braune discale Flïgelfläche distal in zwei Zähne gespalten wird. deren vorderer etwas külzer und zugespitzt, deren hinterer. im hinteren Mediauzwischeuraum liegender länger und abgestumpft ist. Znweilen fliebt der Keilfleck nit dem Medianfleck und letzterer anBerdem uach vorn längs der Mediana und in distaler Richtuug längs des mittleren Medianastes mit dem schwarzen Apicalteil zusummen. Es entsteht damn ein länglicher. in der Nitte beiderseits eingeschnïrter braunel Fleck in ler \%elle und ein in distaler Richtung zugespitzter eirunder Fleck im mittleren Medianzwischenl'aum ron gleicher Firbe. Form und Beschaffenheit dieser Zoichnumg wiederholt sich in älnlicher Treise als Ausnahmefall bei Forma hrumnea der rorigen Lnterart und als Rocrel bei F. i. pellucidus (S. 238). - Hinterflügel mit geschlossenel Mittelbinde wie bei del typischen Unterart. Unterseits des Torderflïgels starke Neigung zur Gelbfärbung zwischen Keilfleck und Apicalteil wie auch in don Medianzwischenräumen. Suhapicalflecke in der Regel trïh gelh. manchmal fast bindenartig zusammengeflosinen. Auch der Hinterflügel zwischen Costal- und Subcostalstreif mehr oder weniger gelb bestäuht. - In übrigen wie die typische Cnterart. Vorderflügellänge ctwa bis $35 \mathrm{~mm}$.

Östliches Ecuador (Santa Inéz in Höhe von $1250 \mathrm{~m}$ ), Colombia.

2d. E. isabella dissolutus Stich. $1903 \mathrm{E}$. i. dissoluta. (O. Standinger in MS.) Stichel in: Berlin, ent. Z., i. 48 p. 6 t. 1 f. 7.

Größere und kräftigere Rasse der Art. - Torderflügel wie bei der typischen Unterart, etwas rariabel in Auslehnung des Schwal'z. Die Grundfarbe meist etwas blasser, gelbbraun. Medianfleck mitunter rergröbert und den hintereu Winkel des mittleren Jedianastes ausfüllend, auch mit einem zweiten, vorderen Medianfleck und mit dem Costalfleck zusammengeflossen. Distale Begrenzung der gelhen oder weißgelhen Querbiude unbeständig, das Schwarz meist am 
Zellende und mittleren Medianzwischenraum stärker in proximaler Richtung zapfenartig: (Randfleck) vortretend, jedoch nie mit den discalen Flecken vereinigt. Subapicalflecke verschieden groß, meist deren drei, seltener noch ein vierter, dem Rande genäherter kleiner Fleck im mittleren Medianzwischenraum. Hinterflügel mit mittlerer Fleckenbinde. Die einzelnen Flecke eirund, an einem oder beiden Enden meist etwas zugespitzt und meist deutlich und reichlich voneinander getrennt, hinter der Zelle zwischen den Adern bis zum vorderen Medianzwischenraum gelegen. - Vorderflügel entspricht also im allgemeinen dem der typischen Unterart, Hinterflügel dem von E. i. hippolinus (S. 236). Die sonstigen Charaktere wie bei ersterer. Torderflügellänge bis $38 \mathrm{~mm}$.

Peru (Tarapoto, La Mercedes), Bolivia.

2 e. E. isabella pellucidus Srnka 1885 E. pellucida, Srnka in: Berlin. ent. Z., v. 29 p. 130 t. 1 f. 3 | 1903 E. isabella 1). †- E. i. p. aberr. vegetissima, Stichel in: Berlin. ent. Z. $v .48$ p. 7 t. 1 f. 8 ; p. 8 (forma v.).

Forma principalis. Stirnpunkte weib, Punktierung des Hinterkopfes und sonstige Körperzeichnung ockergelb. Grundfarbe der Flïgel rotbraun bis ockergelb. Die schwarzen Zeichnungen (Fig. 43) von verschiedener Ausdehnung und in verschiedenen Kombinationen. Keilfleck wie bei der typischen Unterart, gewöhnlich isoliert oder aber nach hinten leicht mit dem Medianfleck zusammenhängend. Letzterer stets längs des mittleren Medianastes durch einen mehr oder weniger breiten Steg durch den Randfleck mit dem schwarzen Apical- und Distalrandteil rerbunden und auch proximal meist nach vorn

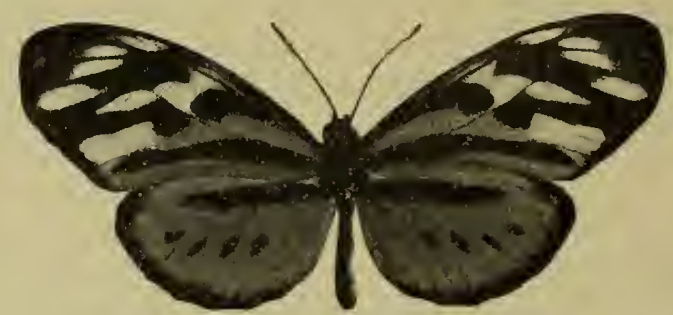

Fig. 43. E. isabella pellucidus, forma principalis, $ᄋ(1 / 1)$.

längs der Mediaua bis in das Schwal\% des Apex ausgeflossen. Es entsteht hierdurch eine Zeichnung, die einem Beil oder einer zweischneidigen Axt, deren Griff durch den Steg am mittleren Medianast gebildet wird. nicht unähnlich sieht. Die hierdurch abgesonderten Flecke blaßgelb oder ockergelb, und zwar ein solcher in der Zelle, quer über die Breite derselben gelagert und in der Mitte beiderseits eingeschnürt, ein weiterer länglicher, distal mehr oder weniger lang und spitz ausgezogener Fleck im mittleren Medianzwischenraum und ein länglicher, meist bis zum schmal schwarzen Distalsaum reichender im hinteren Medianzwischenraum, der proximal in die braune Grundfarbe übergeht und hinten rom Submedianstreif begrenzt wircl. Zuweilen flieBt letzterer im distalen Verlauf nach rorn aus, und es wird hierdurch im Hinterwinkel ein weiterer kleiner gelber Fleck abgetrennt. Die schwarzen Zeichnungen beim $O^{\pi}$ reichlicher und kräftiger entwickelt. beim $Q$ alle gelben Flecke ausgedehnter, namentlich auch der Subcostalfleck und die subapicalen Flecke, von denen die beiden rorderen meist zusammengeflossen sind. In seltenen Fällen herrscht auch im proximalen Teil des Torderflügels gelbe Bestäubung 
vor, und die brame Grundfarbe ist nur hinter dem Subnedianstreif, aber auch dort in alogeschwäclitem 'Ton, erhalten. - Hinterflügel mit mittlerer Fleckenbinde wie bei der rorigen Unterart, in etlichen Fällen, namentlich beim $₹$, die einzehen Flecke noch stärker verkleinert, an Hinterrande ganz verschwindend und nur deren 4 rom mittleren Median- bis zum rorderen Radialzwischenranm wahruehıbar. Vor dieser Fleckenbinde solten ockergolbe Bestänhung beim $q$. Lntere Scito der oheren entsprechend, aler matter. - In ührigen wie die typische Unterart. Torlertlïgellänge his $38 \mathrm{~mm}$.

l'eru ('Turapoto), Ėcuador (Arrhidona, Sarayacu), Bolivia, ('olombia.

Forma vegetissimi. Ton der Hauptform durch sattere Fïrhung, rein schwefelgelbe und reichlichere Flock- und Bindenzeichnung im Apex und Discus unterschieden. Der Medianfleck ist rom Keilfleck und dem Schwarz des Apex getrennt und nur durch einen schmalen Steg mit dem Distalrande rerbunden. Subapicalflecke hindenartig znsammengeflossen, der hintere laängt proximal mit dem gelben Discalteil lose zusammen. Der Submedianstreif endet kur\% ror dem Hinterwinkol. Flecke der Mittelhinde des Hinterflügels sehr klein.

\section{Ecuador (S'anta Inéz).}

2 f. E. isabella hübneri Ménétr. $1857 \mathrm{E}$. l., Ménétriés, Lép. Ac. St.-Pétersb., n. 2 p. 116 t. 8 f. 5 | 1862 E. h., H. W. Butes in: 'Tr. Linn. Soc. Loudon, $c .23$ p. 563 1871 E. h., W. F. Kirby, (at. diurn. Lep., p. $146 \mid 188 j$ E. h., O. Staudinger (\& Schatz), Exot. Schrnett., $v .1$ p. $81 \mid 1890$ E. $h$., Weymer (\& Massen), Lep. Reise Stübel, p. 36 1901 E. h., Therese von Bayern in: Berlin. ent. Z.. e. 46 p. $254 \mid 1861$ E. dynastes. ( . \& R. Felder in: Wien. ent. Monschr., v. 5 p. 1021900 E. l., A. (t. Butler in: Entomolngist, v.33 p.190 1871 E. cleobaea var., W. F. Kirby. ('at. diurn. Lep., p.146:1880 E. c. (err., non Geyer 1832!), F. L). Godman \& O. Salvin in: T'r. ent. Soe. London. j. 1221003 E. isabella hïbneri + E. i.h. aberr. spoliuta, Stichel in: Berlin. ent. Z.. v. 18 p. 8 ; p. 9 (forma s.).

Forma principalis. Stirnflecke weißlich, P'unktierung des Hinterkopfes und sonstige Körperzeichnung ockergell, his bräunlich. - Vorderfliigel etwa wie beim 0 von E. i. pellucidus gezeichnet. Keilfleck meist mit dem Medianfleck, und dieser längs des mittleren Medianastes durch den Randfleck mit dem schwarzen Distalrande verflossen. Medianfleck auberdem mehr oder weniger längs der Mediana mit dem schwarzen Apicalteil rerbunden, die hierdurch im I)iscus abgesonderten. wie anch die subapicalen Flecke schwefelgelh, und zwall: ein die Breite der /elle ausfüllender, in distalen Teil derselben gelegener Fleck, der in der Mitte heiderseits eingeschnürt ist; ein weiterer, lïinglicher, proximal rundlicher, distal spitz auslaufender Fleck im mittleren Medianzwischenraum; endlich ein länglicher Fleck im hinteren Medianzwischemaum, rom Medianfleck bis zum schmal schwaren Distahande reichend. Der letzte Fleck zuweilen in der Mitte, infolge rapfenartiger Verbreiterung des Submedianstreifes nich vorn und des Randfleckes sowie des längs rles mittleren Medianastes verlaufenden Steges nach hinten, mehr oder weniger eingeschnürt. Subapicalflecke meist grob. namentlich beim q, die rorderen beiden in der Regel nur durch die schwarz hestäubte vordere Radialis getrennt. - Hinterflügel oherseits mit geschlossener, vorn und hinten an den Adern gekerbter Mittelhinde oder mit lose zusammenhängender Fleckenhinde, unterseits stets mit isolierter Fleckenreihe an Stelle der Binde. - In ülrigen wie die typische Unterart. Torderflügellänge 31-40 mm.

Venezuela (Curacas), Colombia (Cauca. Huzo, Antioquia, Mlata). 
Forma spoliata. $\quad$. Torderflügel infolge Verbreiterung der dunklen Zeichnung fast ganz dunkelrauchbraun. Die rotbraune Grundfarbe proximal nur als zwei wischartige Streife an der Subcostalis und ror der Mediana, sowie am Hinterrande bis zur Submediana erhalten. Im distalen Teil der Zelle vorn ein ganz kleines, hinten an der Mediana ein größeres Fleckchen, ein Wischfleck im proximalen T'eil des mittleren Medianzwischenraumes, ein weiterer kleiner, unregelmäßig herzförmiger Fleck im Hinterwinkel, distal des Zellendes ein länglicher Subcostal- und drei Subapicalflecke wie bei der Hauptform, sämtlich gelb, im Apex drei trüb weißliche Fleckchen. Unterseite trüb braungrau, rerwaschen, sonst wie die Oberseite gezeichnet. Hinterflügel bellbraum, leicht rötlich, mit starkem, spitz endigendem, nach hinten zwei kleine Zapfen bildendem, braunschwarzem Subcostalstreif, ziemlich breiter, geschlossener, vorn und hinten etwas gewellter, gleich gefürbter Mittelbinde und ebensolchem Distalrande mit weißen Saumpünktchen. Unterseite matter, Flügelwurzel ror dem Subcostalstreif gelblicb. - Sonst wie die Hauptform. Vorderflügellänge $32 \mathrm{~mm}$.

Colombia (Caucia).

2g. E. isabella arquatus Stich. 1903 E. i. arquata, Stichel in: Berlin. ent.Z., v. 48 j. 9 t. 1 f. 9.

Ton der vorigen Unterart im besonderen durch Verbreiterung der gelben Zeichuung des Torderflügels und Reduzierung des Schwarz unterschieden. - Keilfleck vom Medianfleck getrennt, letzterer nur durch einen schmalen Steg mit dem Saum verbunden oder ganz isoliert. Es entsteht hierdurch eine geschlossene gelbe Binde, die derjenigen der typischen Unterart ähnlich, aber im distalen Teil breiter ist. Dieselbe verläuft von dem schmal schwarzen Vorderrande zwischen Keilfleck und schwarzem Apicalteil schräg bis 7.um Distalrande, füllt sowobl den mittleren als auch den binteren Medianz.wischenraum fast ganz aus und ist nur durch den schon erwähnten mehr oder weniger rollkommenen Steg am mittleren Medianast gespalten. Subapicalflecke meist stark vergrößert, fast zusammenhängend oder nur durch schmal schwarze Bestäubung an den Adern getrennt, ebenso auch der hintere Fleck von dem distalen vorderen Ausläufer der Querbinde abgetrennt, so daß eine größere, lose zusammenhängende gelbe Fläche entsteht, in der am Zellende ein schwarzer, umregelmäßiger Fleck eingeschlossen ist. Zuweilen ein kleiner isolierter vorderer Medianfleck im mittleren Medianzwischenraum. Das Gelb der Binde und Flecke weniger intensiv als bei der typischen Unterart. manchmal ockergelb, wenig von der Grundfarbe abgehoben und an den Berührungsstellen in dieselbe übergehend. Submedianstreif in der Regel voll und kräftig bis zum Hinterwinkel, im einzelnen Falle diesen nicht erreichend. - Hinterflügel mit kräftiger, meist etwas gekerbter Mittelbinde, in seltenen Fällen mit gelblicher Bestäubung zwischen dieser und dem Subcostalstreif. Diese Gelbfärbung auf der Unterseite meist vor und hinter dem Subcostalstreif vorhanden, wenige Stücke ganz ohne dieselbe. Die Mittelbinde in der: Regel in Flecke aufgelöst, aber mitunter auch roll und zusammenhängend. Unterseite sonst wie die Oberseite, aber matter. - Im übrigen wie die typische Unterart. Torderflügellänge $36 \mathrm{~mm}$.

Colombia (Cauca), Panama (Bugaba).

\section{E. cleobaea Geyer}

O. Stirnflecke weiß oder gelhlich weiß, Punktierung des Hinterkopfes und sonstige von der Grundfarbe abweichende Körperzeichnung gelb bis 
bräunlich. Form der Flügel wie hei den rorigen drtell. Grundfarbe rothis gelbbraun. - Torderrand des Vorderflügels schwar\%. I)ie Grundfarbe schneidet am Keilfleck in schräger Richtung nach dem Hinterwinkel bis zum Submedianstreif gegen den schwarzen und gelben distalen und apicalen Flügelteil ah uud ist der Länge nach ron dem kräftigen Submedianstreif unterbrochen. Keilfleck mit Medianfleck mehr orler weniger, letzterer stets längs des mittleren Medianastes mit dem schwarzen Saum des Distalrandes rerflossen. Wis entsteht hierdurch ein schmales schwarzes, unregelmäßig begrenztes Band, an welches sich distal eille bis zum breit schwarzen Apex reichende schmale schwefel- bis ockergelbe Binde anschließt. Diese ist meist an der Mediana durch Zusammenfließen des Nedianfleckes mit dem schwarzen Apicalteil und auch durch beiderseitige Einschniirung des rorderen Teiles in der Zelle in 2 oder 3 einzelne Flecke zerlegt, deren distal steheuder spitz gegen den Distalrand ausläuft. Im linteren Medianzwischenraum ein länglicher. diesen rom Medianfleck bis zum schmal schwarzen Distalrande ausfüllender, schwefel- bis ockergelber Fleck, der in der Mitte manchmal heiderseits eingeschuürt ist und hinten voll dem iu unmittelbarer Nähe ror der Submediana verlaufenden Submedianstreif begrenzt wird. Distal rou der Zelle ein länglicher, einfacher oder doppelter Subcostalfleck und hinter ihm, etwas nach dem Distallande volgeschoben, 3 scbräg gestellte, ziemlich große, längliche. nur schmal roneinander getrennte Subapicalflecke; diese sämtlich ron der Farbe der Disealbinde oder Discalflecke. Untere Seite wie die obere, aber matter gezeichnet, das Schwarz weniger intensiv, bei schräger Beleuchtung mit starkem, metallisch bläulichem Glanz, am Apex eine oder 7.wei Reihen weißer Saumfleckehen, die distale Reihe nur rudimentär. Hinter der Mediana nur ein schmaler brauner Streif längs des hinteren Astes, Hinterrandfeld sodann grau glänzeud his zur Submediana und hiuter dieser rötlichbraun glïnzend. - Hinterflügel mit sturk grauglänzendem Vorderrandfelde bis zur Subcostalis. Hieran unmittelbar anschließend ein bis zum Apex durchgehender schwarzer Subcostalstreif, sodann eine gestreckte, gerade oder distal nur sehr wenig nach roln gebogene, geschlossene schwarze Mittelbinde, welche auch in Flecke aufgelöst sein kann, und ein ziemlich breiter schwarzer Saum meist mit weißlichen Saumpunkten, wenigstens in der Nïhe des Hinterwinkels. Unterseite mit schwarzem Costal- und ebensolchem Subcostalstreif, welche sich im Apex miteinander und mit der schwarzen Saumbinde vereinigen. Letztere proximal bogenförmig gekerbt, mit meist zwei Reihen weißer Saumpunkte, die Punkte der distalen Reihe nur klein, zuweilen rerschwindend oder nur schwer zu erkennen; die Punkte beider Reihen stehen paarweise in den Aderzwischenräumen, nur im Apex sind diejenigen der proximalen Reihe zusammengeflossen. Flügelwurzel mit gelbem Fleck oder Wisch, der sich zuweilen hinter dem Costalstreif iu distaler Richtıng ungewiß endigend fortsetzt. Auch hier die schwarze Zeichnuug metallisch glänzend. - - o. Neist größer wic das $0^{*}$, in der Zeichnung diesem entsprechend. Torderflügel auch oben im Apex mit weißen Fleckclien, die Saumflecke des Hinterflügels schärfer markiert. Im übrigen mit den charakteristischen Geschlechtsunterschieden, also ohne Glanz im Hinterrandteil der Unterseite des Vorderflügels und Vorderrandteil der Oberseite des Hinterflügels. In ersterem der starke schwarze Submedianstreif und hinter letzterem der durchgehende Subcostalstreif deutlich ausgeprägt. Die schwarzen Zeichnungen der Tnterseite weniger stark glänzend. mitunter teilweise ganz stumpf schwarz- oder dunkelbraun. - - Die ganze Zeichnung sehr ähnlich derjenigen von E. isabella hübneri (S. 239), aber spezifisch ron dieser durch den rollkommenen, bis zum Apex reichenden Subcostal- 
streif des Hinterflügels und in den meisten Fällen auch durch die doppelte Saumfleckenreihe auf der Unterseite desselben unterschieden. Vorderflügellänge $35-45 \mathrm{~mm}$.

Mittel-Amerika, Antillen; Florida(?).

Diese Art zerfällt in 2 Unterarten:

3a. E. cleobaea cleobaea Geyer 1832 E.c., C. Geyer, Zutr. exot. Schmett., $v .4$ p. 7 t. f. $601,602 \mid 1848$ E. c., E. Doubleday (\& Westwood), Gen. diurn. Lep., v. 1 p. 147 1871 E. c., W. F. Kirby, Cat. diurn. Lep., p. $145 \mid 1877$ E. c., H. Dewitz in: Ent. Zeit. Stettin, v. 38 p. 238 | 1881 E. c. (part.), J. Gundlach, Contr. Ent. Cubana, v. 1 p. 22 | 1887 E. c., Möschler in: Abh. Senckenb. Ges., v. 15 I p. 95 | 1903 E.c.typica, Stichel in: Berlin. ent. Z, v. 48 p. 10.

Dadurch gekennzeichnet, daß die zwischen dem bindenartig zusammengeflossenen Keil-, Median- und Randfleck und dem schwarzen Apicalteil liegenden gelben Flecke zusammenhängen und eine schmale geschlossene Schrägbinde bilden, die in ihrem rorderen Teil in der Zelle beiderseits etwas eingeschnürt ist. Diese Zeichnung kann bei der Insel-Form als die überwiegende angesehen werden, wenngleich bei einzelnen Tieren mehr oder minder deutliche Neigung dazu vorhanden ist, daß der Medianfleck nach vorn längs der Mediana ausfließt und den vorderen, in der Zelle liegenden Teil der Binde ablöst. Hinterflügel mit geschlossener Mittelbinde. Die gewöhnlich rötlichbraune Grundfarbe in einzelnen Fällen blasser, fast ockergelb. Vorderflügellänge etwa bis $42 \mathrm{~mm}$.

Raupe auf Asclepiadis-Arten.

Cuba, Porto Rico.

3b. E. cleobaea zorcaon Reak. $1857 \mathrm{E}$. anaxa (Boisduval in MS.) (err., non E. cleobcea Geyer 1832 !), Ménétriés, Lép. Ac. St.-Pétersb., v. 2 p. $21 \mid 1866$ E. zorcaon, Reakirt in: P. Ac. Philad., p. $243 \mid 1871$ E. cleobaea var. z., W. F. Kirby, Cat. diuru. Lep.: p. 145 | 1881 \& 1901 E. z., F. D. Godman \& O. Salviu in: Biol. Centr.-Amer., Lep.Rhop. v. 1 p. 165 ; v. 2 p. $670 \mid 1874$ E. cleobaea (err., non Geyer 1832!), A. G. Butler \& Herb. Druce in: P. zool. Soc. London, p. 351 | 1885 E. c., O. Staudinger (\& Schatz), Exot. Schmett., v. 1 p. 81 | 1903 E.c.zorcaon + E.c.z. aberr. adusta, Stichel iu: Berlin. ent. Z., v. 48 p. 11 ; p. 11 (forma a.).

Forma principalis. Zwischen den bindenartig zusammengeflossenen schwarzen Discalflecken des Torderflügels und dem schwarzen Apicalteil mindestens zwei schwefelgelbe, deutlich getrennte Flecke, deren vorderer schräg in der Zelle liegt, diese ganz ausfïllt und von der angrenzenden schwarzen Zeichnung beiderseits eingeschnürt ist, zuweilen so stark, daß in der Mitte eine Trennung erfolgt und anstatt zwei, deren drei in schräger* Richtung vom Vorderrande bis mehr oder weniger nahe zum Distalrande gestellte gelbe Flecke vorhanden sind. Der distal liegende Fleck ron rerschiedener Ausdehnung, gegen den Distalrand zu spitz ausgezogen. Hinterflügel mit geschlossener, gerader oder nur wenig gekrïmmter, schwarzer Mittelbinde, die verschieden breit, $2-4 \mathrm{~mm}$, und beiderseits etwas unregelmäßig und unscharf begrenzt ist. Im übrigen wie bei der Art beschrieben. Vorderflügellänge bis $45 \mathrm{~mm}$.

Es kommen weniger typisch ausgeprägte Tiere ror, deren Trennuug ron der vorigen Unterart kaum möglich ist.

Panama, Costa Rica, Honduras, Guatemala, Nicaragua, Mexiko, Florida (?).

Forma adusta. Discal- und Subapicalflecke des Torderflügels nicht schwefel-, sondern ockergelb oder bräunlich wie die mitunter aufgehellte Grundfarbe. Der im hinteren Medianzwischenraum nahe dem Hinterwinkel 
liegende lange Fleck an der Becïhrungsstelle mit der Grundfarbe in diese übergeliend. Querbinde des Hinterflïgels meist geschlossen, zuweilen aber auch in einzelne Flecke aufgelöst. Sonst wie die Hauptform, scheint aber eine hauptsächlich dem o eigentümliche Abart zu sein.

Chiricuii. Honduras.

\section{b. Coh. Riciniformes}

Kopf und Körper schwarzhraun, allgemeiner Ball und \%eichnung wie bei der vorigen Gruppe. Dio Längsstreife des Abdomen sehr undeutlich, manchmal nur als einzelno Punktstriche erhalten. - Vorderflügel schlank, schmaler als bei den Dianassiformes (S. 231). Torderrund fast geride, nur distal etwas gekrümmt. Apex spitzer abgerundet, Distahrand vorn schwach stumpfwinklig, wemlgleich ohne rigentliche Ecke gehogen, sodanı fast gerade in proximaler Richtung abgeschrägt. Hinterwinkel stumpf, Hinterand schwach S-förmig gebogen, etwa von der Länge des Distalrandes. Hinterflïgel fast dreicckig mit konvexen Sriten, Apex wemig hervortuetend, Hinterwinkel ahgerundet; Distalsaum wellig. - $\delta$ mit mattem grauem Hinterrandteil auf der Unterseite des Vorderflügels und breitem, über die Subcostalis reichendem grauem Vorderrandfelde auf der Oberseite des Hinterflügels, beide mit nur geringem, sammetartigem Glanz. \& an diesen Stellen in ähnlicher aber ganz inatter Färbung, das graue Torderandfeld des HinterHïgels schmaler, nur bis zur Submedima ausgedehnt.

Nur ein Vertreter bekannt, welcher nach Färbung, Zeichnung und Gestalt eher an die Thaletoformes (S. 264) anzureihen wäre, vermöge der Morphologie des Vorderflügelgeäders aber den Macroscenae angehört.

1 Art.

4. E. ricini (L.) 1705, M. S. Mlerian, Ins. Surin., t. 30 | 1756. Rösel, InsectenBelustig., v. 4 p. 42 t. 5 f. $1 \mid 1758$ Papilio (Heliconiues) ricini, Linné, Syst. Nat., ed. 10 p. 466 | 1764 P. r., Linné, Mus. Ludov. Ulr., p. 227 | 1774 P. r., St. Müller, Naturs. Linné, v. 5 I p. $584 \mid 1779$ "P. r.", Goeze, Ent. Beytr., v. 31 p. $100 \mid 1782$ "Ricini“, P.r., P. Cramer, Pap.exot., $v .4$ p. 174 t. 378 f. A, B; p. $251 \mid 1790$ P. r., J. F. W. Herbst, Naturs. Ins. Schmett., v. 4 p. 146 t. 74 f. 3 | 1816 Apostraphia r., Jac. Hübner, Verz. Schmett., p. 13 | 1819 Heliconia r., (Latreille \&) J. B. Godart in: Ene. méth., v. 9 p. 209 | 1844 H. r., E. Doubleday, List. Lep. Brit. Hus. v. 1 p. $54 \mid 1847$ H. r., E. Doubleday (\& Westwood), Gen. diurn. Lep., v. 1 p. 103 | 1848 H. r., J. Sepp, Surin. Vlinders, $v .1$ p. 13 t. 3 | 1851 H. $r$, Chenu \& H. Lucas, Enc. Hist. nat., Pap. diurn. p. 68 t. 23 f. 2 | 1862 Heliconius r., H. W. Bates in: Tr. Linn. Soc. London, v.23 p. 562 | 1869 H. $r$, A. G. Butler, Cat. diurn. Lep. Fabr., p. 123 | 1871 \& 77 H. r., W. F. Kirby, Cat. diurn. Lep., p. 144; Suppl. p. 721 | 1878 H. r., Möschler in: Ent. Zeit. Stettin, v. 39 p. 426 | 1882 H. r., Chr. Aurivillius in: Srenska Ak. Handl., n. ser. $v .19$ nr. 5 p. 44 1885 H. r., O. Staudinger (\& Schatz), Exot. Schmett., v. 1 p. $76 \mid 1900$ Eueides r., Riffarth in: Berlin. ent. Z., v. 45 p. 195 | 1903 E. $v$.. Stichel in: Berlin. ent. Z., v. 48 p. 32 | 1775 Papilio myrti, J. C. Fabricius, Syst. Ent., p. 461, $462 \mid 1781$ P. m., J. C. Fabricius, Spec. Ins., v. 2 p. 30, $123 \mid 1787$ P. m., J. C. Fabricius, Mant. Ins., v. 2 p. 15 1793 P. m., J. C. Fabricius, Ent. syst., v.31 p. 167, $169 \mid 1806$ P. polyhymnia, G. Shaw, Gen. Zool., v. 6 I p. 211 t. 67.

๙. Palpen gelblich, schwarz gesäumt, Punktierung des Kopfes, auf dem Hilskiagen, Flecke auf dem 'Thorax und Zeichnung des Abdomen schwefelgelb. Antennen schwarzbraun. Grundfarbe der Flügel schwarzbraun. Beiderseits dec Mediana, von der Flügelwurzel aus ein schwefelgelber Streif, in der Zelle ein die Breite derselben ausfüllender, hell schwefelgelber Fleck, der sich in schräger Richtung nach hinten in einem zweiten, durch die fein 
schwarzbraune Mediana getrennten, größeren, fast stumpfwinklig dreieckigeu gleichgefärbten Fleck bindenartig fortsetzt. Letzterer sitzt in ganzer Breite dem hinteren Medianast auf, füllt aber den Basiswinkel desselben an der Mediana nicht ganz aus. Der vordere Fleck der Binde in der Zelle ist beiderseits etwas eingeschnürt und seime hintere, distale Ecke längs der Mediana bis zur Abzweigung des mittleren Medianastes ausgezogen, um hier in den hinteren Fleck, schräg nach hinten abfallend, überzugehen. Mitunter ist auch der Scheitel des Winkels vor dem mittleren Medianast etwas gelb ausgefüllt. Distal von dieser Binde eine schmale, von den Adern schwarz durchschnittene, schräg liegende Subapicalbinde, die dicht hinter dem Vorderrande bei der Abzweigung des 3. Subcostalastes beginnt und unweit des Distalrandes bei der hinteren Radialis endet. Unterseite ebenso, aber matter in der Farbe, die subapicale Binde undeutlicher, distal ron derselben ungewisse weißliche Bestäubung. Hinterrandteil schwach grauglänzend. Am Torderrande ein kurzer roter Streif von der Flügelwurzel aus. - Hinterflügelwurzel kurz keilförmig schwarzbraun hinter einem matt grauglănzendem Vorderrandfelde, welches bis über die Subcostalis reicht. In dem schwarzen Wurzelstreif 3 rote Punkte. Hinter dem grauen Torderrandfelde eine rote bindenartige Fläche, die breit nächst dem Hinterrande einsetzt und, hinten etwas gebogen, in schräger Richtung nach rorn abgegrenzt ist. Distal reicht dieselbe mit der vorderen Spitze etwa bis zum zweiten Drittel der Flügellänge. Der übrige, hintere distale Flügelteil schwarzbraun. Unterseite mit gelbem Wurzelstreif am Vorderrande, den drei roten Wurzelpunkten hinter der Costalis, in der Zelle und hinter der Mediana, sowie einem vierten Fleckchen auf der Hinterrandader und endlich einem ebensolchen in der Nähe des Hinterwinkels. Färbung der Flügelfläche schwarzbraun, der hintere Teil etwas heller, zwischen den Adern je zwei weißliche Streife, die in etwas deutlicher weißen Saumfleckchen enden. - - 2 . Größer als das ơ, die letzten Kolbenglieder der Antennen rötlichbraum. Grundfarbe etwas matter, nächst dem Vorderrande des Torderflügels an der Subcostalis ungewiß gelblich bestäubt. Die weißen Saumfleckchen der Hinterflügelunterseite scheinen oben schwach durch, die weißlichen Streife der Unterseite sind etwas deutlicher. Hinterrandteil der Vorderflügelunterseite wesentlich heller, grau aber matt, Vorderrandfeld der Hinterfliggeloberseite nur wenig heller als die schwarzbraune Grundfarbe, schmaler und ohne Glanz. Im übrigen wie das 0 . - - Vorderflügellänge $34-38 \mathrm{~mm}$.

Raupe im Januar und Februar auf Passiflora laurifolia.

Guayana, nördliches Brasilien (östliches Amazonas).

\section{Sect. Brachyscenae}

Zelle des Vorderflügels von halber Länge des Vorderrandes oder kürzer. Der 1. Subcostalast entspringt unmittelbar an der vorderen Zellecke oder nur in geringem Abstande proximal von derselben, der 2. Subcostalast in beträchtlicher Entfernung distal von dieser. - Verschieden gefärbte und gezeichnete Falter, entweder braun oder schmutziggrau (durchscheinend) mit schwarzer, oder dunkelbraun mit gelblicher oder weißlicher, oder schwarz mit rerschieden bunter Zeichnung.

\section{a. Coh. Lampetoformes}

Kopf sehwarz, Stirn mit 2 weißen, teilweise von den Palpen verdeckten Flecken an der Antennenwurzel, Hinterkopf mit 4 kleineren weißen oder 
weiblichen Punkten zwischen den Augen. Letztere schwarzraun, hinten weiß gesäumt, ohen luänfig noch mit je einem kleinen weißen Punkt. Palpen weiß, sclimal schwarz gesäumt, Spitze schwarz. Antennen unter halber Iänge des Vorderiandes, heim ô dorsal bis zur Spitze, rentral his zunn letzten Drittel schwar\% oder schwarzhraun, sonst ockergelh, heim o vorwiegend ockergelb, nur proximal schwarzhrann. Körper selhwar bis scliwarzbraun. Halskragen ohen mit zwei weißlichen oder bräunlichen Fleckehen, Thorax in der Mitte beiderseits und hinten gelbbrau oder weißlich gefleckt. Abdomen wenig oder gar niclit üher den Hinterflügel hinausragend, ventral weißlich punktiert, lateral nuten mit einer weiblichen, stellenweise unterbrochenen, manchmal undeutlichen Doppellinie oder ebensolchen Streifen, darüber mit einer Reihe kleiner Punkte derselhen Färhung auf den einzelnen Segmenten. Tibia des Vorderheines weiß, Tarsus desselben und die übrigen Beine an den Hïften weißlich bestäubt, sonst schwarz. Thorax ventral jederseits dicht rorn an der Flïgelwurzel nit einem weißen Fleck, zwisclıen den Hüften mul hinter ihnen mit weißer Bestäubung. - Vorderflügel stumpfwinklig dreieckig, der flach gek riimmte Torderrand als Basis gedacht. Apex leiclit abgerundet, Distalrand voru leicht konvex, Hinterrand schwach S-förmig gekrünınt, letztere heide etwa gleich lang. Hinterwinkel stumpf, kam geeckt. Hinterflügel nahezu eirund, ror'n abgeflacht, Apex wenig vortietend, Hinterwinkel abgerundet. Lehhaft rotgelhe Falter mit schwarzem Apex nnd schwarzen Binden und Flecken in ähulicher Anlage wie bei den Dianassiformes (S. 231). ठ auf der Unterseite des Vorderfiügels hinter dem hinteren Mediamast nur mit eiuem schmalen Streif stumpf branner Schuppen, dahinter lebhaft grau- his rötlichbraun seidenglänzend. Torderrandteil des Hinterflügels bis zur Suhcostalis grau seidenglänzend. O ohne diese Merkmale, an den erwïhnten Stellen mit der etwas matteren Zeichnung der entsprechenden Gegenseite.

1 Art, die in 3 Unterarten zerfällt.

\section{E. lampoto Bates}

ơ. Grundfarbe der Flügel rotbraun bis rötlich ockergelh. - Zeichnung des Vorderflügels schwarz, und zwar: schmaler Saum an Vorderrande; Keilfleck in der Zelle rundlich oder unregelmäßig länglich nnit einem der Subcostalis anliegenden spitzen oder keilförmigen Ausläufer in proximaler Richtung ron größerer oder geringerer Breite; ein unregelmäßiger Endzellfleck von rerschiedener Ausdehnung, zuweilen nur als gewinkelter Strich rorhanden; ein unregelmäBiger, meist länglicher, zuweilen bis zum Distalrande rerlängerter Randfleck im mittleren Medianzwischenraum; zuweilen ein häufig nur schattenhaft angedeuteter Medianfleck im linteren Medianzwischenraum; Apex in melir oder minder beträchtlicher Ausdehmung, zuweilen so weit, daß das Schwar\% mit dem Endzellfleck und mit dem Randfleck zusammenfließt und namentlieli letzteren rollstïndig anfnimmt; endlich ein mehr oder weniger langer und breiter Suhmedianstreif, der fleckartig verkürzt sein kan und dann breit lanzettförmig oder verschohen rechteckig gestaltet ist. Unterseite matter, Grundfarbe manchmal ockergelb, zuweilen rauchbraun angeflogen; im allgemeinen mit den Zeichnungen der Oberseite, aber Keilfleck meist ohne Ausläufer; isoliert im mittleren Teil der Zelle, Medianfleck meist deutlicher, wenn anch unsicher begrenzt; zuweilen ein zweiter, vorderer, schattenhaft angelegter Medianfleck im mittleren Medianzwischenraum. im Apex und häufig auch am Distalrande einige weiße Saumfleckehen. Vorderraud proximal mit kurzem gelbem Wurzelstreif. - Hinterflügel eiruncl, vorı stark und am Distalrande schwäclıer abgeflacht, mit gauz kurzem scliwarzem Suh- 
costalstreif in Gestalt eines keilförmigen Fleckchens an der Wurzel, der dicht an den grau bis rötlichgrau glänzenden Vorderrandteil anschließt, schwarzer Saumbinde, die zuweilen stark ausgezackt ist, und mehr oder minder geschlossener ebensolcher Mittelbinde aus deutlich getrennten oder zusammenhängenden länglichen Flecken; in letzterem Falle ist diese Binde beträchtlich verbreitert oder zu eimem großen schwarzen Fleck ausgeflossen, der nur einen costalen und apicalen Teil der Grundfarbe freiläßt und von der Saumbinde nur ungewiß durch eine Reihe bräunlicher Fleckchen getrennt ist. Unterseite in der Regel matter, meist auch weniger schwarz gezeichnet, so daß die Mittelbinde, wenn auch fleckartig verbreitert, deutlich vorn und hinten isoliert ist. An der Flügelwurzel ein gelblicher Fleck, Costal- und Subcostalstreif schwarzbraun, meist deutlich getrennt, zuweilen aber auch, namentlich distal, verflossen. Saumbinde vorn stets sehr tief gezackt, so daß sie eine Reihe spitzer, nur an der Flügelwurzel zusammenhängender Dreiecke oder Keilflecke darstellt. In den einzelnen Keilflecken nächst dem Apex je ein, in den übrigen je zwei weiße Saumfleckchen. - - o. Mit breiterem Torderflügel. Grundfarbe meist etwas blasser, namentlich im distalen Teil nächst dem schwarzen Apex, sonst mit denselben Zeichnungsanlagen, nur auf dem Hinterflügel stärkere Neigung zur Verbreiterung des Schwarz vorhanden, und mit den charakteristischen, bei der Gruppe erwähnten Geschlechtsunterschieden; im Saum des Hinterflügels auch oberseits mehr oder minder deutliche weiße Randfleckchen. - - Sehr variable Art, so daß kaum ein Stïck dem anderen gleicht.

Gebiet des oberen Amazonen-Stroms (von São Paulo de Olivença bis Ecuador and Peru).

\section{Diese Art zerfällt in 3 Unterarten:}

5a. E. lampeto lampeto Bates 1862 E. l., H. W. Bates in: Tr. Linn. Soc. London, v. 23 p. $563 \mid 1871$ E. l., W. F. Kirby, Cat. diurn. Lep., p. $146 \mid 1885$ E. $l$., O.Staudinger (\& Schatz), Exot.Schmett., v. 1 p.81 | 1903 E.l.typicus, Stichel in: Berlin. ent. Z., v. 48 p. 12.

Grundfarbe der Flügel lebhaft rotbraun, Torderrand und Apex des Vorderflïgels schmal schwarz; schwarz außerdem: Keilfleck in der Zelle mit Wurzelausläufer, breiter, 'spitz auslaufender Submedianstreif, eim Endzellfleck und eim verloschener Medianfleck. Im Apex zwei weißliche Punkte. Hinterflügel mit unvollkommenem Subcostalstreif, einer Mittelbinde hinter der Zelle, bestehend aus länglichen, von den Adern geteilten Flecken, und breitem schwarzem Saum mit weißen Randfleckchen. Torderflïgellänge etra $34 \mathrm{~mm}$. - Nach einem o beschrieben, aber vermutlich auch das $\sigma$ in annähernd übereinstimmender Zeichnung vorkommend, alsdann ohne weiße Apical- und Saumpunkte auf der Oberseite.

São Paulo de Olivença.

5 b. E. lampeto fuliginosus Stich. 1903 E. l.aberr. fuliginosa + E.l.aberr.amoena + E.l.aberr. carbo, Stichel in: Berlin. ent. Z., v. 48 p. 12 t. 1 f. 10 ; p. 13 (forma a.); p. 13 t. 1 f. 11 (forma c.).

Forma principalis. $\sigma^{\tau}$. Von dem $Q$ der typischen Unterart hauptsächlich dadurch unterschieden, daß die Flecke der mittleren Binde des Hinterflïgels zusammengeflossen und $\mathrm{zu}$ eimem breiten längtichen schwarzen Discalfelde ausgebreitet sind, welches von der braunen Mediana und den teilweise braunen Medianästen durchschnitten wird. Die Randbinde ist nur schmal und zum Teil auch nur undeutlich abgetrennt. Randfleck des Torderflügels entweder isoliert im mittleren Medianzwischenraum oder bis zum Saum ausgeflossen. 
Medianfleck nur in verloschenen Spuren wahruehmbar. - Das $q$ mit rerküratem Submedianstreif, welcher nur bis z.n ${ }^{2} / 3$ der Länge des Hinterrandes reicht. Disealer und distaler Teil des Vorderflingels heller als die Wurzel, ockergelb. - Vorderflügellänge $33-34 \mathrm{~mm}$.

Ecuador (Santa Inéz; Baños, in Höhen von 1200-2000 m).

Forma amoena. Apex des Vorderflïgels mit Findzell- und Randfleck zu einer hreiten schwarzen Fläche zusanmengeflossen. Keilfleck kräftig, mit Auslïlfer bis zur Flïgelwurzel wie hei dell anderen Formen. Submedianstreif proximal sehr breit, sodann verschmälert und spitz am letzten Drittel der Submediana endigend. Distalrand schwarz. Medianfleck schwach angedeutet, unterseits deren zwei, etwas schärfer. Die Ausdehnung des Schwarz im Apex und die Gestalt des Submedianstreifes variieren etwas, letzterer reicht in einem Falle nur bis zur Hälfte der Ader. - Hinterfliigel mit breiter Randbinde, die unterseits, zuweilen auch oben (namentlich beim $ᄋ$ ), tief spitzwinklig gezähnt ist. Mittelbinde aus lose zusammenhängenden, länglichen, mindestens durch die brannen Adern getrennten Flecken bestehend. — Sonst wie die Hauptform.

Ecuador (Santa Inéz in Höhe von $1250 \mathrm{~m}$ ), Bolivia.

Forma carbo. Der vorigen Form ähnlich, aber Submedianstreif des Vorderflingels noch breiter und kürzer (Fig. 44). Derselbe folgt vorn der Mediana in kurzem Abstande, ist gegen die Mitte der Submediana beiderseits ahgeschrägt und bildet einen proximal und distal zugespitzten, breiten, läng-

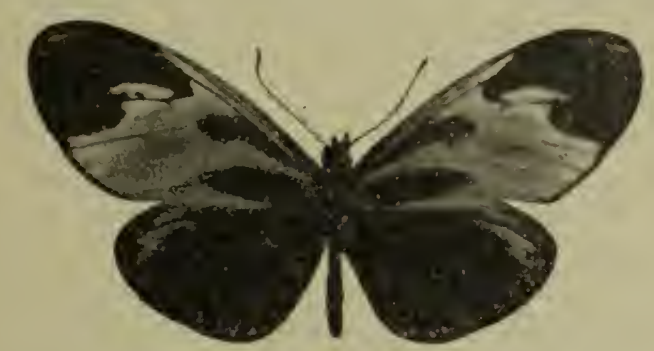

Fig. 44. E. lampeto fuliginosus, forma carbo, 오 ( $\left.{ }^{1} /{ }_{1}\right)$.

lichen Fleck etwa in Gestalt eines Parallelogramms. Nittelbinde des Hinterflïgels bedeutend verbreitert, so daß dieselbe ganz mit dem schwarzen Sanm zusammengeflossen ist und die Flïgelfläche bis auf den Apex und einen kleinen Streif hinter dem Vorderrande schwarz ist, oder die schwarze Fläche ist nur durch eine Reihe verlosehener branner länglicher Fleckehen von dem Vorderrandfelde getrennt. Interseite des Hinterflügels mit der fïr die Art charakteristischen Saumbinde aus spitzen Dreiecken; die Nittelbinde in Gestalt schattenhaft begrenzter länglicher Flecke.

Ecuador (Santa Inéz). Im November.

5 c. E. lampeto acacates Hew. 1869 E. a., Hewitson, Equat. Lep., p. 22 | 1871 E. a., W. F. Kirby, Cat. diul'n. Lep.. p. 146 | 1903 E. lampeto aberr. a., Stichel in: Berlin. ent. Z., $v .48$ p. 12.

Wie die typische Cnterart, aber der schwarze Apex proximal und nach hinten verbreitert und mit dem Randfleck zusammengeflossen, Endzellfleck jedoch isoliert. Der Medianfleck fehlt. könnte aber auch, wie bei den anderen Unterarten, angedentet sein. Hinterflïgel mit proximalwärts stark gezackter Saumbinde und einer aus länglichen Flecken bestehenden mittleren Querbinde. 
Es kommen Übergänge zur nächsten Form vor, bei denen der Apex des Vorderflügels längs der Radiales und am vorderen Medianast mit dem Endzellfleck streifenartig zusammengeflossen ist; Medianfleck verloschen wahrnehmbar.

Curaray, Peru (Tarapoto).

\section{b. Coh. Vibiliiformes}

Merkmale und Zeichnung des Kopfes, der Palpen. der Augen, Beine und des Körpers wie bei den Lampetoformes (S. 244). Antennen beim o in der Regel ganz schwarzbraun, nur die Unterseite des Kolbens bräunlich anfgehellt, oder mit ocker- bis rotgelbem Kolben und distalem Drittel des Schaftes, beim $q$ ebenfalls meist schwarzbraun, der Kolben zuweilen etwas deutlicher bräunlich oder gelblich oder nur proximal schwarz, sonst ockergelb. Vorderflügel schlank, Vorderrand leicht gekrümmt, Apex abgerundet, Distalrand vorn leicht konvex, Hinterwinkel stumpf, Hinterrand leicht S-förmig geschweift, etwas länger als der Distalrand. Hinterflügel abgerundet dreieckig, mit wenig hervortretendem Apex und kaum markiertem Hinterwinkel. Schwarzbraune Falter mit helleren Zeichnungen, oder gelb- bis rotbraune Arten oder solche von grau durchschemender Grundfarbe mit schwarzer und gelber Zeichnung, die sich im allgememen und mit werigen Ausnahmen noch auf die typische Zeichnung der Dianassiformes (S. 231) zurückführen läßt. — Der Torderflügel läßt Keilfleck, Submedianstreif, Apex und Vorderrand in dunkler Anlag'e auf hellerem Grunde meist erkennen. Im Apex häufig eine Fleckenbinde, die sich manchmal zu einem großen geschlossenen Fleck ausbildet, welcher nur durch eimen schmalen Steg vom Discus abgesondert ist. Medianund Randfleck nur bei gewissen Formen als zusammenhängende Binde zn erkennen. Bei den ersten, den Übergang darstellenden Tertretern der Gruppe die dunklen Zeichnungen unter sich zusammengeflossen, derart, daß die als Grundfarbe angenommene hellere Farbe auf Streif und Fleckenbildung zurückgedrängt wird. - Hinterflügel stets ohne Mittelbinde, aber mit mehr oder minder breiter, an den Adern ausgeflossener dunkler Saumbinde. - Mehrere Arten dieser Gruppe durch auffallenden Geschlechtsdimorphismus ansgezeichmet. ठ mit grau oder graugelb seidenglänzendem Hinterrandteil der Vorderflïgelunterseite und ebensolchem Vorderrandteil der Hinterflügeloberseite. $q$ ohne diese Eigenschaften, sondern mit der etwas matteren Zeichnung der entsprechenden Gegenseite an jenen Stellen. - Die letzte Art (S. 258) stimmt in der Zeichnung der Flügel mit denen der Lybüiformes (S. 260) ïberein.

5 Arten, von denen 3 in 10 Unterarten zerfallen.

6. E. edias Hew.

ơ. Punktierung der Stirn weiß, die des Kopfes weißlich oder gelblich, Thorax dorsal fast schwarz. Antennen schwarzbraun, distal mitunter rötlichbraun, manchmal auch nur der Kolben ventral etwas heller. - Vorderflügel dunkelbraun mit gelblichen oder rötlichen Flecken, durch deren Lage die typische dunkle Zeichnung in der Regel wie folgt erkannt wird: Vorderrand verschmolzen mit dem proximalen Ausläufer des Keilfleckes; Endzellfleck distal streifen- oder strahlenartig mit dem Apex rerflossen; Medianfleck einerseits nach vorn mit dem Keilfleck und dem Endzellfleck, distal längs des mittleren Medianastes mit dem dunklen Distalrande und Apicalteil verbunden; endlich ein breiter Submedianstreif, der nur einen schmalen rötlichen Hinterrand freiläßt, vorn an der Mediana anliegt, aber distal etwas verjüngt in den Hinterwinkel ausläuft. Bei überwiegend schwarz- 
hrauner Färbnng des Flïgels befindet sich darin ein manchnal nur schattenhaft angedeuteter rötlicher Wruzelstreif ror der Mediana, ein gelblicher Fleck in distılen Teil der Zelle, eine schräge Reihe ebensol(her länglicher subapicaler Flecke und je ein Fleck im mittleren und hinteren Medianzwischen anm. Hinterrand melır oder weniger rötlichbrann. Untere Seite im allgeneinen wie die obere, die dunklen Töne nleist matter, im Apex und nächst dem Distalraude melı oder weniger weiße Saumfleckchen. - Hinterflïgel rothraun mit melr oder minder breitem schwarzbraunem Saum. Unterseite mit dunkelgranem oder schwärzlichem Costal- und Subcostalstreif, die nicht selten völlig verschmolzen sind, und eiuem mehr oder minder deutlichen weiBen Fleck an der Flïgelwurzel. Saumbinde undeutlich, mu schattenhaft oder in dunklerem Grundfarbenton angedeutet. Der mittlere Teil weißlich anfgehellt. Zwisthen den Adern vorn je ein, sodann je zwei weiße Saumfleckchen, distal von ihnen nächst dem Flügelrande zuweilen noch Sampiinkteheı. - o. Meist größer als das $\sigma^{\pi}$, Antennen nur proximal schwarzbraun, soust ockergelb. Grundfarbe der Flügel bedentend heller, braungelb oder graugelb, mitunter glasartig durchscheinend, nur spärlich graugelb bestäubt, mit den beim $\sigma^{*}$. beschriebenen dunklen 7eichnungen. Im übrigen mit den bei der Gruppe erwähnten Geschlechtsunterschieden.

Von Costa Rica bis Colombia. Venezuela, Ecuador.

Diese Art zerfällt in 4 Unterarten:

6a. E. edias edias Hew. 1861 E. e., Herritson in: J. Ent.. $v .1$ p. 155 t. 10 f. 2 ! 1871 E. e., W. F. Kirby, Cat. diurn. Lep., p. 146 | 1880 Eurides (laps.) e., F. D. Godman \& O. Salvin in: Tr. ent. Soc. London, p.130| 1877 Eueides künowii, H. Dewitz in: Mit. Münch. ent. Ver., e. 1 p. 89 t. 2 f. 5 | $1903 \mathrm{E}$. edias typicus, Stichel in: Berlin. ent. Z., v. 48 p. 14 t. 1 f. 12.

Vorderfliigel vorherrschend dunkelbraun. Proximal, von der Flügelwurzel ausgehend, ein rötlicher Streif vor der Mediana, welcher den dunkelbraunen Snbmedianstreif ron dem Auslänfer des Keilfleckes der typischen Zeichnung trennt. Dieser rötliche Streif wendet sich ain Ursprunge des hinteren Medianastes in distaler Richtung und folgt letaterem bis zu einem im hinteren Medianzwischenraum liegenden länglichen gelbbraunen Fleck, der mit ihm entweder zusammenhängt oder ron ihm durch einen schmalen Steg getrennt ist. Ein Fleck gleicher Färbung im distalen Teil der Zelle. schräg' gestellt, die ganze Breite derselben ausfïllend und beiderseits etwas eingeschniirt. Derselbe trennt den dunklen Keilfleck rom Endzellfleck und schwarzbraunen Apicalteil. Distal ron ihm, im mittleren Medianzwischenraum, ein eirunder, distal etwas spitzer, gleichartiger Fleck und vor demselben. subcostal anfangend, eine schräge Reihe durch die Adern getrennter länglicher ebenso gefärbter Flecke oder Wischflecke. Alle diese Flecke leicht schwärzlich ïberstäubt, zuweilen stärker rötlich statt rotgelb. Hinterrand schmal rotbraun oder rotgelb. Unterseite matter, die helle, meist gelbliche Zeichnung verbreitert, so dab cliese als Grundfarbe mit den bei der Art erwähnten charakteristisehen dunklen Zeichnungen zu erkennen ist. Die dunklen Töne lichter, die hellen Teile im distalen Teil rauchbraun überstäuht. Einige weiße Apical- und Saumfleckchen, letztere in der Nähe des Hinterwinkels, vorhanden. - Hinterflügel rotbraun, an der Wurzel ein kurzer keilartiger schwarzer Subcostalstreif. Iistalsaum etwa 3-5 nun breit schwarz oder scliwar\%braun, seine proximale Begrenzung unscharf, an und auf den Adern etwas ausgeflossen. Die Saumfleckchen der Interseite scheinen schwach durch. Tnterseite viel heller, im mittleren Felde gelblichweils, nur proximal in Hinterfelde 
und vor dem Distalrande rötlichbraun. Vorn ein schwärzlicher Costal- und ebensolcher Subcostalstreif, die sich in etwa zwei Drittel ihrer Länge vereinigen und in deu gleichgefärbten Apex einmïnden. Distalraud ohne deutliche Binde, nur zwischen den Adern mit bogenförmig angeordneten dunkleren Fleckchen von ungewisser Begrenzung, in denen je zwei weiße Saumflecke stehen, die rorn gegen den Apex zu einem verschmelzen. Nächst dem Saum, namentlich am Apex, uoch eine weitere Reihe ungewisser Saumpunkte. Unmittelbar an der Flügelwurzel nächst dem Vorderrande und hinter der Mediana je ein weißer Fleck. - - . Viel heller und größer als das $\sigma^{2}$, die hellen Teile des Vorderflügels fast grau, etwas durchscheinend. Zeichnung wio bei dem $\delta^{2}$, aber einige weißliche Saumfleckchen im Apex und hinteren Teil des Distalrandes. Die subapicalen Flecke der Gruudfarbe länger und fast bindenartig zusammenstehend. Unterseite blasser, die hellen Zeichnungen schmutzigweiß, nahe dem Distalrande eine vollständige Reihe weißer Saumfleckchen, von denen die zwei vordersten wischartig ausgeflossen sind. - Hinterflügel graugelblich, am Vorderraude und gegen deu Distalrand rötlichbraun. Letzterer breit dunkelbraun mit einer Reihe paarweise, nur vorn einzeln stehender weißer Fleckchen, die Adern rom Saum her bis kurz hinter der Zelle dunkelbraun bestäubt. Von der Flügelwurzel aus ein keilförmiger, distal von der Zelle ungewiß. endigender Subcostalstreif. Unterseite im mittleren Teil weißlich, Vorderrand, Subcostalstreif dunkelbraun, das Feld zwischen beiden rötlichbraun, ebenso die Flügelwurzel, der Hinterrand und ein proximal ungewiß begrenzter Streif nahe dem Distalrande. Letzterer duukel rauchbraun, mit einer Reihe größerer weißer Flecke, die bis auf die vordersten drei paarig stehen, und einer zweiten Reihe kleinerer Saumfleckchen. Antennen ockergelb bis auf das proximale Drittel, welches schwarzbraun ist. Sonst wie das $\sigma^{\circ} . \ldots$ - - Vorderflügellänge $\sigma^{\top}$ etwa 35 , ㅇ $41 \mathrm{~mm}$.

Colombia.

6b. Đ. edias luminosus Stich. 1903 E. e. l., Stichel in: Berlin. ent. Z., v. 48 p. 16.

Zwischenform von der typischen zur nächsten Unterart. $-\sigma$. Antennen schwarzbraun. Torderflügel vorherrschend dunkelbraun. Ton der Flügelwurzel aus, im hinteren Teil der Zelle bis auf das erste Drittel des hinteren Medianastes, ein rötlichbrauner Streif. Im distalen Teil der Zelle, im mittleren und hinteren Medianzwischeuraum je ein länglicher weißlicher Fleck, im letzteren am größten und etwas über deu hinteren Medianast hinaus verbreitert. Distal von der Zelle ein trübe weißlicher Subcostalfleck, daran auschließend, schräg gegeu den Distalrand gerichtet, drei leicht bräunlich überstäubte, subapicale, längliche, weißliche Flecke. Hinterraud von der Nähe der Flügelwurzel aus bis gegen den Hinterwinkel schmal rötlichbraun. Unterseite ebeuso, aber matter, hinter der Mediaua grauglänzend. - Hinterflügel lebhaft rotbraun mit kurz-keilförmigem schwarzem Subcostalstreif an der Flügelwurzel und breitem, zwischen den Adern etwas gezacktem, schwarzbraunem Distalrande. In diesem schwach durchscheiuende Saumfleckchen. Unterseite im Mittelund Wurzelteil weißlich aufgehellt, mit dunkelbraunem Costal- und Subcostalstreif und weißem Fleck an der Wurzel. Saum dunkler ohne deutlich abgesonderte Binde, mit eiuer Reihe weißlicher Fleckchen, von deneu die drei vorderen einzelu, die übrigen paarweise zwischen den Adern stehen; außerdem im Apex zwei undeutliche weißliche Saumfleckcheu. - Sonst wie die typische Unterart. Torderflügelläng'e $33 \mathrm{~mm}$.

Venezuela. 
6c. E. edias vulgiformis Butl. \& Jnuce 1872 K. v., A. G. Butler \& Herb. Druce in: Cistula ent., v. 1 p. $102 \mid 1874$ L. v., A. G. Butler \& Herb. Druce in: 1'. zool. Soc. London, p. $351 \mid 1877$ E. v., W. F. Kirby, Cat. diurn. Lep., Suppl. p. 723 | 1881 \& 82 E. v., F. D. Godman \& G. Salvin in: Biol. Centr.-Amer., Lep.-KLop. v. 1 p. 162; t. 19 f. 3 | 1901 E. v., F. D. Godman \& O. Salvin in: Biol. Centr.-Amer., Lep.-Rhop. v. 2 p. $669 \mid 1903$ E. edias $v$., Stichel in: Berlin. ent. Z., v. 48 p. 15.

Äbnlich der vorigen Unterart, aber sämtliche Flecke kleiner. — Wurzel des schwarzbraunen Torderflügels einfarbig, ohne rötlichen Streif in der Zelle. Hinterrand nur zur Hälfte schmal rötlichbraun. Im distalen 'Teil der Zelle und in den Radialzwischenräumen je ein länglicher Fleck, im vorderen Medianzwischeuraum nächst dem Distalrande, etwa in der Mitte des mittleren und hinteren Medianzwischenraumes, ein etwas breiterer Fleck, sämtlich sehmutzigweiß. Lnterseite matter, Torderrand an der Flügelwurzel und Zelle proximal rötlichbraun, einige weißliche Apical- und Saumfleckchen vorhanden, letzterc namentlich gegen den Hinterwinkel. - Hinterflïgel rothraun mit kurz-keilförmigem Subcostalstreif und schwarzbraunem, etwas bestimmter begrenztem Distalsaum von etwa $3 \mathrm{~mm}$ Breite, der also schmaler als bei der vorigen Cuterart ist. Adern vom Saum aus auf einige Entfernung fein schwar\%. Cnterseite mit auffälligem rundlichem weißem Wurzelfleck, schwarzhraunem Costal- und ebensolchem Subcostalstreif. Rotbraune Grundfarbe rauchbraun üherstäubt, im mittleren Teil nicht aufgehellt. Schwarze Saumbinde deutlich rou der Grundfarbe ahgehoben, proximal schwach gewellt, mit weißen Saumpunkten wie bei der rorigen Lnterart. - Sonst wie die typische Unterart. Torderfügcllänge $3 \pm \mathrm{mm}$.

Costa Rica, Panama, Guatemala.

6d. E. edias eurysaces Hew. 1864 E. eurysaces, Hewitson in: Tr. ent. Soc. London, ser. 3 r. 2 p. 248 t. 16 f. $3 \mid 1871$ E. e., W. F. Kirby, Cat. diurn. Lep., p. 1.6 | 1903 E. edias eurysaces, Stichel in: Berlin. ent. Z., v. 48 p. 16 t. 1 f. 13.

§ั. Grundfarbe der Flügel (Fig. 45) ungewiß gelbgrau, Hinterrand des Vorderflügels und Wurzelteil des Hinterflïgels gelblichrot. - Vorderflügel mit breitem schwarzbraunem Torderrande und damit vorn in ganzer Läuge zasammenhängendem Keilfleck. Submedianstreif sehr breit, vorn bis

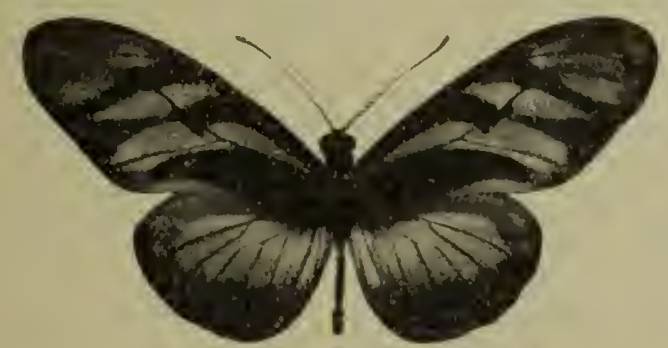

Fis. 45. E. edias eurysaces, $\sigma^{7}\left({ }_{1}^{1}\right)$.

kurz ror dem hinteren Medianast der Mediana anliegend, dann in Hacher Krïmmung ron dieser abgewendet und ziemlich spitz in den Hinterwinkel auslaufend. Hinter dem Streif bleibt der Hinterrand etwa ron der Mitte an in flachem Bogen frei. Keilfleck längs des mittleren Medianastes unter distaler Terbreitung mit dem sehwarzbraunen Distalrande zusammengeflossen. Distal von der Zelle, das Ende derselben berühreud, cin schwarzbraunel Costalfleck, der auch durch einen schrägen Steg längs des vorderen Medianastes mit dem Distalrande in Verbindung steht. Fs wird hierdurch ein länglich viereckiger Fleck in der Zelle und ein ciförmiger, distal zugespitzer 
Fleck der leicht schwärzlich überstäubten Grundfarbe abgetrennt. Apicalfeld ungewiß schwärzlich ïberstäubt, am Rande und an den Radiales dnnkler schattiert. Unterseite viel heller, weißlich, die dunklen Zeichnungen schattenhaft angedentet, Hinterrand bis nahe zur Mediana glänzend, nächst Apex und Distalrand eine Reihe weißer, vorn einzeln, binten par'weise zwischen den Adern stehender Flecke, die oben schwach durchscheinen. - Hinterflügel mit grauglänzendem Torderrandfelde bis zur Subcostalis, schwarzbraunem keilförmig'em knrzem Costalstreif und breitem schwarzbraunem, vorn Inngewiß begrenztem Saum, in dem verloschene weißliche Fleckehen stehen. Diese Sammbinde beginnt am distalen Drittel des Hinterrandes und zieht sich allmählich etwas verschmälert bis zum Apex. Medianäste und Radiales schwarzbraun bestäubt. Unterseite matter, Hinterrand und Wurzelfeld gelblich, ungewiß begrenzt und in ein weißliches Mittelfeld übergehend. Sammbinde schmaler, an den Adern stark eingekerbt, Begrenznng etwas bestimmter. Am Distalrande unweit des Saumes eine Reihe im Apex einfach, sonst doppelt angeordneter, weißer, kräftiger Flecke und distal von denselben stellenweise, namentlich gegen den Hinterwinkel und Apex, undeutliche kleinere weißliche Saumfleckchen. - Antennen ockergelb, nur proximales Drittel schwarz. - Q. Größer. Antennen ockergelb bis auf die schwarzbraune Wurzel. Vorderflügel glasig, leicht schwarzgrau überstäubt, proximal gelblich. Torderrand mit Keilfleck, Costal- und Endzellfleck wie beim ơ verflossen. aber schwächer und matter in der Färbung. Apex schmal grauschwarz mit länglichen weißen Randflecken, im distalen Teil des Flügels nur die Aderı kräftiger grauschwarz und leicht bräunlich bestäubt, mittlerer und vorderer Medianast etwas stärker als die übrigen, Distalrand ebenfulls schmal grauschwarz, vom vorderen zum hinteren Medianast etwas breiter, mit verloschenen weißen Saumfleckchen. Submedianstreif etwas kräftiger in der Farbe, vorn in mäßigem Abstande dem hinteren Medianast folgend, andererseits ganz dem Hinterrande aufsitzend und in den Hinterwinkel mündend. Unterseite bedeutend matter Ind noch spärlicher beschuppt, Saumflecke deutlicher, Apicalflecke größer. Hinterflügel glasig grau, Wurzelfeld bis in den mittleren Teil und Hinterwinkelfeld gelblich, Subcostalstreif matt schwarzbraun bis zum Apex, dort in den gleichgefärbten Distalsaum übergehend; letzterer mit einer Reihe verloschener, im Apex deutlicherer, weißer Randfleckchen, am Hinterrande breit und in ungewisser Begrenzung endigend, proximal unscharf begrenzt, an den Adern ausgeflossen; diese selbst bis zur Zelle oder fast bis zu derselben schwarzbraun. Unterseite heller, die gelbe Bestäubung spärlicher, der schwarzbraune Vorderrand mit dem Subcostalstreif bis auf etwas lichtere Bestäubung: hinter der Costalis zusammengeflossen, Saumflecke deutlicher, wie beim 0 . — - Torderflügellänge 34-38 mm.

Ecuador (Balzapamba, Palmar, Quito).

7. E. procula Doubl. 1848 E. p., E. Doubleday (\& Westwood), Gen. diurn. Lep., v. 1 p. 146 t. 20 f. 1 | 1851 E.p., Chenu \& H. Lucas, Enc. Hist. nat., Pap. diurn. p. 81 f. $179 \mid 1871$ E. p., W. F. Kirby, Cat. diurn. Lep., p. $145 \mid 1903$ E. p., Stichel in: Berlin. ent. Z., v. 48 p. 17.

ऊ’. Pnnktierung des Kopfes weiß, die des Halskragens nnd spärliche Zeichnung auf dem Thorax gelblich, die übrige Körperfleckung weißlich. Antennen schwarzbraun, nur der Kolben ventral etwas heller, rotbraun. Flïgelform wie die der vorigen Art. - Torderflïgel schwarzbraun, proximal in der Zelle an der Mediana ein bis zur Abzweigung des hinteren Medianastes reichender schmaler rotbrauner Streif, im Discus eine weißliche oder weißgelhe, 
hindenartige Fleckengruppe, bestehend ans einem etwa rechteckigen Fleck im distalen Teil der \%elle, die ganze Breite derselben ausfüllend, einem weiteren im proximalen Ende des mittleren Medianzwischenraumes, der einerseits den Winkel am Ersprunge des mittleren Medianastes ausfïllt, rorn bis nahe zum vorderen Medianast reicht und distal abgeschrägt ist. Daran linten anschließend ein Fleck etwa in Gestalt eines Parallelogramms, der rom hinteren Medianast abgesclnitten ist. Diese 3 Flecke nur durch die fein schwarzbraunen Adern getrennt. Hinterrand in der Nitte in einem flach hogenförmigen Streif braumot. Distal von der Zelle, etwa in der Mitte zwischen der Fleckenbinde und dem Apex, 2 oder 3 verloschene, weiBliche wischartige Subcostalflecke. Unterseite blasser, rötliche Wurzelbestäubung loreiter, bis zum Vorderrande und über die ganze Breite der Zelle in ungewisser Begrenzung reichend. Snbcostalflecke deutlicher, 11ächst dem Hinterwinkel cinige weiße Saumfleckchen. - Hinterflïgel rotbraun mit kurzem keilförmigem schwarzem Subcostalwisch hinter dem grauglänzenden Torderrandfelde und breiter; zwischen den Adern zahnartig ausgeflossener schwarzbranner Randbinde. Adern von der Binde aus in ungewisser Entfermung schwärzlich bestänbt. Nahe dem Distalrande ungewiß durchscheinende weißliche Saumfleckchen. Unterseite bleicher, nur am Hinterrande und vorn hinter der Subcostalis lebhafter rötlicl. Vorderrand und Subcostalstreif sclwwärzlich, zwischen beiden ebenfalls sin ungewiß begrenzter rötlichbrauner Wisch. Distalland breit schwärzlich, in unscharfer Begrenzung allmählich in die weißliche und rötliche Färbung des mittleren Flügelfeldes ühergehend. Saumflecke reiuweib, in der Anordnung wie bei den vorhergehenden Formen. _ - o. Mit der Zeichnnmgsanlage des $\sigma^{\circ}$. Farbton etwas matter, Suhcostalfecke gar nicht oder sehr schwach bemerkbar. Unterseite des Vorderflügels fast grau mit etwas rötlichem Glanz, die des Hinterflügels rötlichgrau, in der Mitte weißlich aufgehellt, olme eigentliche Saumbinde, nur an Distalrande etwas dunkler schattiert. Sonst wie das $\sigma^{\top}$, jedoch mit den charakteristischen Geschlechtsunterschieden. - Vorderflïgellänge $34-35 \mathrm{~mm}$.

Venezuela (Puerto Cabello), Colombia.

\section{E. vibilia (Godart)}

○. Stirn- und Kopfpunkte weiß, Punktierung des Halskragens und Flecke auf dem Thorax gelblich, Zeichnung des Abdomen weißlich oder ockergelb. Antennen schwarzbraun, uur der Kolben rentral bräunlich. Flïgelform wie bei der vorigen Art. Grundfarbe der Flïgel rot- bis gelbbriun. -Torderflügel mit schwarzem Torderrande und folgender schwarzer Zeichnung: Keilfleck, vorn der Subcostalis anliegend und längs derselben in proximaler Richtung ausgeflossen, hinten entweder an der Mediana endigend oder iiber dieselbe hinaus durch den Winkel am Ursprunge des hinteren Medianastes und selbst über letzteren bis zum Submedianstreif ausgeflosser. Dieser meist kräftig, der Suhmediana anliegend und etwas verschmälert in den Hinterwinkel auslaufend. Distal ron der Zelle in numittelbarer Folge eine schräg rom Vorderrande zum hinteren Teil des Distalrandes verlaufende, mehr oder weniger schmale Binde, die vorn und hinten etwas breiter als in der Mitte ist und häufig läng's der Mediana mit dem Keilfleck zusammenhängt. Apex ebenfalls schwarz. von dieser Querbinde durch einen geschlossenen länglichen Fleck der Grundfarbe oder durch eine schräg gestellte Reilıe läng:licher, an den Adern abgesonderter Flecke getrennt. Zuweilen fehlen diese Elecke, dann ist die schwarze Schrägbinde mit dem Apex mehr oder weniger innig zusammengeflossen, mitunter derart, daß die ganze distale Flïgellälfte 
schwarz ist und nur ein trüber Wischfleck der Grundfarbe darin zurückbleibt. Die durch die schwarze Zeichnung im Discus und Apex abgesonderten hellen Flecke entweder im Farbenton der Wurzelfläche oder ockergelb. Die gesamte dunkle Zeichnıng überwiegt manchmal derart, daß proximal nur ein distal etwas verbreiterter und stumpf gewinkelter rotbranner Streif vor dem schwarzen Subcostalstreif übrig bleibt und der Flügel den Eindruck einer dunklen Grundfläche mit brauner oder ockergelber Fleck- und Streifzeichnung macht. Unterseite der oberen Seite entsprechend, viel blasser, am Torderrande ein kurzer gelblicher Wurzelstreif, nächst dem Apex und Distalrande weißliche Saumflecke. - Hinterflügel rötlichbraun, an der Wurzel hinter dem grauglänzenden Vorderrandfelde ein kleiner schwarzer keilförmiger Fleck. Distalrand in ungewisser Begrenzung mehr oder weniger breit schwarz oder schwarzbraun. Unterseite blasser, mit schwärzlichem Costal- und Subcostalstreif bis zum Apex, deren Trennung mitunter unsicher ist; an der Wurzel, von der Praecostalis begrenzt, ein weißlicher Fleck, Distalrand ungewiß verdunkelt, ohne eigentliche Binde, mit weißen Saumflecken in der Wreise wie bei den vorigen Arten. Adern mehr oder weniger schwarz bestäubt. - - o. Dem ö ähnlich, Grundfarbe meist heller braun bis ockergelb, zuweilen mit gelber geschlossener Discalbinde proximal des breit schwarzen Apicalteiles, Keilfleck meist bis zum Subcostalstreif ausgeflossen, die discale Fläche in eine bindenartig zusammenhängende Fleckengruppe zerlegt. Der distal ron dieser liegende schwarze Steg vom Torderrande zum Distalrande inniger als beim $0^{7}$ mit dem Apicalfelde zusammenhängend, so daß das distale Feld als einheitliches Ganze in schwarzer Färbung mit eingeschlossenen subapicalen Flecken oder einer subapicalen Fleckenbinde erscheint. Unterseite mit zwei Reihen apicaler weißer Fleckchen, von denen die distalen kleiner, spärlicher, meist auch undeutlich sind. Randbinde des Hinterflügels meist unscharf begrenzt, zuweilen der größere Teil des Flïgels rerdunkelt, die Adern bis zur Zelle kräftig schwarz angelegt. Am Distalrande nächst den größeren weißen Saumflecken meist noch ungewisser angelegte, dem Rande unmittelbar anfsitzende weißliche Punkte.

Brasilien, Colombia, Ecuador, Mittel-Amerika.

Diese Art zerfällt in 1 Unterarten:

8a. E. vibilia vibilia (Godart) 1816 Colaenis mereaui (nom. nud.), Jac. Hübner, Verz. Schmett., p. $32 \mid 1823$ C. m., Jac. Hübner, Zutr. exot. Schmett., $v .2$ p. 7 t.f. 201, 202 (ठ) 1862 Eucides m., H. W. Bates in: Tr. Linn. Soc.London, v.23 p. $563 \mid 1819$ Cethosia vibitia, (Latreille \&) J. B. Godart in: Enc. méth., v. 9 p. 245 (ठ) | 1825 Colaenis v., Jac. Hübner, Zutr. exot. Schmett., v. 3 p. 16 t. f. 449,450 ( 9 ) | 1844 Semelia v., E. Doubleday, List. Lep. Brit. Mus., v. 1 p. 64 | 1874 S. v., Capronnier in: Ann. Soc. eut. Belgique. v. 17 p. $24 \mid 1874$ Eueides v., A. G. Butler \& Herb. Druce in: P. zool. Soc. London, p. 350 | 1896 E. v., Bönninghausen in: Verh. Ver. Hamburg, v.9 p. $32 \mid 1848$ E. $v$. E. mereaui, E. Doubleday (\& Westwood), Gen. diurn. Lep., v. 1 p. $146 \mid 1871$ E. v. + E. m., W. F. Kirby, Cat. diurn. Lep., p.145 | 1881 Semelia $v .+$ S. var. m., Capronnier in: Ann. Soc. ent. Belgique, v. 25 p. $99 \mid 1903$ Eueides v. typica + E. v. aberr. pallens, Stichel in: Berlin. ent. Z., v. 48 p. 19 ; p. 19 (forma p.).

Forma principalis. $\sigma^{\top}$. Rotbraun. Torderrand, Keilfleck, Querbinde vom Torderrande hinter dem Zellende bis zum Distalrande, dieser selbst, Apex und Submedianstreif schwarz, in Gestalt und Anordnung wie bei der Art beschrieben. Keilfleck hinten längs der Mediana mehr oder weniger deutlich mit dem schwarzen Apex verbunden. Der zwischen der Querbinde und dem Apex liegende Teil der Grundfarbe meist in Gestalt eines geschlossenen, schräg liegenden, an den Rändern stellenweise etwas ron 
dem Schwar\% ciugeschnittenen, eiförmigen F'leckes oder als Fleckenbinde, infolge Ausfließens der scliwarzen Begrenzung an den Aderis, abgrisondert. Der Submedianstreif beginnt breit an der Fligelwurzel, liegt der Subnediana volı an und läuft ziemlich spitz in den Hinterwinkel aus. Hinterrand nielit gesäumt. Unterseite ehenso, aber matter, das Schwarz zu einem unsicheren IBraungrau abgestumpft. An Distalrande eine Reihe weißlicher Saumfleckchen. die sich am Apex etwas rom Rande entfernen. - Hiuterfliggel mit etwa 4-5 mm breiter schwarzer Saumbinde, welche vorn unscharf begrenzt ist, zwischen den Adern kleine, ungewisse Zapfen bildet nud anf denselben schnial bis liurz zur Zelle ausgeflossen ist. Hinterrand schmal schwärzlich. Hinterandader und Submediana ebenfalls fein schwarz. An der Flïgelwurzel, hinter dem glänzenden Costalfleck, ein kurzer keilförmiger Streif. Unterseite bleicher, Grundfarbe fast ockergelb, im mittleren 'Teil weißlich. Vorderrand bis zur Subcostalis braungrau, an der Flügelwurzel ein gelbliches Fleckchen und ron da vor und hinter der Costalis je ein mehr oder weniger deutlicher bräunlicher Streif, der sich distal in der schwärzlichen Bestäubung auflöst. Distalrand schwärzlich, proximal bogenförmig ungewiß) begrenzt, zuweilen zwischen den Adern keilförmig ausgoflossen. mit weißen Fleckchen, welcho rorn im Apex einzeln, in iibrigen parweise in den Aderzwischenräumen stehen. Adern hinter der Zelle mehr oder weniger schwärzlich angelegt. Im übrigen wie bei der Art beschrieben. - - $Q$. Größer. Grundfarbe der Flügel hlasser. auf dem Torderflïgel nur im proximalen Teil rötlichbraun, in Discus und distalen Felde binden- und fleckartig isoliert, ockergelb. Torderand, Keilfleck und Submedianstreif schwarzbraun, der Keilfleck nach hinten durch den Basiswinkel des linteren Medianastes stegartig bis zu diesem ausgoflossen und vorn längs der Mediana mit dem durch den Zellschluß laufenden schwarzbraunen Querband rerbunden. In der hierdurch abgesonderten ockergelben, an der Mediana unterbrochenen Schrägbinde der dieselbe durchschneidende Teil des mittleren Medianastes schwarz bestäubt. Diese Schrïghinde endet liurz hinter dem hinteren Medianast und wird dort rom Submedianstreif begrenzt. Distal von dem schwarzbrannen, unregelmäßig begrenzten Querbande cine meh oder weniger zusammenhängende, subapical, schräg gestellte Reihe ockergelber Flecke, die meist nur an den Adern schwarz getrennt nud bindenartig ancinandergereiht sind. Distalrand schwarz, im Hinterwinkel in den Submedianstreif iibergehend. Cuterseite matter mit weißlichen Distalrandfleckehen. - Hinterflügel wie beim ơ, mit den charakteristischen Geschlechtsunterschieden und obne den keilförmigen Subcostalstreif an der Turzel. Die Adern hinter der Zelle stïrker schwarz bestäubt. Unterseite blasser, rorn. in und um der Zelle weißlichgelb. Saum schärfer abgegrenzt, rorn lieiloder bogenartig. - Sonst wic das $\sigma^{\top}$. - - Vorderfliigellänge 28 ( $\left.\sigma^{\top}\right)$ his 36 (q) $1 \mathrm{~mm}$.

Brasilien (Espirito Santo, Rio de Janeiro, Tabajos, Ipanema).

Forma pallens. Zeichuung wie beim o der Hauptform, aber intensiver schwarzbraun und roller, namentlich der Submedianstreif und der den Keilfleck mit letzterem verbindende Steg. Subapicalflecke des Vorderflïgels verkleinert. der lintere deutlich als länglicher schmaler Streif abgetrennt. Grundfarbe hell ockergelb, fast weißlich, nur der im hinteren Teil der Zelle liegende Streif etwas rötlicher, dagegen der sehr schmale Hinterrand rotbrann. Saum des Hinterflïgels bedentend verbreitert und reichlich bis z.n ein Drittel der Flïgelfläche geschwärzt, seine proximale Begrenzung ungewiß, zwischen den Adern kleine, spitze, nach vorn gerichtete Zapfen aus dem schwarzen 
Schatten hervortretend. Unterseite wie die Oberseite gezeichnet, die schwarze Zeichnung aber noch schärfer abgehoben. Sonst wie die Hauptform. Nähert sich dem 0 ron E. r. vicinalis, ist aber noch bleicher.

Brasilien (Espirito Santo).

8 b. E. vibilia vicinalis Stich. 1903 E. vibilia vicinalis, Stichel in: Berlin. ent. Z., v. 48 p. 21 .

ऽ unbekannt. - $q$. Grundfarbe bleich ockergelb, nur am Hinterrande des Vorderfiügels und im mittleren Teil des Hinterflügels schwach rötlichbraun. jedoch bleicher als beim o der typischen Unterart. Zeichnung im allgemeinen wie bei diesem, aber Submedianstreif des Vorderflügels zwischen zwei lebhafter dunklen schmalen Streifen auf der Ader und vor derselben nur schattenhaft angedeutet. Die Fleckenzeichnung im allgemeinen mehr eingeschränkt, selten ist der mittlere Medianzwischenraum ganz schwarzbraun ausgefüllt. Dunkler Saum des Hinterflügels breiter oder wenigstens breiter schattiert in die Grundfarbe übergehend. Zelle tief und breiter schwarz umrandet, Medianäste und Radiales ebenfalls stärker schwarz. Unterseite matter, Hinterflïgel ohne deutlich abgesetzte Saumbinde, sondern rom Saum aus dunkel rauchbraun schattiert, allmählich heller werdend, im Wurzelteil bleich ockergelb; alle Adern dunkler, ebenso der Yorderrand und ein durchgehender Subcostalstreif. Nahe dem Distalrande beider Flügel weiße Fleckehen wie bej der typischen Unterart. Torderflügellänge $36-37 \mathrm{~mm}$.

Ecuador (Yalmar). In Höhe ron $100 \mathrm{~m}$.

8c. E. vibilia vialis Stich. $1881 \& 1901$ E. vibilia (err., non Cethosia v. Godart 1819 !), F. D. Godman \& O. Salvin in: Biol. Centr--Amer., Lep.-Rhop. v. 1 p. 162; v. 2 p. $659 \mid 1903$ E. vibilia vialis, Stichel in: Berlin. ent. Z., v. 48 p. 20 t. 1 f. $14,15$.

ऽ. In der Zeichnung dem o der typischen Unterart entsprechend, aber lebhafter sowohl in der Grundfarbe als auch in der schwarzbraunen Zeichmung. Gewöhnlich ist der Keilfleck distal nach hinten mit dem kräftigen Submedianstreif zusammengeflossen und der discale und subapicale Fleckenteil heller, ockergelb abgetönt, oder es bleibt ein schmaler Streif hinter dem hinteren Medianast und dem Submedianstreif frei und die genannten Flecke ind Fleckenbinden sind nur wenig matter gefärbt als der Wurzelteil. In diesem Falle ist aber der Keilfleck mindestens bis in den Basiswinkel des hinteren Medianastes ausgeflossen und andererseits längs der Mediana mit dem schwarzen Apicalteil verbunden. - o. In der Zeichmung demjenigen der typischen Unterart entsprechend. Submedianstreif in der Regel aber weniger voll, so zwar daß nur seine Begrenzung auf der Ader und vor derselben deutlicher ausgeprägt und dazwischen schwächere dunkle Bestäubung erkennbar ist. Grundfarbe trüber rotbraun, namentlich auf dem Hinterflïgel, dessen Saum viel breiter geschwärzt ist. Die proximale Begrenzung der Randbinde ist ungewiß und rerliert sich in schwach schwärzlicher Bestäubung erst etwa in der Hälfte des Flügels. Untere Seite wie die obere, aber matter, Hinterflïgel bis anf einen rotbraunen, ungewiß begrenzten Streif am Hinterrande und in der Zelle rauchbraun überflogen, ohne das für die typische Unterart charakteristische aufgehellte, fast weißliche Mittelfeld. - Sonst wie die typische Unterart. Vorderflügellänge $33-35 \mathrm{~mm}$.

Colombia, Panama, Costa Rica, Guatemala.

8d. E. vibilia unifasciatus Butl. 1873 E. $\iota .$, A. G. Butler in: Cistula ent, $v .1$ p. $169 \mid 1877$ E. u., A. G. Butler in: Tr. ent. Soc. London, p. 123 | 1877 E. u., W. F. Kirby, Cat. diurn. Lep., Suppl. p.723 | 1903 E. vibilia u. (E. v. var. arcita Plötz in MS.), Stichel in: Berlin. ent. Z., v. 48 p. 20 t. 1 f. 16. 
ठ․ Schwarzer Apex des Vorderflügels bis zn dem schwarzen Querbande ausgeflossen, so daß der distale Flïgelteil nnit schräger, zwischen den Medianästen etwas ausgebuchteter; proximaler Begrenzung rom Vorderrande uach dem Hinterwinkel geschwärzt ist; nur im vorderen Medianzwischenrauın befindet sich ein trüber bränulicher Wischffeck. Snbmedianstreif breiter, im distalen Verlauf vorn fast dem hinteren Medianast anliegend. Hinterflingel wie

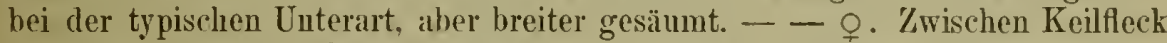
und den völlig einfarbig schwarzen Apicalteil bindenartig gelblich oder gelb aufgehellt. Diese schräg liegende Binde geht proximal an der Berïhrungsstelle allmählich in die dunkelrotbraune Wurzelfärbung über, fällt in ihrem letzten Verlauf distal steil gegen den hinteren Medianast ab und wird von diesem abgeschnitten. Submedianstreif proximal ungewiß zerstäubt, nur auf der Ader stärker markiert, im weiteren Verlauf dichter bestäubt und, schließlich bis zum hinteren Medianast verbreitert, in den Distalrand und Hinterwinkel einlaufend. Hinterrand schmal rotbraun. Unterseite bedeutend blasser. Hinterflügel rom Distalrande her in ungewisser Begrenzung breit schwarzh)raun bestäubt, die Adern bis zur Zelle breit schwarz bestäubt, allmählich zugespitzt, die rerbleibende Grundfarbe dunkel rotbrann. Näichst dem Distalrande verloschene weißliche Fleckchen. Unterseite zwar nicht so dunkel im Farbton, aber die breite Rand- und Aderbestäubung deutlicher von der Grundfarbe abgehoben. Randflecke deutlicher, doppelreihig, die distale Reihe jedoch kleiner und undeutlicher. - - Vorderflügellänge $33-35 \mathrm{~min}$.

Westliches Amazonas (Ega).

9. E. pavana Mlénétr. 1857 L. p., Hénétriés, Lép. Ac. St.-Pétersb., v. 2 p. 116 t. 8 f. 4 | 1886 E. p., (ŕ. W'. Müller in: Zool. Jahrb., v. 1 p. $433 \mid 1896$ E. p., Bönninghausen in: Verh. Ver. Hamburg, v. 9 p. $32 \mid 1903$ E. p., Stichel in: Berlin. ent. Z., v. 48 p. 22 t. 1 f. $17 \mid 1860$ E. thyana, C. \& R. Felder in: Wien ent. Monschr., v. 4 p. 105 ( \&) 1871 E. pavana + E. t., W. F. Kirby, Cat. diurn. Lep., p. 145 | 1881 E. vibilia (err., non Cethosia v. Godart 1819!), F. D. Godman \& O. Salvin in: Biol. Centr.-Amer., Lep.Rhop. v. 1 p. 162.

ऽ`. Punktierung der Stiru und des Kopfes weiß, Körperzeichnung gelbliclı bis weißlich. Antemnen schwarz. Flügelform wie bei der vorigen Art. Grundfarbe der Flügel rotbraun. - Die im Discus und Apex abgetrennten Teile des Vorderflïgels ockergelb, teilweise rötlich angeflogen. Zeichnung des Vorderflügels derjenigen ron E. vibilia ribilia (S. 254) sehr ähnlich. Vorderrand, der demselben rorn anliegende Keilfleck und der Submedianstreif schwarzbraun. Keilfleck durch den Basiswinkel des hinteren Nedianastes bis zum Submedianstreif bindenartig ansgeflossen. Es wird hierdurch ein von der schwarzen Mediana durchzogener, langer, schmaler Fleck der Grundfarbe isoliert. Distal von dem schwarzen Steg eine ockergelbe, von schwarzen Adern durchzogene Binde, gebildet von einem etwa viereckigen, seitlich etwas eingeschnürten Fleck in der Zelle, einem kleinen Dreieck im proximalen Winkel des mittleren Medianzwischenraumes, einem etwa rechteckigen Fleck im hinteren Medianzwischenraum, der distal durch einen schmalen, rom Distalrande her einspringenden, ziemlich langen Zapfen tief gespalten wird, und einem kleineren Wisch hinter dem hinteren Medianast. Apex bis zu dieser hellen Binde breit schwarz. Im Apicalfeld eine schwach schwärzlich überstäubte, schräg gestellte, von den Adern dnrchschnittene und umregelmäßig begrenzte, ockergelbe Binde. Unterseite wie die Oberseite, aber matter, mit weißlichem Schein im mittleren Teil und verloschenen weißlichen Saumfleckchen; am Vorderrande mit kurzem gelblichem Wurzelstreif. - Hinterflügel rotbraun, in der Zelle ein durch zwei feine schwarze linien gebildeter, mit dem 
Scheitel nach der Flïgelwurzel zu gerichteter spitzer Winkel. Distalsaum schwarz, zwischen den Adern in lange, vorn etwas kürzere, scharf abgesetzte, zugespitzte Strahlen bis nahe zur Zelle auslaufend. Umrandung der Zelle und die Adern hinter und distal von ihr voll schwarz bestäubt. Vorderrandteil grauglänzend, von der fein schwarzen Subcostalis durchschnitten. Unterseite matter, an der Flügelwurzel ein gelblicher Fleck, Vorderrand grau bis zur Costalis. Hinter dieser ein schmaler, bis etwa zur Flïgelmitte reichender, gelblicher Streifenwisch, die Fläche zwischen Costalis und Subcostalis im übrigen graubraun, weißlich überstäubt. Ebensolche weißliche Überstäubung dicht hinter der Subcostalis und spärlicher auch distal von der Zelle, die zwischen den Adern liegenden, aus dem schmaler verdunkelten Saum auslaufenden Strahlen länger, auch rorn fast die Zelle berïhrend. Saum mit verloschenen weißlichen Fleckchen, die paarweise in den Ader-

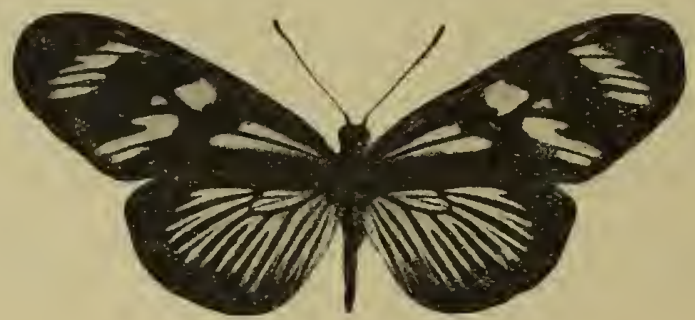

Fig. 46. E. pavana, ㅇ $(1 / 1)$.

zwischenräumen stehen. _-_ _ o. Größer; wie das o gezeichnet; Grındfarbe indes bleich ockergelb bis schmutzigweiß, zuweilen durchscheinend, mit spärlicher Bestäubung. Die schwarzen Zeichnungien (Fig. 46) ausgedehnter, Submedianstreif bis zum Hinterrande verbreiter't, so daß der Vorderflügel vorherrschend schwarzbraun wird, proximal mit einem länglichen keilförmigen Fleck, discal mit der der Art eigentümlichen, beim $\sigma^{\pi}$ beschriebenen, aber schmaleren Schrägbinde und eimer subapicalen Fleckenbinde in der hellen Farbe. Hinterflügel in der Regel etwas lebhafter gelblichrot, am Vorderrande und am Distalrande breit schwarzbraun gesäunt und wie das $\delta^{\pi}$ gezeichnet. Unterseite auf beiden Flügeln matter, an den dunkleren Stellen reichlich weiß überstäubt. Antennen mit ockergelbem Kolben. Sonst wie das $\widetilde{c}$, aber mit den charakteristischen Geschlechtsunterschieden. - - Vorderflïgellänge $34-36 \mathrm{~mm}$.

Raupe an Passiflora. Die Eier werden nebeneiuander za über 100 Stück an die Unterseite der Blätter geklebt.

Brasilien (Espirito Santo, Rio de Janeiro); Colombia(?).

\section{E. lineatus Salv. \& Godm.}

$0^{\pi}$. Grundfarbe der Flïgel rotbraun. Am Vorderrande ein schwarzer Streif, welcher an der Flügelwurzel schmal einsetzt, sich dann allmählich verstärkt und am Ende der Zelle seine gröBte Breite erreicht. Von da wendet el sich, wiederum etwas verschmälert, über die Discocellulares in stumpfem Winkel nach dem Distalrande und mïndet dort hinter dem vorderen Medianast, diesen noch einschließend, und bei der Einmündung nach vorn und hinten etwas ausgezogen. Vorderrand distal von der vorderen stumpfen Ecke dieses Streifes auf etwa $3 \mathrm{~mm}$ fein schwarz, damn setzt ein breiterer schwarzer Rand ein, der am Apex am breitesten, sich bei der Eimmündung 
des Querstreifes verschmälert unl bis zum Hinterwinkel rieht. Auf diese Weise wird oin länglicher subapicaler Fleck der Gundfarbo aligesondert. dor von der foin schwarzen Subcostalis durchschnitten und in dom die Radiales mehr oder weniger stark und woit schwar\% bestäubt sind. Sulymedianstreif kräftig und breit, spitzer in den Hinterwinkel auslaufend oder proximal von demselhen endigend. Unterseite ungewiß rötlichbraun, Hinterrandteil nächst einem sclumaleu Streif bräunlicher Beschuppung grauglänzend; distal von der Zelle ein ungewiß begrenzter, lellerer, fast ockergelher Fleck. Ähnliche hellere Abtönung in den Radial- und Medianzwischenräumen. Zeichnung der Oberseite kaum in etwas dunklerer Schatticrung durchscheinend, am Distalıande in der Nälıe des Hinterwinkels einige verloschene weißliche Saumfleckchen. --- Hinterflügel mit kurzem keilförmigem schwarzem Wrurzelstreif hinter dem grauglänzenden Vorderrandfelde. Distalsaum schwar\% und zwar am Hinterwinkel am breitesten, gegen den Apex stark verschmälert, zwischen. den Adern kleine, vorspringende, ungewiß begrenzte Zapfen, die Adern bis etwa zur Mitte schwarz, Hinterrand schwärzlich bestäubt. Unterseite hellbraun, am Saum nnd streifenartig zwischen den Adern dunkler rötlichbrann; Vorderrand graubraun his zur Subcostalis, hinter derselben ein gelblicher Wurzolfleck und cin kurzer gelber Wurzelstreif, Subcostalis ebenfalls rauchbraun angelegt. Am Distalrande eine Reihe paarweise in den Aderzwischenräumen stehender, rein weißer Saumfleckchen, die sich am Apex etwas verlängern. - - . GröBer, Grundfarbe der Flïgel heller, rötlich ockergelb, Zeichnung wie beim $\sigma^{*}$, aber nicht so intensiv, dunkelbraun. Dic Saumfleckchen der Unterseite des Hinterflïgels scheimen schwach durch. Unterseite ebenfalls viol heller, die Zeichnung der Oberseite, namentlich der Querstreif, rotbraun abgohoben. Sonst wie das $\sigma^{\pi}$.

Mittel-Amerika, Französisch-Guayana.

Diese Art zerfällt in 2 Unterarten:

10a. E. lineatus lineatus Salv. \& Godm. $1868 \mathrm{E}$. lineata, O. Salvin \& F. D. Godman in: Ann. nat. Hist., ser. 4 v. 2 p. $145 \mid 1874$ E. l., A. G. Butler \& Herb. Druce in: P. zool. Soc. London, 1. $350 \mid 1881 \& 82$ E. l., F. D. Godman \& O. Salvin in: Biol Centr.-Amer., Lep.-Rhop. $v .1$ p. 163 ; t. 19 f. 2 | 1901 E. ., F. D. Godman \& O. Salvin in: Biol. Centr.-Amer., Lep.-Rhop. v. 2 p. 670 | 1903 E.l.typica, Stichel in: Berlin. ent. Z.' v. 48 p. 23.

Der schwarze Submedianstreif (Fig. 47) des Vorderflügels reicht deutlich, wenn auch etwas verschmälert, bis zum Hinterwinkel, der im Apex abgesonderte bindenartige Fleck der Grundfarbe von den Adern vom Rande lier leicht

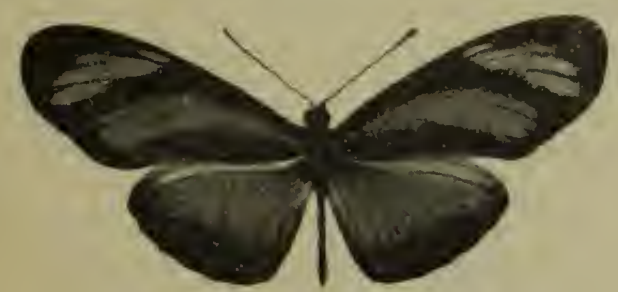

Fig. 47. E. lineatus lineatus, ơ (1/1).

durchschnitten, mittlerer Medianast bis nahe zur Zelle schwar bestäubt. Hinterrand nur schmal rötlichbraun, Hinterwinkel breit schwar\%. Vorderflügollänge $30-34 \mathrm{~mm}$.

Guatemala, Costa Rica, Honduras (San Pedro Sula), Ilexiko. 
10 b. E. lineatus libitina Staud. 1885 E. libitina, O. Staudinger (\& S'chatz), Exot. Schmett., v. 1 p. $80 \mid 1903$ E. lineata libitina, Stichel in: Berlin. ent. Z., v. 48 p. 23.

Der Submedianstreif des Vorderflügels endet spitz in der Nähe des Hinterwinkels, ohne diesen zu erreichen. Der im Apex ron der dunklen Zeichnung abgesonderte Fleck der Grundfarbe kleiner. Unterseite des Hinterflügels mit zwei roten Wurzelfleckchen. Sonst wie die typische Unterart.

Französisch-Guayana.

\section{c. Coll. Lybiiformes}

Kopf und Palpen wie bei der vorigen Gruppe. Augen braun. Antennen unter halber Länge des Vorderrandes, schwarzbraun. Halskragen rötlichbraun, nur in der Mitte fein schwar\%, oder schwarz mit gelblichen Flecken. Thorax rötlichbraun, nur dorsal, der Länge nach, schmal schwarz, oder schwarz und seitlich bräunlich gefleckt. Abdomen kurz, wenig oder gar nicht über den Hinterflügel binausreichend, ockergelb bis rötlichbraun, ventral heller, seitlich und dorsal mit je einem schwärzlichen Streif. Vorderbein vorherrschend weiß behaart, die übrigen Beine schwar\%, weißlich bestäubt, ebenso wie die Hüften und der Thorax ventral zwischen diesen. - Torderflügel sehr schlank, Torderrand schwach gebogen, Apex fast eckig; nur schwach abgerundet, Distalrand hinter den Radiales ganz schwach stumpf gewinkelt oder konvex hervortretend, sociann in ganz flach konkaver Krümmung in proximaler Richtung abgeschrägt. Hinterwinkel stumpf, Hinterrand leicht S-förmig geschweift. - Hinterflügel fast dreieckig mit flach konvex gebogenen Rändern. Apex ziemlich merklicb hervortretend, Hinterwinkel abgerundet. - Kleinere Falter von rotbrauner Grundfarbe mit schwarzer Binde und schwarzer Berandung, im Apex zuweilen mit weißem Fleck. $\sigma^{\pi}$ mit stark aufgehelltem. hinten und distal grau angelegtem, schmalem und schwach seidenglänzendem Torderrandfelde des Hinterflügels, aber obne Glanz am Hinterrandteil der Vorderflügelunterseite. Vorderrandfeld des Hinterflügels des 오 nicht glänzend, nur in der Grundfarbe aufgehellt oder ganz. schmal glänzend bis zur Mitte und mit anschließendem matt dunkelgrauem breitem Costalstreif.

3 Arten, von denen 2 in 4 Unterarten zerfallen.

\section{E. aliphera (Godart)}

ठ․ Punktierung des Kopfes weiß. Thorax stark rötlichbraun behaart, nur in der Mitte der Länge nach mit einem schwarzen Strich. Abdomen ockergelb oder bräunlich, ventral gelblichweiß, dorsal schmal schwärzlich. lateral mit je einer schwarzen, manchmal undeutlichen Linie. Grundfarbe der Flügel hellrotbraun. - Torderrand des Vorderflügels schmal schwarz. Hinter der Subcostalis, dieser dicht anliegend, von der Flügelwurzel aus ein schmaler schwarzer Streif, der sich am Ende der Zelle verbreitert und sich dort in stumpfem Winkel zum Distalrande wendet. Aper und Distalrand schwarz, ebenso ein Submedianstreif von verschiedener Länge und Breite. Unterseite ungewiß gelbbraun, die Zeichnung der Oberseite undeutlich und verschwommen. hinter der Mediana gelblich. - Hinterflügel mit schwarzem, ziemlich scharf abgegrenztem Distalsaum, der proximal auf den Adern dünn ausläuft und zwischen denselben kleine vorspringende Zapfen bildet. Torderrandfeld aufgehellt, unmittelbar am Vorderrande, namentlich in der proximalen Hälfte, etwas seidenglänzend, distal und im proximalen Teil hinter der Subcostalis etwas grau bestäubt. - — o. Heller in der Grundfarbe, alle Zeichnungen 
undeutlicher, aluch teilweise ganz fehlond, namentlich unterscits. Forderrand les Hinterflïgels nur schwach aufgehellt, olne Glanz oder graue Bestäubung.

Ei einzeln an der Unterseite von Passiflora amcthystina Mek. - Raupe in der Jugend mit Höruern von Kopfläuge. Kopf weiß und braun oder schwar\%. Körper weißlich mit braunen Querbinden und schwarzen Dornen mit heller Spitze auf granen Warzen. Ältere 'Tiere lateral weiß, darïber sehwarz, dorsal mit gelben Punkten. Dornen schwarz, lateral weiß oder schwarz mit weißer Spitze. - Puppe nach Anheftung und Gestalt ähnlich der ron E. isabella (S. 234). Dornen weniger entwickelt, nach a.Ben gerichtet. Grundfarbe weiß, Dornen und Höcker schwarz, chenso die Dorsallinie, Seitenstreif und Flügelgeäder.

Paraguay, Brasilien, Peru, Colombia. Mittel-Amerika, Curaçao.

Diese Art zerfällt in 2 Unterarten:

11 a. E. aliphera aliphera (Godart) 1819 Cethosia a., (Latreille *) I. B. Godurt in : Euc. méth., v.9 p. 246 1816-24 Colaenis a., Jac. Hiibner, Exot. Schnett.. $v$. 2 t. 21 1824 Acraea a., (Latreille \&) .J. B. Godart in: Enc. méth., v. 9 p. $806 \mid 1836$ Eneides u., Boisduval. Spéc. gén. Lép., $t .1$ t. 11 f. $4 \mid 1848$ E. a., E. Doubleday (\& Westwood), (ien. diurn. Lep., v. 1 p. $147 \mid 1862$ E. a., H. W. Bates in: Tr. Linu. Soc. London, c. 23 p. $564 \mid 1871$ E. a., W. F. Kirby, Cat. diurn. Lep., p. $145 \mid 1877$ E. u., A. G. Butler in: Ann. nat. Hist., ser. 4 c. 20 p. $120 \mid 1878$ E. a., Fritz Müller in: Lint. Zeit. Stettin, v. 39 p. $296 \mid 1880$ E. a., F. J). Godman \& O. Salvin in: 'T'r. ent. Soc. London, p. 122 | 1885 E. a., (). Staudinger (\& Schatz), Exot. Schmett.. $v .1$ p. $80 \mid 1886$ E. a., (r. W. Müller in: Zool. Jahrb., r. 1 p. 432 (Metamorph.) | 1887 E. a., P. Snellen in: 'l'ijdschr. Ent., v. 30 p. 16 | 1890 E. a., Seitz in: Ent. Zeit. Stettin, v. 51 p. 93 | 1890 E. a., Weymer (\& Maassen), Lep. Reise Stübel, p. 10, 21, 27 | 1896 E. a., Bönuinghausen in: Verh. Ver. Hamburg, v.9 p.33|1900 E. a., W. F. Kirby, Exot. Schmett. Hübner, p.13 1844 Semelia a., E. Doubleday, List. Lep. Brit. Hus., v. 1 p. $6 \pm$ ! 1903 Eneides a.typica, Sticliel in: Berlin. ent. Z., v. 48 p. 23.

ơ. Torderrand desVorderflïgols stellenweise durch schwärzliche Bestäubung mit dem linter der Subcostalis liegenden schwarzen Stroif leicht rerbunden. Dieser an cler Biegung auf den Discocellnlares verbreitert, daselbst distal scharf stumpfwinklig; proximal allmähliclı bogenfö̀nuig in die transversale lichtung ïbergehend, sodann wieder verschmälert und dicht hinter dem rorderen Medlianast in den Distalrand einminndend. Aper ziemlich hreit. Distalsaun schmaler scliwarz, an ler Einmündung des Quersteges etwas ausgeflossen. ebenso an den Aclem in fcinen Spitzen ausgezogen. Subcostalis auch zwischen der Querbinde nnd dem Apex schwarz bestäubt. Submedianstreif anfangs etwa $1 \mathrm{~mm}$ breit, der Ader aufliegend, distal allmählich verschmälert und in ganz dïnner Bestäubung anf der Ader iı den Hinterwinkel inslaufend. Unterseite wie bei der Art geschildert. - Randbinde des Hinterfiügels etwa $2-3 \mathrm{~mm}$ breit, auf den Adern spitz bis etwa auf die Hälfte des Flügelfeldes hinter der Zelle ausgeflossen und zwischen den Adern mit kleinell, spitzen Zapfen versehen. Unterseite fast zeichungslos und vicl heller. Sanm nur undentlich dunkler. Flügelwurzel am Vorderrande gelblich. I.etzterer ebenfalls mugewiß dunkler schattiert. _ _ o. Von hellerer, fast ockergelber Grundfarbe, die Zeichumug des s' stark reduziert. versillwommen, der vom Vorderrande nach dem Distalrande lanfende Steg undeutlich, in der Mitte scliattenhaft, fast fehlend, ebenso die Randzeichmung des Hinterflügels reduziert und abgeschwächter. I'nterseite eintönig gelblich brium, nur lice und da, ramentlich an den der oberen Zeichnung entsprechenden Stellen, etwas dunkler schattiert. - - Vorderflügellänge $28-31 \mathrm{~mm}$.

Paraguay, Brasilien (Espiritn Santo. liio de Janciro, Santos), Colombia, Peru, Curngao. 
11 b. E. aliphera gracilis Stich. $1881 \& 1901$ E. $a$. (err., non Cethosia a. Godart 1819 !), F. D. Godman \& U. Salvin in: Biol. Centr.-Amer., Lep.-Rhop. v. 1 p. $163 ; v .2$ p. 669 1903 E. a. gracilis, Stichel in: Berlin. ent. Z., v. 48 1. 23.

ot. Meist etwas heller als die typische Unterart, aber nicht minder lebhaft in der Grundfarbe. Besäumung der Flïgel, namentlich am Apex des Vorderflïgels, sowie der Schrägstreif schmaler, der Snbmedianstreif auf Schwarzfärbung der Ader oder eines Teiles derselben beschränkt. Der schmalere Samm des Hinterflügels schärfer von der Grundfarbe abgesetzt and die zwischen den Adern stehenden knrzen Spitzen kräftiger, ibre Begrenzung schärfer.

Costa Rica. Nicaragua, Guatemala. Honduras, Mexiko.

12. E. lybia (F.)

ठ઼. Punktiermug des Kopfes weiß, die des Halskragens und dic Flecke auf dem Thorax ockergelb. Antennen schwarzbraun, stärker als bei der vorigen Art. Abdomen brännlich oder ockergelb, ventral weißlich, dorsal schmal schwärzlich, lateral mit je einer dunklen Limie, die manchmal moleutlich ist. - Vorderflügel wie bei der vorigen Art, nur etwas breiter. Grundfarbe rothram, am Vorderrande ein schwarzer Streif, der an der Flïgelwurzel schmal einsetzt, sich linten allmählich ïber die Subcostalis rerbreitert und in flachem Bogen durch die Zelle his zn deren hinterer Ecke ausdehnt, längs des mittleren Medianastes etwas verschmälert als schräg liegendes Querhand bis zum Distalrande länft. Die proximale Begrenzung dieses Schrägstreifes bildet vor der rorderen Zellecke einen stımpfen Winkel mit dem Torderrande. Apex breit, Distalsamm etwas sclunaler schwarz, an der Berübrungsstelle mit dem Querstreif etwas ansgeflossen. Inrch letzteren wird ein schräg liegender länglicher Snbcostalfleck der Grundfarbe abgesondert, der vorn his zum foin schwarzen Torderrande reicht and vou der schwar\% bestänbten Subcostalis durchschnitten wird. Submedianstreif roll und breit, etwas rerschmälert in den Hinterwinkel anslanfend. Unterseite bleicher, Grmalfarbe fast ockergelb. die dunklen Stellen der oberen Zeichmung braungraul. - Hinterflïgel fast dreieckig mit flach gebogenen Seiten wie bei der rorigen Art. Torlerrand schmal gelblich glämzend, mit anschlicßendem granem Costalstreif bis zmm Apex. Distalrand in ziemlich gerader mul bestimmt markierter Begrenzung; etwa $3 \mathrm{~mm}$ breit schwarz, an der Flügelwurzel ein kurzer keilförmiger Sulhcostalstreif dicht hinter dem grauen Torderrandfelde. Cnterseite matter. Vorderrand mit gelblichem Wurzelstreif, Costalstreif gran, Randbinde grangelb, proximal dunkler gesäumt. — - o. Größer als das $\sigma^{\prime}$, Grundfarbe etwas heller, Costalstreif des Hinterflügels linter dem sebr schmal gelblich glänzenden Torderrande intensiver granschwarz. Sonst ohme Unterschiede in der Zeichnung: zuweilen jedoch der subapicale Fleck des Vorderflïgels bleicher.

Nördliches Sïd-Amerika, Mittel-Amerika.

Diese Art zerfällt in 2 Unterarten:

12 a. E. lybia lybia (F.) 1775 Papilio l., J. C. Fabricius, Syst. Ent., p. 4601781 P. $l$., J. C. Fabricius, Spec. Ins., v. 2 p. $28 \mid 1787$ P. l., J. C. Fabricius, Mant. Ins., $v .2$ p. 14 I793 P. l., J. C. Fabricius, Ent. syst., v. 3r p. 163| 1816 Colaenis l., Jac. Hübner, Velz.Schmett., p. $32 \mid 1819$ Cethosia l., (Latreille \&).J. B. Godart in: Enc. métl., v. 9 p. 245 1848 Eueides l., E. Doubleday (\& Westwood), Gen. diurn. Lep., v. 1 p. 147 | 1862 E. l., H. W. Bates in: Tr. Linu. Soc. London, v. 23 p. $563 \mid 1871 \& 77$ E. l., W. F. Kirby, Cat. diurn. Lep., p.145; Suppl. p. $723 \nmid 1879$ E. l., Hopffer in: Ent. Zeit. Stettin. v. 40 p. 435 188:) E. l., O. Staudinger (\& Schatz), Exot. Schmett., $r$ 1 p. $80 \mid 1890$ E.l., Weymer (\& 
Maassen), Lep. Reise Stübel, p. 88 | 1896 L. l., Bönninghausen in: Verh. Ver. Humburg, c. 9 p. 32 | 1903 E. l. typica, Stichel in: Berlin. ent. Z.. v.48 p. 2.4 1777 ,Hypsipyle“, Papilio hypsipyle, P. Cramer, Pap. exot., v.2 p. 12 t t.177 f.C, 1); p. $149 \mid 1779$ „P.h."+ "P. cinereomaculatus", Gueze, Ent. Beytr., v. 3 I p. 117; 121 |" 1779 ,.P. fasciatus", Goeze, Ent. Beytr., v. 3 I p. 114.

Vorderflïgel proximal mit einem kleinen roten bleck in dem schwar\%braunen Costalwisch, unterseits mit kurzem roteu Costalstreif von der Flügelwnrzel aus. Hinterflïgel im schwarzbrannen keilförunigen Sulorostalstreif ebenfalls unit einem roten leukt, unterscits mit eineu weiben und zwei roten Wmrzelfeckehen. rou denen rines hinter der Costalis, das andore hinter der Mediana liegt. Sonst wie bei der Art beschrieben. Vorderflügellänge $28-31 \mathrm{~mm}$.

Nieder]ändisch- und Britisch-Guayana, Brasilien (Pará. Rio de Janeiro, A mazonas).

12 b. E. lybia lybioides Staud. 1876 E. lybioides, 0. Standinger in: Verh. Ges. IIien, v.25 Abh. p. 99 | 1877 E. l., W. F. Kirby, ('at. dimon. Lep., Suppl. p. 723 | 1881 F. l., F. J). (iodman \& O. Salvin in: Biol. Centr.-Amer.. Lep.-Rhop. v. 1 p. $164 \mid 1885$ E. l., O. Staudinger (\& Schat\%), Exot. Schmett., 1. 80 t.32 1901 E. l., F. D. Godman \& (1. Salvin in: Biol. Centr.-Amer., J.ep.-Khop. r.2 1.670|1903 E. lybin lybioides, Stichel in: Berlin. ent. Z.. i. fri j. 24.

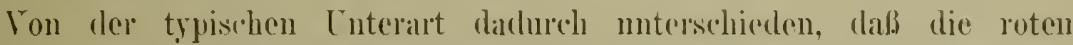
Fleckehen am Vorderrande des Forderflïgels und im Subcostalstreif des Hinterflïgels, sowie der rote Costalstreif mul die roten Wur\%alflecke auf der [nterseite beider Flïgel fellen. In Stelle des roten ein gellner Costalstreif inf der Cuterseite des Vorlerflïgols von der Wurzel aus. Suhapicalfleck des Vorderfliigels etwas leeller als dic Grmolfarle, namentlich heim o und auf der Cnterseite. Soust ohme muterschiedliche Cliaraktere.

Mittel-Amerika (Janama, Mexiko). Kount auch einzelı neben der typischen Unterart ror.

13. E. olympia (F.) 1793 Papilio o., J. C. Fabricius, Ent. syst., r.3 I p. 166 $1 \$ 19$ Heliconic 0., (Latreille \&) J. 13. Godart in: Énc. méth.. t. 9 1. 218 | 1848 H. o., E. Doubleday (\& Westwool), Gen. diurn. Lep). 1) 133 | 1869 Lineides o., A. G. Butler, ('at. diurn. Lep. Fabr.. p. 1201881 \& 82 E. o., F. J). Godman \& O. Salvin in: Biol. ('entr.Amer., Lep.-Rhop. $x .1$ p. 164 ; t. 19 f. 1 | 1903 K. o., Sticliel in: Berlin. ent. Z.. v. 48 1. $25 \mid 1866$ E. leueomma, H. W. Bates in: Eut. monthly Hag.. e. 3 p. $88 \mid 1871 \mathrm{k} . l$., II. H. Kirby, Cat. diurn. Lep., p. 145.

Antenuen kräftig wie hej L. lyhia, schwar\%. Thorax rom jederseits mit kleinem, dahinter mit gröberem gelblichem Fleck. Punkticlung auf Kopf und Halskragen weiß. Ablomen orkergelh. rentral heller, dorsal

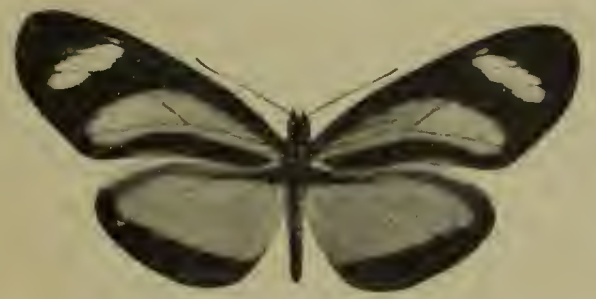

Fig. 48. E. olympia, $f\left({ }_{1}^{1}\right)$.

schmal schwar\%, lateral mit je eineu schwarzbraunen längsstrich. Gestalt der Flügel (Fig. 48) wie bei W. lybia. Torderflïgel von der Wurzel aus vorn scluwarzhraun. Dic Färbung begimut streifenartig sehmal an der Wrurel. 
verbreitert sich allmählich in flachem Bogen durch die Zelle bis hinter den mittleren Medianast und geht hier in den schwarzen Distalrand über. Submedianstreif kräftig, ebenfalls schwarzbraun, nur einen flachen Bogenstreif am Hinterrande freilassend und in den ebenso gefärbten Hinterwinkel auslaufend. In dem schwarzen Apicalteil ein schräg gestellter, länglicher, rein weißer Fleck, der hinter der Subcostalis beginnt, rou den ganz fein schwärzlich angelegten Adern durchschnitten wird und am vorderen Medianast endet. Der übrige Flügel hell rotbraun, an den Grenzen gegen das Schwarz ein wenig dunkler im Farbenton. Untere Seite wie die obere, aber viel matter, im mittleren Teil weißlich, die dunkle Zeichnung graubraun, am Vorderrande ein gelber kurzer Wurzelstreif. - Hinterflügel mit grauem Costalstreif und schmal gelblich glänzendem Torderrande. An der Flügelwurzel, an den grauen Streif hinten anschließend, ein kurzer keilförmiger schwarzer Subcostalstreif. Apex und Distalrand breit schwarzbraun, die übrige Fläche in der hell rötlichbraunen Grundfarbe. Unterseite mit gelbem Wurzelstreif am Vorderrande und zwei weißen Wurzelflecken, je einem in der Zelle und hinter derselben, sonst wie die Oberseite, aber viel heller, namentlich die Saumbinde fast weißgrau, nur ein vorderer Streif derselben dunkler, granbraun. - E. lybia ähnlich, durch andere Lage und weiße Farbe des suhapicalen Fleckes des Vorderflügels unterschieden. Geschlechtsunterschiede wie bei dieser Art. Torderflügellänge bis $30 \mathrm{~mm}$.

Mittel-Amerika (Nicaragua, Panana), Colombia.

\section{d. Coh. Thaletoformes}

Merkmale und Zeichnumg des Kopfes, der Palpen, Augen und Beine wie bei der vorhergehenden Gruppe. Antennen schwarzbraun, Kolben beim o nur wenig bräunlicb aufgehellt, beim o meist ockergelb. Abdomen schwarz bis schwarzbraun, ventral weiß punktiert oder mit 2 weißlichen Streifen, die sich hinten vereinigen, lateral mit undeutlicher weißlicber Limienund Punktzeichnung oder ockergelben Streifen, die sich manchmal so aushreiten, daß nur ein schmaler schwarzer dorsaler Streif frei bleibt. Torderflügel schlank, Vorderrand schwach gekrïmmt, Apex abgerundet, Distalrand vorn leicht konvex, sodann ziemlich gerade in proximaler Richtung abgeschrägt, Hinterwinkel stumpf, Hinterrand schwach S-förmig gebogen, etwas länger als der Distalrand. Hinterflügel fast dreieckig mit flach konvex gebogenen Seiten. Apex kaum hervortretend, Hinterwinkel abgerundet. - Schwarze oder schwarzbraune Falter, Yorderflügel mit gelben, seltener mit roten Discalflecken, häufig mit roter Wurzelbestäubung. Hinterflïgel einfarbig oder mit roter his rotgelber Strahlenzeichnung oder breit rotem Wurzelfelde. - o mit dunkelgrau glänzendem Hinterrandfelde auf der Cuterseite des Vorderflügels. Der Glanz beginnt entweder unmittelbar hinter der Mediana oder nächst einem Streif matterer Bestäubung. Torderrand des Hinterflïgels oberseits dunkelgrau glänzend bis zur Subeostalis. Q ohne diese Merkmale. an den betreffenden Stellen ıur mit etwas heller abgetönter Grundfärbung.

Die Vertreter dieser Gruppe ähneln sehr einigen Arten der Eratoformes und Clysonymoformes der Gattung Heliconius (S. 187 und 218).

3 Arten, die in 9 Unterarten zerfallen.

14. E. tales (Cram.)

ठ. Punktierung des Kopfes weib, die des Halskragens und seitliche Flecke auf dem Thorax ockergelb bis bräunlich. Abdomen schwarz, ventral 
mit zwei sich hinten rereinigenden weißlichen Streifen, lateral mit je einem lunkel ockergelben Strich oder Doppelstrich. der sich stellenweise verliert oder uur voru deutlich auftritt. - Torderflïgel mit roter, vou den Hauptadern mehr oder weniger breit durchschnittener Wurzelbestäubung. Im nnmittelbaren oder mittelhareu Anschluß hieran im distalen Teil der Zelle ein mehr oder weuiger großer gelber Fleck. Distal ron der Zelle ein schmaler gelber Subcostalfleck und hieran nacl hinten anschließend eine gebogene Reihe ebensolcher Flecke, die zuweilen teilweise zusammengeflossen und zipfelartig in distaler Richtung verlängert sind. Untere Seite der oheren entsprechend, matter, am Torderrande ein kurzer gelber, in seiner Verlängerung roter Streif, die rote Wurzelbestäubung in der Regel anf cinen roten Wisch im vorderen Teil der Zelle verringert, im Hinterwinkel einige in 2 Reihen angeorlnete weiße Silumfleckchen. Hinterwinkel auf den Adern mit roter Bestäubung. welche jeuc selhst manchmal fein schwarz durchtreten läßt. Diese Bestäubung tritt als Cinrandung der Zelle und in stralılenförmigen Streifen von verschiedener Lülnge hinter und distal von ihr auf. In manchen Fällen ist dieselbe zu kleinen, ungewiß begrenzten Wischen an der Flügelwurzel riickgebildet oder fehlt ganz. Unterseite mit einem gelben Fleck an der Flügelwurzel und anschließendem rotem Costalstreif. Die roten Strahlen meist rollkommener wie obcrseits, zuweilen sämtliche Alern anBer der Costalis rot bestäubt bis anf rimige Finteruung rom Distalrande und dort durch eine gebogene Querlinie rerbunden. Am Saum eine Doppelreihe waißer Fleckchel. _ ठै älnnlich, mit gleicher \%eichmmg, aber das Rot weniger grell, meist gelblicl, und der Hinterflïgel meist mit stärker ausgebildeter Strahlenzeichnung. In übrigen mit den charakteristischen Geschlechtsunterschieden.

Guayana, nördliches Brasilien.

1)iese Art zerfällt in 3 Unterarten:

14 a. E. tales tales (Cram.) $1775 \& 76$,Tales", Papilio t., P. Cramer. Pap. exot., $x: 1$ p. 62 t. 38 f. C, D; 1. $154 \mid 1777$ P. thales, J. C. Fabricius, Gen. Ins., p. $255 \mid 1779$ „P.t.", (roeze, Ent. Beytr., v. 3 I p. $113 \mid 1781$ P.t., J. C. Fabricius, Spec. Ins., v. 2 p. $30 \mid 1787$ $P . t$, J. C. Fabricius, Mant. Ins., v. 2 p. $14 \mid 1790$ P.t., J. F. W. Herbst, Naturs. Ins. Schmett., $v .4$ p.136 t. 73 f. 2, 3 | 1793 P.t., J. C. Fabricius, Ent. syst.. v. 3 I 1. $168 \mid 181$ i Migonitis t., Jac. Hübuer. Verz. Schmett. p. 12 | 1844 Heliconia t., E. Doubleday, List. Lep. Brit. Jus., Ł. I p. 54 | $18+8$ Eueides t., E. Doubleday (\& Westwood), Gen. diurn. Lep., $v .1$ p. 146 ! 1862 E. $t$., H. W. Bates in: Tr. Linn. Soc. London, v. 23 p. 563 , 1869 k. $t$. A. G. Butler, Cat. dium. Lep. Fabr., p. 119 | 1871 E. $t$. (part.), H. F. Kirby. Cat. diurn. Lep., p. $1+j \mid 1877$ E. $t$. var., A. G. Butler in: Tr. ent. Soc. Loudon, 13. $123 \mid 1885$ E.t. (part.), O. Staudinger (\& Sehatz), Exot. Schmett.. v. 1 p. 80 t. $32 \mid 1819$ Heliconir thalestris, (Latreille \&) J. B. (Hodart in: Enc. méth., v. 9 1). 2061903 Eueides thales typicus, Stichel in: Berlin. ent. Z., 1.48 p. 26 t. I f. 18.

ठ․ Wurzelhestäuhung des Vorderflïgels (Fig. 49) hochrot, Vorderrand sulhalrz, hinter deuselhen 1111 ein meist schmaler und undeutlichor Wisch. die ïhrige rote Bestäuhung dureh die Mediana und Submediana getrennt, distal tief eingeschnitten mud in unscharfer Begrenzung endigend, der hinterste Teil zu einem etwas längeren, spitz auslanfenden Streif am Hinterrande versclımälert. Im distalen 'T'il der '/elle ein die ganze Breite derselben ansfïllender, aber das Rot nicht herührender. gelber Fleck vou nmegelmäßiger, meist an den Seiten etwas eingeschnürter Gestalt. Distal vou der Zelle ein schunaler Subcostalfleck, dauan naıclı hinte'u hogenförmig anschließend ein läıglicher Doppelfleck und zwei einzelne Fleckellen im mittleren und hinteren Medianzwischenraum, sämtlich hellgeth. - Hinterflïgol mit roter Turaudnug der 
Zelle und hiervon ausgehenden, mit mäßig langen, von den fein schwarzen Adern gespaltenen roten strahleuförmigen Streifen, die nächst dem Hinterrande am längsten sind und sich gegen den Torderrand verkürzen. Unterseits sämtliche Aderu außer der Costalis bis kurz vor den Distalrand gelbrot bestäubt und dort durch eine rote Bogenlinie miteinander verbunden. Nahe dem Distalrande zwei Reilien weißer, parweise in den Aderzwischenräumen stehender Saumfleckchen. Abdomen vorherrschend schwarz, ventral mit zwei weißen Linien, lateral mit ungewissen dunkel ockergelhen Tupfen.

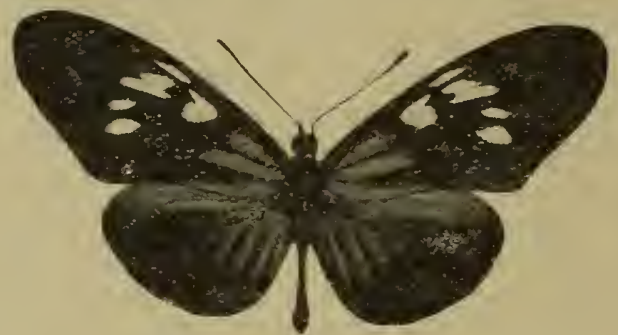

Fig. 4y. E. tales tales, $\sigma^{\pi}(1 / 1)$.

den Resten eines Seitenstreifs. In übrigen wie bei der drt beschrieben. - . . Nit etwas breiterem Torderflügel, .TTurzelbestäubung gelbrot, die gelben Discalflecke in der Regel etwaś größer, der im mittleren Medianzwischenraum stehende Fleck aber manchmal zu einem kleinen Wisch verkleinert. Strahlen des Hinterflügels ebenfalls gelbrot, meist aber von derselben Länge wie unterseits, aher ohne die Terbindungslinie an deren Enden, die Zelle zuweilen bis auf einen kleinen Kern rötlichgell überstäubt. Die Saumfleckchen scheinen schwach durch. Abdomen vorherrschend dunkel ockergelb. Sonst wie das $\sigma^{\pi}$. jedoch mit den charakteristischen Geschlechtsunterschieder. _ - Torderflügellänge $32-35 \mathrm{~mm}$.

Es kommen Übergänge zur folgenden Form ror.

Britisch-, Niederländisch- und Französisch-Guayana, Amazonas.

11b. E. tales pythagoras F. Kirby 1806-19 "Nereis festiva thales", Jac. Hüłuer, Exot. Schmett., v. 1 t. 10 f. $1-4 \mid 1900$ Eueides pythagoras, W. F. Kirby, Exot. Schmett. Hübner. p. $13 \mid 1903$ E. thales heraldicus, Stichel in: Berlin. ent. Z., v.48 p. 27 t. 1 f. 19.

Gelber Zellfleck des rorderflügels vergrößert, proximal ganz oder fast ganz die rote, ebenfalls verstärkte Wurzelhestäubung berïhrend. Die zwischen den Radiales und dem rorderen Medianast liegenden Flecke beiderseits wie ein Schiffswimpel lang ausgeflossen, proximal zusammenlängend, distal tief eingeschnitten. Zuweilen bildet der sonst sehr kleine Teil des Fleckes zwischen Subcostalis und rorderen Radialis chenfalls einen distal ausgeflossenen Zipfel, so daß das Gebilde dem Fittich eines heraldischen Adlers nicht unähnlich ist. Tor dieser Fleckengruppe ein kleinerer. etwas in proximaler Richtung zurücktretender Subcostalffeck, linter derselben zwei längliche oder eirunde Flecke im mittleren und hinteren Medianzwischenraum. Unterseite ebenso, aber matter, das Rot des Wurzelfeldes beim $\sigma^{2}$ nur schwach ain Torderrande und in der Zelle erlalten. Im Hinterwinkel einige mehr oder weniger deutliche weiße Fleckehen. - Hinterflügel mit rot umrandeter oder fast ganz rot ansgefüllter Zelle und starker Strahlenbildung an den Adern, rorzüglich heim 0 . hei dem die Streife sich vor dem Distalrande an den Enden verhreitern und dazu neigen, wie auf der Lnterseite zusammenzuflieben. Der 
Farbton der roten Keichnungen auch beim o' etwas gelblicher als bei der nördlichen Form, beim o rotgclib. - Vorderflïgcllänge 29--35 inm.

Gebiet des unteren Amazonen-Stroms bis Santarem.

$14 \mathrm{c}$. E. tales surdus Stich. 1903 E. thales $s .+$ E. t. s. aberr. aquilifer. Stichel in: Bertin. ent. Z., v. 48 p. 27 t. 1 f. $20 ;$ p. 28 t. 1 f. 21 (forma a.).

Forma principalis. Gröbere Form. Rot des Wurzelfeldes auf den Vorderflügel beim on purpurfarben, beim o lichter, his zimnoberfarben. Fleckenbildung iu der Zelle und distal ron ihr wio bei der typischen Cnterat. Hintertlïgel chtwoder ganz seliwal\% oder mit geringern Spuren roter Aderbestäubulg all der Wurzel; anch aul der Unterseite nul ganz geringe Spuren ron Rot in oder linter der Zelle vorhanden. dagegen Hinterandader und submediama mehr oder weniger rot angelegt und beim ơ zonweilen eine ziemlicl vollkommene, den Sam folgende rote Wellenlinie rop den weiben Sammpunkter. dic aber etwa hei der hinteren Radialis endet. Alolomen in beiden Geschlechtern vorlereschend schwarzhanu. Sonst wie die typische Lnterat. Vorderfliugellänge $35-37 \mathrm{~mm}$.

V'ielleicht Zeitform.

Gebiet des unteren Amazonen-Stroms (Obidos. (ameta), (iuayana.

Forma aquilifer. Vorderflïgol wie bei li. t. pythagoris gezeichnet, also mit vergröbertem. das rote Wurzolfeld berïhendem Zellfeck und lang zipfelartig ausgeflossemem lopprelferek distal vou d(r Zelle. Gröber als die genanute Tnterart. das Rot gesättiger. heinalı purpurfarben. - HintelHügel wie bei der Hauptform, cinfarhig schwarz oder mur mit geringen Spincen roter Aderbestïubung der Flügolwurzel.

Gebiet des unteren Amazonen-Stroms (Obidos).

\section{E. heliconioides C. \& R. Felder}

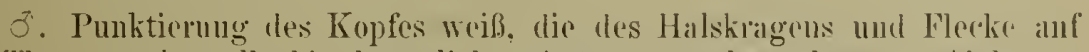

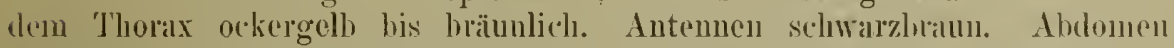

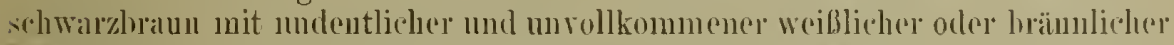
J.ängsstreifung. - Torderflügel in Gestalt wie bei den rorigen Arten. Grundfarbe schwatz lis schwarzhaun. An der Flïgelwurzel zwischen den Aderu vier rote. distal unscliarf endigende Streifenwisele, deren vorderer, dicht linter dem Vorderande gelegen. mur selı selmal und kim\% und deren hinterer. dem Hinterrande unmittelhal anliegend, der längste ist. In Diseus eiur schwal"\% gekelute bindenatige gello Fleckengluppe, geloildet alus: einem Fleck im distalen Teil der Zelle. der proximal ziemlich gerade alogeschuitten ist und (las Rot der Wurzelbestïubung nieht herïlıt, distal jelorh winkelförnig, entsprechend der Lage der Discocellulares, eingekerbt ist: einem läuglichen Sul)costalfleckelien vor dem \%ellende: hieraur anschließend. un dhrcelı die Subeostalis fein sehwar\% getrennt, ainem vollen. otwal leerz- obler breit keilförmigen, mit dem schmalen Ende distalwärts gerichteten l'leck, der linten rom vorderen Medianast. leggrenzt wird; eiuem weiteren, beinalıe stumpfwinklig dreieckigen Fleck, deswen Basis den linteren Medianist anflicgt. Zwisehen letzterem und dem rorhlolgelienden Fleck ist die Binde, als Gamzes betrachtet. am rorderen Medianist selıarf spitzwinklig von der Grundfarbe ringekerbt. I)e in der Zelle liegrude

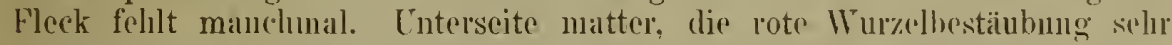
rerringert und ungewib, das Gelb der discalen Flerelingruppe tribere fast ockergell, im Hinterwinkel cinige weiße Fleckrhen. - Hinterfligel rimus. 
roru abgeflacht. Apex wenig hervortretend, Hinterwinkel stark abgerundet, schwarz bis schwarzbraun, Zelle rot umrandet oder rot ausgefüllt, hinter derselben mehr oder weniger rote zacken- oder strahlenartige Bestäubung auf den Adern. Unterseite mit rötlichem Costalstreif an der Flügelwurzel, stärkerer roter Bestäubung der Adern, die nahe dem Distalrande manchmal teilweise durch eine rote Bogenlinie verbunden sind, und einer Doppelreihe weißer Saumpunkte, paarweise zwischen den Adern. - - o. Meist etwas größer. Vorderflügel wenig breiter, mit den meist etwas ausgedehnteren Zeichnungen des $\sigma^{\pi}$. Geschlechtsunterschiede wie bei der vorigen Art.

Colombia, Ecuador(?).

Diese Art zerfällt in 2 Unterarten:

15a. E. heliconioides heliconioides C. \& R. Felder 1861 E. h., C. \& R. Felder in: Wien. ent. Monschr., v. 5 p. $102 \mid 1865$ E. h., C. \& R. Felder in: Reise Norara. r. 21 I p. $378 \mid 1885$ E. h., O. Staudinger (\& Schatz), Exot. Schmett., v. 1 p. $80 \mid 1903$ E. h., Stichel in: Berlin. ent.Z., v.48 p.28 t. 1 f. 22 | 1861 E. thales var., Hewitson in: J. Ent., v. 1 p. 156 t. 10 f. 3 | 1871 E. t. var. + E. heliconioides, W. F. Kirby, Cat. diurn. Lep., p. 145 | 1890 E. cognata, Weymer (\& Maassen); Lep. Reise Stiibel, 1) 27.

Vorderflügel wie bei der Art beschriehen. - Hinterflügel mit roter Lmrandung der Zelle und roter strahlenförmiger Bestäubung der Aderı hinter derselben in größerer oder geringerer Länge. Diese Strahlen gewöhulich am Hinterrande sowie auf dem vorderen und mittleren Medianast bis nahe zur Flügelhälfte reichend, auf den Radiales nur als kurze Spitzen ansgebildet, auf der Unterseite bis zu der Doppelreihe weißer Saumpunkte rerlängert, aber ohne diese zu berühren. An ihrem Ende verbreitern sie sich etwas, und einige, nächst dem Hinterrande gelegene, sind durch eine rote Querlinie mehr oder minder deutlich verbunden. An der Flügelwurzel meist noch ein gelbes Fleckchen, welches in den roten Costalstreif ühergeht. - Torderflügellänge $31-36 \mathrm{~mm}$.

Colombia, Ecuador.

15 b. E. heliconioides xenophanes C. \& R. Felder 1865 E. $x$. C. \& R. Felder in: Reise Novara, v. 2 II p. 377 t. 46 f. 14, $15 \mid 1871$ E. x., W. F. Kirby, Cat. diurn. Lep, p. $145 \mid 1885$ E. x., O. Staudinger (\& Schatz), Exot. Schmett., v. 1 p. 80 : 1903 E. heliconioides aberr. $x$., Stichel in: Berlin. ent. Z., v. 48 p. 28.

Torderffügel ohne Fleck in der Zelle, die distal ron dieser liegende Fleckengruppe bindenartig verschmälert, die rote Wurzelbestäuhung auf zwei Streifenwische rückgebildet. Hinterflügel mit reichlicher roter Wurzelbestäubung. welche den ganzen proximalen Flügelteil überzieht und hinter der Zelle in kurzen Strablen ausläuft. Im übrigen wie die typische Unterart. namentlich auch die Unterseite des Hinterflïgels.

Colombia.

16. E. eanes Hew.

$0^{\pi}$. Antennen schwarzbraun, die distalen Glieder kaum merklicl aufgehellt. Ahdomen schwar\%hraun, ventral etwas weißlich punktiert. namentlich hinten, lateral mit je einer weißlichen Doppellinie, die häutig uuvollkommen oder gar nicht erhalten ist, und einer Reihe weißlicher. luäutig auch sehr undeutlicher Punkte. Punktierung auf Kopf und Halskragen meist weiß. Thorax ungefleckt oder mit zwei dorso-lateralen, runden, gelhlichen Fleckchen. Torderflïgel wie bei der Gruppe charakterisiert. schwarz 
bis scliwarzbraun, entweder mit roter Bestäubung proxinial nud einer gelben Fleckengruppe im Disces oder nur init letzterer. Diese setzt sich in vollster Gestalt aus folgenden, bindenartig augeordueten 'Teilen zusammen: ein Fleck im distalen 'Teil der Zelle, der proximal wenig oder gar nicht, distal dagegen tief winklig eingeschnürt und durch einen schwar\%en Kern von den iibrigen getrennt ist; vor demselben, etwas in distaler Richtung vorgeschoben, ein schmaler kurzer Fleck; daran nach hinten anschließend, durch die Adern fein schwarz unter sich und von ersteren getrenut, zwei etwas breitere Fleckchen; hinter diesen, im mittleren Mediauzwischenraum ein in distaler Richtung weit vorspringender, dort etwas zugespitzter Fleck; im hinteren Medianzwischemramm, wiederum durch den Medianast fein schwarz getrennt, oin letzter, etwas kür\%er Fleck, der proximal ziemlich gerade vom Basiswinkel des mittleren bis zum hinteren Medianast abgeschritten, distal aber etwas abgerundet ist. Dieser Fleck sowie derjenige in der Zelle fehlt zuweilen, und die Fleckengruppe ist zu einer im letzten Teil merklich in distaler Richtung vorspringenden, kurzen, mehr oder weniger breiten Querbinde distal von der Zelle reduziert. Dieso Zeichnungsanlagen koinmeu in allen Kombinationen mit und ohne rote Wurzelbestiubung vor. Ihre Farbe ist heller als die entsprechende Zeichnung der vorigeu Art, sogar fast schwefelgelb, in selteneren Fällen rot. Unterseite matter, am Torderrande stets ein roter Wurzelstreif. Die rote Wurzelbestäubung der Oberseite auf einen mehr oder minder dentlichen Wisch in der Zelle reduziert, jedoch auch da vorhanden, wo sie oberseits fehlt. Die discalo Fleckengruppe viel blasser, die hinteren Flecke weißlich, bei denjenigen Formen, welche bier oberseits rot gefärbt sind, die vorderen gelb, die hinteren licht rötlich weiß. Hinterrandfeld schwach grauglänzend hinter einem schmaleu matt beschuppten Streif an der Mediana. - Hinterflügel schwach wellig gesäumt, mit roter Strahlenzeichuung oder einfarbig schwarz bis schwarzbraun. Erstere setzt sich zusammen aus einem durch die schwarzen Adern isolierten Streif längs in der Zelle und aus verschieden langen und breiteu, meist spitz bis dicht an den Distalrand verlaufenden Streifen in den Aderzwischenräumen hinter der Zelle. Forderrandfeld bis zur Subcostalis schwach dunkelgran glänzend. Unterseite matter, mit gelblichem Fleck an der Flügelwurzel, der meist zu einem rötlichen Wisch am Vorderrande verlängert ist, einem roteu, mehr oder weniger deutlicheu und langen Subcostalstreif und schmaler Strahlenzeichnung wie bei der Oberseite geschildert, auch bei den Formen, denen dieselbe dort fehlt. Nahe dem Distalrande eine Reihe parweise in den Aderzwischenräumen stehender weiber Saumpunkte. - - $q$. Wie das $\sigma^{\pi}$, meist etwas größer, ohne glänzenden Hinterrandteil der Vorderflügelunterseite und ohne glänzenden Vorderrandteil del Hinterflügeloberseite; an diesen Stellen die Grundfarbe nur etwas heller. Saumflecke der Unterseite des Hinterflügels stärker, meist noch von einer zweiten, distalen Reihe kleinerer, weniger scharfer weißer Pünktchen begleitet.

Peru, Bolivia, Ecuador.

Diese Art zerfällt in 4 Unterarten:

16 a. E. eanes eanes Hew. 1861 E. e., Hewitson in: J. Ent., v. 1 p. 155 t. 10 f. $1 \mid 1862$ E. e., H. W. Bates in: Tr. Linn. Soc. London, v. 23 p. $563 \mid 1871$ E. e., W. F. Kirby, Cat. diurn. Lep., p. $145 \mid 1879$ E. e., Hopffer in: Ent. Zeit. Stettin, v. 40 p. 434 | 1885 E. e., O. Staudinger (\& Schatz), Exot. Schmett., v. 1 p. 80 | 1903 E. e., Stichel in: Berlin. ent. Z., $v .48$ p. 29 t. 1 f. 23.

Vorderflügel mit gelblichroter, von den Adern schwarz durchschnittener Wurzelbestäubung, die distal etwa durch eine schräge Linie ron der Mitto 
der Zelle nach dem letzten Drittel des Hinterraudes unscharf begrenzt ist und durch die distal eindringende Grundfarbe in vier zwischen den Hauptadern liegende Streife oder Felder zerlegt wird. Zelle ohne Fleck oder nur mit einem kleinen gelben Wischfleck vorn im distaien Ende. Distal von der Zelle eine kurze, bei der Artbeschreibung charakterisierte, hellgelbe Fleckenbinde bis zum mittleren Medianast, die zuweilen stark reduziert ist. so daf der Subcostalfleck fast ganz fehlt und die hinter der Subcostalis liegenden Fleckchen auf eine Breite ron $2.5-3 \mathrm{~mm}$ verschmälert sind. Stets jedoch ist das für die Art charakteristische Merkmal, der distal stark rorspringende Fleck im mittleren Medianzwischenraum, unverkennbar. Hinterflügel mit gelblichrotem Längsstreif in der Zelle, der diese his auf eine schwarze Aderumrandung ausfüllt. Um die Zelle liegen in den Aderzwischenräumen lange, mit Ausnahme der vorderen. bis dicht an den Distalrand laufende, allmählich zugespitzte Streife von gleicher Farbe, die vorn meist nur durch die schwarzen Adern getrennt sind. Der vor dem hinteren Medianast liegende Strahl ist meist in der Längsrichtung durch einen schmalen schwarzen Streif schlitzartig gespalten. Die Strahlen deutlich bis in den hinteren Radialzwischenraum, im vorderen nur durch einen mehr oder weniger undeutlichen schmalen Iängswisch angedeutet. Im übrigen wie bei der Art beschrieben. _ _ Vorderflügellänge $34-35 \mathrm{~mm}$.

Peru, Bolivia.

16b. E. eanes eanides Stich. 1865 E. heliconioides var. $\beta$, C. \& R. Felder in: Reise Novara, v. 2 II p. 378 t. 46 f. 16 (forma aides) | 1903 E. eanes aberr. eanides (O. Staudinger in MS.) $+E$. eanes aberr. farragosa $+E$. e. aberr. aides $(O$. Staudinger in IIS.), Stichel in: Berlin. ent. Z., v. 48 p. 30 t. 1 f. 24 ; p. 30 (forma f.); p. 30 (forma a.).

Forma principalis. Rote Zeichnung der Flügel (Fig. 50) wie bei der typischen Unterart, aber etwas lebhafter zinnoberfarben, die Strahlen des Hinterflügels schmaler, auch proximal an der Zelle weiter voneinander getrennt, der Streif zwischen Submediana und hinterem Medianast in der Längsrichtung stärker geschlitzt. Vorderflügel mit einem breiten gelben Fleck im distalen

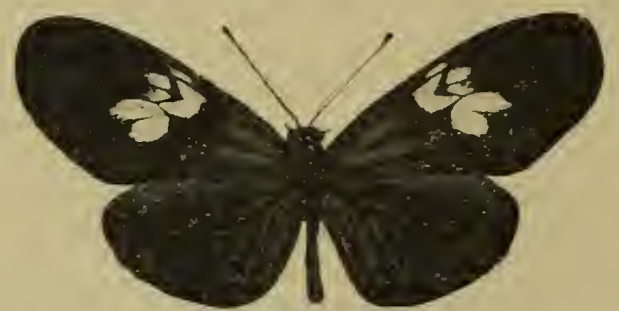

Fig. อ̃ . E. eanes eanides, forma principalis, $\delta(1 / 1)$.

Teil der Zelle, der proximal fast gerade begrenzt oder nur wenig eingeschnïrt, distal aber, entsprechend der Lage der Discocellulares, tief spitzwinklig eingekerbt ist. Vor demselben, etwas distal herausgerückt, ein kleiner länglicher Subcostalfleck, daran nach hinten anschließend zwei rundliche oder kurz-eiförmige, im mittleren Medianzwischenraum ein distal weit vorspringender breiter und länglicher und endlich im hinteren Medianzwischenraum ein die ganze Breite desselben ausfüllender, wiederum etwas kürzerer Fleck, sämtlich schwefel- bis ockergelb, durch die fein schwarzen Adern getrennt und derart um das Zellende gruppiert, daß dieses als schwarzer dreieckiger Kern rerbleibt. Die Anlage der distal dieses Kernes liegenden Flecke wie bei der typischen Unterart, aber um den im hinteren Medianzwischenraum liegenden 
Fleck rermehrt. Unterseite matter, das Gell, der Discalflecke weißlich. Sonst wio bei der Art beschrieben.

Bolivia (La Paz), Peru (Mareapata).

Forma farrigosa. Wurzel des Vorderflïgels olne oder nur mit gan\% geringen Spuren roter Bestäubung. discale Fleckengruppe wie bei der Hauptform. Hinterflügel mit schmaleren strichartigen Strahlen, die sich nach vorn schon im vorderen Medianzwischenraum verlieren oder ganz undeutlich werden. in der Zelle nur mit Spuren eines roten Längsstreifes. Lnterseite mit vollkommenen, wem auch etwas matter roten Streifen in allen Aderwischenräumen und in der Zelle. Im ïbrigen wie die Hauptform.

Übergangsstufe der Hauptform zur näclisten Form.

Peru (Jareapata).

Forma aides. Torderflügel wie bei der rorigen Form. Proximales Fold völlig schwarz. nur die diseale gelbe Fleckengruppe in voller Ausbildung. Hinterflügel oberseits gänzlich zeichnungslos, unterseits mit schmalen roten Streifen in der Zelle und den Aderzwischenränmen.

Peru (Hillapani, Huanaco), Bolivia (La Paz), Peru (Cuzco); Fcuador(?).

16c. E. eanes felderi Stich. 1865 E. heliconioides var, $\gamma$, C. \& R. Felder in: Reise Novara, v. 2 II p. 378 , 1903 E. eanes aberr. felderi + E. e. aberr. pluto (O. Staudinger in MS.), Stichel in: Berlin. ent. Z., v. 48 p. 31 ; p. 32 (forma p.).

Forma principalis. Torderflūgel mit roter Trurzelbestäubung wie bei der typischen Unterart und mit zinnoberroter, nicht gelber, discaler Fleckengruppe wie bei Forma aides der vorigen Unterart. Hinterfiugel wie bei der typischen Cnterart mit roter Strahlenzeichnung in der Zelle und hinter derselben. Im ganzen demuach wie die Hauptform von E. e. eanides gezeichnet, aber mit roter statt gelber Fleckengruppe im Discus des Vorderflïgels.

Ecuador.

Forma pluto. Vorderflügel ohne rote Wurzelfäloung, aber mit roter Fleckengruppe im Discus wie bei der Hauptform. Hinterflügel einfurbig: schwarz. Zeichnung wie bei Forma aides, aber rot anstatt gelb gefarbt. Auf der Unterseite bleiben die. Flecke indes vorn und in der Zelle gelblich und verfärben sich in den Medianzwischenräumen weißlichrot.

Peru (Hillapani).

16d. E. eanes riffarthi stich. 1903 E. e. aberr. r., Stichel in: Berlin. ent. Z.. v. 48 p. 31 .

Ganz schwal\%, nur auf dem Vorderflügel distal ron der Zelle eine schmale, bis zum mittleren Medianast reichende, hellgelbe Fleckenbinde, bestehend aus einem kleinen wischartigen Subcostalfleck, 2 kurzen Flecken hinter demselben und einem distal rorspringenden, cirunden Fleck im mittleren Medianzwischenraum. Diese Zeichnung wie bei der typischen Unterart, aber noch mehr reduziert. Unterseite matter, das Gelb der Vorderflügelflecke weißlich, am Vorderrande ein kurzer. auf und linter der Subcostalis ein längerer roter Wisch. Hinterflügel mit gelblichem Wrurzelfleck, am Torderrande mit kurzem rotem Wischfleck, in der Zelle sowic in den Aderzwischenräumen mit schmalen hellroten Strahlen, nahe dem Distalrande mit paarweise in den Aderzwischenräumen stehenden weißen Saumfleckchen.

Südliches Peru, Bolivia (La Paz). 


\section{Alphabetisches Register.}

\begin{tabular}{|c|c|c|}
\hline & Seite & Seite \\
\hline acacates (Eueides) . . . . . & 247 & aliphera typica (Eueides) . . . . \\
\hline acacates (Eueides lampeto) . . & 247 & alithea (Heliconia)... \\
\hline cacates (Eueides lampeto aberr.). & 247 & alithea (Heliconius) . . . . \\
\hline craeoid-Heliconidae... & 1 & alithea (Heliconius cydno) \\
\hline adusta (Eueides cleobaea zorcaon aberr:) & 242 & amalfreda (Heliconius phyllis) . . \\
\hline aerotome (Heliconius) . . . . . . & 60 & amalfreda (Heliconius phyllis aberr.) \\
\hline aërotome (Heliconius) . . . . & 60 & amandus (Heliconius) . . . . 127, 210 \\
\hline aërotome (Heliconius ethilla) & 60 & amandus (Heliconius melpomene) 127 \\
\hline aerotome (Heliconius eucoma) . . & 60 & amaryllis amaryllis (Heliconius). \\
\hline aerotome var. dilatus (Heliconius) & 85 & amaryllis euryades (Heliconius). \\
\hline aganice (Heliconius). . . . . & 216 & amaryllis euryas (Heliconius). . . . \\
\hline aganippe (Heliconius) & 77 & amaryllis (Heliconia) . . . . \\
\hline aglaope (Heliconius) . . . . . & 121 & amaryllis (Heliconius). \\
\hline aglaope (Heliconius melpomene) . & 120 & amaryllis (Heliconius) . . . 129, 130 \\
\hline conius melpomene) & 121 & amaryllis (Heliconius amaryllis) 129 \\
\hline aglaope (Heliconit & 121 & amaryllis rosina (Heliconius) . \\
\hline aglaopeia (Heliconius melpomene) . & 119 & amaryllis var. euryades (Heliconius). \\
\hline aglaopeia (Heliconius thelxiope var.) & 118 & amaryllis var. pseudamaryllis (Heli- \\
\hline aides (Eueides eanes aberr.) . . . & 270 & conius) . . . . . . \\
\hline Ajantis . . . . . & & amathusia (Heliconius erato) . . . \\
\hline alba (Heliconius antiochus) & 179 & amathusia (Heliconius erato aberr.). \\
\hline alba (Heliconius antiochus aberr.) & 179 & amathusia (Papilio) . . . . . \\
\hline albicilla (Heliconius) . . . . & 98 & amatus (Heliconius) . . . . . \\
\hline albimaculata (Heliconius apseudes var. & 183 & amatus (Heliconius phyllis) . • \\
\hline albimaculata (Heliconius sara) & 183 & amazona (Heliconius erato). \\
\hline albinea (Heliconius sara) ... & 185 & amazona (Heliconius phyllis). . \\
\hline albinea (Heliconius sara aberr.) & 185 & amazona (Heliconius vesta var.). \\
\hline albipunctata (Heliconius clara). . . & 98 & amoena (Eueides lampeto aberr.). \\
\hline albipunctata (Heliconius zuleika aberr.) & 98 & amor (Heliconius) . . . . . \\
\hline ius) . . . . . & 98 & amor (Heliconius melpomene) \\
\hline ucilla (Heliconius anderida) & 98 & amphitrite (Heliconius) . . \\
\hline albucilla (Heliconius clara). . . . & 98 & amphitrite (Heliconius phyllis). \\
\hline albula (Heliconius sara) . . & 184 & anaclia (Heliconius) . . . . \\
\hline albula (Heliconius sara aberr.) & 184 & anacreon (Heliconius) .... \\
\hline aliphera (Acraea) . . . . & 261 & anacreon (Heliconius erato). . \\
\hline aliphera aliphera (Eueides) & 261 & anacreon (Heliconius phyllis). . . 210 \\
\hline aliphera (Cethosia) . . . . & 261 & anactorie aberr.sanguineus (Heliconius) 208 \\
\hline aliphera (Colaenis) . . . . . & 261 & anactorie aberr. venustus (Heliconius) 208 \\
\hline aliphera (Eueides). . . . . . & 260 & anactorie (Heliconia) . . . . 207 \\
\hline aliphera (Eueides) . . . . . & 262 & anactorie (Heliconius) . . . . 207, 210 \\
\hline aliphera (Eueides aliphera) . . & 261 & anactorie (Heliconius erato) . . . 207 \\
\hline aliphera gracilis (Eueides) . . . & 262 & anactorie (Heliconius phyllis). . \\
\hline aliphera (Semelia). . . . . . & 261 & 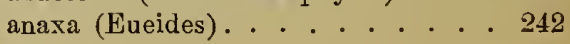 \\
\hline
\end{tabular}


Seite

anderida albucilla (Heliconius) . 98 anderida anderida (Heliconius) . 95 anderida annetta (Heliconius). . $\quad 97$ anderida fornarina (Heliconius) . 100 anderida (Heliconia). . . . . . . 95 anderida (Heliconius) . . . . . . 94 anderida (Heliconius) . . . . . . 95 anderida (Heliconius anderida) . 95 anderida (Heliconius clara) . . . . 95 anderida melicerta (Heliconius) . 95 anderida semiphorus (Heliconius) 97 anderida zuleika (Heliconius) . . 98 andremona (Heliconia). . . . . . 198 andremona (Heliconius) . . . . . 198 andremona (Heliconius arato forma) 198 andremona (Heliconius melpomene var.) . . . . . . . . . . andremona (Heliconius phyllis) . . . andremona (Papilio). . . . . . . . 198 andremona var. udalrica (Helicouia) . 198 andremone (Mligonitis). . . . . . . 198 annetta (Heliconius anderida). . 97 annetta (Heliconius clara) . . . . . 97 annetta (Heliconius clara vur.) . . . 97 authioca (Heliconius) . . . . . . . 179 antigona (Heliconins lyddara) . . . 196 antigona (Heliconius hydara var.) . . 196 antigona (Heliconius hydarus) . . 196 antiocha (Ajantis). . . . . . . 179 antiocha (Heliconia). . . . . . . 179 antiocha (Heliconius) . . . . . . . 179 autiocha (Papilio). . . . . . . 170, 179 Antiochiformes . . . . . . 178 antiochus aberr. alba (Heliconius) . 179 antiochus aberr. divisus (Heliconius) 180 antiochus alla (Heliconius) . . . 179 antiochus antiochus (Heliconius) 179 antiochus aranea (Heliconius). . 180 antiochus (Heliconius) . . . . 178 antiocluus (Heliconius). . . . . 179, 180 antiochus (Heliconius antiochus) 179 antiochus ocannensis (Heliconius) 181 autiochus ocanuus (Heliconius). . . 181 antiochus (Papilio (Heliconius)) . . 179 antiochus salvinii (Heliconius) . 181 antioclus var. aranea (Heliconius) . 179 antiochus var. araneicles (Heliconius) 179 antiochus zobeide (Heliconius) . 180 antioquensis (Heliconius sylvana ral.) 53 aoede aoede (Heliconius) . . . . 147 aoede astydamia (Heliconius) . . 148 aoede bartletti (Heliconius) . . . 149 aoede (Heliconia) . . . . . . . . 147 aoede (Heliconius) . . . . . . . 146 aoede (Heliconius) . . . . . . 147, 198 aoede (Heliconius aoede) . . . 147 aoede lucretius (Heliconius). . . 148 anede (Migonitis) . . . . . . 147 aocle var. astydamia (Heliconius) . 148 Aoediformes . . . . . . . . 144 aphrodyte (Heliconius) . . . . . 114 aplirodyte (Heliconius melpomene) 114 Apostraphia . . . . . . . . 2, 224 apseudes aberr. brevimuculata (Heli-

conius) . . . . . . . . 185 apsendes (Heliconia) . . . . . . 184 apseudes (Heliconias) . . . . . . 184 apseudes (Heliconius) . . . . . 183, 184 apseudes (Heliconius sara) . . . 184 apseudes (Sicyonia) . . . . . . 184 apseudes var. magdalena aberr. albi-

maculata (Heliconius) . . . . 183 apseudes var. magdalena (Heliconius) 183 apseudes var.parauapurae (Heliconius) 177 aquilifer (Eueides thales surdus aberr.) 267 aranea (Heliconia) . . . . . . 180 aranea (Heliconius) . . . . . . . . 180 aranea (Heliconius antiochus) . . 180 aranea (Heliconins antiochus var.) . 179 aranea (Papilio) . . . . . . . 180 arane (Heliconia) . . . . . . . 180 araneides (Heliconius autiorlus var.) 179 arcita (Eueides vibilia var.) . . . . 256 arcuatus (Heliconius) . . . . 101 arcuella (Heliconius) . . . . . . 79 arcuella (Heliconius aristiona) . 73 arethusa (Heliconius) . . . . . . 68 Argynitae . . . . . . . . 1 aristiona arcuella (Heliconius) . 79 aristiona aristiona (Heliconius) . $7: 3$ aristiona aurora (Heliconius) . . 78 aristiona bicoloratus (Heliconius) 7.1 aristiona elegans (Heliconius) . . . 78 aristiona euphone (Heliconius) . Ti aristiona euphrasius (Heliconius) 75 aristiona floridus (Heliconius) . . 78 aristiona (Heliconia). . . . . . . 73 aristiona (Heliconius) . . . . . 71 aristiona (Heliconius) . . . . . . . 73 aristiona (Heliconius aristiona) . 73 aristiona idalion (Heliconius) . . 77 aristiona lenaeus (Heliconius) . . 77 aristiona messene (Heliconius) . 75 aristiona phalaris (Heliconius) . 74 aristiona pretiosus (Helicouius) . . . 80 aristiona seraphion (Heliconius) . . 78 nristiona splendidus (Heliconius) . . 73 aristiona staudingeri (Heliconius) 80 aristiona tarapotensis'(Heliconius) $\quad 76$ aristiona timaeus (Heliconius). . 73 aristiona var. peruana (Heliconius) . 74 aristiona var. splendidus (Heliconius) 73 aristomache (Heliconius doris) . 166 arquata (Eueides isabella) . . . 240 
Seite

arquatus (Eueides isabella) . . . 240 artifex (Heliconius phyllis). . . . . 209 artifex (Heliconius phyllis aberr.) . . 209 astraea (Heliconius egeria) . . . 156 astraea (Heliconius egeria var.) . . 156 astydamia (Heliconia) . . . . . . 148 astydamia (Heliconius aoede) . . 148 astydamia (Heliconius aoede var.) - 148 atrosecta (Heliconius melpomene) . . 112 atrosecta (Heliconius melpomene aberr.) 112 Atthidiformes . . . . . . 135 atthis (Heliconia) . . . . . . 136 atthis (Heliconius) . . . . . 136 augusta (Heliconius). . . . . . . 205 augusta (Heliconius melpomene) . . 119 augusta (Heliconius melpomene var.) 118 aulicus (Heliconius) . . . . . . 65 aurora (Heliconius) . . . . . . 78 aurora (Heliconius aristiona) . . 78 aurora var. isabellinus (Heliconius) . 48 bari (Heliconia). . . . . . . . 120 bari (Heliconius melpomene) . . 120 bartletti forma lucretius (Heliconius) 148 bartletti (Heliconius) . . . . . . . 149 bartletti (Heliconius aoede) . . . 149 batesi (Heliconius) . . . . . . 133 besckei (Heliconia) . . . . . . 135 besckei (Heliconias) . . . . . . . 135 besckei (Heliconius) . . . . . 135 bicoloratus (Heliconius) . . . . . 74 bicoloratus (Heliconius aristiona) 74 bicoloratus var. phalaris (Heliconius) 74 bidentatus (Heliconius) . . . . . 134 Blanchardia . . . . . . . . 2 bouqueti (Heliconius demeter var.) • 207 bouqueti (Heliconius erato) . . . 207 bourcieri (Heliconius) . . . . . 136 Brachyscenae . . . . . . . 244 brevimaculata (Heliconius apseudes aberr.) brevima brevimaculatus (Heliconius $\cdot 185$ brunnea (Eueides isabella hippolinus aberr.) . . . . . . . . 236 buqueti (Heliconius phyllis) . . . . 207 burneyi burneyi (Heliconius) . . 158 burneyi catharinae (Heliconius) . 159 burneyi (Heliconia) . . . . . . . 158 burneyi (Heliconius) . . . . . 157 burneyi (Heliconius) . . . . . . . 158 burneyi (Heliconius burneyi) . . 158 burneyi huebneri (Heliconius) . 159 burneyi lindigii (Heliconius) . . 160 burneyi (Migonitis) . . . . . . . 158 burneyi var. huebneri (Heliconius) . 159 caerulea (Heliconius doris). . . . . 162 callicopis (Heliconia) . . . . . . . 202 callicopis (Heliconius) . . . . . . 202 callicopis (Heliconius melpomene rar.) 202 callicopis (Papilio) . . . . . . . 202 callicopis (Sunias) . . . . . . . . . 202 callista (Heliconius phyllis) . . . . 202 callista (Heliconius phyllis aberr.) . 202 callycopis forma viculata (Heliconius) 202 callycopis (Heliconius) . . . . . 202 callycopis (Heliconius erato) . . 202 callycopis (Heliconius melpomene var.) 202 callycopis (Heliconius phyllis) . . . 202 callycopis (Papilio) . . . . . . . 202 carbo (Eueides lampeto aberr.) . . 246 carolina (Heliconius) . . . . 213 carolina (Papilio). . . . . . . . 213 cassandra (Heliconius) . . . . . 140 caternaulti (Heliconia) . . . . . . 151 catharinae (Heliconius) . . . . . . 159 catharinae (Heliconius burneyi) . 159 cephallenia (Heliconius) . . . . . . 60 cephallenia (Heliconius ethilla) . 60 cephallenia (Heliconius eucoma) . . 60 Cethosia . . . . . . . . . . . 224 charithonia (Apostraphia) . . . . 214 charithonia charithonia (Heliconius). . . . . . . . . . 214 charithonia (Heliconius) . . . 213 charithonia (Heliconius) . . . . . 214 charithonia (Heliconius charithonia) . . . . . . . . . . 214 charithonia (Papilio (Heliconius)) . . 214 charithonia peruviana (Heliconius) . 216 charithonia peruvianus (Helico-

nius). . . . . . . . . 216 Charithoniformes . . . . 213 charitonia (Apostraphia). . . . . 214 charitonia (Heliconia) . . . . . . 214 charitonia (Heliconius) . . . . . 214 charitonia (Papilio) . . . . . . . . 214 charitonius (Heliconius) . . . . . 214 chestertoni (Heliconius) . . . . . . 196 chestertonii (Heliconia) . . . . . 196 chestertonii (Heliconius) . . . . 196 chestertonii (Heliconius hydara) . . 196 chestertonii (Heliconius hydarus) 196 chioneus (Heliconius) . . . . . . 106 chioneus (Heliconius cydno) . . 106 chioneus (Heliconius cydno var.) . . 106; chiriquensis (Heliconius petiverana var.) . . . . . . . . . . 193 choarina (Heliconia) . . . . . 139 choarinus (Heliconius) . . . . . 134 chrysantis (Heliconius). . . . . . 98 chrysantis (Heliconius clara) . . . . 98 cinereofuscus (Heliconius) . . . 168 clara albipunctata (Heliconius) . . . 98 clara albucilla (Heliconius) . . . 98 
clara anderida (Heliconius) . . . $\quad 95$ clara annetta (Heliconius) . . . . . 97 clara chrysantis (Heliconius) . . . . 98 clara discomaculatus (Heliconius) . . 98 clara fornarina (Heliconius) . . . 100 clara (Heliconia) . . . . . . . . 95 clara (Heliconius). . . . . . . . . 95 clara holcophorus (Heliconius) . . . 97 clara jucundus (Heliconius) . . . . 98 clar^ (Melinaea) . . . . . . 5 1,95 clara (Papilio) . . . . . . . . 95 elara semiphorus (Heliconius) . . . 97 clara var. annetta (Heliconius) . . . 97 clara xantbicus (Heliconius) . . . . 98 clara \%uleika (Heliconius) . . . . 98 clarescens (Heliconius) . . . . . 14 clarescens (Heliconius ismenius) 14 claudia (Heliconius) . . . . . . . . 59 claudia (Heliconius ethilla) . . . 59 claudia (Heliconius eucoma). . . . 59 cleobaea cleobaea (Eueides). . . 212 cleobaca (Eueides) . . . . 239, 242, 242 cleobaea (Eueides) . . . . . . . 240 cleobaea (Eueides cleobaea). . . 242 cleobaea typica (Eueides) . . . . 242 cleobaea var. zorcaon (Eueides) . . 242 cleobaca zorcaon aberr. adusta (Eueides)........... 242 cleobaea zorcaon (Eueides) . . 242 elysonimus (Heliconius) . . . . . 220 clysonimus hygiana (Heliconius) . . 221 clysonimus montanus (Heliconius) . . 220 clysonyına (Heliconia). . . . . . 219 Clysonymoformes . . . . . 218 elysonymus clysonymus (Heliconius). . . . . . . . 219 clysonymus (Heliconius) . . . 219 clysonyraus (Heliconius) . . . . . . 219 clysonymus (Heliconius clysonymus) . . . . . . . . . . . 219 clysonymus hygiana (Heliconius) 221 clysonymus montanus (Heliconius) 220 clytia aberr. parvimaculata (Heliconius) 171 clytia colon (Heliconius). . . . 171 clytia elsa (Heliconius) . . . . . 169 clytia flarescens (Heliconius) . . . 171 clytia (Heliconia) . . . . . . 170 clytia (Heliconius) . . . . . . 170 clytia mimulinus (Heliconius) . . 170 elytia ('’apilio)........ . 170 clytia parviulaculata (Heliconius) . . 171 clytia rur. colon (Heliconius) . . . 171 clytia var. elsa (Heliconius) . . . . 169 clytia var. flavescens (Heliconius). . 171 clytia var. sulphurea (Heliconius). . 171 clytia var. wallacei (Heliconius) . . 169 clytia wallacei (Heliconius) . . . 169 cognata (Eueides) . . . . . . . 268

Colaenis . . . . . . . . . 224

colepta (Heliconius) . . . . . . 77

colombina (Heliconius hydara) . . 195

colonıbira (Heliconius petiveranus var.) . . . . . . . . . . . 195 colombinus (Heliconius hydarus) 195 colon (Heliconius clytia). . . . . . 171 colon (Heliconius clytia var.) . . . 171 colon (Heliconius wallacei) . . 170 concors (Heliconius felix rar.) . . 92 coneors (Heliconius quitalena) . . 92 congener (Heliconius) . . . . . 177 congenor (Heliconius) . . . . . . 177 contiguus (Heliconius) . . . . . . 125 contiguus (Heliconius melpomene) • 125 contiguus (Heliconius melpomene timarcta aberr.) . . . . . . . 12\% coralii (Heliconius) . . . . . . . 202 corallii (Heliconius phyllis) . . . . 202 crenis (Migonitis) . . . . . . . . . 162 crispus (Heliconius) . . . . . . . 138 cybele aber'. cybelina (Heliconius) . 201 cybele (Heliconia) . . . . . . . 114 cybele (Heliconius) . . . . . . . 111 cybele (Heliconius erato forma) . . 114 cybele (Heliconius melpomene) . . 114 cybele (Heliconius melpomene var.) . 114 cybele (Papilio). . . . . . . . . . 111 cybelina (Heliconius cybele aberr.) . 201 cybelina (Heliconius phyllis) . . . 201 cybelina (Heliconius vesta). . . . . 201 cybelinus (Heliconius erato) . . 201 cybile (Papilio) . . . . . . . . . 114 cydnides (Heliconius cydno) . . 103 cydnides (Heliconius eydno rar.) . . 103 cydno aberr. laenschi (Heliconius) . 104 cydno aberr. stübeli (Heliconius) . . 106 cydno alithea (Heliconius) . . . 104 cydno chioneus (Heliconius) . . 106 cydno cydnides (Heliconius) . . 103 cydno cydno (IIeliconius) . . . . 102 eydno diotrephes (Heliconius) . . . 106 cydno epicydnides (Heliconius) . . 103 Cydnoformes . . . . . . . 101 cydno galanthus (Heliconius) . . 106 cydno gustari (Heliconius) . . . . 107 cydno hrenschi (Heliconius) . . . . 104 cydno hahneli (Heliconius) . . . 105 cydno (Heliconia) . . . . . . . 102 cydno (Heliconius) . . . . . . 102 cydno (Heliconius) . . . . . . . 10: cydno (Heliconius cydno) . . . . 1(12) cydno hermogenes (Heliconius) . 105 cydno stübeli (Helicnnius) . . . . . 106 cydno subcydnides (Heliconius). . . 103 cydno temerinda (Heliconius) . . 105 
eydno termerinda (Heliconius) . . 105 cydno val. chioneus (Heliconius) . 106 cydno rar. cydnides (Heliconius) . . 103 cydno var. epicydnides (Heliconius) . 103 cydno var. subcydnides (Heliconius) 103 cydno weymeri (Heliconius) . . . . 107 cydno zelinde (Heliconius) . . 107 cynisca (Heliconia) . . . . . . . 198 cyrbia aberr: diformata (Heliconius) 190 cyrbia cyrbia (Heliconius) . . . 190 cyrbia diformata (Heliconius) . . 190 cyrbia juno (Heliconius) . . . . 191 cyrbia (Heliconia). . . . . . 190 cyrbia (Heliconius) . . . . . . . 189 cyrbia (Heliconius) . . . . . . . 190 cyrbia (Heliconius cyrbia) . . . 190 cyrbia var. juno (Heliconius) . . . . 191 cyrbia venus (Heliconius). . . 191 cythera (Heliconia) . . . . . . 132 cythera (Heliconius) . . . . . . . 132 cythera (Heliconius vulcanus). . 132 daguanus (Heliconius eucoma var.) . $\quad 59$ damysus (Heliconius) . . . . . . 196 decolorata (Eueides dianasa aberr.) . 232 deinia (Heliconius) . . . . . . . 114 deinia (Heliconius erato forma) . . 114 deinia (Heliconius melpomene) . . . 111 delila (Heliconius doris) . . . . . 162 delila (Heliconius doris forma) . . 162 delila (Heliconius doris var.). . . 162 demeter (Heliconius) . . . . . 206 demeter (Heliconius erato) . . . 206 demeter (Heliconius phyllis) . . . . 206 demeter var. bouqueti (Heliconius) . 207 demophoon (Heliconia) . . . . 193 demophoon (Heliconius) . . . . . . 193 demophoon (Heliconius petiverana) 193 demophoon (Heliconius petiverana var.) 193 demophoon (Heliconius petiveranus) 193 diana (Heliconius melpomene) . . 114 diana (Heliconius melpomene aberr.) 114 dianasa aberr. decolorata (Eueides) . 232 dianasa (Eueides) . . . . . . . 232 dianasa (Eueides isabella var.) . . . 232 dianassa (Eueides) . . . . . . . 232 Dianassiformes . . . . . . 231 diffusus (Heliconius). . . . . . . 51 diffusus (Heliconius silvana) . . . . 51 diformata (Heliconius cyrbia). . . . 190 diformata (Heliconius cyrbia aberr.) 190 dilatus (Heliconius aerotome rar.) . 85 dilatus (Heliconius pardalinus) . . 85 dionasa (Eueides). . . . . . . 232 diotreplies (Heliconia) . . . . . 106 diotrephes (Heliconius) . . . . . 106 diotreplies (Heliconius cydno) . . . 106 discomaculatus (Heliconius) . . . . 98 discomaculatus (Helicouius clara) . . 98 dismorphia (Blanchardia) . . . . 139 dissoluta (Eueides isabella) . . . . 237 dissolutus (Eueides isabella) . . 237 distincta (Heliconius) . . . . . . . 42 divisus (Heliconius antiochus aberr.) 180 Doridiformes. . . . . . . 160 doris aberr. thetis (Heliconius) . . . 145 doris aristomache (Heliconius) . $16 \%$ doris caerulea (Heliconius) . . . . 162 doris delila (Heliconius) . . . . . 162 doris doris (Heliconius). . . . 162 doris forma delila (Heliconius) . . . 162 doris (Heliconia) . . . . . . . 162 doris (Heliconius) . . . . . . 161 doris (Heliconius) . . . . . . . . 162 doris (Heliconius doris) . . . . 164 doris (Heliconius elato) . . . . . 162 doris (Heliconius erato aberr.) . . . 162 doris (Heliconius erato var.) . . 162, 166 doris (Laparus) . . . . . . . . 162 dolis (Papilio) . . . . . . . . . 162 doris (Papilio (Heliconius)) . . . 162 doris (Sicyonia) . . . . . . . . . . 162 doris transiens (Heliconius) . . 165 doris var. delila (Heliconius) . . . . 162 doris var, erato (Heliconius) . . . 162 doris viridis (Heliconius) . . . 160 dryalus (Heliconius). . . . . . . 51 dryope (Heliconius phyllis) . . . . 202 dryope (Heliconius phyllis aberr.) . 202 dynastes (Eueides) . . . . . . . 239 eanes aberr. aides (Eueides) . . . . 270 eanes aberr. eanides (Eueides) . . . 270 eanes aberr. farragosa (Eueides) . . 270 eanes aberr. felderi (Eueides). . . . 271 eanes aberr. pluto (Eueides) . . . . 271 eanes aber'. riffarthi (Eneides) . . . 271 eanes eanes (Eueides) . . . . . 269 eanes eanides (Eueides) . . . 270 eanes (Eueides). . . . . . . . 268 eanes (Eueides). . . . . . . . . . 269 eanes (Fueides eanes). . . . . . 269 eanes felderi (Eueides) . . . . . 271 eanes riffarthi (Eueides) . . . . 271 eanides (Eueides eanes). . . . . 270 eanides (Eueides eanes aberr.) . . . 270 edias edias (Eueides) . . . . . . 249 edias (Eueides) . . . . . . . . . 248 edias (Eueides) . . . . . . . . . . $2 \pm 9$ edias (Eueides edias) . . . . . . 249 edias (Eurides) . . . . . . . . . . 249 edias eurysaces (Eueides) . . . . 251 edias luminosus (Eueides). . . . 250 edias typicus (Eueides) . . . . . 249 edias vulgiformis (Eueides) . . . 251 
egeria astraea (Heliconius) . . . 156 egeria egeria (Heliconius) . . . . 15j egeria egerides (Heliconius) . . 155) egeria (Heliconius) . . . . . . . 154 egeria (Helicouius) . . . . . . . 155 egeria (Heliconius egeria). . . . 15\% egeria hyas (Heliconius) . . . 156 'geria (Pupilio). . . . . . . . 155 egeria var. astraea (Heliconius). . . 156 egeria var. egerides (Helicouius) . . 155 egerides (Heliconius egeria). . . 15\% egerides (Heliconius egeria var.) . 15is Egeriformes . . . . . . . 151 Fieides . . . . . . . . . . 224 Eisides 1. . . . . . . . . . 289 elegans (Heliconius). . . . . . . . 78 elegans (Heliconius aristiona) . . . 78 eleuchia (Heliconia)....... 176 eleuchia (Heliconius) . . . . . . 176 eleuchia (Heliconius sapho) . . . 176 eleuchia (Heliconius sappho) . . . 176 eleusinus (Heliconius) . . . . . . 175 eleusinus (Heliconius sapho) . . 175 eleusinus (Heliconius sappho) . . . 175 elevatus (Heliconius) . . . . . . 120 elevatus (Heliconius melpomene) 120 elimaea (Heliconia) . . . . . . . 202 elimaea (Heliconius melpomene var.) 202 elimaea (Heliconius phyllis) . . . 202 elsa (Heliconius clytia) . . . . . 169 elsa (Heliconius clytia var.) . . . . 169 emma (Heliconius phyllis). . . . 205 emmelina (Heliconia) . . . . . . 148 ennius (Heliconius) . . . . . . . 89 ennius nigrofasciatus (Heliconius). . 89 ennius var. nigrofasciatus (Heliconius) 89 epicydnides (Heliconius cydno) . . . 103 epicydnides (Heliconius cydno var.) . 103 Epimetes . . . . . . . . . 224 Epinetes . . . . . . . . . . 224 epiphyllis (Heliconius). . . . . . . 135 erato aber.. amathusia (Heliconius) . 162 erato aberr. doris (Heliconius) . . . 162 erato aberr. metharmina (Heliconius) 162 erato aber'r. tecta (Heliconius) . . . 162 erato umathusia (Heliconius) . . . 162 erato amazona (Heliconius) . . . 201 erato anacreon (Heliconius) . . . 210 erato anactorie (Heliconius) . . . 207 erato bouqueti (Heliconius) . . . 207 erato callycopis (Heliconius) . . 202 erato cybelinus (Heliconius) . . 201 erato demeter (Heliconius) . . . 206 erato doris (Heliconius) . . . . . . 162 erato erato (Heliconius) . . . . 198 erato eratonius (Heliconius) . . . . 165 erato estrella (Heliconius) . . . 205 crato forma audremona (Heliconius) 198 erato forma eybele (Heliconius) . . 111 erato forma deinia (Heliconius) . . 114 erato forma eryturaea (Heliconius) . 198 erato forma fuuebris (Heliconius). . 114 (rato forma palantia (Heliconius) . . 202 crato formu rubra (Heliconius) . . . 162 erato formu thelxiope (Heliconius) . 117 Eratoformes . . . . . . . 187 erato,(Heliconia) . . . . . . . . 162 erato (Heliconius) . 145, 162, 165, 165, 198 erato (Heliconius) . . . . . . 197 erato (Heliconius doris var.) . . . . 162 erato (Heliconius erato) . . . . 198 erato lativitta (Heliconius) . . . 207 erato luminosus (Heliconius). . . . 165 erato magnificus (Heliconius) . . 204 erato metharmina (Heliconius) . . . 162 erato (Migonitis) . . . . . . 198.201 eratonius (Heliconius erato) . . . 1 $16 i$ eratonius (Heliconius erato var.) . . $\mathbf{1 6 5}$ erato obertliüri (Heliconius) . . . . 198 erato obscurus (Heliconius) . . . . 165 erato (Papilio) . . . . . . . 162, 198 erato (Papilio (Heliconius)) . . . . 198 erato phyllis (Heliconius) . . . . 208 erito tecta (Heliconius) . . . . . 162 erato tellus (Heliconius) . . . . . 198 erato transiens (Heliconius) . . . 16i eruto var. doris (Heliconius) . . 162, 166 erato var. eratonius (Heliconius) . . I65 erato var. mars (Heliconius) . . . 162 erato var. obscurus (Heliconius) . . 165 erato var. transiens (Heliconius) . . 165 erato var. viridis (Heliconius) . . . 165 erato viridis (Heliconius) . . . . 16i) erebiu (Heliconius melpomene). . . 127 erebia (Heliconius timareta aberr.) . 127 erebius (Heliconius melpomene) . 127 ergatis (Heliconia) . . . . . 155 erythraea (Heliconia) . . . . . . . 198 erythruea (Heliconius) . . . . . . . 198 erythraea (Heliconius erato forma) . 198 erythraea (Heliconius melpomene var.) 198 crythraea (Heliconius phỵllis) . . . 198 erythrea (Heliconius) . . . . . . 198 erythrea (Migonitis). . . . . . 198 erythrea (Papilio) . . . . . . . 198 estrella (Heliconius) . . . . . . . 205 estrella (Heliconius erato) . . . 205 estrella (Heliconius phyllis) . . . . 205 estrella (Helicouius vesta forma) . . 205 ethilla aërotome (Heliconius) . . $\quad$ (i0 ethilla cephallenia (Heliconius) . 60 ethilla claudia (Heliconius) . . . 59 ethilla ethilla (Heliconius) . . . 55 ethilla eucomus (Heliconius) . . 5t; 
ethilla (Helicouia) . . . . . . . 55

ethilla (Heliconius) . . . . . . 54

ethilla (Heliconius) . . . . . . . . 55

ethilla (Heliconius ethilla) . . . 55

ethilla juntanus (Heliconius) . . 59

ethilla mentor (Heliconius) . . . 58

ethilla metalilis (Heliconius) . . 58

ethilla numismaticus (Heliconius) 58

ethilla semiflavidus (Heliconius) . 59

ethilla tyndarus (Heliconius) . . 57

etholéa (Heliconius) . . . . . . 95

ethra (Eueides) . . . . . . . . . 54

ethra (Heliconia) . . . . . . . 54

ethra (Heliconius silvana) . . . 54

etylus (Heliconius) . . . . . . 205

etylus (Heliconius phyllis). . . . 205

euclea (Heliconia) . . . . . . . 101

euclea (Heliconius) . . . . . . . 101

eucoma aerotome (Heliconius) . . . 60

eucoma cephallenia (Heliconius) . . 60

eucoma claudia (Heliconius) . . . . 59

eucoma (Eueides) . . . . . . . 56

encoma flavidus (Heliconius) . . . 55

eucoma flavofasciatus (Heliconius) . 56

eucoma (Heliconia) . . . . . . 56

eucoma (Heliconius). . . . . . . 56

eucoma juntana (Heliconius) . . . . 59

encoma mentor (Heliconius) . . . 58

eucoma metalilis (Heliconius) . . . 58

eucoma numismaticus (Heliconius) . 58

eucoma semiflavidus (Heliconius) . . 59

eucoma tyndarus (Heliconius) . . . 57

eucoma var. daguanus (Heliconius) . $\quad 59$

eucoma var.flavofasciatus (Heliconjus) 56

eucoma var, numismaticus (Heliconius) 58

eucoma var. pardalinus (Heliconius) 84

eucomus (Heliconius ethilla) . . 56

eucrate (Heliconia) . . . . . 40

eucrate (Heliconias) . . . . . . . 40

eucrate (Heliconius) . . . . . . . 40

eucrate (Mechanites) . . . . . . . 40

eucrate (Mechanitis) . . . . . . . 40

eucrate var. iufuseata (Heliconius) . 40

eucrato (Heliconia) . . . . . . . 40

Eueides . . . . . . . . . 2

Eueides. . . . . . . . . . 224

eulalia (Heliconius melpomene) . 123

eulalia (Heliconius melpomene aberr.) 123

euphone (Heliconius) . . . . . . . 76

euphone (Heliconius aristiona) . 76

euphrasius (Heliconius) . . . . . 75

euphrasius (Heliconius aristiona) 75

Eurides . . . . . . . . . . 224

euryades (Heliconius amaryllis) 129

emryades (Heliconius amaryllis rar.) . 129

emryas (Heliconia) . . . . . . 130

euryas (Heliconius) . . . . . . . 130 euryas (Heliconius amaryllis) . . . . 130

eurysaces (Wileides) . . . . . . . 251

eurysaces (Fueides edias) . . . 251

Eveides . . . . . . . . . 224

Evides . . . . . . . . . . . . 289

farragosa (Eueides eanes aberr.) . . 270

fasciatus (Heliconius) . . . . . . . 42

fasciatus (Heliconius ismenius) . 12

fauuus (Heliconius) . . . . . . . . 43

faunus (Heliconius ismenius) . . 43

faunus (Heliconius metaphorus var.) 13

faustina (Heliconius) . . . . . . . 114

faustina (Heliconius melpomene) . . 114

favorinus (Heliconius). . . . . . 191

felderi (Eueides eanes) ... . \& . 271

felderi (Eueides eanes aberr.) . . . 271

felix (Heliconius) . . . . . . . . 92

felix (Heliconius quitalena) . . . . 92

felix (Heliconius quitalenus) . . 92

felix var. concors (Heliconius) . . . 92

flavescens (Heliconius clytia) . . . . 171

flavescens (Heliconius clytia var.) . 171

flavidus (Heliconius eucoma) . . . . 55

flavidus (Heliconius metalilis rar.) . 55

flavofasciatus (Heliconius eucoma) . $\quad 56$

flavofasciatus (Heliconius eucoma var.) 56

flavomaculatus (Heliconius narcaea). 40

flavomaculatus (Heliconius narcaea var.) 40

floridus (Heliconius). . . . . . 78

floridus (Heliconius aristiona) . . 78

formosus (Héliconius) . . . . . . . 142

formosus (Heliconius hecalesia) 142

fornarina (Heliconia) . . . . . . 100

fornarina (Heliconius) . . . . . . 100

fornarina (Heliconius anderida) 100

for'narina (Heliconius clara) . . . . 100

fortunatus fortunatus (Heliconius) 87

fortunatus (Heliconius) . . . . . 86

fortunatus (Heliconius) . . . . . . 87

fortunatus (Heliconius fortunatus) 87

fortunatus spurius (Heliconius) . 87

fritschei (Heliconius) . . . . . . . 42

fruhstorferi (Heliconius) . . . 218

fuliginosa (Eueides lampeto aberr.) . 246

fuliginosus (Eueides lampeto) . . 246

funebris (Heliconius) . . . . . . . 114

funebris (Heliconius erato forma) . 114

funebris (Heliconius melpomene) 114

gaea (Heliconius) . . . . . . . . 114

galanthus (Heliconius). . . . . . 106

galanthus (Heliconius cydno) . . 106

geminatus (Heliconius) . . . . . . 49

geminatus (Heliconius numata) . . . 49

godmani (Heliconius) . . . . . . 115

gordius (Heliconius). . . . . . . ty

gordius (Heliconius numata) . . . . 49

gordius (Heliconius numatus) . . 49 
Seite

gracilis (Eueides aliphera) . . . 262 gradatus gradatus (Heliconius) . 62 gradatus (Heliconius) . . . . . 61 grarlatus (Heliconius) . . . . . . 62, 62 gradatus (Heliconius gradatus) . 62 gradatus thielei (Heliconius) . . $1 ; 2$ guarica (Heliconius) . . . . . . 195 guriea (Heliconius hydara) . . . . 195 guarica (Heliconius liydarus) . . 195 guayana (Heliconius) . . . . . . 195 guiensis (Heliconius numata) . . . . 46 gustavi (Heliconius cydno) . . . . . 107 gustavi (Heliconius weymeri aberr.) . 107 gyıraesia (Heliconia) . . . . . . . 112 gyuraesia (Heliconius) . . . . . . . 142 gynuesia (Heliconius hecalesia) . . . 142 gynaesius (Heliconius hecalesia) 142 haenschi (Heliconius cydno) . . . . 104 haenschi (Heliconius cydno aberr.) . 104 hagar (Heliconius) . . . . . . 171 hahneli (Heliconius) . . . . . . . . 105 hahneli (Heliconius cydno) . . . 105 liecale (Ajantis). . . . . . . . 70 lecale (Heliconia) . . . . . . . 70 hecale (Heliconius) . . . . . 70 hecalc (Papilio). . . . . . . . . 70 hecalesia formosus (Heliconius) . 142 hecalcsia gynaesia (Heliconius) . . . 142 hecalesia gynaesius (Feliconius) 142 hecalesia hecalesia (Heliconius) 141 hecalesia (Heliconia) . . . . . . 141 hecalesia (Heliconius). . . . . 140 hecalesia (Heliconius) . . . . . 141, 142 hecalesia (Heliconius hecalesia) 141 Hecalesiformes . . . . . . 137 hecuba (Heliconia) . . . . . . . 138 hecuba (Heliconius) . . . . . 138 Heliconia . . . . . . . . . . . 2, 224

Heliconias . . . . . . . . . . . 2

Heliconidae . . . . . . . . 1

Heliconidi... . . . . . . 1

Heliconidae........ 1

Heliconiinae........ 1

Heliconina... . . . . . . . 1

Heliconinae. . . . . . . . 1

heliconioides aberr. xenophanes (Eueides) .

heliconioides (Eueides) . . . . . 267

helieonioides (Eucides) . . . . . . 268

heliconioides (Eueides heliconisides) . . . . . . . . . . . 268

heliconioides heliconioides (Eueides) . . . . . . . . . 268

heliconioides zenoplianes (Eueides) . . . . . . . . 268

Heliconius . . . . . . . . . 2

Heliconius . . . . . . . . . 224 heraldicus (Eueides thales). . . . 266

hermanni (Heliconius ismenius) . $\quad 13$

lermunni (Heliconius ismenius var.) . I:3

hermathenn (Heliennia) . . . . . 212

hermathena (Heliconius) . . . . 212

liermogenes (Helieonia) . . . . 105)

hermogenes (lleliconius) . . . . 105

hermogenes (Heliconius cydno) . 10:)

heurippa (Heliconia) . . . . . . 110

hourippa (Heliconius) . . . . 110

hewitsoni (Heliconia) . . . . . 176

howitsoni (Heliconius) . . . . 17f;

hierax (Heliconia) . . . . . . 167

hierax (Heliconius) . . . . . 167

himela (Heliconia) . . . . . . 187

himera (Heliconius) . . . . 187

hippola (Heliconia). . . . . . . 15

hippola (Heliconius) . . . . . 14

hippola (Heliconius) . . . . . . 45

hippola (Heliconius hippola) . . 4i

hippola hippola (Heliconius) . . 45

hippola lyrcaeus (Heliconius). . 4h

hippolinus aberr. brunnea (Eueides isabella) . . . . . . . . 236

hippolinus aberr. margaritifera

(Eueides isabella aberr.) . . . . 236

hippolinus aberr. personata (Eueides

isabella) . . . . . . . . 2:36

hippolinus (Eucides) . . . . . . 236;

hippolinus (Eueides isabella) . . $236^{\circ}$

hippolyte (Heliconius melpomene) . 116

hippolyte (Heliconius melpomene var.) 116

holcophorus (Heliconius clara) . . . 97

holcophorus (Heliconius semiphorns

aberr.) . . . . . . . . 9 97

hortense (Heliconia) . . . . . . 221

hortense (Heliconius) . . . . . 221

lortensia (Heliconia) . . . . . . . 221

hortensia (Heliconius) . . . . . . . 221

hübneri aberr. spoliata (Eneides isabella)

hiibneri (Eueides) . . . . . . . . . 239

hübneri (Eueides isabella) . . . 239

huebneri (Heliconius burneyi) . 159

huebneri (Heliconius burneyi var.) . 150

hyas (Heliconius) . . . . . . . 156

hyas (Heliconius egeria) . . . 156

hydara aberr. nocturna (Heliconius) , 196

hydara antigona (Heliconius) . . . 196

hydara chestertonii (Heliconius) . . 1!(6;

liydara colombina (Ileliconius) . . 195

hydara guarica (Holiconius) . . . 19:

liydara (Heliconia) . . . . . . . 194

hydara (Heliconius). . . . . . . . 194

liydara noeturna (Heliconius) . . . 196

hydara var. antigona (Heliconius) . 196;

hydarus antigona (Heliconius) . 19(j 


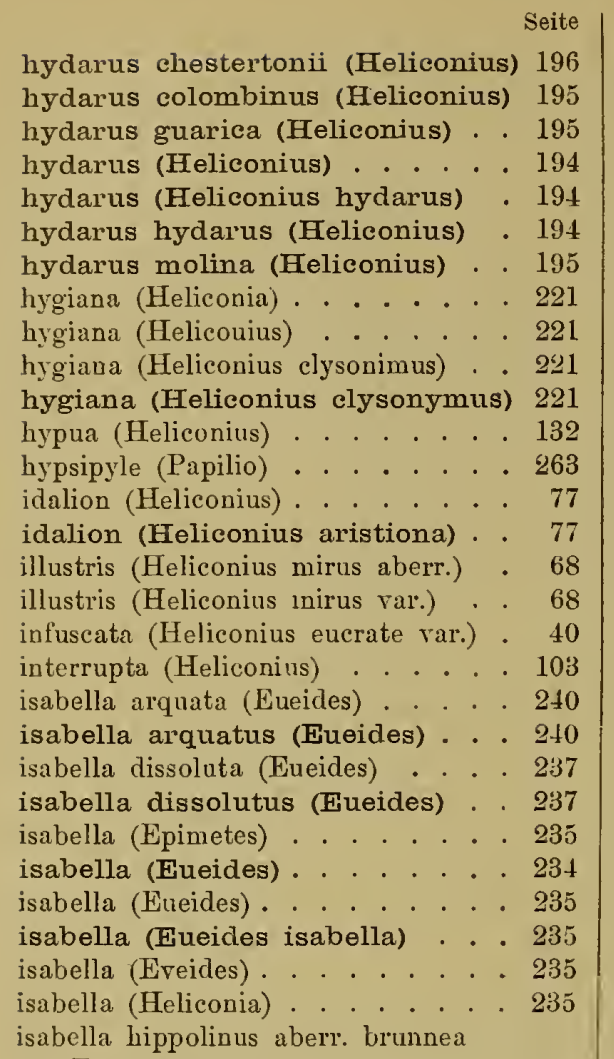

(Eueides) . . . . . . . 236 isabella hippolinus aberr. margariti-

fera (Eueides) . . . . . . isabella hippolinus aberr. personata

(Eueides) . . . . . . . 236 isabella hippolinus (Eueides) . . 236 isabella hübneri abert. spoliata

(Eueides) . . . . . . . . . 239

isabella hübneri (Eueides) . . 239 isabella isabella (Eueides) . . . 235 isabella (Papilio) . . . . . . . 235 isabella pellucida aberr. vegetissima

(Eueides) . . . . . . . . 238 isabella pellucida (Eueides) . . . 238 isabella pellucidus (Eueides) . . 238 isabella seitzi (Eueides) . . . . 237 isabella typica (Eueides). . . . . 235 isabella var. dianasa (Eueides) . . . 232 isabelliuus (Heliconius aurora var.) . 48 isabellinus (Heliconius numata). . 48 isabellinus (Heliconius numata var.) 48 isabellinus (Heliconius numatus) 48 isaea (Heliconius) . . . . . . . 155 isaea (Migonitis) . . . . . 155 ismenia (Heliconia) . . . . . . . 42 ismenius clarescens (Heliconius) 44 ismenius faseiatus (Heliconius) . 42 ismenius faunus (Heliconius) . . 43 ismenius (Heliconius) . . . . . . 41 ismenius (Heliconius) . . . . . . 12 ismenius (Heliconius ismenius) . 42 ismenius hermanni (Heliconius). 43 ismenius ismenius (Heliconius) . 42 ismenius telchinia (Heliconius) . 43 ismenius var. hermanni (Heliconius) 43 ithaka (Heliconius) . . . . . 80 ithaka (Heliconius) . . . . . . 81 ithaka (Heliconius ithaka) . . . 81 ithaka ithaka (Heliconius) . . 81 ithaka marius (Heliconius) . . . 82 ithaka vittatus (Heliconius) . . . 82 jonas (Heliconius) . . . . . . . . 93 jonas (Heliconius quitalena) . . . 93 jucundus (Heliconius) . . . . . . 98 jucundus (Heliconius clara) . . . . 98 jucundus (Heliconius zuleika var.) . 98 jucundus var. xanthicus (Heliconius) 98 judith (Heliconius) . . . . . . . . 119 juno (Heliconius eyrbia) . . . 191 juno (Heliconius cyrbia rar.) . . . 191 juntana (Heliconius eucoma) . . . . 59 juntanus (Heliconius ethilla) . $\quad 59$ justina (Heliconius) . . . . . . . . . 114 karschi (Heliconius melpomene) . . 112 karschi (Heliconius melpomene aberr.) 112 künowii (Eueides) . . . . . . . 249 lampeto aberr. acacates (Eneides) . 247 lampeto a berr. amoena (Eueides) . . 246 lampeto aberr. carbo (Eueides) . . 246 lampeto aberr. fuliginosa (Eueides) . 246 lampeto acacates (Eueides) . . 247 lampeto (Eueides). . . . . . 245 lampeto (Eueides) . . . . . . . 246 lampeto (Eueides lampeto) . . 246 Lampetoformes . . . . . . 244 lampeto fuliginosus (Eueides) . . 246 lampeto lampeto (Eueides) . . 246 lampeto typicus (Eueides) . . . . . 246 Laparus . . . . . . . . . 2 lativitta (Heliconius) . . . . 207 lativitta (Heliconius erato) . . 207 lativitta (Heliconius phyllis) . . . . 207 latus (Heliconius paraensis). . . 64 leda (Heliconius phyllis). . . . 198 leda (Heliconius vesta aberr.) . . . 198 lenaeus (Heliconius) . . . . . . . 77 lenaeus (Heliconius aristiona). . 77 leopardus (Heliconius). . . . . 68 leopardus (Heliconius inirus forma). 68 leopardus (Hcliconius noratus) . . . 68 leucadia (Heliconius) . . . . . 181 leucadia (Heliconius) . . . . . . 182 leucadia (Heliconius leucadia). . 182 leucadia leucadia (Heliconius). . 182 
leucadia pseudorhea (Heliconius) 182 leuce (Heliconia) . . . . . . . 174 leuce (Heliconius) . . . . . . . . 174 leuce (Heliconius sapho) . . . 174 leuce (Heliconius sappho) . . . . 174 leucomma (Eueides). . . . . . 263 libitina (Kueides) . . . . . . 260 libitina (Eueides lineatil). . . . 260 libitina (Eueides lineatus) . . . 260 lindigii (Heliconius) . . . . . . 160 lindigii (Heliconius burneyi) . . 160 lineata (Eueides) . . . . . . 259 lineata libitina (Eueirles). . . . . 260 lineata typica (Eueides) . . . . . . 259 lineatus (Eueides) . . . . . 258 lineatus (Eueides lineatus) . . . 259 lineatus libitina (Eueides). . . 260 lineatus lineatus (Fueides) . . . 259 locris (Heliconius) . . . . . . . 208 longarena (Heliconia) . . . . . 143 longarena (Heliconius). . . . . 143 longarenus (Heliconius) . . . . 143 lucescens (Heliconius pardalinus) 84 luceseens (Heliconius pardalinus var:) $8 \pm$ lucia (Heliconia) . . . . . . . 112 lucia (Heliconius) . . . . . . . 112 lucia (Heliconius melpomene) . . . 112 lucia (Heliconius melpomene var.) . 112 lucia (Papilio) . . . . . . . 112 lucia (Sunias) . . . . . . . . 112 lucinda (Heliconius melpomene) . . 112 lucinda (Heliconins melpomene var.) 112 lueretius (Heliconius) . . . . . 148 lucretius (Heliconius aoede) . . 148 lucretius (Heliconius bartletti forma) 148 luminosus (Eueides edias) . . 250 luminosus (Heliconius erato). . . 165 lybia (Cethosia) . . . . . . . 262 lybia (Colaenis). . . . . . . 262 lybia (Eueides) . . . . . . 262 lybia (Eueides) . . . . . . . . 262 lybia (Eueides lybia) . . . . 262 lybia lybia (Eueides) . . . . 262 lybia lybioides (Eueides) . . . 263 lybia (Papilio) . . . . . . . . . 262 lybia typica (Eueides) . . . . . 263 Lybiiformes . . . . . . 260 lybioides (Eueides) . . . . . . 2633 lybioides (Eueides lybia) . . . 263 lyreaeus (Heliconius) . . . . . . 45 lyreaeus (Heliconius hippola). . 45

Macroscenae . . . . . . 231 maecenas (Heliconius numata var.) . 49 Inaeon (Heliconius) . . . . . 85 maeon (Heliconius pardalinus) . 85; inagdalena aberr. albimaculata (Heliconius apseudes valr.). . . . . magdalena (Heliconius) . . . 183 magdalena (Heliconius apseudes rar.) 183 magdalena (Heliconius rhea var.). . 183 Inagnifiea (Heliconius phyllis) . . . 204 magnifica (Heliconius phyllis var.) . 204 magnificus (Heliconius erato). . $2(1) 4$ margurita (Heliconius melpomene) . 19.4 margarita (Heliconius. melponene aberr.) 124 margaritifera (Eueicles isabella hippo-

linus aberr.). . . . . . 236 marius (Heliconius) . . . . . 82 marius (Heliconius ithaka) . . 82 mars (Heliconius erato rar.) . . . . 162 marors (Heliconius numata) . . . 18 mavors (Heliconius numatus) . 48 mavors (Heliconius superioris var.) • 48 Jechanites . . . . . . . 2 Mechanitis . . . . . . 2, 162, 208 melanippe (Heliconius melponene) . 118 inelanippe(Heliconius melpomene var 118 melanops (Heliconius nuniata) . . 46 melanops (Heliconius numata var.) . $\$ 48$ melete (Heliconius) . . . . . . 152 melete (Heliconius xanthocles) . 152 melicerta (Heliconius) . . . . . 95 melicerta (Heliconius anderida). 95 Melinaea . . . . . . . . . 2 melior (Heliconius) . . . . . . 15is melior (Keliconius xanthocles) . 153 melittus (Heliconius) . . . . 153 melittus (Heliconius xanthocles) $1: 33$ melpemone (Papilio) . . . . . . 111 melpomene aberr. atrosecta (Heliconius) . . . . . . . . 112 melpomene aberr. diana (Heliconius) 114 melpomene aberr. eulalia (Heliconius) 12:3 melpomene aberr. karschi (Heliconius) 112 melpomene aberr. inargarita (Heliconius) . . . . . . . 124 melpomene aberr. melpomenides (Helicouius) . . . . . . . 112 melpomene aberr. mirabilis (Heliconius) . . . . . . . 121 melpomene aberr. pelopeia (Heliconius) . . . . . . . . 124 melpomene aberr. peuelopeia (Heliconius) ......... 124 melpomene aglaope (Heliconius) . . 120 melpomene aglaope (Heliconius) 121 melpomene aglaopeia (Helicouius) . 119 melpomene amandus (Heliconius) 127 melpomene amor (Heliconius) . . . 122 melpomene aphrodyte(Heliconius) 114 melpomene atrosecta (Helieonius) . . 112 melpomene augusta (Heliconins) . . 11! 183 melpomene bari (Heliconius) . 120 
melpomene contiguus (Heliconius) , 125 melpomene cybele (Heliconius) . . . 114 melpomene deinia (Heliconius) . . 114 melpomene diana (Heliconius) . . . 114 melpomene elevatus (Heliconius) 120 melpomene erebia (Heliconius) . . . 127 melpomene erebius (Heliconius) 127 melpomene eulalia (Heliconius) . 123 melpomene faustina (Heliconius) . . 114 Melpomeneformes . . . . . 109 melpomene funebris (Heliconius) 114 melpomene (Heliconia) . . . . 111, 202 melpomene (Heliconius) . . . . 110 melpomene (Heliconius) . . 111, 130, 194 melpomene (Heliconius melpo-

mene) . . . . . . . . . 111 melpomene hippolyte (Heliconius) . 116 melpomene karschi (Heliconius) . . 112 melpomene (Japarus) . . . . . . . 111 melpomene lucia (Heliconius) . . . 112 melpomene lucinda (Heliconius) . . 112 melpomene margarita (Heliconius) . 124 melpomene melanippe (Heliconius) . 118 melpomene melpomene (Heli-

conius). . . . . . . . . 111 melpomenemelpomenides (Heliconius) 112 melpomene mirabilis (Heliconius) . . 122 inelpomene (Papilio) . . . . . 111, 202 melpomene (Papilio (Heliconius)) . . 111 melpomene penelamanda (Heliconius) 124 melpomene penelope (Heliconius) 124 melpomene penelopeia (Heliconius) - 124 melpomene (Phlogris) . . . . . . . 111 melpomene pluto (Heliconius) . . . 124 melpomene richardi (Heliconius) . . 125 inelpomene rufolimbatus (Heliconius) 122 melpomene (Sunias) . . . . . . . 112 melpomene thelxiope (Heliconius) 117 melpomene thelxiopeia (Heli-

conius) . . . . . . . . . . 118 melpomene timareta aberr. contiguus

(Heliconius) . . . . . . . . . 125 melpomene timareta aberr. richardi

(Heliconius) . . . . . . . 125 melpomene timareta aberr. virgata

(Heliconius) . . . . . . . . 125 melpomene timareta (Heliconius) 125 melpomene tyche (Heiiconius) . 116 melpomene unimaculata (Heliconius) 122 melpomene var. andremona (Heli-

conius) . . . . . . . . . 198 melpomene var. augusta (Heliconius) 118 melpomene var. callicopis (Heliconius) 202 melpomene var. callycopis (Heliconius) 202 melpomene rar. cybele (Heliconius) 114 melpomene var. elimaea (Heliconius) 202 melpomene var. erythraea (Heliconius) 198 melpomene var. hippolyte (Heliconius) 116 melpomene var, lucia (Heliconius) . 112 melpomene var. lucinda (Heliconius) 112 melpomene var.melanippe(Heliconius) 118 melpomene var. tyche (Heliconius) . 116 melpomene var. udalica (Heliconius) 198 melpomene riciua (Heliconius) . . . 122 melpomene vicinus (Heliconius). 122 melpomenides (Heliconius mel pomene) 112 melpomenides (Heliconius melpomene aberr.) . . . . . . . . . 112 mentor (Heliconius) . . . . . . 58 mentor (Heliconius ethilla) . . 58 mentor (Heliconius eucoma) . . . 58 mereaui (Colaenis) . . . . . . . $25 t$ mereaui (Eueides). . . . . . . 254 mereaui var. (Semelia) . . . . . 254 messene (Heliconius) . . . . . . 75 messene (Heliconius aristiona) . 75 metabilis (Heliconia) . . . . . . 58 metabilis (Heliconius) . . . . . 58 metalilis (Heliconia) . . . . . . 58 metalilis (Heliconius) . . . . . 58 metalilis (Heliconius ethilla) . . 58 metalilis (Heliconius eucoma) . . 58 metalilis rar. flavidus (Heliconius) . 55 metalilis rar. semiflavidus (Heliconius) 59 metaphorus (Heliconius) . . . . . 53 metaphorus (Heliconius silvana) 53 metaphorus var. faunus (Heliconius) 43 metaphorus var. semiphorus (Heli-

conius) . . . . . . . . 97 metellus (Heliconius) . . . . . . 68 metellus (Heliconius vetustus) , 68 methame (Heliconius) . . . . . 145 metharme (Heliconia) . . . . . . 145 metharme (Heliconius) , . . . 145 metharmina (Heliconius erato) . . . 162 metharmina (Heliconius erato aberr.) 162 mexicana (Heliconia) . . . . . 193 mexicana (Heliconius) . . . . . . 193 Migonitis . . . . . . . . . . 2, 224 milesia (Heliconius) . . . . . . . 119 mimulinus (Heliconius) . . . . . 170 mimulinus (Heliconius clytia) . . 170 mimulinus (Heliconius wallacei) 170 mirabilis (Heliconius melpomene) . . 122 mirabilis (Heliconius melpomene

aberr.) . . . . . . . . . . 121 mirus aber'r. illustris (Heliconius) . . 68 mirus forma leopardus (Helicouius) . $\quad 68$ mirus (Heliconius) . . . . . . . 68 mirus (Heliconius noratus). . . . 68 mirus var. illustris (Heliconius). . . 68 modesta (Heliconius vulcanus aberr.) 132 modestus (Heliconius vulcanus). . . 132 molina (Heliconius) . . . . . . . 195 
molina (Heliconius Lydarus) . . 19; montanus (Heliconius) . . . . . . 220 montanus (Heliconius clysonimus) . 220 montanus (Heliconius clysonymus) 220 mutabilis (Heliconius) . . . . . 114 mutabilis (Heliconius thelxiope var.) 114 myrti (Papilio) . . . . . . . . 243 nanna (Heliconius) . . . . . . 134 uarcaea flavomaculatus (Heliconius) . 10 narcaea (Heliconia). . . . . . 40 narcaea (Heliconius) . . . . . . 39 narcaea (Heliconius). . . . . . . . 40 narcaea (Heliconius narcaea) . . 40 narcaea narcaea (Heliconius) . . 40 narcaea polychrous (Heliconius) 41 narcaea satis (Heliconius) . . . . . 40 narcaea var. flavomaculatus (Heliconius) . . . . . . . . . . . . narcaea var. polychrous (Heliconius) narcaea var. satis (Heliconins) . . . narcea (Heliconia) . . . . . . . . nattereri (Heliconius) . . . . . . 217 nattereri (Heliconius) . . . . . . . 218 nigrofasciatus (Heliconius ennius) . . 89 uigrofasciatus (Helicouius ennius var.) 89 nocturna (Heliconius hydara) . . . 196 nocturna (Heliconius hydara aberr.) 196 notabilis (Heliconius) . . . . . . . 189 notabilis (Heliconius xenoclea) . 189 novatus (Heliconius) . . . . . . 68 noratus leopardus (Heliconius) . . 68 novatus mirus (Heliconius) . . . . . 68 nubifer (Heliconius) . . . . . . . 50 nubifer (Heliconius numata) . . . 50 nubifer (Heliconius numatus) . . 50 numata geminatus (Heliconius). . . 49 numata gordius (Heliconius) . . . . 49 numata guiensis (Heliconius) . . . . 46 numata (Heliconia) . . . . . . 46 numata (Heliconius) . . . . . . . . $46^{\circ}$ numata isabellinus (Heliconius) . . . 48 numata navors (Heliconius) . . . . 48 numata melanops (Heliconius) . . . 46 numata nubifer (Heliconius) . . . . 50 numata (Papilio) . . . . . . . . . 46 numata superioris (Heliconius) . . . 49 numata var. isabellinus (Helicouius) 48 uumata var. maecenas (Heliconius) . 49 numata rar. melanops (Heliconius) . 46 numatus gordius (Heliconius) . . 49 numatus (Heliconius) . . . . . 45 numatus (Heliconius numatus) . 46 numatus isabellinus (Heliconius) 48 numatus mavors (Heliconius). . 48 numatus nubifer (Heliconius) . . 50 numatus numatus (Heliconius) . 46 numatus superioris (Heliconius) numismaticus (Heliconius ethilla) 58 numismaticus (Heliconins eucoma) . 58 numismaticus (Ilelienuius eucoma var.) 58 oberthüri (Heliconius crato) . . . 198 olscurus (Heliconius) . . . . . . 165 obscurus (Heliconius erato) . . 165 obscurus (Heliconius erato var.) . . 165 ocania (Heliconius) . . . . . . 53 ocanna (Heliconius) . . . . . . . 53 ocannensis (Heliconius antiochus) 181 (cannus (Heliconius) . . . . . . 181 ocannus (Heliconius antiochus) . . 181 octavia (Heliconius). . . . . 143 olede (Heliconius) . . . . . . . 152 olympia (Eueides). . . . . . 263 olympia (Heliconia) . . . . . . 263 olympia (Papilio). . . . . . . 263 Opisogymi . . . . . . . . . 38 Opisorhypari . . . . . . . 137 ottonis (Heliconius phyllis) . . . . 210 ottonis (Heliconius phyllis aberr.) . 210 pachinus (Heliconia) . . . . . . 108 pachinus (Heliconius) . . . . . 108 pichynus (Heliconius) . . . . . . 108 palantes (Heliconius) . . . . . 202 palantia (Heliconius erato forma). . 202 pallens (Eucides ribilia abcr.) . . . 254 Papilio . . . . . . . . . . . . . 2, 224 paraensis (Heliconius) . . . . 63 paraensis (Heliconius) . . . . . . 61 paraensis (Heliconius paraensis) 64 paraensis latus (Heliconius). . . 64 paraensis paraensis (Heliconius) 64 paranapurae (Heliconius apseudesvar.) 177 paraplesius forma valia (Heliconius) 151 paraplesius (Heliconius) . . . . . 152 paraplesius (Heliconius xan- 152 thocles) . . . . . . . . . 152 pardalinus dilatus (Heliconius). . 85 pardalinus (Heliconius) . . . . 82 pardalinus (Heliconius) . . . . . 84 pardalinus (Heliconius eucoma var.) 84 pardalinus(Heliconius pardalinus) 84 pardalinus lucescens (Heliconius) 84 pardalinus maeon (Heliconius) . 85 pardalinuspardalinus(Heliconius) 81 pardalinus radiosus (Heliconius) 85 pardalinus tithoreides(Heliconius) 86 pardalinus var. lucescens (Heliconius) 84 parvimaculata (Heliconius clytia) . . 171 parvimaculata(Heliconius clytiaaberr.) 171 pasithoe (Heliconia) . . . . . . 70 pasithoe (Heliconius) . . . . . . 70 pasithoe (Papilio) . . . . . . . . . 70 pavana (Eueides) . . . . . . . 257 pellucida aberr. vegetissima (Fneides isabella) . . . . . . . 238 
pellucida (Eueides) . . . . . . . 238 pellucida (Eueides isabella) . . . 238 pellucidus (Eueides isabella) . . 238 pelopeia(Heliconius melpomeue aber'r.) 124 penelamanda (Heliconius melpomene) 124 penelamanda (Heliconius penelope aberr.) . . . . . . . . . . penelope aberr. penelamanda (Heliconius) . . . . . . . . . . . . penelope aberr. pluto (Heliconius) . penelope (Helicnnius) . . . . . . penelope (Heliconius melpomene) penelopeia (Heliconius melpomene) penelopeia (Heliconius melpomene aberr.) . . . . . . . . . . . . personata (Eueides isabella bippolinus aberl.) . . . . . . . . . . . peruana (Heliconius aristiona var.). peruviana (Heliconia) . . . . . . peruviana (Heliconius) . . . . . . peruviana (Heliconius charithonia) . peruvianus (Heliconius) . . . . 216 pexuvianus (Heliconius chari-

thonia) . . . . . . . . . . . 216 petiverana aberr. tristis (Heliconius) 193 petiverana demophoon (Heliconius) 193 petiverana (Heliconia) . . . . . 193 petiverana (Heliconius) . . . . 193, 193 petiverana var. chiriquensis (Heliconius) . . . . . . . . . 193 petiverana var. demophoon (Heliconius) . . . . . . . . . . 193 petiveranus demophoon (Heliconius) . . . . . . . . . . . . 193 petiveranus (Heliconius). . 130, 193, 193 petiveranus (Heliconius) . . . . 192 petiveranus (Heliconius petiveranus) . . . . . . . . . . . . . petiveranus petiveranus (Heliconius) . . . . . . . . . . . 193 petiveranus rar. colombina (Heliconius) . . . . . . . . . 195 petiverea (Heliconius) . . . . . . . 193 phalaris (Heliconius aristiona) . 74 phalaris (Heliconius bicoloratus var.) 74 philadelphus (Heliconius) . . . . 201 Phlogris . . . . . . . . . . . . 2 phyllides (Heliconius) . . . . . . 210 pliyllides (Heliconius phyllis) . . . 209 phyllides (Heliconius phyllis forma) . 209 pliyllidis (Heliconius) . . . . . . . 209 phyllis aberr. amalfreda (Heliconius) 201 phyllis aberr. amatus (Heliconius) . 209 phyllis aber'r. artifex (Heliconius) . 209 phyllis aberr. callista (Heliconius) . 202 phyllis aberr. dryope (Heliconius) . 202 phyllis abeir. ottonis (Heliconius) . 210 plıyllis amalfreda (Heliconius) . . . 201 phyllis amatus (Helicouius) . . . . 209 phyllis amazona (Heliconius) . . . . 201 phyllis anphitrite (Heliconius) . . . 211 phyllis anacreon (Heliconius) . . . 210 phyllis anactorie (Heliconius) . . . 208 phyllis andremona (Heliconius) . . . 198 phyllis artifex (Heliconius) . . . . 209 phyllis buqueti (Heliconius) . . . . 207 phyllis callista (Heliconius) . . . . 202 phyllis callycopis (Heliconius) . . . 202 phyllis corallii (Heliconius) . . . . 202 phyllis cybelina (Heliconius) . . . . 201 phyllis demeter (Heliconius) . . . . 206 phyllis dryope (Heliconius) . . . . 202 phyllis elimaea (Heliconius) . . . . 202 phyllis emna (Heliconius) . . . . 205 phyllis erythraea (Heliconius) . . 198 phyllis estrella (Heliconius) . . . 205 phyllis etylus (Heliconius) . . . . . 205 phyllis forma phyllides (Heliconius). 209 phyllis (Beliconia) . . . . . . 209 phyllis (Heliconias) . . . . . . . . 209 pliyllis (Heliconius) . . . . . . . . 209 phyllis (Heliconius erato) . . . 208 phyllis (Laparus) . . . . . . . . 209 phyllis lativitta (Heliconius) . . . . 207 phyllis leda (Heliconius) . . . . . 198 phyllis magnifica (Heliconius) . . . 204 phyllis ottonis (Heliconius). . . . 210 phyllis (Papilio) . . . . . . . 208 phyllis phyllides (Heliconius) . . . . 209 phyllis sanguineus (Heliconius) . . . 208 phyllis (Sunias) . . . . . . . . . . 208 phyllis udalrica (Heliconius) . . . . 198 phyllis var. magnifica (Heliconius) . 204 phyllis var. viculata (Heliconius) . . 202 phyllis veuustus (Heliconius) . . . . 208 phyllis vesta (Heliconius) . . . . . 198 phyllis viculata (Heliconius) . . . . 202 phyllus (Heliconia) . . . . . . . 209 piera (Heliconius). . . . . . . . . 106 pione (Eueides). . . . . . . . . 46 pluto (Eueides eanes aberr.) . . . . 271 pluto (Heliconius inelpomene) . . . 124 pluto (Heliconius penelope aberr.) . 124 pochinus (Heliconius) . . . . . 108 polychrous (Heliconius) . . . . . . 41 polychrous (Heliconius narcaea) . $\$ 1$ polychrous (Heliconius nareaea var.) 41 polylyymnia (Papilio) . . . . . . 243 pretiosus (Helicouins aristiona) . . 80 pretiosus (Heliconius staudingeri var.) 80 primularis (Helicouius) . . . . . 17i primularis (Heliconius sapho). . 175 primularis (Heliconius sappho) . . 175 procula (Eueides) . . . . . . 252 
pseudamaryllis (Helicouius amaryllis rar.) . . . . . . . 119 pseudorhea (Heliconius) . . . . 182 pseudorhea (Heliconius leucadia) 182 pythagoras (Eueides) . . . . . 266 pythagoras (Eueides tales) . . 266 quirina (Papilio) . . . . . . . . . 162 quitalena concors (Heliconius) . . . 92 quitalena felix (Heliconius) . . . . 92 quitalena (Heliconia) . . . . . . 91 quitalena (Heliconius) . . . . . . 91 quitalena jonas (Heliconius) . . . . 93 'quitalena sisyphus (Heliconius) . . . 93 'juitalena versicolor (Heliconius) . . 9:3 quitalenus felix (Heliconius) . . 92 quitalenus (Heliconius) . . . . . 90 quitalenus (Heliconius quitalenus) 91 quitalenus quitalenus (Heliconius) 91 quitalenus sisyphus (Heliconius) 93 quitalenus versicolor (Heliconius) 93 radiatus (Heliconius) . . . . . . . 122 radiosus (Heliconius) . . . . . . 85 radiosus (Heliconius pardalinus) 8.; rhea (Heliconius) . . . . . . . 183, 185 rhea (Heliconius sara) . . . . . 185 rhea (Papilio) . . . . . . . . 185 rhea var. magdalcua (Heliconius). . 183 rhea var. veraepacis (Helicouius) . . 186 richardi (Heliconius melpomene) . . 125 richardi (Heliconius melpomene timnreta aberr.) . . . . . . . 125 richardi (Heliconius timareta aberr.) 125 ricini (Apostraphia) . . . . . . . . 243 ricini (Eueides) . . . . . . . 243 Riciniformes . . . . . . . . 243 ricini (Heliconia) . . . . . . . . 243 ricini (Heliconius). . . . . . . . 243 ricini (Papilio) . . . . . . . . 162, 243 ricini (Papilio (Heliconius)) . . . 243 riffarthi (Eueides eanes) . . . . 271 riffarthi (Eueides eancs aberr.) . . . 271 robigus (Heliconias) . . . . . . . 52 robigus (Heliconius). . . . . . . 52 robigus (Heliconius silvana) . . 52 rosina (Heliconia). . . . . . . 130 rosina (Heliconius) . . . . . . . 130 rosina (Heliconius amaryllis) . . 130 roxane (Papilio) . . . . . . . . 209 rubellius (Heliconius) . . . . . . 110 rubra (Heliconius erato forma) . . . 162 rufolimbatus (Heliconius) . . . . . 122 rufolimbatus (Heliconius melpomene) 122 salvinii (Heliconius) . . . . . . 181 salvinii (Heliconius antiochus) . 181 sanguineus (Heliconius anacturie aberr.) . . . . . . . . 208 sanguineus (Heliconius phyllis) . . . 208 sapho eleuchia (Heliconius) . . 176 sapho eleusinus (Heliconius) . . 175 sapho (Heliconia)....... 173 sapho (Heliconius) . . . . . . 172 sapho (Heliconius) . . . . . 17:3 sapho (Heliconius sapho) . . . 173 sapho leuce (Heliconius) . . . 171 sapho (Papilio). . . . . . . 17:3 sapho primularis (Heliconius). . 175 sapho sapho (Heliconius) . . . 17:3 sappho (Ajantis) . . . . . . . 173, 174 sappho eleuchia (Heliconius) . . . 176 sappho eleusinus (Heliconius) . . 17.) Sapphoformes . . . . . 172 sappho (Heliconia) . . . . . 173 sappho (Heliconius) . . . . . . 173 sappho leuce (Heliconius) . . . . 17t sappho (Papilio) . . . . . . . . 173 sappho primularis (Hcliconius) . . 175 sara aberr. albinea (Heliconius) . . 185 sara aberi. albula (Heliconius) . . 184 sura albimaculata (Heliconius) . . 183 sara albinea (Heliconius) . . . . 185 sara albula (Heliconius) . . . . . 181 sara apseudes (Heliconius) . . . 184 sara brevimaculata (Heliconius) . . 185 sara brevimaculatus (Heliconius) 18; sara (Heliconia) . . . . 170, 184 sara (Heliconius) . . . . . . 182 sara (Heliconius) . . . . . . 183 sara (Heliconius sara). . . . . 183 sara (Laparus) . . . . . . . . . 183 sara (Papilio). . . . . . . . 183 sura rhea (Heliconius) . . . . . 18.5 sara sara (Heliconius). . . . . . 183 sara (Sicyonia) . . . . . 170 sara sprucei (Heliconius) . . . 18i sara thamar (Heliconius) . . . 185 sara theudela (Heliconius) . . 186 sara veraepacis (Heliconius) . 186 satis (Heliconias) . . . . . . 40 satis (Heliconius) . . . . . . 40 satis (Heliconius narcaea) . . . . 40 satis (Heliconius narcaea var.) . . . 10 schulzi (Heliconius) . . . . . . 65 seitzi (Eueides isabella) . . . . 237 Semelia . . . . . . . . 224 semiflavidus (Heliconius ethilla) $\quad$ i9 semiflavidus (Heliconius eucoma) . . $\quad$.9 semitlavidus (Heliconius metalilis var.) scniphorus aberr. holcophorus (Heliconius) . . . . . . . 97 semiphorus (Heliconius anderida) 97 semiphorus (Heliconius elara) . . . 97 semiphorus (Heliconius metaphorus var.) . . . . . . . . . 97 seraphion (Heliconius). . . . . is 
seraphion (Heliconius aristiona) . . 78

sergestus (Heliconius) . . . . 88

Sicyonia . . . . . . . . . 2

sikinos (Heliconius) . . . . . . . 75

silvana diffusus (Heliconius) . . . . 51

silvana ethra (Heliconius). . . . 54

silvana (Heliconius) . . . . . . . 50

silvana (Heliconius) . . . . . . . 51

silvana (Heliconius silvana) . . 51

silvana metaphorus (Heliconius) 53

silvana (Papilio) . . . . . . . . 51

silvana robigus (Heliconius) . . 52

silvana silvana (Heliconius) . . 51

Silvaniformes . . . . . . 38

sisyphus (Heliconius) . . . . . . 93

sisyphus (Heliconius quitalena) . . . 93

sisyphus (Heliconius quitalenus) 93

sotericus (Heliconius) . . . . . . . 224

sotericus (Heliconius telesiphe) . 224

sotericus (Heliconius telesiphe var.) . 224

spadicarius (Heliconius) . . . . . . 68

splendidus (Heliconius aristiona) . . 73

splendidus (Heliconius aristiona var.) 73

spoliata (Eueides isabella hübneri

aberr.) . . . . . . . . . 239

sprucei (Heliconius) . . . . . . 185

sprucei (Heliconius sara) . . . . 185

spurius (Heliconius) . . . . . . . . 87

spurius (Heliconius fortunatus) . 87

staudingeri (Heliconius) . . . . . 80

staudingeri (Heliconius aristiona) 80

staudingeri var: pretiosus (Heliconius) 80

stübeli (Heliconius cydno) . . . . . 106

stübeli (Heliconius cydno aberr.) . . 106

subcydnides (Heliconius cydno) . . 103

subcydnides (Heliconius cydno var.) 103

sulphurea (Heliconius clytia var.). . 171

sulphureus (Heliconius) . . . . . 62

Sunias . . . . . . . . . 2

superioris (Heliconius) . . . . . . 49

superioris (Heliconius numata) . . . 49

superioris (Heliconius numatus). 49

superioris var. mavors (Heliconius) . 48

surdus aberr. aquilifer (Eueides thales) 267

surdus (Eueides tales) . . . . 267

surdus (Eueides thales) . . . . . 267

Sycionia . . . . . . . . . . 2

sylvana (Heliconia) . . . . . . . 51

sylvana (Heliconius). . . . . . . 51

sylvana var. antioquensis (Heliconius) 53

tales (Eueides) . . . . . . . . 264

tales (Eueides tales) . . . . . 265

tales (Papilio) . . . . . . . . 265

tales pythagoras (Eueides) . . . 266

tales surdus (Eueides) . . . . . 267

tales tales (Eueides) . . . . . 265

tamarinda (Heliconius) . . . . 10ø tarapotensis (Heliconius aristiona) 76

tecta (Heliconius erato)...... 162

tecta (Heliconius erato aberr.) . . . 162

telchinia (Heliconia). . . . . . 43

telchinia (Heliconius) . . . . . . 43

telchinia (Heliconius ismenius) . 43

telesiphe (Heliconia) . . . . . . 223

telesiphe (Heliconius). . . . . . 222

telesiphe (Heliconius) . . . . . . . 223

telesiphe (Heliconius telesiphe) . 223

telesiphe sotericus (Heliconius) . 224

telesiphe telesiphe (Heliconius) . 223

telesiphe rar. sotericus (Heliconius) . 224

tellus (Heliconia vesta) . . . . . 198

tellus (Heliconius erato) . . . . . 198

telxiope (Heliconius) . . . . . 117

temerinda (Heliconia) . . . . . . 105

temerinda (Heliconius) . . . . . 105

temerinda (Heliconius cydno) . . 105

termerinda (Heliconius cydno) . . . 105

thales (Eueides) . . . . . . . 265

thales (Heliconia) . . . . . . . 265

thales heraldicus (Eueides) . . . . 266

thales (Migonitis) . . . . . . . 265

thales (Papilio) . . . . . . . . . . 265

thales surdus aberr. aquilifer (Eueides) 267

thales surdus (Eueides) . . . . . . 267

thalestris (Heliconia) . . . . . 265

thales typicus (Eueides) . . . . . 265

Thaletoformes. . . . . . . 264

thamar (Heliconius) . . . . . . 18?

thamar (Heliconius sara) . . . . 18

thamar (Sicyonia). . . . . . . 185

thelxiope aberr. thelxiopeia (Heli-

conius) . . . . . . . . 118

thelxiope (Heliconia) . . . . . . 117

thelxiope (Heliconius) . . . . . 117

thelxiope (Heliconius erato forma) . 117

thelxiope (Heliconius Inelpomene) 117

thelxiopeia (Heliconia) . . . . . . 119

thelxiopeia (Heliconius melpo-

mene). . . . . . . . 118

thelxiopeia (Heliconius thelxiope

aberr.) . . . . . . . . 118

thelxiope (Migonitis) . . . . . . . 117

thelxiope var. aglaope (Heliconius) . 121 thelxiope var. aglaopeia (Heliconius) 118 thelxiope var. mutabilis (Heliconius) 114 thelxiope var. ricina (Heliconius) . . 122 thelxiope var. vicinus (Heliconius) . 122 thetis (Heliconia) . . . . . . . . 145 thetis (Heliconius) . . . . . . . . 145 thetis (Heliconius doris aberr.) . . . 145 theudela (Heliconia). . . . . . 186 theudela (Heliconius) . . . . . . . 186 theudela (Heliconius sara) . . . 186 thielei (Heliconius gradatus) . . 62 
Seite

thyana (Eueides) . . . . . . 257

timaeus (Heliconius) . . . . . . 73

timaeus (Heliconius aristiona) . 73

timareta aberr. contiguns (Heliconius melpomene) ....... 125

timareta aberr. erebia (Heliconius) . 127 timareta aberr. richardi (Heliconius) 125 timarcta aberr. richardi (Heliconins melpomene) ....... 125 timareta aberr. virgata (Helironins melpomene) ....... 125 timareta (Heliconia) . . . . . 125 timareta (Heliconius) . . . . . 125 timareta (Heliconius melpomene) 125 tithoreides (Helicouius) . . . . 86 tithoreides(Heliconius pardalinus) $\quad 86$ tleson (Heliconius) ...... . 76 transiens (Heliconius doris). . . 165 transiens (Heliconius erato) . . . 165 transiens (Heliconius erato var.) . . 165 tristis (Heliconius petiverana aberr.) . 193 tyche (Heliconius melpomene) . 116 tyche (Heliconius melpomene rar.) . 116 tyndarus (Heliconius) . . . . . 57 tyndarus (Heliconius ethilla) . . 57 tyndarus (Heliconius eucoma) . . . 57 typica (Eueides aliphera) . . . . 261 typica (Eueides cleobaea) . . . . 242 typica (Eueides isabella). . . . 235 typica (Eueides lineata) . . . . 259 typica (Eueides lybia) . . . . 263 typica (Eueides ribilia) . . . . . 254 typicus (Eueides edias) . . . . . 249 typicus (Eueides lampeto) . . . . 246 typicus (Eueides thales) . . . . 265 udalrica (Heliconia andremona rar.) 198 udalrica (Heliconius) . . . . . 198 udalrica (Heliconius melpomene rar.) 198 udalrica (Heliconius phyllis) . . . 198 udalrica (Papilio) . . . . . . 198 ulrica (Migonitis) . . . . . . . 198 unifasciatus (Eueides) . . . . . 256 unifasciatus (Eueides vibilia) . . 256 unimaculata (Heliconia) . . . . 121 unimaculata (Heliconius) . . . . . 121 unimaculata (Heliconius melpomene) 122 urania (Heliconius) . . . . 70 urania (Papilio). . . . . . . . 70 vala (Heliconius) . . . . . . 151 vala (Heliconius xanthocles) . . 151 vala (Heliconius paraplesius forma) 151 redius (Heliconius) . . . . . 149 reget issima (Eueides isabella pellucida aberr.) . . . . . . . 238 venus (Heliconius) . . . . . 191 venus (Heliconius cyrbia) . . . 191 renustus (Heliconius) . . . . 207 renustus (Heliconius anactorie aberr.) 208 renustus (Heliconius phyllis) . . . 208 reraepacis (Heliconius) . . . . 186 veraepacis (Heliconius rhea var.). . 186 veraepacis (Heliconius sara) . . 186 versicolor (Heliconius) . . . . . 93 versicolor (Heliconius quitalena) . . 93 versicolor (Heliconius quitalenus) 93 vesta aber1. leda (Heliconius) . . 198 vesta crbelina (Heliconius) . . . . . 201 resta forma estrella (Heliconius) . 205 resta (Heliconia) . . . . . . 198 resta (Heliconius) . . . . . . . . 198 vesta (Heliconius phyllis) . . . . 198 restalis (Heliconius vesta var.) . . . 205 vesta (Papilio) . . . . . . . 198 vesta tellus (Heliconia) . . . . . 198 resta rar. amazona (Heliconius) . . 201 resta rar. restalis (Heliconius) . . 205 vetustus (Heliconius) . . . . 66 retustus (Heliconius) . . . . . 67 vetustus (Heliconius vetustus) . 67 vetustus metellus (Heliconius) . 68 vetustus vetustus (Heliconius) . vialis (Eueides vibilia) . . . . 256 vibilia aberr. pallens (Eueides) . . 254 vibilia (Cethosia) . . . . . . 254 vibilia (Colaenis) . . . . . 254 vibilia (Eueides) . . . . . . 253 ribilia (Eueides) . . . 254. 256, 257 vibilia (Eueides vibilia) . . . . 254 vibilia (Semelia) . . . . . 254 ribilia typica (Eueides) . . . . 254 vibilia unifasciatus (Eueides) . . 256 vibilia var. arcita (Eueides) . . . 256; vibilia vialis (Eueides) . . . 256 vibilia vibilia (Eueides) . . . . 254 vibilia vicinalis (Eueides) . . . 256 Vibiliiformes...... 248 vicina (Heliconia) . . . . . . 122 vicina (Heliconius melpomene). . . 122 vicina (Heliconius thelxiope var.). . 122 vicinalis (Eueides vibilia) . . . 256 vicinus (Heliconius melpomene) . 122 vicinus (Heliconius thelxiope var.) . 122 viculata (Heliconius callycopis forma) $20 \%$ viculata (Heliconius phyllis) . . . 202 viculata (Heliconius phyllis var.) . . 202 rirgata (Heliconius melpomene tima-

reta aberr.) . . . . . . 125 viridis (Heliconius doris) . . . 16: viridis (Heliconius erato) . . . 165 viridis (Heliconius erato rar.) . . 165 vittatus (Heliconius) . . . . . . 82 vittatus (Heliconius ithaka) . . 82 vuleanus aberr. modesta (Heliconius) 132 vulcanus eythera (Heliconius) . 132 
rulcauns (Heliconia) . . . . . . 131 vulcanus (Heliconius) . . . . . 131 vulcanus (Heliconius) . . . . . 131 vulcanus (Heliconius vulcanus). 131 vulcauus modestus (Heliconius). . . 132 vulcanus vulcanus (Heliconius). 131 vulgiformis (Eueides) . . . . . 251 vulgiformis (Eueides edias) . . . 251 wallacei colon (Heliconius) . . . 170 Wallaceiformes . . . . . . 168 wallacei (Heliconius) . . . . . 169 wallacei (Heliconius) . . . . . . . 169 wallacei (Heliconius clytia) . . . 169 wallacei (Heliconius clytia var.) . . 169 wallacei (Heliconius wallacei) $\quad 169$ wallacei mimulinus (Heliconius) 170 wallacei wallacei (Heliconius). . 169 weymeri aberr. gustavi (Heliconius) . 107 weymeri (Heliconius) . . . . . 107 weymeri (Heliconius cydno) . . . 107 xunthicus (Heliconius). . . . . . . 98 xauthicus (Helicouius clara) . . . . 98 xauthicus (Heliconius jucundus var.) 98 xanthicus (Heliconius zuleika var.) . 98 xanthoceras (Heliconia) . . . 198 Xanthocled oformes . . . 149 xanthocles (Heliconius) . . . . 150 xanthocles (Heliconius) . . . . . 151 xanthocles (Heliconius xant-

hocles) . . . . . . 151 xanthocles melete (Heliconius) . 152 xanthocles melior (Heliconius) . 153 xanthocles melittus (Heliconius) 153 xanthocles paraplesius (Heliconius). . . . . . . . . 152 xanthocles vala (Heliconius) . . 151 xanthocles xanthocles (Heliconius) 151 xenoclea (Heliconi: ) . . . . 188 xenoclea (Heliconius) . . . . . 188 xenoclea (Heliconius) . . . . . . . 188 xenoclea (Heliconius xenoclea) . 188 xenoclea notabilis (Heliconius) . 189 xenoclea xenoclea (Heliconius) . 188 xenophanes (Eueides) . . . . . 268 xenophanes (Eueides heliconioides) . . . . . . . . . . . 268 xenophanes (Eueides heliconioides aberr.) . . . . . . . . 268 zagora (Heliconins) . . . . . . . 95 zelinde (Helicouius) . . . . . . . 107 zelinde (Heliconius cydno) . . . 107 zobeide (Heliconius) . . . . . . . 180 zobeide (Heliconius antiochus) . 180 zoreaon aberr. adusta (Eueides cleo-

baea).......... . 212 zorcaon (Eneides) . . . . . . . . 242 zorcaon (Eueides cleobaea) . . . 242 zorcaon (Eueides cleobaea var.) . . 242 zudeika (Heliconia) . . . . . . 98 zuleika aberr. albipunctata(Heliconius) 98 zuleika (Heliconia) . . . . . . . . 98 zuleika (Heliconius) . . . . . . . . 98 zuleika (Heliconius anderida). . 98 zuleika (Heliconius clara) . . . . . 98 zuleika var. jucundus (Eleliconius) . 98 zuleika var. xanthicus (Heliconins) . 98 


\section{Nomenclator generum et subgenerum.}

Ajantis Jacob Hiibner, Verz. Schmett., p. 13. 1816. Sp.: A. sappho, A. antiocha, A. hecale.

Apostraphia Jacob Hiibner, Verz. Schmett., p. 13. 181t. Sp.: A. ricini, A. brassolis, A. charitonia.

Blanchardia Henricus Buchecker, Syst. Ent., Lep. t. 51. [1880?]. Sp.: B. dismorphia.

Colaenis Jacob Hii bner, Verz. Schmett., p. 32. 1816. Sp.: C. julia, C. delila, C. lybia, C. mercani.

Eieides [pro: Eueides Jac. Hübner 1816] Jacob Hübner, Exot. Schmett., v. 2 Index p. [3]. 1821 xi 22.

Eisides [pro: Eneides Jac. Hübner 1816] Samuel H. Scudder, Nomencl. zool., suppl. L. p. 119. 1882.

Epimetes Gust. Joh. Billberg, Lnum. Ins., p. 77. 1820. Sp.: E. sebethis, $E$. aacile, E. isabella, E. calliope, E. nyctimene, E. syra, E. polymnia, E. psidii, E. diaphanus.

Epinetes [pro: Epimetes Billberg 1820] Samuel H. S'cudder in: J'. Amer. Ac., v. 10 p. 164.1875.

Eueides Jacob Hïbner, Verz. Schnett, 1. 11. 1816. Sp). E. dianassa, E. halia, E. pasinuntia, E. eucoma, E. mneme, F. pionc, E. harmonia.

Eurides [pro: Eueides Jac. Hübner 1816] F. Du Cane Godin an \& Osbert Salvin in: 'Tr. ent. Soc. London, 1880 p. 130. 1880.

\footnotetext{
Das Tierreich. 22. Lief.: H. Stichel \& H. Riffarth, Heliconiidae.
}

veides [pro: Eueides Jac. Hübner 1816] [Jean A.] Boiśdural, Consid. Luép. Guatemala. p. 35. 1870.

Evides pro: Eueides Jac. Hübner 1816. L. A gassiz, Nomencl. zool.. Index p. $147,153.18+6$.

Heliconia [pro: Heliconius Linné 1758] ([Pierre André] Latreille \&) [Jean Baptiste] Godart in: Enc. méth., v. 9 p. 203.1819.

Heliconias [pro: Heliconius Linné 1758] Victor von Bönningh a usen in: Verh. Ver. Hamburg, v. 9 p. 32.1896.

Heliconius [Subgen.] Carolus Linna eus, Syst. Nat., edl. 10 p. $₫ 66,465.1758$. Sp.: Pupilio apollo, P. mnemosyne, P. piera, $P$. aglaja, $P$. terpsicore, $P$. calliope, $P$. polymnia, $P$. urania, $P$. euterpe, $P$. ricini, $P$. psidii, $P$. clio, $P$. thalia, $P$. crato, P. melpomene.

Laparus Gust. Joh. Billberg, Enum. Ins., 1. 77. 1820. Sp.: L. sara, L. doris, L. phyllis, L. melpomene.

Mechanites [pro: Mechanitis J.C. Fabricius 1807] Jacob H ïbner, Exot. Schmett. v. 2 t. [1]. [1822-26.]

Mechanitis([.JohannChristian] Fabricius in:) Karl Illiger in: Mag. Insektenk., r. 6 p. 28t. 1807. Sp.: Papilio calliope, P.polymnia, P.doris, P.psidii, P.phyllis, et aliac.

Melinaea Jacob Hübner, Verz. Schmett., 1. 11. 1816. Sp.: H. egina, M. clara, M. equicola, M: eunice, $M$. ircnc. 
Migonitis Jacob H übner, Verz. Schmett., p. 12. 1816. Sp.: M. thales, M. aoede, M. erato, $M$. burneyi, $M$. thelxiope, $M$. andremone, $M$. ulrica, $M$. erythrea, $\boldsymbol{M}$. isaea, $M$. crenis.

Phlogris Jacob Hübner, Exot. Schmett., v. 2. t. [5]. [1822-26.] Sp.: P. melpomene.

Semelia ([J. A.] Bois dural in MS.) [Edward D o u b le d a y], List Lep. Brit. Mus., v. 1 p. 64 . 1814. Sp.: S. vibilia, S. aliphera.
Sicyonia [pro: Sycionia Jac. Hübner 1816] Jacob Hübner, Verz. Schmett., p. 13. 1816.

Sunias Jacob Hübner, Verz. Schmett., 1.12. 1816. Sp.: S. phyllis, S. lucia, S. melpomene, S. callicopis.

Sycionia Jacob H iibner, Verz. Schmett., p. 13, Anz. p. 7. 1816. Sp.: Sicyonia sara, S. thamar, S. apseudes, S. doris. 
Beiräte: Prof, F. Blochmann in Tübingen (Brachiopoda). - Prof. O. Boettger in Frankfurt a. MI. (Amphibia \& Reptilia). - Staatsrat Prof. M. Braun in Königsberg i. Pr. (Platyhelminthes). - I'rof. C. Chun in Leipzig (Cnidaria \& Ctenophora). - Prof. F. Dahl in Berlin (Arachnoidea excl. Acarina). ㄱof. C. W. v. Dalla Torre in Innsbruck (Hymenoptera). - Prof. L. Döderlein in Straßburg i. E. (Mammalia). (reh. Reg.-Kat Prof. E. Ehlers in Göttingen (Bryozoa). - Prof. D)r. W. Giesbrecht in Neapel (Crustacea). Gymnasiallehier E. Girschner in Torgau (Diptera). - Mag. pliarn. A. Handlirsch in Wien (Rhynchota \& Neuroptera). - P'rof. R. Hertwig in Jï̈chen (Protozoa). - Dr. W. Kobelt in Seliwanheim (Mollusca). Prof. H. J. Kolbe in Berlin (Colcoptera). Dr. H. Krauss in Tübingen (Orthoptera). - Dir. Prot. R. Latzel in Klagenfurt (Myriopoda). - Dr. H. Lohmann in Kiel (Acarina). Geh. Reg.-Rat Prof. H. Ludwig in Bonn (Echinoderma). - Prof. G. Pfeffer in Hamburg (Pisces). - Prof. A. Reichenow in Berlin (Aves). -.. (Geh. Reg.-Rat Prof. F. E. Schulze in Berlin (Porifera). - Dir. Dr. A. Seitz in Frankfurt a. II. (Lepidoptera). Geh. Hofrat Prof. J. W. Spengel in Gießen (Tunicata de Vermes exçl. Platyhelminthes).

Be a rbeiter: Dr. Bastelberger in Eichberg i. Rheingau, Stadtbaurat T. Becker in Liegnitz, Graf H. v. Berlepsch auf Schloß Berlepsch, Prof. R. Blanchard in Paris, Prof. F. Blochmann in 'lïbingen, Prof. O. Boettger in Frankfurt a. M., A. de Bormans in 'Turin, Dr. K. Börner in Berlin, Prof. E.-L. Bouvier in Paris, Prof. K. Brandt in Kiel. Staatsrat Prof. M. Braun in Königsberg i. Pr.. Dr. I. Breitfuss in Katharinenhafen, G. Budde-Lund in Kopenhagen. Prof. O.Bürger in Santiago (Chile), Prof. G. Canestrini in Padua ( + ). Prof. C. Chun in Leipzig. Prof. J. Csokor in Wien, P. I. Czerny in Pfarrkirchen. Prof. C. W. v. Dalla Torre in Innsbruck. Dr. F. Doflein in München, Prof. C. Emery in Bologna, 11. G. Enderlein in Berlin, Dr. K. Escherich in Straßburg i. E., Dir. Dr. O. Finsch in Braunschweig, H. Friese in Jena, Prof. A. Giard in Paris, Yrof. Dr. W. Giesbrecht in Neapel. Hofrat Prof.I. v. Graffin Graz, Dr. K. Grünberg in Berlin, Prof. V. Häcker in Stuttgart, Dir. E. Harter't in 'Tring, Dr. R. Hartmeyer' in Berlin, C. E. Hellmayr in München, Dr. F. J. M. Heylaerts in Breda, Dr. W. E. Hoyle in Mtanchester, Prof. A. Jacobi in Tharandt. 1)r. K. Jordan in Tring. Prof. J. J. Kieffer in Bitsch, Dr. W. Kobelt in Sclıwanheim, Prof. C. A. Kofoid in Berkely: (California). Prof. H. J. Kolbe in Berlin, Dir. 'rof. K. Kraepelin in Hamburg. Prof. P. Kramer in Magdeburg ( + , Dr. H. Krauss in Tübingen. Prof. W. Kükenthal in Breslau, Dir. Prof. L. Kulczynski in Krakau, Dr. A. Labbé in Paris, Dr. R. Lauterborn in Lıdìigsla fen a. Rh., Prof. R. v. Lendenfeld in Prag. Dir. Dr. H. Lenz in I übeck, Dr. H. Lohmann in Kiel, Geh. Keg.-Rat Prof. H. Ludwig in Bonn, Dr. M. Lüle in Königsberg i. Pr... A. D. Michael in London, Dr. W. Michaelsen in Hamburg. Dr. T. Mortensen in Kopenhagen, Prof. G. W. Müller in Greifswald, Prof. J. P. Mc Murrich in Ann Arbor, Prot. A. Nalepa in Wien, Prof. I.-G. Neumann in Toulouse, Prof. A. Nosek in Caslau, W. R. Ogilvie-Grant in Edinburgh, Prof. A. E. Ortmann in Princeton. Geh. Sanitätsrat Dr. A. Pagenstecher in IViesbaden, Prof. K. A. Penecke in Graz. Prof. G. Pfeffer in Hamburg. 1)ir. Dr. R. Pier'sig in Anmaberg, Prof. L. Plate in Berlin, Prof. A. Reichenow in Berlin, Prof.L. Rhumbler in Göttingen. H. Riffarth in Berlin, Dir. D1·. F. Ris in Rheinau (Sehweiz), 'The Hon.W. Rothschild in Tring, E.H. Rübsaamen in Berlin. Reg.-Rat Dr. F. Schaudinn in Berlin, E. Schenkel in Basel. Dr. P. Schiemenz in Berlin-Friedrichshagen. Prof. O. Schmeil in Jagleburg, Prof. O. Schmiedeknecht in Blankenburg, Geh. Reg.-Rat Prof. F. E. Schulze in Berlin, Dr. F. Schwangart in Münchell, Dr. R. B. Sharpe in London, Dr. P. Speiser in Bischofsburg, Geh. Hofrat Prof. J.W. Spengel in GieBen, Rev. T. R. R. Stebbing in Tunbridge Wells, Oberlehrer P. Stein in Genthin. H. Stichel in Hagen (Westfalen), Dr. T. Stingelin in Olten, Kustos Dr. J. Thiele in Berlin. Prof. D’A. W. Thompson in Dundee, Schuldirektor S. Thor in Christiania. Dr. E.-L. Trouessart in Paris, Dr. H. Uzel in Königgrätz. Dr. B. Wandolleck in Dresden. Prof. W. Weltner in Berlin, Dr. F. Werner in Wien, Prof. C. Zelinka in Yzernowitz.

Erschienen sind:

Probelieferung. Heliozoa. Bearbeitet ron F. Schandinn (Berlin). 24 Seiten mit (Protozor.) 10 Abbildungen. 1896. Preis Mark 1,50.

1. Liefernng. Podargidae, Caprimulgidae und Macropterygidae. Bearbeitet (Aves.) von E. Hartert (Tring). VIII und 98 Seiten init 16 Abbildungen und 1 Beilage (Telminologic des Vogelkörpers, ron A. Reichenow. 4 Seiten mit 1 Abbildung). 1897 II.

Subskriptionspreis Mark 4,50. Einzelpreis Mark 7,-.

2. lieferung. Paradiseidae. Bearbeitet ron The Hon. W. Rothsehild. VI und (Aves.) 52 Seiten mit 15 Abbildungen. $1898 \Gamma$.

3. Lieferuug Subskriptionspreis Mark 2,80. Einzelpreis Mark 3,60 Oribatidae. Bearbeitet ron A. 1). Michael (London). XII.. nnd (Acarina.) 93 Seiten mit 15 Abbildungen. 1898 VII.

4. Lieferungskriptionspreis Mark 4,50. Einzelpreis Mark 6,80. (Acorbeitet von A. Nalepa (Wien). (Acarina.) IX und $7+$ Seiten mit 3 Abbildungen. $1898 \mathrm{~V} 111$.

Subskriptionspreis Mark 3,80. Einzelpreis Mark 5, . 
5. Lieferung

(Protozoa.)

b. Lieferung (Crustricen.)

7. Lieferung (Acarina.)

8. Lieferung. (Arachnoidea.)

9. Lieferung. (Aves.)

10. Lieferung (Vermes.)

11. Lieferung. (Orthoptera.)

12. Lieferung. (Arachnoidea.)

13. Lieferung.

14. Lieferung. (Lepidopter*n.)

15. Lieferung. (Aves.)

16. Lieferung (Mollusca.)

17. Lieferung. (Lepidoptera.)

18. Liefernng. (Aves.)

19. Lieferung. (Porifera.)

20. Lieferung. (Platyhelminthes.) 22. Lieferung. (Tepidoptera.)

23. Lieferung. (Platyelminthes.) (Acarina.)

Sporozoa. Bearbeitet vou A. Labbé (Paris). XX und 180 Seiten mit 196 Abbildungen. 1899 VII.

Subskriptionspreis Mark $\mathbf{8 , 8 0}$. Einzelpreis Mark 12,-.. Copépoda, I. Gymnoplea. Bearbeitet von W. Giesbrecht (Neapel) und O. Schmeil (Magdeburg). XVI und 169 Seiten mit 31 Abbildungen. 1898 XII.

Subskriptionspreis Mark 8,40. Einzelpreis Mark 11, . Demodicidae und Sarcoptidae. Bearbeitet ron G. Canestrini (Padua) und P. Kramer (Magdeburg). XVI und 193 Seiten mit 31 Abbildungen. 1899 IV.

Subskriptionspreis Mark 9,20. Einzelpreis Mark 12,-... Scorpiones und Pedipalpi. Bearbeitet ron K. K $\mathrm{r}$ a epelin (Hamburg). XVIII und 265 Seiten mit 94 Abbildungen. $1899 \mathrm{III}$.

Subskriptionspreis Mark 12,60. Einzelpreis Mark 17, . Trochilidae. Bearbeitet von E. Hartert (T'ring). IX und 254 Seiten mit 34 Abbildungen. 1900 II.

Subskriptionspreis Mark 12,--. Einzelpreis Mark 16,-. Oligochaeta. Bearbeitet von W. Michaelsen (Hamburg). XXIX und 575 Seiten mit 13 Abbilduugen. $1900 \mathrm{X}$.

Subskriptionspreis Mark 26,60. Einzelpreis Mark 35,-. Forficulidae und Hemimeridae. Bearbeitet ron A. de Bormans (Turin) und H. Kranss (Tübingen). XV und 142 Seiten mit 47 A bbildnngen. $1900 \mathrm{X}$.

Subskriptionspreis Mark 7,--.. Einzelpreis Mark 9, . . Palpigradi nnd Solifugae. Bearbeitet von $\mathrm{K}$. Kraepelin (Hamburg). XI und 159 Seiten mit 118 Abbildungen. 1901 II.

Subskriptionspreis Mark 8,-- Einzelpreis Mark 10,Hydrachnidae und Halacaridae. Bearbeitet von R. Piersig (Annaberg) und H. Lohmann (Kiel). XVIII und 336 Seiten mit 87 Abbildungell. $1901 \mathrm{VI}$.

Subskriptionspreis Mark 16,- . Einzelpreis Mark 21,--. Libytheidae. Bearbeitet von A. Pagenstecher (Wiesbaden). IX und 18 Seiten mit 4 Abbildungen. 1901 II.

Subskriptionspreis Mark 1,50. Einzelpreis Mark 2, Zosteropidae. Bearbeitet rou O.F in s ch (Leiden). XIV und 55 Seiten mit 32 Abbildungen. 1901 III.

Subskriptionspreis Mark 3,60. Einzelpreis Mark 4,80. Cyclophoridae. Bearbeitet ron W. Kobelt (Schwanheim). XXXIX und 662 Seiten mit 110 Abbildungen und 1 Landkarte. 1902 VII.

Subskriptionspreis Mark 32,--. Einzelpreis Mark 42,-.. Callidulidae. Bearbeitet von A.Pagenste cher (Wiesbaden). IX und 25 Seiten mit 19 Abbildungen. $1902 \mathrm{III}$.

Subskriptionspreis Mark 2,- . Einzelpreis Mark 3,- . Paridae, Sittidae und Certhiidae. Bearbeitet von C. E. Hellm a y (München). XXXI und 255 Seiten mit 76 Abbildungen. 1903III. Subskriptionspreis Mark 12,60. Einzelpreis Mark 16,-. Tetraxonia. Bearbeitet von R. r. Lendenfeld (Prag). XV und 168 Seiten mit 44 Abbildungen. 1903 VII.

Subskriptionspreis Mark 8,40. Einzelpreis Mark 11,-.. Nemertini. Bearbeitet ron Otto Bürger (Santiago). XVII und 151 Seiten mit 15 Abbildungen. 1904 VIII.

Subskriptionspreis Mark 7,40. Einzelpreis Mark 9,60. Heliconiidae. Bearbeitet ron H. Stichel \& H. Riffarth. XY und 290 Seiten mit 50 Abbildungen. $1905 \mathrm{X}$.

Subskriptionspreis Mark 14,- . Einzelpreis Mar'k 18,Turbellaria, I. Acoela. Bearbeitet ron Ludwig ron Graff (Graz). VIII und 35 Seiten mit 8 Abbildungeu. $1905 \mathrm{~V}$.

Subskriptionspreis Mark 2,40. Einzelpreis Mark 3,-.Im Druck befindet sich:

21. Lieferung. Amphipoda I. Bearbeitet ron T. R. R, Stebbing.

Es wird ersucht, Subskriptions-Anmeldungen baldigst an die unterzeichnete Verlags-Buchhandlung direkt. vder durch Vermittlung anderer Buchhandlungen, zu richten.

Berlin, Oktuber 1905.

NW. 6, Karlstr. 11. 
$$
\text { , }
$$ 





\section{QL561.H42 S7}

Ilclicrumelic

Harvard MCZ Library

11 H+105

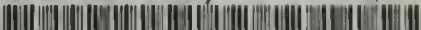

32044062343660 
